\title{
Influencias en la percepción sonora y en la interpretación del rebajado de la lengüeta del oboe
}

\section{CAROLINA BLASCO YEPES}

Tesis doctoral dirigida por Blas Payri Doctorado de música Diciembre 2012 
A la meua família 



\section{Agradecimientos}

En primer lugar, me gustaría dar las gracias a mi director Blas Payri por toda su ayuda en la realización de esta tesis.

Gracias a todas las personas que han participado directa e indirectamente para que este trabajo sea una realidad, especialmente a los oboístas Rafa Tamarit, Femín Clemente, Jorge Clemente, Rafa Alonso, Santi Guillot, Irene Vendrell, Pepe Bou, Fede Gascó y Jesús Garrigues.

A mis amigos del pueblo, por el afecto y el apoyo recibido en todo momento.

Gràcies Miquel pel disseny de la coberta de la tesi i sobre tot gràcies pels teus savis consells aquell any a l'ISEA que junt al nostre company de taula compartírem un any inoblidable.

I finalment, gràcies als meus pares i a la meua iaia, per la seua confiança $i$ comprensió en tot moment. Gràcies al meu germà, pel seu suport, ànims i ajuda en la realització d'aquest treball. Gracias Santi por todo tu trabajo, tu ayuda y tus ánimos, sin ti esta tesis no se habría realizado. Gràcies Rubén per haver-ho accelerat tot i per fer que cada dia siga més feliç que l'anterior. 



\section{Resumen}

Esta investigación estudia la influencia de la lengüeta del oboe (estilo de rebajado, molde, grosor) en la acústica y percepción del sonido obtenido y en la propiocepción instrumental de los oboístas al interpretar. Para ello se fabrican 18 lengüetas con un diseño factorial de 3 estilos de rebajado (fr=francés, ge=alemán, us=americano), 3 moldes y 2 grosores. Diez oboístas profesionales, con el mismo oboe, graban cinco ejercicios con un micrófono de cercanía y evalúan propioceptivamente 19 criterios (escala de 1 a 7) para cada lengüeta tras cada ejercicio.

Las mediciones acústicas sobre las 1900 muestras obtenidas muestran una influencia del estilo de rebajado en la afinación $\left(p<, 001 ; \eta^{2}=, 72\right.$; ge más aguda), la estabilidad de afinación ( $p<, 001 ; \eta^{2}=, 04$; fr más inestable), la intensidad $\left(p<, 001 ; \eta^{2}=, 09\right.$; fr menor intensidad), el centro de gravedad espectral $\left(p<, 001 ; \eta^{2}=, 14\right.$; fr menor riqueza espectral) y la armonicidad ( $p<, 001 ; \eta^{2}=, 02 ;$ fr menor armonicidad). El molde y grosor dan resultados significativos pero marginales.

Para estudiar las diferencias de timbre, diecinueve músicos realizaron una clasificación holística sobre un conjunto de 19 notas do5 (1 oboísta, 3 rebajados, 3 moldes y 2 grosores) y otro de 20 notas do5 (5 oboístas, 3 rebajados, 2 grosores). No aparecen diferencias significativas por estilo de rebajado, molde ni grosor. Sólo existen diferencias por intérpretes para el segundo conjunto $(p<, 01)$, corroborando un estudio previo que no destacaba diferencias de timbre por estilo de rebajado.

Las respuestas propioceptivas obtienen diferencias significativas para: la evaluación de flexibilidad ( $p<, 001 ; \eta^{2}=, 45$; fr mayor), timbre $\left(p<, 001 ; \eta^{2}=, 23\right.$; ge mejor), rigidez $\left(p<, 001 ; \eta^{2}=, 18\right.$; fr menor), equilibrio $\left(p<, 01 ; \eta^{2}=, 15\right.$; us peor) y evaluación global sin el molde $168\left(p<, 01 ; \eta^{2}=, 15\right.$; us peor). El rebajado francés genera más facilidad para el arpegio $\left(p<, 001 ; \eta^{2}=, 36\right)$, diminuendo $\left(p<, 001 ; \eta^{2}=30,\right)$ y legato $\left(p<, 001 ; \eta^{2}=, 54\right)$. El americano obtiene peor calidad de sonido para el arpegio $\left(p<, 01 ; \eta^{2}=, 13\right)$, diminuendo $(p<$, $\left.01 ; \eta^{2}=, 15\right)$ y legato $\left(p<, 01 ; \eta^{2}=, 14\right)$, y el alemán mejor para el fortissimo $\left(p=, 001 ; \eta^{2}=\right.$, 17). La concordancia de respuestas es muy alta en los intérpretes $(\alpha>, 8$ en la facilidad y $\alpha>$, 7 en el resto).

Seis oboístas evaluaron la calidad de sonido y de ejecución de 54 ejercicios diminuendo grabados por ellos mismos, por un intérprete de escuela francesa y otro de escuela alemana. Aparece una gran concordancia de respuestas $(\alpha>, 8$ en la calidad de ejecución) pero no hay diferencias significativas de percepción auditiva de la calidad del sonido y la ejecución, excepto en algunos casos puntuales. La comparación para un mismo 
oboísta de su evaluación propioceptiva respecto a su evaluación auditiva muestra que no existe correlación en las respuestas de calidad de sonido $(r=, 08)$ y que la calidad del sonido evaluada auditivamente está más ligada a parámetros acústicos $\left(\mathrm{R}^{2}=, 60\right)$ que la evaluada al interpretar $\left(\mathrm{R}^{2}=, 10\right)$, sugiriendo que la percepción sonora del oboísta está muy influenciada por su propiocepción muscular/vibrotáctil.

El rebajado influye significativamente en la propiocepción del intérprete, pero no en la calidad del sonido obtenido. Los oboístas concuerdan en la valoración propioceptiva de las lengüetas. 


\section{Resum}

Aquest treball de recerca estudia la influència de la llengüeta de l'oboè (estil de rebaixat, motle, grossària) en l'acústica i percepció del so obtingut i en la propiocepció instrumental dels oboistes a l'hora d'interpretar. Així doncs, es fabriquen 18 llengüetes amb un disseny factorial de 3 estils de rebaixat (fr=francès, ge=alemany, us=americà), 3 motles i 2 grossàries. Deu oboistes professionals, amb el mateix oboè, graven cinc exercicis amb un micròfon de rodalia i avaluen propioceptivament 19 criteris (escala d' 1 a 7) per a cadascuna de les llengüetes després de cada exercici.

Les mesures acústiques sobre les 1900 mostres obtingudes mostren una influència de l'estil de rebaixat en l'afinació ( $p<, 001 ; \eta^{2}=, 72$; ge més aguda), l'estabilitat d'afinació $\left(p<, 001 ; \eta^{2}=, 04\right.$; fr més inestable), la intensitat $\left(p<, 001 ; \eta^{2}=, 09\right.$; fr menor intensitat), el centre de gravetat espectral $\left(p<, 001 ; \eta^{2}=, 14\right.$; fr menor riquesa espectral) i l'armonicitat $\left(p<, 001 ; \eta^{2}=, 02\right.$; fr menor armonicitat). El motle i grossària donen resultats significatius però marginals.

Per a estudiar les diferències de timbre, dèneu músics realitzaren una classificació holística sobre un conjunt de 19 notes do5 ( 1 oboista, 3 rebaixats, 3 motles i 2 grossàries) i un altre de 20 notes do5 ( 5 oboistes, 3 rebaixats, 2 grossàries). No apareixen diferències significatives per estil de rebaixat, motle ni grossària. Sols existeixen diferències per intèrprets per al segon conjunt $(p<, 01)$, corroborant un estudi previ que no destacava diferències de timbre per estil de rebaixat.

Les respostes propioceptives obtenen diferències significatives per a: l'avaluació de flexibilitat ( $p<, 001 ; \eta^{2}=, 45$; fr major), timbre $\left(p<, 001 ; \eta^{2}=, 23\right.$; ge millor), rigidesa $(p<, 001$; $\eta^{2}=, 18$; fr menor), equilibri ( $p<, 01 ; \eta^{2}=, 15$; us pitjor) i avaluació global sense el motle 168 $\left(p<, 01 ; \eta^{2}=, 15\right.$; us pitjor). El rebaixat francès genera més facilitat per a l'arpegi $(p<, 001$; $\left.\eta^{2}=, 36\right)$, diminuendo $\left(p<, 001 ; \eta^{2}=30,\right)$ i legato $\left(p<, 001 ; \eta^{2}=, 54\right)$. L'americà obté pitjor qualitat de so per a l'arpegi $\left(p<, 01 ; \eta^{2}=, 13\right)$, diminuendo $\left(p<, 01 ; \eta^{2}=, 15\right)$ i legato $(p<, 01$; $\left.\eta^{2}=, 14\right)$, i l'alemany millor per al fortissimo $\left(p=, 001 ; \eta^{2}=, 17\right)$. El concordament de respostes és molt alt en els intèrprets ( $\alpha>, 8$ en la facilitat $i \alpha>, 7$ en la resta).

Sis oboistes avaluaren la qualitat de so i d'execució de 54 exercicis diminuendo gravats per ells mateix, per un intèrpret d'escola francesa i altre d'escola alemanya. Apareix un gran concordament de respostes ( $\alpha>, 8$ en la qualitat d'execució) però no hi ha diferències significatives de percepció auditiva de la qualitat del so i l'execució, excepte en alguns casos puntuals. La comparació per a un mateix oboista de la seua avaluació propioceptiva respecte a la seua avaluació auditiva mostra que no existeix correlació en les 
respostes de qualitat de so $(r=, 08)$ i que la qualitat del so avaluada auditivament està més lligada a paràmetres acústics $\left(\mathrm{R}^{2}=, 60\right)$ que la que s'avalua quan s'interpreta $\left(\mathrm{R}^{2}=, 10\right)$, suggerint que la percepció sonora de l'oboista està molt influenciada por la seua propiocepció muscular/vibrotàctil.

El rebaixat influeix significativament en la propiocepció de l'intèrpret, però no en la qualitat del so obtingut. Els oboistes concorden en la valoració propioceptiva de les llengüetes. 


\section{Abstract}

This research studies the influence of the oboe reed (reed-making style, gouging and shape) on the acoustics and the perception of the obtained sound and on the oboists' proprioception during performance. Eighteen reeds were made following a factorial design of 3 reed-making styles ( $\mathrm{fr}=$ french; ge=german; us=american), 3 shapes and 2 gouging thickness. Ten professional oboists, using the same oboe, recorded five exercises with an instrument microphone and evaluated their own perception by using 19 criteria (on a scale of 1 to 7) for each reed, after each exercise.

The acoustic measurements of 1900 samples show an influence of the reed style on pitch $\left(p<.001 ; \eta^{2}=.72 ;\right.$ ge higher pitched $)$, pitch stability $\left(p<.001 ; \eta^{2}=.04 ;\right.$ fr=more unstable), intensity $\left(p<.001 ; \eta^{2}=.09 ;\right.$ fr=less intensity), spectral center of gravity $(p<.001$; $\eta^{2}=.14$; fr=lower spectral richness $)$ and harmonicity $\left(p<.001 ; \eta^{2}=.02\right.$; fr=less harmonic). Reed shape and thickness gave significant but marginal results.

To study the differences in timbre, nineteen musicians made a holistic classification on a set of 19 notes of $\mathrm{C}_{5}$ ( 1 oboist, 3 reed-making styles, 3 shapes, and 2 gouging widths), and another set of 20 notes of $\mathrm{C}_{5}$ ( 5 oboists, 3 reed-making styles, 2 sizes). There are no significant differences between reed-making styles, shape or width. There are significant differences only between the oboists for the second group $(p<.01)$, corroborating a previous study where no differences in timbre between reed-making styles were found.

Proprioceptive responses yielded significant differences for the ratings on flexibility $\left(p<.001 ; \eta^{2}=.45 ;\right.$ fr=more flexible $)$, timbre $\left(p<.001 ; \eta^{2}=.23\right.$; ge=best $)$, rigidity $\left(p<.001 ; \eta^{2}=.18 ;\right.$ fr=less $)$, balance $\left(p<.01 ; \eta^{2}=.15 ;\right.$ us= worst $)$ and global evaluation excluding shapes with cast $168\left(p<.01 ; \eta^{2}=.15\right.$; us=the worst $)$. French reed-making style is rated as easier for the arpeggio $\left(p<.001 ; \eta^{2}=.36\right)$, diminuendo $\left(p<.001 ; \eta^{2}=.30\right)$ and legato $\left(p<.001 ; \eta^{2}=.54\right)$. American reed-making style is rated worse for sound quality for arpeggio $\left(p<.01 ; \eta^{2}=.13\right)$, diminuendo $\left(p<.01 ; \eta^{2}=.15\right)$ and legato $\left(p<.01 ; \eta^{2}=.14\right)$, while german reed-making style is rated best for sound quality for fortissimo $\left(p=.001 ; \eta^{2}=.17\right)$. Performers agreement is very high ( $\alpha>8$ for easiness and $\alpha>$.7 for the remaining criteria). 
Six oboist evaluated the quality of sound and the performance of 54 diminuendo exercises recorded by themselves, by an interpreter of the french school and another of the german school. Agreement is high ( $\alpha>.8$ on performance) but no significant differences between reeds arised for auditory ratings on sound quality and performance, except in some specific cases. The comparison of the proprioceptive and auditory ratings for the same oboist shows no significant correlation in the responses of sound quality $(r=.08)$. Furthermore, sound quality auditory ratings are more closely linked to acoustic parameters $\left(\mathrm{R}^{2}=.60\right)$ than the ratings made while performing $\left(\mathrm{R}^{2}=.10\right)$, suggesting that the oboist's sound perception is highly influenced by its muscular/vibrotactile proprioception.

Reed-making style has a significant on the performer's proprioception, but not in the sound quality obtained. Oboists agree on the proprioceptive evaluation of the reeds. 


\section{Resumen extendido}

Esta investigación estudia experimentalmente la influencia perceptiva, acústica y propioceptiva de los diferentes estilos de rebajado de las lengüetas del oboe.

Se han realizado dos experimentos, uno preliminar y otro principal, utilizando diferentes métodos y materiales.

En el experimento preliminar se han realizado una serie de cuatro tareas de percepción tímbrica y un análisis acústico utilizando seis lengüetas realizadas a mano, dos por cada estilo de rebajado (alemán, francés y americano). Dos oboístas, con dos oboes diferentes, han grabado una serie de diez ejercicios con cuatro posiciones fijas de micrófono: uno de los oboístas grabó diez ejercicios con las seis lengüetas y el otro oboísta grabó cinco ejercicios con tres lengüetas.

La primera tarea de percepción consistía en la escucha de dieciocho sonidos largos ( $\mathrm{sol}_{4}$ en diminuendo), en la segunda tarea los oyentes escuchaban 18 notas cortas $\mathrm{re}_{4}$ atacadas con y sin lengua, en la tercera 18 notas cortas sol 6 atacadas con y sin lengua y en la cuarta tarea 18 frases de cuatro notas re $_{4}$ y cuatro notas sol 6 atacadas con y sin lengua. Las notas de la segunda y tercera tarea fueron extraídas de las frases de la cuarta tarea. Cuarenta oyentes (veinte oboístas y veinte músicos no oboístas) realizaron una comparación holística de las cuatro tareas, para ver si emergían parámetros idénticos en la asociación de los sonidos. Los resultados concluyen que aunque aparecen ciertas diferencias para los estilos de rebajado (tarea 1: oboístas $p=, 048$; tarea 4: no oboístas $p=$, 020) esas diferencias se debieron a las particularidades de las lengüetas entre sí (tarea 2 : oboístas $p=, 002$; tarea 3: no oboístas $p=, 046$; tarea 4: no oboístas $p=, 013$, oboístas $p<, 000$ ). Además, los diferentes ataques en la interpretación de las notas $(p<, 000$ para las 4 tareas en los dos grupos de oyentes) y los diferentes oboístas sí son reconocidos por los oyentes (tarea 1: no oboístas $p<, 000$, oboístas $p=, 001$; tarea 2: no oboístas $p=, 142$, oboístas $p=, 002$; tarea 3: no oboístas $p=, 005$, oboístas $p=, 525$; tarea 4: no oboístas $p=, 001$, oboístas $p<, 000$ ).

El análisis acústico consistió en un análisis estadístico de 35 parámetros relacionados con la afinación y su estabilidad, la intensidad y su estabilidad, la facilidad de vibración, la armonicidad y su estabilidad y el timbre. Los resultados muestran que existe una diferenciación para los parámetros ligados al timbre, específicamente a la distribución 
de la energía en el espectro (Kurtosis y Skewness espectrales) donde las lengüetas alemanas son las que mayores valores obtienen en estos dos parámetros, siendo significativo en todos los casos $(p<, 05)$. En el resto de parámetros medidos, no se distingue un patrón ligado al estilo de rebajado.

En el experimento principal se han realizado una serie de dos tareas de percepción tímbrica, un análisis acústico, un experimento de evaluación interpretativa, un experimento de evaluación auditiva y una comparación entre el experimento de evaluación interpretativa y auditiva, utilizando dieciocho lengüetas según un diseño factorial de 3 estilos de rebajado, 3 moldes y 2 grosores de pala. Las lengüetas fueron realizadas a máquina (para el rebajado alemán y francés) y a mano (para el rebajado americano), utilizando la misma sección de caña para las lengüetas de cada rebajado. Diez oboístas, con un mismo oboe, han grabado una serie de cinco ejercicios con tres posiciones fijas de micrófono siendo una de ellas un micrófono de cercanía.

La primera tarea de percepción consistía en la escucha de diecinueve notas do5, utilizando a un único oboísta, tres rebajados, tres moldes y dos grosores; en la segunda tarea los oyentes escuchaban veinte notas do5, utilizando a cinco oboístas, tres rebajados, un molde, dos grosores para el rebajado alemán y un grosor para el resto $(59 \mathrm{~mm})$. Diecinueve músicos realizaron una comparación holística de las dos tareas, para ver si emergían parámetros idénticos en la asociación de los sonidos. Los resultados concluyen que las diferentes escuelas de rebajado no influyen en la percepción de los oyentes $(p>, 05)$ y tampoco el molde $(p>, 05)$ ni el grosor $(p>, 05)$, mientras que el único factor que se distingue son los diferentes intérpretes para los estímulos de la segunda tarea $(p=, 009)$.

El análisis acústico consistió en un análisis estadístico de 10 parámetros relacionados con la afinación y su estabilidad, la intensidad y su estabilidad, la facilidad de vibración, la armonicidad y su estabilidad y el timbre. Un total de 11 ejercicios editados con 181 muestras sonoras por ejercicio fueron analizadas. Los resultados muestran que el estilo de rebajado influye de forma significativa en todos los parámetros acústicos estudiados, siendo más influyente en la frecuencia media $\left(\mathrm{F}=1260,7, p<, 001, \eta^{2}=, 685\right)$ con el rebajado francés más grave y el americano más agudo. El molde $\left(\mathrm{F}=1,71, p=, 190, \eta^{2}=\right.$, 001 para la frecuencia media y $\mathrm{F}=9,3, p<, 001, \eta^{2}=, 011$ para la intensidad) y el grosor $\left(\mathrm{F}=77,81, p<, 001, \eta^{2}=, 063\right.$ para la frecuencia media y $\mathrm{F}=19,55, p<, 001, \eta^{2}=, 011$ para la 
intensidad) también influyen en el estudio acústico, pero con una significatividad menor que el oboísta $\left(\mathrm{F}=203,46, p<, 001, \eta^{2}=, 637\right.$ para la frecuencia media y $\mathrm{F}=497,6, p<, 001$, $\eta^{2}=, 743$ para la intensidad) y el rebajado. Mientras que el molde influye en todos los parámetros excepto en los ligados a la frecuencia y su estabilidad y a la diferencia de energía por bandas, el grosor lo hace en todos los parámetros excepto en la desviación estándar de la frecuencia, en la armonicidad media y en las diferencias de energía por bandas.

El experimento de evaluación interpretativa se basó en la puntuación de diferentes aspectos ligados a la ejecución y a la calidad sonora de los ejercicios interpretados. Diez oboístas puntuaban mientras interpretaban cada ejercicio en una escala de 1 a 7 la facilidad de ejecución del ejercicio, la calidad del ejercicio, los aspectos globales de la lengüeta (flexibilidad, rigidez, equilibrio, timbre y globalidad) y cómo sería interpretar con las lengüetas cuatro piezas de diferentes estilos. Un total de 3610 puntuaciones fueron analizadas. Los resultados determinan que el estilo de rebajado influye en estas puntuaciones. Para la valoración de la calidad del sonido, el rebajado americano es el que más diferencias marca respecto al alemán y al francés $(p<, 05)$ con excepción del pianissimo que no genera diferencias $(p>, 05)$, y del fortissimo, donde las lengüetas que marcan la diferencia son las alemanas $(p<, 05)$. Para la pregunta facilidad, las lengüetas francesas son las más fáciles de forma muy significativa $(p<, 001)$ a excepción del fortissimo y del pianissimo que no generan diferencias significativas $(p>, 05)$. Para la pregunta equilibrio las lengüetas menos valoradas son las americanas respecto a las francesas $(p=, 016)$ y a las alemanas $(p=, 001)$. Las lengüetas francesas son significativamente $(p<, 001)$ más flexibles que las lengüetas de las otras dos escuelas. Las lengüetas alemanas son significativamente más rígidas que las francesas $(p<, 001)$, pero no lo son más que las americanas $(p=, 903)$. En cuanto al timbre, las lengüetas peor valoradas son las americanas respecto a las francesas $\mathrm{y}$, de forma muy significativa, respecto a las alemanas $(p<, 001)$. De forma global, las lengüetas mejor valoradas son las francesas respecto a las alemanas y a las americanas $(p<, 001)$. Para los estilos musicales, la lengüeta peor valorada es la americana y de forma muy significativa su utilización en el concierto en do mayor de Vivaldi $(p<, 001)$, en el concierto en do mayor de Mozart $(p=, 018)$, y en la sonata de Dutilleux $(p=, 017)$, respecto a la francesa. En general, los oboístas se ponen de 
acuerdo en valorar el comportamiento de una lengüeta para la evaluación global de la facilidad $(\alpha=, 813)$, la evaluación global de la calidad de cada ejercicio $(\alpha=, 760)$ y los parámetros globales de la lengüeta $(\alpha=, 778)$. Se obtiene una correlación muy fuerte entre la facilidad del arpegio y la facilidad del legato $(\mathrm{r}=, 821)$, así como entre la calidad del arpegio y la calidad del legato $(\mathrm{r}=, 824)$, seguramente porque los dos ejercicios son los más largos y los únicos que abarcan todo el registro del oboe.

El experimento de evaluación auditiva se diseñó a partir de las grabaciones realizadas por los oboístas, de forma que cinco oboístas intérpretes puntuaron sus propios sonidos (autoevaluación auditiva) y los mismos cinco oboístas más un oboísta externo al experimento puntuaron los sonidos de los representantes de la escuela de interpretación francesa y alemana (evaluación auditiva) respondiendo a las preguntas de calidad de ejecución y calidad sonora del diminuendo. Un total de 54 sonidos fueron escuchados por los oboístas intérpretes, excepto el representante de la escuela alemana y el oboísta externo que sólo escucharon 36 sonidos. Los resultados concluyen que los diferentes estilos de rebajado no influyen de forma significativa en la evaluación auditiva, ni en la ejecución ni en la calidad del sonido $(p>, 05)$. Sin embargo, cuando se analizan las evaluaciones que han hecho los oboístas sobre sus propios ejercicios (autoevaluación auditiva), se observa que algunos evaluadores distinguen entre estilos de rebajado (evaluador 6: $p<, 001 \mathrm{y}$ evaluador 4: $p=, 038$ para la ejecución; evaluador 3: $p=, 028$ y evaluador $6: p=, 043$ para la calidad del sonido).

El estudio comparativo entre la evaluación interpretativa y la autoevaluación auditiva se realizó para averiguar si los oboístas intérpretes eran capaces de dar la misma puntuación cuando interpretaban que cuando escuchaban el diminuendo. Los resultados concluyen que los oboístas evaluadores se ponen de acuerdo, aunque no completamente, consigo mismos cuando puntúan la calidad de ejecución del ejercicio, pero no cuando puntúan la calidad del sonido.

Finalmente, una serie de análisis se realizaron para averiguar qué parámetro acústico estaba relacionado con las puntuaciones de los oboístas en la evaluación interpretativa, en la evaluación auditiva y en la autoevaluación auditiva. Los resultados concluyen que siempre existe algún parámetro acústico relacionado con las puntuaciones dadas por los oboístas, tanto interpretativa como auditivamente. Sin embargo, en la 
evaluación interpretativa la calidad sonora parece estar explicada mediante parámetros acústicos ligados al timbre, aunque con un $\mathrm{R}^{2}$ corregido muy bajo $\left(\mathrm{R}^{2=}, 108\right)$ y en la evaluación y autoevaluación auditiva los parámetros acústicos relacionados poco tienen que ver con la calidad del sonido, sino más bien con la ejecución interpretativa, aunque con un $\mathrm{R}^{2}$ corregido más alto que en la evaluación interpretativa $\left(\mathrm{R}^{2}\right.$ evaluación auditiva $=, 252$ y $\mathrm{R}^{2}$ autoevaluación auditiva $=, 587$ ), por lo que todo parece indicar que los oboístas privilegian la ejecución interpretativa, quizás por hábito de profesores o intérpretes, o quizás porque la información sonora no permite realmente distinguir entre calidades de sonido. Además, al realizar la comparación de los parámetros acústicos que explican la evaluación interpretativa (sólo de los cinco oboístas que han realizado también la autoevaluación auditiva) y la autoevaluación auditiva, los resultados muestran que, tanto en la ejecución como en la calidad sonora, la autoevaluación auditiva ( $\mathrm{R}^{2}$ autoevaluación auditiva ejecución=,316 y $\mathrm{R}^{2}$ autoevaluación auditiva sonido=,587) obtiene un $\mathrm{R}^{2}$ corregido mayor que la evaluación interpretativa $\left(\mathrm{R}^{2}\right.$ evaluación interpretativa ejecución=, 053 y $\mathrm{R}^{2}$ evaluación interpretativa sonido=,095), dando a entender que cuando a los oboístas se les pide que puntúen en la audición centran su atención en más aspectos auditivos que cuando están sólo interpretando.

En conclusión, las lengüetas peor valoradas son las americanas en el equilibrio, timbre y puntuación global; las lengüetas francesas son las más flexibles y las mejor valoradas globalmente y las alemanas son las más rígidas y las mejor puntuadas en el timbre. 


\section{Índice}

1. Introducción y objetivos generales 21

1.1. Introducción general 22

1.1.1.El oboe y sus distintas clasificaciones 22

1.1.2. La lengüeta: definición y proceso de construcción 26

Herramientas necesarias 28

El atado de las lengüetas $\quad 30$

El rebajado de las lengüetas $\quad 31$

1.1.3. La lengüeta: historia y evolución 31

1.2. Objetivos generales 38

2. Antecedentes 40

2.1. Percepción tímbrica 41

2.2. Acústica de la lengüeta 46

2.3. Evaluación interpretativa y auditiva 53

2.3.1. Evaluación interpretativa 53

2.3.2. Propiocepción vibrotáctil $\quad 57$

2.3.3. Evaluación auditiva $\quad 59$

3. Estudio preliminar: percepción tímbrica y acústica de la lengüeta 64

3.1. Introducción $\quad 65$

3.2. Objetivos

$\begin{array}{ll}\text { 3.3. } & \text { Material experimental } \\ \end{array}$

3.3.1.Lengüetas $\quad 67$

$\begin{array}{ll}\text { 3.3.2. Oboístas } & 68\end{array}$

3.3.3. Grabación $\quad 69$

$\begin{array}{ll}\text { 3.3.4. Material grabado } & 70\end{array}$

$\begin{array}{lll}\text { 3.4. } & \text { Experimento de percepción } & \mathbf{7 4}\end{array}$

3.4.1.Hipótesis $\quad 74$

3.4.2. Método $\quad 76$

$\begin{array}{ll}\text { 3.4.3. Resultados } & 77\end{array}$

3.4.4. Discusión $\quad 81$

3.4.5. Conclusiones $\quad 82$

\begin{tabular}{lr} 
3.5. & Estudio acústico \\
\hline
\end{tabular} 
3.5.2. Respuestas acústicas en función del ejercicio de interpretación $\quad 84$

Ejercicios que miden el ataque: ataque, staccato, doble staccato $\quad 85$

$\begin{array}{ll}\text { Legato } & 87\end{array}$

$\begin{array}{ll}\text { Oscillato } & 88\end{array}$

Afinación $\quad 89$

Frullato $\quad 91$

Intensidad $\quad 93$

Diminuendo 94

Dobles sonidos armónicos $\quad 97$

Comparación de la afinación en el conjunto de ejercicios 98

$\begin{array}{ll}\text { 3.5.3. Respuestas acústicas globales de las lengüetas } & 101\end{array}$

Mediciones acústicas realizadas $\quad 101$

$\begin{array}{ll}\text { Intensidad sonora } & 102\end{array}$

Variabilidad de la intensidad 103

$\begin{array}{ll}\text { Afinación } & 104\end{array}$

Estabilidad en la afinación $\quad 104$

$\begin{array}{ll}\text { Facilidad de vibración } & 105\end{array}$

$\begin{array}{ll}\text { Armonicidad } & 106\end{array}$

$\begin{array}{ll}\text { Timbre } & 107\end{array}$

Correlaciones entre los parámetros acústicos $\quad 108$

3.5.4. Discusión 110

$\begin{array}{ll}\text { 3.5.5. Conclusiones } & 111\end{array}$

4. Estudio principal: percepción tímbrica, estudio acústico y evaluación interpretativa y auditiva de la lengüeta 112

$\begin{array}{lr}\text { 4.1. Introducción } & 113\end{array}$

$\begin{array}{ll}\text { 4.2. Objetivos } & 113\end{array}$

$\begin{array}{ll}\text { 4.3. Confección de las lengüetas } & 114\end{array}$

4.3.1. Selección de los tubos $\quad 114$

4.3.2. Obtención de las palas 116

$\begin{array}{ll}\text { 4.3.3. Forma de las palas } & 117\end{array}$

$\begin{array}{lr}\text { 4.4. Material experimental } & 118\end{array}$

4.4.1.Lengüetas 118

$\begin{array}{ll}\text { 4.4.2. Oboístas } & 120\end{array}$

4.4.3. Grabación 123

$\begin{array}{ll}\text { 4.4.4. Material grabado } & 123\end{array}$

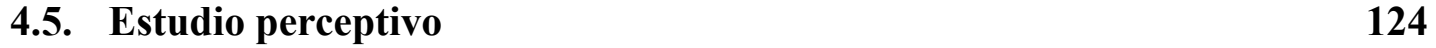


4.5.2. Método 125

$\begin{array}{ll}\text { 4.5.3. Resultados } & 127\end{array}$

4.5.4. Discusión 130

$\begin{array}{ll}\text { 4.5.5. Conclusiones } & 130\end{array}$

$\begin{array}{ll}\text { 4.6. Estudio acústico } & 131\end{array}$

4.6.1.Introducción 131

4.6.2. Hipótesis 133

4.6.3. Método y material 134

Mediciones acústicas $\quad 134$

Mediciones físicas de las lengüetas 135

4.6.4. Respuestas acústicas globales de las lengüetas 138

Mediciones relativas a la afinación $\quad 138$

Mediciones relativas a la estabilidad de la afinación $\quad 143$

Mediciones relativas a la intensidad 151

Mediciones relativas a la variabilidad de la intensidad 156

Mediciones relativas a la facilidad de vibración $\quad 160$

Mediciones relativas a la armonicidad 162

$\begin{array}{ll}\text { Parámetros relativos al timbre } & 170\end{array}$

$\begin{array}{ll}\text { 4.6.5. Análisis de datos mediante T-test } & 178\end{array}$

$\begin{array}{ll}\text { Influencia del grosor } & 178\end{array}$

Influencia del rebajado $\quad 181$

Influencia del molde $\quad 184$

4.6.6. Análisis de datos mediante el escalamiento multidimensional 187

4.6.7. Respuestas acústicas en función del ejercicio diminuendo 188

Duración de la nota $\quad 189$

Variación de la afinación $\quad 189$

Ámbito de intensidad 191

Correlación entre ámbito de intensidad y de afinación 193

4.6.8. Respuestas acústicas en función del ejercicio pianissimo 195

Intensidad mínima 195

Estabilidad en la afinación $\quad 197$

4.6.9. Respuestas acústicas en función del ejercicio fortissimo 200

Intensidad máxima $\quad 200$

Riqueza en el timbre $\quad 202$

4.6.10.Comparación de las lengüetas en el ejercicio fortissimo y pianissimo 205

4.6.11.Discusión 209

$\begin{array}{ll}\text { 4.6.12.Conclusiones } & 210\end{array}$ 
4.7. Experimento de evaluación interpretativa (propiocepción del instrumentista)

4.7.1. Introducción 212

4.7.2.Hipótesis 213

4.7.3. Método 213

$\begin{array}{ll}\text { 4.7.4. Resultados } & 214\end{array}$

Concordancia de las respuestas $\quad 214$

Influencia del rebajado 216

Correlaciones 226

4.7.5. Comparación de la evaluación interpretativa con la acústica 233

Resultados 233

4.7.6. Discusión 250

4.7.7. Conclusiones 251

4.8. Experimento de evaluación auditiva 252

4.8.1.Introducción 252

4.8.2. Hipótesis 252

4.8.3. Método 253

4.8.4. Resultados 254

Concordancia de las respuestas 254

Influencia del rebajado 254

4.8.5. Análisis de la evaluación auditiva comparada con el análisis acústico 256

Resultados 256

4.8.6. Discusión 258

$\begin{array}{ll}\text { 4.8.7. Conclusiones } & 259\end{array}$

4.9. Comparación de la evaluación interpretativa y la autoevaluación auditiva

4.9.1. Resultados 259

Correlaciones 259

4.9.2. Análisis de la autoevaluación auditiva comparada con el análisis acústico

Resultados $\quad 262$

4.9.3. Discusión 266

4.9.4. Conclusiones 267

5. Discusión general y conclusiones 268

$\begin{array}{ll}\text { 5.1. Discusión general } & 269\end{array}$

5.1.1.Percepción tímbrica 269 
5.1.2. Estudio acústico $\quad 270$

5.1.3. Evaluación interpretativa y auditiva 275

$\begin{array}{lr}\text { 5.2. Conclusiones } & \mathbf{2 8 0}\end{array}$

6. Referencias bibliográficas $\quad 284$

$\begin{array}{ll}\text { 6.1. Bibliografía } & 285\end{array}$

7. Anexos 299

7.1. ANEXO A. Tablas y figuras complementarias de análisis estadístico 300

7.1.1. Experimento preliminar $\quad 300$

Percepción tímbrica $\quad 300$

Acústica de la lengüeta $\quad 306$

7.1.2. Experimento principal $\quad 311$

Percepción tímbrica $\quad 311$

Acústica de la lengüeta 313

Experimento de evaluación interpretativa (propiocepción del instrumentista)334

Experimento de evaluación auditiva $\quad 349$ 
1. Introducción y objetivos generales 


\subsection{Introducción general}

Las razones y el deseo de realizar una investigación sobre las lengüetas del oboe en el área de la percepción tímbrica, la acústica de las lengüetas y la evaluación interpretativa y auditiva, se debe a la experiencia de la autora como oboísta al intentar entender cómo responden las lengüetas cuando se les aplica un tipo u otro de rebajado.

Se entiende por rebajado el proceso de eliminar la madera sobrante de una caña en bruto hasta conseguir producir el sonido deseado. Todos los oboístas cuando empiezan el estudio con el instrumento dependen directamente de la producción de las lengüetas por parte del profesor, una vez el proceso es asimilado, el alumno imita el rebajado dedicando mucho esfuerzo a este proceso. Junto con la evolución en la construcción de los oboes y la creación de las diferentes escuelas oboísticas, los rebajados de las lengüetas se han ido modificando y evolucionando, existiendo varias escuelas y preferencias muy marcadas.

Aunque el sonido del oboe depende del cuerpo del instrumento, del instrumentista en sí y de las lengüetas, la opinión principal, extendida entre los oboístas en general, es que las diferentes escuelas de rebajado de las lengüetas pueden distinguirse tímbricamente. En esta investigación se estudia sistemáticamente los diferentes estilos de rebajado de lengüetas actualmente más utilizados, definidos por Ledet (2008) en su libro Oboe Reed Styles. Theory and Practice: el alemán, el francés y el americano. Para entender su evolución es necesario hacer un recorrido histórico sobre el oboe, sus clasificaciones y el desarrollo de las lengüetas junto con las diferentes escuelas oboísticas.

\subsubsection{El oboe y sus distintas clasificaciones}

Existen diversas teorías para la clasificación de los instrumentos musicales y todas ellas tienen su origen en las colecciones sistemáticas que se efectuaron en el siglo XIX. Los tratados elaborados durante los siglos XVI y XVII sólo tenían interés por describir los instrumentos musicales de su tiempo, como sucede con el de Martín Agrícola, Pierre Trichet y Pere Marín Mersenne (Tranchefort, 2002, p. 15 y ss). Sin embargo, en la antigua China existía un modelo de clasificación, considerado el más antiguo, según los materiales de composición de los instrumentos. Ejemplo de esta clasificación son Los cuatro libros de Confucio (1982), concretamente en su primer libro donde se realiza una clasificación de 
instrumentos musicales según el material del que están construidos: el metal, la piedra, la tierra, la madera (en ella se hayan enmarcados los instrumentos de doble lengüeta emparentados con el oboe occidental), el bambú, la calabaza, la piel y la seda.

La clasificación más habitual situaba al oboe con los instrumentos de viento de la orquesta (Olazábal, 1954): Cerone (1613) ya utilizaba esta clasificación, basándose en características musicales análogas como el timbre, la agilidad o la expresividad. En otras clasificaciones, como la del compositor y musicólogo belga François Auguste Gevaert (1828-1908), se clasifican según el tipo de entonación: libre, variable y fija. Por otro lado, en su Historia de los Instrumentos Musicales, el musicólogo alemán Curt Sachs (1881-1959) advierte de la ilógica de la clasificación usual en instrumentos de cuerda, viento y percusión y propone junto con su colega Hornbostel (1877-1935), una sistematización de todos los instrumentos musicales existentes, al margen de su origen, en cinco grandes clases subdivididas a su vez en grupos, subgrupos, géneros, etc. (Riemann, 1979). Esta categorización se basa en la que realizó Victor Mahillón como fundador y director del Museo Instrumental de Bruselas para ordenar los instrumentos a su cargo:

1) Idiófonos: Son los instrumentos formados por materiales intrínsecamente sonoros. Se subdividen según el modo de excitación en: raspados, punteados, sacudidos, frotados, $\ldots$

2) Aerófonos. Los instrumentos de esta clase utilizan el aire como fuente de sonido. Se dividen en dos subclases: aerófonos de columna, que constan de un tubo sonoro cuya columna de aire actúa como un cuerpo sonoro determinando la frecuencia de los sonidos emitidos predominando incluso sobre el dispositivo de excitación; y aerófonos libres, en los que el dispositivo que excita la columna de aire es el que determina la frecuencia de los sonidos que producen (el armonio, los tubos de lengüeta del órgano y algunos zumbadores primitivos).

3) Membranófonos. El sonido se produce mediante una o varias membranas tendidas sobre sendas aberturas. Se dividen en grupos según la posición en que son ejecutados, su dimensión, el número de membranas o parches, etc.

4) Cordófonos. El sonido se produce por medio de una o varias cuerdas 
sometidas a una tensión adecuada. Se subdividen en cítaras (instrumentos con cuerdas tendidas sobre los extremos de una caja o tabla), laúdes (con cuerdas tendidas en un extremo sobre una caja y en el otro sobre un mango), liras (con cuerdas tendidas en un extremo sobre una caja y en el otro sobre un travesaño que une un mango doble) y arpas (con cuerdas tendidas en un plano perpendicular a la caja entre esta y un travesaño que parte oblicuamente de ella).

5) Electrófonos. El sonido se produce o modifica mediante corrientes eléctricas. Se dividen en dos grandes grupos: instrumentos mecánico-eléctricos (las vibraciones sonoras son producidas por métodos usuales y luego transformadas en oscilaciones eléctricas), e instrumentos radio-eléctricos (fundamentados íntegramente en oscilaciones eléctricas).

En España, Felipe Pedrell publicó en 1901 su Emporio científico, donde al margen de relatar su visión sobre cómo se inventaron, emplearon y progresaron los instrumentos de música, establece una clasificación en cuatro grandes clases:

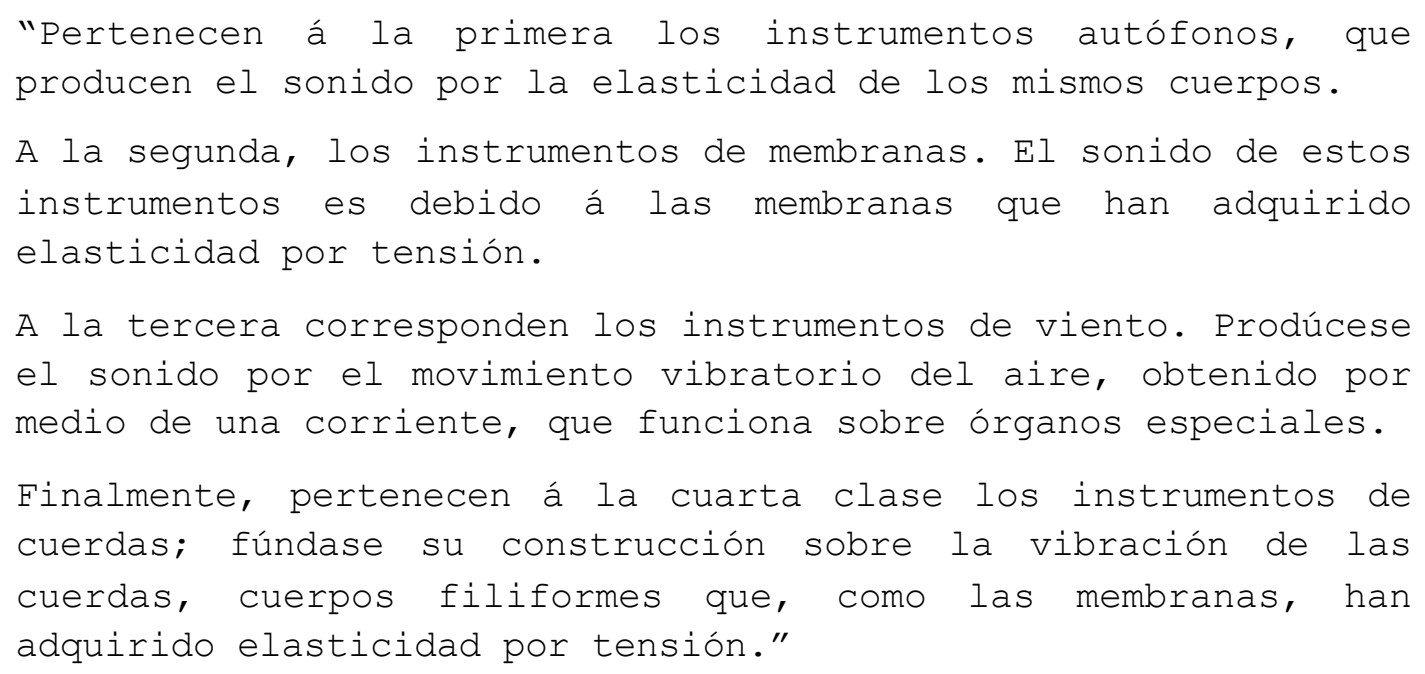

Dentro de cada clase de esta clasificación Pedrell distingue varias ramas, y a veces subdivide éstas en varias secciones. Asimismo, cuando describe a los instrumentos de viento, los divide en tres ramas diferenciadas por el modo de excitación de la columna de aire: Instrumentos de lengüeta, de embocadura y de boquilla. Cada una de estas ramas la subdivide a su vez en secciones:

A) "Instrumentos de lengüeta.- Las lengüetas son sencillas ó dobles, de caña adelgazada ó de laminillas de metal..." 


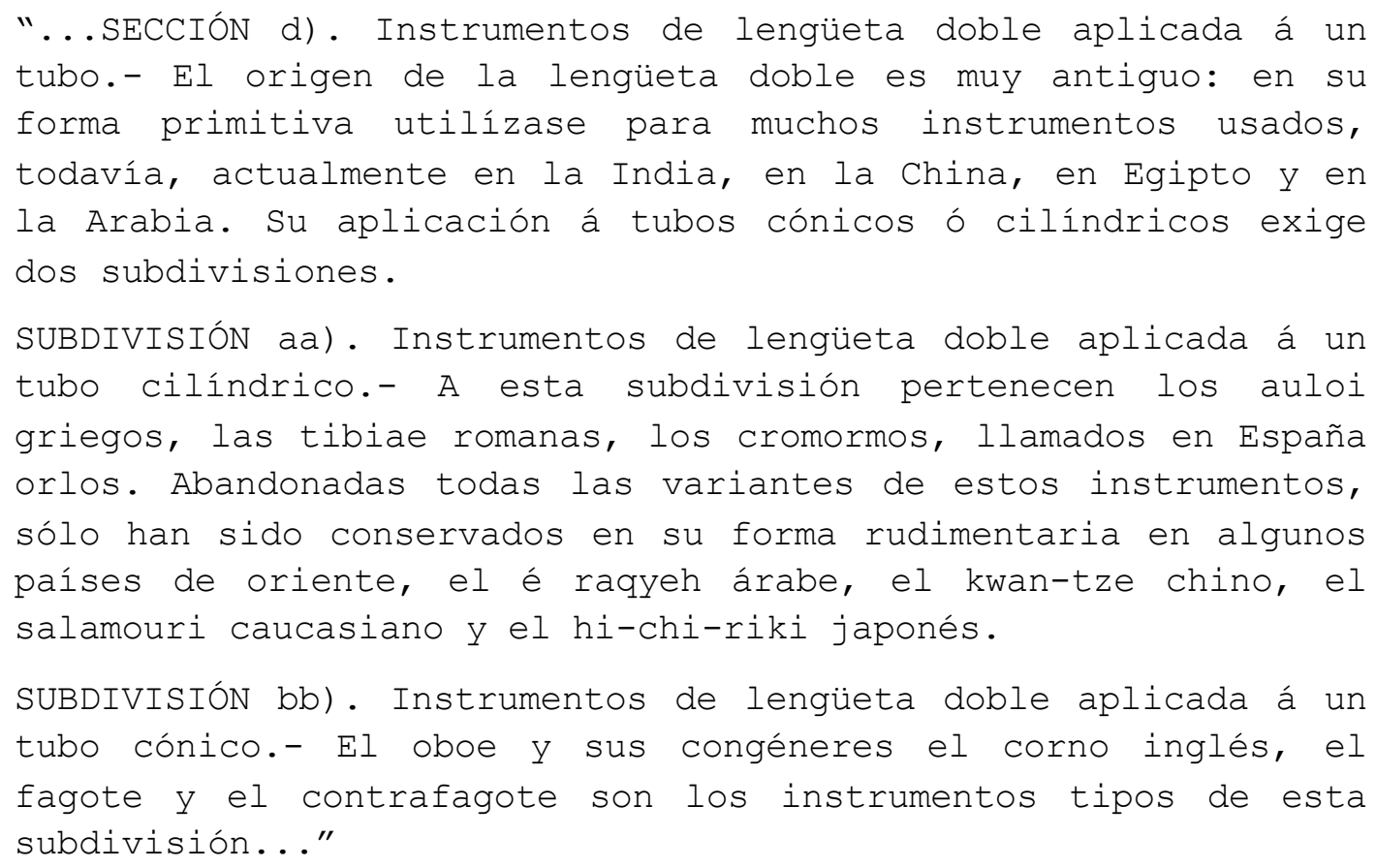

Tras la revisión de todas estas clasificaciones, se puede concluir que el oboe (del francés hautbois, "madera alta") es un instrumento soprano en Do (Michels, 1982), de viento madera, generalmente fabricado con granadilla o ébano (Baines, 1991, p. 91) pero también de otros materiales como plásticos resistentes. Consta de tres partes de taladro interior cónico: superior, medio e inferior o pabellón. Formado originalmente con tres orificios en cada sección, ha evolucionado hasta llegar a los veintitrés orificios actuales, según los diferentes fabricantes. En la Antigüedad, los primitivos orificios se accionaban con los tres dedos de cada mano: índice, corazón y anular, sin llave alguna. Actualmente, el oboe está dotado de un complejo sistema de llaves que facilitan a los músicos la interpretación de las obras más antiguas y posibilitan las obras contemporáneas.

La emisión del sonido se realiza mediante la vibración de una lengüeta doble, fabricada a partir de la caña común Arundo donax (Bigotti, 1974, p. 7). Estas lengüetas, denominadas específicamente palas, se unen entre ellas mediante el atado a un tudel cónico, (tubo metálico generalmente de latón o alpaca que termina en un revestimiento de corcho y se utiliza para unir las lengüetas mediante hilo de nailon), dejando entre las dos palas una pequeña abertura por donde pasa el aire insuflado por el oboísta.

La extensión del instrumento moderno abarca un total de treinta y seis notas desde un $\mathrm{sib}_{3}$ hasta un la (índices acústicos del sistema internacional, la $4=440 \mathrm{~Hz}$ ) de las cuales las dieciséis primeras son notas fundamentales. El resto son armónicos que se producen 
con la ayuda de ciertas llaves especiales (Bate, 1975, p. 4), por lo que el oboe es el instrumento de viento madera con menor extensión (Baines, 1991 ,p. 91).

Existen actualmente varios instrumentos de la familia del oboe con diferente afinación:

1) la musette en Fa, una cuarta por arriba del oboe (Bigotti, 1974 p. 20);

2) el oboe de amor en La, comúnmente utilizado como alto aunque también a veces como mezzo-soprano;

3) el corno inglés en Fa, el tenor de la familia;

4) el oboe barítono en Do;

5) el heckelphone también en Do, el más grave (Bate, 1975 p. 4).

El oboe barítono y el heckelphone son comúnmente confundidos como un mismo instrumento, pero no es así. El heckelphone tiene un diámetro más ancho que el oboe barítono, su extensión es más grave (dos semitonos) y su timbre más amplio (Burgess \& Haynes, 2004, p. 187).

\subsubsection{La lengüeta: definición y proceso de construcción}

Como se ha comentado anteriormente, el oboe es un instrumento aerófono que necesita de una lengüeta para la producción de su sonido. Esta lengüeta es doble, ya que está formada por dos láminas de madera que vibran a una frecuencia determinada, dependiendo de sus dimensiones, masa y elasticidad. Esta vibración, excita las ondas periódicas de presión de la columna de aire situada dentro del tubo del oboe. La lengüeta está formada por dos palas y un tudel que se unen con hilo de nailon, para luego ser raspada con una navaja de un filo.

La elaboración de la lengüeta es un proceso bastante laborioso que requiere paciencia y tiempo. Una vez plantadas y secadas las cañas, se crean tubos a partir de la caña para ser partidos en tres trozos con la ayuda de un divisor de cañas. A continuación, se procede a cortarlas a una longitud de $75 \mathrm{~mm}$, aproximadamente. El siguiente proceso, el gubiado, requiere que las cañas estén húmedas y una máquina de gubiar cañas -eléctrica o manual- para darles una forma ligeramente curva ( $c f$. figura 4.5-arriba y centro). Luego se 
emplea una máquina de modelar palas que consta de un molde y un prensa ( $c f$. figura 4.6), accionada mediante un resorte que apretará la caña con el molde y la cortará de la forma idónea. La pala, a su vez, saldrá doblada por la mitad sin llegar a partirse gracias a que la máquina incorpora una cuchilla que corta el esmalte de la caña.

El siguiente paso es el atado de la caña, para el que se emplean hilo de nailon especial, tudeles, en donde se atará la caña, y un tudelero, mango de madera con un punzón metálico donde se inserta el tudel, que sirve de ayuda para un buen atado (cf. figura 1.1). Una vez atada la caña al tudel, se parte con una guillotina de precisión milimétrica ( $c f$. figura 1.1). Por último, se procede al rebajado, empleando una navaja (cf. figura 1.1) de gran precisión para ir rebajando cada pala y dándole la forma, y una espátula (pieza pequeña de metal o madera), que se inserta entre ambas palas. Se puede añadir hilo de alambre enrollado en la parte inferior de la lengüeta a unos $3 \mathrm{~mm}$ del final del tudel.

La técnica de realización de las lengüetas es uno de los principales problemas con los que se encuentra el estudiante de oboe durante toda su carrera. Y es que este proceso no es una ciencia exacta, por lo que viene condicionado por la práctica y la destreza de cada estudiante y el material del que se dispone. Así pues, Caswell (1987) realiza un proyecto de investigación en la Universidad de Calgary para mejorar el acero de las navajas. Lehrer (1980) aporta su experiencia personal en la construcción de las lengüetas y explica los factores a tener en cuenta para la elección de un buen material. Hewitt (1991) recomienda a los estudiantes la lectura del libro The Reed Makers Manual de Weber y Capps (1990) como complemento a las explicaciones de los profesores de oboe y así poder mejorar el proceso de elaboración de las lengüetas. Dusté (1984) aporta una descripción detallada y con imágenes sobre el estilo americano descrito por Ledet (2008). Incluso Bonar (1983) se plantea el por qué de la existencia de diferentes estilos de rebajado concluyendo que la elección de uno u otro estilo depende de factores como la embocadura, la posición o el ángulo del instrumento respecto al cuerpo.

La elección de un buen material es un tema que ha desarrollado bastante literatura: Trentacosti (1978) dice "hay que tener en cuenta las fibras de la pala, el gubiado, el molde, etc.” Reid (1983) habla incluso de los factores a tener en cuenta para una buena cosecha de cañas y de cómo deben elegirse y secarse. Tan importante es el material, que no debería 
sorprender leer artículos sobre oboístas americanos que viajan a Var con el fin de encontrar la mejor fábrica de Arundo donax (Hardy, 1994).

Otro de los temas que preocupan a los oboístas es la conservación de sus lengüetas. Tanto Bartlett (1990) como Orcutt y Roscoe (1975) y Mack (1974) explican cómo cuidar las lengüetas y almacenarlas manteniendo la cantidad correcta de humedad. Sin embargo, son varios los experimentos aparecidos para mejorar las condiciones de vida y el rendimiento de las cañas, como por ejemplo el realizado por Fox (1987) que trata de modificar la composición y configuración química de las fibras de las cañas mediante un nuevo tratamiento, el BFC o Lakin (1975) que realiza un experimento con lengüetas de diferentes oboístas tratando la madera con PEG o Lacy (1988) que se atreve a empapar las palas en agua durante 8 meses.

A partir del s. XX, la aparición de monográficos y guías explicando tanto el proceso de construcción de las lengüetas, como incluso el rebajado paso a paso, ha sido de gran utilidad para alumnos y profesores (e.g. Mayer y Rohner, 1953; Sprenkle y Ledet, 1961; Steins, 1964; Artley, 1968; Russell, 1971; Hendrick, 1972; Andraud, 1976; Rothwell, 1979; Girard, 1983; Light, 1983; Larson, 1983; Berman, 1988; Weber y Capps, 1990; Shalita, 2003).

Actualmente, existe una gran cantidad de libros que realizan estudios sobre el oboe, las lengüetas, su historia y evolución, sus características acústicas, etc. (e.g. Bigotti, 1974; Bate, 1975; Goossens, 1977; Joppig, 1981; Baines, 1991; Haynes, 2001; Burgess y Haynes, 2004; Ledet, 2008).

\subsubsection{Herramientas necesarias}

El proceso de construcción de una lengüeta consiste en una serie de pasos bien definidos. A continuación se explican los procesos del atado y del rebajado y se describen las herramientas necesarias.

Las herramientas necesarias para la elaboración de las lengüetas son:

1) Navajas (figura 1.1, $\mathrm{n}^{\mathrm{o}}$ 4), su cuchilla debe estar afilada. Es bueno tener varias debido al uso tan frecuente que de ellas se hace.

2) Tudelero (figura 1.1, $\mathrm{n}^{\mathrm{o}}$ 5), es un punzón de acero pulido perfectamente 
redondo que tiene una forma oval en disminución. El uso de esta herramienta no es otro que proporcionar más facilidad al montaje de la lengüeta sobre el tudel.

3) Pala (figura $1.1, n^{0} 8$ ), es la caña con forma de la lengüeta.

4) Tudeles (figura 1.1, $\mathrm{n}^{\mathrm{o}}$ 7), tubo cónico sobre los que se montan las palas. $\mathrm{Su}$ longitud es de 47 milímetros, aunque existen también de 45 y $46 \mathrm{~mm}$. Su diámetro interior puede variar tanto en su extremo superior como inferior, dependiendo de los fabricantes. Su longitud y los diámetros influyen sobre el timbre, el volumen y la afinación del instrumento.

5) Guillotina (figura 1.1, $\mathrm{n}^{\mathrm{o}}$ 1), es una herramienta con la que se cortan la extremidad y las esquinas de las lengüetas.

6) Espátula (figura 1.1, $n^{\circ} 3$ ), es una pestaña de plástico fina y redondeada por los extremos que se coloca en la apertura de la lengüeta con el fin de ayudar a reducir los extremos del raspado tanto como sea necesario.

7) Hilo de nailon (figura 1.1, $\mathrm{n}^{\mathrm{o}}$ 2), necesario para realizar el atado de las palas sobre los tudeles.

8) Pie de rey (figura 1.1, $n^{\circ} 6$ ), útil para controlar la longitud de la lengüeta.

9) Micrómetro externo (figura 1.2), herramienta para medir el grosor externo de la pala.

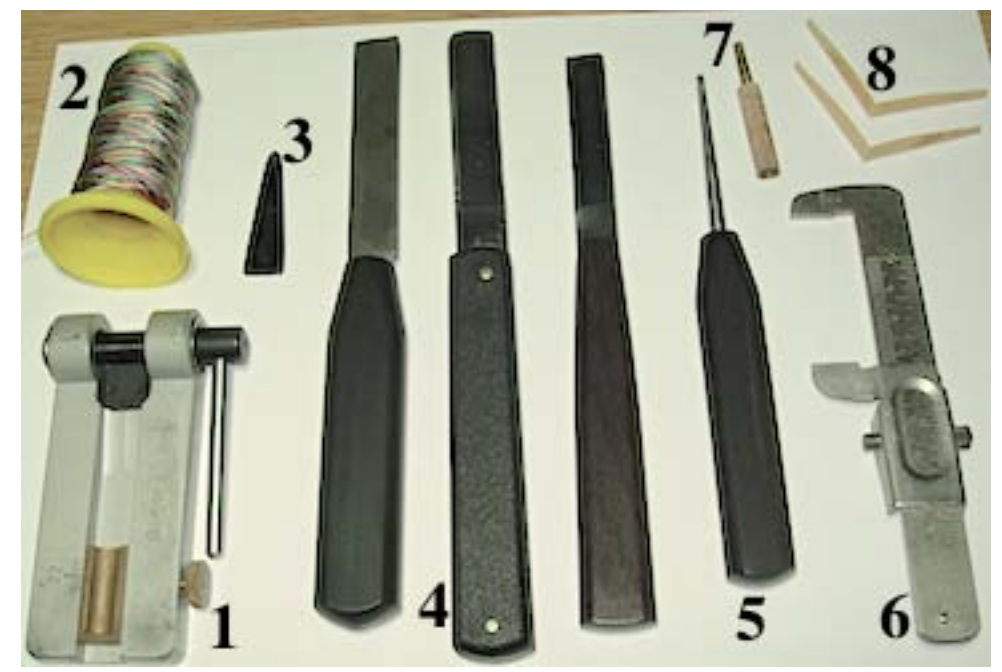

Figura 1.1. Herramientas en la elaboración de las lengüetas. 1: guillotina Rieger; 2: hilo de nailon; 3: espátula de plástico; 4: navajas Chiarugi, Graff plegable y Graff fija; 5: tudelero; 6: pie de rey; 7: tudel; 8: palas. 


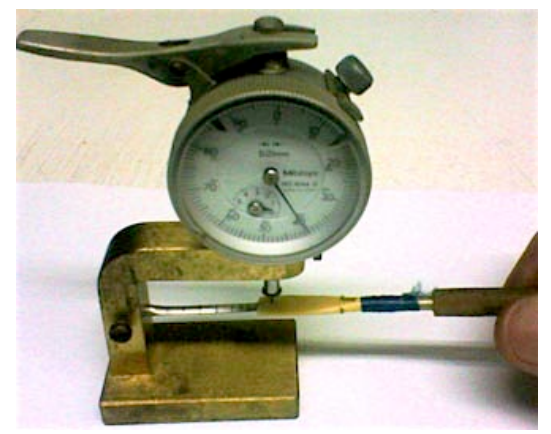

Figura 1.2. Micrómetro de Kunibert Michael

\subsubsection{El atado de las lengüetas}

En primer lugar, la pala se ata al tudel con el hilo de nailon, que nunca debe deshacerse, dando vueltas sobre la pala y el tudel ( $c f$. figura 1.3) y procurando apretar bien. El atado debe llegar hasta el final del tudel (por su extremo superior); si la lengüeta no cierra aún cuando llegamos al final, aunque sólo falte una única vuelta para hacerlo, es necesario deshacer el atado a fin de introducir la caña un poco más sobre el tudel, y reiniciar otra vez el atado. Si los lados se juntan antes de que el hilo haya llegado a poco más de medio milímetro del final del tudel, también es necesario deshacer el atado y, entonces, rehacer la lengüeta a fin que pueda cerrarse correctamente. Cuando la lengüeta está bien cerrada por cada lado, un extremo del hilo se pasa por encima, con las vueltas ya hechas, y acaba de cubrir la parte del tudel que está entre el final de la lengüeta y el tudel. Para asegurar que la lengüeta está bien atada, solo es necesario soplar aire por el extremo grande del tudel, y comprobar que la lengüeta retenga bien este aire. Una vez controlado este aspecto, no hay más que proceder al rebajado.

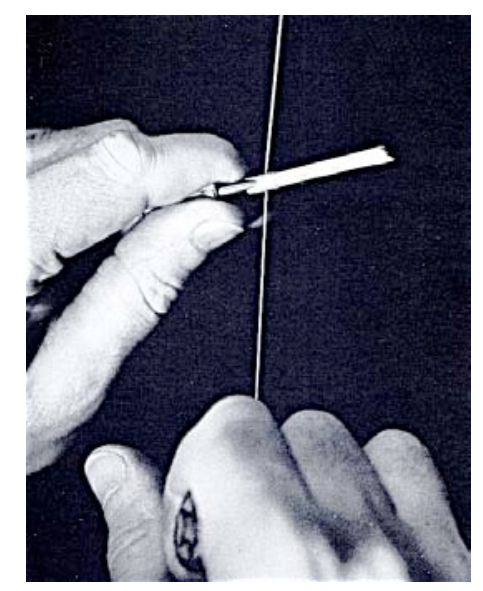

Figura 1.3. Atado de una lengüeta (Sprenkle y Ledet, 1961, p. 78). 


\subsubsection{El rebajado de las lengüetas}

Primero, con una navaja, se rebaja el esmalte natural de la pala, luego se cortan las pala unos dos milímetros y se coloca la espátula entre las dos láminas. Posteriormente se reduce cada lado en forma de bisel hasta que el final no sea más grueso que el papel de cartas, soplando dentro de ella se debe dar una especie de ronquido. La totalidad de la lengüeta y sobre todo la punta, debe desgastarse de los dos lados de igual forma, en la medida de lo posible, para mantener un equilibrio que aporte a la lengüeta calidad en la sonoridad. Las lengüetas acabadas no están finalizadas, por lo que a menudo se irán rebajando poco a poco para ir habituándolas a las características de cada oboísta.
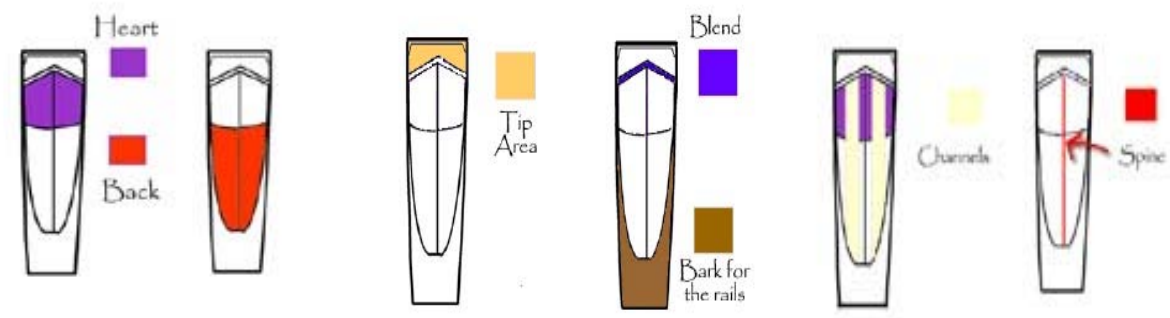

Figura 1.4. Esquema de las diferentes partes de una lengüeta. Heart: centro; Back: parte de atrás; Tip: punta; Blend: parte de atrás de la punta; Channels:canales o lados; Spine: espina central (Shalita, 2003, pp.45-46).

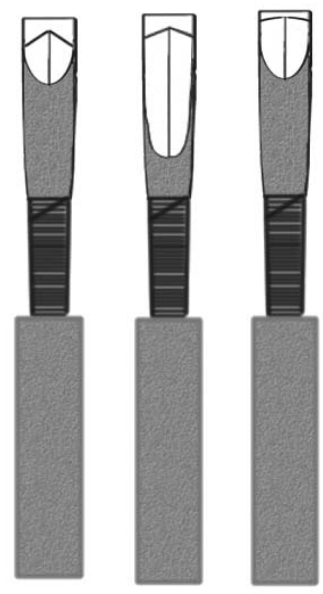

Figura 1.5. Esquema de los tres estilos de rebajado utilizados: francés (izquierda), americano (centro) y alemán (derecha). En las tres lengüetas se puede apreciar claramente las diferencias en la punta y la parte de atrás del rebajado.

\subsubsection{La lengüeta: historia y evolución}

La forma más antigua de lengüeta que se conoce es la lengüeta simple y aunque no han llegado muestras hasta la actualidad, sí han pervivido numerosos instrumentos que detallan cómo eran estas lengüetas (Baines, 1991, p. 190). 
Por otra parte, la utilización de la lengüeta doble se remonta hasta la antigüedad. Actualmente existen en los museos algunas muestras de lengüetas dobles de civilizaciones como Egipto, Grecia, Roma, Oriente,... que las utilizaban para sus diferentes instrumentos: el aulos, la tibiae, etc. (Bate, 1975, p. 11).

La forma de las lengüetas dobles ha ido evolucionando paralelamente al diseño de los oboes, amoldándose así a las características del sonido típico del mismo.

Aunque las instrucciones detalladas sobre cómo era la construcción de las lengüetas empiezan a aparecer en el s. XIX, la mayor parte de esta información es muy superficial, sugiriendo que las más importantes técnicas aún se transmiten de forma oral. Los tratadistas de la época consideraban que el proceso de realización de las lengüetas era ampliamente conocido, por lo que no era necesario escribir sobre ello, pensando quizá que los estudiantes aprendían mejor directamente de la demostración del profesor que de un libro (Burgess \& Haynes, 2004, p. 157)

Además, existía una tradición secreta alrededor del proceso de elaboración de las lengüetas que, como las demás artesanías, estaban controladas por el proteccionismo tradicional de los gremios. Una de las grandes frustraciones de Denis Diderot en su Encyclopédie fue su intento de reunir la información técnica necesaria para la construcción de lengüetas directamente de los artesanos, una actividad que era desconocida antes de la Ilustración de mediados del siglo XVIII. Las cañas antiguas, no se describían en las fuentes pero sí se dibujaban y se pintaban. Los dibujos muestran, no sólo las proporciones y las formas de las cañas, sino también las dimensiones reales (Haynes, 2001, p. 99 y ss).

Los métodos de oboe como los de Garnier (ca. 1800), Vogt (1816-1824), Sellner (1825), Veny (ca. 1828), Brod (ca. 1825, 1830), Barret (1850), Fahrbach (1843), Salviani (1848), Cappelli (ca. 1853) y Marzo (1870), incluyen ilustraciones de las herramientas usadas para realizar lengüetas, así como varias etapas de su manufactura.

Cabe remarcar, ya desde el principio, que los únicos autores que se refieren a un estilo o forma de construcción de lengüetas, haciendo ver por tanto que existían otros estilos, son Brod (1830) y Marzo (1870). Según este último, “destaca la calidad de las lengüetas de construcción francesa, que son más convenientes por su flexibilidad aunque le achaca un exceso de cuerpo o entereza que impide la obtención de un sonido más 
redondo y, según él, grato. Esa entereza no debe impedir que la lengüeta despida bien y con toda libertad en todo el registro del oboe" (Llimerà, 2006).

El método de Garnier (1800) explica la forma de elaborar las lengüetas, pero en ningún momento habla de la existencia de diferentes formas o estilos de rebajarlas. Sí explica las consecuencias de tener una lengüeta demasiado delgada o demasiado gruesa:

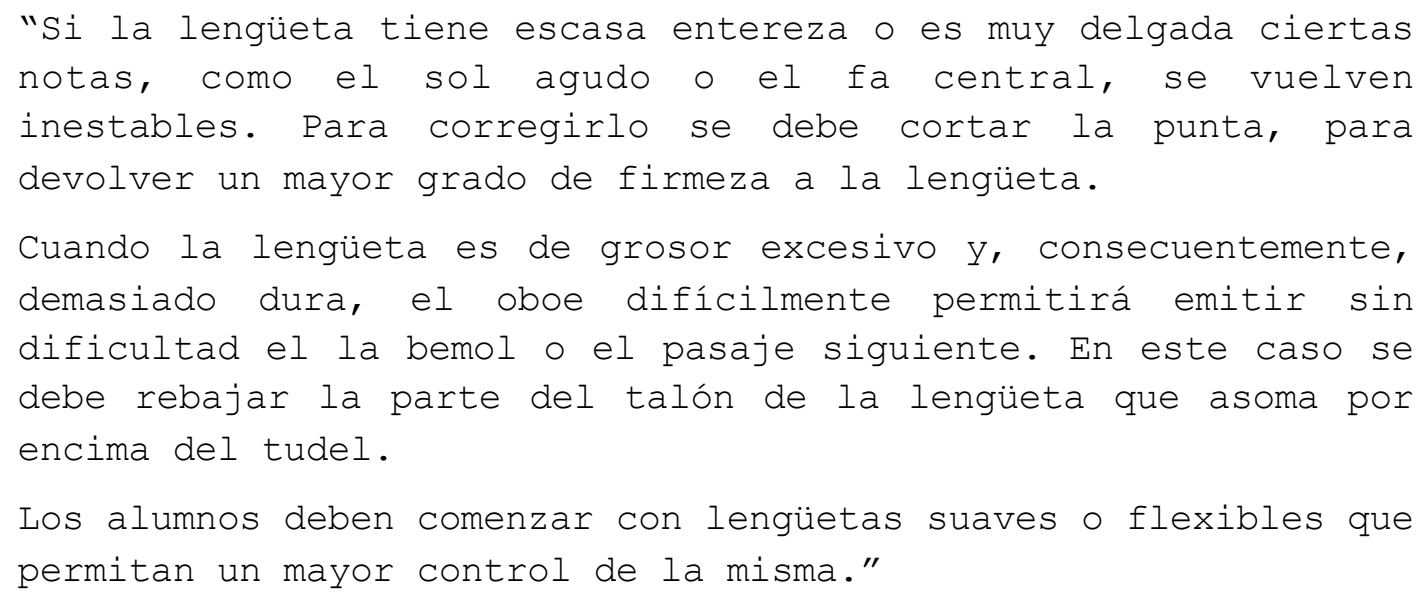

Los alumnos deben comenzar con lengüetas suaves o flexibles que permitan un mayor control de la misma."

Vogt (1816-1824), al igual que Garnier, tampoco nombra las diferentes formas de rebajar, sin embargo da indicaciones más detalladas que las de Garnier sobre los problemas que pueden derivar lengüetas excesivamente largas, cortas, anchas, duras, etc.:

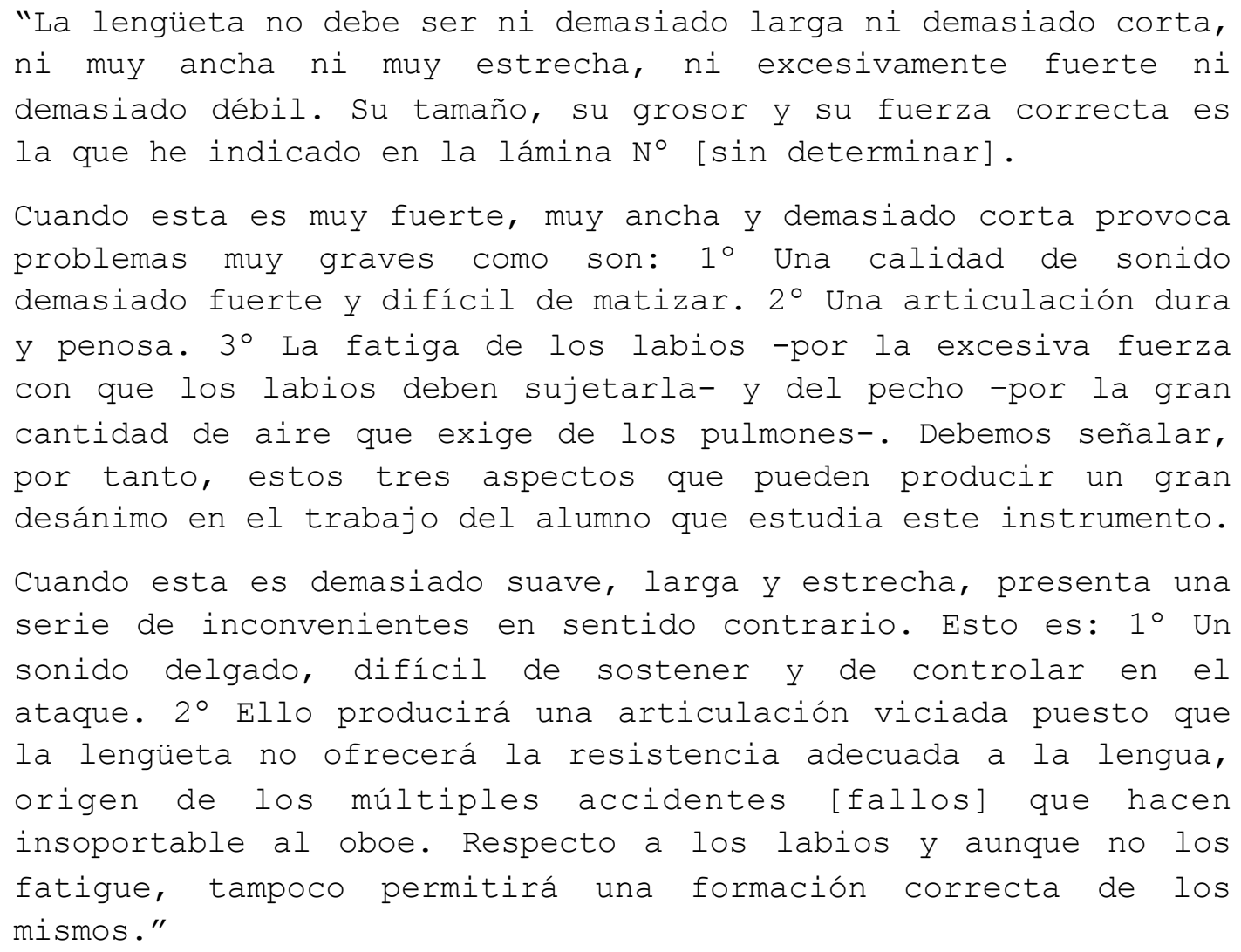


Sellner (1825) prescinde de detallar la elaboración de las lengüetas al considerar que existen suficientes tratados anteriores al suyo que así lo explican. Ahora bien, al igual que los dos anteriores, recomienda sin hacer mención a ningún estilo de rebajado qué debe permitir una buena lengüeta:

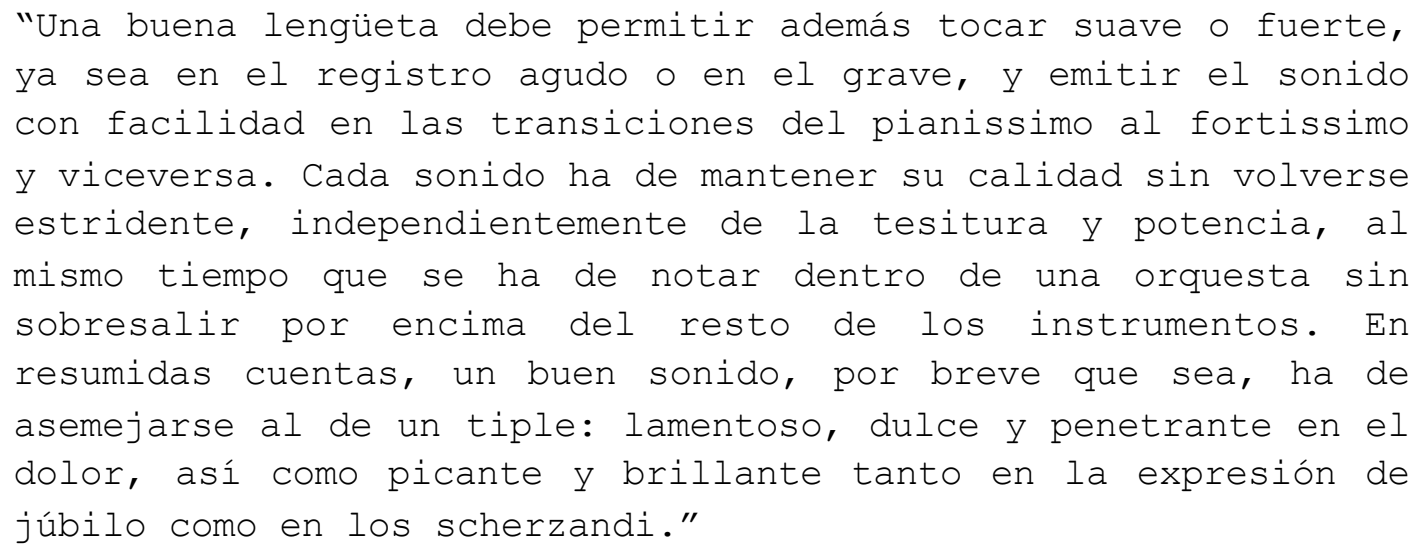

Veny (1828) prescinde hablar de las lengüetas, tan solo lo hace para dar consejo a los alumnos:

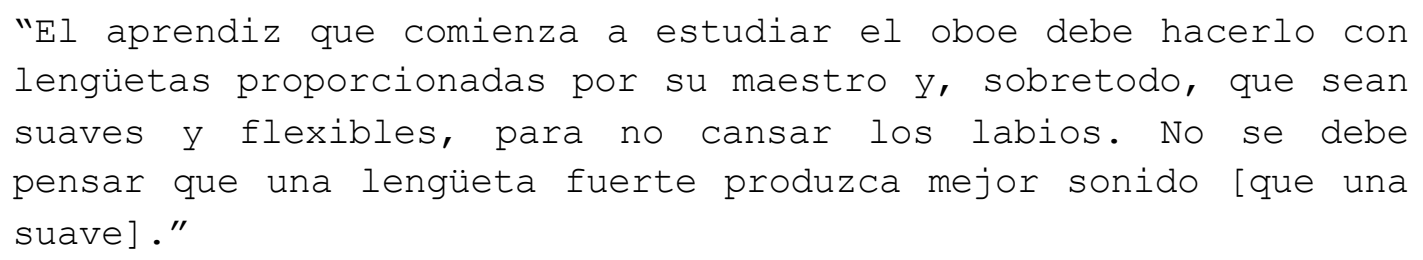

Brod (1825) en su primer volumen, al contrario que los demás, hace hincapié en las diferentes formas de rebajar las lengüetas por parte de los italianos, alemanes y demás extranjeros respecto a los franceses. Es curioso como Ledet (2008) después incluye a los italianos en el mismo estilo que los franceses:

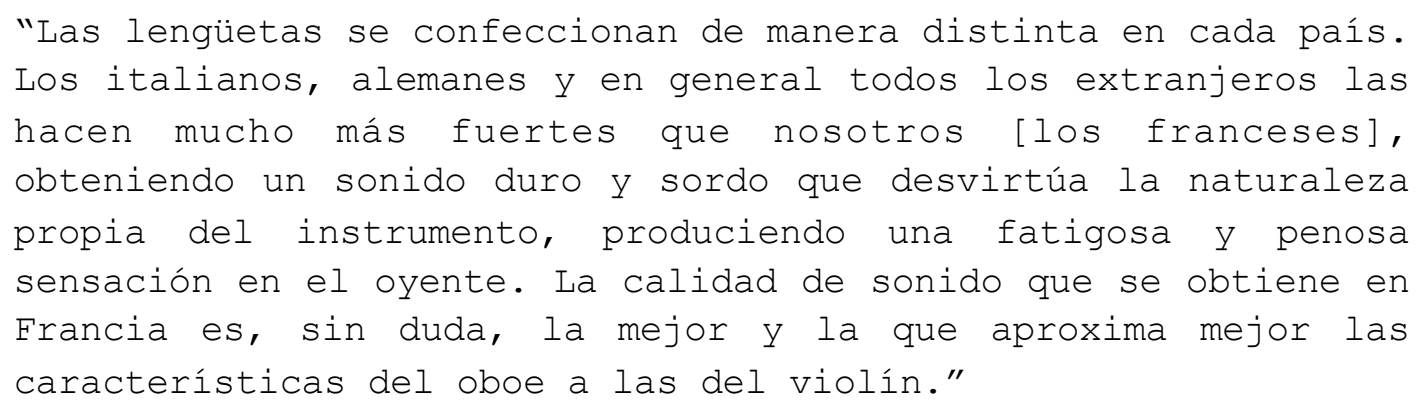

En el segundo volumen de su método, Brod (1830) realiza una descripción detallada de cómo elaborar las lengüetas, desde la forma de la pala, el atado, las medidas, etc. hasta la forma final del rebajado externo. Llama la atención que, aun habiendo 
explicado la existencia de diferentes formas de rebajar la lengüeta, Brod sólo describe lo que más tarde tanto Rothwell (1979) como Ledet (2008) nombrarán como estilo francés:

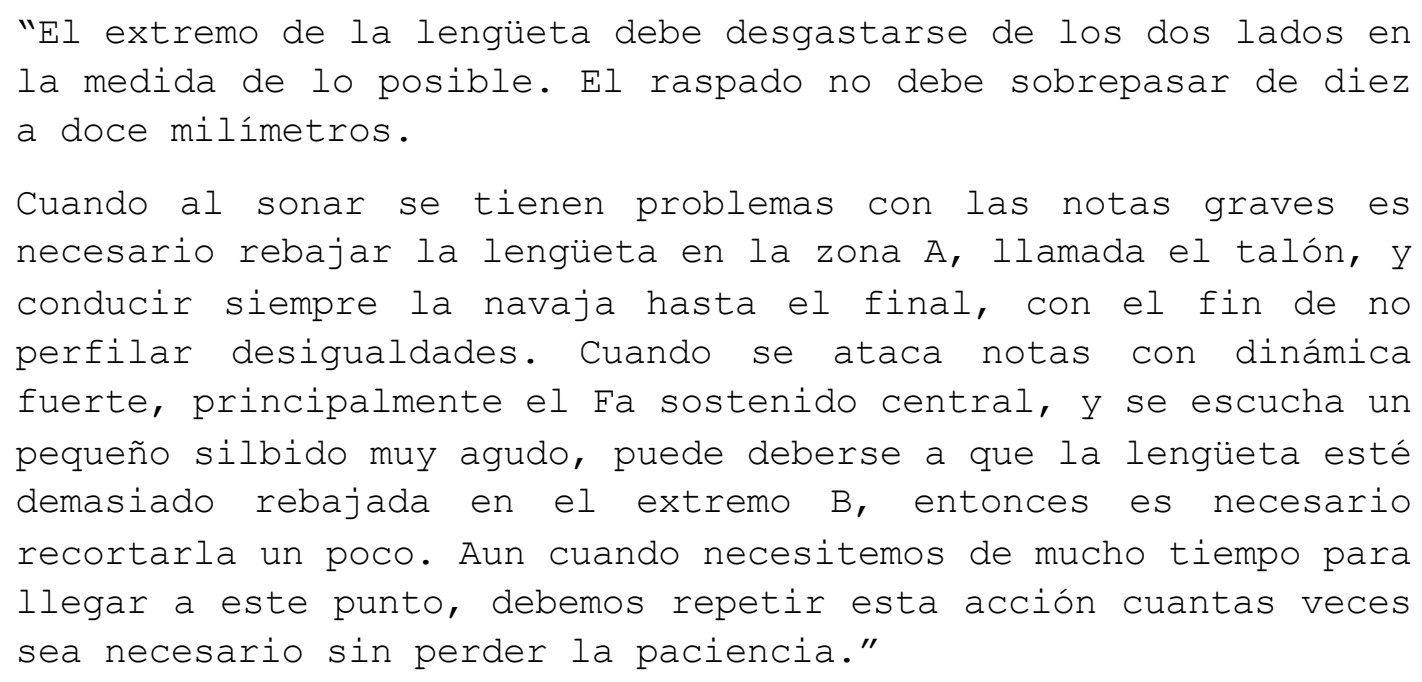

Salviani (1848) no detalla la forma del rebajado de las lengüetas sino que, como la mayoría, da unos consejos sobre lo que se debe realizar si la caña se ha rebajado demasiado o demasiado poco:

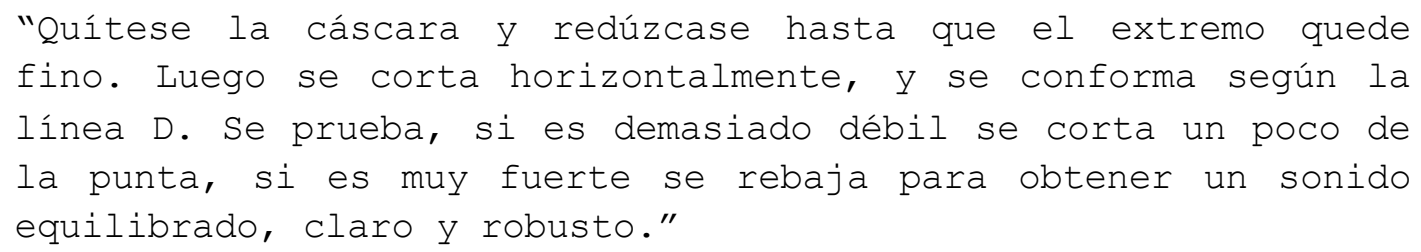

Barret (1850) habla de la importancia y de la dificultad de la fabricación de las lengüetas por parte de los oboístas pero tampoco explica las diferentes formas de rebajarlas:

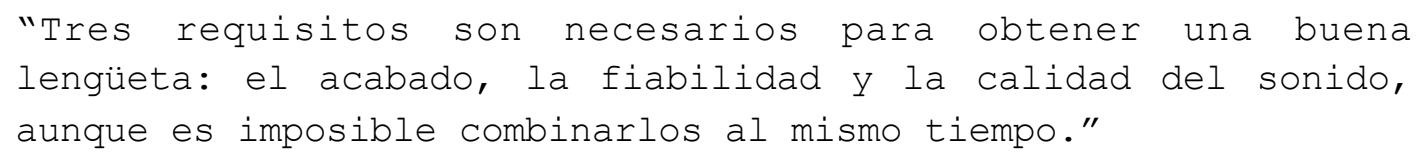

Actualmente una lengüeta doble consiste en una pala (dos láminas de caña plegadas sobre sí misma), que se une por la cara cóncava sobre un tudel (tubo de metal cónico). Una vez atada, la corteza del esmalte de la caña se retira y se rebaja la superficie. Este rebajado tiene una gran influencia en el comportamiento y la sonoridad de la lengüeta, así como del oboe; es por ello que existen diversos estilos de rebajado dependiendo del oboísta y su concepción estética (The New Grove, Dictionary of Music \& Musicians, 1980). 


\subsubsection{Los diferentes tipos de rebajado y sus escuelas}

Después de haber realizado un exhaustivo estudio sobre diferentes lengüetas de oboístas mundialmente reconocidos, Ledet (2008) en su Oboe Reed Styles. Theory and Practice define seis diferentes tipos de rebajado.

Según Ledet, "una escuela de intérpretes es reconocida cuando estos, de una determinada época o lugar, demuestran similitudes en la calidad del sonido y en el estilo de interpretar, que pueden estar relacionados con los principios estéticos y los métodos que emplean (consciente o inconscientemente). Esto significa, intérpretes que tienen una concepción estética similar, los mismos principios respiratorios y de embocadura y que utilizan instrumentos con características similares e incluso idénticas. Y, además, tienen la misma localización musical y utilizan un mismo patrón para construir sus propias cañas englobándose en grupos representativos".

1) El estilo francés se define como aquel que se caracteriza por una longitud total de las lengüetas de $72 \mathrm{~mm}$, un raspado corto (de entre 9 y $13 \mathrm{~mm}$ ) con su correspondiente pendiente pronunciada y sin quitar nada del esmalte de la parte de atrás de la caña.

2) El estilo americano es una modificación del francés y se logró como resultado directo de la construcción de las cañas, la enseñanza, y la experimentación de Marcel Tabuteau durante la primera y la segunda décadas del s. XX. Este estilo llegó a ser predominante en los EEUU en los últimos 30 o 40 años porque muchos de los viejos oboístas del estilo francés se retiraron de las orquestas profesionales norteamericanas, y los instrumentistas jóvenes preferían el sonido producido por las cañas con un raspado largo (14-22 mm) y con el centro de la lengüeta más denso. La punta y la pendiente (en cuanto a su perfil) son más bien cortas, y el esmalte se quita desde la parte de atrás en cantidades variables. La longitud total es generalmente más corta que la de estilo francés para compensar la delgadez causada por el amplio raspado de la parte de atrás.

3) Al contrario del americano, el estilo inglés se caracteriza por un raspado muy corto $(9 \mathrm{~mm})$ y lados más delgados que las lengüetas del actual estilo francés. 
4) El estilo holandés se utiliza en conjunción con la embocadura típica holandesa. Estas cañas son necesariamente más cortas en todas sus dimensiones porque el espesor del gubiado (entre $94 \mathrm{~mm}$ y $76 \mathrm{~mm}$ ), la larga punta, la longitud del raspado (12-16 mm), el corazón, y su ancha forma (7’05-8 mm), tienden a producir lengüetas con una afinación más baja (por la poca resistencia que ofrecen al flujo del aire).

5) Las cañas del estilo vienés no tienen nada que ver con las anteriormente descritas, ya que están hechas para ser tocadas en oboes vieneses, de construcción muy diferente a los demás, sobre todo por su tubo de gran diámetro. Estas cañas tienen un tudel corto $(37-38 \mathrm{~mm})$, con una punta y raspado largos (15-16 mm) y su final en forma de cola de golondrina (W). La resistencia es ligera y la afinación agradable.

6) Es posible definir otro estilo menos obvio el cual es una combinación del raspado francés (corto) y del raspado americano (largo). Este es el estilo alemán, cuyas cañas tendrían una longitud del raspado entre corto y medio.

Por otra parte, Rothwell (1979, p.43) en su libro The Oboist's Companion. Volumen 3. Reed, sólo diferencia entre el estilo americano y el francés. A las características explicadas anteriormente, Rothwell añade ventajas y desventajas de los dos tipos de rebajado:

1) Entre las ventajas del estilo americano, Rothwell explica que el control de la embocadura no es tan crítica como con el estilo francés y que además ofrece una mayor estabilidad en la afinación, mayor facilidad en la emisión de los ataques, en el rango de dinámicas y en la producción de un sonido oscuro. Sobre las desventajas, cabe destacar las críticas que, en ocasiones, puede ofrecer este tipo de sonido demasiado oscuro y pesado. Este sonido suele ser grande, lleno y muy bonito para el oboísta pero puede no proyectar la suficiente calidad y volumen necesarios para las últimas filas de las salas de conciertos, obteniéndose, sin embargo, el efecto contrario al deseado: un sonido más bien pequeño y delgado.

2) Con el estilo francés se facilita el picado y la obtención de un corto, ligero y 
rápido staccato. Una de sus mayores ventajas es la poca resistencia a la columna del aire que estas lengüetas ofrecen, facilitando así la ejecución de largos solos, sin incrementar la fatiga y el esfuerzo. Su peor desventaja es la dificultad para obtener un sonido oscuro y lleno, ya que tienden a producir un sonido brillante característico, proyectando bien pero llegando incluso a molestar en la orquesta. Además, la afinación es menos estable y aumenta la dificultad de controlarla. Estas cañas requieren un gran control muscular de la embocadura. Los ataques suelen ser más duros y la realización de un verdadero diminuendo sin que la afinación caiga es tremendamente difícil.

Baines (1991, p. 82) sólo diferencia el final (la base) de las lengüetas: "un final en U (común en Inglaterra) o una pronunciada V (en Francia)", sin explicar nada respecto a sus efectos en el sonido o en la interpretación. Burgess y Haynes (2004, p.159) hablan sobre los diferentes estilos de rebajado, pero no explican los detalles sobre su construcción o sobre el rebajado.

Steins (1964, p. 26) es uno de los oboístas que sí explica cómo realizar un rebajado alemán y habla sobre el sonido ideal, considerando el francés como el no ideal: "cuando escuchamos un oboe lo preferimos lleno y con un sonido suave. El gusto francés por los colores brillantes ya no se considera internacionalmente como un ideal.”

\subsection{Objetivos generales}

El principal objetivo de esta tesis es averiguar si las diferentes escuelas de rebajado de las lengüetas influyen en la percepción de los oyentes, en las mediciones acústicas generales y en la propiocepción de los intérpretes.

Para ello, se han realizado dos series de experimentos: uno preliminar con seis lengüetas, tres tipos de escuela de rebajado (alemán, francés y americano), dos oboístas y dos oboes; y otro principal con dieciocho lengüetas, tres escuelas de rebajado (alemán, francés y americano), tres moldes de palas (21, 107 y 168 de Hörtnagl), dos grosores de gubiado interno de palas (57/100 mm y 59/100 mm), diez oboístas y un oboe.

En el segundo capítulo se realiza un estudio de los antecedentes utilizados en esta investigación. Los antecedentes se dividen según los estudios que se han realizado en esta 
tesis: percepción tímbrica, acústica de las lengüetas y evaluación interpretativa (propiocepción) y auditiva (percepción).

El estudio preliminar viene explicado en el tercer capítulo, donde se detalla el método utilizado en el experimento y se realiza un estudio perceptivo del timbre y otro acústico. En primer lugar se intenta averiguar si existe o no un patrón de escucha diferente entre los oyentes oboístas y los oyentes músicos no oboístas, utilizando diferentes estímulos musicales variados en complejidad, notas, ataques, etc. En segundo lugar, se miden las lengüetas de forma individual comparándolas con una serie de parámetros acústicos y posteriormente se analizan los resultados de forma global.

El cuarto capítulo está dedicado al estudio principal, donde se detalla el método utilizado y se realiza, además del estudio perceptivo y acústico, un estudio propioceptivo y auditivo. En el estudio perceptivo, en esta ocasión, se realiza un experimento utilizando sólo dos estímulos simples, de una sola nota, normalizados en intensidad y afinación, y sin diferenciar a los oyentes entre oboístas y no oboístas. En el estudio acústico, se miden las lengüetas y se comparan según unos parámetros acústicos, teniendo en cuenta que, en esta ocasión, se añaden otros factores de la construcción de las lengüetas que pueden influir en los resultados acústicos (moldes, y grosores de las palas). Por último, en el estudio propioceptivo y auditivo, se realiza un análisis de las respuestas de los oboístas al terminar las grabaciones (evaluación interpretativa) y se analiza la percepción de los intérpretes a través de un nuevo experimento, donde algunos de los oboístas intérpretes $(\mathrm{N}=5)$ escuchan y evalúan sus propios sonidos (autoevaluación auditiva) y los de los representantes de la escuela alemana y francesa (evaluación auditiva). Asimismo, estos resultados se comparan con las mediciones acústicas anteriores, para averiguar si existe algún parámetro acústico que pueda explicar las puntuaciones tanto interpretativas como auditivas. Finalmente se añade un análisis comparando los resultados de la evaluación interpretativa junto a la autoevaluación auditiva. 
2. Antecedentes 


\subsection{Percepción tímbrica}

La revisión teórica destaca que unas de las características que diferencian a los estilos de rebajado es el timbre, o la calidad del sonido, independientemente de que unos manuales recomienden uno $\mathrm{u}$ otro tipo de sonido (Brod, 1830; Rothwell, 1979). Es necesario pues establecer una definición de timbre y los métodos y resultados que la literatura propone sobre la percepción tímbrica para poder investigar la calidad del sonido de los estilos de rebajado. Identificar el timbre de los diferentes instrumentos musicales o de la voz es uno de los temas que más literatura produce actualmente, existiendo una gran cantidad de estudios de percepción sobre el reconocimiento del timbre de instrumentos musicales.

Existen, además, muchos métodos utilizados en la descripción y en la medición de la percepción de timbre. McAdams (1993) describió seis categorías que se han utilizado específicamente para el timbre de instrumentos musicales: la discriminación, las escalas de evaluación psicofísica (escala semántica o calificación de un atributo verbal), la similitud por comparación (o calificación de proximidad), conjuntos, clasificación e identificación. Estos modelos de descripción y medición del timbre suelen explicar la relación entre las variables de la percepción y de la física (Hajda et al., 1997).

Sin embargo, pocos son los artículos encontrados que tengan en cuenta el proceso de percepción ligado al reconocimiento de algunas de las características del oboe. Russell (1953) (citado por Fitzgerald, 2003), por ejemplo, formuló que los oyentes podían distinguir los diferentes timbres en las interpretaciones oboísticas y propuso que estas diferencias se debían al intérprete, al tipo de lengüeta utilizada y al instrumento en sí. El estudio de Prodan (1977) fue determinar si el "ronquido" que posee una lengüeta cuando se finaliza, influye o no en la calidad del timbre del oboe. Romero et al. (2006) realizaron un estudio preliminar del comportamiento de las cañas, con tres tipos de fabricantes de palas diferentes. Grabaron en la cámara anecoica el sonido la $4(440 \mathrm{~Hz})$ y realizaron un estudio acústico y otro subjetivo, a través de una encuesta a oboístas profesionales, preguntándoles sobre la importancia de la caña en comparación con el instrumento. Los resultados de la encuesta fueron que para los oboístas la caña es más importante que el instrumento y que no existía preferencia por una marca de palas en concreto, siendo la 
humedad el factor más influyente en el comportamiento de las lengüetas. Dahl (2001) realizó un test con diferentes cañas a cinco oboístas de reconocido prestigio. No utilizó la diferencia del rebajado como parámetro, sino los cambios en los elementos que forman la estructura de la lengüeta: diversos diámetros del tubo, diferentes casas suministradoras de palas, varios gubiados internos, etc.

El trabajo de Snitkin (1975) se asemeja bastante a esta investigación. Snitkin (1975) examinó brevemente el concepto de la calidad del timbre del oboe, tratando de analizar los efectos de la caña, del intérprete y la capacidad del oyente de discriminar las diferencias en el timbre del oboe. Para determinar si los sujetos podían juzgar cualquier diferencia perceptible en el timbre, Snitkin utilizó a dos oboístas para llevar a cabo una serie de tareas con dos formas diferentes de rebajar el estilo americano. Se rebajaron seis cañas para tener muestras de los dos tipos de rebajado y propuso dos preguntas de investigación para evaluar la triple relación entre oboísta, oyente y lengüeta:

1) ¿pueden los oyentes distinguir entre diferentes tipos de rebajados de lengüetas del oboe cuando los mismos extractos son interpretados por el mismo oboístas?

2) ¿pueden los oyentes distinguir entre dos oboístas interpretando con la misma lengüeta y el mismo oboe?

Snitkin (1975) reveló que los oyentes podían distinguir los dos tipos de lengüeta, por encima del puro azar pero el grado de discriminación lo consideró insuficiente. Su principal resultado fue que los oyentes podían distinguir dos oboístas diferentes interpretando con la misma lengüeta y el mismo oboe, concluyendo que las características de calidad de sonido de cada oboísta fueron mucho más importantes que las propiedades de la lengüeta para el oyente. (Fitzgerald, 2003).

Jost (1967) combinó un análisis armónico y una investigación semántica para definir las propiedades tímbricas del clarinete. Para ello utilizó tres tipos de clarinetes diferentes y grabó una serie de sonidos que los oyentes escuchaban de forma original y con diferentes dinámicas (piano, forte y mezzo-forte). En los resultados descubrió que el espectro del sonido era importante, además de la frecuencia y de la intensidad, en la 
definición de los atributos de la percepción de la intensidad, el volumen y la densidad (Webster et al., 1970).

Figgs (1981) investigó, con siete modelos diferentes de trompeta, siete sonidos aislados y cuatro fragmentos musicales realizados por el mismo intérprete para que los sujetos valoraron la calidad de los sonidos. En los análisis sugirió que existían diferencias significativas que se debían a la particularidad del timbre de la trompeta.

McAdams (1999) analizó espectralmente los sonidos de siete instrumentos musicales; a partir de estos sonidos realizó simplificaciones y combinaciones de los sonidos originales y preguntó a los oyentes si eran capaces de discriminar los sonidos resintetizados simples y los combinados. Los oyentes distinguían cuando se simplificaba la envolvente espectral o la coherencia de la envolvente de la amplitud, pero tenían poca sensibilidad para las simplificaciones en las variaciones de frecuencias de los armónicos, las variaciones o aplanamiento de la frecuencia y en las variaciones de la amplitud. McAdams intentó con este estudio averiguar hasta qué punto ciertos parámetros acústicos podían ser simplificados con respecto a los sonidos originales, manteniendo sus características tímbricas para poder ser discriminados.

Melka (1994) analizó el sonido del trombón a través de una investigación, donde pasó un test de escucha a trombonistas de orquesta. En primer lugar, los trombonistas debían utilizar adjetivos para describir la calidad de los sonidos de los trombones y más tarde diez oyentes comparaban dos pasajes orquestales interpretados por el mismo intérprete y la misma dinámica, con once modelos diferentes de trombón y con la misma boquilla. Uno de los pasajes era un solo tocado en $m f$ y el otro un tutti tocado en $f f$. Los oyentes debían comparar por pares y agrupar qué par era el que mejor calidad sonora tenía y por qué. Los resultados fueron que la predicción sobre las cualidades del timbre no se pudo comprobar debido a la falta de adecuados juicios de percepción, por lo que Melka (1994) concluyó que no debían hacerse generalizaciones sobre los resultados ya que estaban muy fuertemente arraigados a los sujetos, pasajes musicales e instrumentos y sugirió que sería necesario una serie adicional de experimentos en un contexto más amplio para validar los resultados. Melka et al. (1996) también investigaron descriptores verbales para la descripción de las propiedades de los sonidos del violín con estudiantes de cuerda: utilizando hablantes checos y alemanes. 
Para investigar los atributos multidimensionales de los timbres musicales, Plomp (1970) extrajo períodos aislados de la parte estable del sonido de nueve instrumentos diferentes (trompeta, trombón, trompa, oboe, fagot, clarinete, violín, viola, cello) y generó estímulos sintetizados para cada instrumento en la nota fa $4(394 \mathrm{~Hz})$, eliminando cualquier aspecto temporal con el fin de cuantificar la percepción y las relaciones físicas entre las notas. Los resultados obtenidos mediante el escalamiento multidimensional ofrecieron tres dimensiones aplicables a los resultados e indicaron que los tres factores físicos analizados tenía una correlación con las frecuencias de los dos formantes más graves y con el nivel del segundo formante. Wessel (1973) también probó la validez de los resultados de Plomp (1970) para las diferencias físicas entre los sonidos. Usó los mismos instrumentos que Plomp (1970) pero utilizó un sonido más grave: mib $4(311 \mathrm{~Hz})$. Los resultados de Wessel (1973) obtuvieron dos dimensiones explicables: la primera dimensión distinguía las familias de los instrumentos de metal, madera y cuerda, mientras que la segunda dimensión se refería a la "brillantez" del sonido. Wedin y Goude (1972) realizaron el mismo experimento que Plomp (1970) y Wessel (1973) pero utilizaron la nota la $(440 \mathrm{~Hz}$ ) y la flauta en vez de la viola. Los resultados identificaban tres parámetros principales: riqueza de armónicos correspondiéndose al nivel de energía en los agudos a través de los parciales; pobreza de armónicos correspondiéndose a la disminución de la intensidad de los parciales más agudos; e intensidad baja de la frecuencia fundamental con un incremento en la intensidad de los primeros armónicos. Hajda et al. (1997) indicó que los resultados de estos tres estudios muy similares no eran consistentes: en el estudio de Plomp (1970) no encontraron los mismos resultados, al haber eliminado los aspectos temporales, mientras que con los estudios de Wedin y Goude (1972) y Wessel (1973) encontraron discrepancias con la longitud y elección de los sonidos utilizados. Hajda et al. (1997) sugirieron que podría haber otros factores más destacados que contribuyeran a las diferencias en los resultados, tales como el vibrato, la naturaleza amusical de los estímulos, las condiciones de grabación, la forma de manipular un sonido y la variabilidad en la calidad del sonido entre los intérpretes. Estudios paralelos realizados por Donnadieu et al. (1994), Krimphoff et al. (1994) y McAdams et al. (1995), investigaron sobre los dieciocho sonidos de Wessel (1987). 
McAdams et al. (1995) realizaron un experimento para mejorar la labor de los dos estudios realizados por Donnadieu et al. (1994) y Krimphoff et al. (1994), y así estudiar la estructura de la percepción del timbre y los efectos de la formación musical. Noventa y ocho sujetos con diversos grados de formación musical fueron asignados a tres grupos: músicos profesionales, músicos aficionados y no músicos. Se les pidió la tarea de diferenciar los dieciocho sonidos de Wessel (usados por Donnadieu et al. 1994) en una escala de nueve puntos. Los análisis estadísticos se realizaron eliminando a diez sujetos que puntuaron de forma muy dispar a la media. Se encontraron cinco subgrupos de sujetos para explicar la aparición de tres dimensiones: el tiempo de ataque largo, el centroide espectral y el grado de variación espectral. El grupo de los músicos dieron respuestas más precisas y concordantes que los no músicos o aficionados. Los nuevos resultados sugirieron que el timbre musical posee características específicas que no se contabilizan por estas dimensiones de percepción compartida.

Cabe destacar también, todos los estudios de Grey sobre la investigación del timbre musical: en 1975, Grey utilizó dieciséis notas diferentes de veinte instrumentos diferentes para investigar las características multidimensionales atribuidas al timbre y unos años más tarde (Grey, 1978), comparó la diferenciación de los timbres del clarinete, la trompeta y el fagot en distintos contextos: en notas aisladas y en pasajes polifónicos.

Otras investigaciones que tienen en cuenta el proceso de percepción son, por ejemplo, la experiencia de Goad y Keefe (1986) que trataron la identificación de los timbres de varios instrumentos grabados en diferentes lugares de una misma sala de conciertos o Lakatos (2000), que realizó una serie de tests a músicos y no músicos con el fin de aislar las principales dimensiones de timbre. Hennig (2008) realizó una experiencia variando el timbre y manteniendo siempre la misma frecuencia, en la que demostró que las variaciones en el tiempo de ataque, en el centro de gravedad espectral y en la atenuación armónica constante provocaban diferencias en la percepción, según el parámetro que se variase. Los estudios de Acevedo (2003) mostraron que un porcentaje elevado de la población no identificaba los instrumentos musicales y no era capaz de asociar su timbre correctamente.

Para la investigación de similitudes entre parejas de instrumentos de viento, Kendall y Carterette (1991) grabaron diferentes sonidos y frases melódicas en la flauta, 
oboe, saxofón alto, clarinete y trompeta. Los resultados mediante escalamiento multidimensional mostraron dos dimensiones evidentes y una posible tercera dimensión. Estudios posteriores utilizando atributos verbales (Kendall y Carterette, 1993a, 1993b) demostraron la existencia de dos dimensiones: nasal versus no nasal, brillante versus no brillante y una posible tercera dimensión: simple versus complejo, siendo el oboe el instrumento considerado más nasal, la trompeta el más brillante y el saxofón el más rico. Años más tarde, Carterette y Kendall (1996) y Kendall et al. (1999) investigaron la correspondencia de los análisis acústicos (focalizándose en las características, tanto naturales como de sonidos de instrumentos orquestales sintetizados), con el fin de asignar las propiedades acústicas a cualquier diferencia tímbrica percibida para los sonidos de estos instrumentos.

Para resumir, la literatura sobre el timbre suele, pues, utilizar siempre un método de comparación holística o global, ya sea comparando pares de sonidos o agrupando los sonidos por similitud. Estos sonidos deben estar previamente normalizados en altura, intensidad y duración ya que el timbre siempre se define por defecto, como lo que distingue a sonidos normalizados en las otras dimensiones. Por otra parte, no parecen existir estudios que indiquen que los oyentes distinguen de manera consistente el timbre de sonidos obtenidos con un mismo tipo de instrumentos; en particular, los estudios no muestran una diferenciación por lengüeta del oboe.

\subsection{Acústica de la lengüeta}

El rebajado de la lengüeta no es una ciencia exacta, ya que se realiza a mano y utiliza material natural (la caña) por lo que no puede estar estandardizado, siendo esta característica una excepción en los instrumentos actuales. Por consiguiente, el estudio acústico de las lengüetas ayuda a entender su comportamiento físico respecto a todos los materiales que la componen. Mediante la revisión teórica se intenta conocer las investigaciones realizadas sobre las lengüetas de los instrumentos musicales e incluso sobre los instrumentos musicales en general, para así proponer un método de estudio de los efectos de los estilos de rebajado en las mediciones acústicas.

Existe una gran cantidad de investigaciones acústicas sobre los instrumentos musicales y, más aún, sobre el clarinete y el comportamiento de su caña. Sin embargo, el 
funcionamiento de las lengüetas es muy complejo, siendo los materiales y las dimensiones que los forman irregulares y la predicción de su comportamiento es bastante complicado al estar formada por materiales no homogéneos (Heinrich, 1991). Sus propiedades mecánicas son variables y dependen fuertemente de la humedad retenida (Heinrich, 1991; Marandas et al., 1994; Obataya y Norimoto, 1999). Obataya y Norimoto (1999) consideraron que el aumento de la humedad mejoraba la calidad de las cañas y la densidad y la fricción interna, obteniendo así una mejor reacción de las cañas, que poseían una respuesta más rica y suave. Backus (1966) estudió la influencia de seis parámetros en las cañas del clarinete de forma acústica: la rigidez; el grosor en la punta; la amortiguación del material; la distancia entre la punta de la caña y la boquilla (la abertura); las fugas de aire soplado durante la interpretación; y el impacto de la vibración de la caña contra la boquilla (producción de impulsos que se transmiten a los dientes y de allí por conducción ósea a los oídos del artista).

Hirschberg et al., (1991) estudió la forma de la caña a partir de la experiencia de los músicos que se fabricaban sus propias lengüetas. Afirmó que las variaciones de algunas centésimas de milímetro en las dimensiones de la curvatura de los lados podían llevar a un cambio de comportamiento perceptibles por el músico. Hadden y Vas-Dias (1976) realizaron un diseño de cómo debían ser las lengüetas de los oboes antiguos, reconstruidos como versiones del s. XVIII, buscando un diseño óptimo y apoyados en estudios acústicos. Stetson (2011) investigó sobre el modo de vibración de las cañas del clarinete mediante medición holográfica. Anderson (1996) afirmó que la fabricación de las cañas del clarinete por fabricantes no puede igualar la calidad de las cañas hechas a mano por los profesionales, comparando la producción del sonido entre ambas. Benade y Richards (1983) midieron la longitud real resonadora y la frecuencia en una escala de do5 a do6, para averiguar si existía un octava real, una tercera real, etc. Consideraron que muchas veces el volumen diferencial de dos notas a la octava era muy grande y concluyeron que tanto el movimiento de la caña, la amortiguación de la fricción en ésta y los labios del instrumentista, contribuían en el volumen efectivo producido. A su vez, estos elementos eran influenciados por la fuerza de los labios, la rigidez y la elasticidad de la caña, la humedad de la caña y la abertura en la punta de caña cuando la embocadura aún no ha intervenido en la ejecución musical. Como consecuencia de ello, consideraron que para 
mejorar la eficacia de las cañas, lo ideal era realizar variaciones en la forma de rebajar las lengüetas (cambios en la rigidez), más que los cambios de la geometría aportados por la modificación de los tudeles. Pinard et al. (2003) estudiaron la existencia de una relación directa entre el modo de vibración de las cañas del clarinete y su calidad musical. Clasificaron veinticuatro cañas (Vandoren: V12, grosor 3'5 mm) en un ranking de "muy pobre" y "muy buena", elegidas al azar de diversas cajas y sin haber sido modificadas ni rebajadas. Dos profesionales del clarinete (solistas de la National Opera francesa y de la Orquesta de París) las probaron con sus propios instrumentos (RC Buffet Crampon) y boquillas (Vandoren B40) y evaluaron la calidad musical resultante, así como la posibilidad y la facilidad de poder hacer vibrar las cañas a través de todo el espectro del clarinete. Los dos clarinetistas, aún con formas diferentes de interpretar, estuvieron de acuerdo en las clasificaciones. Más tarde, realizaron un estudio acústico y prepararon el holográfico indicando cuál era el área de vibración de las cañas cuando están ligadas a la boquilla, obteniendo así los patrones de vibración en seco y en mojado (condiciones de humedad). Concluyeron que existe una relación directa entre la forma de vibrar de las cañas y su calidad sonora y que esto es fácilmente medible gracias a la holografía. Además afirmaron que las esquinas de las cañas del clarinete son muy importantes para la aparición del primer modo de torsión (first torsional mode), al contrario que en la doble caña, donde los cortes o deterioros de las esquinas no influyen para el deterioro de la calidad musical (J. Veragh y A. Leroy, comunicación privada en Pinard et al., 2003). Dalmont et al. (2003) consideraron que el comportamiento mecánico de las lengüetas dependía del acoplamiento caña-labios (embocadura), siendo este parámetro muy difícil de medir. Thompson (1979) mostró, después de la realización de varios experimentos sobre el clarinete, que puede haber unos ajustes por parte del instrumentistas sobre la frecuencia de resonancia de la caña de unos dos o tres kHz. Almeida et al. (2007) estudiaron el comportamiento físico de la presión en el oboe y en el fagot y lo compararon con los instrumentos de lengüeta simple. Para esta investigación, unificaron el material de las lengüetas utilizado (palas glotín) y decidieron usar una caña ya acabada para poder ser tocada con facilidad. Afirmaron que las lengüetas varían según su edad, condiciones y tiempo de uso y que además existe una gran variedad de rebajados, remarcando que para una investigación futura, deberían realizar el estudio sobre los diferentes rebajados de los oboístas. 
Bakus (1963) fue el primero en desarrollar un modelo matemático satisfactorio que describía las pequeñas oscilaciones del sonido en el clarinete y más tarde (Backus, 1974) realizó un trabajo acústico de la influencia de la impedancia en los instrumentos de viento de lengüeta: como el clarinete, el fagot y el oboe. Este estudio fue completado por Plitnik y Strong (1979) donde explicaron la importancia del estudio de las impedancias de los cuerpos de los instrumentos de viento madera, particularmente en el oboe, para el buen entendimiento de la entonación, afinación, calidad sonora e interacción de la lengüeta con el cuerpo del instrumento.

Benade y Gans (1968) fueron los primeros en investigar los aspectos no lineales del clarinete, desarrollando un modelo oscilatorio para los instrumentos de viento en general. Worman (1971) continuó con el trabajo no lineal de Benade y Gas (1968), pero aplicó este modelo directamente al clarinete y, al contrario que Backus (1963), consideró a la caña como un elemento no lineal. Unos años más tarde, la representación más realista del tratamiento de la caña del clarinete, lo realizaron Stewart y Strong (1980): consideraron al clarinete como un simple tubo cilíndrico sin orificios y cerrado por una embocadura. Schumacher (1981), sin embargo, investigó las cañas del clarinete y las trató como un elemento oscilador armónico simple con el que desarrolló un método eficiente para obtener, tras una serie de cálculos, la presión existente en la boquilla, aumentando así las posibilidades de realizar futuros estudios teniendo en cuenta un sistema físico del clarinete más perfecto. Facchinetti et al. (2003) realizaron un estudio teórico analizando la relación entre la caña y el clarinete, pero con la diferencia de que no trataron a la caña del clarinete como un sistema no linear y al tubo como uno lineal, sino que consideraron la caña como un sistema mecánico lineal acoplado al tubo donde la interacción con el instrumentista no se analizó.

Benade y Gebler (1974) realizaron un primer estudio de la influencia de la impedancia en instrumentos de lengüeta cónicos y unos años más tarde, Benade y Kouzoupis (1985) estudiaron acústicamente las envolventes musicales de los espectros de los diferentes instrumentos de la orquesta, encontrando similitudes entre ellos y considerándose que los instrumentos musicales pueden ser comparados en términos del espectro de sonido que producen (Beauchamp, 1999). Sin embargo, todos estos estudios no tienen en consideración el efecto de la columna de aire del intérprete, ya que ésta es 
representada como una presión constante. A partir de los estudios de Benade y Hoejke (1982) y Benade (1983), se estudiará la relación entre la impedancia de la columna de aire del intérprete, la impedancia de las cañas, la conductividad a través de éstas y la impedancia del clarinete. Más tarde, Sommerfeldt y Strong (1988) desarrollaron un modelo para el estudio del clarinete teniendo en cuenta la columna de aire del intérprete, las cañas y el clarinete. Lindevald y Gower (1997) completaron el estudio de Hoekje sobre el modo de vibración de las cañas del clarinete.

A partir de los años ochenta, aparecieron más estudios que no sólo tenían en consideración la columna de aire del intérprete, sino que además consideraban el tracto vocal de los instrumentistas como una posible variable. Allen y Strong (1985) estudiaron la influencia del tracto vocal y encontraron una interacción significativa entre el sistema subglotal, la glotis y el sistema supraglotal. Sin embargo, Backus (1985) realizó un estudio para averiguar la influencia del tracto vocal en el timbre de los instrumentos de viento e ideó un sistema para poder medir la impedancia en el tracto vocal en el clarinete obteniendo que la presión sonora en el tracto era menor que la esperada en el clarinete. Después sustituyó el tracto vocal por un sistema de boquilla artificial, mucho más cambiante que el tracto vocal, y observó que los cambios realizados no eran mayores de los esperados, por lo que concluyó que el tracto vocal no influía en el timbre de los instrumentos. Fritz y Wolfe (2005), realizaron un estudio del tracto vocal de los clarinetistas, midiendo la impedancia compleja del espectro de los instrumentistas usando un adaptador dentro de la embocadura del clarinete, descubrieron que la mayoría de los instrumentistas mantienen constante el tracto para la mayoría del rango interpretativo excepto para el registro agudo y para efectos drásticos como el glisandi y el portamento.

El umbral de oscilación de las cañas en el clarinete ha sido ampliamente estudiado en experiencias como las de Grand et al. (1997) y Kergomard et al. (2000). Por ejemplo, Fabrice et al. (2008) estudiaron primero la estabilidad entre el equilibrio de la caña, la inestabilidad de la embocadura (caña, embocadura e instrumentista) y del propio instrumento. Según sus resultados, dos fueron los componentes que actuaban en los valores del umbral de oscilación: el primero debido a la caída de la presión entre la boca y la embocadura, mientras que el segundo debido al movimiento de la caña. Por otro lado, Dalmont et al. (2002) y Atig et al. (2004), estudiaron el umbral de extinción. Dalmont y 
Gilbert (2005) realizaron una síntesis de estos dos umbrales estudiando el rango dinámico existente en la interpretación del clarinete, es decir, realizaron un estudio sobre el umbral necesario en la oscilación y la extinción de las cañas del clarinete. Mostraron que el rango dinámico del clarinete dependía de dos factores: la presión mínima necesaria para cerrar el canal de la caña en un régimen estático y el balance entre la embocadura y el tubo.

Muchas son las investigaciones que tratan de calcular las oscilaciones y el funcionamiento de las cañas aplicando métodos físicos, sobre todo en las lengüetas simples como en el clarinete, el acordeón y el órgano. Idogawa et al. (1988) investigaron acústicamentela vibración de las lengüetas de los instrumentos de viento al insuflarles una presión artificial, tanto creciente como decreciente. Vergez y Caussé (2006) realizaron mediciones acústicas de la influencia del flujo en la caña doble del oboe y Agulló y Barjau (1990) compararon el comportamiento acústico de las lengüetas dobles en instrumentos cónicos (oboe, fagot, chirimía, etc.) con el del clarinete (cilíndrico) y cómo el mecanismo de acoplamiento y el de Bernoulli colaboraban en los instrumentos cónicos, pero no en los cilíndricos. Cottingham (2004) primero y después junto a Dieckman (Cottingham y Dieckman, 2009) realizaron varios estudios acústicos sobre instrumentos exóticos y asiáticos de lengüeta libre. Miller (1999) explicó la construcción del khaen y comparó su comportamiento con los instrumentos asiáticos de lengüeta libre mientras que AgosEsparza et al (2008) estudiaron la influencia de la forma de las cañas de metal en el sonido del txistu. Avanzini (2002) realizó un estudio cuantitativo de simulaciones en tiempo discreto de modelos físicos en las cañas simples. Ricot (2005) estudió la excitación aerodinámica y la producción de sonido en el acordeón y Tonon (2009) centró su investigación en el estudio acústico del acordeón y cómo influían sus cañas en la producción del sonido. Behrens et al. (2009) investigaron sobre los diferentes modos de torsión en las lengüetas del acordeón. Harris et al. (1963) realizaron un estudio acústico del espectro de las caña de la gaita, la influencia de los tubos de resonancia de los armónicos y cómo la longitud de esos tubos afectaba a la frecuencia. El estudio se llevó a cabo con los sonidos de 4 gaiteros, cada uno con su propio instrumento. Ayers y Nordquist (2009) estudiaron los drones de las gaitas y la relación entre su forma, la calidad del sonido y la afinación. Miklós et al. (2003) explicaron el comportamiento de las vibraciones de las cañas en los tubos de los órganos y años más tarde, (Miklós et al., 2006) realizaron un 
estudio de cómo influía la generación del sonido en las lengüetas de los tubos del órgano para así permitir a los constructores de órganos y flautas, obtener el sonido deseado de forma más sencilla. Braasch y Ahrens (1999) realizaron un estudio comparando el comportamiento de las lengüetas de vibración libre y las batientes en el órgano. Cox y Rossing (2002) estudiaron acústicamente el sonido generado en los tubos de un órgano, concretamente en seis tubos, comparando dos tubos de trompeta, dos de oboe, un krummhorn y un rankett. Dalmont et al. (2003) mejoraron la caracterización del comportamiento de la boquilla del clarinete para perfeccionar así la comprensión del fenómeno físico. Ricardo da Silva et al. (2007) estudiaron la relación en el clarinete entre la interacción del fluido-estructura durante los regímenes de flujo dinámico, y del comportamiento transitorio y de estado estable del sistema en función de la geometría de la boquilla. Farner et al. (2005) utilizaron el modelo HBM para los casos de cañas simples y Smyth y Abel (2010) realizaron un estudio acústico sobre las lengüetas. Estos estudios se centran en el comportamiento físico de la lengüeta y sus puntos y modos de vibración, pero sin aportar unos datos acústicos concretos que permitan caracterizar a los diferentes tipos de lengüetas.

Nief et al. (2008) cuestionaron la influencia de las paredes del tubo sobre los instrumentos de viento, construyendo un instrumento de lengüeta simplificado, formado por un tubo de latón conectado a una boquilla de clarinete. Desarrollaron un modelo teórico y consideraron que los resultados obtenidos en el instrumento simplificado debían compararse con los instrumentos reales. Los resultados obtenidos en el instrumento simplificado demostraron que la impedancia de entrada podía afectar ligeramente el tono del color del sonido obtenido, pero que era poco probable que ocurriera en los instrumentos reales a excepción de algunos tubos del órgano.

Otro estudio acústico sobre el timbre de instrumentos musicales fue el producido por Dalmont et al. (2006) que partieron de la hipótesis que el timbre del saxofón estaba formado por una mezcla del timbre del oboe y del fagot, preguntándose cuál era el verdadero timbre de los saxofones. Realizaron varias grabaciones de notas del saxofón, las analizaron y las compararon con otros instrumentos como el oboe. Baumgart et al. (2008) estudiaron la influencia de los bocales en el fagot, comparando el comportamiento acústico de dos bocales en el mismo fagot mediante un soplado artificial. Después experimentaron 
con fagotistas, usando siempre la misma lengüeta. Con este estudio determinaron cómo los materiales de construcción de los bocales y el espesor y contorno del mismo influían en el timbre del fagot. Un resultado interesante es que la geometría de los bocales tenía una mayor influencia en el comportamiento acústico (10\%) que los materiales de fabricación (2\%). Plitnik (2000) estudió la influencia de la shallot en el timbre del órgano utilizando tres tipos diferentes: el estilo americano o inglés, el estilo francés y el estilo alemán. Los resultados mostraron que por cada shallot, la frecuencia se incrementaba proporcionalmente con el grosor y la proporcionalidad de la presión del aire; además, la frecuencia era inversamente proporcional a la longitud cuando las otras variables se mantenían constantes. Por último, la influencia del tipo y grado de curvatura en la vibración de la lengüeta se examinó brevemente: el aumento de la curvatura de la caña tendía a disminuir la frecuencia de vibración y aumentar la intensidad del sonido mediante la creación de un espectro más rico. Un año antes, Plitnik y Lawson (1999) publicaron un estudio sobre el comportamiento acústico de las diferentes boquillas de la trompa y las preferencias de los trompistas por ellas. Trataron de identificar las cualidades subjetivas más importantes que, probablemente, estuvieran influenciadas por la geometría de la boquilla de la trompa. Las variables psicoacústicas evaluadas fueron: la flexibilidad, el control de la afinación, la facilidad de interpretación, la entonación, la tonalidad (la calidad del sonido producido), rango dinámico, y la claridad del ataque (la suavidad y rapidez en el inicio).

\subsection{Evaluación interpretativa y auditiva}

\subsubsection{Evaluación interpretativa}

Con la evaluación interpretativa se analizan las respuestas de los oboístas una vez acabada la interpretación de cada ejercicio. Se quiere averiguar cuál es la sensación del instrumentista cuando interpreta con diferentes lengüetas y, además, cuando lo hace con un estilo de rebajado completamente diferente al suyo. Es importante indicar que se estudia la interpretación y esto es de gran dificultad, ya que no se puede medir directamente lo que hace el oboísta al tocar, sino que se debe pasar por una introspección y una respuesta verbal del oboísta. La revisión teórica establece la definición de propiocepción y la 
cantidad de información que ofrece sobre el cuerpo tanto para el músico como para el oyente que visualiza esos movimientos corporales del intérpretes.

El término propiocepción fue acuñado por el neurofisiólogo Charles Sherrington (1906) que lo definió como la información que se obtiene del propio cuerpo (Peñalba, 2011, p. 219). Cuando se toca un instrumento musical, las acciones están monitorizadas por la propiocepción, que da información sobre el cuerpo: las manos, brazos, presión, balance, etc. La propiocepción contribuye a la conciencia de uno mismo y determina que la experiencia de escuchar o interpretar es subjetiva en el sentido en que se convierte en pensamiento propio. Asimismo, Gibson (1979, p. 116, citado en Peñalba, 2011, p. 219) consideró que la percepción y la propiocepción eran concurrentes y estaban ligadas al conocimiento en general y al conocimiento musical en particular. Peñalba (2011) explicó que el conocimiento musical se basaba en el cuerpo y aunque consideraba que es un término muy difícil de definir, por su implicación no sólo de diferentes actividades sino también de diferentes niveles de conciencia, fue capaz de dividir el conocimiento en dos tipos de conciencia: primaria y de orden superior. Cuando la música está sonando, el conocimiento musical puede diferenciar entre elementos como el ritmo, la melodía, los instrumentos, etc. Sin embargo, el conocimiento musical también implica emociones, imágenes y memorias, elementos que están estrechamente ligados a uno mismo. De esta forma, la conciencia primaria tiene lugar en los estímulos sensoriales de la percepción, refiriéndose al "estado mental de ser consciente en el mundo" mientras que la conciencia de orden superior se refiere a la percepción de uno mismo, es decir requiere "el reconocimiento por parte del sujeto de sus propias acciones y afectos" (Edelman, 1989, citado por Peñalba, 2011, p. 215). Así pues, la propiocepción es la herramienta a través de la cual podemos se conscientes del conocimiento musical (Peñalba, 2011, p. 215).

A partir de la definición de la propiocepción, aparece una gran cantidad de literatura que intenta investigar la relación existente entre el aprendizaje musical y el control del cuerpo. Galvao y Kemp (1999) investigaron sobre la relación existente entre la cinestesia y la educación musical, concretamente en la enseñanza de un instrumento musical. Consideraron que la cinestesia y la propiocepción no eran sinónimos y concluyeron que para la práctica instrumental era necesario una correcta ejecución de la motricidad fina, siendo el control cinestésico (unión mente-cuerpo: cambios de posición, 
velocidad, etc.) desconocido y de gran importancia, tanto para los profesores como para los estudiantes, aunque estos últimos aún no lo desarrollaban. Además, Galvao (2006) investigó la influencia que la actividad musical podía tener sobre el desarrollo cognitivo de los estudiantes, considerando que se podían ver afectadas las condiciones físicas y psíquicas de los alumnos, porque la interpretación de un instrumento musical es una de las actividades humanas más complejas al tratarse de una actividad cognitiva, emocional y cinestésica. Pederiva (2005) también realizó un estudio para ver la relación existente entre cuerpo e instrumento en el contexto de la enseñanza y el aprendizaje. Los resultados mostraron diferentes significados para el cuerpo, incluyendo cuerpo-instrumento, cuerpomente, cuerpo de base, cuerpo, cuerpo-emoción, etc. y afirmó que el modo de concebir el cuerpo influía en la forma de proceder de los profesores en su enseñanza, por lo que indicó la necesidad de cambios en los procedimientos de enseñanza y la revisión de las bases del proceso de enseñanza-aprendizaje en la práctica instrumental.

La memoria motriz es una memoria de control propioceptivo muy importante en la interpretación, por los movimientos empleados en la ejecución musical. La memoria musical ha sido ampliamente estudiada: Hughes (1915), Matthay (1913, 1926), y Gieseking y Leimer (1932/1972) que describieron tres formas principales de memorizar la música: auditiva, visual y cinestésica (Egulaz, 2009). Aiello y Williamon (2002) recogieron las aportaciones de los primeros pedagogos sobre la forma en que los músicos y concretamente los pianistas, memorizaban sus obras. Cuartero y Payri (2010) aplicaron estos tipos de memoria en un experimento con alumnos de piano y Cahn (2008) experimentó con la práctica mental y la física en sesenta estudiantes de jazz concluyendo que el rendimiento del grupo que había utilizado la práctica física era significativamente superior a los de la práctica mental en la tarea más difícil. Highben y Palmer (2003) estudiaron el efecto de dos prácticas mentales en el estudio de una pieza desconocida para pianistas: la auditiva y la motora, y concluyeron que la práctica auditiva era importante para el exitoso desempeño de la memoria.

Muchos estudios han examinado los factores que influyen en el desempeño del aprendizaje de la música. Uno de los factores más importantes es la práctica, siendo los dos componentes más importantes de ésta la información auditiva que los músicos reciben acerca de sus producciones y la información motora que reciben de los movimientos 
asociados a la ejecución (Finney y Palmer, 2003; Palmer y Meyer, 2000; Ross, 1985). Finney y Palmer (2003) mostraron que la falta de retroalimentación auditiva durante la práctica de una pieza desconocida no afectaba a la precisión de los pianistas mientras la partitura estaba en frente de ellos, pero la falta de esta retroalimentación auditiva afectó al rendimiento cuando lo interpretaron de memoria. Palmer y Meyer (2000) demostraron que los pianistas noveles eran más dependientes de la información motora (posición de las manos y de los dedos) en el aprendizaje que los pianistas profesionales. Ross (1985) investigó la influencia de esta práctica mental en el trombón.

Los estudios de Feltz y Landers (1983) y Feltz, Landers y Becker (1988) mostraron que la combinación de práctica mental y física podía mejorar los resultados de la práctica física de forma aislada. Schuster et al. (2011) realizaron una revisión de toda la literatura en las diferentes disciplinas e intentaron averiguar el efecto beneficioso de la práctica mental si se combinaba con la práctica física. El objetivo de su estudio fue identificar las características y el éxito de una sesión de entrenamiento de práctica mental y comparar los resultados de diferentes disciplinas.

Según Peñalba (2005), existen muchas teorías que le dan al cuerpo y a la acción corporal un papel fundamental en la cognición y que es a partir de la teoría de la metáfora formulada por Johnson (1987, citado en Peñalba, 2005) cuando esta importancia cognitiva del cuerpo se aplica a la teoría de la música. Peñalba (2005) consideró que las experiencias corporales se experimentaban a través de lo que se denominan propiocepciones y que a su vez, éstas "regulan el movimiento, sirven para conceptualizar los esquemas motores, intervienen en la percepción y tienen función de autoconsciencia.” Más tarde, Pañalba (2008) aplicó esta teoría junto a otras dos en la práctica instrumental, estudiando el rol que desempeñaba el cuerpo en la interpretación. Del mismo modo, Vargas et al. (2007) consideraron que la información proveniente del procesamiento del propio movimiento corporal, se utilizaba ampliamente en la cognición y que muchos pedagogos como Dalcroze o Suzuki daban una gran importancia a la comprensión del movimiento en la ejecución musical. Sin embargo, afirmaron que esta importancia era más una intuición de pedagogos y músicos, porque el conocimiento sobre la verdadera influencia de la actividad cinestésica y propioceptiva en el entendimiento musical era escaso. Sin embargo, Reed (2007) realizó un estudio para averiguar la relación existente entre el acto de imaginarse la 
interpretación y la acción de la interpretación en sí misma, aplicada al clarinete. Concluyó que la propiocepción es el deseo de sentir aquello que va a sonar y esta sensación debe estar en conexión con la ejecución, no sólo para los clarinetistas, sino para todos los músicos. Broughton y Stevens (2008) también investigaron la importancia del movimiento del cuerpo en la ejecución musical, esta vez centrándose en la marimba. Llegaron a la conclusión de que el movimiento corporal crea una información visual que puede influir en la información auditiva que reciben los oyentes.

Juchniewicz (2008) investigó la influencia del movimiento y la interpretación. Ciento doce participantes evaluaron la interpretación de un pianista profesional tocando un extracto musical grabado en tres condiciones físicas de movimiento: sin movimiento, con movimiento de la cabeza y la cara, y con movimiento completo del cuerpo. Se investigó las relaciones de estos movimientos con el fraseo, la dinámica, el rubato y la interpretación general. Los resultados indicaron que los movimientos físicos del pianista aumentaron significativamente las puntuaciones de los participantes de las diferentes actuaciones. Además, cuando los movimientos físicos del pianista aumentaron, también lo hicieron sus calificaciones de fraseo, dinámica, rubato e interpretación musical general. Morrison et al. (2009) aplicaron esta investigación a los movimientos expresivos del director en las agrupaciones corales. Dos directores participaron grabando dos pasajes con alta y con baja expresividad. Ciento dieciocho participantes evaluaron la expresividad de la interpretación y la mitad de ellos también evaluaron la expresividad del director. Los resultados mostraron que las puntuaciones más altas en expresividad fueron dadas a las agrupaciones con los directores utilizando movimiento más expresivos.

\subsubsection{Propiocepción vibrotáctil}

La propiocepción vibrotáctil aborda la influencia que puede tener la propiocepción muscular y la sensación vibrotáctil en la evaluación del sonido en el campo de la interpretación instrumental musical. Los estudios sobre las interacciones entre la audición y el tacto pueden dividirse entre: por una parte, los que estudian la sensación subjetiva de intensidad (generalmente la adecuación de la intensidad sonora y la intensidad de una vibración percibida de manera táctil, Gillmeister y Eimer, 2007; Yarrow et al., 2008), como por ejemplo Schürmann et al. (2004) que mostraron que los sujetos percibían con mayor 
intensidad sonora los sonidos que iban acompañados con un estímulo vibrotáctil de misma frecuencia; y por otra parte, los estudios basados en la detección o discriminación objetiva de la presencia de una señal en una de las modalidades (Wilson et al., 2009; Yau et al., 2009; Ro et al., 2009). La interacción entre sensación vibrotáctil y audición puede ser parcialmente suprimida cuando todos los estímulos sonoros van acompañados de un equivalente vibrotáctil, con lo que dicha interacción no parece que se produzca en un nivel perceptivo temprano (Yarrow, Haggard y Rothwell, 2008). Estos autores indicaron que el aparente cambio en la sensación auditiva podía no ser estrictamente percepción auditiva, sino simplemente la percepción de un cambio en cualquier estímulo.

La integración de los estímulos auditivos y vibrotáctiles depende de que ambos estímulos estén en la misma frecuencia o sus múltiplos (Wilson, Reed y Braida, 2010) y de que estén sincronizados en el tiempo (Wilson, Reed, y Braida, 2009), pero es independiente a la fase temporal de las señales. En el caso de la interpretación musical, la sincronía y la frecuencia son exactamente las mismas para el sonido y para la vibración, ya que es la vibración del instrumento que genera dicho sonido. Chang y O’Sullivan (2008) extendieron los conceptos que Chion (1998) desarrolló para la audio-visión al campo audio-táctil: sincronización, linearización temporal, enmascaramiento y síncresis. El fenómeno de síncresis es particularmente relevante: se puede definir como la síntesis de un nuevo objeto perceptivo único cuando dos informaciones ocurren de manera congruente y sincrónica. Es decir, cuando el instrumentista ejecuta unas notas, forzosamente va a generarse una síncresis entre sus sensaciones táctiles, su propiocepción corporal para generar esas notas y el sonido que es emitido por el instrumento: cada nota interpretada se convierte en un objeto perceptivo único audio-táctil (y propioceptivo).

O’Sullivan y Chang (2006) indicaron que los humanos eran menos sensibles a las variaciones de frecuencia en el modo táctil respecto al auditivo: por ejemplo, las frecuencias superiores a $250 \mathrm{~Hz}$ se perciben como más "lisas" y como generalmente más agudas, y las frecuencias más graves $(100-150 \mathrm{~Hz})$ son percibidas como "rugosas" y como zumbidos. Los humanos apenas distinguen táctilmente entre un estímulo de $100 \mathrm{~Hz}$ y otro de $110 \mathrm{~Hz}$, mientras que auditivamente la diferencia es muy obvia. 
En general el vocabulario del modo sensorial táctil es impreciso y cuando se percibe en paralelo a otro modo (auditivo generalmente) se adoptan las descripciones del otro modo.

La interacción audio-táctil es particularmente relevante en el ámbito de la interpretación instrumental musical, donde el instrumentista debe conseguir un cierto sonido generando y controlando la vibración del instrumento. Es relevante en todas las familias de instrumentos, pero especialmente en los instrumentos de cuerda y aún más en los instrumentos de viento. Destacan en particular los instrumentos de viento que utilizan lengüetas para generar la vibración sonora, ya que el instrumentista debe controlar la tensión en los músculos orofaciales así como la presión de la columna de aire (Schade, 2007). Al mismo tiempo, debe probar el comportamiento de la lengüeta controlando los puntos mínimos y máximos de presión y cantidad de aire que permiten la correcta vibración, lo cual es crucial en instrumentos de doble caña como el oboe. El oboísta debe así ajustar la altura, la intensidad y el timbre del sonido producido utilizando tanto su propiocepción muscular como la sensación vibrotáctil de la lengüeta y el retorno auditivo. Los instrumentistas profesionales y los profesores de instrumento deben evaluar constantemente la calidad del sonido producido por ellos mismos o los alumnos (evaluación auditiva) ligándola al modo de producción del sonido (propiocepción muscular y percepción táctil).

\subsubsection{Evaluación auditiva}

La evaluación auditiva analiza si las evaluaciones sobre la ejecución y la calidad del sonido de las lengüetas dadas por los oboístas son evaluaciones puramente auditivas o, si por el contrario, existe una parte importante que se debe a la propiocepción y al control de la lengüeta en el momento de ejecutar los ejercicios por parte de los oboístas. Es importante remarcar que la evaluación auditiva no es una tarea de percepción del timbre, sino que es la evaluación de la correcta ejecución de un ejercicio u obra musical y, por consiguiente, contiene cierta subjetividad necesaria para cualquier evaluación musical. La revisión teórica analiza la importancia de la visualización o no del intérprete dentro de las evaluaciones así como las variables que interactúan en las valoraciones de los oyentes. 
Uno de los temas bastante concurrentes en la investigación musical sobre la evaluación de las interpretaciones musicales, es la de realizar experimentos utilizando varios grupos de evaluadores que van a disponer de diferentes herramientas para la evaluación. Ejemplo de este tipo de investigación es la realizada por Wapnick et al. (1997) que intentaron determinar si el atractivo físico de los cantantes afectaba en la calificaciones de los jueces de sus interpretaciones vocales. Para ello, realizaron tres grupos: un grupo evaluaba sólo con el video y sin la voz; el grupo dos evaluaba tanto la imagen como la voz; y el último grupo sólo evaluaba la voz. Los resultados revelaron un tratamiento significativo por el sexo del cantante y por la interacción de su atractivo físico. En la evaluación de la voz solo, no hubo diferencia en los índices de interpretación entre los cantantes más atractivos y menos atractivos para los cantantes masculinos, pero las calificaciones del grupo audiovisual favoreció significativamente a los cantantes más atractivos respecto a los menos atractivos. Además, los resultados mostraron que, tanto para los cantantes masculinos como femeninos, los evaluadores masculinos eran más severos que las evaluadoras femeninas y que las puntuaciones fueron superiores en el grupo audiovisual que en el grupo de audio solo. Vanweelden y McGee (2007) investigaron la influencia de la raza de los directores en la evaluación por parte de los oyentes de las interpretaciones de música espiritual y occidental. Los resultados mostraron que la raza del director y el estilo de música afectaron significativamente a las puntuaciones. Los evaluadores dieron mayor puntuación al grupo con el director blanco que al grupo con el director negro para el mismo extracto de música occidental. Asimismo, el grupo del director negro fue calificado más alto que el grupo del director blanco al realizar el mismo fragmento de música espiritual. Madsen (2009) estudió la influencia de los modos de presentación de los extractos musicales en la evaluación de los oyentes, para interpretaciones de música coral y de sus directores. Los modos de presentación utilizados fueron: sólo audio, sólo vídeo y audio y vídeo. Los resultados concluyeron que no existían diferencias significativas como resultado de los modos de presentación. Napoles (2009) intentó determinar si la visualización de una partitura musical mientras se escuchaba la música, en oposición a no verla, afectaba en las puntuaciones de los músicos cuando interpretaban fragmentos corales. Utilizó cuatro grupos: un grupo que veía la partitura de los cuatro fragmentos; otro grupo que no veía la partitura; y los otros dos grupos que vieron la partitura para dos de los fragmentos, pero no para los otros dos. Los resultados 
indicaron diferencias significativas entre los grupos: el grupo que nunca vio las partituras dio puntuaciones significativamente más bajas que el grupo que vio las partituras de todos los extractos. Por otra parte, Yarbrough et al. (1979) compararon el efecto de dos técnicas educativas sobre la mejora de las habilidades en los directores noveles. Para ello, utilizaron el vídeo y realizaron dos grupos: uno de los grupos visualizaba el vídeo después de sus actuaciones junto con un profesor que indicaba los errores efectuados; el otro grupo veía el vídeo por ellos mismos. El grupo de evaluadores puntuaban las interpretaciones antes y después. Los resultados demostraron que no existían diferencias significativas entre las puntuaciones obtenidas por los dos grupos, aunque sí para la mejoría entre el antes y el después.

Las características de los evaluadores han sido estudiadas para ver cómo influyen en la puntuación de las interpretaciones musicales. Así, Kinney (2009) realizó un estudio para averiguar cómo influía la familiaridad y la experiencia musical en la evaluación de las interpretaciones. Los resultados indicaron que tanto la experiencia musical y la familiaridad afectaban significativamente la coherencia interna de los evaluadores y que estos dos factores interactuaban de manera significativa. Hewitt y Smith (2004) estudiaron la influencia de la formación musical de ciento cincuenta evaluadores al puntuar las interpretaciones de seis estudiantes de trompeta. Los resultados indicaron que no destacaban diferencias significativas, con lo que los oyentes sin una formación musical avanzada podían evaluar con los mismos criterios una interpretación musical.

Del mismo modo, las características musicales que influyen en la evaluación de las interpretaciones musicales también han sido estudiadas por diversos investigadores. Geringer y Johnson (2007) investigaron los efectos de la duración, tempo y nivel de interpretación en las bandas de música. Para ello, noventa y seis estudiantes de música evaluaron diferentes actuaciones de una banda, que variaba en el nivel de interpretación (secundaria, universidad y profesional), en el tempo (rápido y lento), y en la duración (aproximadamente doce, veinticinco y cincuenta segundos). Los resultados no mostraron un efecto principal de la duración de forma aislada, aunque sí hubo una interacción significativa entre la duración, el tempo y nivel de interpretación. Las puntuaciones de los oyentes fueron más altas para las duraciones medias y largas en las interpretaciones de los profesionales y universitarios que las duraciones cortas. En contraste, las duraciones 
medias y largas fueron calificadas más bajas que los extractos breves para las actuaciones de secundaria y el extracto lento fue evaluado mejor que el extracto rápido sólo para las actuaciones profesionales. Davis (1998) y Yarbrough y Madsen (1998) estudiaron la influencia de los ensayos en las interpretaciones y evaluaciones de los grupos corales. Davis (1998) llegó a la conclusión de que el aumento de los ensayos mejoraba el ritmo y hacía decrecer las explicaciones del director. Duke y Henninger (1998) diseñaron un estudio para comparar los efectos de las declaraciones de retroalimentación negativas en contraste con las explicaciones específicas en la enseñanza de la interpretación musical. Veinticinco alumnos universitarios y otros veinticinco de $5^{\circ}$ y $6^{\circ}$ de grado interpretaron un tema de memoria. En la mitad de las clases el profesor daba la clase con un feedback negativo y en la otra mitad, daba explicaciones concretas con aquello que debían hacer. Todos los alumnos expresaron una actitud positiva y alcanzaron el objetivo final de interpretación a tiempo en todos los casos.

Por otra parte, Geringer y Madsen (1998) intentaron buscar un patrón de evaluación de los músicos sobre las buenas y las malas interpretaciones musicales. Los oyentes escuchaban diferentes extractos musicales y puntuaban varias características musicales (fraseo, expresión, afinación, ritmo, dinámica y calidad sonora), además de dar una puntuación global. Los resultados indicaron que todos los oyentes discriminaron correctamente las buenas y la malas interpretaciones, siendo la afinación el ítem más susceptible en la evaluación. Wapnick y Ekholm (1997) entrevistaron a varios expertos para intentar averiguar los criterios de evaluación de la interpretación vocal. Para ello, se construyó una escala con el fin de poder evaluar a los jueces, que escucharon diecinueve actuaciones diferentes y seis de ella se escucharon dos veces. Los resultados mostraron que los elementos más fiables eran la puntuación global y la precisión de la afinación.

Existen bastantes estudios que intentan averiguar cuáles son las variables que interactúan en las puntuaciones obtenidas por diferentes grupos de música en los festivales organizados en Estados Unidos. Hash (2012) analizó todas las puntuaciones obtenidas por las diferentes agrupaciones desde el año 2008 al 2010 y concluyó que los datos indicaban diferencias significativas en ocho de los dieciocho jurados para las agrupaciones musicales en el año 2010. Del mismo modo, Norris y Borst (2007) compararon dos festivales de diferente importancia por su asistencia y midieron la fiabilidad de las puntuaciones de los 
jueces y las diferencias entre esas puntuaciones. Prince y Chang (2005) y Prince (2006) realizaron una serie de investigaciones sobre la evaluación en las puntuaciones de los ensembles de música en los festivales y la relación existente entre la calidad de la dirección y la puntuación general y entre la expresividad de la dirección y la puntuación general. Concluyeron que no encontraron una relación aparente entre la expresividad con las calificaciones del festival, así como tampoco encontraron una relación directa entre las puntuaciones obtenidas por la calidad de la dirección con la puntuación final. Bergee (2007) realizó un estudio donde se evaluaba a ocho intérpretes ejecutando solos musicales. Diez evaluadores cualificados expresaban la calidad de las interpretaciones entre un rango de 0 (pobre) y 10 (excelente). El análisis de datos concluyó que los evaluadores fueron una gran fuente de error, obteniendo una fiabilidad baja, sin existir un patrón de puntuación. Por otra parte, Bergee y Platt (2003), Bergee y McWhirter (2005), Bergee y Westfall (2005) y Bergee (2006) realizaron una serie de experimentos con el fin de encontrar cuáles eran las variables extra musicales (tamaño de la escuela, tipo de evento, nivel económico, etc.) que se daban en el mismo festival de música organizado en diferentes años. Intentaron averiguar qué relación existía entre las puntuaciones obtenidas por el jurado y las variables extra musicales citadas anteriormente. Llegaron a conclusión que, por ejemplo, una interpretación solística, que no se diera al principio del día, de una escuela con un nivel económico alto y de una gran ciudad era ya una predisposición para el éxito en el festival. Continuando con la investigación de parámetros extra musicales que influyen en la evaluación de las interpretaciones musicales, se encuentra también el estudio de Pettijohn y Sacco (2009) que investigaron cuál era la relación entre la elección del número uno del billboard con las condiciones sociales y económicas de EEUU entre los años 1995 y 2003. Llegaron a la conclusión que cuando los tiempos económicos y sociales eran relativamente amenazantes, las canciones de mayor duración, con más significado en el contenido, más románticas y más lentas eran las más populares; y que en estas mismas condiciones también eran más populares los artistas con características faciales maduras, ojos más pequeños y caras más delgadas con las barbillas grandes. 
3. Estudio preliminar: percepción tímbrica y acústica de la lengüeta 


\subsection{Introducción}

El experimento preliminar consiste en dos estudios: uno perceptivo y otro acústico. A partir de seis lengüetas con tres rebajados diferentes y todos los demás parámetros de construcción de las lengüetas manteniéndose constantes, se realizan los experimentos y se extraen los resultados y las conclusiones.

En el experimento perceptivo, se estudia si existen o no diferencias en el sonido del oboe dependiendo del tipo de rebajado utilizado en las lengüetas. Además, se averigua si puede darse un patrón de escucha diferente entre los oyentes oboístas y los oyentes músicos no oboístas. Según los diferentes tratados teóricos del oboe, como por ejemplo Brod (1830) o Rothewell (1979) los diferentes rebajados otorgan propiedades al sonido tales como "brillante, suave, duro, etc." ( $c f$. punto 1.1.3 para más detalle), por lo que se intenta demostrar si los oyentes son capaces de discriminar estas características mediante el experimento de percepción.

En el estudio acústico, se realiza una descripción acústica del comportamiento de los diferentes rebajados en las lengüetas del oboe.

\subsection{Objetivos}

El objetivo de este primer experimento consiste en averiguar si los diferentes estilos existentes para la técnica del rebajado de la lengüeta influyen en aspectos técnicointerpretativos del oboe (análisis acústico) y en la percepción de los diferentes timbres por parte de los oyentes (análisis perceptivo).

Se trata, por tanto, de realizar una investigación sobre diferentes ejercicios del oboe: el ataque, el oscillato, la afinación, el staccato, el doble staccato, el frullato, la intensidad, la dinámica, los dobles sonidos armónicos y el legato (cf. definiciones en el punto 3.3.4).

Para cada una de las cuestiones perceptivas y de realización de la lengüeta, se estudian los siguientes parámetros:

1) Tipos de lengüeta: se limitan a tres los estilos de rebajado para, además de reducir el número de combinaciones posibles, centrarse en los estilos que 
actualmente se utilizan. Estos tres estilos son: el alemán, el francés y el americano.

2) Instrumento e instrumentista: uno de los factores más importantes es la variabilidad que introduce tanto el instrumento como su intérprete. En este caso, la cuestión a tener en cuenta es ante todo la influencia de la lengüeta; sin embargo se debe poder contestar si la variabilidad del instrumentista es mayor que la de la lengüeta, sobre todo para recursos interpretativos no convencionales o complicados. El estudio pues se basa en un solo intérprete, por la existencia de una gran complejidad de variaciones, y se utiliza a un segundo intérprete para detectar si se reproducen las variaciones debidas a la lengüeta o no.

3) Recursos técnico-interpretativos: frullato, oscillato, dobles sonidos armónicos, doble staccato.

4) Funcionamiento y posibilidades interpretativas del oboe: variaciones de altura e intensidad, velocidad de ataque y precisión, estabilidad y flexibilidad, afinación.

El objetivo es saber si los diferentes oyentes saben diferenciar el timbre del oboe según los diferentes estilos de rebajado de las lengüetas. Para ello, en el análisis, se contestan a cuestiones como: si influyen los diferentes modos de rebajar una lengüeta en la percepción del ataque, el timbre, la afinación, etc.; se averigua qué parámetro tiene mayor importancia, si los diferentes tipos de rebajado o los diferentes intérpretes o qué estilos de rebajado perciben los oyentes como más parecidos.

Se deja fuera de la investigación otros aspectos como el reconocimiento de los diferentes instrumentistas y las escuelas a las que pertenecen, los aspectos técnicos que forman las lengüetas (qué clase de palas se utilizan, qué tudeles, etc.) o la marca comercial de los diferentes instrumentos que se tocan. 


\subsection{Material experimental}

\subsubsection{Lengüetas}

Para la preparación de la experiencia se utilizaron seis lengüetas, dos por cada tipo de estilo de rebajado (figura 3.1), definidos por Ledet (2008): el alemán, el francés y el americano.

Todas las lengüetas mantenían las mismas características en cuanto a grosor y molde de la pala, tudel, longitud, etc.:

1) Gubiado interno: $57 / 100 \mathrm{~mm}$

2) Longitud total (atadas): $74 \mathrm{~mm}$

3) Longitud total (cortadas): $73 \mathrm{~mm}$

4) Diámetro del tubo: $10,25-10,50 \mathrm{~mm}$

5) Molde de las palas: RC12

6) Fabricante de las palas: Le Rousseau Chantant

7) Tudel: Chiarugi $472+$

Las lengüetas se realizaron expresamente para este experimento de investigación entre mayo y junio de 2009. Se ataron en total veinticinco lengüetas, construidas todas ellas a partir de palas Le Rousseau Chantant y utilizándose para todas el tudel Chiarugi 2+ de $47 \mathrm{~mm}$. Tanto el gubiado interno de las palas, como el diámetro del tubo y la longitud total (atadas y cortadas) se mantuvo constante en todas las lengüetas. Una vez finalizado el proceso del atado, se rebajaron todas a mano, escogiendo para la grabación las lengüetas con el mejor material.

Las lengüetas seleccionadas fueron terminadas poco a poco durante las dos semanas anteriores al día de la grabación y durante la semana anterior a este día, fueron estudiadas media hora al día para habituarlas al proceso de interpretación, obteniéndose así el mejor resultado posible de todas ellas. 


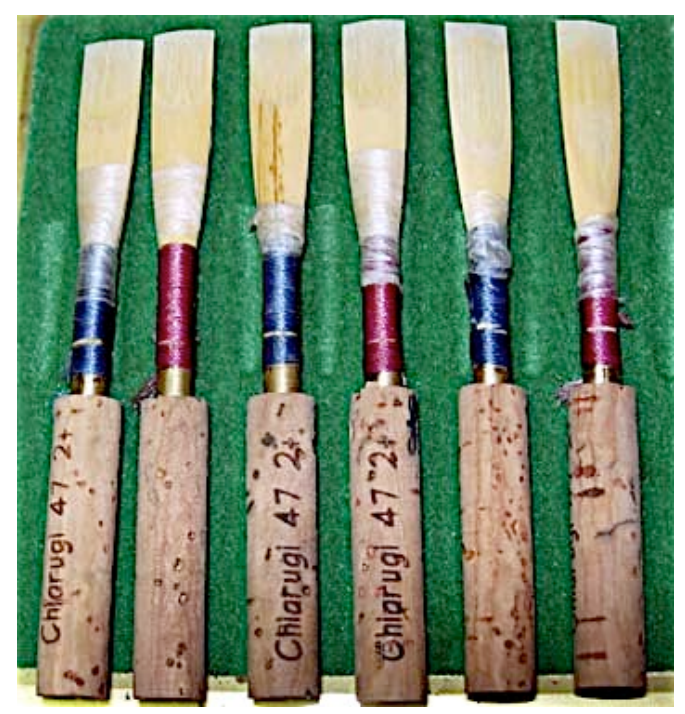

Figura 3.1. Lengüetas realizadas y utilizadas en la grabación del experimento preliminar. De izquierda a derecha: las dos lengüetas alemanas, las dos francesas y las dos americanas.

\subsubsection{Oboístas}

Los dos oboístas escogidos para la grabación de este primer experimento fueron Fermín Clemente Bo y Carolina Blasco Yepes, ambos alumnos, directa o indirectamente, de la escuela alemana. Ambos intérpretes son profesores y profesionales activos del oboe, por lo que la realización de los ejercicios de forma correcta estuvo garantizada.
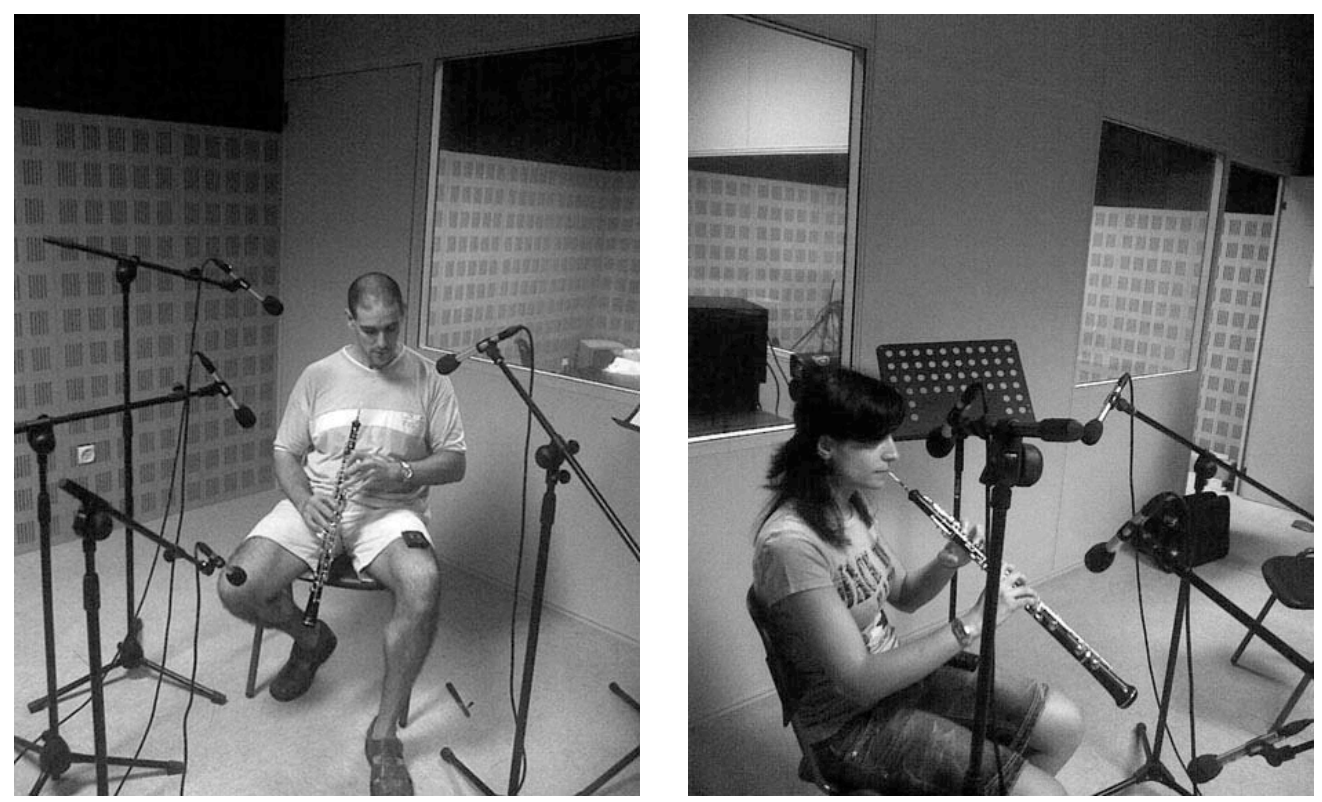

Figura 3.2. Fotografías del estudio de grabación en el momento de la grabación de los sonidos, mostrando las posiciones del oboe y el oboísta, y de los cuatro micrófonos.

Los dos intérpretes (figura 3.2) grabaron con oboes Yamaha Custom 831 semiautomáticos, los números de serie son: 3925 y 4371. 


\subsubsection{Grabación}

La grabación se realizó el viernes 26 de junio de 2009, a las 16 h, en la sala de grabación del estudio de radio del Campus de Gandia de la Universitat Politècnica de València. Esta sala tiene unas características adecuadas para la grabación de voz e instrumentos, porque ha sido acondicionada para evitar reverberaciones audibles. No es una sala completamente anecoica, ya que produciría unas condiciones de grabación artificiales e incómodas para el instrumentista.

Las condiciones de temperatura y humedad relativa se mantuvieron constantes durante las tres horas de grabación, la temperatura era de $25^{\circ} \mathrm{C}$ y la humedad relativa del 75\%. El mantenimiento de una temperatura constante es muy importante, ya que uno de los problemas que más afectan a los instrumentistas de viento es la temperatura, porque las diferencias en ella pueden provocar cambios en la afinación de las notas (Fletcher y Rossing, 1998, p. 470).

Se utilizaron cuatro micrófonos AKG C451B (figura 3.3) situados uno arriba, otro abajo y dos laterales, uno a cada lado de los intérpretes, que se encontraban sentados.

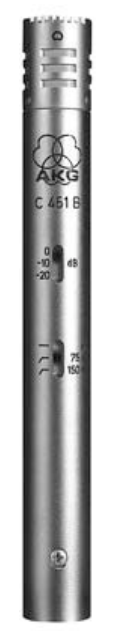

Figura 3.3. Micrófono AKG C451B usado en la grabación.

Las instrucciones dadas a los dos intérpretes fueron siempre a nivel interpretativo. Los oboístas tenían delante, en un atril, la experiencia definida con los diferentes ejercicios escritos en pentagramas; además disponían de la ayuda de un metrónomo (sólo visual) para los ejercicios establecidos para una velocidad determinada. En ningún momento se dispuso de afinador. 
Los oboístas sabían en cada momento con qué tipo de lengüeta estaban interpretando, además de por la forma del rebajado, que las hacía evidente, porque las lengüetas estaban numeradas: $f_{1}, f_{2}$ para las francesas; $g_{1}, g_{2}$ para las alemanas y $a_{1}, a_{2}$ para las americanas.

Para empezar todas las lengüetas fueron humedecidas con agua y después se interpretó con todas ellas unos minutos, adecuándolas así a las condiciones climáticas y de humedad de la sala. Durante la grabación, cuando se cambiaba de lengüeta, se volvía a tocar un poco con la lengüeta correspondiente antes de realizar los ejercicios, para que así no interviniese el factor sorpresa.

Todos los ejercicios se interpretaron seguidos con la misma lengüeta por parte del oboísta principal. Después, se cambiaba de lengüeta para volver a grabarlos. El orden de grabación fue: lengüeta francesa 2 , lengüeta francesa 1 , lengüeta alemana 1 , lengüeta alemana 2, lengüeta americana 2, lengüeta americana 1.

El oboísta secundario grabó los ejercicios de ataque, afinación, staccato, dinámica y legato, con sólo una lengüeta representativa de cada estilo: francesa 1, alemana 2 y americana 1.

\subsubsection{Material grabado}

Se ha grabado una serie de ejercicios confeccionados expresamente para realizar esta experiencia. Los ejercicios son:

Ataque: dar la primera acometida para la producción de una nota.

Se ejecutaron dos notas en los registros grave y sobreagudo (figura 3.4). El ataque se realizó de dos formas: primero con un ataque de lengua (pronunciando la letra " $\mathrm{t}$ ") y segundo con un ataque con aire (sin lengua).

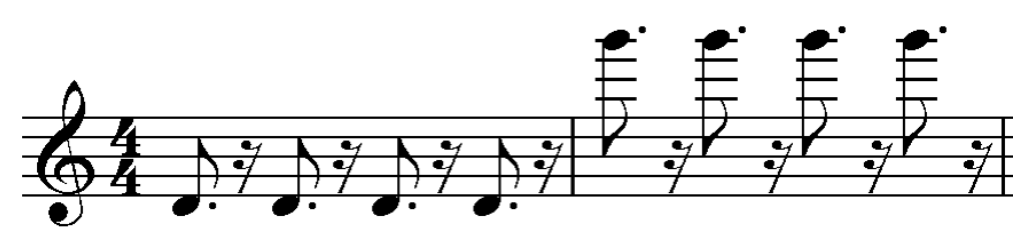

Figura 3.4. Ejemplo musical del ejercicio ataque.

Oscillato: ligera fluctuación de la afinación hacia arriba y hacia abajo, producida por un glissando de rápida evolución en ambas direcciones (Holliger, 1979). 
El ejercicio se realiza en un sol4, por no ofrecer esta nota dificultad al recurso técnico y poder apreciar mejor las características de flexibilidad de las diferentes lengüetas.

Afinación: se suele considerar como la precisión acústica y artística de cantar o tocar, pero tiene un papel indispensable en la expresión musical a través de la inflexión del tono deliberadamente, para crear excitación o tensión, o como un medio de caracterización de un repertorio o un estilo particular de interpretación. Las inflexiones del tono que forman parte inherente de la propia representación se suelen considerar como una cuestión de entonación en lugar de afinación. Por tanto, la entonación será el tratamiento de la altura musical en la interpretación (The New Grove, Dictionary of Music \& Musicians, 1980).

En este ejercicio se interpretaron el do4, do5 y do6, ligados y con una duración de blancas (figura 3.5).

Es importante remarcar que la compensación por parte del intérprete, producida a través de un aumento en la presión de la columna de aire, puede contaminar el objetivo del ejercicio, por lo que a los intérpretes se les ha explicado insistentemente que el cambio de octavas se debe realizar sin buscar la afinación "correcta", sino la que la lengüeta proporciona.

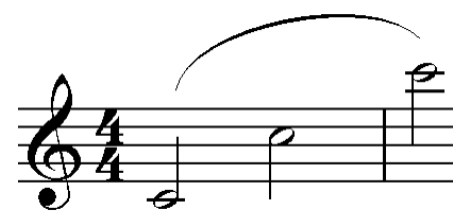

Figura 3.5. Ejemplo musical del ejercicio afinación.

Doble staccato: técnica empleada por los instrumentistas de viento madera o metal, para articular las notas separadas en ritmos muy rápidos. La punta de la lengua y la garganta se utilizan alternativamente, formando las consonantes " $\mathrm{T}$ " $\mathrm{y}$ " $\mathrm{K}$ " sucesivamente: ta-ka-ta-ka,... (The New Grove, Dictionary of Music \& Musicians, 1980).

Se intenta en este ejercicio apreciar la nitidez del doble staccato; para ello se graba un compás de $4 / 4$ en semicorcheas ( $\mathrm{fa \#}_{5}$ ) y otro compás en corcheas a una velocidad de metrónomo de negra igual a 152 (figura 3.6). A esta velocidad, la utilización del doble staccato en el compás de corcheas no es real, ya que este recurso se utiliza para pasajes muy rápidos. La intención al grabarlo también con corcheas es poder apreciar, de forma 
más lenta, la nitidez de la lengüeta. La utilización de la nota fa\#$_{5}$ responde a la voluntad de facilitar al máximo el ejercicio, ya que es una nota que no ofrece resistencia al doble staccato.

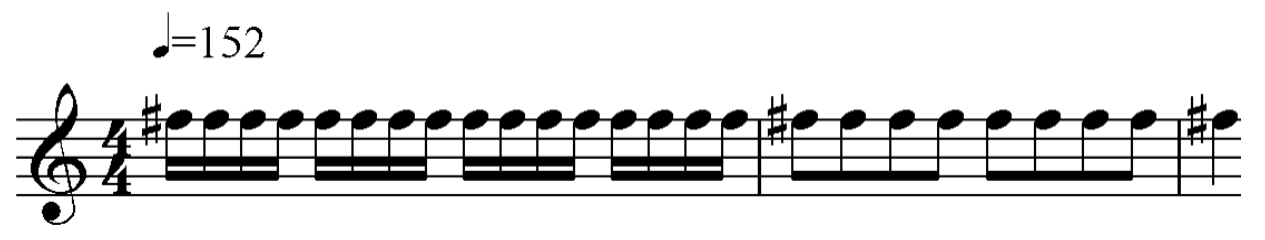

Figura 3.6. Ejemplo musical del ejercicio doble staccato.

Frullato: aparece cuando se realiza una $\mathrm{R}$ continua en el paladar, hasta que la $\mathrm{R}$ perturba la caña (Holliger, 1979). Se realizó en un re 6 con una R continua en el paladar.

Intensidad: la intensidad de un sonido es la cualidad que indica que un sonido es más fuerte o más débil que otro (Calvo-Manzano, 1991). Se graba el arpegio de sol mayor, ligado y con blancas (figura 3.7).

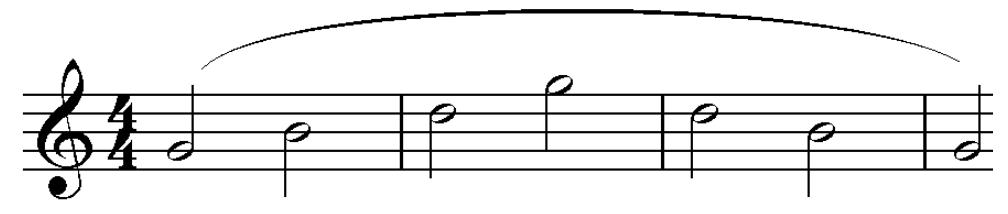

Figura 3.7. Ejemplo musical del ejercicio intensidad.

Staccato: "detached (separada)". Nota individual, separada de las demás por un silencio en la articulación. La separación puede estar, pero no siempre, acompañada de un cierto grado de énfasis, y en ocasiones el término puede significar el énfasis, sin separación física. El término puede ser considerado como el antónimo de legato (The New Grove, Dictionary of Music \& Musicians, 1980).

Se realiza el ejercicio con la nota do4, en semicorcheas, compás 4/4 e indicación de velocidad de negra a 120 (figura 3.8). La realización de este ejercicio supone una dificultad tanto por la elección de la nota (el registro grave es siempre más difícil de picar) como por la velocidad (120 empieza a ser el límite entre el staccato simple y el doble).

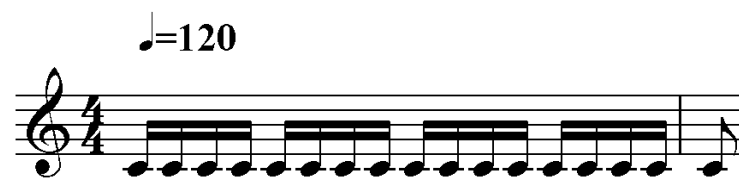

Figura 3.8. Ejemplo musical del ejercicio staccato. 
Dinámica: relación en decibelios entre el matiz más débil y el más fuerte con que puede ser producido un sonido (Calvo-Manzano, 1991).

Se graba un sol4, con una duración de tres redondas, a una velocidad de metrónomo de negra igual a 60 y realizando un diminuendo progresivo (figura 3.9). El ejercicio empieza con un matiz fortissimo (ff) y finaliza con un pianissimo (pp).

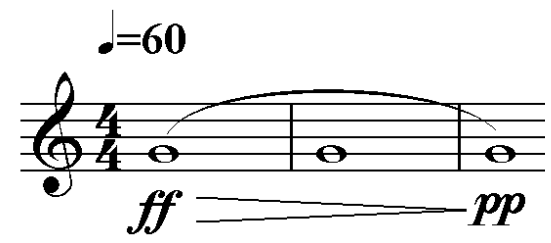

Figura 3.9. Ejemplo musical del ejercicio dinámica.

El sol 4 es una de las notas más problemáticas a la hora de realizar un diminuendo, a causa de las características físicas del oboe. Es una nota susceptible a la afinación, por lo que si las lengüetas son demasiado flexibles, óptimas en todo caso para realizar un buen diminuendo, la afinación se verá afectada. Es importante remarcar que también para este ejercicio la compensación por parte del intérprete puede "solucionar" el problema de la desafinación, por lo que a los intérpretes se les ha explicado, al igual que en el ejercicio de afinación, la importancia de no compensar mediante el aumento de la presión de la columna de aire.

Dobles sonidos armónicos: son una de las posibilidades más ampliamente usadas de multifónicos. La dificultad para lograr estos sonidos radica en el hecho de que la presión labial (y del aire) debe ser medida para atraer dos armónicos de un sonido fundamental que debe ser eliminado. Holliger (1979) define el multifónico como un acorde complejo en donde los parciales no representan múltiplo exacto de una frecuencia fundamental.

Se interpreta a la vez un $\operatorname{sib}_{3}$ y un fas (figura 3.10). Este ejercicio, a parte de la dificultad añadida que representa realizar un doble sonido, tiene la ventaja de ser uno de los más sencillos, ya que el fas es el armónico (a la treceava: octava más quinta) de sib 3 y se produce con la misma posición de los dedos, sin tener que complicar para nada la digitación. 


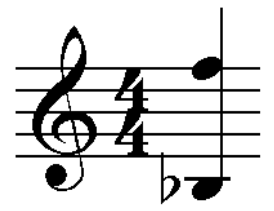

Figura 3.10. Ejemplo musical del ejercicio dobles sonidos armónicos.

Legato: notas sucesivas, unidas sin ningún tipo de silencio en la articulación. En la práctica, la unión o la separación de las notas es relativa, y se han logrado grados de unión y de separación que varían del legatissimo (que representa el grado más próximo de unión), tenuto, portamento, legato, portato, non legato, mezzo-staccato, staccato (el antónimo natural de legato), al staccatissimo, llegando algunos de estos términos a tener una connotación más allá de simples grados de unión o de separación (The New Grove, Dictionary of Music \& Musicians, 1980).

Para este ejercicio se graban dos compases de 4/4, en corcheas $\operatorname{sib}_{4} \mathrm{y} \mathrm{sib}_{3}$, a una velocidad de metrónomo de negra igual a 60 (figura 3.11). Al escoger un cambio de registros del central al grave y, sobre todo con el $\mathrm{sib}_{3}$ (nota más grave del oboe), se pone al límite la dificultad técnica de este ejercicio, porque se pasa de tener un tubo quasi abierto a un tubo completamente cerrado. Una lengüeta muy flexible se adapta rápidamente a estos cambios de registro, al contrario, si la lengüeta es muy rígida, estos cambios se producirán de forma brusca o incluso se cortará el sonido.

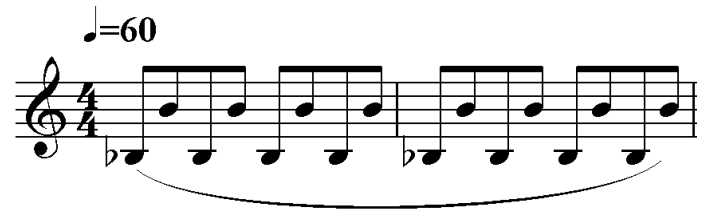

Figura 3.11. Ejemplo musical del ejercicio legato.

\subsection{Experimento de percepción}

\subsubsection{Hipótesis}

Si el experimento se centra en las teorías sobre las lengüetas del oboe que han ido surgiendo desde los manuales prácticos, se pueden resumir las diferencias existentes en los diferentes estilos de rebajado en características de elasticidad y rigidez, es decir, que los diferentes estilos de rebajado otorgan a las lengüetas características más o menos flexibles o más o menos rígidas. Los teóricos del oboe (Brod, 1830 y Rothewell, 1979) distinguen 
entre el sonido del rebajado alemán al que se asocian descriptivos como "suave", "lleno", "duro", "sordo", el del francés como "brillante" y "ligero" y el americano como "oscuro", "grande", "lleno" y "bonito". Otros teóricos como Fletcher y Rossing (1998, p. 484) definen el sonido de los instrumentos de lengüeta como la relación existente entre la presión de la columna de aire y la vibración de la lengüeta. Según Fitzgerald (2003) la fuerza de la caña puede tener un efecto dominante sobre la estructura de los formantes: una caña blanda tiene una superficie de vibración y capacidad elástica de recuperación menor que una caña dura (aunque el diámetro del tudel también afecta levemente en la fuerza de la caña). Heptner (1987) analiza diferentes propiedades espectrales de las cañas blandas y duras y afirma que por el rebajado de pequeñas cantidades de madera de las cañas es posible alterar la calidad del timbre y que para muchas personas la diferencia entre las cañas blandas y duras no es objetivamente demostrable, aunque según su experiencia, las cañas blandas y duras pueden ser reconocibles por instrumentistas profesionales.

El sonido de las lengüetas blandas es descrito como "brillante" y por lo general tienen muy pronunciado el área de los formantes, mientras que una lengüeta más dura suele ser descrita como "oscura" o "suave". Si se parte pues de estas teorías, se obtiene la hipótesis que los diferentes estilos de rebajados influyen en la vibración de la lengüeta y por consiguiente afectan el "color" del sonido, siendo el rebajado francés más "brillante"y rico en agudos, y el alemán más “oscuro” y con más energía en el grave.

En este experimento se estudia si los oyentes son capaces de discriminar estas características que tanto parecen advertir los oboístas. Para ello, se utiliza un test de clasificación libre o escucha holística como tarea de percepción más aceptada en los estudios del timbre, según los estudios descritos por Grey (1977, 1978) o McAdams (1995). En este tipo de tareas, los oyentes agrupan los sonidos de acuerdo a la similitud general percibida. Los experimentos de investigación del timbre, comparan sobre todo las diferencias entre varios instrumentos, pero este método también es adecuado para detectar diferencias tímbricas dentro de los sonidos de un mismo instrumento. Como se explica posteriormente, se normalizan los sonidos en altura e intensidad, así como la duración de los estímulos sonoros, trabajando así con la definición más aceptada de timbre: diferenciación de varios sonidos de igual altura, intensidad y duración. 


\subsubsection{Método}

Como en este experimento se precisaba que los oyentes analizasen las diferencias de timbre y no de altura o intensidad, se normalizaron cada muestra en intensidad y en altura, sin provocar ninguna alteración apreciable del timbre. Se han utilizado las seis lengüetas con las características detalladas en el punto 3.3.1. De todos los ejercicios grabados (cf. punto 3.3.4) se agruparon varios ejercicios en cuatro estímulos diferentes. Una vez que los oyentes completaban la agrupación del primer conjunto de sonidos, empezaban a realizar el siguiente, incrementándose cada vez en complejidad y diversidad. Se estableció un orden de presentación de los diferentes estímulos, teniendo en cuenta que las notas aisladas procedían de la frase larga de ocho sonidos. Así pues, como el objetivo era obligar a los oyentes a realizar una escucha reducida tal y como describe Schaeffer (1977), el primer estímulo que realizaban los oyentes eran las notas aisladas y el último, la frase larga. El estímulo diminuendo fue el más sencillo de agrupar por parte de los oyentes, ya que tenía menos elementos variantes (no habían diferentes ataques). Los conjuntos sonoros se presentaron en este orden:

1) estímulos de la tarea 1:9 notas largas en diminuendo.

2) estímulos de la tarea 2: 18 notas cortas graves (re4), atacadas con y sin lengua.

3) estímulos de la tarea 3: 18 notas cortas agudas ( ol $\left._{6}\right)$, atacadas con y sin lengua.

4) estímulos de la tarea 4: 18 frases de cuatro notas graves ( $\left.\mathrm{re}_{4}\right)$ y cuatro notas agudas (sol6), atacadas con y sin lengua.

Cuarenta oyentes (veinte oboístas profesionales y veinte músicos no oboístas) realizaron la tarea de categorización libre, donde debían agrupar los sonidos en función de su similitud global (escucha holística). La escucha se efectuó de forma individual, con auriculares y con una duración aproximada total de veinte minutos. Los oyentes utilizaron una interfaz interactiva con la que podían escuchar los sonidos tantas veces como necesitasen y arrastrar los iconos como se muestra en la figura 3.12. Además, los oyentes podían escribir en las casillas una descripción de los diferentes sonidos (verbalización libre) siempre que lo creyesen oportuno. 


\begin{tabular}{|l|l|l|l|}
\hline Ataque soplo & Ataque lengua & & \\
\hline & $\begin{array}{l}\text { Corta sonido } \\
\text { antes aire }\end{array}$ & & \\
\hline $\begin{array}{l}\text { Aire-sonido } \\
\text { fin a la vez }\end{array}$ & & & \\
a
\end{tabular}

Figura 3.12. Captura de pantalla de la herramienta interactiva desarrollada para la percepción sonora.

\subsubsection{Resultados}

El primer elemento que se analiza es si los diferentes participantes llegan a un acuerdo en sus respuestas y, por consiguiente, si los criterios son fiables y compartidos. Se utiliza el alfa de Cronbach para medir la concordancia entre los participantes y se observa la concordancia de las respuestas obtenidas: el grupo de los oboístas tiene una mayor coherencia entre los evaluadores, probablemente debido al hecho de que los oboístas están más acostumbrados a escuchar analíticamente los sonidos del oboe y pueden tener criterios comunes adquiridos en el proceso de aprendizaje. Existen además diferencias entre los estímulos diminuendi (estímulos de la tarea 1) y el resto, esto puedo deberse a que en el diminuendo no hay diferentes tipos de ataque, ya que el único parámetro que cambia es el rebajado y el intérprete, minimizando las diferencias en la producción del sonido y provocando que los oyentes no tengan claro el criterio para agrupar los sonidos (tabla 3.1).

\begin{tabular}{|l|l|r|}
\hline Estímulos & Oyentes & Alfa de Cronbach \\
\hline \multirow{2}{*}{ diminuendo } & Oboístas & $\mathbf{0 , 4 4 2}$ \\
\cline { 2 - 3 } & No oboístas & $\mathbf{0 , 5 5 4}$ \\
\hline \multirow{2}{*}{ notas aisladas re 4} & Oboístas & 0,782 \\
\cline { 2 - 3 } & No oboístas & 0,613 \\
\hline \multirow{2}{*}{ notas aisladas sol 6} & Oboístas & 0,780 \\
\cline { 2 - 3 } & No oboístas & 0,657 \\
\hline \multirow{2}{*}{ frase } & Oboístas & 0,845 \\
\cline { 2 - 3 } & No oboístas & 0,766 \\
\hline
\end{tabular}

Tabla 3.1. Tabla con los análisis de fiabilidad (alfa de Cronbach) del experimento preliminar ( $\mathrm{N}=20$ para todos los casos). 
Para averiguar si los diferentes estilos de rebajado de las lengüetas influyen en la percepción de los oyentes, se ha realizado la prueba de $\chi^{2}$ de Pearson separando a los oyentes en dos grupos: los músicos profesionales y los oboístas. Se ha comparado si había diferencias significativas en las clasificaciones de los oyentes utilizando los siguientes factores: el oboísta (dos oboístas), el ataque (dos tipos de ataque, a excepción de los diminuendi que sólo presentan un tipo de ataque), la lengüeta (seis lengüetas: variabilidad inter-lengüeta e intra-escuela) y los diferentes tipos de rebajado (tres tipos).

Se puede observar en la tabla 3.2 ( $c f$. A.1, A.2, A.3 y A.4. para más detalle), que la influencia de los diferentes intérpretes es muy significativa en todos los casos excepto en dos ocasiones: mientras que en las notas graves el grupo de oyentes no oboístas no es capaz de diferenciar a los dos intérpretes $(p=, 142)$ y los oboístas los diferencian de forma significativa $(p=, 002)$, en las notas agudas ocurre todo lo contrario: la influencia del intérprete es significativa en el grupo de sujetos no oboístas $(p=, 005)$, pero no lo es en los oboístas $(p=, 525)$.

Como muestran los resultados de la tabla 3.3 ( $c f$. A.5, A.6 y A.7 para más detalle), la influencia de los diferentes ataques es muy significativa en todos los casos $(p<, 001)$ : tanto los oboístas como los no oboístas agrupan teniendo en cuenta los diferentes tipos de ataques utilizados en la interpretación de los ejercicios.

\begin{tabular}{|c|c|c|c|c|}
\hline \multicolumn{5}{|c|}{ Tests (Pearson) $\chi^{2}$} \\
\hline Estímulos & Oyentes & $\chi^{2}$ & gl & Asymp. Sig. (2-sided) \\
\hline \multirow{2}{*}{ Diminuendi } & No oboístas & 13,00 & 1 &, 000 \\
\cline { 2 - 5 } & Oboístas & 11,74 & 1 &, 001 \\
\hline Notas graves & No oboístas & 2,15 & 1 &, 142 \\
\cline { 2 - 5 } & Oboístas & 5,27 & 1 & $\mathbf{, 0 0 2}$ \\
\hline Notas agudas & No oboístas & 7,78 & 1 & $\mathbf{, 0 0 5}$ \\
\cline { 2 - 5 } & Oboístas &, 403 & 1 &, 525 \\
\hline Frases largas & No oboístas & 11,12 & 1 &, 001 \\
\cline { 2 - 5 } & Oboístas & 48,32 & 1 &, 000 \\
\hline
\end{tabular}

Tabla 3.2. Resumen de la prueba de $\chi^{2}$ de Pearson comparando las agrupaciones de los dos grupos de oyentes según los diferentes oboístas para los diferentes conjuntos de estímulos. 


\begin{tabular}{|c|c|c|c|c|}
\hline \multicolumn{5}{|c|}{ Tests (Pearson) $\chi^{2}$} \\
\hline Estímulos & Oyentes & $\chi^{2}$ & gl & Asymp. Sig. (2-sided) \\
\hline \multirow{2}{*}{ Notas graves } & No oboístas & 26,41 & 1 &, 000 \\
\cline { 2 - 5 } & Oboístas & 247,46 & 1 &, 000 \\
\hline \multirow{2}{*}{ Notas agudas } & No oboístas & 15,46 & 1 &, 000 \\
\cline { 2 - 5 } & Oboístas & 34,79 & 1 &, 000 \\
\hline \multirow{2}{*}{ Frases largas } & No oboístas & 121,50 & 1 &, 000 \\
\cline { 2 - 5 } & Oboístas & 317,34 & 1 &, 000 \\
\hline
\end{tabular}

Tabla 3.3. Resumen de la prueba de $\chi^{2}$ de Pearson comparando las agrupaciones de los dos grupos de oyentes según los diferentes ataques para los diferentes conjuntos de estímulos, excepto para el diminuendo.

Por el contrario, cuando se analiza si los oyentes son capaces de agrupar teniendo en cuenta las diferencias entre las lengüetas utilizadas, los resultados muestran en la tabla 3.4 (cf. A.8, A.9, A.10 y A.11 para más detalle), que tanto los oboístas como los no oboístas agrupan teniendo en cuenta estas diferencias: sobre todo en las frases largas, siendo significativo en los no oboístas $(p=, 013)$ y muy significativo en el grupo de los oboístas $(p<, 001)$. Cabe destacar que en las notas agudas, las variaciones inter-lengüeta (intraescuela) son más significativas para los no oboístas $(p=, 046)$ que para los oboístas $(p=, 113)$ y en las notas graves sólo son significativas para los oboístas $(p=, 002)$.

Se resalta que el estilo de rebajado es el elemento que menos diferencias significativas presenta (tabla 3.5, cf. A.12. A.13, A.14 y A.15 para más detalle), apareciendo estas diferencias sólo para las frases de ocho notas en el grupo de oyentes no oboístas $(p=, 020)$, mientras que en los diminuendi se aprecia una diferencia significativa para los oyentes oboístas $(p=, 048)$.

\begin{tabular}{|c|c|c|c|c|}
\hline \multicolumn{5}{|c|}{ Tests (Pearson) $\chi^{2}$} \\
\hline \multirow{2}{*}{ Estímulos } & Oyentes & $\chi^{2}$ & gl & Asymp. Sig. (2-sided) \\
\hline \multirow{2}{*}{ Notas graves } & No oboístas &, 566 & 1 &, 452 \\
\cline { 2 - 5 } & Oboístas & 3,37 & 1 &, 066 \\
\cline { 2 - 5 } & No oboístas &, 745 & 1 &, 388 \\
\hline Notas agudas & No oboístas & 9,81 & 1 & $\mathbf{, 0 0 2}$ \\
\cline { 2 - 5 } & Oboístas & 3,99 & 1 & $\mathbf{, 0 4 6}$ \\
\hline Frases largas & No oboístas & 2,51 & 1 &, 113 \\
\cline { 2 - 5 } & Oboístas & 18,22 & 1 & $\mathbf{, 0 1 3}$ \\
\hline
\end{tabular}

Tabla 3.4. Resumen de la prueba de $\chi^{2}$ de Pearson comparando las agrupaciones de los dos grupos de oyentes según las diferentes lengüetas para los diferentes conjuntos de estímulos. 


\begin{tabular}{|c|c|c|c|c|}
\hline \multicolumn{5}{|c|}{ Tests (Pearson) $\chi^{2}$} \\
\hline Estímulos & Oyentes & $\chi^{2}$ & gl & Asymp. Sig. (2-sided) \\
\hline \multirow{2}{*}{ Diminuendi } & No oboístas &, 140 & 1 &, 709 \\
\cline { 2 - 5 } & Oboístas & 3,91 & 1 & $\mathbf{, 0 4 8}$ \\
\hline \multirow{2}{*}{ Notas graves } & No oboístas &, 237 & 1 &, 626 \\
\cline { 2 - 5 } & Oboístas &, 501 & 1 &, 479 \\
\hline Notas agudas & No oboístas & 1,43 & 1 &, 231 \\
\cline { 2 - 5 } & Oboístas & 1,79 & 1 &, 181 \\
\hline Frases largas & No oboístas & 5,44 & 1 & $\mathbf{, 0 2 0}$ \\
\cline { 2 - 5 } & Oboístas &, 916 & 1 &, 338 \\
\hline
\end{tabular}

Tabla 3.5. Resumen de la prueba de $\chi^{2}$ de Pearson comparando las agrupaciones de los dos grupos de oyentes según las diferentes escuelas de rebajado para los diferentes conjuntos de estímulos.

Al realizar un escalamiento multidimensional (ALSCAL) sobre las matrices de respuestas de las agrupaciones libres, utilizando un modelo de dos dimensiones, se intenta entender si los oyentes utilizan criterios similares en sus clasificaciones. La variablilidad explicada por estas dimensiones es: $\mathrm{RSQ}=65 \%$ (tarea 1 ), $\mathrm{RSQ}=79 \%$ (tarea 2 ) $\mathrm{RSQ}=76 \%$ (tarea 3) $\mathrm{RSQ}=91 \%$ (tarea 4). Solamente en las frases largas la reducción a 2 dimensiones consigue explicar una gran parte de la variabilidad de las respuestas y además se obtienen unas asociaciones claras para las dimensiones: dimensión 1 = tipo de ataque, dimensión $2=$ instrumentista (figura 3.13).

Los resultados muestran que en todos los estímulos los elementos que más influyen en la percepción de los oyentes son el tipo de ataque y los intérpretes, por lo que se puede afirmar que en este experimento preliminar, no aparece una influencia clara del rebajado en el timbre ni en aspectos de ejecución como la calidad del ataque o la regularidad de las frases. 


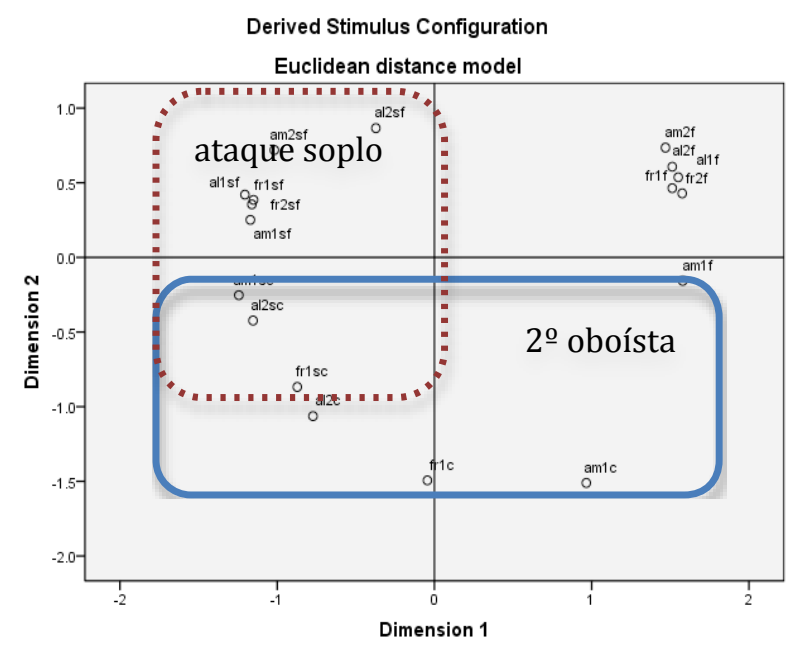

Figura 3.13. Escalamiento multidimensional de los estímulos de la tarea 4 realizado por los dos grupos de oyentes. Las dos primeras letras codifican el tipo de rebajado, la "s" indica un ataque con soplo, la última letra indica el intérprete.

\subsubsection{Discusión}

Si se analizan todos los resultados obtenidos en el experimento preliminar, se puede observar que el escalamiento multidimensional muestra que no emerge una estrategia común para los estímulos de una sola nota, pero que las diferencias de ataque y de instrumento aparecen claramente en las frases largas. Es importante recordar que las notas aisladas (graves y agudas) provienen de las frases largas y que quizás la complejidad y longitud del estímulo hacen que destaquen perceptivamente propiedades diferentes. Los estímulos largos (diminuendi y frases) hacen que se distinga más significativamente la diferencia entre intérpretes como se indica en la tabla 3.2. De hecho, una de las restricciones mayores encontradas en los experimentos sobre timbre instrumental es que los estímulos no comparan notas aisladas y frases. En ninguno de los casos, sin embargo, se puede vislumbrar el tipo de rebajado como una de las dimensiones obtenidas. Los resultados muestran que las diferencias significativas se encuentran ante todo en el tipo de ataque, seguido por el intérprete. 


\subsubsection{Conclusiones}

El principal resultado de este experimento es que el estilo de rebajado tiene un mínimo impacto sobre el reconocimiento del timbre. Se partía de la hipótesis de que los diferentes estilos de rebajados en las lengüetas del oboe alteran el "color" de las notas y que estos cambios de "color" pueden ser percibidos por los oyentes.

Después de la realización del experimento relacionado con la escucha del timbre, se concluye que en los conjuntos de estímulos donde se utilizan notas aisladas de corta duración (dos segundos aproximadamente), los oyentes no son capaces de agrupar los sonidos por estilos de rebajado, dando lugar a una concordancia de las respuestas muy baja. Cuando se utilizan ejercicios con sonidos de mayor complejidad y mayor duración (frases y diminuendi), se observa que aparece alguna diferencia significativa según el estilo de rebajado. Sin embargo, las mayores diferencias vienen dadas por la distinción de los intérpretes y de los diferentes tipos de ataque, aumentando el valor de la concordancia de las respuestas y apareciendo estos dos factores como una estrategia común en el agrupamiento de los sonidos por parte de los oyentes y en ninguno de los casos, se puede vislumbrar el tipo de rebajado como uno de los factores diferenciados.

Se remarca que el hecho de que las muestras largas y complejas conllevan clasificaciones coherentes puede significar que los oyentes centran su atención en las diferencias técnicas de la interpretación: en este experimento ambos intérpretes informaron que algunos ejercicios eran más fáciles de lograr con un tipo de lengüeta que con otra, y, por ejemplo, en algunos casos se tiene un mayor retraso en el inicio de las notas agudas que se interpretan después de las notas graves, o que algunas notas no son estables más frecuentemente con un tipo de lengüeta que con otra. Los diferentes estilos de rebajado de las lengüetas pueden influir en la capacidad técnica para lograr algunos requisitos técnicos y, por lo tanto, influyen en el rendimiento global, pero no sobre el timbre. La normalización de los sonidos en frecuencia e intensidad también puede ser un factor ante la falta de clasificación de estrategias, ya que estos dos factores son siempre los más importantes para los oyentes entrenados y no entrenados.

En conclusión, el experimento preliminar no encuentra una influencia significativa del estilo de rebajado en la percepción del timbre del oboe confirmándose, por una parte, 
los resultados de Russell (1953) (citado por Fitzgerald, 2003) que consideraba que los oyentes podían diferenciar varios timbres en las interpretaciones oboísticas pero siempre gracias a la combinación del intérprete, del tipo de lengüeta y del instrumento utilizado; y por otra parte los de Snitkin (1975) (citado por Fitzgerald, 2003) que concluyó que las características de calidad de sonido de cada oboísta eran más perceptibles para el oyente que las propiedades de la lengüeta.

\subsection{Estudio acústico}

\subsubsection{Hipótesis}

Las características del rebajado para la facilidad y el control de ejecución pueden ser descritas con los conceptos de rigidez y flexibilidad. Los oboístas suelen considerar que las lengüetas alemanas son muy rígidas; las francesas no son ni excesivamente rígidas ni flexibles y las americanas son muy flexibles. Por consiguiente, las lengüetas alemanas son poco flexibles, muy duras en la embocadura del oboísta, con mucha madera, es decir, con más grosor en todas las partes de la lengüeta, y por todas estas características reciben mejor un mayor flujo de aire por parte de los oboístas, consiguen que sus dos palas no se saturen y vibren con toda normalidad ante un fortissimo y son las que mayor intensidad sonora consiguen. Se puede pues emitir la hipótesis de una mayor intensidad sonora para las lengüetas alemanas.

Estas mismas lengüetas, suelen ser muy difíciles de controlar con la embocadura, por lo que la interpretación de diferentes ejercicios con este tipo de lengüetas pueden provocar desviaciones de la intensidad en pequeñas cantidades, que no son controlables por el oboísta. Todo lo contrario ocurre con una lengüeta más estable y no excesivamente flexible, como suele ser la francesa. Estas lengüetas son más fáciles de controlar, por lo que la interpretación de los ejercicios será más estable.

La afinación y su estabilidad también siguen estos dos patrones de rigidez y flexibilidad. Uno de los elementos del rebajado que más influyen en la afinación son los laterales de las cañas. Una lengüeta con los lados espesos (las alemanas) nunca caerá en afinación, al tener más madera su ámbito de afinación es menor y sus vibraciones son más agudas. Esto mismo va a proporcionar a las lengüetas alemanas tener menos margen de 
inestabilidad. Por el contrario, una lengüeta excesivamente flexible (provocado por la eliminación de la madera en la punta y en la parte de atrás de la caña), como es el caso de las americanas, se caracteriza por ser una lengüeta baja en afinación y con una gran variabilidad en la afinación. La facilidad de vibración también viene determinada por la cantidad de madera que tiene la lengüeta: cuanto más rígida sea una lengüeta mucha más presión y energía por parte del oboísta va a necesitar para poder poner a vibrar las dos palas y así producir el sonido. Se emite la hipótesis que a mayor espesor de madera, las lengüetas estarán más altas en la afinación general, además, serán más estables ante una nota dada, es decir, tendrán menor variabilidad en la afinación y la rapidez para que sus lengüetas vibren al emitir sonidos será más costosa que otros rebajados.

Las lengüetas con mayor flexibilidad, y por tanto las más estables en los ejercicios oscillato, diminuendo y dobles sonidos armónicos, deberían ser las lengüetas americanas, que se caracterizan por tener un rebajado muy largo, con unas puntas largas y flexibles y un centro más rígido para poder así equilibrar este rebajado tan flexible.

Sin embargo, para los ejercicios que necesitan unas lengüetas muy rígidas por tener que soportar las oscilaciones y los recursos de la lengua de los instrumentistas, como por ejemplo en el ejercicio frullato, las mejores lengüetas deberían ser las alemanas. Así mismo, el ejercicio intensidad requiere una lengüeta con un rebajado que admita mucho aire, donde las dos palas no se saturen rápidamente, es decir, una lengüeta rígida como es el rebajado alemán.

\subsubsection{Respuestas acústicas en función del ejercicio de interpretación}

En una primera fase, se analizan las respuestas acústicas de las lengüetas en función del ejercicio de interpretación, para destacar detalladamente las características de los tipos de rebajado y su conveniencia para las diferentes exigencias de interpretación. Se realizan mediciones acústicas visibles en el espectro, como por ejemplo de los parámetros frecuencia e intensidad. Por otra parte, en los ejercicios ataque, staccato, doble staccato o legato, se realiza el análisis detectando elementos que aparecen en la señal sonora, como las interrupciones del sonido o el tiempo que tarda en estabilizarse el sonido tras el ataque. 


\subsubsection{Ejercicios que miden el ataque: ataque, staccato, doble staccato}

En ciertos ejercicios, como en el ataque, el staccato, el doble staccato no se encuentra un parámetro acústico simple que indique lo que funciona mejor. En estos casos, se pueden detectar elementos de la señal sonora, como las interrupciones del sonido o el tiempo que tarda en estabilizarse el sonido tras el ataque, que son más fáciles de analizar utilizando el espectrograma ( $c f$ figuras $3.14,3.15$ y 3.16) o las otras representaciones del sonido, en vez de utilizar una medición acústica única.

Los ataques son más estables cuanto más rígida y equilibrada entre todas sus partes es la lengüeta, por lo que las lengüetas como las alemanas y las francesas deben obtener unos buenos resultados, mientras que las americanas deben obtener los peores resultados. Sin embargo, se puede observar en la tabla 3.6 que los diferentes rebajados parecen no influir demasiado en el ejercicio ataque con lengua y en los staccati, sino que es más bien la variabilidad de cada lengüeta y de cada intérprete. No obstante, en el ataque con soplo donde el comportamiento de la lengüeta influye más que en el resto de ejercicios por ser un ejercicio más complejo, parece que tanto en el intérprete 1 como en el 2, las lengüetas demasiado flexibles se saturan rápidamente y no pueden vibrar correctamente, apareciendo más errores que en los otros casos.

Se observa que las lengüetas excesivamente flexibles, como las americanas, suelen producir errores en la emisión de las notas (círculo rojo $c f$. figura 3.14) que no se dan en las lengüetas rígidas como las alemanas.

\begin{tabular}{|l|c|c|c|c|}
\hline & Ataque lengua & Ataque soplo & Staccato & Doble staccato \\
\hline Intérp. 1 alemana 1 & 0 & 0 & 1 & 0 \\
\hline Intérp. 1 alemana 2 & 0 & 0 & 0 & 1 \\
\hline Intérp. 2 alemana 2 & 1 & 0 & 1 & --- \\
\hline Intérp. 1 americana 1 & 1 & 3 & 0 & 0 \\
\hline Intérp. 2 americana 1 & 0 & 3 & 0 & --- \\
\hline Intérp. 1 americana 2 & 0 & 1 & 2 & 0 \\
\hline Intérp. 1 francesa 1 & 0 & 0 & 1 & 0 \\
\hline Intérp. 2 francesa 1 & 2 & 0 & 0 & --- \\
\hline Intérp. 1 francesa 2 & 0 & 0 & 2 & 0 \\
\hline
\end{tabular}

Tabla 3.6. Número de errores en el ataque en los ejercicios "ataque (con lengua y con soplo)", "staccato", y "doble staccato". 


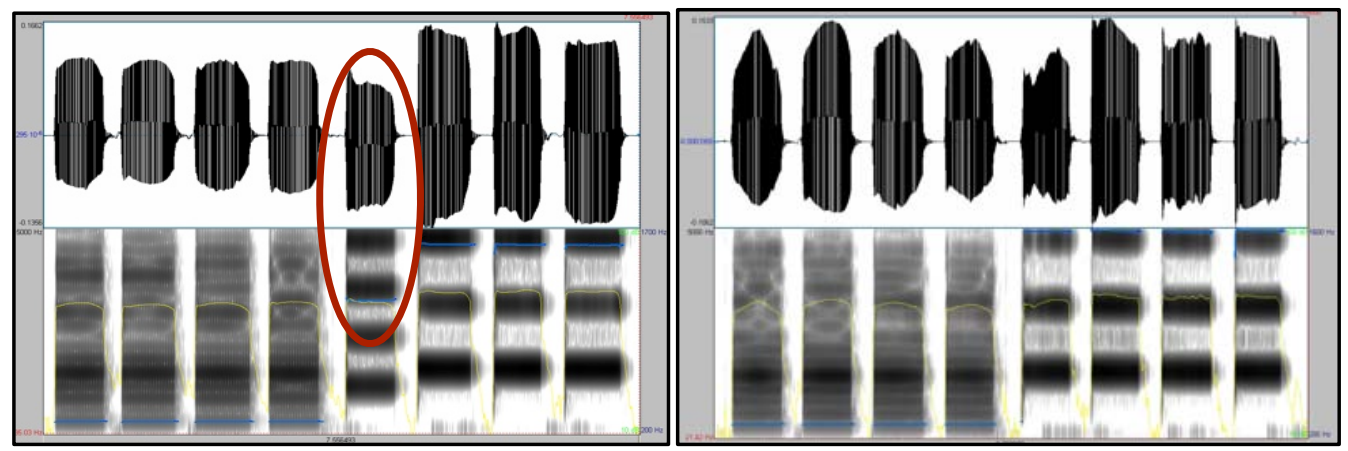

Figura 3.14. Representación en amplitud/tiempo y espectrograma del ejercicio ataque con lengua. Lengüeta americana 1 (izquierda) y alemana 1 (derecha). La línea azul representa la F0 (en Hz) y la línea amarilla la intensidad (en dB).

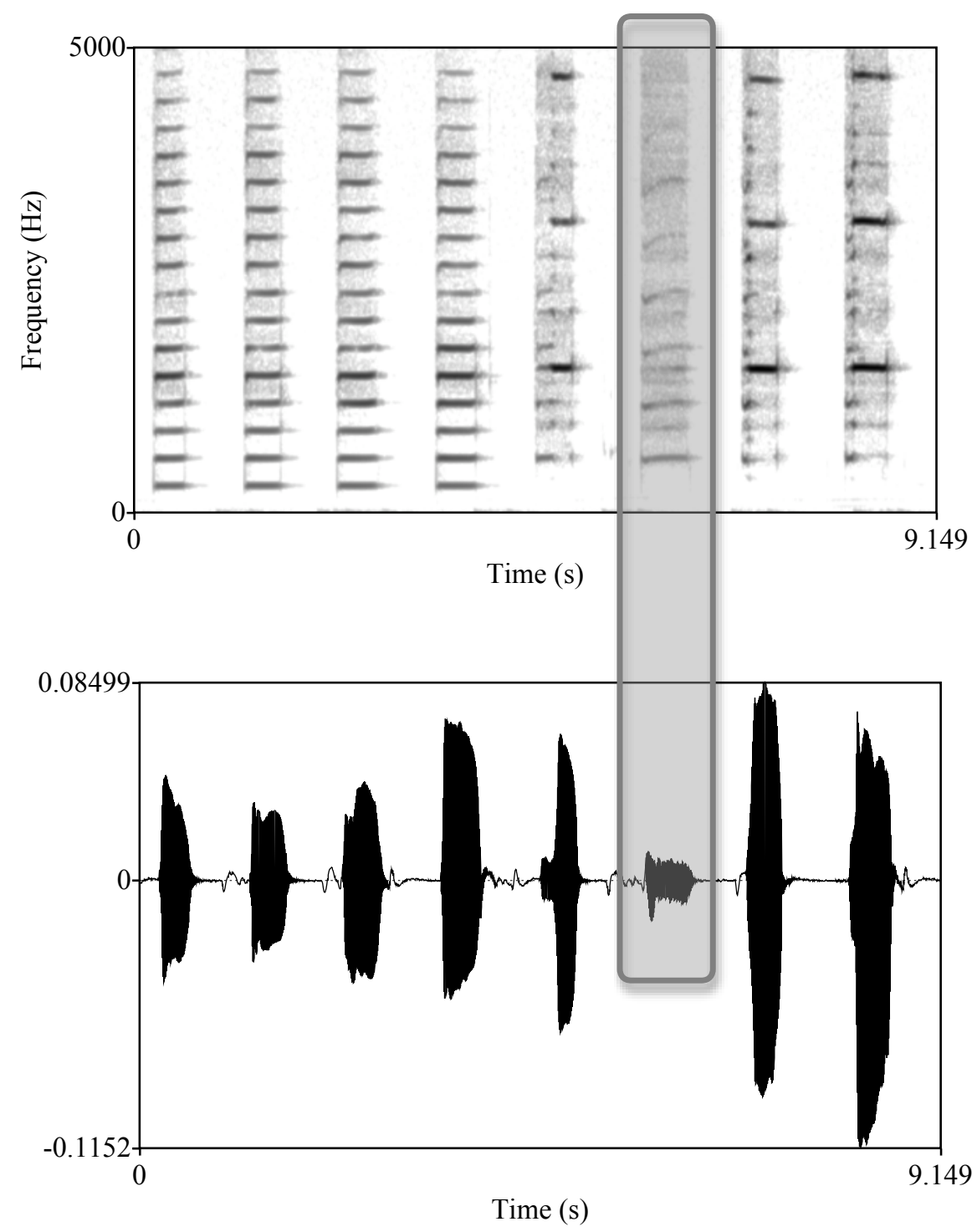

Figura 3.15. Espectrograma (arriba) y representación amplitud/tiempo del ejercicio "ataque con lengua". Lengüeta francesa 1 . Se marca con un recuadro la nota fallida. 


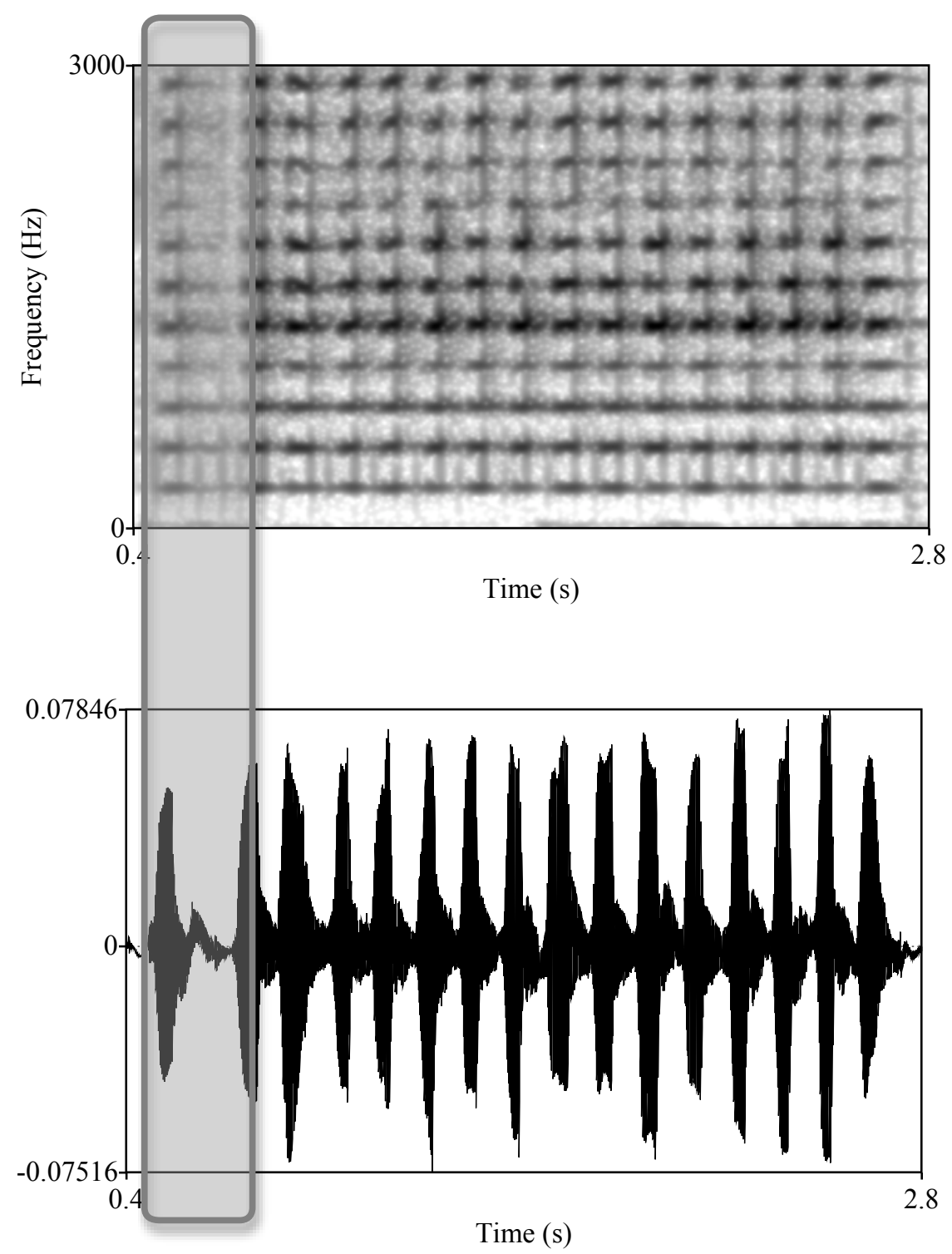

Figura 3.16. Espectrograma (arriba) y representación amplitud/tiempo del ejercicio "staccato". Lengüeta americana 2. Se marca con un recuadro la nota fallida.

\subsubsection{Legato}

Se observa en el sonograma (figura 3.17) las interrupciones del sonido (círculo rojo) y la aparición del primer armónico en vez de la nota real (círculo verde). Este ejemplo corresponde a una lengüeta alemana, caracterizada por su rigidez y su dificultad para adaptarse a los sucesivos cambios de octava. 


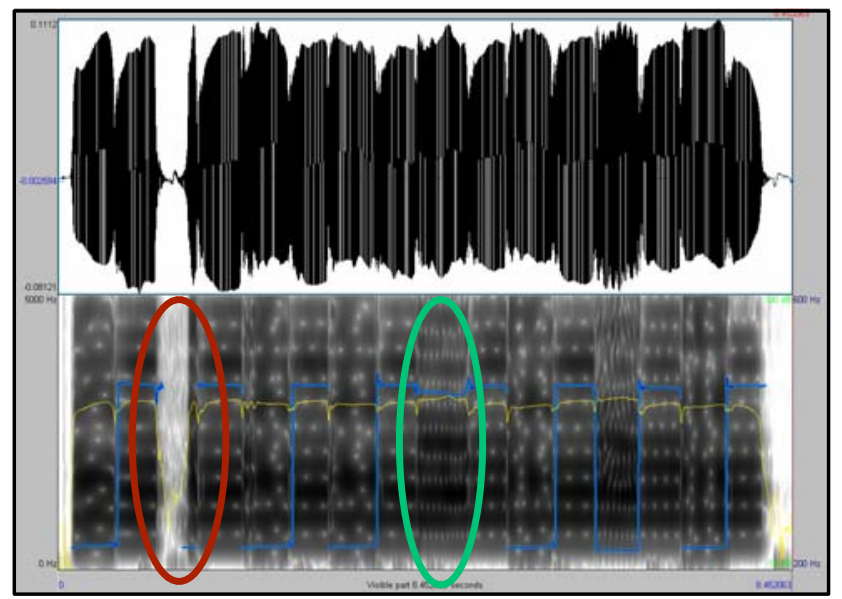

Figura 3.17. Representación en amplitud/tiempo y espectrograma del ejercicio legato. Lengüeta alemana 1. La línea azul: F0 (en Hz) y la línea amarilla: intensidad (en dB).

\subsubsection{Oscillato}

En el oscillato se mide la frecuencia máxima y la mínima con sus correspondientes intensidades. La frecuencia mínima se toma de la segunda oscilación, cuando el oscillato ya es estable ( $c f$. figura 3.18). En la tabla 3.7 se muestran los resultados obtenidos y se calculan las diferencias de las intensidades para concluir que la lengüeta que mayor amplitud posee en el oscillato es la lengüeta americana 1.

Una serie de análisis de varianza (One-Way ANOVA) muestran en la tabla 3.8 que no existen diferencias significativas para este ejercicio dependiendo del factor escuela del rebajado, por lo que se afirma que en el oscillato los diferentes tipos de rebajado no influyen de forma significativa.

\begin{tabular}{|l|r|r|r|r|r|}
\hline \multicolumn{1}{|c|}{ Oscillato } & F0 Max (Hz) & F0 min (Hz) & $\begin{array}{c}\text { Intensidad en } \\
\text { F0 Max (dB) }\end{array}$ & $\begin{array}{c}\text { Intensidad en } \\
\text { F0 min (dB) }\end{array}$ & $\begin{array}{c}\text { Diferencia de F0 } \\
\text { (amplitud del } \\
\text { oscillato) }\end{array}$ \\
\hline alemana 1 & 397,3 & 374,9 & 65,30 & 66,88 & 22,4 \\
\hline alemana 2 & 401,8 & 385,7 & 64,20 & 67,23 & 16,1 \\
\hline americana 1 & 398,7 & 369,9 & 66,10 & 63,58 & 28,8 \\
\hline americana 2 & 397,3 & 376,7 & 65,79 & 65,08 & 20,6 \\
\hline francesa 1 & 394,3 & 373,3 & 64,18 & 65,96 & 21,0 \\
\hline francesa 2 & 389,3 & 361,4 & 66,17 & 63,11 & 27,9 \\
\hline
\end{tabular}

Tabla 3.7. Mediciones de la frecuencia fundamental F0 y de la intensidad sonora en los puntos más agudos y más graves del ejercicio oscillato. 


\begin{tabular}{|l|r|r|r|}
\hline \multicolumn{1}{|c|}{ Oscillato } & \multicolumn{1}{c|}{ df } & \multicolumn{1}{c|}{ F } & \multicolumn{1}{c|}{ Sig. } \\
\hline Maximum F0 & 2 & 4,275 &, 132 \\
\hline Minimum F0 (2nd oscilation) & 2 & 1,656 &, 328 \\
\hline Intensity in F0 Max & 2 &, 836 &, 515 \\
\hline Intensity in F0 min & 2 & 2,633 &, 219 \\
\hline Delta F0 & 2 &, 735 &, 550 \\
\hline
\end{tabular}

Tabla 3.8. One-way Anova de la frecuencia e intensidad dependiendo del factor escuela de rebajado en el ejercicio oscillato.
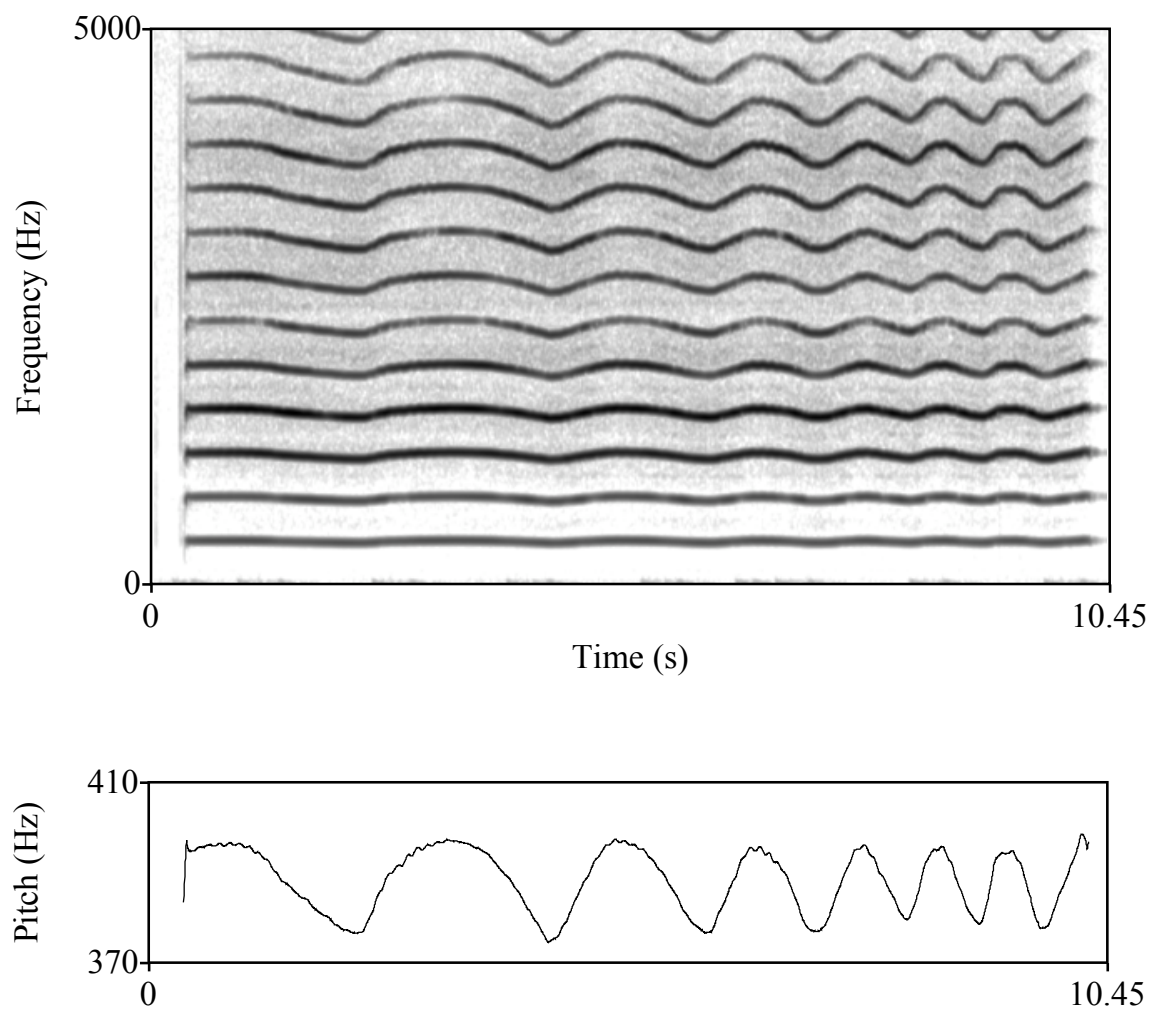

Time (s)

Figura 3.18. Espectrograma (arriba) y frecuencia fundamental (abajo) del ejercicio "oscillato". Lengüeta alemana 1.

\subsubsection{Afinación}

En el ejercicio afinación se miden tanto las frecuencias como las intensidades de las tres notas grabadas. La tabla 3.9 muestra los resultados obtenidos.

En la tabla 3.10 se calcula el intervalo de octava a partir del do4 dado por los intérpretes con cada lengüeta. Es decir, se toma como base la afinación do4 de la grabación y se calcula mediante la proporción de la octava, la frecuencia idónea de do5. A continuación, se realiza el mismo procedimiento: se toma como referencia la frecuencia del do5 obtenida en la grabación y se calcula la frecuencia estimada del do6. El ratio de frecuencias $\left(\mathrm{F}_{1} / \mathrm{F}_{2}\right.$ y $\left.\mathrm{F}_{3} / \mathrm{F}_{4}\right)$ indica que cuando la lengüeta se queda baja el resultado 
obtenido es mayor que 1 , al contrario, si se queda alta el resultado es menor que 1. La lengüeta de afinación perfecta es aquella que da un resultado igual a 1. Se puede observar que la lengüeta que mejor mantiene la afinación de la primera octava es la americana 1 y de la segunda octava la francesa 1 , interpretadas ambas por el oboísta 1.

\begin{tabular}{|l|r|r|r|r|r|r|}
\hline \multicolumn{1}{|c|}{ Afinación } & \multicolumn{1}{c|}{ F0 do4 } & Inten. do4 & \multicolumn{1}{c|}{ F0 do5 } & \multicolumn{1}{c|}{ Inten. do5 } & \multicolumn{1}{c|}{ F0 do } & \multicolumn{1}{c|}{ Inten. do6 } \\
\hline Intérp. 1 alemana 1 & 263,2 & 65,80 & 527,0 & 62,03 & 1044 & 64,85 \\
\hline Intérp. 1 alemana 2 & 266,4 & 64,20 & 533,9 & 61,96 & 1083 & 63,28 \\
\hline Intérp. 1 americana 1 & 262,5 & 65,39 & 525,0 & 63,05 & 1041 & 64,74 \\
\hline Intérp. 1 americana 2 & 261,6 & 63,63 & 524,3 & 61,39 & 1035 & 64,68 \\
\hline Intérp. 1 francesa 1 & 261,8 & 65,24 & 526,0 & 61,62 & 1045 & 64,88 \\
\hline Intérp. 1 francesa 2 & 261,0 & 64,83 & 523,9 & 59,83 & 1039 & 64,41 \\
\hline Intérp. 2 alemana 2 & 264,7 & 62,71 & 532,6 & 56,65 & 1073 & 60,27 \\
\hline Intérp. 2 americana 1 & 261,9 & 61,61 & 520,4 & 55,72 & 1042 & 59,91 \\
\hline Intérp. 2 francesa 1 & 262,1 & 63,22 & 525,9 & 55,91 & 1044 & 59,68 \\
\hline
\end{tabular}

Tabla 3.9. Mediciones acústicas de los ejercicios de afinación: frecuencia en $\mathrm{Hz}$ e intensidad en dB.

\begin{tabular}{|c|r|r|r|r|r|r|r|r|}
\hline Afinación & F0 do4 & $\begin{array}{c}\text { F01 do5 } \\
\text { estimada }\end{array}$ & $\begin{array}{c}\text { F02 dos } \\
\text { obtenida }\end{array}$ & $\begin{array}{c}\text { Ratio de F0 } \\
\text { (F01/F02 }\end{array}$ & F0 do5 & $\begin{array}{c}\text { F03 do6 } \\
\text { estimada }\end{array}$ & $\begin{array}{c}\text { F04 do6 } \\
\text { obtenida }\end{array}$ & $\begin{array}{c}\text { Ratio de F0 } \\
\text { (F03/F04) }\end{array}$ \\
\hline Intérp 1 aleman 1 & 263,2 & 526,4 & 527,0 & 0,9988 & 527,0 & 1052,8 & 1044 & 1,0084 \\
\hline Intérp 1 aleman 2 & 266,4 & 532,8 & 533,9 & 0,9979 & 533,9 & 1065,6 & 1083 & 0,9839 \\
\hline Intérp 1 americ 1 & 262,5 & 525,0 & 525,0 & $\mathbf{1 , 0 0 0 0}$ & 525,0 & 1050,0 & 1041 & 1,0086 \\
\hline Intérp 1 americ 2 & 261,6 & 523,2 & 524,3 & 0,9979 & 524,3 & 1046,4 & 1035 & 1,0110 \\
\hline Intérp 1 frances 1 & 261,8 & 523,5 & 526,0 & 0,9952 & 526,0 & 1047,2 & 1045 & $\mathbf{1 , 0 0 2 1}$ \\
\hline Intérp 1 frances 2 & 261,0 & 522,0 & 523,9 & 0,9963 & 523,9 & 1044,0 & 1039 & 1,0048 \\
\hline Intérp 2 aleman 2 & 264,7 & 529,4 & 532,6 & 0,9939 & 532,6 & 1058,8 & 1073 & 0,9867 \\
\hline Intérp 2 americ 1 & 261,9 & 523,8 & 520,4 & 1,0065 & 520,4 & 1047,6 & 1042 & 1,0053 \\
\hline Intérp 2 frances 1 & 262,1 & 524,2 & 525,9 & 0,9967 & 525,9 & 1048,4 & 1044 & 1,0042 \\
\hline
\end{tabular}

Tabla 3.10. Ratio de frecuencias entre las frecuencias estimadas y las obtenidas, en Hz.

En la tabla 3.11 se obtienen las desviaciones en cents de las frecuencias de cada octava entre las frecuencias de referencia y las obtenidas en el ejercicio grabado. Se observa que la lengüeta americana 2 mantiene mejor la afinación en el do4, la francesa 2 en el do5 y la francesa 1 en el do6. Cabe destacar la diferencia de afinación producida por la lengüeta alemana 2 .

Se realizan una serie de análisis de varianza (One-way ANOVA) para los parámetros frecuencia e intensidad dependiendo de los factores: escuela y oboísta (tabla 3.12). Para el factor escuela, existen diferencias significativas en la afinación de las notas $\operatorname{do} 4(p=, 018)$ y do5 $(p=, 025)$. Cabe destacar que el factor oboísta no influye en la afinación, ya que las variaciones de afinación son debidas realmente al rebajado de la caña y no a cómo se interpreta. También es importante destacar que en el parámetro intensidad pasa 
exactamente lo contrario: el factor escuela no influye en la intensidad conseguida de las notas, pero sí el factor oboísta, que influye de forma muy significativa en las tres notas realizadas $\left(\operatorname{do}_{4} p=, 005, \operatorname{do}_{5} \mathrm{y} \mathrm{do}_{6} p<, 000\right)$.

\begin{tabular}{|l|r|r|r|r|r|r|r|r|r|}
\hline Afinación & $\begin{array}{c}\text { F0 do4 } \\
\text { refer. }\end{array}$ & $\begin{array}{c}\text { F0 do4 } \\
\text { obtenida }\end{array}$ & Diferencia & $\begin{array}{c}\text { F0 do5 } \\
\text { refer. }\end{array}$ & $\begin{array}{c}\text { F0 do5 } \\
\text { obtenida }\end{array}$ & Diferencia & $\begin{array}{c}\text { F0 do6 } \\
\text { refer. }\end{array}$ & $\begin{array}{c}\text { F0 do6 } \\
\text { obtenida }\end{array}$ & Diferencia \\
\hline $\begin{array}{l}\text { Intérp 1 } \\
\text { aleman 1 }\end{array}$ & 261,63 & 263,2 & 10,36 & 523,25 & 527,0 & 12,36 & 1046,5 & 1044 & $-4,14$ \\
\hline $\begin{array}{l}\text { Intérp 1 } \\
\text { aleman 2 }\end{array}$ & 261,63 & 266,4 & $\mathbf{3 1 , 2 8}$ & 523,25 & 533,9 & $\mathbf{3 4 , 8 8}$ & 1046,5 & 1083 & $\mathbf{5 9 , 3 5}$ \\
\hline $\begin{array}{l}\text { Intérp 1 } \\
\text { americ 1 }\end{array}$ & 261,63 & 262,5 & 5,75 & 523,25 & 525,0 & 5,78 & 1046,5 & 1041 & $-9,12$ \\
\hline $\begin{array}{l}\text { Intérp 1 } \\
\text { americ 2 }\end{array}$ & 261,63 & 261,6 & $\mathbf{- 0 , 2 0}$ & 523,25 & 524,3 & 3,47 & 1046,5 & 1035 & $-19,13$ \\
\hline $\begin{array}{l}\text { Intérp 1 } \\
\text { frances 1 }\end{array}$ & 261,63 & 261,8 & 1,12 & 523,25 & 526,0 & 9,07 & 1046,5 & 1045 & $-\mathbf{2 , 4 8}$ \\
\hline $\begin{array}{l}\text { Intérp 1 } \\
\text { frances 2 }\end{array}$ & 261,63 & 261,0 & $-4,17$ & 523,25 & 523,9 & $\mathbf{2 , 1 5}$ & 1046,5 & 1039 & $-12,45$ \\
\hline $\begin{array}{l}\text { Intérp 2 } \\
\text { aleman 2 }\end{array}$ & 261,63 & 264,7 & 20,20 & 523,25 & 532,6 & 30,66 & 1046,5 & 1073 & 43,29 \\
\hline $\begin{array}{l}\text { Intérp 2 } \\
\text { americ 1 }\end{array}$ & 261,63 & 261,9 & 1,79 & 523,25 & 520,4 & $-9,46$ & 1046,5 & 1042 & $-7,46$ \\
\hline $\begin{array}{l}\text { Intérp 2 } \\
\text { frances 1 }\end{array}$ & 261,63 & 262,1 & 3,11 & 523,25 & 525,9 & 8,75 & 1046,5 & 1044 & $-4,14$ \\
\hline
\end{tabular}

Tabla 3.11. Diferencias de frecuencias (cents) entre las frecuencias de referencia y las obtenidas (en $\mathrm{Hz}$ ).

\begin{tabular}{|c|c|c|c|c|c|c|c|}
\hline Afinación: escuela & df & $\mathbf{F}$ & Sig. & Afinación: oboísta & df & $\mathbf{F}$ & Sig. \\
\hline $\mathrm{F} 0 \mathrm{do} 4(\mathrm{~Hz})$ & 2 & 8,529 & ,018 & $\mathrm{F} 0 \mathrm{do}_{4}(\mathrm{~Hz})$ & 1 & ,013 & 912 \\
\hline Inten. $\mathrm{do}_{4}(\mathrm{~dB})$ & 2 & ,275 & ,768 & Inten. $\mathrm{do}_{4}(\mathrm{~dB})$ & 1 & 16,552 &, 005 \\
\hline F0 dos $(\mathrm{Hz})$ & 2 & 7,281 & ,025 & F0 do5 $(\mathrm{Hz})$ & 1 & ,014 & ,908 \\
\hline Inten. do $(\mathrm{dB})$ & 2 & ,096 & ,910 & Inten. $\mathrm{do}_{5}(\mathrm{~dB})$ & 1 & 71,197 &, 000 \\
\hline F0 do6 $(\mathrm{Hz})$ & 2 & 4,601 & ,061 & F0 do $6(\mathrm{~Hz})$ & 1 & 174 & 689 \\
\hline Inten. do $6(\mathrm{~dB})$ & 2 &, 010 & ,990 & Inten. $\mathrm{do}_{6}(\mathrm{~dB})$ & 1 & 141,177 &, 000 \\
\hline Oboísta & 2 & ,000 & 1,000 & Escuela & 1 & ,000 & 1,000 \\
\hline
\end{tabular}

Tabla 3.12. One-way Anova de la frecuencia y la intensidad dependiendo del factor escuela (izquierda) y oboísta (derecha) en el ejercicio afinación.

\subsubsection{Frullato}

La medición del jitter y del shimmer sirve para analizar el frullato ya que proporciona datos objetivos sobre la estabilidad de un sonido tanto para su frecuencia como para su intensidad:

1) el jitter es el porcentaje en la variación de altura respecto de la fundamental media en una ventana temporal. Muestra la inestabilidad en la afinación.

2) el shimmer es el porcentaje en la variación de intensidad en una ventana 
temporal. Muestra la inestabilidad en la intensidad.

La tabla 3.13 muestra que tanto la lengüeta alemana 1 como la francesa 2 son las que permiten un mejor efecto del frullato.

\begin{tabular}{|l|r|r|r|r|}
\hline \multicolumn{1}{|c|}{ Frullato } & Jitter (local \%) & Shimmer (local \%) & Frecuencia (Hz) & Intensidad (dB) \\
\hline alemana 1 & $\mathbf{1 , 1 3 2}$ & $\mathbf{1 0 , 1 6 3}$ & 1182 & 61,45 \\
\hline alemana 2 & 0,546 & 8,052 & 1222 & 70,78 \\
\hline americana 1 & 0,523 & 5,727 & 1189 & 65,86 \\
\hline americana 2 & 0,296 & 2,079 & 1191 & 58,84 \\
\hline francesa 1 & 0,253 & 2,982 & 1180 & 67,99 \\
\hline francesa 2 & $\mathbf{0 , 7 6 2}$ & $\mathbf{9 , 3 3 2}$ & 1188 & 61,15 \\
\hline
\end{tabular}

Tabla 3.13. Medidas acústicas del ejercicio frullato.

El análisis de varianza (One-way ANOVA) muestra en la tabla 3.14 que no existen diferencias significativas para la frecuencia $(p=, 602)$ y la intensidad $(p=, 804)$ en este ejercicio.

\begin{tabular}{|l|r|c|r|}
\hline \multicolumn{1}{|c|}{ Frullato } & df & \multicolumn{1}{c|}{ F } & \multicolumn{1}{c|}{ Sig. } \\
\hline Jitter (local \%) & 2 &, 930 &, 485 \\
\hline Shimmer (local \%) & 2 & 1,07 &, 371 \\
\hline Frecuencia (Hz) & 2 &, 604 &, 602 \\
\hline Intensidad (dB) & 2 &, 235 &, 804 \\
\hline
\end{tabular}

Tabla 3.14. One-way Anova de la frecuencia e intensidad dependiendo del factor escuela en el ejercicio frullato.

En la figura 3.19 se puede observar claramente este ejercicio. La intervención de la lengua para la pronunciación de la nota " $r$ " provoca que las representaciones de la amplitud/tiempo y de la intensidad no sean una onda ni una línea estable, sino todo lo contrario, más bien un trémolo con numerosos picos que demuestran la inestabilidad de la frecuencia (jitter) y de la intensidad (shimmer). 

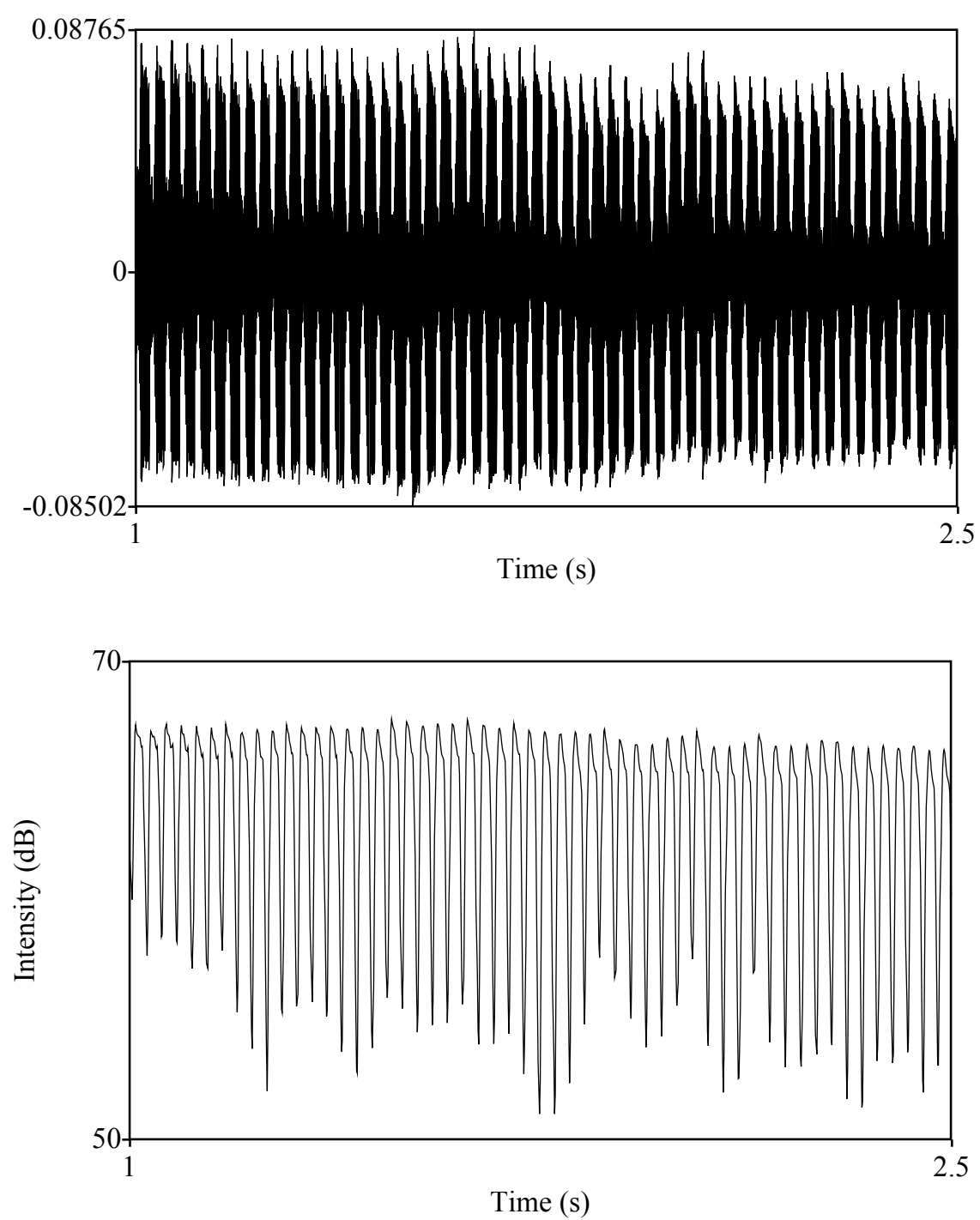

Figura 3.19. Representación de la amplitud/tiempo (arriba) y media de la intensidad en dB (abajo) del ejercicio "frullato". Lengüeta alemana 1.

\subsubsection{Intensidad}

La percepción de la potencia sonora esta relacionada con la intensidad del sonido. Para este ejercicio se ha medido acústicamente tanto la intensidad máxima como la mínima en todo el pasaje musical. Se puede observar en la tabla 3.15 que la lengüeta con mayor potencia sonora es la lengüeta alemana 2. 


\begin{tabular}{|l|r|r|r|}
\hline Intensidad & Intensidad máxima & Intensidad mínima & Diferencia de Intensidad \\
\hline alemana 1 & 74,36 & 66,30 & 8,06 \\
\hline alemana 2 & 72,47 & 61,29 & 11,18 \\
\hline americana 1 & 76,43 & 66,60 & 9,83 \\
\hline americana 2 & 74,22 & 66,02 & 8,20 \\
\hline francesa 1 & 74,29 & 66,36 & 7,93 \\
\hline francesa 2 & 73,91 & 65,04 & 8,87 \\
\hline
\end{tabular}

Tabla 3.15. Medidas acústicas del ejercicio intensidad, en dB.

El análisis de varianza de un factor (One-way ANOVA) (tabla 3.16) muestra que no existen diferencias significativas por tipo de rebajado en el parámetro intensidad: intensidad máxima $(p=, 391)$ e intensidad mínima $(p=, 541)$. Al igual que ocurría en el ejercicio afinación, el factor escuela no parece influir en la intensidad general del sonido del oboe.

\begin{tabular}{|c|c|c|c|}
\hline Intensidad & df & $\mathbf{F}$ & Sig. \\
\hline Intensidad máxima (dB) & 2 & 1,306 & ,391 \\
\hline Intensidad mínima (dB) & 2 & 760 & ,541 \\
\hline
\end{tabular}

Tabla 3.16. One-way Anova de la intensidad dependiendo del factor escuela en el ejercicio intensidad.

\subsubsection{Diminuendo}

En el ejercicio dinámica se ha medido la frecuencia inicial estable y la última frecuencia medible para poder cuantificar la desafinación que se produce. Esta desafinación se puede observar más fácilmente en la figura 3.20 con la representación del espectrograma (arriba) y de la frecuencia fundamental (abajo), apreciándose cómo la curva que representa la frecuencia fundamental soporta un desnivel hacia abajo en la afinación. Además, como lo más importante en la dinámica es saber cuántos decibelios puede llegar a disminuir una lengüeta ( $c f$. figura 3.20-centro), se acompaña a las mediciones de frecuencia, las de la intensidad máxima y mínima en el periodo estable. El último dato recogido es la intensidad en la última parte de la nota, cuando ya no puede ser considerada una nota de calidad, sino más bien un temblor. La elección de la frecuencia inicial estable en vez de la frecuencia inicial se debe a que, tanto en la voz como en los instrumentos de afinación libre, se suelen producir cambios en la frecuencia durante la emisión de una nota. Aunque en muchas ocasiones estos cambios son mínimos, influyen de una manera decisiva en la afinación de la primera nota. 


\begin{tabular}{|l|r|r|r|r|r|r|r|r|}
\hline Dinámica & F0 sol3 & $\begin{array}{c}\text { Fo } \\
\text { inicial }\end{array}$ & $\begin{array}{c}\text { Diferencia (Fo } \\
\text { medido/F0 de } \\
\text { referencia) }\end{array}$ & $\begin{array}{c}\text { F0 } \\
\text { final }\end{array}$ & $\begin{array}{c}\text { Diferencia (Fo } \\
\text { medido/F0 de } \\
\text { referencia) }\end{array}$ & Inten. máx. & $\begin{array}{c}\text { Inten. final } \\
\text { estable }\end{array}$ & Amplitud \\
\hline $\begin{array}{l}\text { Intérp. 1 } \\
\text { alemana 1 }\end{array}$ & 392 & 397,7 & 24,99 & 391,1 & $-3,98$ & 71,67 & 43,83 & 27,84 \\
\hline $\begin{array}{l}\text { Intérp. 1 } \\
\text { alemana 2 }\end{array}$ & 392 & 399,3 & $\mathbf{3 1 , 9 4}$ & 391,9 & $-0,44$ & 68,46 & 41,67 & 26,79 \\
\hline $\begin{array}{l}\text { Intérp. 1 } \\
\text { american. 1 }\end{array}$ & 392 & 395,0 & 13,20 & 390,0 & $-8,86$ & 69,60 & 40,68 & 28,92 \\
\hline $\begin{array}{l}\text { Intérp. 1 } \\
\text { american. 2 }\end{array}$ & 392 & 395,2 & 14,08 & 391,3 & $-3,09$ & 68,25 & 38,39 & $\mathbf{2 9 , 8 6}$ \\
\hline $\begin{array}{l}\text { Intérp. 1 } \\
\text { francesa 1 }\end{array}$ & 392 & 395,1 & 13,64 & 391,5 & $-2,21$ & 70,65 & 41,38 & 29,27 \\
\hline $\begin{array}{l}\text { Intérp. 1 } \\
\text { francesa 2 }\end{array}$ & 392 & 396,4 & 19,32 & 392,2 & 0,88 & 69,88 & 43,67 & 26,21 \\
\hline $\begin{array}{l}\text { Intérp. 2 } \\
\text { alemana 2 }\end{array}$ & 392 & 399,7 & $\mathbf{3 3 , 6 8}$ & 393,5 & 6,61 & 65,81 & 50,73 & $\mathbf{1 5 , 0 8}$ \\
\hline $\begin{array}{l}\text { Intérp. 2 } \\
\text { american. 1 }\end{array}$ & 392 & 393,9 & $\mathbf{8 , 3 7}$ & 390,5 & $-6,64$ & 68,26 & 45,15 & 23,11 \\
\hline $\begin{array}{l}\text { Intérp. 2 } \\
\text { francesa 1 }\end{array}$ & 392 & 396,0 & 17,58 & 391,8 & $-0,88$ & 68,40 & 49,55 & 18,85 \\
\hline
\end{tabular}

Tabla 3.17. Frecuencias (en Hz), diferencias de afinación (cents) y de intensidad (en dB) del ejercicio diminuendo.

Como muestra la tabla 3.17 , la lengüeta menos estable en la afinación es la alemana 2 en los dos intérpretes y además es con la que menos amplitud consigue el oboísta 2. Al contrario, la lengüeta que mejor mantiene la afinación es la americana 1 en el oboísta 2 y la que mayor amplitud consigue es la americana 2 en el oboísta 1.

Se puede ver en la tabla 3.18, al realizar un análisis de varianza de un factor (Oneway ANOVA), que existen diferencias significativas en el parámetro afinación (frecuencia inicial) con el factor escuela $(p=, 002)$. Se afirma, que al igual que pasaba en otros ejercicios, el factor escuela influye en la afinación de las notas. Sin embargo, este factor no es influyente en la intensidad, como se ha podido observar hasta el momento, pero sí lo es el factor oboísta, que influye en la intensidad $(p=, 049, p=, 004, p=, 004)$, pero no en la afinación $(p=, 958, p=, 438)$.

Finalmente, un análisis de varianza muestra que no hay ninguna diferencia significativa $(p=, 068)$ entre estilos de rebajado para la amplitud del diminuendo (diferencia entre intensidad máxima y mínima). Sin embargo en el efecto no deseado de caída de la frecuencia (la afinación suele bajar cuando baja la presión) se ve que hay una diferencia muy significativa $(\mathrm{F}=18, p=, 003)$ y un test post-hoc de Bonferroni muestra que las 
lengüetas alemanas son las que peor se comportan con un cambio de frecuencia mayor que las francesas $(p=, 007)$ y las americanas $(p=, 005)$.

\begin{tabular}{|c|c|c|c|c|c|}
\hline Dinámica: oboísta & $\mathbf{F}$ & Sig. & Dinámica: escuela & $\mathbf{F}$ & Sig. \\
\hline Initial F0 (Hz) & ,003 & ,958 & Initial F0 (Hz) & 20,995 &, 002 \\
\hline Final F0 (Hz) &, 676 & ,438 & Final F0 (Hz) & 2,995 & ,125 \\
\hline Max. Inten. (dB) & 642 &, 049 & Max. Inten. (dB) & 268 &, 774 \\
\hline Stable Final Inten. (dB) & 17,517 & ,004 & Stable Final Inten. (dB) & 817 & ,486 \\
\hline Unstable Final Inten. (dB) & 17,517 & ,004 & \begin{tabular}{|l|} 
Unstable Final Inten. $(\mathrm{dB})$ \\
\end{tabular} & ,817 & 486 \\
\hline
\end{tabular}

Tabla 3.18. One-way Anova de la frecuencia e intensidad dependiendo del factor oboísta (izquierda) y escuela (derecha) en el ejercicio dinámica.

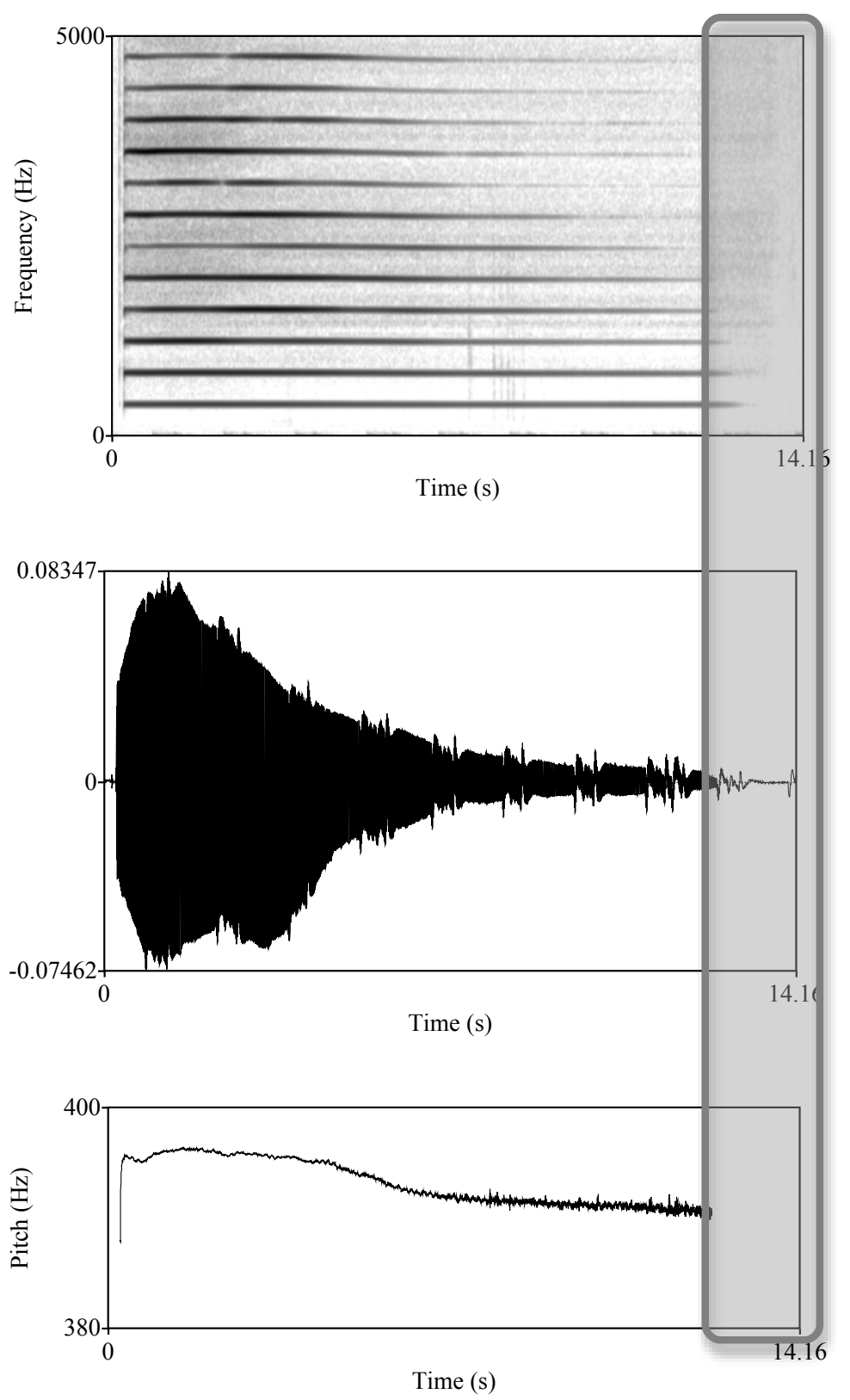

Figura 3.20. Espectrograma (arriba) representación amplitud/tiempo (centro) y curva de la frecuencia fundamental (abajo) del ejercicio "diminuendo". Lengüeta americana 2. El recuadro indica la porción del ejercicio donde ya no hay una altura definida. 


\subsubsection{Dobles sonidos armónicos}

Para el ejercicio de dobles sonidos armónicos se ha medido acústicamente el porcentaje unvoiced frames y el tiempo inicial monofónico, es decir, a partir de qué momento se escuchan los dos sonidos de forma estable. En este ejercicio, primero suena la nota fundamental, y la nota basada en el armónico (quinta de la octava superior) suele tardar más tiempo en aparecer. Se fija, para el análisis acústico, un rango de frecuencia mínima y máxima que corresponde a la nota armónica, de modo que la medición de voiced frames (porción de la señal con una altura definida) corresponde a la porción en la que está presente la nota armónica. La figura 3.21 muestra en qué momento aparecen las dos frecuencias sonando al mismo tiempo. Este parámetro acústico hace referencia a la flexibilidad y rigidez de una lengüeta, cuánto más tarda en aparecer el doble sonido menos flexible es la lengüeta. En la tabla 3.19 se puede observar que la lengüeta con la que más rápidamente aparece el efecto y se mantienen los dos sonidos durante más tiempo es la americana 1 .

\begin{tabular}{|l|r|r|}
\hline Dobles sonidos armónicos & \% unvoiced frames & Tiempo inicial monofónico (seg) \\
\hline alemana 1 & 28,32 & 1,20 \\
\hline alemana 2 & 25,82 & 1,57 \\
\hline americana 1 & $\mathbf{6 8 , 0 1}$ & $\mathbf{0 , 6 2}$ \\
\hline americana 2 & 20,79 & 1,11 \\
\hline francesa 1 & 13,14 & 7,34 \\
\hline francesa 2 & 25,99 & 1,62 \\
\hline
\end{tabular}

Tabla 3.19. Medidas acústicas de los dobles sonidos.

El análisis estadístico (One-way ANOVA) muestra en la tabla 3.20 que el factor escuela no influye de forma significativa en este ejercicio: \% unvoiced frames $(p=, 523)$ y tiempo inicial monofónico $(p=, 375)$.

\begin{tabular}{|l|r|r|}
\hline \multicolumn{1}{|c|}{ Dobles sonidos } & \multicolumn{1}{c|}{ F } & \multicolumn{1}{c|}{ Sig. } \\
\hline \% unvoiced frames &, 811 &, 523 \\
\hline Start time mono (seg) & 1,385 &, 375 \\
\hline
\end{tabular}

Tabla 3.20. One-way Anova dependiendo del factor escuela en el ejercicio dobles sonidos. 


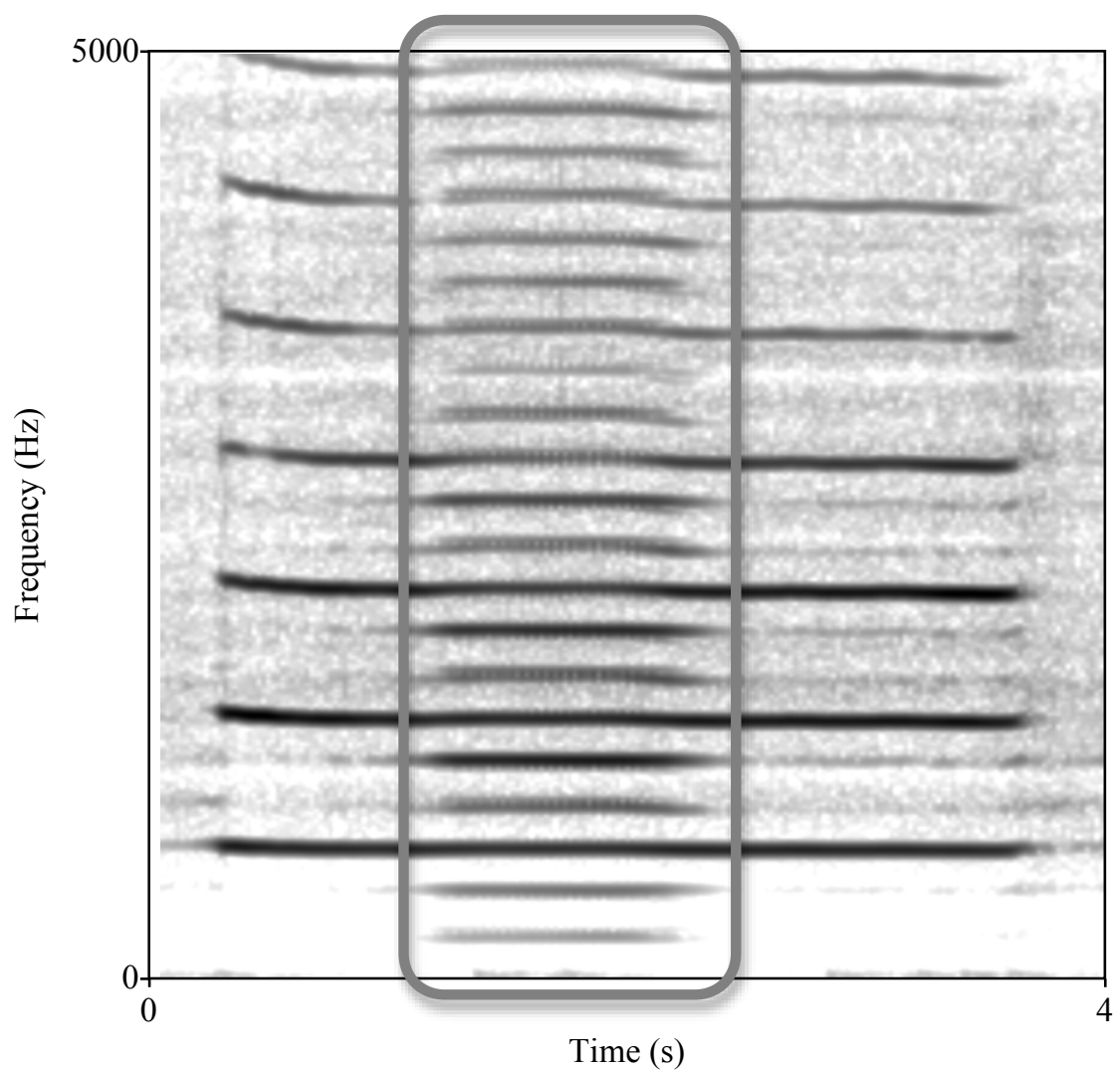

Figura 3.21. Espectrograma del ejercicio “dobles sonidos armónicos”. Lengüeta americana 2. El recuadro indica la porción donde más claramente se oyen ambas frecuencias fundamentales.

\subsubsection{Comparación de la afinación en el conjunto de ejercicios}

Para poder comparar las frecuencias obtenidas con cada lengüeta, se realiza un test T que permite evaluar la significatividad de la diferencia de dos grupos, siempre que la comparación entre los grupos se haga para elementos que correspondan a las mismas condiciones. Los casos corresponden a cada uno de los ejercicios (do4 correspondiente al ejercicio de la afinación, oscillato, etc.) que se realizaron en las mismas condiciones y con el mismo intérprete, cambiando únicamente la lengüeta.

En la tabla 3.21 se pueden observar los resultados obtenidos que demuestran la existencia de una diferencia significativa de frecuencia (F0) entre las lengüetas de la escuela alemana y la americana $(\mathrm{t}=3,36, p=, 002)$, entre la alemana y la francesa $(\mathrm{t}=3,99$, $p<, 001)$, pero no entre la americana y la francesa $(\mathrm{t}=1,58, p=, 124)$. En la figura 3.22 se muestra el Test-T comparando las diferencias entre tipo de lengüeta, agrupándose las que son del mismo tipo de escuela. 


\begin{tabular}{|r|l|r|r|r|r|r|r|r|r|}
\hline \multicolumn{9}{|c|}{ Paired Samples Test } \\
\hline & & \multicolumn{7}{|c|}{ Paired Differences } \\
\hline
\end{tabular}

Tabla 3.21. Test $\mathrm{T}$ comparando las frecuencias medias obtenidas en los diferentes ejercicios grabados con las diferentes lengüetas agrupadas por escuelas.

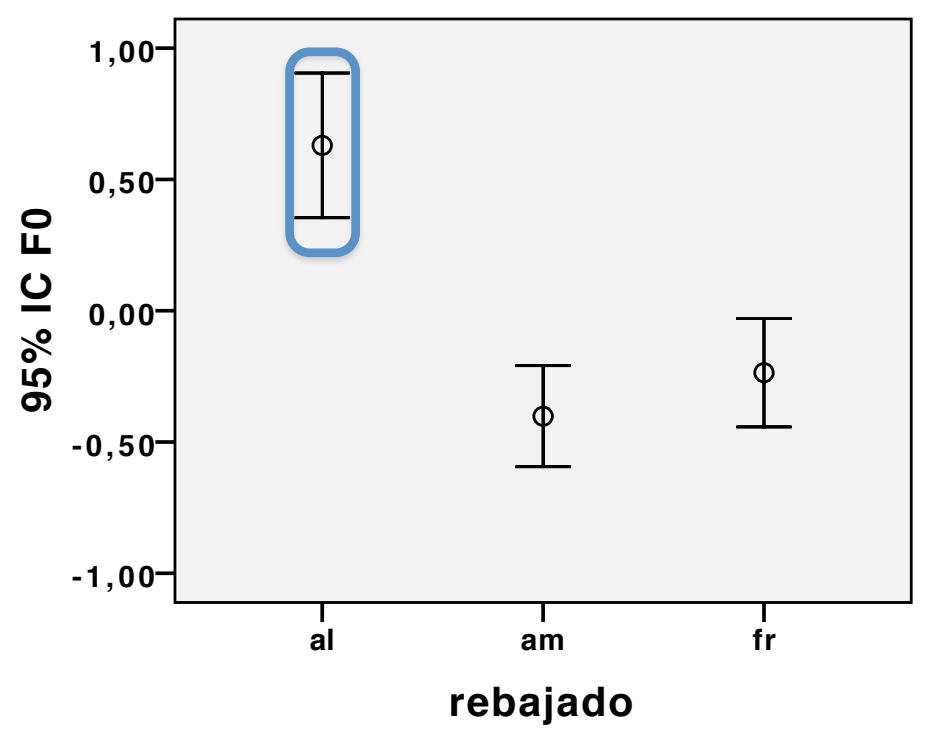

Figura 3.22. Frecuencia fundamental media para cada estilo de rebajado, utilizando los valores normalizados de cada ejercicio. Se marca con un círculo azul los valores que se diferencian significativamente.

Para verificar si las diferencias de frecuencia media se deben a las diferentes escuelas en general o son específicas a cada lengüeta, se realiza un segundo test $\mathrm{T}$ comparando los resultados lengüeta por lengüeta (tabla 3.22).

Los resultados muestran que hay diferencias significativas entre lengüetas, en particular la lengüeta alemana 2 se distingue del resto de lengüetas ( $c f$. figura 3.23). Pero se puede observar que no hay diferencias significativas entre las dos lengüetas de escuela francesa $(p=, 417)$ ni entre las lengüetas de escuela americana $(p=, 597)$. Si se exceptúa la lengüeta alemana 2, sólo se encuentran diferencias significativas entre las lengüetas alemana 1 - francesa $1(p=, 017)$ y alemana 1 - francesa $2(p=, 037)$. 


\begin{tabular}{|c|c|c|c|c|c|c|c|c|c|}
\hline \multicolumn{10}{|c|}{ Paired Samples Test } \\
\hline & & \multicolumn{8}{|c|}{ Paired Differences } \\
\hline & & \multirow[t]{2}{*}{ Mean } & \multirow[t]{2}{*}{$\begin{array}{c}\text { Std. } \\
\text { Deviation }\end{array}$} & \multirow{2}{*}{$\begin{array}{c}\text { Std. } \\
\text { Error } \\
\text { Mean }\end{array}$} & \multicolumn{2}{|c|}{$\begin{array}{c}95 \% \text { Confidence Interval of } \\
\text { the Difference }\end{array}$} & \multirow[t]{2}{*}{$\mathrm{t}$} & \multirow[t]{2}{*}{$\mathrm{df}$} & \multirow[t]{2}{*}{$\begin{array}{l}\text { Sig. (2- } \\
\text { tailed) }\end{array}$} \\
\hline & & & & & Lower & Upper & & & \\
\hline Pair 1 & \begin{tabular}{|l} 
F0 alemana1 - \\
F0 americana1
\end{tabular} & 1,2958 & 2,9810 & ,8268 &,- 5055 & 3,0972 & 1,567 & 12 & 143 \\
\hline Pair 2 & $\begin{array}{l}\text { F0 alemanal - } \\
\text { F0 francesa1 }\end{array}$ & 2,2839 & 2,9855 &, 8280 & ,4798 & 4,0880 & 2,758 & 12 &, 017 \\
\hline Pair 3 & \begin{tabular}{|l|} 
F0 alemana1 - \\
F0 alemana2
\end{tabular} & $-8,1973$ & 12,3655 & 3,4296 & $-15,6697$ &,- 7249 & $-2,390$ & 12 & ,034 \\
\hline Pair 4 & $\begin{array}{l}\text { F0 alemana1 - } \\
\text { F0 americana2 }\end{array}$ & ,7949 & 3,8092 & 1,0565 & $-1,5069$ & 3,0968 & ,752 & 12 & ,466 \\
\hline Pair 5 & $\begin{array}{l}\text { F0 alemana1 - } \\
\text { F0 francesa2 }\end{array}$ & 3,5819 & 5,5168 & 1,5301 & ,2481 & 6,9157 & 2,341 & 12 & ,037 \\
\hline Pair 6 & $\begin{array}{l}\text { F0 americana1 - } \\
\text { F0 francesa1 }\end{array}$ & 1,3472 & 6,3802 & 1,4267 & $-1,6388$ & 4,3333 & ,944 & 19 &, 357 \\
\hline Pair 7 & $\begin{array}{l}\text { F0 americana1 - } \\
\text { F0 alemana2 }\end{array}$ & $-9,6606$ & 11,2541 & 2,5165 & $-14,9276$ & $-4,3935$ & $-3,839$ & 19 & 001 \\
\hline Pair 8 & $\begin{array}{l}\text { F0 americana1 - } \\
\text { F0 americana2 } \\
\end{array}$ &,- 5009 & 3,3217 & ,9213 & $-2,5082$ & 1,5064 &,- 544 & 12 &, 597 \\
\hline Pair 9 & $\begin{array}{l}\text { F0 americana1 - } \\
\text { F0 francesa2 }\end{array}$ & 2,2861 & 6,5770 & 1,8241 & $-1,6883$ & 6,2605 & 1,253 & 12 & 234 \\
\hline Pair 10 & $\begin{array}{l}\text { F0 francesa1 - } \\
\text { F0 alemana2 }\end{array}$ & $-11,0078$ & 12,1314 & 2,7127 & $-16,6855$ & $-5,3301$ & $-4,058$ & 19 & ,001 \\
\hline Pair 11 & $\begin{array}{l}\text { F0 francesa1 - } \\
\text { F0 americana2 }\end{array}$ & $-1,4890$ & 5,6535 & 1,5680 & $-4,9054$ & 1,9274 &,- 950 & 12 &, 361 \\
\hline Pair 12 & \begin{tabular}{|l|} 
F0 francesa1 - \\
F0 francesa2
\end{tabular} & 1,2980 & 5,5732 & 1,5457 & $-2,0699$ & 4,6659 & 8,840 & 12 & ,417 \\
\hline Pair 13 & $\begin{array}{l}\mathrm{F} 0 \text { alemana2 }- \\
\mathrm{F} 0 \text { americana2 } \\
\end{array}$ & 8,9922 & 13,9082 & 3,8574 & ,5876 & 17,3969 & 2,331 & 12 & ,038 \\
\hline Pair 14 & $\begin{array}{l}\text { F0 alemana2 - } \\
\text { F0 francesa2 }\end{array}$ & 11,7792 & 13,7829 & 3,8227 & 3,4503 & 20,1082 & 3,081 & 12 & ,010 \\
\hline Pair 15 & $\begin{array}{l}\text { F0 americana2 - } \\
\text { F0 francesa2 }\end{array}$ & 2,7870 & 7,9550 & 2,2063 & $-2,0201$ & 7,5941 & 1,263 & 12 & ,231 \\
\hline
\end{tabular}

Tabla 3.22. Test $\mathrm{T}$ comparando las frecuencias medias obtenidas en los diferentes ejercicios grabados con las diferentes lengüetas. 


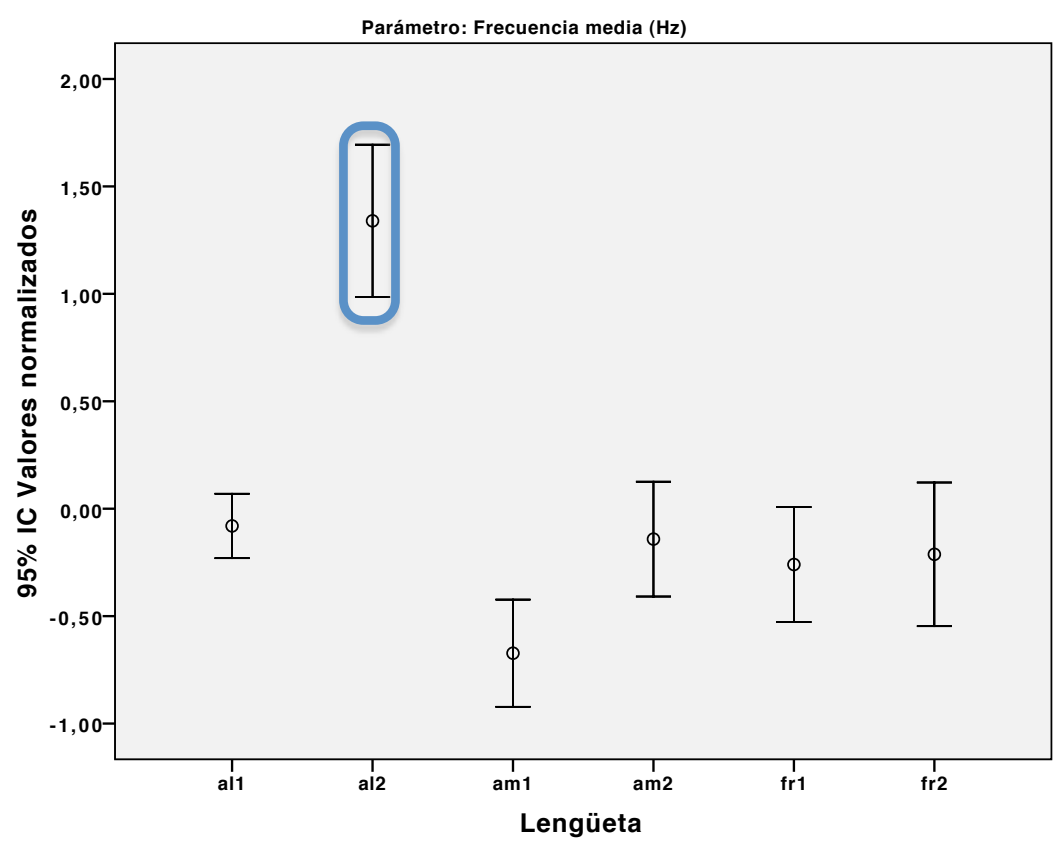

Figura 3.23. Frecuencia fundamental media de las lengüetas utilizando los valores normalizados de cada ejercicio. Se marca con un círculo azul los valores que se diferencian significativamente.

\subsubsection{Respuestas acústicas globales de las lengüetas}

En esta parte se estudian las características acústicas generales de cada lengüeta, utilizando todos los ejercicios de interpretación grabados. Para ello, se realiza una serie de pruebas $\mathrm{T}$ pareadas comparando para cada par de lengüetas las mediciones acústicas de un mismo ejercicio de interpretación. De esta manera se puede distinguir las características del tipo de rebajado y la variabilidad que proviene de las particularidades de la caña de origen. En las tablas 3.23 a 3.28 se indica los valores de la prueba $t$, sólo cuando son significativos $(p<, 05)$, indicando $n s$ en caso de no llegar a un resultado significativo. Las tablas se construyen siguiendo la siguiente convención: para una casilla de la fila $i$ y la columna $j$, si el valor de la prueba $t$ es positivo, indica que hay una media de valor superior para la lengüeta $i$ (fila) respecto a la lengüeta $j$ (columna), y viceversa cuando el signo es negativo.

\subsubsection{Mediciones acústicas realizadas}

Utilizando el programa Praat (Boersma y Weenink, 2011) se miden los principales parámetros acústicos agrupándose en las siguientes categorías representativas del funcionamiento de la lengüeta del oboe:

1) parámetros relativos a la intensidad: amplitud media, intensidad máxima y 
media (en $\mathrm{dB}$ ), energía, potencia y media cuadrática (Root-mean-square RMS).

2) parámetros relativos a la variabilidad de la intensidad: desviación estándar de la amplitud, shimmer.

3) parámetros relativos a la afinación: frecuencia fundamental máxima, mínima y media (en $\mathrm{Hz}$ y en semitonos).

4) parámetros relativos a la estabilidad de la afinación: desviación estándar (en $\mathrm{Hz}$ y en semitonos) de la frecuencia fundamental, pendiente media de la frecuencia fundamental (en $\mathrm{Hz}$ y en semitonos, eliminando o no las octavas), jitter.

5) parámetros relativos a la facilidad de vibración: cantidad de ciclos con una altura definida ( $N^{o}$ voiced frames).

6) parámetros relativos a la armonicidad: armonicidad media y su desviación estándar.

7) parámetros relativos al timbre: diferencia de energía de bandas entre las frecuencias por debajo de 100, 200, 300, 400, 500, 700, 1000 y $2000 \mathrm{~Hz}$, centro de gravedad del espectro, momento central del espectro, Kurtosis del espectro, Skewness del espectro, y desviación estándar del espectro.

\subsubsection{Intensidad sonora}

Se comparan las lengüetas según diferentes medidas acústicas relacionadas con la intensidad, utilizándose la medición de la intensidad (en dB) como medida más representativa y comparando cada par de lengüetas con una prueba $\mathrm{T}$ pareada (paired samples T-test) todos los valores de intensidad para todos los ejercicios, como se puede ver en la tabla 3.23 ( $c f$. A.16 para más detalle).

La lengüeta francesa 2 y la americana 2 son las que menos intensidad consiguen siendo significativo en todos los casos. La intensidad sonora general parece estar ligada a características de la caña y no del rebajado en este caso (figura 3.24). 


\begin{tabular}{|c|c|c|c|c|c|}
\hline & al2 & am1 & am2 & fr1 & fr2 \\
\hline al1 & $\mathrm{ns}$ & $\mathrm{ns}$ & $2.5^{*}$ & $\mathrm{~ns}$ & $4.6^{*}$ \\
\hline al2 & & $\mathrm{ns}$ & $3.3^{*}$ & $\mathrm{~ns}$ & $4.6^{*}$ \\
\hline am1 & & & $2.1^{*}$ & $\mathrm{~ns}$ & $3.5^{*}$ \\
\hline $\mathbf{a m 2}$ & & & & $-2.4^{*}$ & $2.3^{*}$ \\
\hline fr1 & & & & & $4.0^{*}$ \\
\hline
\end{tabular}

Tabla 3.23. Resumen del análisis de la prueba T, comparando las diferentes lengüetas en los valores de intensidad (en $\mathrm{dB})$. (* test significativo al .05; ns test no significativo)

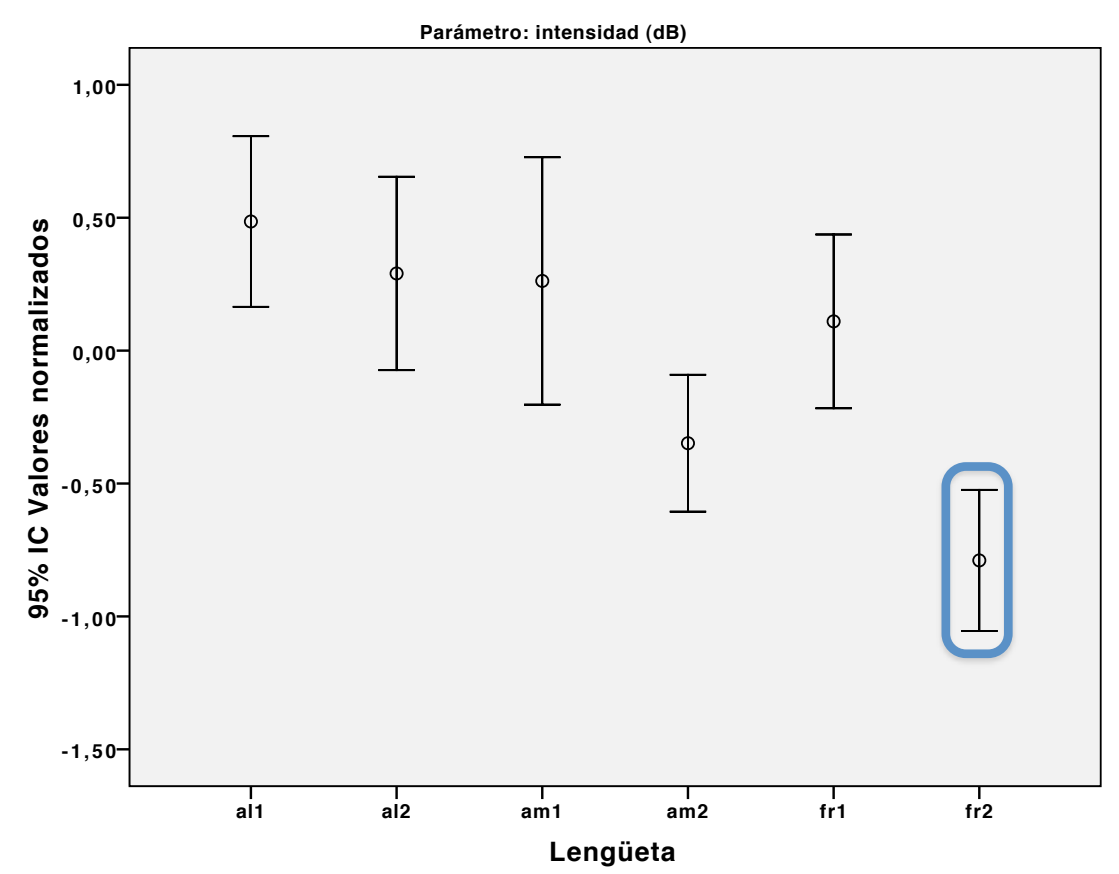

Figura 3.24. Media de los valores normalizados por ejercicio de la intensidad para cada lengüeta. Se marca con un círculo azul los valores que se diferencian significativamente.

\subsubsection{Variabilidad de la intensidad}

Se utiliza la medición de la desviación estándar de la amplitud como medida más representativa de la variabilidad de la intensidad. Los resultados de la prueba $\mathrm{T}$ pareada pueden verse en la tabla 3.24 ( $c f$. A.17 para más detalle).

Destacan la francesa 2 y la americana 2 por su menor desviación, siendo significativo en todos los casos. Se puede indicar pues, que la variabilidad de la intensidad parece estar ligada a las características de la caña más que al estilo de rebajado. 


\begin{tabular}{|c|c|c|c|c|c|}
\hline & al2 & am1 & am2 & fr1 & fr2 \\
\hline al1 & ns & ns & $2.9^{*}$ & ns & $4.7^{*}$ \\
\hline al2 & & ns & $2.9^{*}$ & $\mathrm{~ns}$ & $3.9^{*}$ \\
\hline am1 & & & $2.5^{*}$ & $\mathrm{~ns}$ & $4.0^{*}$ \\
\hline am2 & & & & $-2.5^{*}$ & $2.4^{*}$ \\
\hline fr1 & & & & & $4.3^{*}$ \\
\hline
\end{tabular}

Tabla 3.24. Resumen del análisis de la prueba $\mathrm{T}$, comparando las diferentes lengüetas en los valores de desviación estándar de la amplitud. (* test significativo al .05; ns test no significativo)

\subsubsection{Afinación}

La medición de la frecuencia media (en semitonos) se utiliza como medida más representativa de la afinación. Con la prueba $\mathrm{T}$ pareada se obtienen los resultados de la tabla 3.25 ( $c f$. A.18 para más detalle).

La lengüeta alemana 2 destaca por estar significativamente más alta que todas las otras lengüetas, seguida por la francesa 2, también más alta que el resto de lengüetas excepto la alemana 2. La afinación en este caso parece estar ligada a las características de las lengüetas más que al estilo de rebajado.

\begin{tabular}{|c|c|c|c|c|c|}
\hline & al2 & am1 & am2 & fr1 & fr2 \\
\hline al1 & $-2.4^{*}$ & $\mathrm{~ns}$ & $\mathrm{~ns}$ & $\mathrm{~ns}$ & $-2.1^{*}$ \\
\hline al2 & & $2.5^{*}$ & $2.3^{*}$ & $2.1^{*}$ & $2.4^{*}$ \\
\hline am1 & & & $\mathrm{ns}$ & $\mathrm{ns}$ & $-2.1^{*}$ \\
\hline am2 & & & & $-2.1^{*}$ & $-2.1^{*}$ \\
\hline fr1 & & & & & $\mathrm{ns}$ \\
\hline
\end{tabular}

Tabla 3.25. Resumen del análisis de la prueba T, comparando las diferentes lengüetas en los valores de frecuencia media ( $\mathrm{F} 0$ en semitonos). ( $*$ test significativo al .05; $\mathrm{ns}$ test no significativo)

\subsubsection{Estabilidad en la afinación}

Se comparan las lengüetas según diferentes medidas acústicas relacionadas con la estabilidad de la afinación. La medición de la desviación estándar en semitonos y el jitter, son las medidas más representativas y los datos del análisis estadístico pueden verse en la tabla 3.26 ( $c f$. A.19 y A.20 para más detalle).

La lengüeta más inestable es la alemana 2, es decir, es la que menos mantiene la nota interpretada de forma estable (figura 3.25). Por el contrario, la lengüeta más estable es la francesa 2. Los resultados no parecen destacar una tendencia clara, y en cualquier caso no parecen ligados al estilo de rebajado. 


\begin{tabular}{|c|c|c|c|c|c|c|c|c|c|c|c|}
\hline & al2 & am1 & am2 & fr1 1 & fr2 & & al2 & am1 & am2 & fr1 & fr2 \\
\hline al1 & $2.5^{*}$ & ns & ns & ns & $2.3^{*}$ & al1 & $2.2 *$ & ns & ns & ns & $3.2^{*}$ \\
\hline al2 & & ns & $-2.7^{*}$ & $-2.4^{*}$ & $\mathrm{~ns}$ & al2 & & ns & $-2.7^{*}$ & ns & ns \\
\hline am1 & & & ns & ns & ns & am1 & & & ns & ns & $2.5^{*}$ \\
\hline am2 & & & & ns & $2.6^{*}$ & am2 & & & & ns & $3.8 *$ \\
\hline fr1 & & & & & $2.3 *$ & fr1 & & & & & ns \\
\hline
\end{tabular}

Tabla 3.26. Resumen del análisis de la prueba T, comparando las diferentes lengüetas en los valores de desviación estándar en semitonos (izquierda) y jitter (derecha). (* test significativo al .05; ns test no significativo)

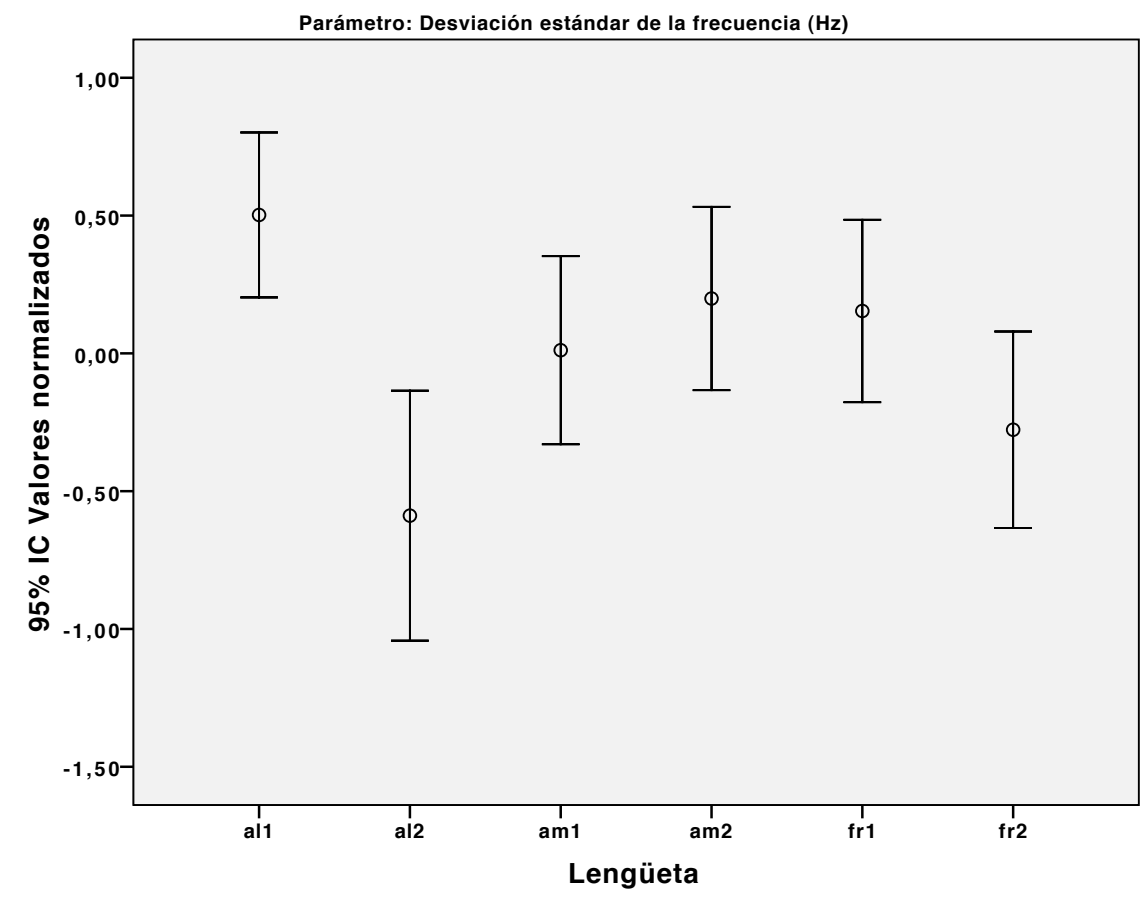

Figura 3.25. Media de los valores normalizados por ejercicio de la desviación estándar de la frecuencia fundamental para cada lengüeta.

\subsubsection{Facilidad de vibración}

Se utiliza la medición de $N^{o}$ voiced frames como medida más representativa de la facilidad en la vibración (figura 3.26). Una prueba $\mathrm{T}$ pareada entre todos los pares de lengüetas sólo muestra una diferencia significativa entre las lengüetas francesa 1 y francesa $2(t=-2,6, p<, 05)$ con lo que el experimento no muestra diferencias claras en la facilidad de vibración de las lengüetas ( $c f$. A.21 para más detalle). 


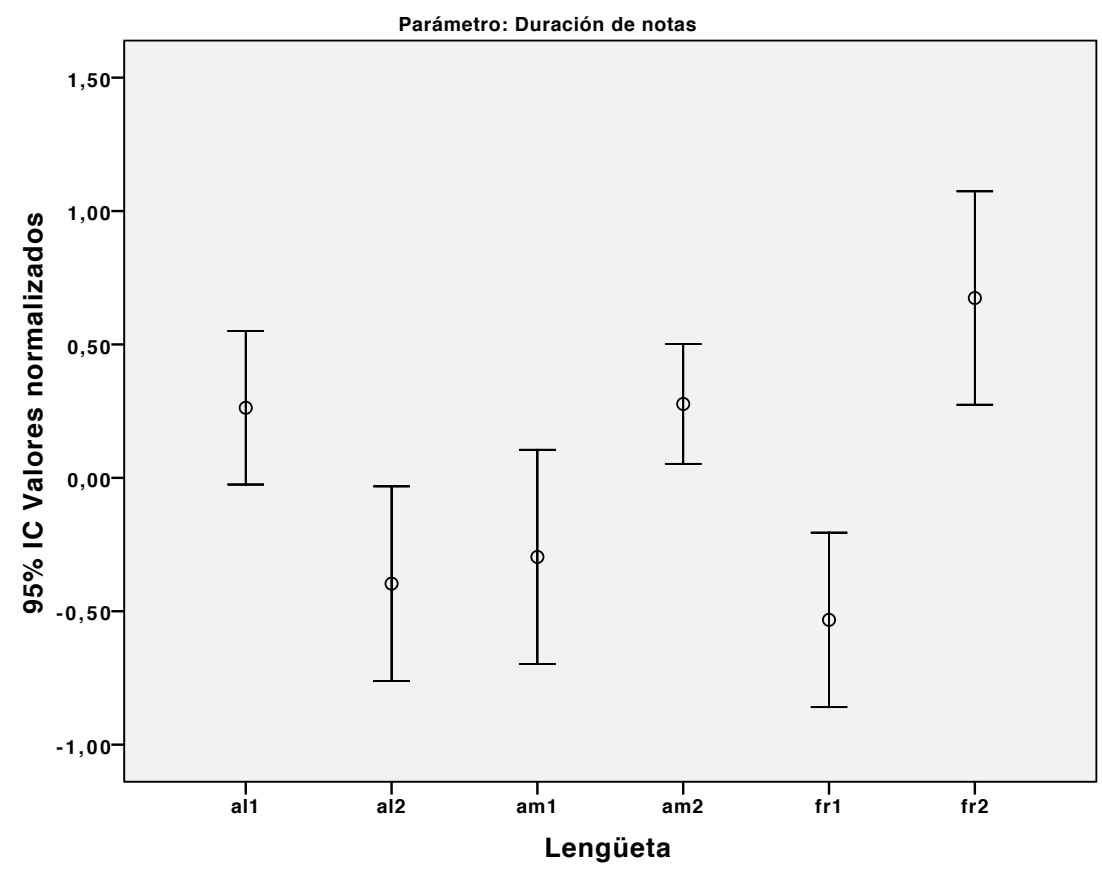

Figura 3.26. Media de los valores normalizados por ejercicio de la duración de notas (number of voiced frames) para cada lengüeta.

\subsubsection{Armonicidad}

Se comparan las lengüetas según diferentes medidas acústicas relacionadas con la armonicidad. Utilizándose la medición de la media de la armonicidad (harmonics-to-noise ratio) como medida más representativa. Con el análisis estadístico obtenemos los valores de la tabla 3.27 ( $c f$. A.22 para más detalle).

Se observa (figura 3.27) que la lengüeta americana 1 es la que menos armonicidad tiene, siendo significativo en todos los casos, distinguiéndose en segundo lugar la americana 2 que tiene menos armonicidad que la alemana 2. El rebajado americano parece pues introducir más ruido en el sonido producido, aunque parece debido sobre todo a las propiedades de la lengüeta americana 1 , más que al estilo de rebajado en general.

\begin{tabular}{|c|c|c|c|c|c|}
\hline & al2 & am1 & am2 & fr1 & fr2 \\
\hline al1 & $\mathrm{ns}$ & $3.1^{*}$ & $\mathrm{~ns}$ & $\mathrm{~ns}$ & $\mathrm{~ns}$ \\
\hline a12 & & $3.4^{*}$ & $2.3^{*}$ & $\mathrm{~ns}$ & $\mathrm{~ns}$ \\
\hline am1 & & & $-3.9^{*}$ & $-4.3^{*}$ & $-2.7^{*}$ \\
\hline am2 & & & & $\mathrm{ns}$ & $\mathrm{ns}$ \\
\hline fr1 & & & & & $\mathrm{ns}$ \\
\hline
\end{tabular}

Tabla 3.27. Resumen del análisis de la prueba T, comparando las diferentes lengüetas en los valores de armonicidad media. (* test significativo al .05; ns test no significativo). 


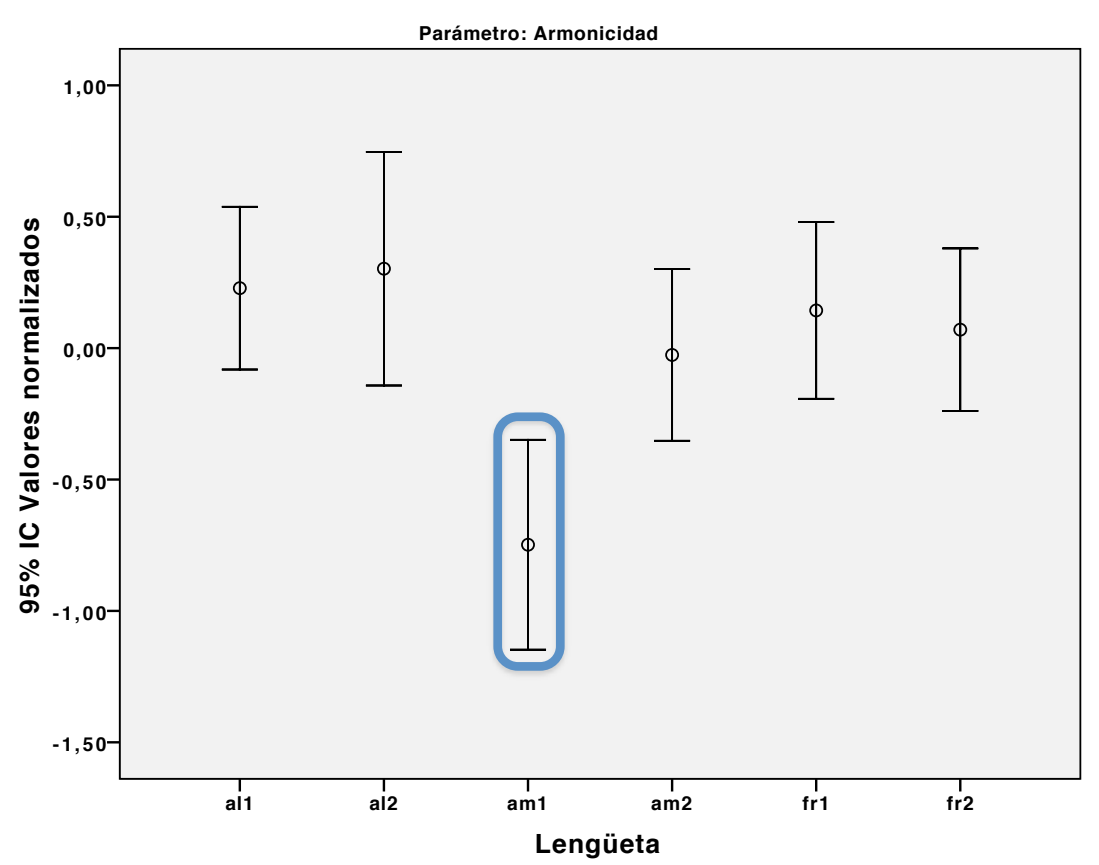

Figura 3.27. Media de los valores normalizados por ejercicio de la armonicidad para cada lengüeta. Se marca con un círculo azul los valores que se diferencian significativamente.

\subsubsection{Timbre}

Se comparan las lengüetas según diferentes medidas acústicas relacionadas con el timbre. Al medir la Kurtosis y la Skewness del espectro, se observa que las lengüetas alemanas son las que mayores valores tienen en estos dos parámetros, siendo significativo en todos los casos, como se puede ver en la tabla 3.28 ( $c f$. A.23 y A.24 para más detalle). Una Kurtosis alta indica que hay más energía entorno al centro espectral, y una Kurtosis baja indica, en general, un espectro más plano. Del mismo modo, una Skewness más alta indica que la energía se distribuye más en la parte grave (inferior al centro espectral). Se observa que para el rebajado de estilo alemán, existe una distribución de la energía en la parte central y grave del espectro, con formantes más marcados. Las mediciones de energía por bandas de frecuencias fijas no crean diferencias significativas entre lengüetas.

En la figura 3.28 se muestran los valores medios del centro de gravedad espectral, que está relacionado con el timbre espectral: unos valores altos corresponden a un espectro con más energía en el agudo, es decir con más brillo. En este caso, las pruebas T pareadas confirman las diferencias gráficas: se distinguen las lengüetas alemana 1 y francesa 2 por tener un centro más bajo y esto puede confirmar que los estilos de rebajado sí influyen en algunos parámetros acústicos. 


\begin{tabular}{|c|c|c|c|c|c|c|c|c|c|c|c|}
\hline & al2 & am1 & am2 & fr1 & fr2 & & al2 & am1 & am2 & fr1 & fr2 \\
\hline al1 & $-2.1 *$ & $2.7 *$ & $2.6^{*}$ & $2.5^{*}$ & $2.8 *$ & al1 & $-2.6^{*}$ & $2.6^{*}$ & $2.1 *$ & $3.6^{*}$ & $3.6^{*}$ \\
\hline al2 & & $2.7^{*}$ & $3.0 *$ & $2.7^{*}$ & $2.8^{*}$ & al2 & & $2.9 *$ & $3.0 *$ & $3.9 *$ & $3.6^{*}$ \\
\hline am1 & & & $\mathrm{ns}$ & $-2.2 *$ & ns & am1 & & & ns & ns & ns \\
\hline am2 & & & & ns & ns & am2 & & & & $\mathrm{ns}$ & $\mathrm{ns}$ \\
\hline fr1 & & & & & ns & fr1 & & & & & $\mathrm{ns}$ \\
\hline
\end{tabular}

Tabla 3.28. Resumen del análisis de la prueba T, comparando las diferentes lengüetas en los valores de Kurtosis (izquierda) y Skewness (derecha). (* test significativo al .05; ns test no significativo).

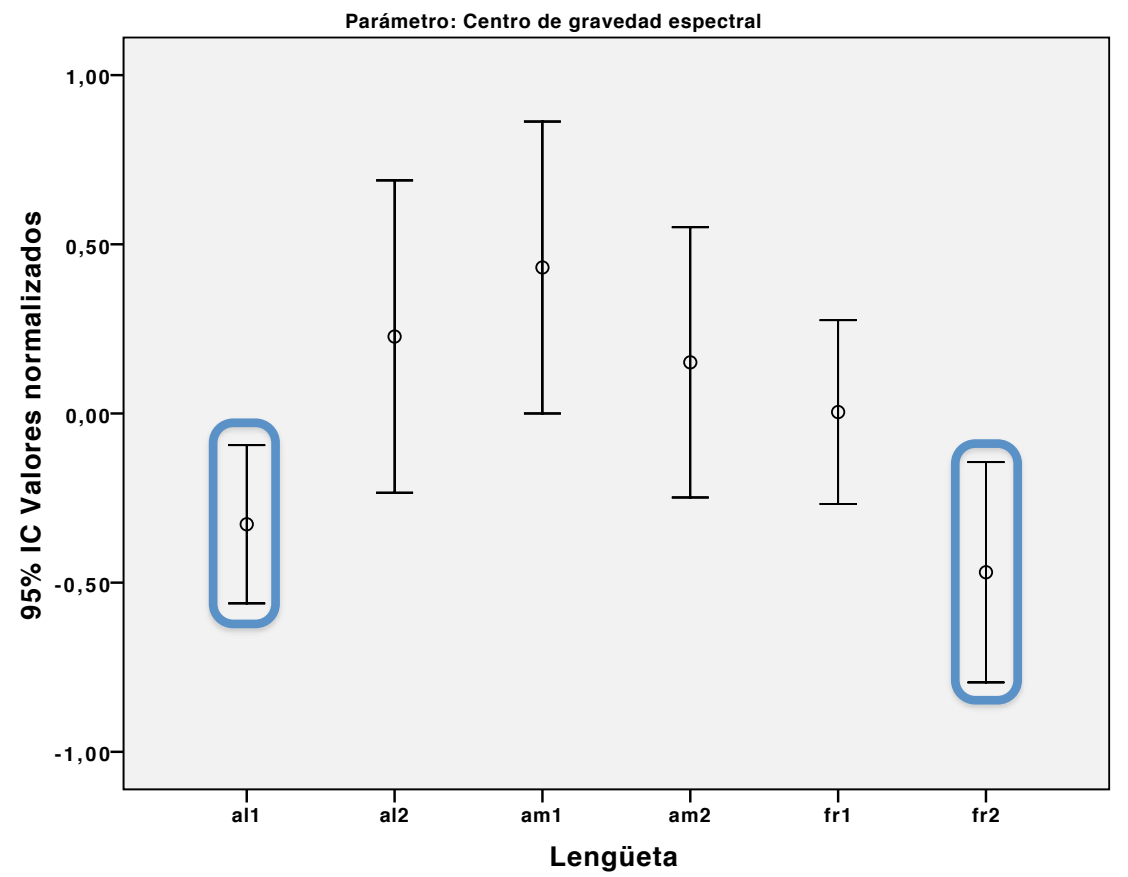

Figura 3.28. Media de los valores normalizados por ejercicio del centro de gravedad espectral para cada lengüeta. Se marca con un círculo azul los valores que se diferencian significativamente.

\subsubsection{Correlaciones entre los parámetros acústicos}

Finalmente, para los parámetros acústicos normalizados por ejercicio se realiza una serie de correlaciones bilaterales de Pearson con los resultados que se muestran en la tabla 3.29. Estos valores no comparan las lengüetas y los estilos de rebajado, sino las relaciones entre las propiedades acústicas.

Se puede observar que los parámetros de jitter y de centro de gravedad espectral no están relacionados con ningún otro parámetro acústico.

La frecuencia fundamental media está positivamente correlacionada con la armonicidad, con lo que las lengüetas que se desvían en afinación hacia lo agudo también tienen mayor armonicidad (o menor componente ruidoso en el sonido). También hay una 
correlación con la desviación estándar de frecuencia, lo cual puede ser simplemente un resultado matemático (a mayor frecuencia, mayor desviación de frecuencia). Curiosamente, no hay relación alguna entre la afinación y la intensidad.

La intensidad media está correlacionada negativamente con la duración de las notas, es decir, las lengüetas que consiguen una mayor intensidad media tienen más dificultad para vibrar. La explicación es que las lengüetas más duras admiten mayor volumen de aire dentro de ellas porque sus palas no se saturan tan rápidamente como las lengüetas blandas, así que pueden vibrar fácilmente con mayor cantidad de aire; por el contrario, en una lengüeta blanda sus palas empiezan a vibrar muy pronto necesitando muy poca cantidad de aire para conseguir sonar, por lo que la vibración de sus palas se saturan mucho antes que en las lengüetas más duras (no admitiendo más aire y apareciendo inestabilidades en el sonido, armónicos no deseados, etc.). La intensidad también está correlacionada positivamente con la armonicidad, siendo las lengüetas con mayor intensidad sonora las que menos ruido proporcionan.

\begin{tabular}{|c|c|c|c|c|c|c|c|c|}
\hline & & Fo & intensidad & $\begin{array}{c}\text { duración } \\
\text { notas }\end{array}$ & \begin{tabular}{c|c} 
centro \\
espectral
\end{tabular} & armonicidad & jitter & $\begin{array}{c}\text { desviación } \\
\text { est. F0 }\end{array}$ \\
\hline \multirow[t]{2}{*}{ Fo } & Corr. & 1,000 & ,046 &,- 067 & ,142 & , 260** &,- 135 &,$- 377^{* *}$ \\
\hline & Sig. & & -577 & ,419 & ,085 & , 001 & ,102 & , 000 \\
\hline \multirow[t]{2}{*}{ intensidad } & Corr. & ,046 & 1,000 &,$- 310^{* *}$ & ,000 &, $396^{* *}$ &,- 057 &,- 027 \\
\hline & Sig. & ,577 & & ,000 & |991 & ,000 & ,491 &, 746 \\
\hline \multirow{2}{*}{\begin{tabular}{|l|}
$\begin{array}{l}\text { duración } \\
\text { notas }\end{array}$ \\
\end{tabular}} & Corr. &,- 067 &,$- 310^{* *}$ & 1,000 &,- 134 &,- 099 & ,077 &,- 028 \\
\hline & Sig. &, 419 &, 000 & & , 104 & ,229 & ,349 &, 736 \\
\hline \multirow{2}{*}{$\begin{array}{l}\text { centro } \\
\text { espectral }\end{array}$} & Corr. & ,142 & ,000 &,- 134 & 1,000 &,- 130 & ,045 & ,001 \\
\hline & Sig. &, 085 & ,991 & ,104 & &, 115 & ,587 & ,988 \\
\hline \multirow[t]{2}{*}{ armonicidad } & Corr. &, $260^{* *}$ & $396^{* *}$ &,- 099 &,- 130 & 1,000 &,- 062 &,$- 180^{*}$ \\
\hline & Sig. & ,001 & ,000 & ,229 & ,115 & & ,453 &, 028 \\
\hline \multirow[t]{2}{*}{ jitter } & Corr. &,- 135 &,- 057 &, 077 &, 045 &,- 062 & 1,000 &, 065 \\
\hline & Sig. & ,102 & ,491 & ,349 &, 587 & ,453 & &, 430 \\
\hline \multirow{2}{*}{$\begin{array}{l}\text { desviación } \\
\text { est. F0 }\end{array}$} & Corr. &,$- 377^{* *}$ &,- 027 &,- 028 & ,001 &,$- 180^{*}$ &, 065 & 1,000 \\
\hline & Sig. & ,000 & ,746 & ,736 & ,988 & ,028 & ,430 & \\
\hline
\end{tabular}

Tabla 3.29. Correlaciones bilaterales de Pearson para los valores normalizados por ejercicio de las mediciones acústicas principales de las lengüetas. $\mathrm{N}=149$ en todos los casos. ** La correlación es significativa al nivel 0,01 (bilateral). *La correlación es significante al nivel 0,05 (bilateral). 


\subsubsection{Discusión}

Si se analizan los resultados globales de la comparación de las lengüetas, se observa que existe una diferenciación clara para los parámetros ligados al timbre, específicamente a la distribución de la energía en el espectro (Kurtosis y Skewness espectrales) con el rebajado alemán asociado a un sonido distribuido en el medio y el grave y con formantes más marcados, correspondiéndose con las apreciaciones subjetivas generalmente asociadas a las lengüetas alemanas: más graves, menos brillantes y más resonantes, por lo que proporcionan más claridad en la interpretación y un centro tonal mucho más claro.

En el resto de parámetros medidos, no se distingue un patrón ligado al estilo de rebajado, y predominan las características intrínsecas de cada lengüeta. Por ejemplo, la lengüeta alemana 2 se caracteriza por ser la más rígida de las seis lengüetas utilizadas en este experimento y poseer una frecuencia más alta y con mayor armonicidad, pero esto no caracteriza a la otra lengüeta alemana. Del mismo modo, la francesa 2 y la americana 2 son las más estables y las que menos intensidad generan, pero esto no se encuentra en las otras lengüetas francesa y americana. En cierto modo, se parecen más estas dos lengüetas con rebajados diferentes que otras lengüetas con el mismo rebajado.

Cuando se analizan las diferencias de comportamiento de las lengüetas en cada ejercicio, no suele haber diferencias por estilo de rebajado. Se encuentra, sin embargo, que el comportamiento de las lengüetas varía en ciertas ocasiones en función del registro: por ejemplo, las lengüetas alemanas se han desviado hacia lo agudo unos veinte cents respecto al temperamento para las notas do4 y do5, pero no en el registro más agudo del do6. Las lengüetas alemanas tienen una caída de afinación más pronunciada para el ejercicio de la dinámica, bajando en frecuencia con el diminuendo. Pero no hay diferencias significativas entre tipos de lengüeta en el oscillato, en el que se realizan variaciones de frecuencia deseadas. 


\subsubsection{Conclusiones}

La principal conclusión de este estudio es que los diferentes estilos de rebajado muestran una influencia baja en las mediciones acústicas. Se emitían las hipótesis que los diferentes rebajados influían en las mediciones acústicas dependiendo de las características rígidas y flexibles otorgadas a las lengüetas. Sin embargo, se puede observar que los resultados acústicos de este experimento preliminar muestran la existencia de más variabilidad en las lengüetas entre sí que una diferenciación por estilos de rebajado.

Es más, aunque los parámetros acústicos asociados al timbre, como la Kurtosis y la Skewness espectrales, asocian al rebajado alemán con un sonido grave y menos brillante, las mediciones de energía por bandas de frecuencias fijas no crean diferencias significativas entre lengüetas, por lo que la influencia del rebajado en los parámetros acústicos del timbre debe tomarse con precaución.

Por consiguiente, en el estudio principal es necesario aumentar la cantidad de lengüetas para obtener un mayor número de muestras y disminuir la variabilidad entre las lengüetas. Esta disminución de la variabilidad debe hacerse desde el mismo momento de la selección del material y confección de las lengüetas, extrayendo los tres tipos de rebajado de la misma sección de caña y controlando todo los parámetros del rebajado mediante la utilización de máquinas de rebajar y herramientas de precisión para las mediciones. 
4. Estudio principal: percepción tímbrica, estudio acústico y evaluación interpretativa y auditiva de la lengüeta 


\subsection{Introducción}

El experimento principal se centra en tres estudios: uno perceptivo, otro acústico y otro propioceptivo y auditivo. A partir de dieciocho lengüetas, con tres rebajados diferentes se realizan los diferentes experimentos y se extraen los resultados y las conclusiones. Asimismo, mediante la ampliación del primer experimento, también se estudia la influencia de otros parámetros que afectan a la construcción de las lengüetas, no sólo el rebajado, sino también los diferentes grosores y moldes de las palas.

En el experimento perceptivo, al igual que en el estudio preliminar, se estudia si existen o no diferencias en el sonido del oboe dependiendo del tipo de rebajado utilizado en las lengüetas. En esta ocasión, los oyentes no están separados en oboístas y músicos no oboístas, por lo que todos los oyentes realizan dos tareas de percepción y, a diferencia del experimento preliminar, sólo se utilizan sonidos de duración corta (aproximadamente 2 segundos) sin diferenciaciones interpretativas, normalizados en intensidad y frecuencia. La única variación aplicada en una de las tareas es la utilización de varios oboístas.

En el estudio acústico, se analizan los diferentes parámetros acústicos en función de los diferentes tipos de rebajado, de los moldes y de los grosores utilizados.

El estudio propioceptivo se realiza a partir de los resultados obtenidos en el estudio preliminar, ya que los oboístas consideran que son capaces de discriminar tímbricamente los diferentes estilos de rebajado. Así pues, se quiere averiguar si la evaluación de la calidad del sonido de la lengüeta es realmente una calidad del sonido puramente auditiva, o si hay una parte importante que se debe a la propiocepción y el control de la lengüeta en el momento de ejecutar los diferentes ejercicios.

\subsection{Objetivos}

El objetivo de este segundo experimento consiste en averiguar si los diferentes estilos de rebajado influyen en la percepción del timbre por parte de los oyentes, en los aspectos interpretativos del oboe y en la propiocepción de los oboístas. En general, se intenta afinar los resultados obtenidos en el experimento preliminar controlando al máximo la variabilidad entre lengüetas. 
Para ello, se realizan nuevas lengüetas y en mayor cantidad, dieciocho en total, obteniendo más muestras sonoras. Además se aumentan el número de instrumentistas participantes, diez oboístas, se mantiene constante la variable del oboe y se añaden más variables: grosor de la pala $(57 / 100 \mathrm{~mm}$ y $59 / 100 \mathrm{~mm})$ y molde de la pala $(21,107,168 \mathrm{de}$ Hörtnagl). En esta ocasión, los diferentes ejercicios diseñados, no intentan poner al límite las posibilidades técnico-interpretativas del oboe como en el experimento preliminar, sino que son ejercicios sencillos donde los oboístas, las lengüetas y el oboe, responden de la mejor forma posible. Los ejercicios grabados son: arpegio, legato, diminuendo, fortissimo y pianissimo.

\subsection{Confección de las lengüetas}

\subsubsection{Selección de los tubos}

Mientras que en el experimento preliminar no se realizó una selección de los tubos, por utilizar palas con forma compradas directamente al fabricante, en el experimento principal, se confeccionó desde los tubos el material necesario para la realización de las palas.

El material utilizado para las palas del experimento principal son tubos del comercio "Uwe Henze” del año 2001 (figura 4.1).

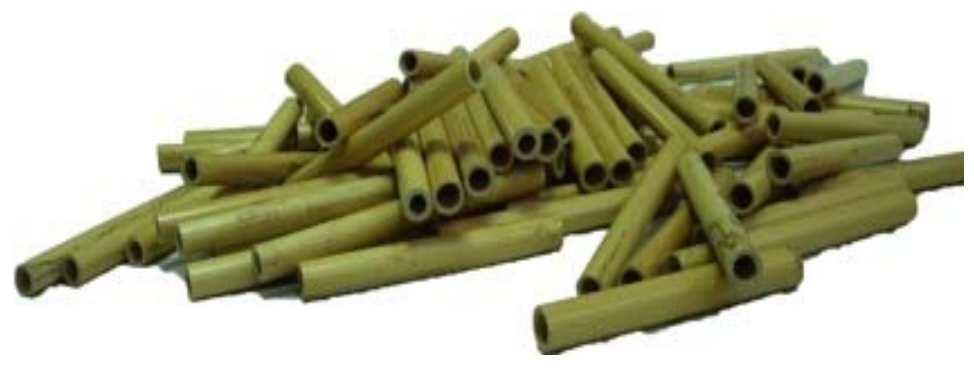

Figura 4.1. Tubos de caña Arundo donax.

El primer paso que se da es la selección de los tubos para que de cada uno de ellos se obtengan tres palas. Aunque parece obvio, no de todos los tubos pueden salir tres palas, ya que muchos tubos no tienen el diámetro correcto en toda su longitud.

Los tubos a utilizar deben tener un diámetro de $10^{\prime} 5 \mathrm{~mm}$, por lo que se debe crear una anilla con ese diámetro y pasar todos los tubos por ella, seleccionando sólo los que tengan un diámetro correcto (figura 4.2). 


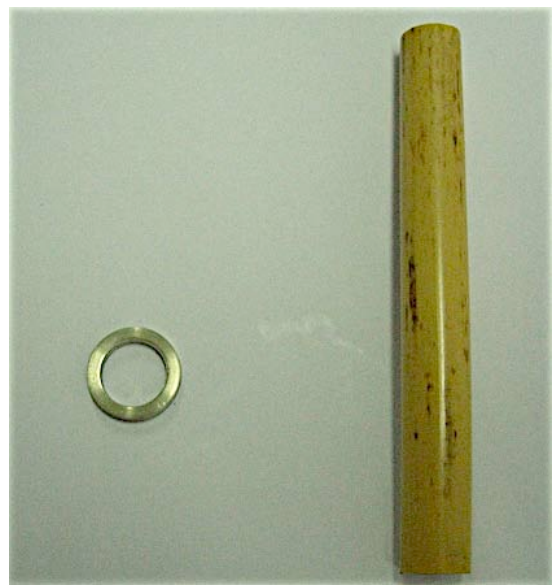

Figura 4.2. Anilla de diámetro $10^{`} 50 \mathrm{~mm}$ para la selección de los tubos.

Una vez seleccionados todos los tubos, se necesita una herramienta (un cuchillo de tres hojas, figura 4.3) capaz de seccionarlos en tres partes idénticas, es decir, a $120^{\circ}$. De estas tres partes se obtienen tres palas, cada una para un tipo de rebajado (alemán, francés y americano).
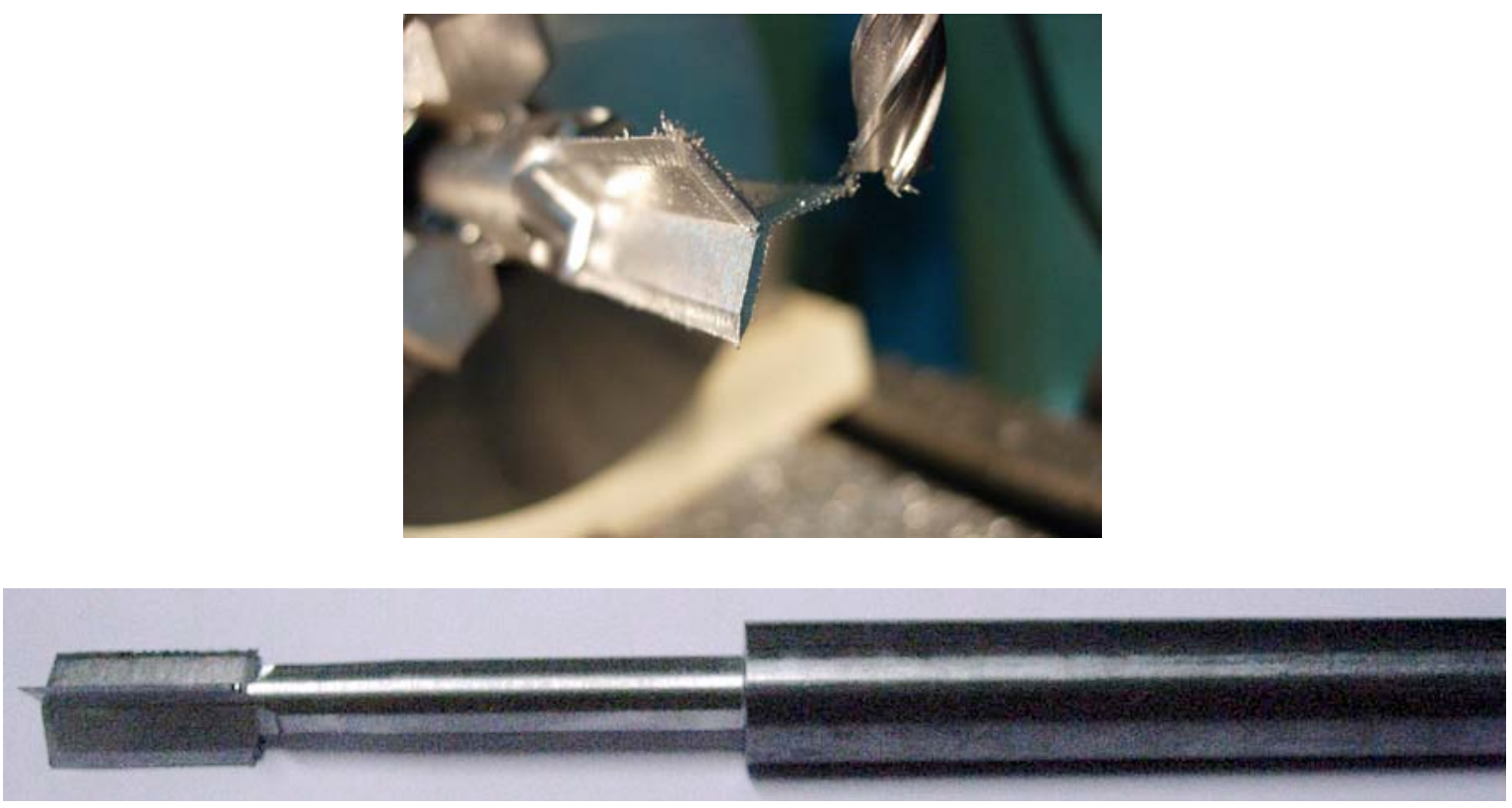

Figura 4.3. Fotografías de la fabricación del cuchillo de 3 hojas.

Con todo el material necesario, se realizan algunas pruebas con tubos no seleccionados para la investigación, para así ajustar al máximo las máquinas que se utilizan en la confección de las lengüetas.

Es necesario remarcar que aunque sólo se necesitan dieciocho lengüetas finalizadas para realizar el experimento principal, es decir seis tubos, se debe seleccionar alguno más, 
ya que si alguna lengüeta se rompe en el proceso de fabricación, se debe empezar de nuevo.

\subsubsection{Obtención de las palas}

Para poder seccionar los tubos y que no se rompan en el proceso de fabricación, primero se humedecen, poniéndolos en agua durante una hora y después, todos los tubos se cortan con el cuchillo de tres hojas fabricado (figura 4.4).

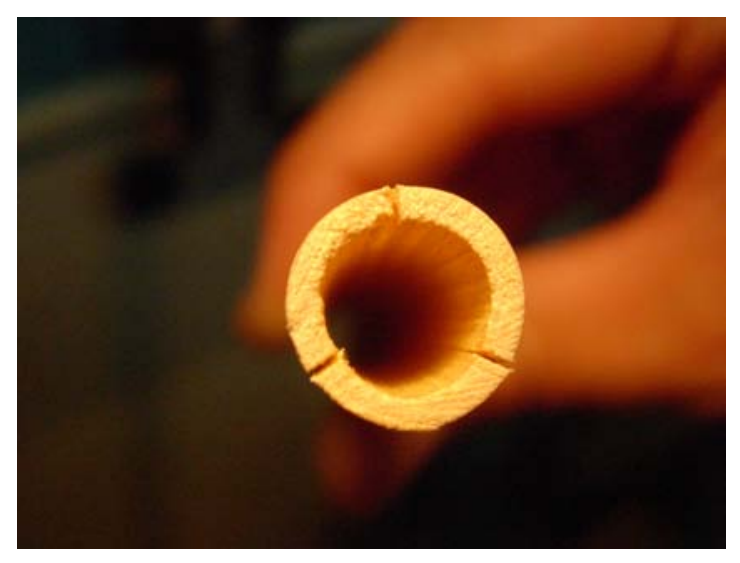

Figura 4.4. Fotografía de uno de los tubos con las tres secciones realizadas por el cuchillo de tres hojas.

Una vez cortados los tubos, se pasan por la pre gubiadora de Kunibert Michael, se les corta los extremos y se gubian nueve palas a $57 \mathrm{~mm}$ y otras nueve a $59 \mathrm{~mm}$. Se comprueban las medidas del gubiado para todas las palas con el reloj medidor de Kunibert Michael (figura 4.5). 

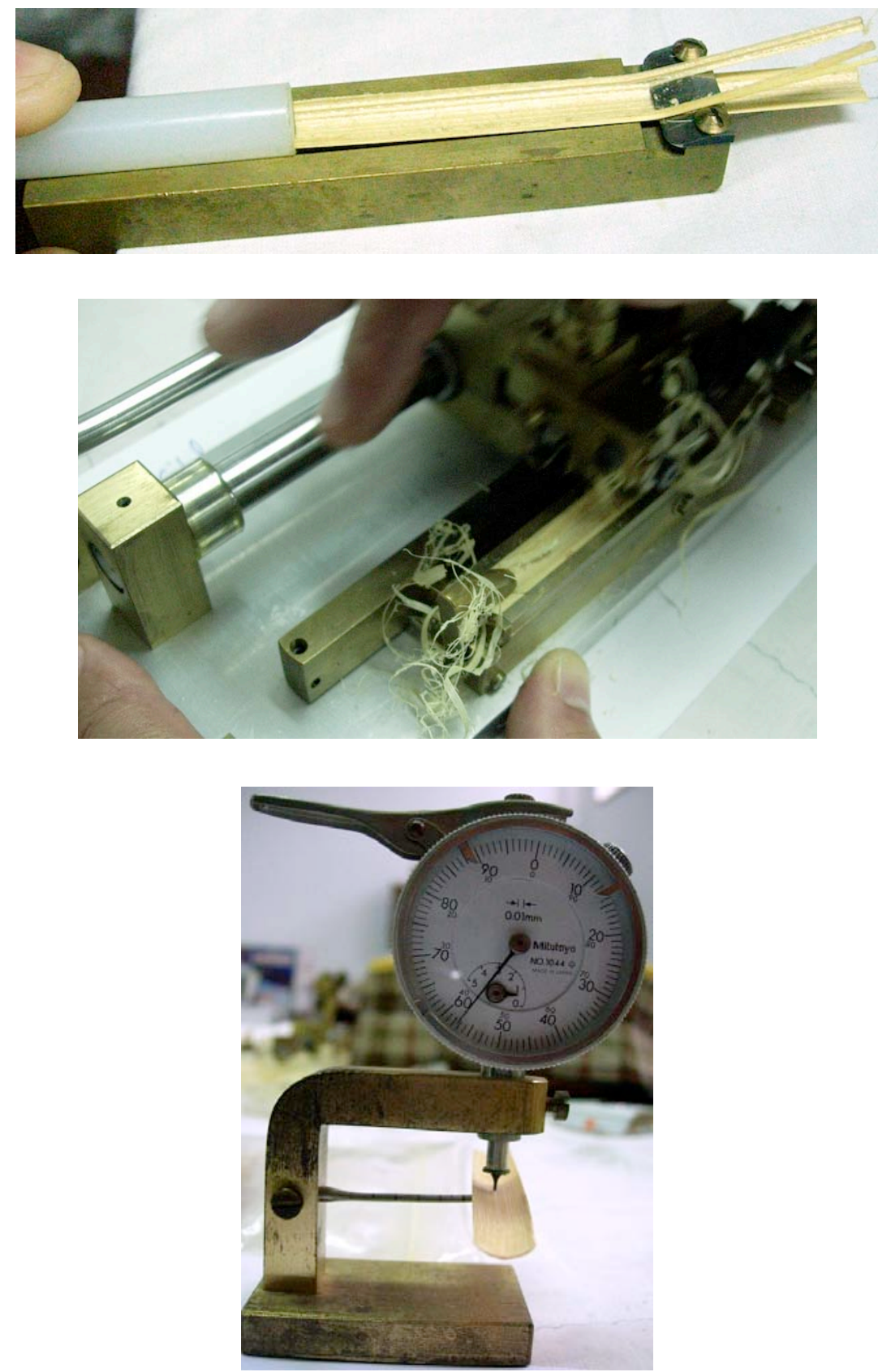

Figura 4.5. Fotografías del proceso de gubiado: pre-gubiado manual (arriba), gubiado con máquina de K. Michael (centro) y medición del gubiado con reloj de K. Michael (abajo)

\subsubsection{Forma de las palas}

Una vez gubiadas las palas, se deben volver a humedecer, por lo que se ponen en agua durante otra hora para que el proceso del moldeado no las rompa. Para dar la forma a estas palas, se utiliza la máquina de formas de Adolf Hörtnagl (figura 4.6), empleando tres moldes también de Adolf Hörtnagl: el 21, el 107 y el 168, todos ellos de latón. 

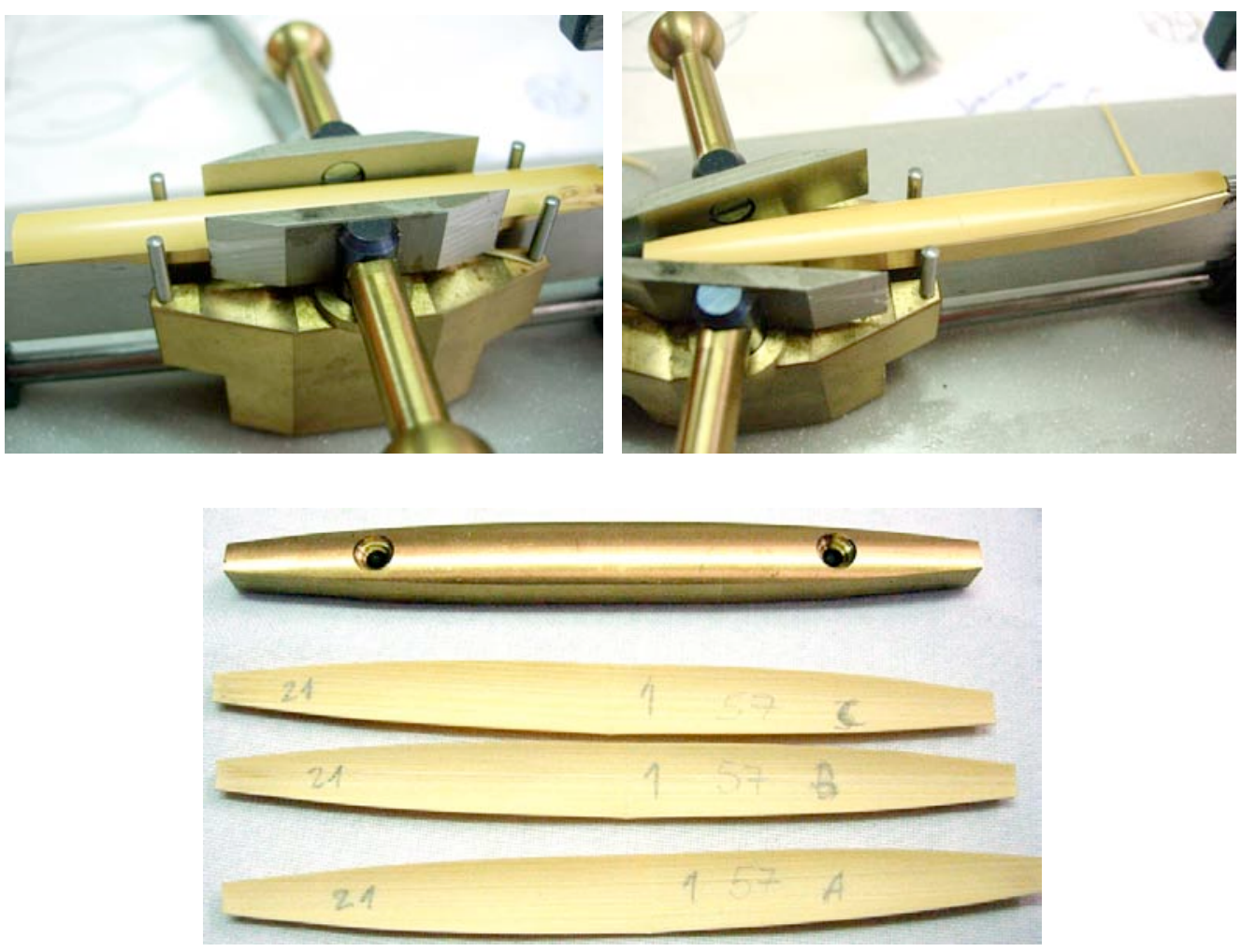

Figura 4.6. Fotografías de la máquina de formas de A. Hörtnagl (arriba) y de uno de los tres moldes utilizados con las tres palas obtenidas (abajo)

Se atan las cañas y se marcan los tudeles con las siglas: G2157, F2157, A2157; G10759, F10759, etc. según hagan referencia al tipo de rebajado, tipo de molde y grosor de la pala.

Las lengüetas se han atado con una temperatura de $27^{\circ}$ y una humedad relativa del 75\%. Las francesas y alemanas se han atado a $74 \mathrm{~mm}$ y las americanas a $72 \mathrm{~mm}$, para así adaptarse mejor al rebajado americano.

\subsection{Material experimental}

\subsubsection{Lengüetas}

Al igual que en el primer experimento, el parámetro esencial del estudio va a ser los diferentes tipos de rebajado. Para ello se aumenta el número de lengüetas de seis a dieciocho y se añaden otros factores que también influyen en la confección de las lengüetas: dos grosores diferentes (57 $\mathrm{mm}$ y $59 \mathrm{~mm}$ de gubiado interno) y tres moldes diferentes de Hörtnagl, todo ellos fabricados en latón (21, 107 y 168). Todos los demás 
parámetros permanecieron constantes: diámetro del tubo (10'50 mm), tudel (chiarugi 2+ $47 \mathrm{~mm}$ ) y fabricante (Uwe Henze año 2001).

Las lengüetas se ataron con una temperatura de $27^{\circ} \mathrm{C}$ y una humedad relativa del $75 \%$. Las francesas y alemanas a $74 \mathrm{~mm}$ y las americanas a $72 \mathrm{~mm}$, para así adecuar las características del rebajado americano tan largo con la longitud total de la lengüeta.

Todas las lengüetas se confeccionaron, ataron y rebajaron en agosto de 2010. Las lengüetas alemanas y francesas se rebajaron a máquina, con dos máquinas preparadas para ello. Las dos máquinas de la marca Rieger, una con un molde francés y otra con uno alemán. Las lengüetas americanas se rebajaron a mano, midiendo y manteniendo constantes todos los grosores y parámetros que afectan a las lengüetas. Antes de empezar con el rebajado de las lengüetas seleccionadas para el experimento principal, se realizaron pruebas en otras lengüetas, para así poder ajustar al máximo las máquinas que iban a realizar ese rebajado.

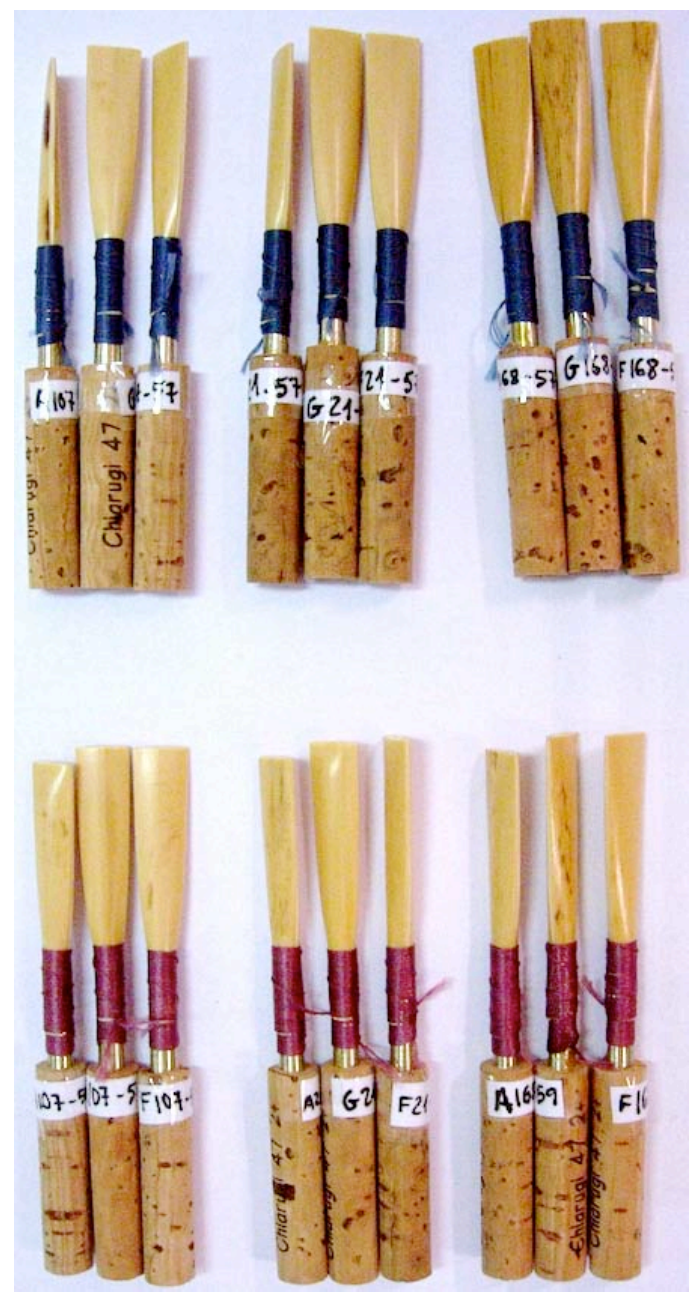

Figura 4.7. Lengüetas realizadas y utilizadas en el segundo experimento. 


\subsubsection{Oboístas}

En este segundo experimento han participado diez oboístas profesionales. Todos ellos han interpretado la totalidad de los ejercicios y han grabado en sesiones diferentes.

En esta ocasión, a los intérpretes no se les ha dado ninguna indicación explícita sobre si debían o no compensar mediante la presión diafragmática para que las notas sonasen correctamente, sino que por el contrario, se les ha dicho que intentasen tocar lo mejor posible con cada una de las cañas.

Los oboístas, al igual que en el anterior experimento, sabían con qué lengüeta estaban interpretando en cada momento, ya que podían leer las indicaciones en las lengüetas de "fr02157" que correspondía a la lengüeta con el rebajado francés, el molde 21 y el grosor $57 \mathrm{~mm}$, por poner un ejemplo. Si bien hay que decir, muchos de estos oboístas no sabían siquiera de qué trataba el experimento, por lo que su realización fue sin ningún tipo de influencia.

Para empezar, todas las lengüetas fueron humedecidas con agua y después se interpretó con todas unos minutos, adecuándolas así a las condiciones climáticas y de humedad de la sala. Durante la grabación, cuando se cambiaba de lengüeta, se volvía a tocar con la lengüeta correspondiente antes de realizar los ejercicios, para que no interviniese el factor sorpresa.

Todos los ejercicios se interpretaron seguidos con la misma lengüeta. Después, se cambiaba de lengüeta para volver a grabarlos. En una primera fase, el orden de grabación de las lengüetas fue distinto, para averiguar si los oboístas se acostumbraban al proceso de puntuación y valoración de las lengüetas. En una segunda fase, el resto de los oboístas interpretaban con el mismo orden. Al finalizar cada ejercicio, los oboístas puntuaban en una escala del 1 al 7 la facilidad con la que habían interpretado ese ejercicio y la calidad con la que habían percibido que se realizaba. Una vez finalizada toda la sesión de grabación, los oboístas repetían una lengüeta, analizando así la variabilidad de las respuestas dadas por ellos mismos.

Los oboístas que participaron en los experimentos fueron:

1) Fermín Clemente Bo: profesor del Conservatorio Profesional de Música de 
Cullera.

2) Santiago Guillot Martínez: profesor del Conservatorio Superior de Música de Castellón.

3) Jorge Clemente Bo: profesor del Conservatorio Profesional de Música de Logroño.

4) Jesús Garrigues Pérez: profesor del Conservatorio Profesional de Música de Cullera.

5) Carolina Blasco Yepes: profesora del Conservatorio Profesional de Música de Valencia.

6) Rafael Alonso Aragó: profesor de la Orquesta de Euskadi.

7) José Manuel Bou Bou: profesor del Conservatorio de Melilla.

8) Federico Gascó Falcó: profesor del Conservatorio Superior de Santa Cruz de Tenerife.

9) Irene Vendrell Criado: titulada superior de oboe.

10) Rafael Tamarit Torremocha: profesor de la Orquesta Nacional de España.
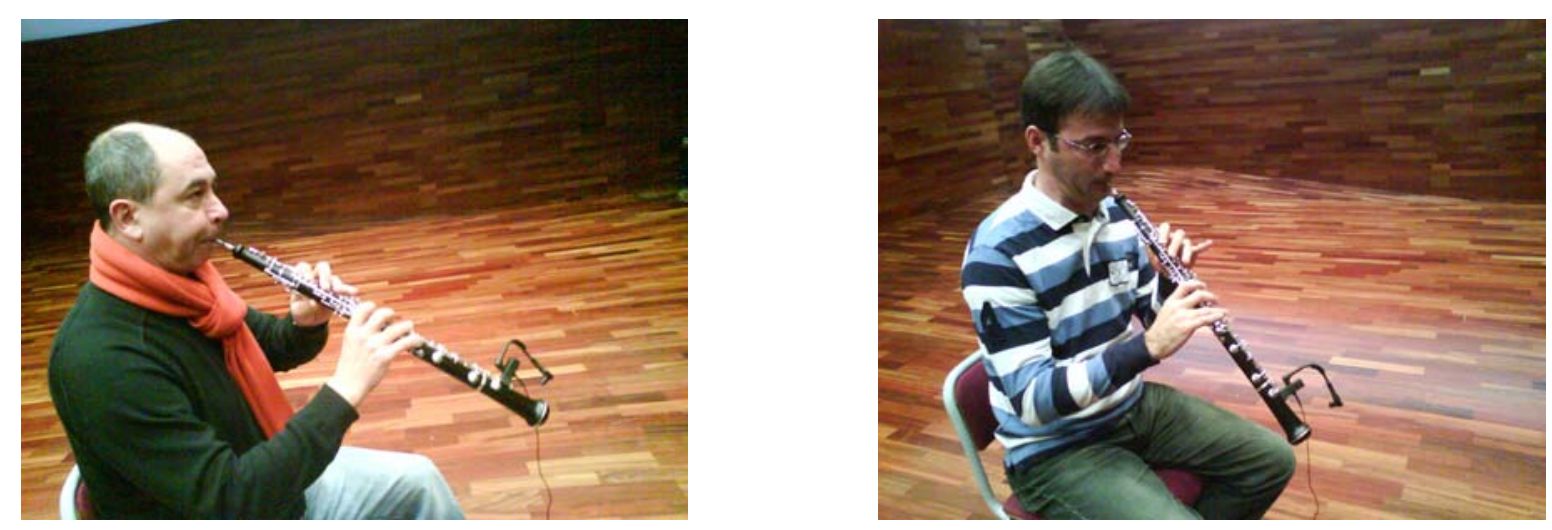

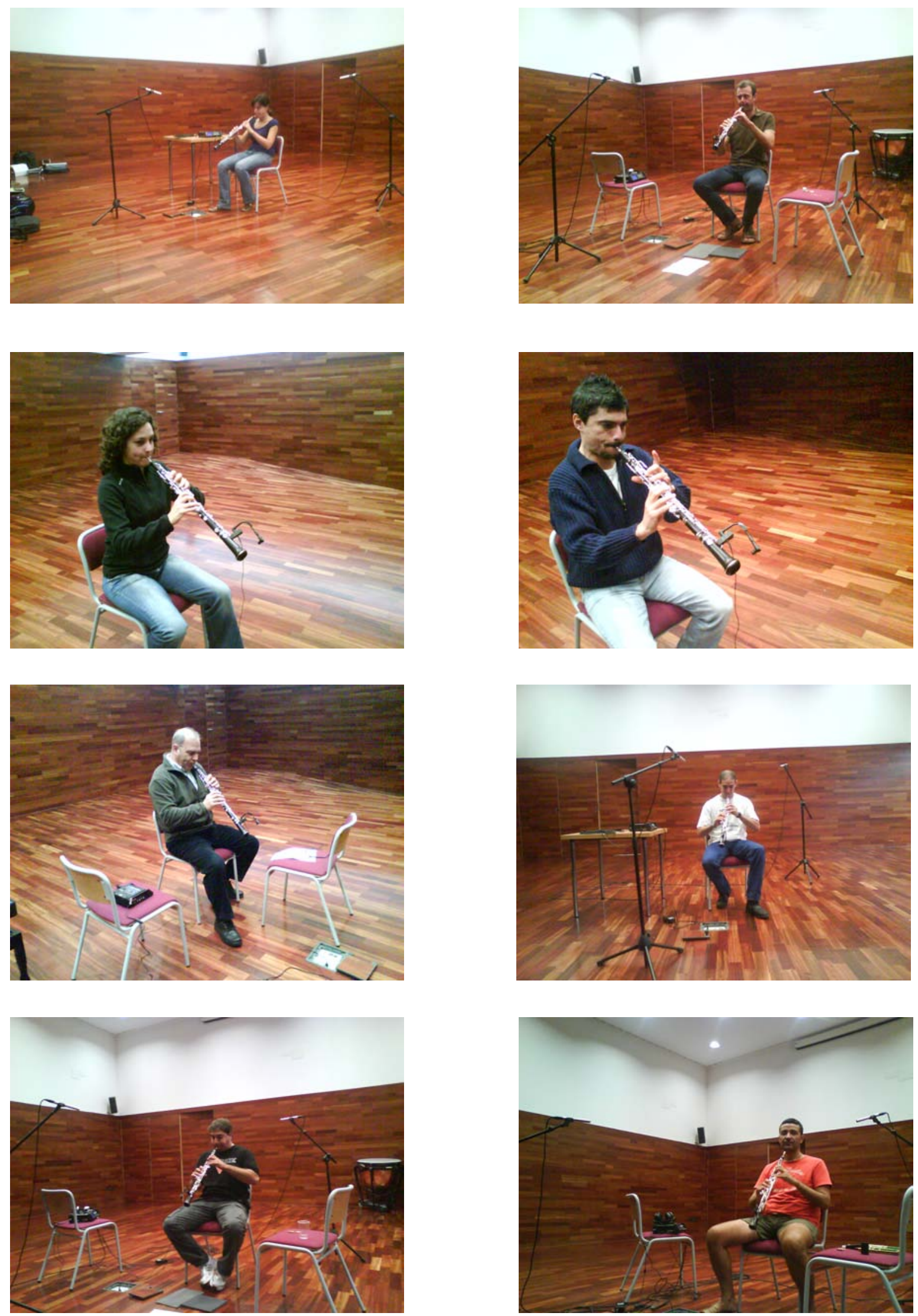

Figura 4.8. Fotografías de los diferentes oboístas en el momento de la grabación. 


\subsubsection{Grabación}

La grabación se realizó en varias sesiones durante el mes de septiembre de 2010 y diciembre del mismo año, en la sala de conciertos del Conservatorio Profesional de Música de Cullera, sin controlar las condiciones de temperatura y de humedad relativa.

Se utilizaron dos micrófonos AKG C451B de posición y uno de proximidad Shure Beta 98H/C colocado en la campana del oboe, para mantener constante la distancia entre el micro y la fuente sonora y evitar diferencias en la intensidad. Los sonidos se registraban en un R4 (figura 4.9).

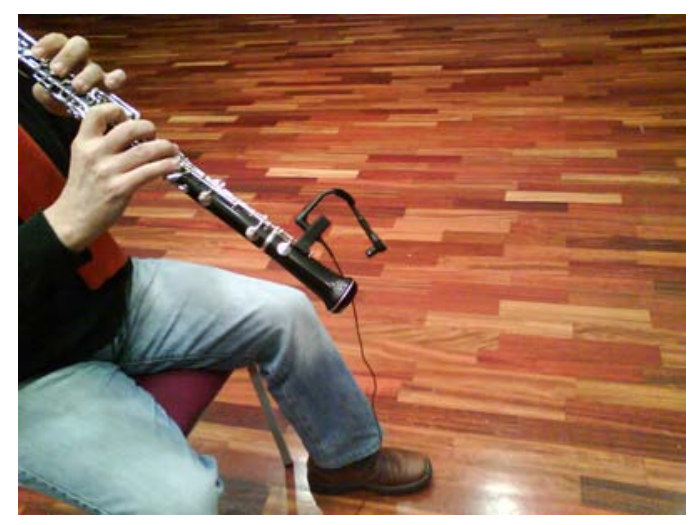

Figura 4.9. Micrófono de proximidad Shure Beta 98H/C usado en la grabación.

\subsubsection{Material grabado}

Arpegio: arpegio de do mayor ascendente, en compás de 3/4, con valores de blanca y silencio de negra.

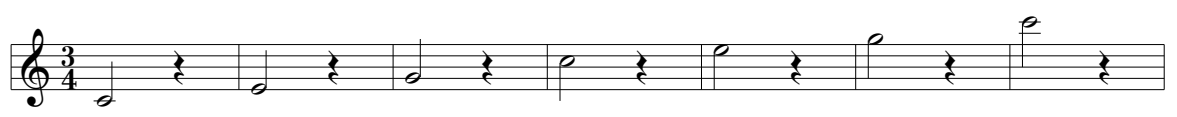

Figura 4.10. Ejemplo musical del ejercicio arpegio.

Legato: quintas de re mayor, ascendente y descendente en dos octavas, en compás de $2 / 4$ y con valor de negra para cada nota.

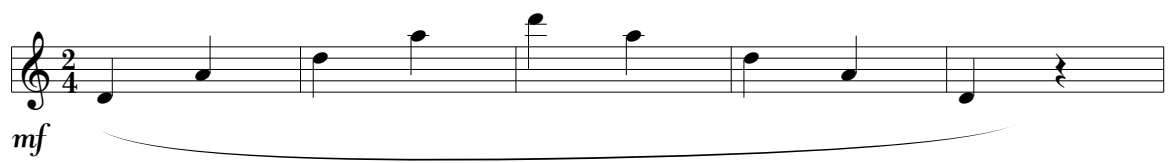

Figura 4.11. Ejemplo musical del ejercicio legato. 
Diminuendo: al igual que en el primer experimento, en el ejercicio diminuendo se utilizó la nota sol4, por ser una nota muy característica y susceptible en el oboe. Los oboístas realizaron un diminuendo progresivo de tres redondas en un compás de 4/4.

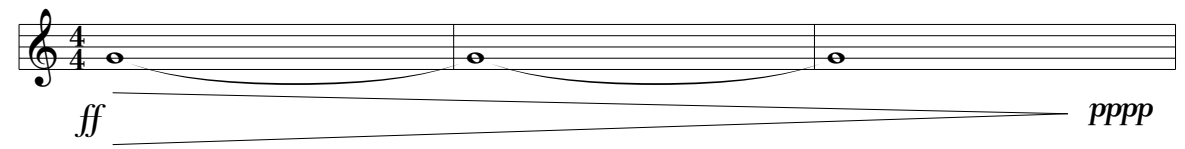

Figura 4.12. Ejemplo musical del ejercicio diminuendo.

Fortissimo: se intenta analizar la capacidad de las diferentes lengüetas para admitir una gran cantidad de aire soplado. Se interpretó un si4, redonda, en compás de 4/4, con toda la potencia sonora posible.

Pianissimo: se intenta analizar el límite de las lengüetas en la dinámica piano. Al igual que el fortissimo, se interpretó un si4, redonda y en compás de 4/4.

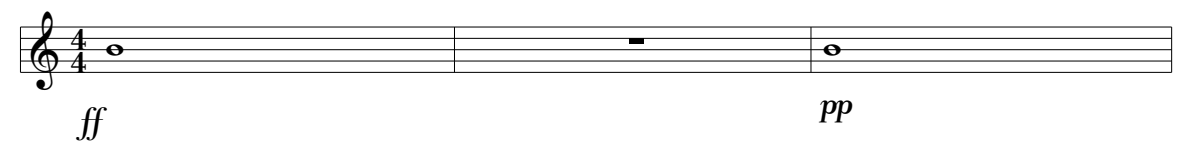

Figura 4.13. Ejemplo musical de los ejercicios fortissimo (izquierda) y pianissimo (derecha).

\subsection{Estudio perceptivo}

\subsubsection{Hipótesis}

Como se explicaba anteriormente, en el punto 3.4.1, los teóricos del oboe otorgan características al sonido del oboe dependiendo del tipo de rebajado de la lengüeta con la que se interpreta. Aunque en el experimento preliminar se ha descartado que los oyentes son capaces de distinguir esta asociaciones de los teóricos del oboe, en este experimento principal, se emite la hipótesis que al limitar al máximo la variabilidad de las nuevas lengüetas, los oyentes sí serán capaces de distinguir los diferentes "colores” del sonido producidos por los estilos de rebajado.

En esta ocasión, se eliminan los diferentes componentes de interpretación del experimento preliminar: las muestras sonoras no se interpretan con diferentes ataques. Además, al introducir nuevos factores que influyen en la construcción de las lengüetas, como el molde y el grosor de las palas, se emite la hipótesis que los oyentes también serán capaces de agrupar los sonidos dependiendo de los diferentes moldes $\mathrm{y}$, en menor medida, 
de los diferentes grosores, al ser este último parámetro menos influyente en la totalidad del conjunto de la lengüeta.

Del mismo modo que en el experimento preliminar, se utiliza un test de clasificación libre o escucha holística, de forma que los oyentes agrupan los sonidos de acuerdo a la similitud general percibida.

\subsubsection{Método}

En el experimento principal, se utilizó un material más específicamente orientado a la comparación de timbre, eliminando los factores de interpretación del experimento preliminar: notas aisladas que no varían en intensidad ni en altura, con una duración de dos segundos. Los estímulos sonoros se presentaron en este orden:

1) estímulos de la tarea 1: 19 notas aisladas (do5) de dos segundos de duración con el mismo oboísta, tres rebajados, tres moldes y dos grosores.

2) estímulos de la tarea 2: 20 notas aisladas (do5) de dos segundos de duración con cinco oboístas, tres rebajados, un molde, dos grosores para el rebajado alemán y un grosor para el resto $(59 \mathrm{~mm})$.

Todos los sonidos utilizados en los dos estímulos se normalizaron en afinación (523 $\mathrm{Hz}$ ) e intensidad (70 dB) uno a uno (figura 4.13b), de forma manual mediante el software informático Melodyne Studio versión 3.1.2.0. De esta forma, los sonidos quedan dentro de la definición más generalizada de timbre: propiedad que distingue dos sonidos de la misma altura, intensidad y duración. 

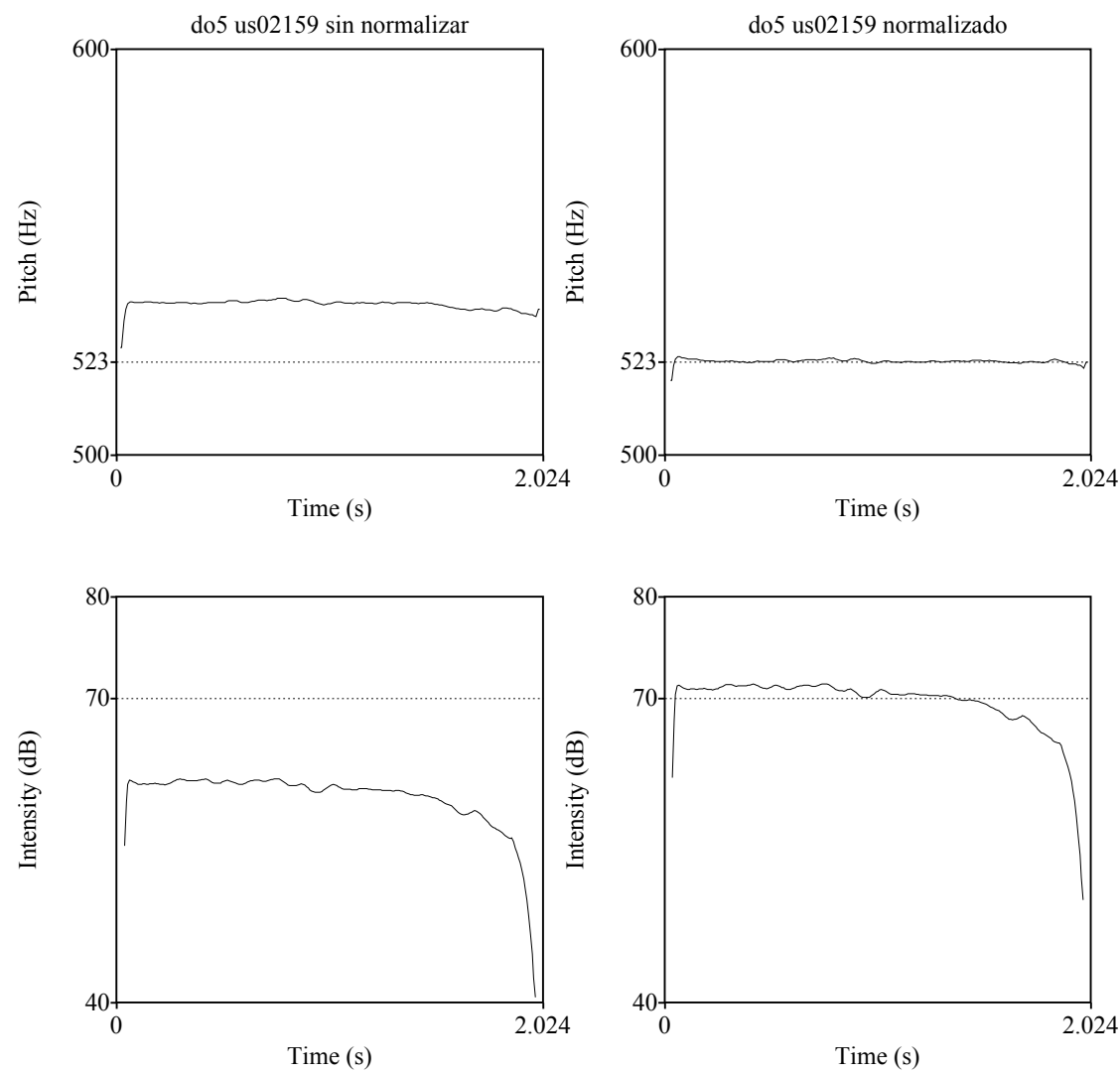

Figura 4.13b. Ejemplo de la normalización en altura e intensidad (Melodyne Studio) de un sonido. Izquierda: sonido original. Derecha: sonido normalizado.

Para estudiar la percepción del timbre por los oyentes, se utiliza un test de clasificación libre o escucha holística como tarea de percepción más aceptada en los estudios del timbre, según los estudios descritos por Grey $(1977,1978)$ o McAdams (1995), de forma que los oyentes agrupan los sonidos de acuerdo a la similitud general percibida (figura 4.13c). 


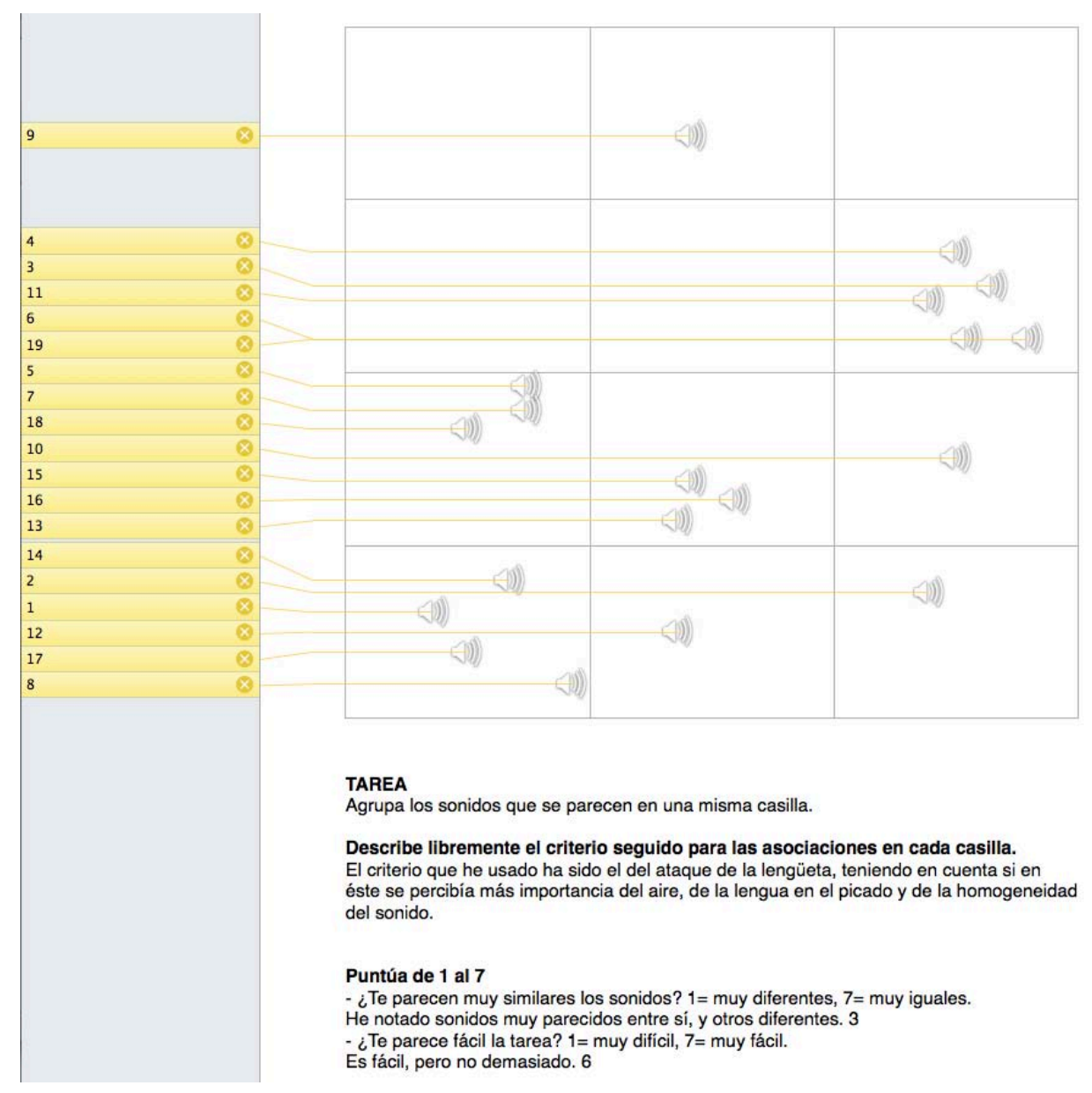

Figura 4.13c. Captura de pantalla de la herramienta interactiva desarrollada para el test de percepción tímbrica.

Diecinueve oyentes (músicos profesionales) realizaron una tarea de categorización libre, donde debían agrupar los sonidos en función de su similitud global. La escucha se efectuó de forma individual, con auriculares y con una duración aproximada total de cuarenta minutos.

\subsubsection{Resultados}

$\mathrm{Al}$ igual que en el experimento preliminar, el primer elemento que se analiza es la concordancia de las respuestas de los oyentes (tabla 4.1). Se puede observar que en el conjunto de sonidos de la tarea 1 (estímulo de notas aisladas con un oboísta) ocurre lo mismo que en el experimento preliminar: el alfa de Cronbach es un valor muy bajo, incluso más bajo. En el conjunto de se sonidos de la tarea 2 aparecen cinco oboístas y se observa en la tabla 3.6 como el alfa sube de valor, aunque aún es un valor bajo. Se ve pues que al disminuir los factores que marcan la diferencia entre los sonidos de los dos 
estímulos (de cinco a un oboísta), los oyentes no tienen suficiente información para agruparlos.

\begin{tabular}{|l|l|r|}
\hline Estímulos & $\begin{array}{l}\text { Oyentes/Tipo } \\
\text { de pregunta }\end{array}$ & Alfa de Cronbach \\
\hline notas aisladas $\mathrm{do}_{5} 1$ oboísta & todos &, 355 \\
\hline notas aisladas $\mathrm{do}_{5} 5$ oboístas & todos &, 602 \\
\hline
\end{tabular}

Tabla 4.1. Tabla con los análisis de fiabilidad (Alfa de Cronbach) del experimento principal.

Para averiguar si los diferentes estilos de rebajado de las lengüetas influyen en la percepción de los oyentes, se realiza la prueba de $\chi^{2}$ de Pearson, comparando si existen diferencias significativas en las clasificaciones de los oyentes utilizando los siguientes factores: mismo oboísta (un oboísta en los estímulos de la tarea 1 y cinco en los estímulos de la tarea 2), misma escuela de rebajado (tres tipos de rebajados), mismo molde (tres moldes en los estímulos de la tarea 1 y un molde en los estímulos de la tarea 2) y mismo grosor (dos grosores en los estímulos de la tarea 1 y en los estímulos de la tarea 2: dos grosores para el rebajado alemán y un grosor para el resto).

Se puede observar en la tabla 4.2, que ninguno de los factores utilizados (escuela, molde, grosor) en los estímulos de la tarea 1 es significativamente diferenciador y que el único parámetro que se diferencia es el intérprete para los estímulos de la tarea $2(p=, 009)$, por lo que se puede afirmar que el rebajado no se percibe en la diferenciación del timbre del oboe ( $c f$. A.25, A.26, A.27, A.28, A.29 y A.30 para más detalle).

\begin{tabular}{|c|c|c|c|c|}
\hline \multicolumn{5}{|c|}{ Tests (Pearson) $\chi^{2}$} \\
\hline Factor & Estímulos & $\chi^{2}$ & gl & Asymp. Sig. (2-sided) \\
\hline $\begin{array}{c}\text { Misma escuela de } \\
\text { rebajado }\end{array}$ & 1 & 1,01 & 1 &, 314 \\
\cline { 2 - 5 } & 2 &, 418 & 1 &, 518 \\
\hline \multirow{2}{*}{ Mismo grosor } & 1 &, 104 & 1 &, 747 \\
\cline { 2 - 5 } & 2 & 2,89 & 1 &, 089 \\
\hline \multirow{2}{*}{ Mismo molde } & 1 &, 796 & 1 &, 372 \\
\cline { 2 - 5 } & 2 & - & - & ----- \\
\hline Mismo oboísta & 1 & - & - & ----- \\
\cline { 2 - 5 } & 2 & 6,90 & 1 &, 009 \\
\hline
\end{tabular}

Tabla 4.2. Resumen de la prueba de $\chi^{2}$ de Pearson comparando las agrupaciones de los oyentes según los diferentes factores para los diferentes conjuntos de estímulos.

Se realiza un escalamiento multidimensional (PROXSCAL) sobre las matrices de respuestas de las agrupaciones libres utilizando un modelo de dos dimensiones, para poder estudiar si los oyentes utilizan criterios similares en sus clasificaciones. La dispersión 
explicada por estas dimensiones es: $\mathrm{DAF}=72 \%$ (estímulos de la tarea 1) y $\mathrm{DAF}=61 \%$ (estímulos de la tarea 2). En ninguno de los dos casos puede deducirse ninguna dimensión que explique las agrupaciones de los oyentes (figura 4.14 y 4.15 ).

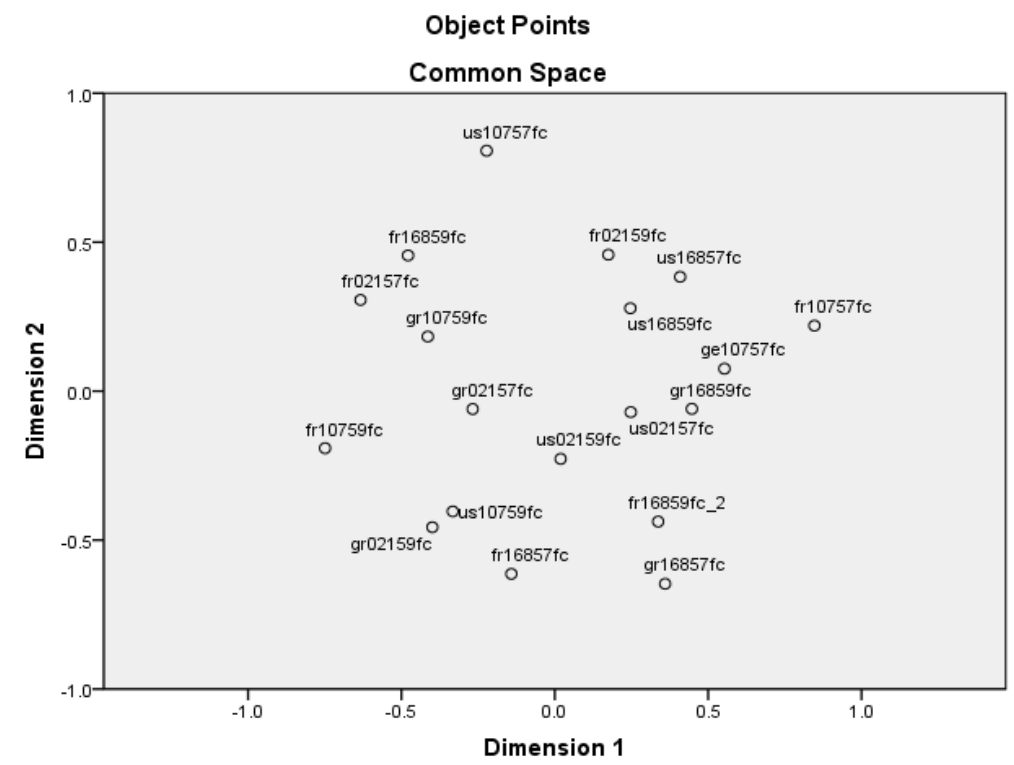

Figura 4.14. Escalamiento multidimensional de los estímulos de la tarea 1. Las dos primeras letras codifican el tipo de rebajado, las tres siguientes cifras el molde y las dos últimas cifras el grosor, las dos últimas letras indican el intérprete.

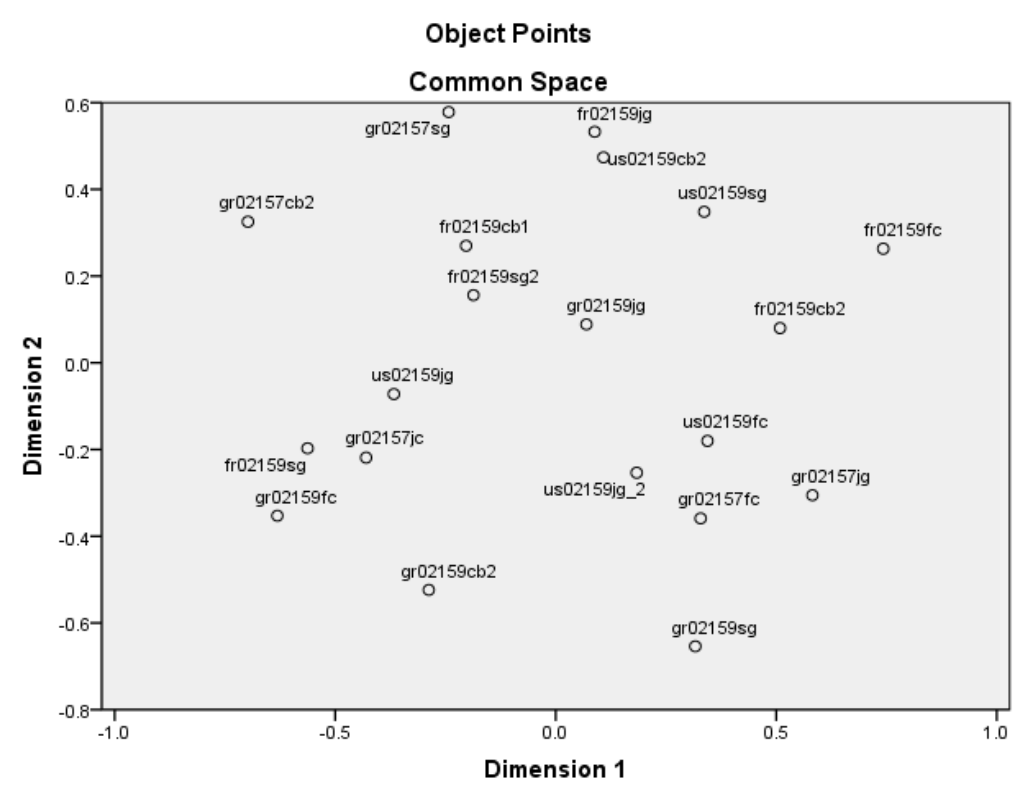

Figura 4.15. Escalamiento multidimensional de los estímulos de la tarea 2. Las dos primeras letras codifican el tipo de rebajado, las tres siguientes cifras el molde y las dos últimas cifras el grosor, las dos últimas letras indican el intérprete. 


\subsubsection{Discusión}

El análisis de los datos del experimento principal no hace más que confirmar todos los resultados obtenidos anteriormente en el experimento preliminar. Al utilizar en esta ocasión sonidos no complejos, los resultados de la tabla 4.2 demuestran que ningún elemento de fabricación de la lengüeta es susceptible a la percepción, sino que el único factor que se distingue son los diferentes intérpretes para los estímulos de la tarea 2. Así pues, los estilos de rebajado no aparecen como un elemento significativo en general en la escucha del timbre del oboe.

\subsubsection{Conclusiones}

El principal resultado de este experimento es que el estilo de rebajado tiene un mínimo impacto sobre el reconocimiento del timbre. Se partía de la hipótesis de que los diferentes estilos de rebajados en las lengüetas del oboe alteran el "color" de las notas y que estos cambios de "color" pueden ser percibidos por los oyentes.

Cuando en un conjunto de estímulos se disminuyen los factores que marcan la diferencia entre ellos, los oyentes deberían prestar toda su atención en los factores que quedan, si son perceptivamente relevantes. Tanto en el experimento preliminar como en el principal, los oyentes no tienen suficiente consistencia para agrupar los sonidos dependiendo del factor escuela de rebajado, así pues, se puede afirmar que el rebajado no es un factor perceptivamente relevante en este tipo de ejercicios.

En conclusión, el experimento preliminar no encuentra una influencia significativa y, sobre todo, el experimento principal confirma muy claramente que no hay influencia del rebajado en la percepción del timbre de las notas normalizadas, realizadas con un mismo oboe y oboísta, variando solamente las lengüetas. Si se añaden varios oboístas, se perciben diferencias entre las notas generadas por los oboístas, pero el rebajado destaca cada vez menos. Se confirman y se profundizan los resultados de Snitkin (1975): los oyentes pueden distinguir a los oboístas pero no los rebajados. De hecho, cuando los oyentes deben clasificar por similitud sonidos de oboe normalizados, encuentran que la tarea es difícil y no emergen criterios obvios. Esta conclusión, contradice el discurso dominante de los oboístas que, en general y tal y como se ha podido ver en las hipótesis, hablan de 
diferencias en el "color" del sonido dependiendo del tipo de rebajado. Así pues, tras no haber sido validada esta hipótesis se debe indagar en el estudio propioceptivo ( $c f$. punto 4.7) y por qué los oboístas son tan sensibles al estilo de rebajado.

\subsection{Estudio acústico}

\subsubsection{Introducción}

El estudio principal parte de la base del estudio preliminar, con la diferencia de haber controlado al máximo las variabilidades existentes en la fabricación de las lengüetas realizadas en el experimento preliminar. Tal y como se ha explicado en el punto 4.3, se han creado dieciocho lengüetas a partir de seis secciones diferentes de caña, de forma que de cada sección de tubo se obtienen tres palas diferentes, cada una para uno de los estilos de rebajado utilizado: francés, alemán y americano.

Además, en este estudio se han incorporado nuevos parámetros que influyen en la construcción del las lengüetas, es decir, no sólo el rebajado, sino también el molde de las palas y el grosor del gubiado interno de éstas.

Después del análisis de datos, se ha comprobado que la utilización del molde 168 desvirtúa de manera considerable los datos referentes a la afinación, ya que es un molde desproporcionado en todas sus partes respecto a los demás moldes utilizados en esta investigación, es excesivamente ancho ofreciendo grandes dificultades en la interpretación.

Las medidas de los moldes se dividen en tes partes básicas: la longitud del molde (que está relacionada con la posibilidad de sacar más pala o menos pala respecto al tudel cuando se ata la lengüeta); la anchura en su mayor punto de grosor (en la punta); y la anchura en la parte de atrás coincidente con el final del tudel. En el molde 168 en concreto, la anchura máxima es excesiva respecto a la longitud de la pala, proporcionando una superficie de vibración demasiado grande para las cañas del oboe. Este problema va a afectar a la ejecución de la afinación, ya que al ser una superficie más amplia de vibración, se necesita un mayor aporte de velocidad de aire para interpretar correctamente las notas de forma afinada y controlar el sonido resultante. 
No obstante, si se construye una caña de oboe de amor, por poner un ejemplo, que necesita una lengüeta de menor longitud y con una superficie de vibración menor, este molde sería perfecto para estas características. En consecuencia, si se extrapola este principio a las lengüetas del oboe y se varían las proporciones de las lengüetas utilizadas en esta investigación, disminuyendo la longitud total y como consecuencia la superficie vibrante, se puede conseguir paliar los problemas de afinación mencionados anteriormente. Sin embargo, al hacer esto, se varían las longitudes estándares de las lengüetas en las escuelas francesas y alemanas, no pudiendo ser utilizadas en este experimento como lengüetas tipo.

Como se observa en las figuras 4.16, 4.17 y 4.18, el molde 168 (número 3) se queda mucho más bajo en afinación que los otros dos moldes utilizados, es por ello que se decide prescindir de los datos recogidos por el molde 3 cuando se analizan los resultados de la afinación, para así no desvirtuar las medidas obtenidas.

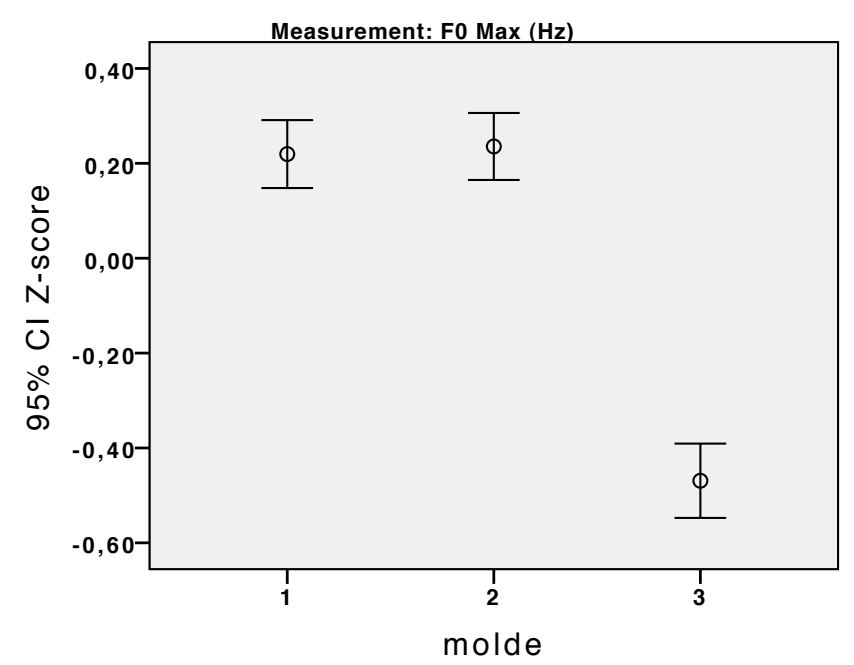

Figura 4.16. Medias con intervalo de confianza de los diferentes moldes en el parámetro frecuencia máxima (en $\mathrm{Hz}$ ). 


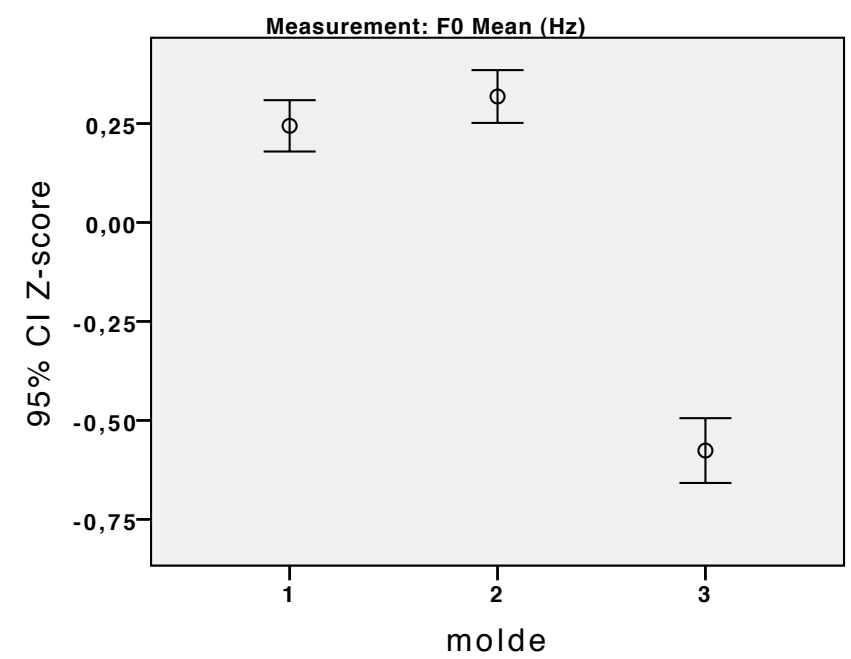

Figura 4.17. Medias con intervalo de confianza de los diferentes moldes en el parámetro frecuencia media (en $\mathrm{Hz})$.

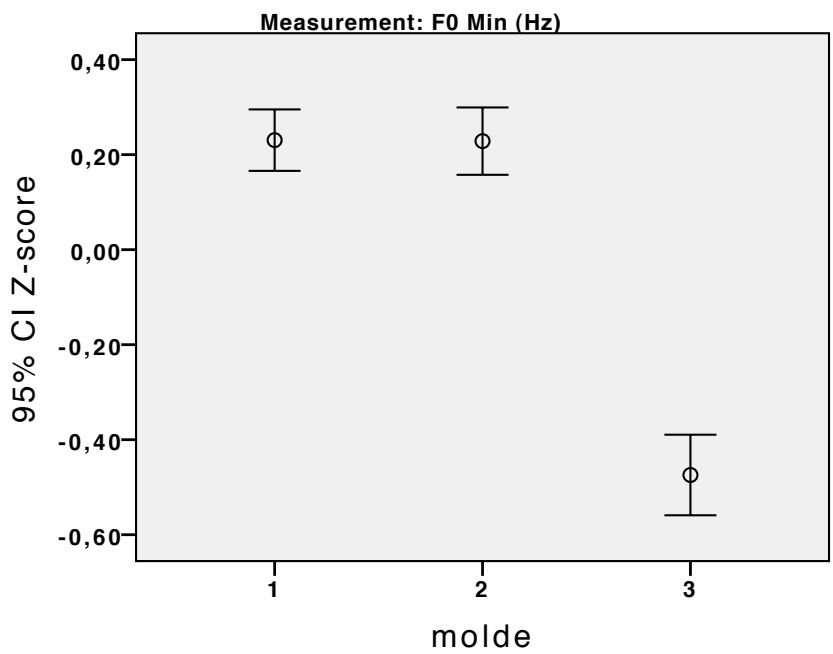

Figura 4.18. Medias con intervalo de confianza de los diferentes moldes en el parámetro frecuencia mínima (en $\mathrm{Hz})$.

\subsubsection{Hipótesis}

Como se explicaba en las hipótesis del experimento preliminar ( $c f$. punto 3.5.1), la facilidad y el control de ejecución de los diferentes ejercicios suelen estar asociados a conceptos de rigidez y flexibilidad de las lengüetas. Los diferentes estilos de rebajado otorgan características más o menos rígidas y flexibles dependiendo de la cantidad de madera que sea eliminada en las diferentes secciones de la pala de la lengüeta. Así pues, las hipótesis que se formulan tienen relación con los conceptos de flexibilidad y rigidez aportados por los diferentes estilos de rebajado. 
Asimismo, los otros dos parámetros introducidos en este estudio, los diferentes moldes y grosores de las palas, van a colaborar en la facilidad y en el control de la ejecución de los ejercicios del oboe. Es decir, los dos grosores utilizados complementan las características de rigidez y flexibilidad otorgadas por los estilos de rebajado, mientras que los diferentes moldes aportan características de equilibrio a la forma global de las lengüetas. Sin embargo, estos dos factores no son tan determinantes en la fabricación de las lengüetas como los estilos de rebajado, por lo que se emite la hipótesis que tanto el grosor como el molde de las palas, influyen en algunos de los parámetros acústicos estudiados y siempre en menor medida que los diferentes tipos de rebajado.

Por consiguiente, se emite la hipótesis que las lengüetas más rígidas, con mayor grosor de pala y más equilibradas en el molde serán las que mejor funcionen en las mediciones de la afinación y su estabilidad, de la intensidad y su estabilidad, de la armonicidad y su estabilidad y de los parámetros acústicos asociados a la medición del timbre. En cuanto a la facilidad de vibración, se emite la hipótesis que las lengüetas más flexibles, con el menor grosor y menor superficie de vibración (molde más pequeño) serán las más idóneas.

\subsubsection{Método y material}

\subsubsection{Mediciones acústicas}

Para el análisis de las mediciones acústicas se utilizan todos los ejercicios grabados del micrófono de cercanía, para así mantener constante la distancia entre el micrófono y la fuente sonora, sobre todo para la fiabilidad de las mediciones de la intensidad y su estabilidad.

El ejercicio arpegio se corta en notas individuales, ya que al estar separadas por silencios no existe ningún problema de reverberación, obteniendo un total de siete notas individuales por cada arpegio grabado.

Por cada ejercicio hay 181 muestras sonoras grabadas, dando una suma total de 1991 muestras sonoras para todo el análisis acústico. 


\subsubsection{Mediciones físicas de las lengüetas}

Además de realizar las mediciones acústicas según los estilos de rebajado, también se ha procedido a medir las dimensiones físicas de las dieciocho lengüetas utilizadas en este experimento, para poder analizar si alguna dimensión física está relacionada con los parámetros acústicos que se van a estudiar. En efecto, la categorización en tres estilos de rebajado (o tres moldes) es reductora respecto al continuo de dimensiones geométricas de cada lengüeta, sobre todo en un proceso que no es industrial y que utiliza materiales naturales. Se estudia pues si las dimensiones reales de la lengüeta pueden explicar mejor la variabilidad acústica que las categorías generales de estilo de rebajado.

Para ello se miden todas las lengüetas desde diferentes partes y después se calculan las diferencias de grosores, superficies, ratios, etc. (tablas 4.aa y 4.bb). La figura 4.18b muestra con una numeración a qué parte de la lengüeta corresponde los valores medidos de la tabla 4.aa. 


\begin{tabular}{|c|c|c|c|c|c|c|c|c|c|c|c|c|c|c|c|c|}
\hline \multirow[b]{3}{*}{ caña } & \multirow{3}{*}{$\begin{array}{c}\text { grosor } \\
\text { gubia } \\
\text { do } \\
\text { centro }\end{array}$} & \multirow[b]{3}{*}{$\begin{array}{l}\text { longitud } \\
\text { rebajado }\end{array}$} & \multicolumn{6}{|c|}{ grosor de la punta a $1 \mathrm{~mm}$} & \multirow{3}{*}{\begin{tabular}{|c|} 
dist7 \\
ancho \\
7
\end{tabular}} & \multirow{3}{*}{$\begin{array}{c}\text { dist8 } \\
\text { libre } \\
8\end{array}$} & \multirow{3}{*}{$\begin{array}{c}\text { dist9 } \\
\text { largo } \\
9\end{array}$} & \multirow{3}{*}{$\begin{array}{c}\text { gr10 } \\
\text { corazo } \\
\mathrm{n} \\
10\end{array}$} & \multirow{3}{*}{$\begin{array}{l}\text { dist11 } \\
\text { cor- } \\
\text { punta } \\
11\end{array}$} & \multirow{3}{*}{$\begin{array}{c}\text { gr12 } \\
\text { atrás } \\
12\end{array}$} & \multirow{3}{*}{$\begin{array}{c}\text { dist13 } \\
\text { cor- } \\
\text { atrás } \\
13\end{array}$} & \multirow{3}{*}{$\begin{array}{c}\text { forma } \\
14\end{array}$} \\
\hline & & & \multicolumn{3}{|c|}{ Lado 1} & \multicolumn{3}{|c|}{ Lado 2} & & & & & & & & \\
\hline & & & $\begin{array}{c}\text { gr1 } \\
\text { izda } \\
1\end{array}$ & $\begin{array}{c}\text { gr2 } \\
\text { centro } \\
2\end{array}$ & $\begin{array}{c}\text { gr3 } \\
\text { dcha } \\
3\end{array}$ & $\begin{array}{c}\text { gr4 } \\
\text { izda } \\
4\end{array}$ & $\begin{array}{c}\text { gr5 } \\
\text { centro } \\
5\end{array}$ & $\begin{array}{c}\text { gr6 } \\
\text { dcha } \\
6\end{array}$ & & & & & & & & \\
\hline us 16857 & 57 & 19 & 11 & 19 & 14 & 9 & 18 & 14 & 7,50 & 23,50 & $70^{\prime} 05$ & 46 & $2^{\prime} 75$ & 58 & 16,26 & 168 \\
\hline fr02159 & 59 & 11,03 & 13 & 28 & 10 & 13 & 26 & 13 & 7,13 & 25,82 & 72,90 & 37 & 1,72 & 53 & 9,58 & 21 \\
\hline ge16857 & 57 & 10,33 & 17 & 24 & 13 & 12 & 24 & 11 & 7,35 & 25,98 & 72,93 & 41 & 1,10 & 54 & 9,21 & 168 \\
\hline us02159 & 59 & 20,78 & 10 & 14 & 12 & 13 & 18 & 15 & 7,18 & 23 & 70,05 & 43 & 2,60 & 58 & 18,14 & 21 \\
\hline fr1 10757 & 57 & 11,05 & 11 & 26 & 11 & 14 & 24 & 11 & 7,10 & 25,48 & 72,94 & 39 & 1,86 & 50 & 9,13 & 107 \\
\hline ge02159 & 59 & 10,14 & 12 & 22 & 15 & 18 & 30 & 12 & 7,15 & 25,95 & 72,91 & 41 & 1,12 & 56 & 9,04 & 21 \\
\hline us 10757 & 57 & 19,34 & 14 & 16 & 14 & 14 & 19 & 21 & 7,13 & 23,90 & 70,06 & 48 & 3,00 & 57 & 16,42 & 107 \\
\hline fr16859 & 59 & 11,06 & 11 & 21 & 11 & 13 & 22 & 13 & 7,40 & 25,95 & 72,99 & 36 & 1,70 & 55 & 9,37 & 168 \\
\hline ge10757 & 57 & 9,90 & 16 & 29 & 15 & 20 & 25 & 15 & 7,13 & 25,41 & 72,91 & 45 & 1,18 & 55 & 8,75 & 107 \\
\hline us 16859 & 59 & 20,12 & 15 & 16 & 14 & 17 & 18 & 16 & 7,60 & 23,17 & 70,25 & 48 & 2,72 & 59 & 17,30 & 168 \\
\hline fr02157 & 57 & 11,10 & 12 & 25 & 11 & 10 & 27 & 12 & 7,19 & 25,96 & 72,93 & 40 & 1,75 & 54 & 9,42 & 21 \\
\hline ge10759 & 59 & 9,91 & 16 & 23 & 13 & 16 & 20 & 13 & 7,14 & 25,41 & 72,97 & 42 & 1,06 & 54 & 8,92 & 107 \\
\hline us02157 & 57 & 20,58 & 12 & 16 & 12 & 11 & 18 & 12 & 7,24 & 23,17 & 70,01 & 46 & 2,51 & 57 & 18,01 & 21 \\
\hline fr10759 & 59 & 11,07 & 13 & 25 & 12 & 13 & 24 & 11 & 7,13 & 26,20 & 72,93 & 35 & 1,80 & 55 & 9,37 & 107 \\
\hline ge02157 & 57 & 10,37 & 15 & 24 & 15 & 16 & 25 & 15 & 7,18 & 25,82 & 72,96 & 45 & 1,15 & 53 & 8,95 & 21 \\
\hline us10759 & 59 & 19,05 & 12 & 13 & 13 & 10 & 13 & 12 & 7,16 & 23,28 & 70,03 & 40 & 2,40 & 61 & 16,63 & 107 \\
\hline fr16857 & 57 & 11,13 & 12 & 20 & 10 & 12 & 20 & 10 & 7,40 & 26,13 & 72,93 & 38 & 1,86 & 52 & 9,33 & 168 \\
\hline ge 16859 & 59 & 10,17 & 15 & 22 & 13 & 14 & 25 & 15 & 7,45 & 25,71 & 72,91 & 45 & 1,20 & 57 & 8,92 & 168 \\
\hline $\begin{array}{l}\text { dist rebaj } \\
\text { gr1 izda: } \\
\text { gr2 centr } \\
\text { gr3 } \text { dcha } \\
\text { gr4 } \text { izda: } \\
\text { gr5 centr } \\
\text { gr6 dcha } \\
\text { dist7 anc } \\
\text { dist } 8 \text { libr } \\
\text { dist9 larg } \\
\text { gr10 cora } \\
\text { dist11 co } \\
\text { gr12 } \text { atrá } \\
\text { dist } 13 \text { co }\end{array}$ & $\begin{array}{l}\text { grosor c } \\
\text { grosor d } \\
\text { o: grosor } \\
\text { grosor c } \\
\text { ho: anch } \\
\text { : longit } \\
\text { o: longit } \\
\text { zon: gro } \\
\text {-punta: } \\
\text { : grosor } \\
\text { r-atrás: } 1\end{array}$ & $\begin{array}{l}\text { r de la pun } \\
\text { de la punta } \\
\text { de la punta } \\
\text { r de la pun } \\
\text { de la punta } \\
\text { hura de la c } \\
\text { tud de la ca } \\
\text { tud total } \\
\text { osor del co } \\
\text { longitud d } \\
\text { r de atrás } \\
\text { longitud at }\end{array}$ & $\begin{array}{l}\text { ta en } \\
\text { en el } \\
\text { en el } \\
\text { ta en } \\
\text { en el } \\
\text { aña } \\
\text { ña (d } \\
\text { razón } \\
\text { el cor } \\
\text { rás al }\end{array}$ & $\begin{array}{l}\text { lo } \\
\text { lado izq } \\
\text { el centro } \\
1 \text { lado de } \\
\text { lado izq } \\
\text { el centro } \\
1 \text { lado de } \\
\text { lel atado } \\
\text { razón a la } \\
\text { corazón }\end{array}$ & $\begin{array}{l}\text { recho d } \\
\text { uierdo } \\
\text { de la p } \\
\text { recho d } \\
\text { a la pur } \\
\text { a punta }\end{array}$ & $\begin{array}{l}\text { la pal } \\
\text { a } 1 \\
\text { la pala } \\
\text { la pal } \\
\text { a } 2 \\
\text { la pala }\end{array}$ & & & & & & & & & & \\
\hline
\end{tabular}

Tabla 4.aa. Mediciones físicas de todas las lengüetas utilizadas en el experimento principal. 


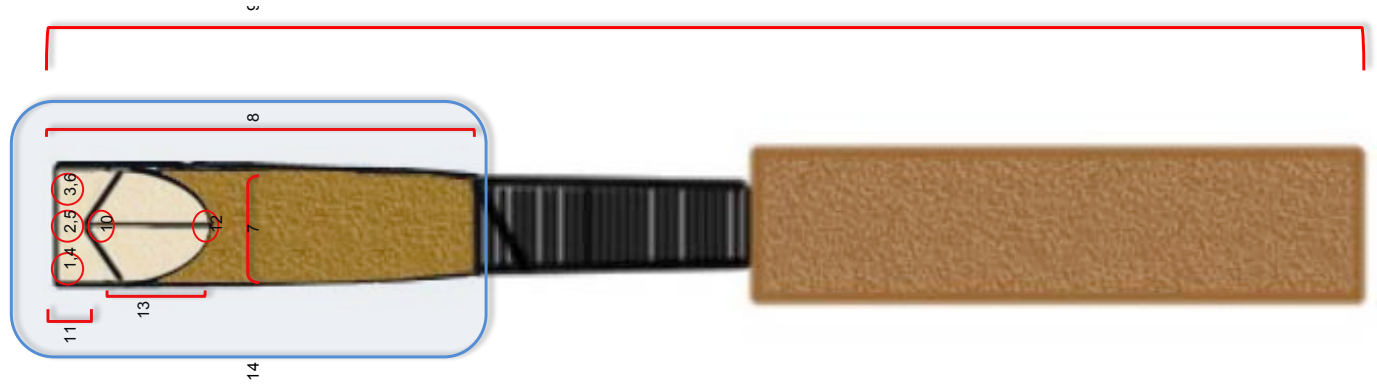

Figura 4.18b. Esquema de las mediciones físicas realizadas en las lengüetas relacionadas con la tabla 4.aa.

\begin{tabular}{|c|c|c|c|c|c|c|c|c|c|c|c|c|c|c|c|c|c|}
\hline & & b & & & $\mathrm{e}$ & $f$ & $\mathrm{~g}$ & $\mathrm{~h}$ & & & $\mathrm{k}$ & & $\mathrm{m}$ & $\mathrm{n}$ & 0 & $\mathrm{p}$ & q \\
\hline & & & & & & & & & & & & & & & & & \\
\hline 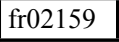 & (1) & 0 & 63 & & & & & 43 & & & & T & & & & & \\
\hline & 50 & 5 & 63 & 75 & & & & & & 0 & & & & & 95 & 0,0 & \\
\hline 02159 &, 50 & 5,00 & 25 & & 28,75 & &, 00 & 30 &, 75 & 4,07 & & 18,67 & & & 47,05 & - & \\
\hline 101 & 0 & 5 & 1 & & 20 & & 0 & & & 2 & & 21 & & & & & \\
\hline $\mathrm{e} 02159$ &, 75 & 2,50 & 20,13 & 75 & 20,88 & 2,04 & 15,00 & 37 & 8,88 & 2,78 & 185 & 8,01 & 64,64 & 112,90 & 46,96 & $-0,04$ & 8,07 \\
\hline 10 & 00 & 25 & ,63 & & & & & & & & & ד & & & & $\mathrm{L}$ & \\
\hline fr16859 & 6,00 & 17,50 & \begin{tabular}{|l|}
16,75 \\
\end{tabular} & 50 & 19,25 & 2,15 & 19,00 & 1,53 & 38,25 & 3,28 & \begin{tabular}{|l|}
192,03 \\
\end{tabular} & 12,58 & 69,34 & 110,11 & 47,04 & 0,04 & 5,01 \\
\hline geiv/ & (25) & 1,25 & 1,75 & 00 & 23,25 & & , & & & 53 & & 8,41 & & & & & \\
\hline 16859 & 5,25 & 7,25 & 16,25 & 00 & 31,75 & 2,95 & 11,00 & 231 & 2,75 & 3,63 & \begin{tabular}{|l|}
176,09 \\
\end{tabular} & 20,67 & 131,48 & & 47,08 & 0,08 & 0,3 \\
\hline (II0215/ & 3,25 & 9,00 & $18,63 \mid$ & 75 . & 21,38 & 2,15 & 4,00 & 35 & 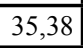 & 2,90 & 18 & \begin{tabular}{|l|}
12,58 \\
\end{tabular} &, 73 & & 46,97 & $|-0,03|$ & , \\
\hline \begin{tabular}{|l|} 
ge10759 \\
\end{tabular} & 3,75 & 17,25 & 18,00 & & \begin{tabular}{|l|}
24,00 \\
\end{tabular} & 2,33 & 12,00 & 27 & 0, & 3,00 & 181 & 7,57 & 59 & & & & 8, \\
\hline 02157 & 4,00 & 4,75 & 4,38 & 75 & 31,63 & 3,20 & 1,00 & & 2 & 3,97 & 10 & \begin{tabular}{|l|}
18,17 \\
\end{tabular} & | 130,59 & & 46,84 & $|-0,16|$ & 7, \\
\hline 10739 & 5,15 & 8,00 & 18,58 & & 16,6 & 1,90 & 20,00 & 1,57 & 30,03 & 2,99 & 100 & 12,83 & 51 & & 73 & 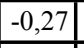 & \\
\hline ge02157 & 9,50 & 20,25 & 19,88 & 75 & 25,13 & 2,26 & 8,00 & 1 & 5, & 2,67 & 185 & 8,26 & 26 & & 47,14 & 0,14 & T, \\
\hline $10 / 59$ &, 1 & 2,00 & (2) & 1 & 2 & & $2,0,0$ & & & 4,931 & & , & & & & & \\
\hline 16857 & 15,50 & 15,50 & 15,50 & 0,00 & 22,50 & 2,45 & 14,00 & 1,37 & 36,5 & 3,35 & 193 & 13,76 & & & 46,80 & \begin{tabular}{|l|l|}
$-0,20$ \\
\end{tabular} & 5, \\
\hline gel6859 & 18,00 & 19,15 & $\mid 18,88$ & $1, / 2$ & 26,13 & 2,38 & 12,00 & (1) & 年 & 3,04 & | $191,04 \mid$ & 8,94 & 年 & | & 47,20 & 0,20 & 1,4 \\
\hline \multicolumn{18}{|c|}{$\begin{array}{l}\text { a) g14 medio punta 1: grosor medio de la punta en la pala } 1 \\
\text { b) g15 medio punta 2: grosor medio de la punta en la pala } 2 \\
\text { c) g16 medio punta: media del grosor medio de las dos palas } \\
\text { d) dg17 asim punta: diferencia de grosor en la punta entre las dos palas } \\
\text { e) dg } 18 \text { cora punta: diferencia del grosor del corazón y del grosor medio de la punta } \\
\text { f) rg } 19 \text { cora punta: ratio del grosor del corazón entre el grosor medio de la punta } \\
\text { g) dg } 20 \text { atrás cora: diferencia del grosor de atrás y del grosor del corazón } \\
\text { h) rg } 21 \text { atrás cora: ratio del grosor de atrás entre el grosor del corazón } \\
\text { i) dg } 22 \text { atrás punta: diferencia del grosor de atrás y del grosor medio de la punta } \\
\text { j) rg } 23 \text { atrás punta: ratio del grosor de atrás entre el grosor medio de la punta } \\
\text { k) su } 24 \text { libre: superficie = anchura caña por longitud caña (del atado a la punta) } \\
\text { l) su } 25 \text { cor punta: superficie = anchura caña por longitud del corazón a la punta } \\
\text { m) su } 26 \text { cor atrás: superficie = anchura caña por longitud atrás al corazón } \\
\text { n) su sin raspar: diferencia de su } 24 \text { menos su } 25 \text { y su } 26 \\
\text { o) dd 9-8: diferencia de la longitud de la caña y la longitud total } \\
\text { p) dd 9-8 } 47 \text { mm: diferencia de dd9-8 y el tudel ( } 47 \text { mm) } \\
\text { q) rd 13/11: ratio de la longitud de atrás al corazón entre la longitud del corazón a la punta }\end{array}$} \\
\hline
\end{tabular}

Tabla 4.bb. Mediciones calculadas de las diferencias de grosores, superficies y ratios de todas las lengüetas utilizadas en el experimento principal. 


\subsubsection{Respuestas acústicas globales de las lengüetas}

Utilizando el programa Praat (Boersma y Weenink, 2011) se miden los principales parámetros acústicos que se agrupan en diferentes categorías representativas del funcionamiento de la lengüeta del oboe.

Cabe indicar que todos los ficheros de sonidos se recortan previamente a mano, para después realizar el análisis solamente sobre la parte armónica (con una altura definida) que se calcula automáticamente con Praat. Se remarca que tanto la frecuencia mínima como la máxima esperada se predeterminan para todos los ejercicios, de forma que se obtiene una mejor resolución en los gráficos y se suprimen saltos de octava en el cálculo de frecuencias.

\subsubsection{Mediciones relativas a la afinación}

\subsection{Frecuencia media (en $\mathrm{Hz})$}

Un ANOVA de varios factores (tabla 4.3) muestra que el rebajado $(\mathrm{F}=1260,7, p<$, 001, $\left.\eta^{2}=, 685\right)$, el oboísta $\left(\mathrm{F}=203,46, p<, 001, \eta^{2}=, 637\right)$ y el grosor $\left(\mathrm{F}=77,81, p<, 001, \eta^{2}=\right.$, 063) son los factores individuales que tienen una influencia significativa, siendo el rebajado el factor más influyente. Además, todos estos factores individuales provocan efectos cruzados de forma significativa. Es relevante indicar que el molde no tiene la menor influencia y que los factores rebajado y oboísta, explican casi el 70\% de los valores obtenidos ( $c f$. A.31 para más detalle).

Se puede observar en la figura 4.19 que el rebajado americano es el que mayor frecuencia media obtiene respecto al alemán y al francés respectivamente. Por consiguiente, el rebajado americano es el más estable en la afinación, provocando medias mucho más parecidas entre ellas que los dos rebajados anteriormente citados.

En la figura 4.20 se puede observar que las diferencias de rebajado obtenidas no son causadas por la variabilidad entre las lengüetas, sino que estas diferencias son provocadas por los diferentes estilos de rebajado. Así pues, todas las lengüetas americanas utilizadas en este experimento son más estables en la afinación que las alemanas y las francesas, sin existir diferencias significativas entre ellas mismas. 


\begin{tabular}{|l|r|r|r|r|r|r|}
\hline Origen & \multicolumn{1}{|c|}{$\begin{array}{c}\text { Suma de } \\
\text { cuadrados tipo III }\end{array}$} & gl & $\begin{array}{c}\text { Media } \\
\text { cuadrática }\end{array}$ & \multicolumn{1}{c|}{ F } & Sig. & $\begin{array}{c}\text { Eta al cuadrado } \\
\text { parcial }\end{array}$ \\
\hline Modelo corregido & 753,012 & 119 & 6,328 & 47,140 & 0,000 & 0,829 \\
\hline Intersección & 130,435 & 1 & 130,435 & 971,685 & 0,000 & 0,456 \\
\hline rebajado & 338,465 & 2 & 169,232 & 1260,714 & 0,000 & 0,685 \\
\hline molde & 0,231 & 1 & 0,231 & 1,718 & 0,190 & 0,001 \\
\hline grosor & 10,445 & 1 & 10,445 & 77,811 & 0,000 & 0,063 \\
\hline oboista & 273,124 & 10 & 27,312 & 203,467 & 0,000 & 0,637 \\
\hline rebajado * molde & 1,860 & 2 & 0,930 & 6,929 & 0,001 & 0,012 \\
\hline rebajado * grosor & 2,005 & 2 & 1,003 & 7,469 & 0,001 & 0,013 \\
\hline rebajado * oboista & 10,344 & 19 & 0,544 & 4,056 & 0,000 & 0,062 \\
\hline molde * grosor & 1,004 & 1 & 1,004 & 7,483 & 0,006 & 0,006 \\
\hline molde * oboista & 7,650 & 9 & 0,850 & 6,332 & 0,000 & 0,047 \\
\hline grosor * oboista & 7,698 & 10 & 0,770 & 5,735 & 0,000 & 0,047 \\
\hline
\end{tabular}

Tabla 4.3. Análisis de varianza factorial sobre la frecuencia media (en semitonos) para los factores rebajado, molde, grosor y oboísta.

Como muestra la tabla 4.3, el efecto cruzado entre rebajado y oboísta es igualmente significativo y se aprecia en la figura 4.21 que el rebajado americano es el que mayor frecuencia media obtiene siendo muy significativo para todos los oboístas.

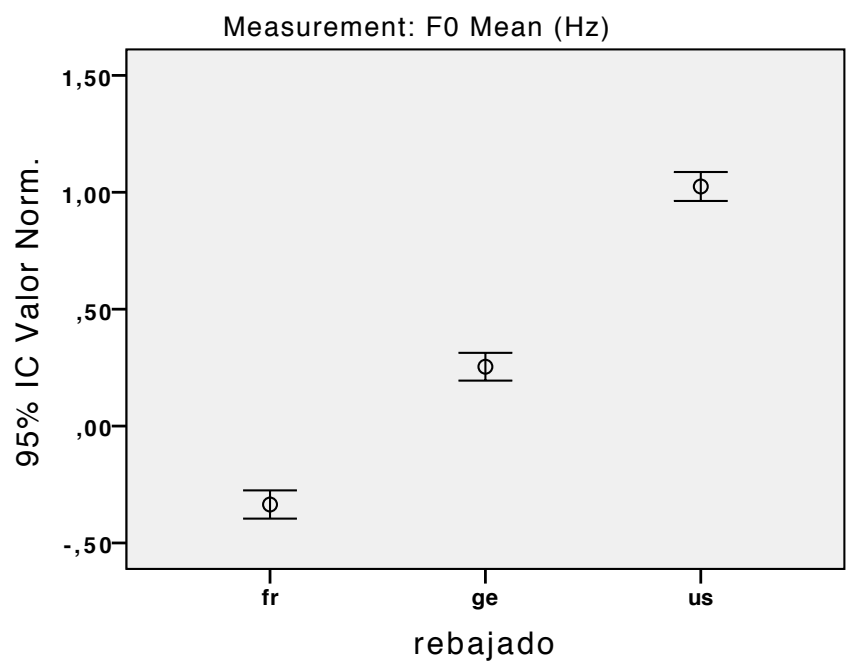

Figura 4.19. Medias con intervalo de confianza de los diferentes estilos de rebajado en el parámetro frecuencia media (en $\mathrm{Hz}$ ). 


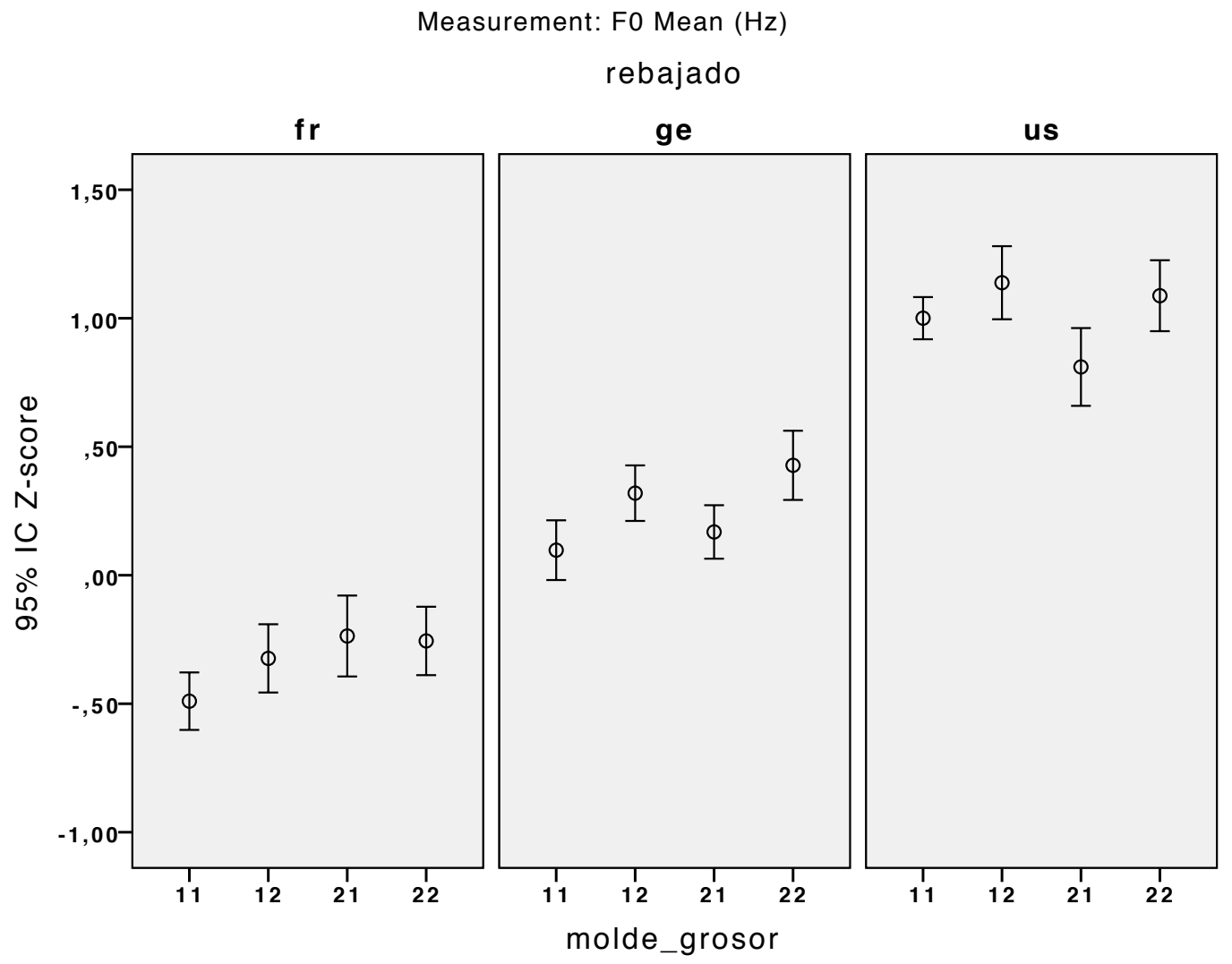

Figura 4.20. Medias con intervalo de confianza comparando todas las lengüetas según el molde, grosor y estilos de rebajado en el parámetro frecuencia media (en $\mathrm{Hz}$ ). El primer número hace referencia al molde $(1=21 ; 2=107 ; 3=168)$ y el segundo número al grosor $(1=57 \mathrm{~mm} ; 2=59 \mathrm{~mm})$.

Measurement: Fo Mean (st)

oboista

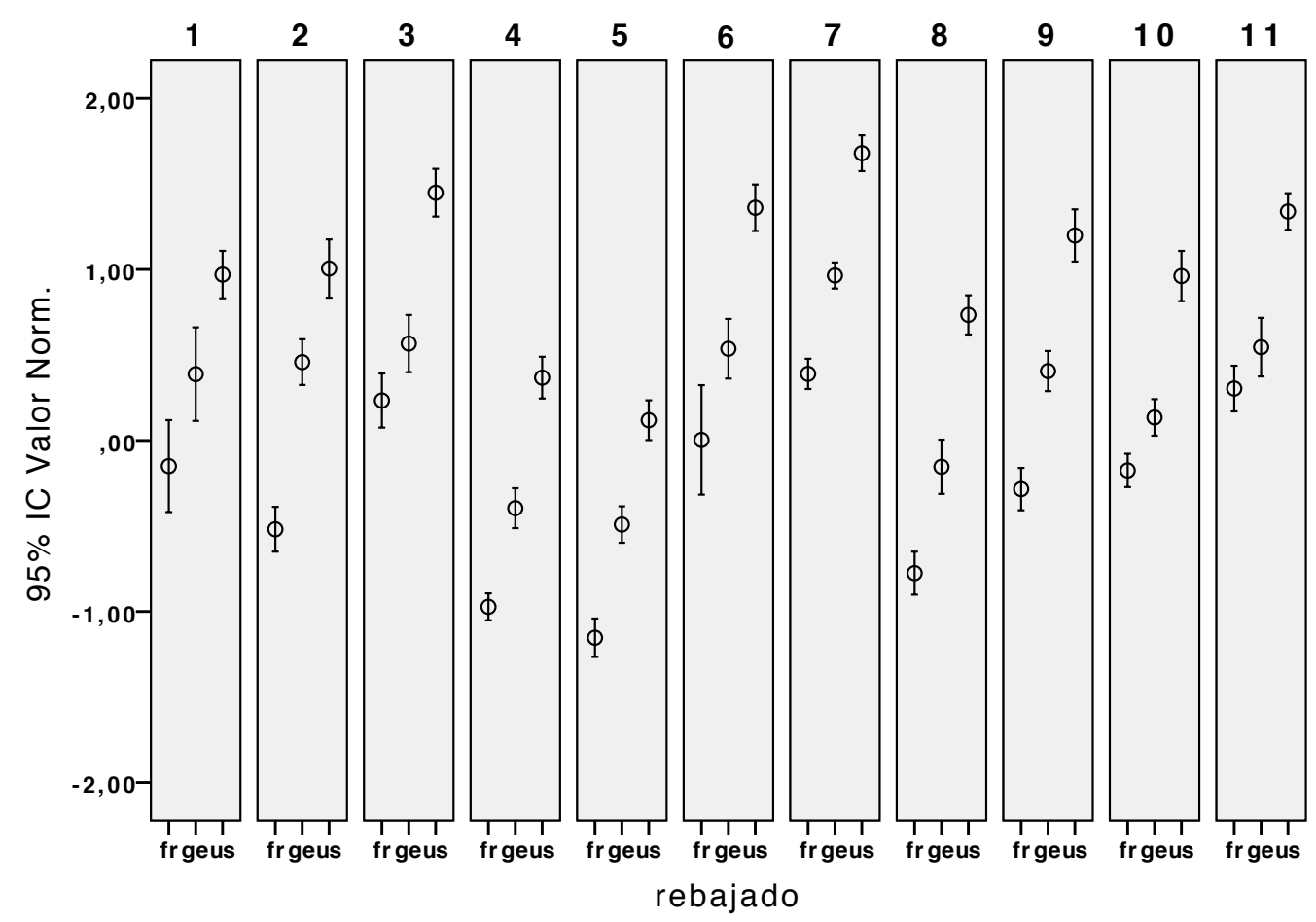

Figura 4.21. Medias con intervalo de confianza de los diferentes estilos de rebajado en función de los oboístas en el parámetro frecuencia media (en Hz). 
Al analizar las lengüetas de todos los oboístas, se observa que la lengüeta con el molde 107 y grosor $59 \mathrm{~mm}$ en el oboísta 3 es la lengüeta donde más diferencias de frecuencia media existe entre rebajados en la nota do6 del ejercicio arpegio. La figura 4.22 confirma visualmente las diferencias existentes entre el rebajado francés (el más bajo en afinación) el alemán (que se sitúa en el centro) y el americano (el más alto en afinación) de la figura 4.21.
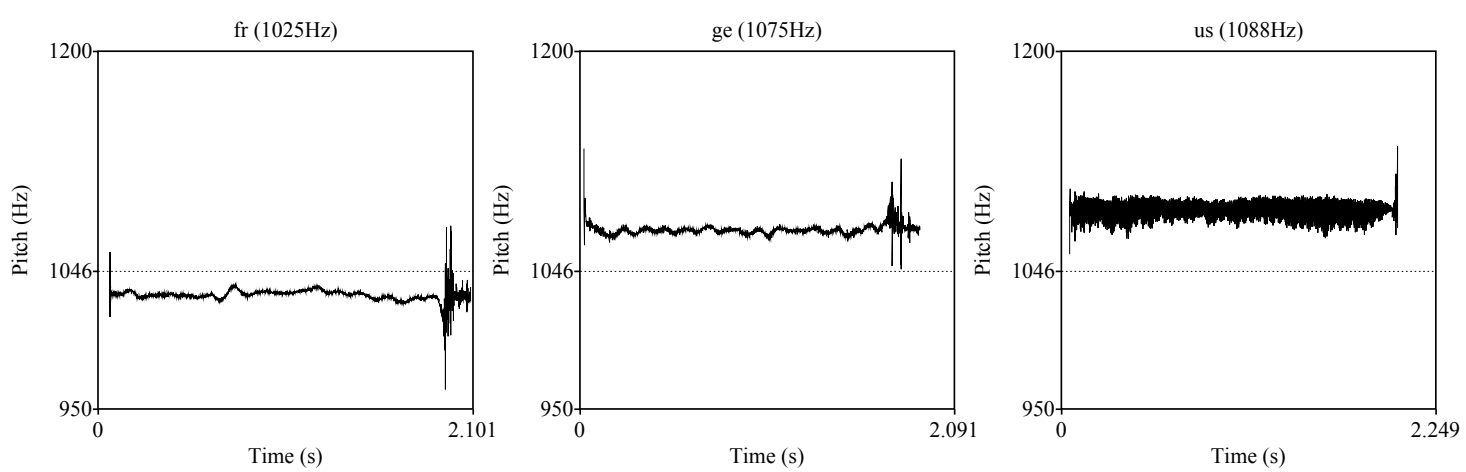

Figura 4.22. Frecuencia fundamental (en $\mathrm{Hz}$ ) de la nota do 6 para las lengüetas francesa, alemana y americana con el molde 107 y el grosor 59 del oboísta 3. Se añade la frecuencia de referencia para el do $6(1046,5 \mathrm{~Hz})$
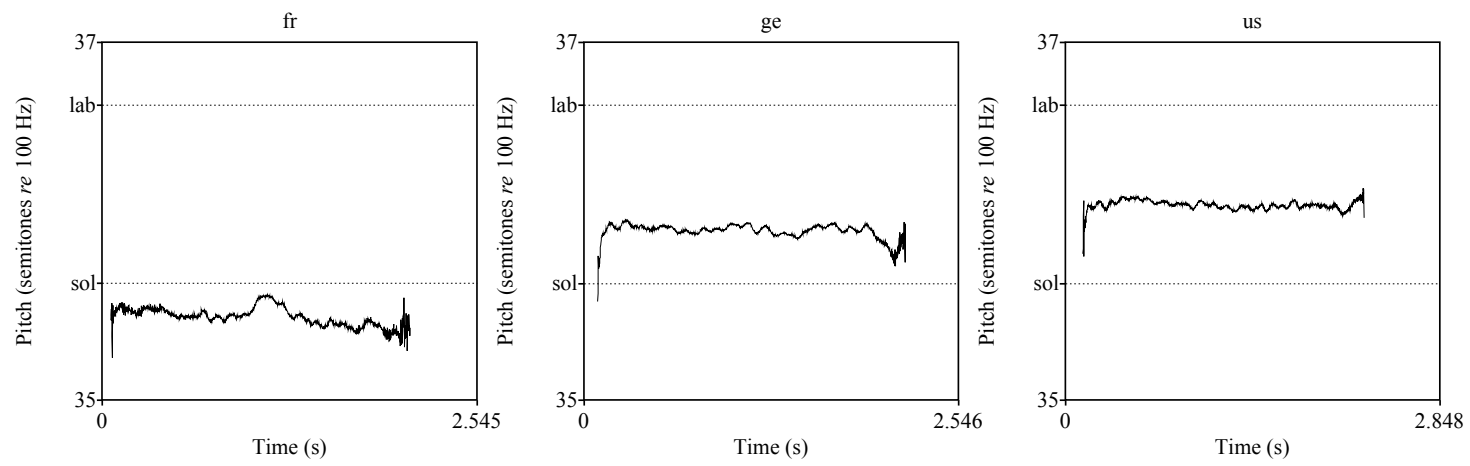

Figura 4.23. Frecuencia fundamental (en semitonos respecto a $100 \mathrm{~Hz}$ ) de la nota $\mathrm{sol}_{5}$ para las lengüetas francesa, alemana y americana con el molde 21 y el grosor 59 del oboísta 2 . Se añade la frecuencia de referencia para el sol $_{5}$ y el la bemol 5.

Para un mismo oboísta, molde y grosor de lengüeta, el rebajado suele provocar desviaciones cercanas al semitono, con la lengüeta francesa siendo la más grave, y la americana la más aguda como se puede observar en las figuras 4.22 y 4.23. Respecto a la afinación, hay que apuntar que el oboísta mantiene la afinación para todas las notas de una lengüeta: si una lengüeta tiene tendencia a tener una afinación baja, esa diferencia de afinación se mantiene para todas las notas del oboe. Como norma general, los oboístas fabrican sus lengüetas utilizando un molde, grosor, rebajado, tudel, etc. que les ayuda a mantener una afinación correcta, es decir, cuando una lengüeta está construida a partir de 
elementos que le otorgan unas características bajas en afinación, esa lengüeta se mantendrá baja en todo el registro del oboe y viceversa si la lengüeta se queda alta. Es por eso, que los oboísta profesionales perfeccionan su técnica de rebajado para conseguir el máximo ajuste de la lengüeta a una afinación correcta y estable.

En el experimento, los oboístas grababan todos los ejercicios para una lengüeta dada antes de pasar a la siguiente, con lo que generalmente tenían una afinación coherente en el primer ejercicio realizado con esa lengüeta.

Si se analizan los resultados de la frecuencia media dependiendo de las dimensiones o medidas físicas de las lengüetas y no sólo del estilo de rebajado, se puede observar en la tabla $4.3 \mathrm{~b}$ que una gran parte de las dimensiones de las lengüetas influyen en la frecuencia media, sobre todo las referentes al grosor de la punta y a la superficie de la pala, tanto rebajada como libre. Esto confirma que el estilo de rebajado sea el parámetro más influyente en la frecuencia media, como se ha visto en las mediciones anteriores, ya que lo que más marca la diferencia entre los estilos de rebajado es el grosor y la forma de la punta y la superficie de rebajado. El $\mathrm{R}^{2}$ corregido obtenido es muy alto $\left(\mathrm{R}^{2}=, 742\right)$. Sin embargo la variabilidad explicada por las dimensiones físicas de la lengüeta con esta regresión múltiple es ligeramente inferior a los resultados del análisis de varianza anterior con factores categóricos $\left(\mathrm{R}^{2}=\eta^{2}\right.$ del modelo corregido $=, 829$ cf. tabla 4.3). Es más, un análisis de varianza con medidas repetidas utilizando únicamente el estilo de rebajado y sus tres categorías indica que el rebajado por sí solo explica una variabilidad similar de frecuencia $\left(\eta^{2}=, 715 c f\right.$. tabla A.41). Teniendo en cuenta que las dimensiones físicas de la lengüeta reflejan no solamente el rebajado, sino también el molde, el grosor y las variabilidades propias de la caña y del proceso de fabricación, podemos decir que las dimensiones físicas de la lengüeta no aportan una información considerable a las tres categorías de rebajado estudiadas en esta investigación. 


\begin{tabular}{|c|c|c|c|c|c|c|c|c|c|}
\hline \multicolumn{10}{|c|}{ Resumen del modelo } \\
\hline \multirow[t]{2}{*}{ Modelo } & \multirow[t]{2}{*}{$\mathrm{R}$} & \multirow[t]{2}{*}{$\mathrm{R}^{2}$} & \multirow{2}{*}{$\begin{array}{c}\mathrm{R}^{2} \\
\text { corregida }\end{array}$} & \multirow{2}{*}{$\begin{array}{c}\text { Error típ. de la } \\
\text { estimación }\end{array}$} & \multicolumn{5}{|c|}{ Estadísticos de cambio } \\
\hline & & & & & $\begin{array}{c}\text { Cambio } \\
\text { en } \mathrm{R}^{2}\end{array}$ & $\begin{array}{c}\text { Cambio } \\
\text { en F }\end{array}$ & g11 & $\mathrm{g} 12$ & $\begin{array}{l}\text { Sig. Cambio } \\
\text { en F }\end{array}$ \\
\hline 15 & 0,862 & 0,743 & 0,742 & 0,50690142 & 0,001 & 9,643 & 1 & 1798 & 0,002 \\
\hline
\end{tabular}

\begin{tabular}{|c|c|c|c|c|c|c|}
\hline \multicolumn{7}{|c|}{ Coeficientes $^{\mathbf{a}, \mathbf{b}}$} \\
\hline \multirow{2}{*}{\multicolumn{2}{|c|}{ Modelo }} & \multicolumn{2}{|c|}{$\begin{array}{l}\text { Coeficientes no } \\
\text { estandarizados }\end{array}$} & \multirow{2}{*}{$\begin{array}{c}\begin{array}{c}\text { Coeficientes } \\
\text { estandarizados }\end{array} \\
\text { Beta }\end{array}$} & \multirow[t]{2}{*}{$\mathrm{t}$} & \multirow[t]{2}{*}{ Sig. } \\
\hline & & $\mathrm{B}$ & Error típ. & & & \\
\hline \multirow[t]{10}{*}{15} & (Constante) & $-119,197$ & 16,977 & & $-7,021$ & 0,000 \\
\hline & su24 libre & $-0,882$ & 0,093 & $-7,710$ & $-9,468$ & 0,000 \\
\hline & rd13/11 & 0,063 & 0,020 & 0,074 & 3,105 & 0,002 \\
\hline & grl izda & 0,154 & 0,013 & 0,310 & 12,017 & 0,000 \\
\hline & gr6 dcha & $-0,044$ & 0,009 & $-0,107$ & $-5,011$ & 0,000 \\
\hline & dg17 asim punta & 0,049 & 0,020 & 0,057 & 2,378 & 0,018 \\
\hline & gr2 centro & $-0,077$ & 0,009 & $-0,358$ & $-8,845$ & 0,000 \\
\hline & dist8 libre & 5,783 & 0,698 & 6,967 & 8,290 & 0,000 \\
\hline & dist7 ancho & 18,323 & 2,275 & 2,777 & 8,052 & 0,000 \\
\hline & gr5 centro & 0,061 & 0,009 & 0,250 & 6,946 & 0,000 \\
\hline
\end{tabular}

Tabla 4.3b. Resumen del modelo (arriba) y coeficientes de las variables predictoras de la regresión de la variable dependiente frecuencia media $(\mathrm{Hz})$ con todas las medidas físicas de las lengüetas. Se muestran los que sí tienen influencia sobre la variable dependiente ( $c f$. leyenda de las variables en la tabla 4.aa y 4.bb)

\subsubsection{Mediciones relativas a la estabilidad de la afinación}

\subsection{Delta de frecuencia}

Un ANOVA de varios factores (tabla 4.4) muestra que el oboísta $\left(\mathrm{F}=5, p<, 001, \eta^{2}=\right.$, 042), el rebajado $\left(\mathrm{F}=9,3, p<, 001, \eta^{2}=, 016\right)$ y el grosor $\left(\mathrm{F}=4,1, p=, 041, \eta^{2}=, 004\right)$ son los factores individuales que tienen una influencia significativa, siendo el oboísta el factor más influyente. Además, existe un efecto cruzado del rebajado*el oboísta $\left(\mathrm{F}=2,3, p=, 001, \eta^{2}=\right.$, 037). Es relevante indicar que el molde no tiene la menor influencia ( $c f$. A.32 para más detalle).

En la figura 4.24 se observa que claramente el estilo de rebajado francés consigue un mayor delta en la frecuencia respecto al rebajado americano y el alemán respectivamente, es decir, las lengüetas francesas generan un mayor ámbito de afinación, por lo que son las que mayor inestabilidad producen en la afinación. 


\begin{tabular}{|l|r|r|r|r|r|r|}
\hline Origen & \multicolumn{1}{|c|}{$\begin{array}{c}\text { Suma de } \\
\text { cuadrados tipo III }\end{array}$} & gl & $\begin{array}{c}\text { Media } \\
\text { cuadrática }\end{array}$ & F & Sig. & $\begin{array}{c}\text { Eta al cuadrado } \\
\text { parcial }\end{array}$ \\
\hline Modelo corregido & 166,794 & 119 & 1,402 & 1,670 & 0,000 & 0,146 \\
\hline Intersección & 7,212 & 1 & 7,212 & 8,593 & 0,003 & 0,007 \\
\hline rebajado & 15,714 & 2 & 7,857 & 9,362 & 0,000 & 0,016 \\
\hline molde & 0,095 & 1 & 0,095 & 0,113 & 0,737 & 0,000 \\
\hline grosor & 3,497 & 1 & 3,497 & 4,167 & 0,041 & 0,004 \\
\hline oboista & 42,747 & 10 & 4,275 & 5,093 & 0,000 & 0,042 \\
\hline rebajado * molde & 2,958 & 2 & 1,479 & 1,762 & 0,172 & 0,003 \\
\hline rebajado * grosor & 0,175 & 2 & 0,088 & 0,104 & 0,901 & 0,000 \\
\hline rebajado * oboista & 37,238 & 19 & 1,960 & 2,335 & 0,001 & 0,037 \\
\hline molde * grosor & 0,796 & 1 & 0,796 & 0,948 & 0,330 & 0,001 \\
\hline molde * oboista & 4,161 & 9 & 0,462 & 0,551 & 0,838 & 0,004 \\
\hline grosor * oboista & 6,203 & 10 & 0,620 & 0,739 & 0,688 & 0,006 \\
\hline
\end{tabular}

Tabla 4.4. Análisis de varianza factorial sobre el delta de la frecuencia para los factores rebajado, molde, grosor y oboísta.

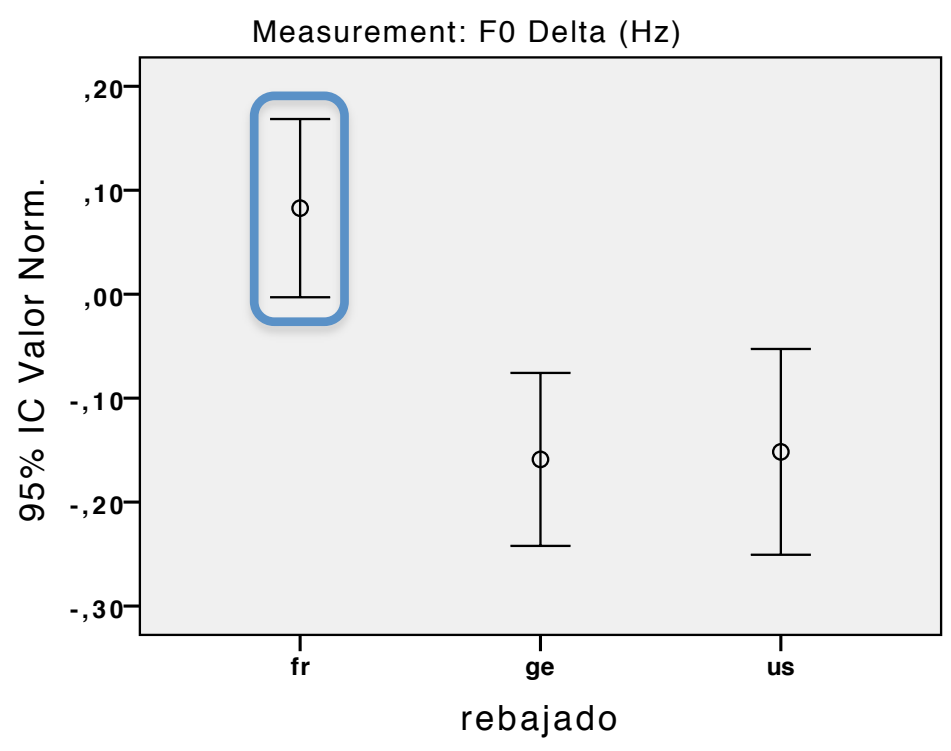

Figura 4.24. Medias con intervalo de confianza de los diferentes estilos de rebajado en el parámetro delta de la frecuencia (en $\mathrm{Hz}$ ). Se marca con un círculo azul los valores que se diferencian significativamente.

Como se puede apreciar en la figura 4.25, el rebajado francés provoca, en general, una mayor diferencia en la afinación, excepto para los oboístas 1, 3, 9 y 11. Para algunos oboístas se presentan diferencias significativas, pero no para todos ellos. 


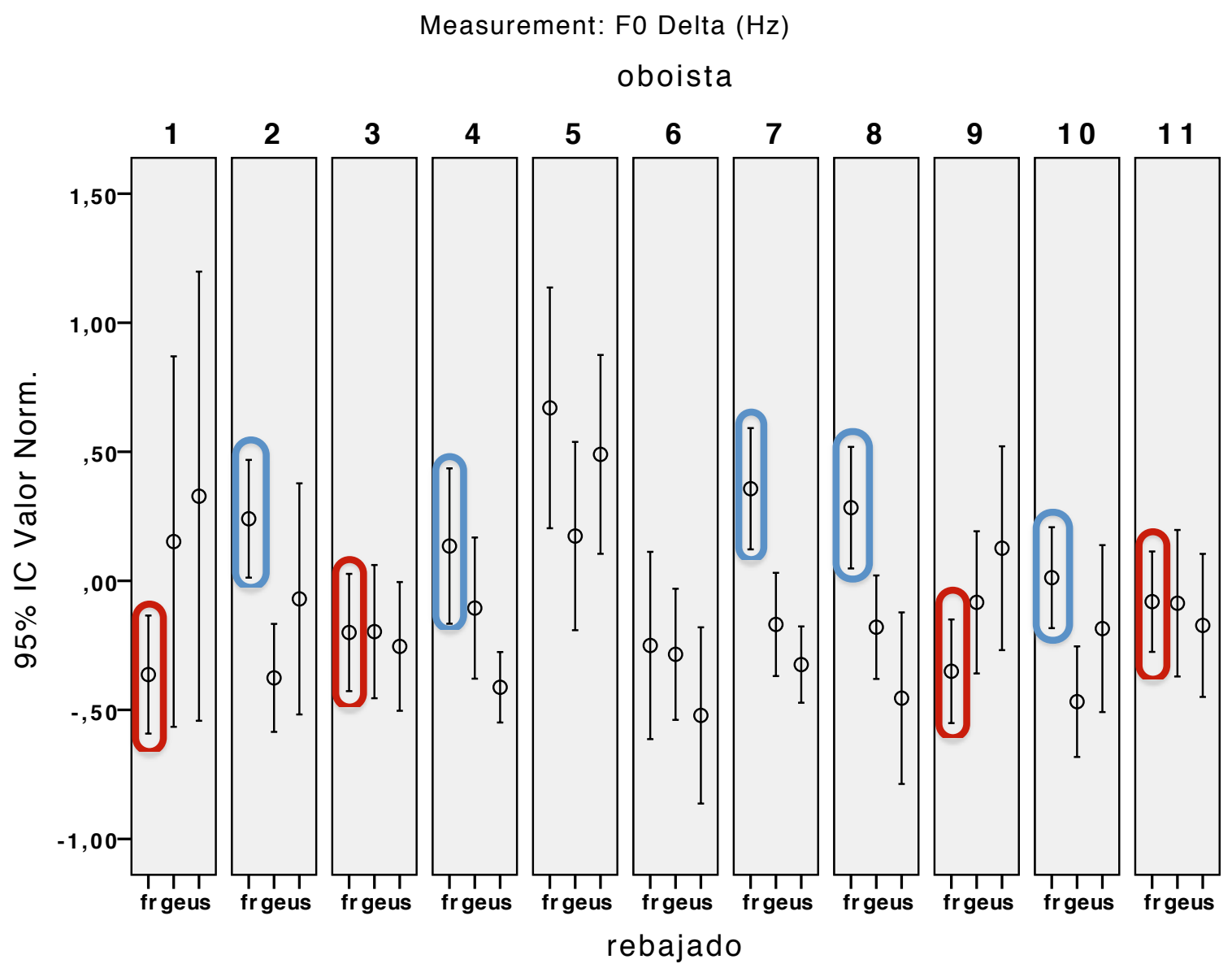

Figura 4.25. Medias con intervalo de confianza de los diferentes estilos de rebajado en función de los oboístas en el parámetro delta de la frecuencia (en Hz). Se marca con un círculo azul los valores que se diferencian significativamente y con un círculo rojo los valores contrarios a la media.
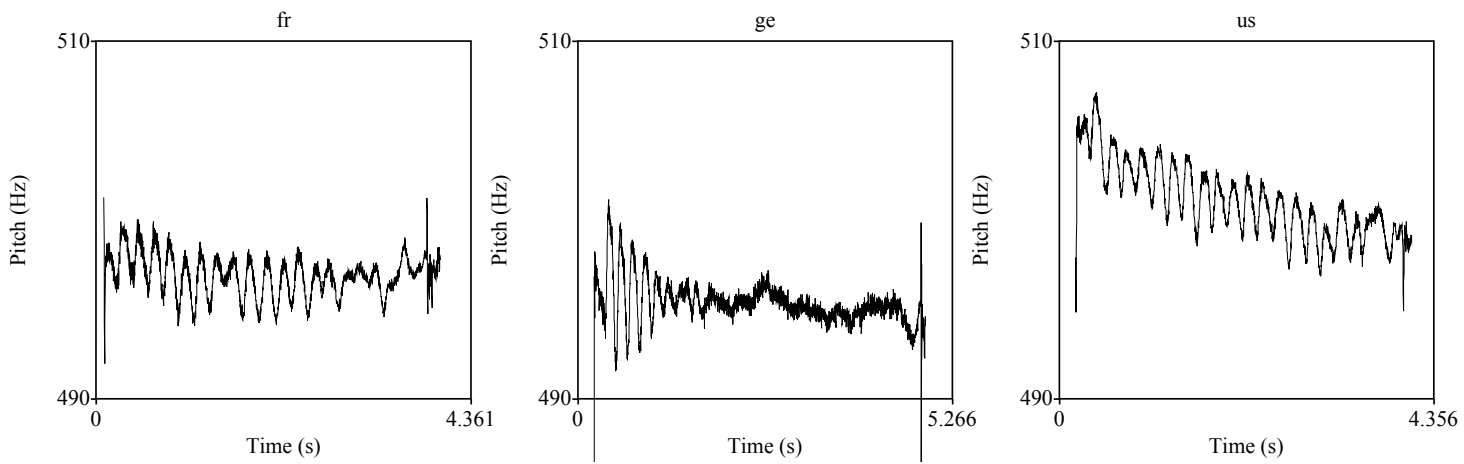

Figura 4.26. Gráfico de la frecuencia fundamental (en Hz) para las lengüetas francesa, alemana y americana con el molde 21 y grosor 57 y oboísta 4.

Como se puede observar en la figura 4.26, la medición del parámetro delta de la frecuencia, entendida como la diferencia entre la frecuencia más aguda y más grave dentro de la nota, es muy sensible a picos puntuales. Estos picos pueden corresponder a una diferencia real de frecuencia, por ejemplo un cambio de frecuencia rápido durante el ataque de la nota, a la inestabilidad de la nota o a errores sobre todo en la falsa detección 
de frecuencias fundamentales en el final de la nota. Por ello, se utiliza esta medición específicamente para medir la caída de la afinación en el ejercicio diminuendo ( $c f$. punto 4.6.5), utilizando la desviación estándar de la frecuencia para medir la estabilidad de la lengüeta, ya que esta medición es menos sensible a picos puntuales.

Si se analizan los resultados del delta de la frecuencia dependiendo de las dimensiones físicas de las lengüetas y no sólo del estilo de rebajado, se puede observar en la tabla 4.4b que algunos grosores de la punta y la diferencia del grosor del centro de la pala y de la parte de atrás del rebajado son muy importantes, al igual que la longitud de la pala. En esta ocasión el $\mathrm{R}^{2}$ corregido obtenido es muy bajo $\left(\mathrm{R}^{2}=, 018\right)$, comparable a la variabilidad explicada por el estilo de rebajado $\left(\eta^{2}=, 012 c f\right.$. tabla A.41).

\begin{tabular}{|c|c|c|c|c|c|c|c|c|c|}
\hline \multicolumn{10}{|c|}{ Resumen del modelo } \\
\hline \multirow[t]{2}{*}{ Modelo } & \multirow[t]{2}{*}{$\mathrm{R}$} & \multirow[t]{2}{*}{$\mathrm{R}^{2}$} & \multirow{2}{*}{$\begin{array}{c}\mathrm{R}^{2} \\
\text { corregida }\end{array}$} & \multirow{2}{*}{$\begin{array}{c}\text { Error típ. de la } \\
\text { estimación }\end{array}$} & \multicolumn{5}{|c|}{ Estadísticos de cambio } \\
\hline & & & & & $\begin{array}{c}\text { Cambio } \\
\text { en } \mathrm{R}^{2}\end{array}$ & $\begin{array}{c}\text { Cambio } \\
\text { en } \mathrm{F}\end{array}$ & gl1 & $\mathrm{g} 12$ & $\begin{array}{l}\text { Sig. Cambio } \\
\text { en } \mathrm{F}\end{array}$ \\
\hline 5 & 0,143 & 0,020 & 0,018 & 0,98835945 & 0,002 & 3,921 & 1 & 1802 & 0,048 \\
\hline
\end{tabular}

\begin{tabular}{|c|c|c|c|c|c|c|}
\hline \multicolumn{7}{|c|}{ Coeficientes $^{\mathrm{a}, \mathrm{b}}$} \\
\hline \multirow{2}{*}{\multicolumn{2}{|c|}{ Modelo }} & \multicolumn{2}{|c|}{$\begin{array}{l}\text { Coeficientes no } \\
\text { estandarizados }\end{array}$} & \multirow{2}{*}{$\begin{array}{c}\begin{array}{c}\text { Coeficientes } \\
\text { estandarizados }\end{array} \\
\text { Beta }\end{array}$} & \multirow[t]{2}{*}{$\mathrm{t}$} & \multirow[t]{2}{*}{ Sig. } \\
\hline & & $\mathrm{B}$ & Error típ. & & & \\
\hline \multirow[t]{6}{*}{5} & (Constante) & $-0,830$ & 0,736 & & $-1,128$ & 0,259 \\
\hline & gr3 dcha & $-0,093$ & 0,021 & $-0,149$ & $-4,512$ & 0,000 \\
\hline & rg31 centro lado & $-0,722$ & 0,144 & $-0,259$ & $-5,015$ & 0,000 \\
\hline & dist8 libre & 0,162 & 0,042 & 0,195 & 3,879 & 0,000 \\
\hline & gr1 izda & $-0,047$ & 0,017 & $-0,094$ & $-2,688$ & 0,007 \\
\hline & dg20 atras cora & $-0,016$ & 0,008 & $-0,057$ & $-1,980$ & 0,048 \\
\hline
\end{tabular}

Tabla 4.4b. Resumen del modelo (arriba) y coeficientes de las variables predictoras de la regresión de la variable dependiente delta de la frecuencia $(\mathrm{Hz})$ con todas las medidas físicas de las lengüetas. Se muestran los que sí tienen influencia sobre la variable dependiente ( $c f$. leyenda de las variables en la tabla 4.aa y 4.bb)

\subsection{Desviación estándar de la frecuencia (en semitonos)}

Con este parámetro acústico se mide la estabilidad de la frecuencia para una nota dada. Un ANOVA de varios factores (tabla 4.5) muestra que el oboísta ( $\mathrm{F}=5,3, p<, 001$, $\left.\eta^{2}=, 044\right)$ y el rebajado $\left(\mathrm{F}=4,4, p=, 012, \eta^{2}=, 008\right)$ son los únicos factores individuales que tienen una influencia significativa. Además, existe un efecto cruzado del rebajado*el oboísta $\left(\mathrm{F}=1,6, p=, 032, \eta^{2}=, 027\right)$. Es relevante indicar que ni el molde ni el grosor tienen la menor influencia ( $c f$. A.33 para más detalle). 
La figura 4.27 muestra que el rebajado francés es el que mayor desviación de la frecuencia provoca, sobre todo y de forma significativa respecto al rebajado alemán. El rebajado alemán, por tanto, es el más estable en la afinación, mientras que el francés es el que más inestabilidades produce. La figura 4.28 muestra que no existen diferencias entre las lengüetas, sino que las desviaciones provocadas en la frecuencia se deben a las diferencias entre los rebajados y no a las particularidades de las lengüetas. Se confirma que el rebajado francés es más inestable que el alemán, sobre todo para la lengüeta con molde 107 y grosor $57 \mathrm{~mm}$. La figura 4.29 confirma que el rebajado francés es más inestable en la afinación, pero por el contrario, se obtienen resultados completamente diferentes para los oboístas 1,3 y 9 .

\begin{tabular}{|l|r|r|r|r|r|r|}
\hline Origen & $\begin{array}{c}\text { Suma de cuadrados } \\
\text { tipo III }\end{array}$ & gl & $\begin{array}{c}\text { Media } \\
\text { cuadrática }\end{array}$ & F & Sig. & $\begin{array}{c}\text { Eta al cuadrado } \\
\text { parcial }\end{array}$ \\
\hline Modelo corregido & $174,777^{\mathrm{b}}$ & 119 & 1,469 & 1,578 & 0,000 & 0,139 \\
\hline Intersección & 3,840 & 1 & 3,840 & 4,125 & 0,042 & 0,004 \\
\hline rebajado & 8,297 & 2 & 4,149 & 4,457 & 0,012 & 0,008 \\
\hline molde & 0,513 & 1 & 0,513 & 0,551 & 0,458 & 0,000 \\
\hline grosor & 0,093 & 1 & 0,093 & 0,100 & 0,752 & 0,000 \\
\hline oboista & 49,824 & 10 & 4,982 & 5,352 & 0,000 & 0,044 \\
\hline rebajado * molde & 1,718 & 2 & 0,859 & 0,923 & 0,398 & 0,002 \\
\hline rebajado * grosor & 0,072 & 2 & 0,036 & 0,039 & 0,962 & 0,000 \\
\hline rebajado * oboista & 29,889 & 19 & 1,573 & 1,690 & 0,032 & 0,027 \\
\hline molde * grosor & 0,101 & 1 & 0,101 & 0,108 & 0,742 & 0,000 \\
\hline molde * oboista & 2,969 & 9 & 0,330 & 0,354 & 0,956 & 0,003 \\
\hline grosor * oboista & 5,257 & 10 & 0,526 & 0,565 & 0,844 & 0,005 \\
\hline
\end{tabular}

Tabla 4.5. Análisis de varianza factorial sobre la desviación estándar de la frecuencia (en semitonos) para los factores rebajado, molde, grosor y oboísta.

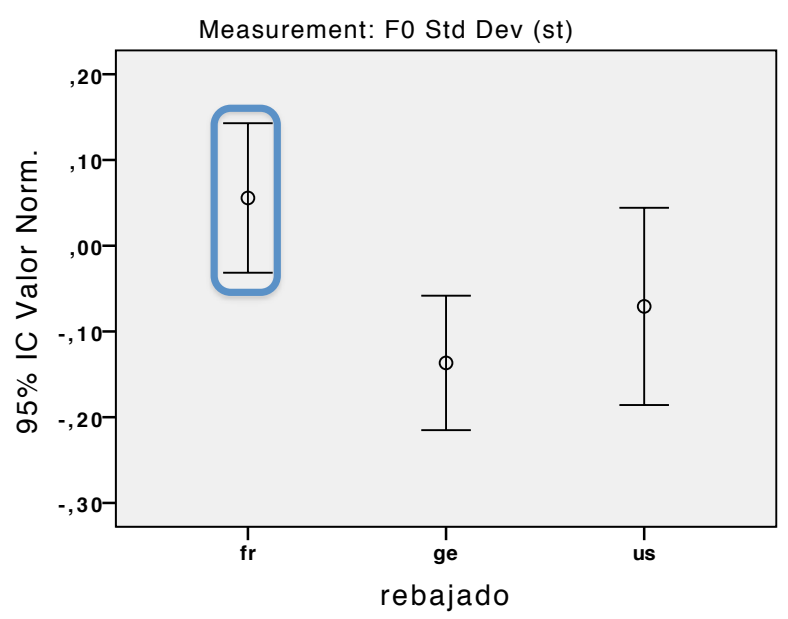

Figura 4.27. Medias con intervalo de confianza de los diferentes estilos de rebajado en el parámetro desviación estándar de la frecuencia (en semitonos). Se marca con un círculo azul los resultados que son significativos. 


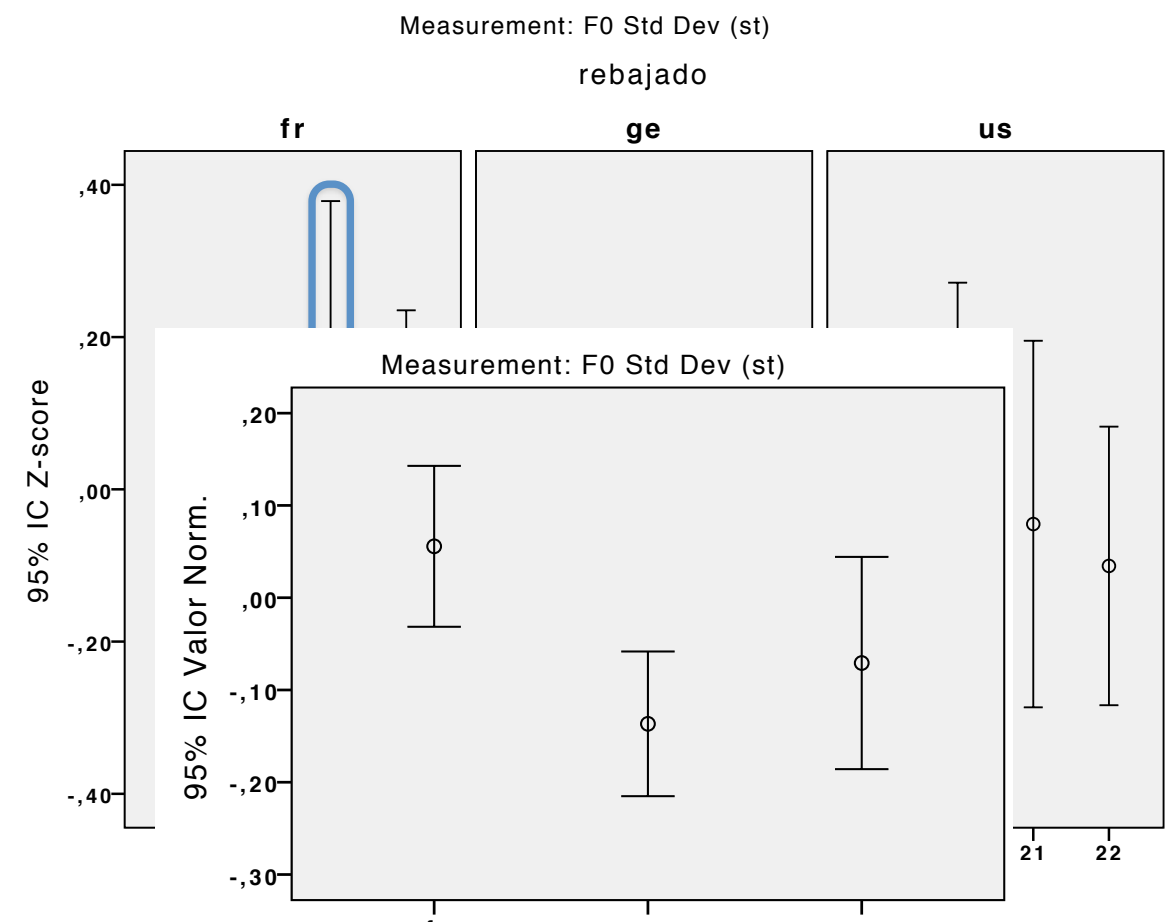

Figura 4.28. Medias con intervalo de confianza comparando todas las lengüetas según el molde, grosor y estilos de rebajado en el parámetro desviación estándar de la frecuencia (en semitonos). El primer número hace referencia al molde $(1=21 ; 2=107 ; 3=168)$ y el segundo número al grosor $(1=57 \mathrm{~mm} ; 2=59 \mathrm{~mm})$. Se marca con un círculo azul los resultados que son significativos.

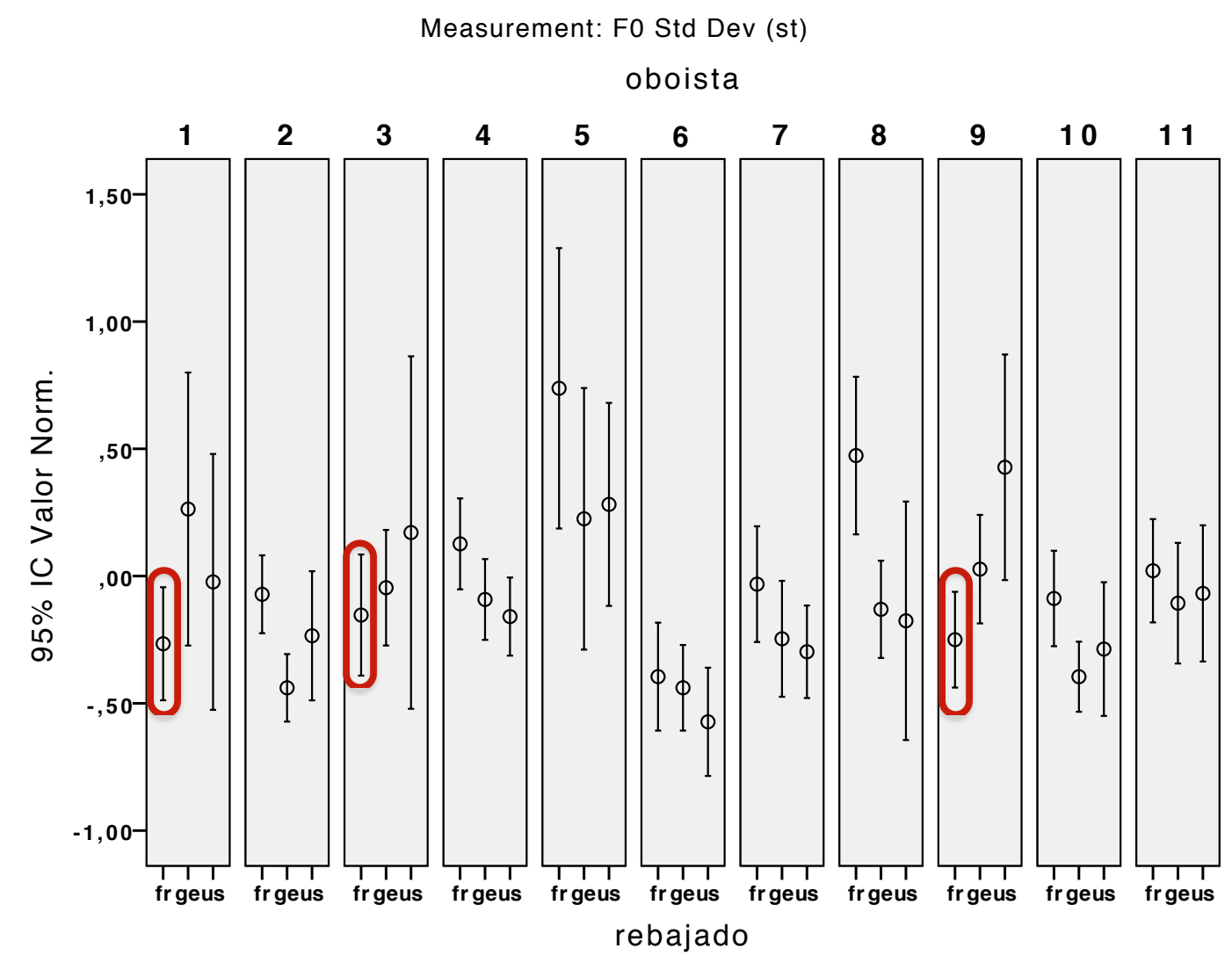

Figura 4.29. Medias con intervalo de confianza de los diferentes estilos de rebajado en función de los oboístas en el parámetro desviación estándar de la frecuencia (en semitonos). Se marca con un círculo rojo los resultados contrarios a la media. 
La desviación estándar de la frecuencia fundamental puede ser debida a varios elementos. Por ejemplo, en la figura 4.30 se observa que los errores de funcionamiento de la lengüeta acarrean automáticamente un aumento de la desviación de la frecuencia, por ejemplo cuando aparecen múltiples frecuencias concurrentes y subarmónicos, con una clara inestabilidad de la lengüeta (en este caso la americana para el do6).

Un segundo caso de desviación de la fundamental se debe al inicio de la nota (onset) durante el cual el oboísta necesita ajustar la presión para conseguir la frecuencia deseada, y se provoca así una inestabilidad inicial como se ilustra en la figura 4.31. En la figura 4.32 se ve que la inestabilidad inicial se puede prolongar hasta alcanzar la frecuencia deseada, lo que aumenta la desviación (sobre todo en el caso de que haya una oscilación de la frecuencia).

Finalmente, el vibrato, deseado o no, conduce a un aumento de la desviación estándar. En el caso de que sea un vibrato deseado por el intérprete, se considerará que la desviación es algo positivo, mientras que si responde a un descontrol de la lengüeta será un efecto negativo (figura 4.33).

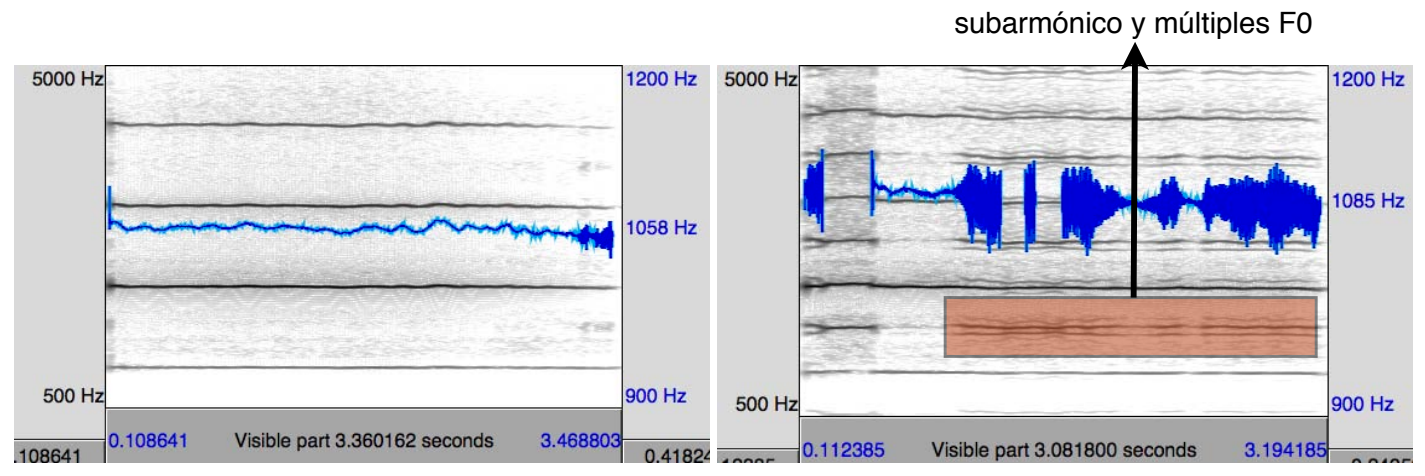

Figura 4.30. Representación del espectro y de la frecuencia fundamental (en azul en Hz) para la lengüeta francesa (izquierda, desviación de $\mathrm{F} 0=3 \mathrm{~Hz}$ ) y de la lengüeta americana (derecha, desviación de $\mathrm{F} 0=12 \mathrm{~Hz}$ ) para la nota do6 (molde 107, grosor 57, oboísta 9) 


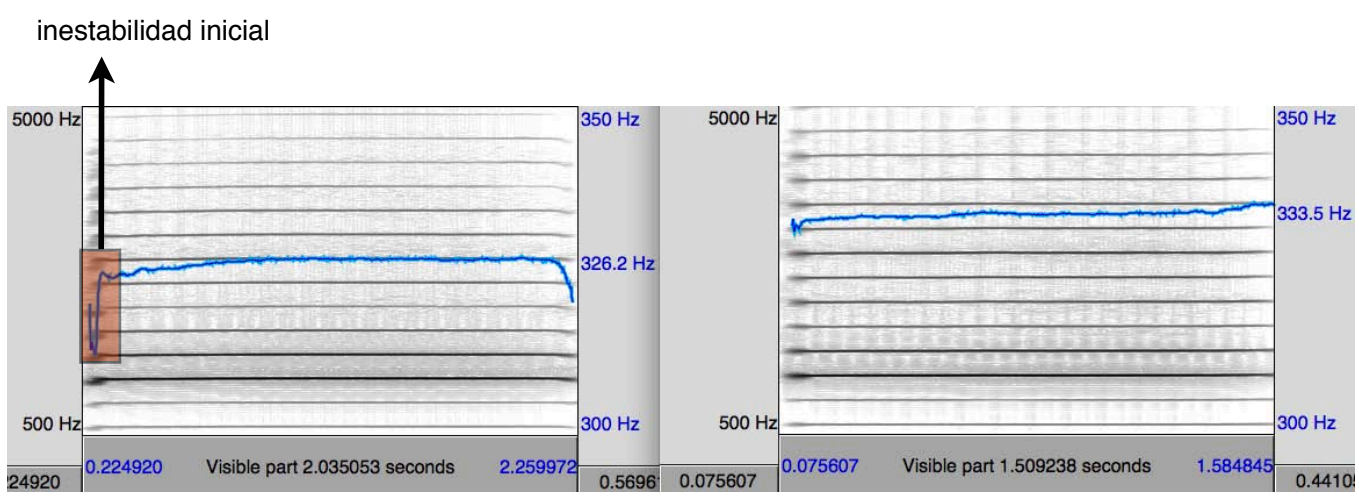

Figura 4.31. Representación del espectro y de la frecuencia fundamental (en azul en Hz) para la lengüeta francesa (izquierda, desviación de $\mathrm{F} 0=2 \mathrm{~Hz}$ ) y de la lengüeta americana (derecha, desviación de $\mathrm{F} 0=0,6 \mathrm{~Hz}$ ) para la nota mi4 (molde 107, grosor 59, oboísta 8).
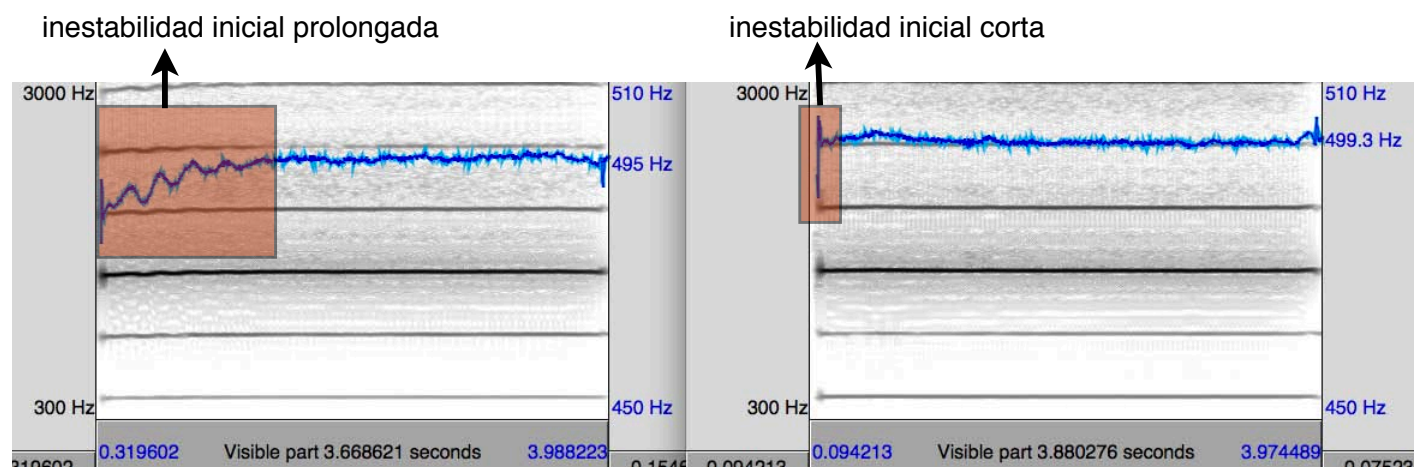

Figura 4.32. Representación del espectro y de la frecuencia fundamental (en azul en Hz) para la lengüeta alemana (izquierda, desviación de $\mathrm{F} 0=2,3 \mathrm{~Hz}$ ) y de la lengüeta americana (derecha, desviación de $\mathrm{F} 0=0,6 \mathrm{~Hz}$ ) para el fortissimo (molde 168, grosor 59, oboísta 10).

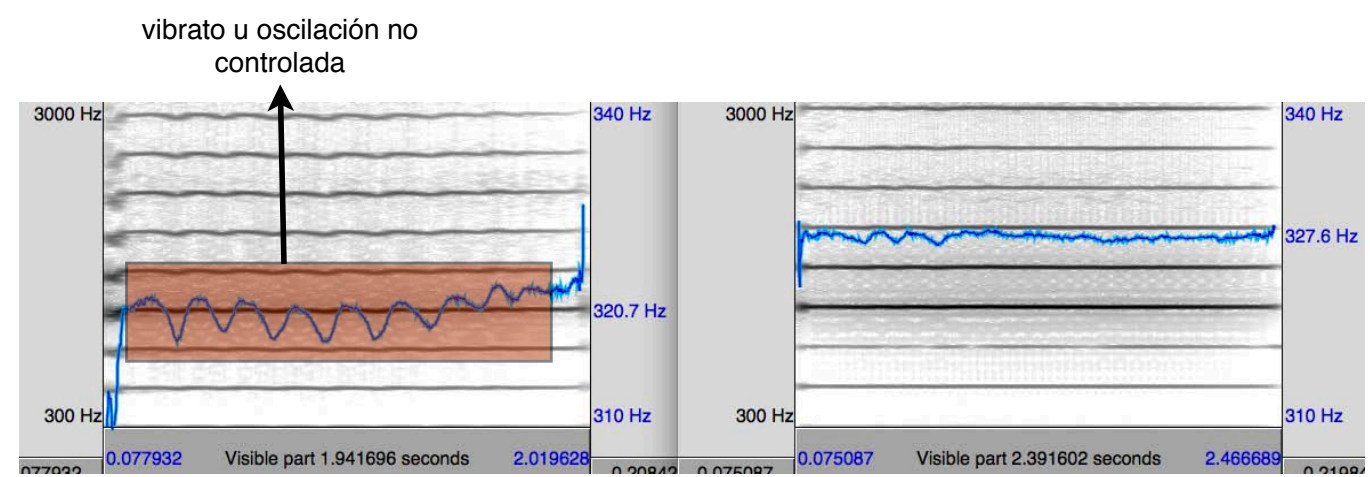

Figura 4.33. Representación del espectro y de la frecuencia fundamental (en azul en Hz) para la lengüeta francesa (izquierda, desviación de $\mathrm{F} 0=2 \mathrm{~Hz}$ ) y de la lengüeta americana (derecha, desviación de $\mathrm{F} 0=0,3 \mathrm{~Hz}$ ) para la nota mi4 (molde 168, grosor 57 , oboísta 4 ).

Si se analizan los resultados de la desviación estándar de la frecuencia dependiendo de las dimensiones físicas de las lengüetas y no sólo del estilo de rebajado, se puede observar en la tabla 4.5b que algunos grosores individuales de la punta, como el grosor medio de la punta y el grosor del gubiado de la pala junto con la superficie de rebajado son los parámetros más importantes, es decir, como ocurría con la frecuencia media, los 
parámetros que suelen marcar las diferencias entre los estilos de rebajado. El $\mathrm{R}^{2}$ corregido obtenido es muy bajo $\left(\mathrm{R}^{2}=, 054\right)$, comparable con la variabilidad explicada por el factor del estilo de rebajado $\left(\eta^{2}=, 034 c f\right.$. tabla A.41).

\begin{tabular}{|c|c|c|c|c|c|c|c|c|c|}
\hline \multicolumn{10}{|c|}{ Resumen del modelo } \\
\hline \multirow[t]{2}{*}{ Modelo } & \multirow[t]{2}{*}{$\overline{\mathrm{R}}$} & \multirow[t]{2}{*}{$\overline{\mathrm{R}^{2}}$} & \multirow{2}{*}{$\begin{array}{c}\mathrm{R}^{2} \\
\text { corregida }\end{array}$} & \multirow{2}{*}{$\begin{array}{c}\text { Error típ. de la } \\
\text { estimación }\end{array}$} & \multicolumn{5}{|c|}{ Estadísticos de cambio } \\
\hline & & & & & \begin{tabular}{c|} 
Cambio \\
en $\mathrm{R}^{2}$
\end{tabular} & $\begin{array}{l}\text { Cambio } \\
\text { en } \mathrm{F}\end{array}$ & gl1 & $\mathrm{g} 12$ & $\begin{array}{l}\text { Sig. Cambio } \\
\text { en F }\end{array}$ \\
\hline 6 & 0,239 & 0,057 & 0,054 & 0,96993094 & 0,003 & 5,871 & 1 & 1801 & 0,015 \\
\hline
\end{tabular}

\begin{tabular}{|c|c|c|c|c|c|c|}
\hline & & & Coeficiente & & & \\
\hline & & $\begin{array}{l}\text { Coefici } \\
\text { estand }\end{array}$ & $\begin{array}{l}\text { tes no } \\
\text { zados }\end{array}$ & $\begin{array}{c}\text { Coeficientes } \\
\text { estandarizados }\end{array}$ & $\mathrm{t}$ & Sig. \\
\hline & & $\mathrm{B}$ & Error típ. & Beta & & \\
\hline 6 & (Constante) & $-1,450$ & 0,658 & & $-2,205$ & 0,028 \\
\hline & gr3 dcha & $-0,164$ & 0,026 & $-0,263$ & $-6,284$ & 0,000 \\
\hline & su24 libre & 0,033 & 0,004 & 0,289 & 7,646 & 0,000 \\
\hline & rg31 centro lado & $-1,356$ & 0,227 & $-0,487$ & $-5,984$ & 0,000 \\
\hline & grl izda & $-0,133$ & 0,026 & $-0,268$ & $-5,057$ & 0,000 \\
\hline & g14 medio puntal & 0,101 & 0,029 & 0,260 & 3,495 & 0,000 \\
\hline & grosor & $-0,117$ & 0,048 & $-0,059$ & $-2,423$ & 0,015 \\
\hline
\end{tabular}

Tabla 4.5b. Resumen del modelo (arriba) y coeficientes de las variables predictoras de la regresión de la variable dependiente desviación estándar de la frecuencia (st) con todas las medidas físicas de las lengüetas. Se muestran los que sí tienen influencia sobre la variable dependiente ( $c f$. leyenda de las variables en la tabla 4.aa y $4 . \mathrm{bb})$

\subsubsection{Mediciones relativas a la intensidad}

\subsection{Intensidad (en $\mathrm{dB})$}

Un ANOVA de varios factores (tabla 4.6) muestra que todos los factores individuales son muy significativos $(p<, 001)$, siendo el oboísta $\left(\mathrm{F}=497,6, p<, 001, \eta^{2}=, 743\right)$ el que mayor variabilidad explica. Además, todos estos factores individuales provocan efectos cruzados de forma significativa ( $c f$. A.34 para más detalle).

En la figura 4.34 se observa claramente que el estilo de rebajado francés consigue menor intensidad que los otros dos rebajados utilizados, lo que puede suponer un inconveniente para la interpretación de algunos ejercicios, que se analizan más adelante en los análisis por ejercicios ( $c f$. puntos 4.6.6, 4.6.7 y 4.6.8). En la figura 4.35 se pueden apreciar diferencias aparecidas entre las lengüetas debidas a sus particularidades, sobre todo destaca la lengüeta americana, molde 21 y grosor $59 \mathrm{~mm}$ como la lengüeta que mayor intensidad consigue y la que mayor diferencia provoca con la misma lengüeta y molde, 
pero grosor $57 \mathrm{~mm}$. La figura 4.36 corrobora los resultados de la figura 4.34, a excepción del oboísta 1, siendo significativo para la mayoría de los oboístas .

\begin{tabular}{|l|r|r|r|r|r|r|}
\hline Origen & $\begin{array}{r}\text { Suma de } \\
\text { cuadrados tipo III }\end{array}$ & gl & $\begin{array}{c}\text { Media } \\
\text { cuadrática }\end{array}$ & F & Sig. & $\begin{array}{c}\text { Eta al cuadrado } \\
\text { parcial }\end{array}$ \\
\hline Modelo corregido & 1466,818 & 180 & 8,149 & 33,102 & 0,000 & 0,776 \\
\hline Intersección & 14,083 & 1 & 14,083 & 57,206 & 0,000 & 0,032 \\
\hline rebajado & 23,116 & 2 & 11,558 & 46,949 & 0,000 & 0,052 \\
\hline molde & 4,581 & 2 & 2,290 & 9,304 & 0,000 & 0,011 \\
\hline grosor & 4,815 & 1 & 4,815 & 19,559 & 0,000 & 0,011 \\
\hline oboista & 1225,114 & 10 & 122,511 & 497,651 & 0,000 & 0,743 \\
\hline rebajado * molde & 3,072 & 4 & 0,768 & 3,120 & 0,014 & 0,007 \\
\hline rebajado * grosor & 1,513 & 2 & 0,756 & 3,073 & 0,047 & 0,004 \\
\hline rebajado * oboista & 30,612 & 20 & 1,531 & 6,217 & 0,000 & 0,067 \\
\hline molde * grosor & 9,903 & 2 & 4,951 & 20,113 & 0,000 & 0,023 \\
\hline molde * oboista & 11,954 & 20 & 0,598 & 2,428 & 0,000 & 0,027 \\
\hline grosor * oboista & 7,780 & 10 & 0,778 & 3,160 & 0,001 & 0,018 \\
\hline
\end{tabular}

Tabla 4.6. Análisis de varianza factorial sobre intensidad (en dB) para los factores rebajado, molde, grosor y oboísta.

El efecto cruzado entre rebajado, molde y grosor es igualmente importante ( $\mathrm{F}=17,4$, $p<, 001, \eta^{2}=, 039, c f$. A.34 para más detalle), como se puede apreciar en la figura 4.37: en general, el rebajado francés junto con el grosor $59 \mathrm{~mm}$ suele provocar una mayor diferencia de intensidad para los dos moldes estándares, el 21 y el 107, mientras que el molde 168 con el grosor $59 \mathrm{~mm}$, no presenta diferencias significativas, pero sí con el grosor $57 \mathrm{~mm}$.

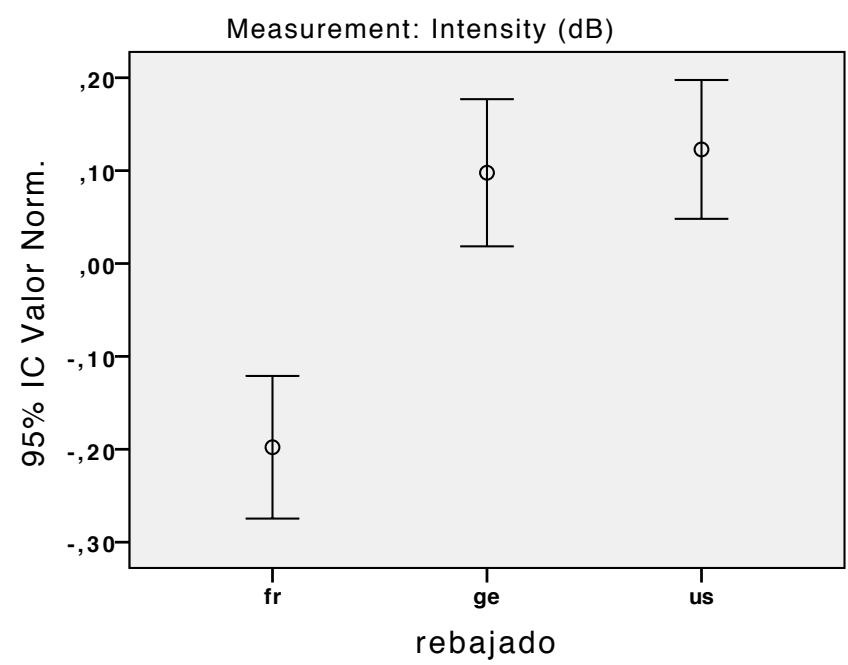

Figura 4.34. Medias con intervalo de confianza de los diferentes estilos de rebajado en el parámetro intensidad (en dB). 


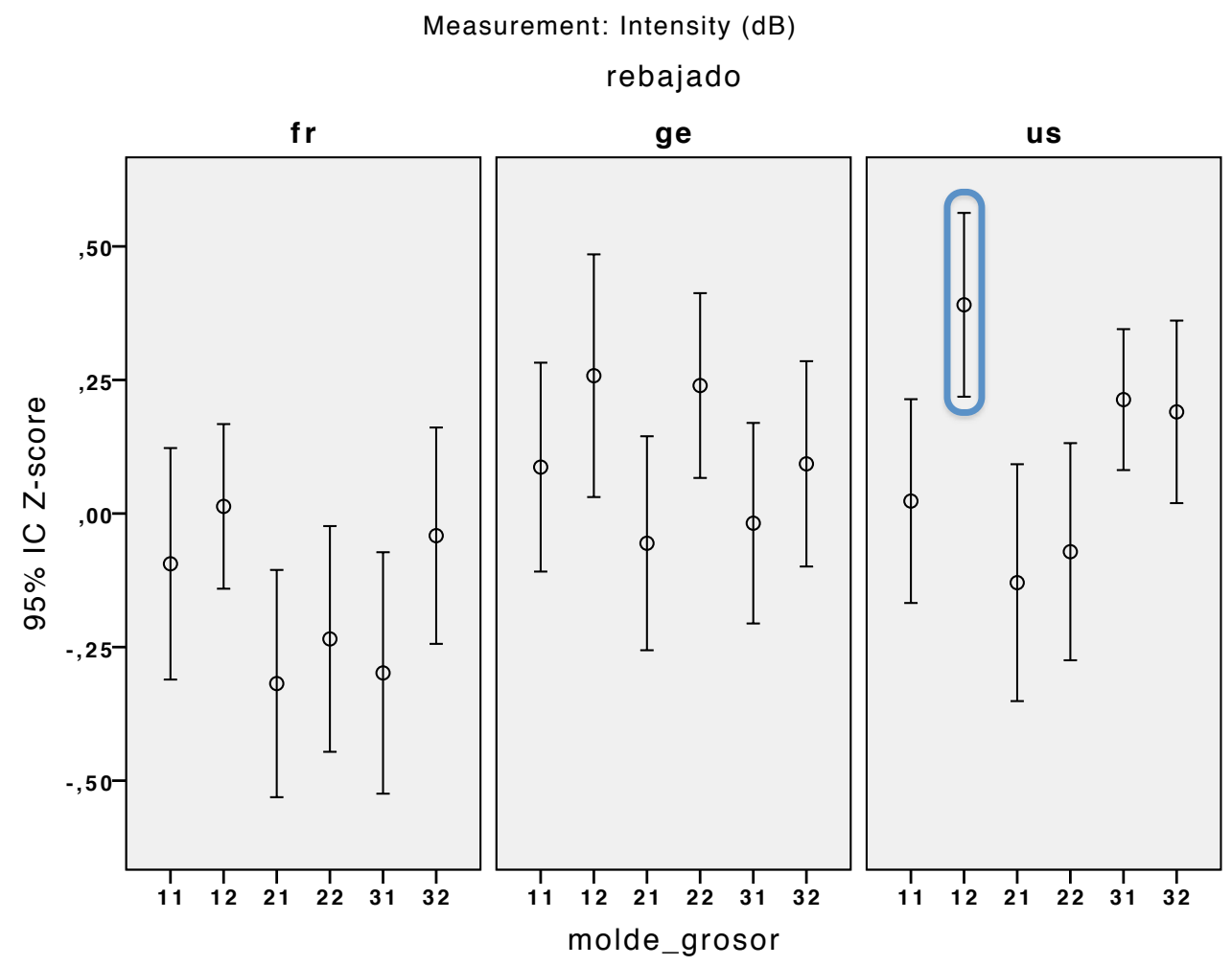

Figura 4.35. Medias con intervalo de confianza comparando todas las lengüetas según el molde, grosor y estilos de rebajado en el parámetro intensidad (en $\mathrm{dB})$. El primer número hace referencia al molde $(1=21$; $2=107 ; 3=168)$ y el segundo número al grosor $(1=57 \mathrm{~mm} ; 2=59 \mathrm{~mm})$. Se marca con un círculo azul los resultados de que son significativos.

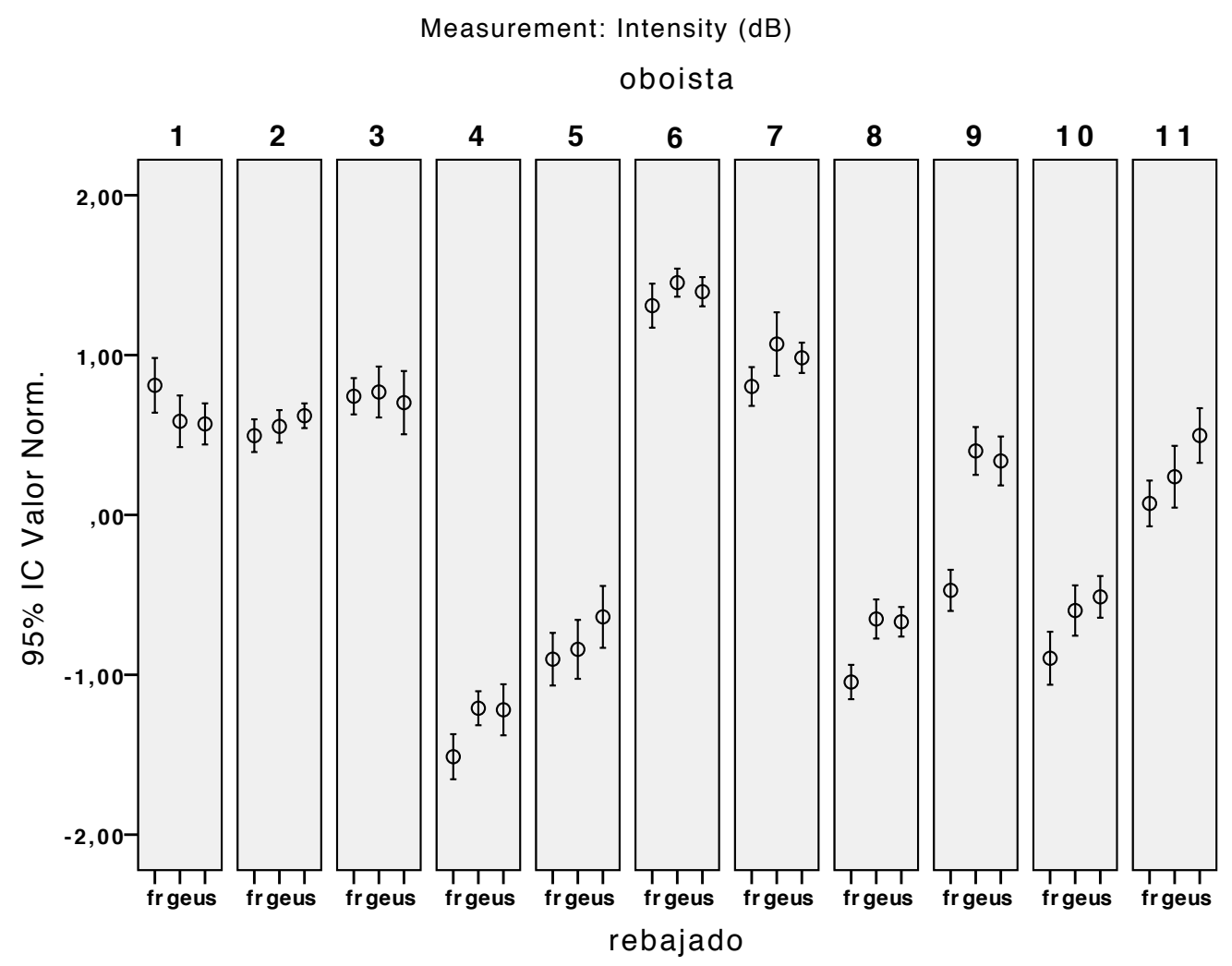

Figura 4.36. Medias con intervalo de confianza de los diferentes estilos de rebajado por oboístas en el parámetro intensidad (en dB). 


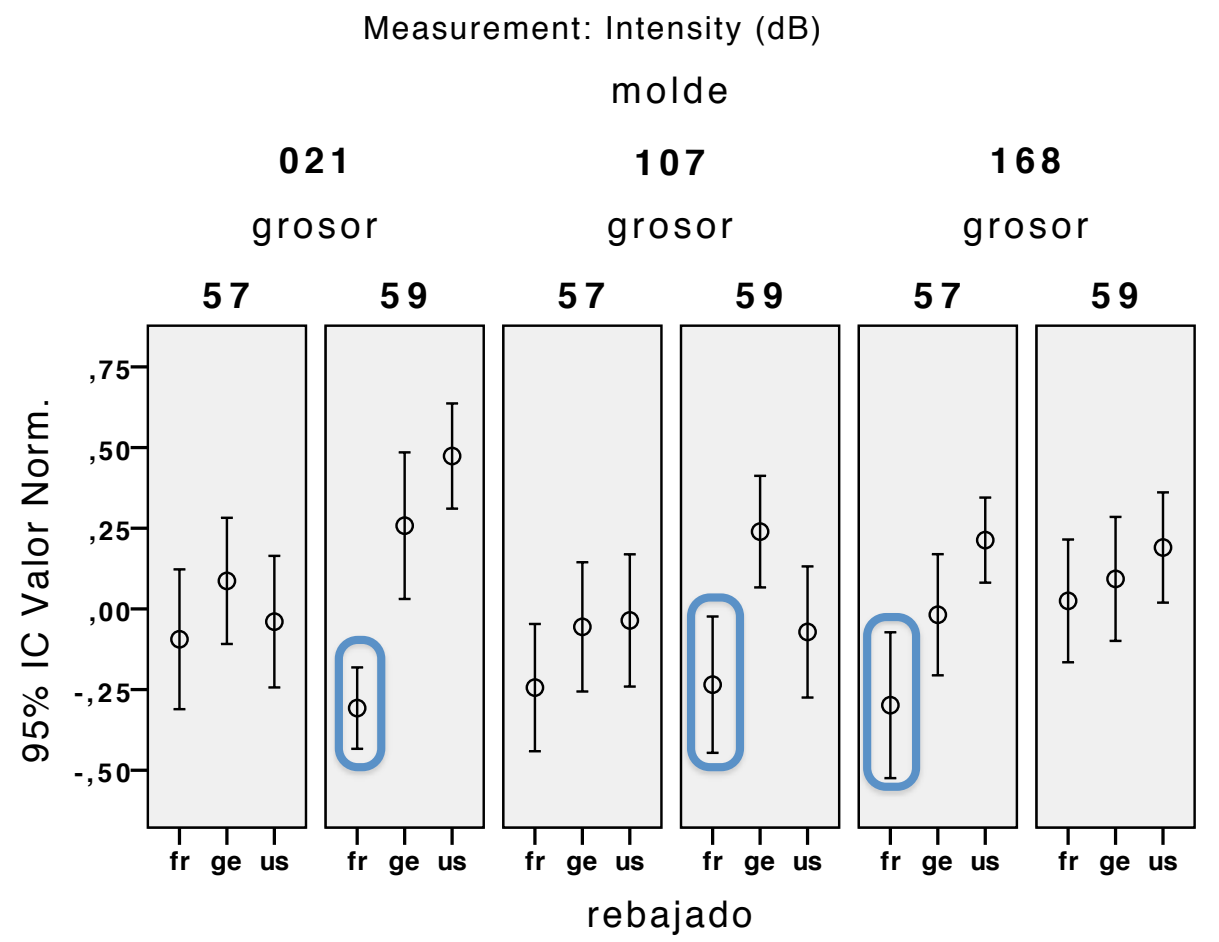

Figura 4.37. Medias con intervalo de confianza de los diferentes estilos de rebajado en función de los moldes y del grosor en el parámetro intensidad (en dB). Se marca con un círculo azul los resultados significativos.

La figura 4.38 muestra la representación de la intensidad global de las tres lengüetas, molde 107 y grosor $59 \mathrm{~mm}$ en el oboísta 9, con una clara diferencia entre la alemana que obtiene la mayor intensidad sonora mientras que la francesa obtiene la menor intensidad. Esta diferencia de energía también corresponde a cambios espectrales como puede observarse en los espectros de la misma figura (abajo).

En la figura 4.40 estas diferencias espectrales pueden verse más claramente: la lengüeta alemana obtiene más potencia, pero sobre todo tiene una presencia mucho más marcada en la parte central y aguda del espectro; mientras que la lengüeta francesa, en este ejemplo, obtiene menos energía en el agudo con una rápida pérdida de armónicos superiores. 

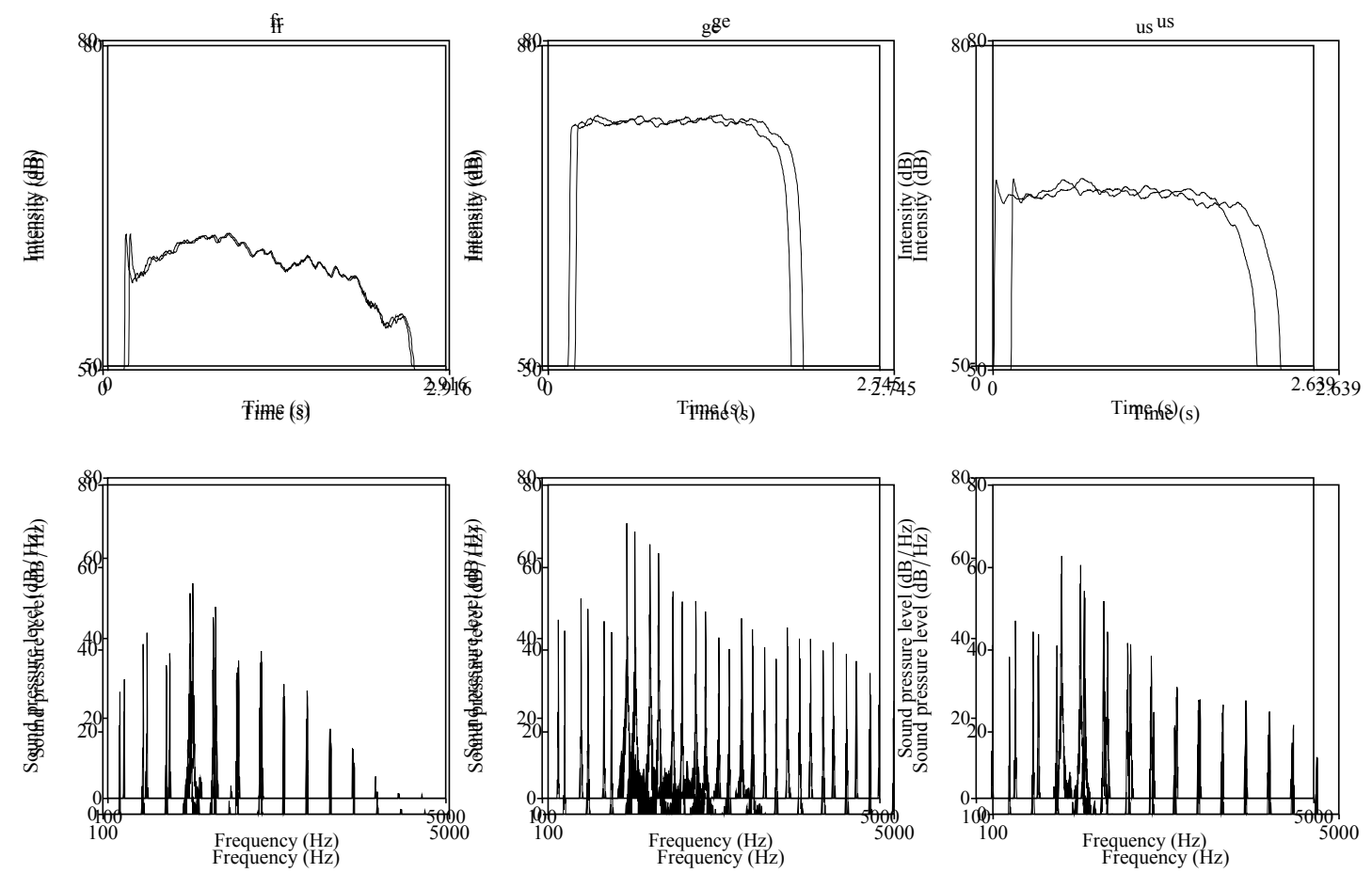

Figura 4.38. Evolución de la intensidad (en dB, arriba) y espectros (abajo) de las lengüetas francesa, alemana y americana para la nota $\mathrm{mi}_{4}$ (molde 107 , grosor 59 y oboísta 9 ).

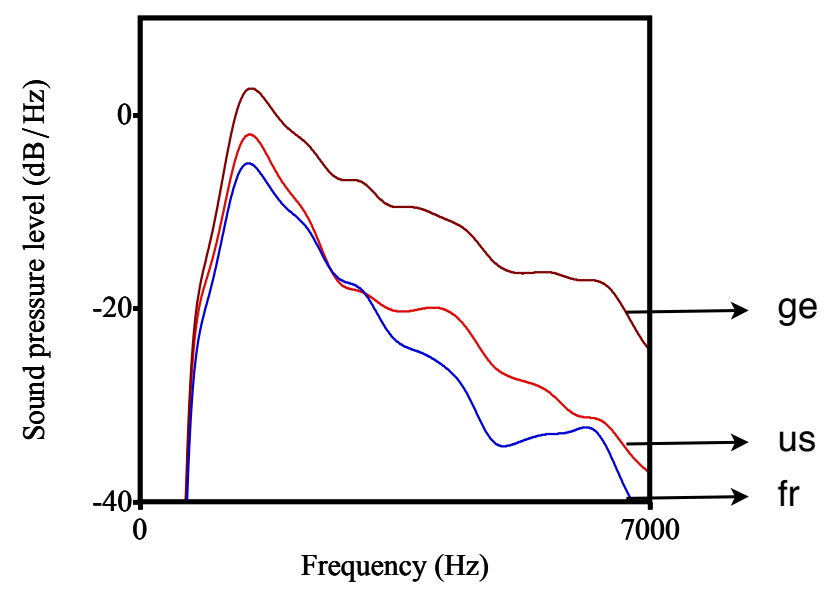

Figura 4.40. Superposición de los espectros alisados (alisado cepstral con ventana de 1000Hz) de las lengüetas francesa (azul), alemana (marrón) y americana (rojo) la nota mi4 (molde 107 grosor 59 y oboísta 9).

Si se analizan los resultados de la intensidad dependiendo de las dimensiones físicas de las lengüetas y no sólo del estilo de rebajado, se puede observar en la tabla 4.6b que los grosores individuales de la punta y la media del grosor de la punta son importantes, pero en menor medida que en las mediciones acústicas relativas a la frecuencia. En esta ocasión, la superficie de la pala sin rebajar, junto con la superficie rebajada de la parte de atrás y la longitud total de la pala, entre otros, son los parámetros más importantes. Es decir, la intensidad no se rige tanto por la superficie y grosor de la punta, sino más por el conjunto de medidas restantes: de la punta hacia el final del rebajado. El $\mathrm{R}^{2}$ corregido 
obtenido es bajo $\left(\mathrm{R}^{2}=, 109\right)$, comparable a la variabilidad explicada por el estilo de rebajado solo $\left(\eta^{2}=, 091 c f\right.$. tabla A.41).

\begin{tabular}{|c|c|c|c|c|c|c|c|c|c|}
\hline \multicolumn{10}{|c|}{ Resumen del modelo } \\
\hline \multirow[t]{2}{*}{ Modelo } & \multirow[t]{2}{*}{$\mathrm{R}$} & \multirow[t]{2}{*}{$\mathrm{R}^{2}$} & \multirow{2}{*}{\begin{tabular}{c|}
$\mathrm{R}^{2}$ \\
corregida
\end{tabular}} & \multirow{2}{*}{$\begin{array}{c}\text { Error típ. de la } \\
\text { estimación }\end{array}$} & \multicolumn{5}{|c|}{ Estadísticos de cambio } \\
\hline & & & & & $\begin{array}{c}\text { Cambio } \\
\text { en } \mathrm{R}^{2}\end{array}$ & $\begin{array}{c}\text { Cambio } \\
\text { en } F\end{array}$ & gl1 & $\mathrm{gl} 2$ & $\begin{array}{c}\text { Sig. Cambio } \\
\text { en } F\end{array}$ \\
\hline 14 & 0,337 & 0,113 & 0,109 & 0,94113087 & 0,005 & 9,637 & 1 & 1801 & 0,002 \\
\hline
\end{tabular}

\begin{tabular}{|c|c|c|c|c|c|c|}
\hline & & & Coeficiente & & & \\
\hline $\mathrm{Mo}$ & & $\begin{array}{l}\text { Coefici } \\
\text { estanda }\end{array}$ & $\begin{array}{l}\text { ites no } \\
\text { zados }\end{array}$ & $\begin{array}{c}\text { Coeficientes } \\
\text { estandarizados }\end{array}$ & $\mathrm{t}$ & Sig. \\
\hline & & $\mathrm{B}$ & Error típ. & Beta & & \\
\hline 14 & (Constante) & 7,436 & 3,496 & & 2,127 & 0,034 \\
\hline & dist8 libre & $-0,497$ & 0,141 & $-0,599$ & $-3,529$ & 0,000 \\
\hline & su27 sin raspar & 0,033 & 0,006 & 1,309 & 5,144 & 0,000 \\
\hline & rg19 cora punta & $-1,487$ & 0,247 & $-0,668$ & $-6,032$ & 0,000 \\
\hline & gr6 dcha & 0,088 & 0,014 & 0,216 & 6,114 & 0,000 \\
\hline & gr1 izda & $-0,160$ & 0,018 & $-0,322$ & $-8,882$ & 0,000 \\
\hline & $\operatorname{rd} 13 / 11$ & 0,759 & 0,076 & 0,890 & 9,968 & 0,000 \\
\hline & su25 cor punta & 0,268 & 0,041 & 1,263 & 6,562 & 0,000 \\
\hline & g16 medio punta & $-0,097$ & 0,031 & $-0,230$ & $-3,104$ & 0,002 \\
\hline
\end{tabular}

Tabla 4.6b. Resumen del modelo (arriba) y coeficientes de las variables predictoras de la regresión de la variable dependiente intensidad $(\mathrm{dB})$ con todas las medidas físicas de las lengüetas. Se muestran los que sí

tienen influencia sobre la variable dependiente ( $c f$. leyenda de las variables en la tabla 4.aa y 4.bb)

\subsubsection{Mediciones relativas a la variabilidad de la intensidad}

\subsection{Desviación estándar de la amplitud}

La desviación estándar de la amplitud calcula la desviación estándar de la parte visible de la señal. Un ANOVA de varios factores (tabla 4.7) muestra que todos los factores individuales son muy significativos $(p<, 001)$, siendo el oboísta $\left(\mathrm{F}=339,4, p<, 001, \eta^{2}=, 664\right)$ el que mayor variabilidad explica. Además, todos estos factores individuales provocan efectos cruzados de forma significativa ( $c f$. A.35 para más detalle).

En la figura 4.41 se observa que el estilo de rebajado francés tiene menos diferencia en la desviación estándar de la amplitud, lo que supone una mayor estabilidad de la intensidad. Como se puede apreciar en la figura 4.42, el efecto cruzado entre rebajado y oboísta es influyente y el rebajado francés suele provocar una menor diferencia de la desviación de la amplitud, pero para algunos oboístas el resultado es muy marcado (oboístas 8 y 9) y para otros no es significativo. 


\begin{tabular}{|l|r|r|r|r|r|r|}
\hline Origen & $\begin{array}{c}\text { Suma de cuadrados } \\
\text { tipo III }\end{array}$ & gl & $\begin{array}{c}\text { Media } \\
\text { cuadrática }\end{array}$ & F & Sig. & $\begin{array}{c}\text { Eta al cuadrado } \\
\text { parcial }\end{array}$ \\
\hline Modelo corregido & 1345,703 & 180 & 7,476 & 23,611 & 0,000 & 0,712 \\
\hline Intersección & 15,216 & 1 & 15,216 & 48,056 & 0,000 & 0,027 \\
\hline rebajado & 14,084 & 2 & 7,042 & 22,240 & 0,000 & 0,025 \\
\hline molde & 5,392 & 2 & 2,696 & 8,515 & 0,000 & 0,010 \\
\hline grosor & 4,104 & 1 & 4,104 & 12,961 & 0,000 & 0,007 \\
\hline oboista & 1074,856 & 10 & 107,486 & 339,461 & 0,000 & 0,664 \\
\hline rebajado * molde & 4,486 & 4 & 1,121 & 3,542 & 0,007 & 0,008 \\
\hline rebajado * grosor & 3,657 & 2 & 1,829 & 5,775 & 0,003 & 0,007 \\
\hline rebajado * oboista & 31,939 & 20 & 1,597 & 5,043 & 0,000 & 0,055 \\
\hline molde * grosor & 10,183 & 2 & 5,092 & 16,081 & 0,000 & 0,018 \\
\hline molde * oboista & 13,777 & 20 & 0,689 & 2,176 & 0,002 & 0,025 \\
\hline grosor * oboista & 13,025 & 10 & 1,302 & 4,114 & 0,000 & 0,023 \\
\hline
\end{tabular}

Tabla 4.7. Análisis de varianza factorial sobre la desviación estándar de la amplitud para los factores rebajado, molde, grosor y oboísta.

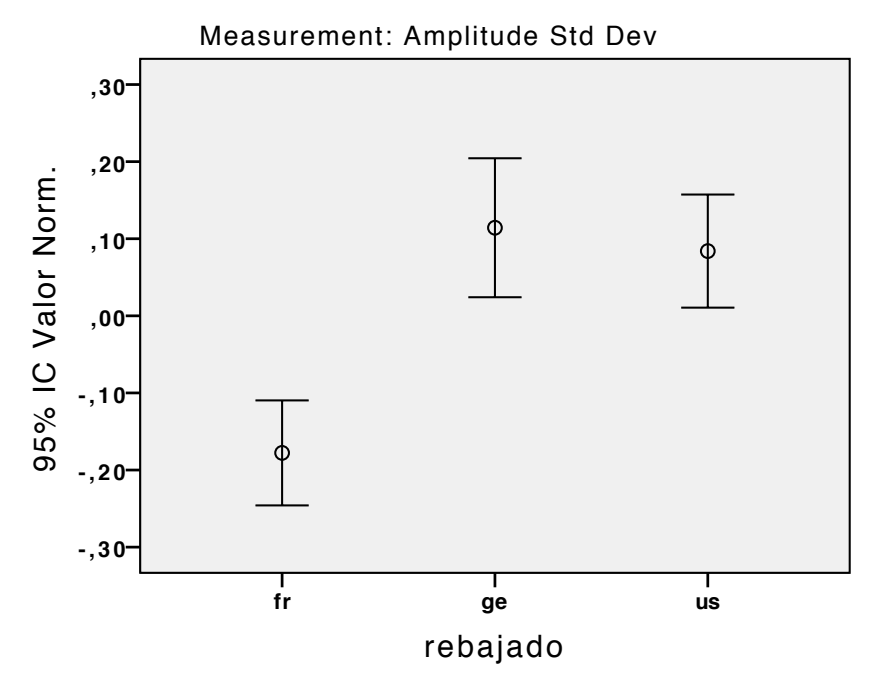

Figura 4.41. Medias con intervalo de confianza de los diferentes estilos de rebajado en el parámetro desviación estándar de la amplitud. 


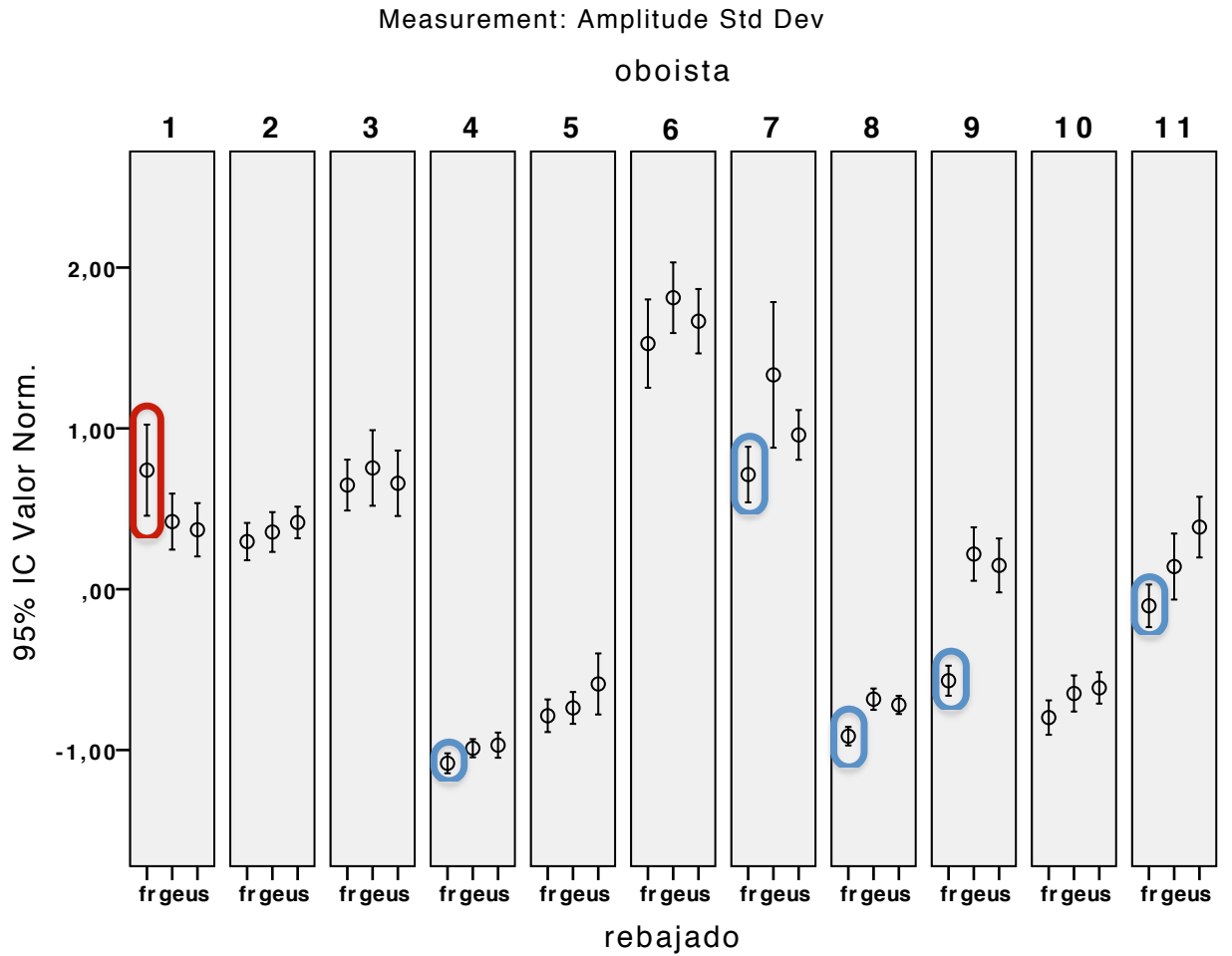

Figura 4.42. Medias con intervalo de confianza de los diferentes estilos de rebajado en función de los oboístas en el parámetro desviación estándar de la amplitud. Se marca con un círculo azul los resultados significativos y con un círculo rojo los resultados contrarios a la media.

$\mathrm{Al}$ analizar las lengüetas de todos los oboístas, se observa que la lengüeta con el molde 21 y grosor $59 \mathrm{~mm}$ en el oboísta 7 es la lengüeta donde más diferencias de desviación estándar de la amplitud existe entre rebajados en la nota do6 $\mathrm{y}$ do5 del ejercicio arpegio. Las figuras 4.43, 4.44 y 4.45 representan la nota do5 del ejercicio arpegio en las lengüetas con el molde 21 y grosor $59 \mathrm{~mm}$ del oboísta 7 . Se confirma visualmente (línea amarilla) las diferencias existentes en este ejemplo entre el rebajado francés (el que más desviaciones provoca; figura 4.43) el alemán (figura 4.44) y el americano (figura 4.45). 


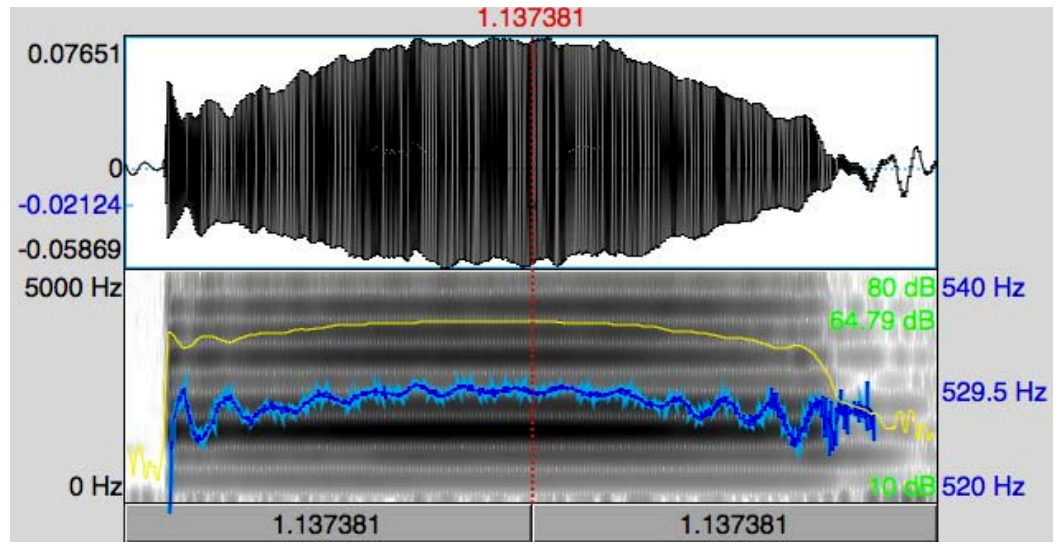

Figura 4.43. Representación en amplitud/tiempo y espectrograma de la lengüeta francesa, molde 21 y grosor 59/100 mm en el oboísta 7 en la nota dos del ejercicio arpegio. La línea azul: F0 (en Hz) y la línea amarilla: intensidad (en dB).

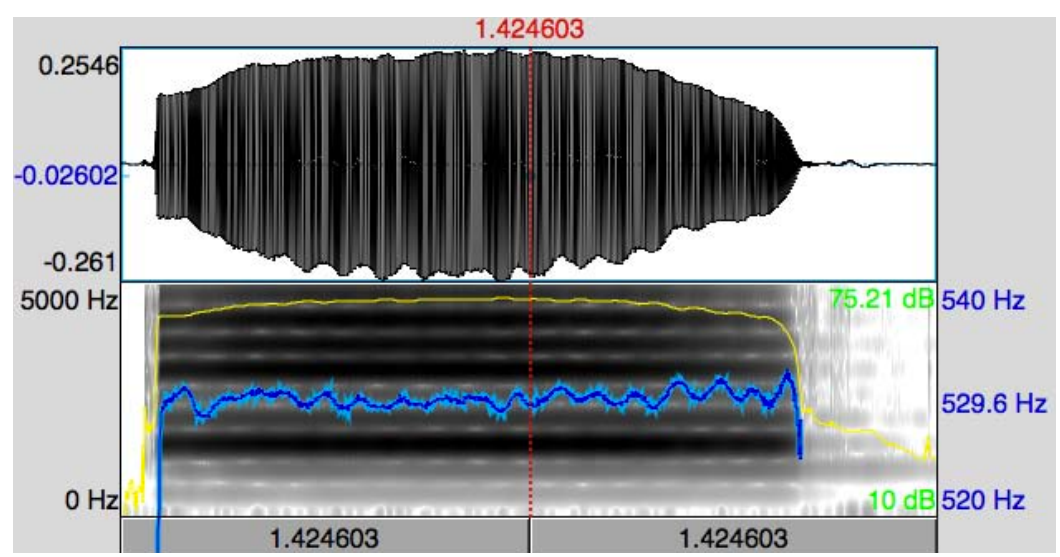

Figura 4.44. Representación en amplitud/tiempo y espectrograma de la lengüeta alemana, molde 21 y grosor $59 / 100 \mathrm{~mm}$ en el oboísta 7 en la nota do5 del ejercicio arpegio. La línea azul: F0 (en Hz) y la línea amarilla: intensidad (en dB).

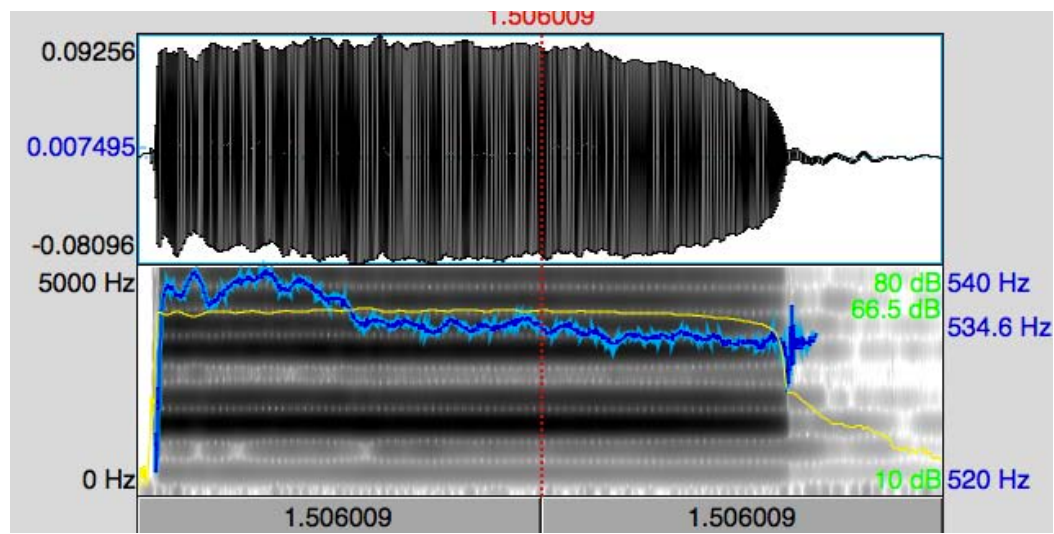

Figura 4.45. Representación en amplitud/tiempo y espectrograma de la lengüeta americana, molde 21 y grosor 59/100 mm en el oboísta 7 en la nota dos del ejercicio arpegio. La línea azul: F0 (en Hz) y la línea amarilla: intensidad (en dB). 
Si se analizan los resultados de la desviación estándar de la amplitud dependiendo de las dimensiones físicas de las lengüetas y no sólo del estilo de rebajado, se puede observar en la tabla 4.7b que los diferentes grosores (de la punta, de la pala, del corazón y de la parte de atrás del rebajado) junto con la superficie de la pala rebajada son los parámetros más importantes. El $\mathrm{R}^{2}$ corregido obtenido es bajo $\left(\mathrm{R}^{2}=, 093\right)$, comparable a la variabilidad explicada por el estilo de rebajado $\left(\eta^{2}=, 058 c f\right.$. tabla A.41).

\begin{tabular}{|c|c|c|c|c|c|c|c|c|c|}
\hline \multicolumn{10}{|c|}{ Resumen del modelo } \\
\hline \multirow[t]{2}{*}{ Modelo } & \multirow[t]{2}{*}{$\overline{\mathrm{R}}$} & \multirow[t]{2}{*}{$\mathrm{R}^{2}$} & \multirow{2}{*}{$\begin{array}{c}\mathrm{R}^{2} \\
\text { corregida }\end{array}$} & \multirow{2}{*}{$\begin{array}{l}\text { Error típ. de la } \\
\text { estimación }\end{array}$} & \multicolumn{5}{|c|}{ Estadísticos de cambio } \\
\hline & & & & & $\begin{array}{l}\text { Cambio } \\
\text { en } \mathrm{R}^{2}\end{array}$ & $\begin{array}{c}\text { Cambio } \\
\text { en } F\end{array}$ & gl1 & $\mathrm{gl} 2$ & $\begin{array}{l}\text { Sig. Cambio } \\
\text { en F }\end{array}$ \\
\hline 7 & 0,311 & 0,097 & 0,093 & 0,94964643 & 0,003 & 6,476 & 1 & 1802 & 0,011 \\
\hline
\end{tabular}

\begin{tabular}{|c|c|c|c|c|c|c|}
\hline & & & Coeficientes & & & \\
\hline & & $\begin{array}{l}\text { Coefici } \\
\text { estanda }\end{array}$ & $\begin{array}{l}\text { ites no } \\
\text { zados }\end{array}$ & $\begin{array}{l}\text { Coeficientes } \\
\text { estandarizados }\end{array}$ & $\mathrm{t}$ & Sig. \\
\hline & & $\mathrm{B}$ & Error típ. & Beta & & \\
\hline 7 & (Constante) & $-1,811$ & 0,817 & & $-2,216$ & 0,027 \\
\hline & dg17 asim punta & 0,091 & 0,030 & 0,107 & 3,081 & 0,002 \\
\hline & $\operatorname{rd} 13 / 11$ & 0,176 & 0,036 & 0,207 & 4,936 & 0,000 \\
\hline & gr1 izda & $-0,121$ & 0,021 & $-0,243$ & $-5,861$ & 0,000 \\
\hline & gr6 dcha & 0,045 & 0,017 & 0,111 & 2,609 & 0,009 \\
\hline & su24 libre & 0,009 & 0,004 & 0,075 & 2,414 & 0,016 \\
\hline & grosor & 0,237 & 0,070 & 0,119 & 3,400 & 0,001 \\
\hline & dg20 atras cora & $-0,030$ & 0,012 & $-0,107$ & $-2,545$ & 0,011 \\
\hline
\end{tabular}

Tabla 4.7b. Resumen del modelo (arriba) y coeficientes de las variables predictoras de la regresión de la variable dependiente desviación estándar de la amplitud con todas las medidas físicas de las lengüetas. Se muestran los que sí tienen influencia sobre la variable dependiente ( $c f$. leyenda de las variables en la tabla 4.aa y 4.bb)

\subsubsection{Mediciones relativas a la facilidad de vibración}

\subsubsection{1. $N^{o}$ voiced frames}

El parámetro number voiced frames mide el número de elementos que existen en una frecuencia definida, es decir, la cantidad de ciclos con una altura definida. Hay que tener en cuenta que los oboístas no contaban con un metrónomo para verificar la velocidad de la pulsación en la interpretación de los ejercicios, por lo que en esta medición existen longitudes en los ejercicios muy dispares, no siendo un problema de la lengüeta, sino de la realización del ejercicio. 
Un ANOVA de varios factores (tabla 4.8) muestra que el oboísta $(\mathrm{F}=32,14, p<, 001$, $\left.\eta^{2}=, 158\right)$, el rebajado $\left(\mathrm{F}=10,13, p<, 001, \eta^{2}=, 012\right)$ y el grosor $\left(\mathrm{F}=8,33, p=, 004, \eta^{2}=, 005\right)$ son los factores individuales que tienen una influencia significativa, siendo el oboísta el factor más influyente. Además, existe un efecto cruzado del rebajado*el oboísta $(\mathrm{F}=6,33$, $\left.p=, 001, \eta^{2}=, 069\right)$. Es relevante indicar que el molde no tiene la menor influencia ( $c f$. A.36 para más detalle).

\begin{tabular}{|l|r|r|r|r|r|r|}
\hline Origen & $\begin{array}{c}\text { Suma de } \\
\text { cuadrados tipo III }\end{array}$ & gl & $\begin{array}{c}\text { Media } \\
\text { cuadrática }\end{array}$ & F & Sig. & $\begin{array}{c}\text { Eta al cuadrado } \\
\text { parcial }\end{array}$ \\
\hline Modelo corregido & 610,328 & 180 & 3,391 & 4,555 & 0,000 & 0,323 \\
\hline Intersección & 0,891 & 1 & 0,891 & 1,197 & 0,274 & 0,001 \\
\hline rebajado & 15,090 & 2 & 7,545 & 10,135 & 0,000 & 0,012 \\
\hline molde & 1,700 & 2 & 0,850 & 1,142 & 0,319 & 0,001 \\
\hline grosor & 6,206 & 1 & 6,206 & 8,337 & 0,004 & 0,005 \\
\hline oboista & 239,265 & 10 & 23,927 & 32,141 & 0,000 & 0,158 \\
\hline rebajado * molde & 0,734 & 4 & 0,184 & 0,247 & 0,912 & 0,001 \\
\hline rebajado * grosor & 1,510 & 2 & 0,755 & 1,014 & 0,363 & 0,001 \\
\hline rebajado * oboista & 94,244 & 20 & 4,712 & 6,330 & 0,000 & 0,069 \\
\hline molde * grosor & 9,195 & 2 & 4,597 & 6,176 & 0,002 & 0,007 \\
\hline molde * oboista & 27,998 & 20 & 1,400 & 1,880 & 0,010 & 0,021 \\
\hline grosor * oboista & 13,494 & 10 & 1,349 & 1,813 & 0,054 & 0,010 \\
\hline
\end{tabular}

Tabla 4.8. Análisis de varianza factorial del $N^{o}$ Voiced Frames para los factores rebajado, molde, grosor y oboísta.

La figura 4.46 muestra que las lengüetas con el estilo de rebajado francés tienen una mayor facilidad para la vibración que el resto de rebajados.

En la figura 4.47 se puede apreciar la relación entre los rebajados y los oboístas, pero tal y como se ha explicado anteriormente, los ejercicios no se han realizado con un metrónomo, por lo que para cada oboísta existe un rebajado más fácil con el que interpretar que otro, dependiendo de la duración de la nota y no pudiendo verificarse si la duración de la nota es a consecuencia del rebajado de la lengüeta o de la interpretación de cada oboísta. 


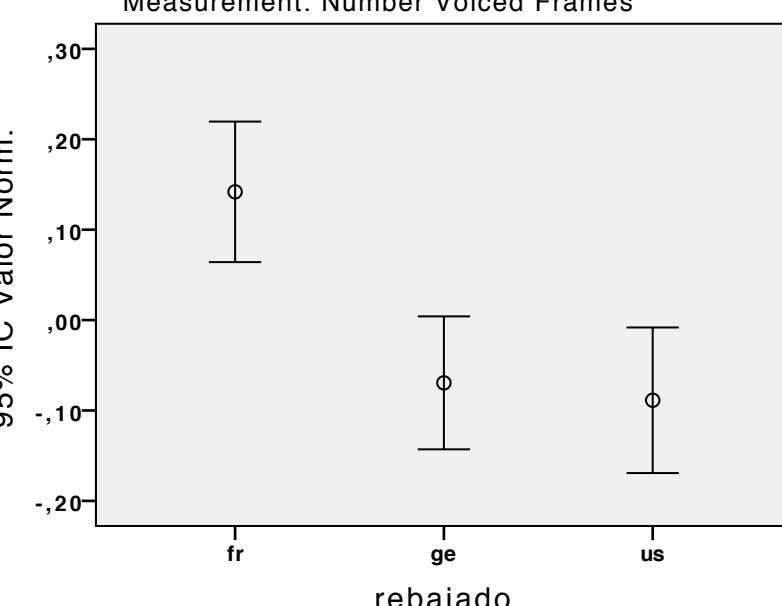

Figura 4.46. Medias con intervalo de confianza de los diferentes estilos de rebajado en el parámetro number voiced frames.

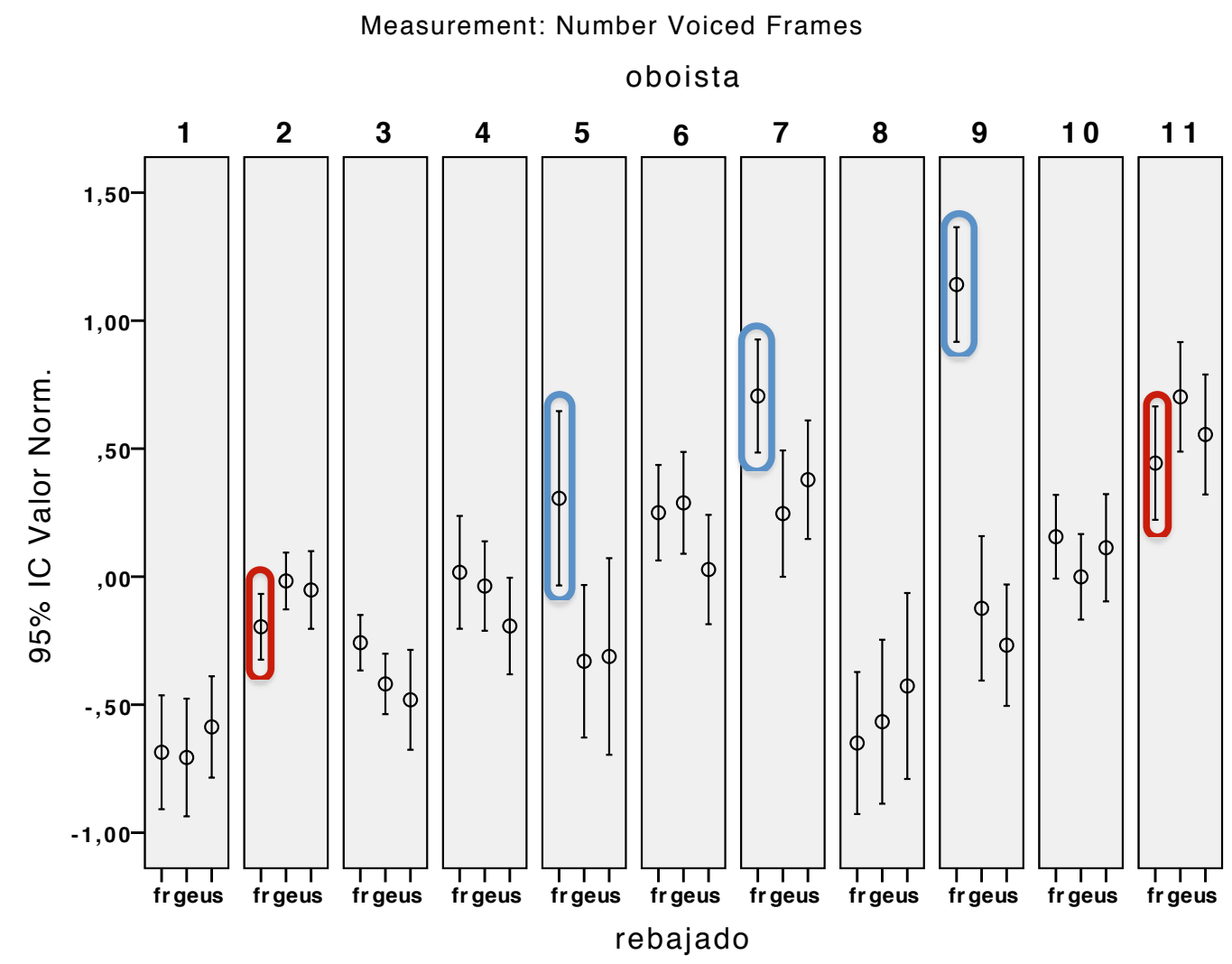

Figura 4.47. Medias con intervalo de confianza de los diferentes estilos de rebajado en función del oboísta en el parámetro number voiced frames. Se marca con un círculo azul los resultados significativos y con un círculo rojo los resultados contrarios a la media.

\subsubsection{Mediciones relativas a la armonicidad}

\subsection{Armonicidad media}

La armonicidad mide la energía que tiene el componente armónico formado por la fundamental y los múltiplos de la fundamental (los armónicos) respecto a la energía que 
corresponde al resto del espectro (ruido o componente inarmónico). En este caso se hace el ratio energía armónica/energía inarmónica (SNR o signal-to-noise ratio).

Un ANOVA de varios factores (tabla 4.9) muestra que el oboísta $(\mathrm{F}=75,12, p<, 001$, $\left.\eta^{2}=, 304\right)$, el rebajado $\left(\mathrm{F}=9,05, p<, 001, \eta^{2}=, 010\right)$ y el molde $\left(\mathrm{F}=5,1, p=, 006, \eta^{2}=, 006\right)$ son los factores individuales que tienen una influencia significativa, siendo el oboísta el factor más influyente. Además, existe un efecto cruzado del rebajado*el oboísta $(\mathrm{F}=2,58, p<, 001$, $\left.\eta^{2}=, 029\right)$. Es relevante indicar que el grosor no tiene la menor influencia ( $c f$. A.37 para más detalle).

\begin{tabular}{|l|r|r|r|r|r|r|}
\hline Origen & \multicolumn{1}{|c|}{$\begin{array}{c}\text { Suma de } \\
\text { cuadrados tipo III }\end{array}$} & gl & $\begin{array}{c}\text { Media } \\
\text { cuadrática }\end{array}$ & F & Sig. & $\begin{array}{c}\text { Eta al cuadrado } \\
\text { parcial }\end{array}$ \\
\hline Modelo corregido & 737,328 & 180 & 4,096 & 6,109 & 0,000 & 0,390 \\
\hline Intersección & 2,107 & 1 & 2,107 & 3,142 & 0,076 & 0,002 \\
\hline rebajado & 12,139 & 2 & 6,070 & 9,052 & 0,000 & 0,010 \\
\hline molde & 6,850 & 2 & 3,425 & 5,108 & 0,006 & 0,006 \\
\hline grosor & 0,193 & 1 & 0,193 & 0,288 & 0,592 & 0,000 \\
\hline oboista & 503,746 & 10 & 50,375 & 75,125 & 0,000 & 0,304 \\
\hline rebajado * molde & 3,125 & 4 & 0,781 & 1,165 & 0,324 & 0,003 \\
\hline rebajado * grosor & 3,977 & 2 & 1,988 & 2,965 & 0,052 & 0,003 \\
\hline rebajado * oboista & 34,700 & 20 & 1,735 & 2,587 & 0,000 & 0,029 \\
\hline molde * grosor & 1,727 & 2 & 0,864 & 1,288 & 0,276 & 0,001 \\
\hline molde * oboista & 12,604 & 20 & 0,630 & 0,940 & 0,535 & 0,011 \\
\hline grosor * oboista & 4,577 & 10 & 0,458 & 0,683 & 0,742 & 0,004 \\
\hline
\end{tabular}

Tabla 4.9. Análisis de varianza factorial de la armonicidad media para los factores rebajado, molde, grosor y oboísta.

En la figura 4.48 se observa que las lengüetas con el estilo de rebajado alemán, son las que tienen una mayor armonicidad respecto a las americanas y a las francesas. Las lengüetas francesas son las menos armónicas frente a los otros dos estilos de rebajado, de forma significativa. 


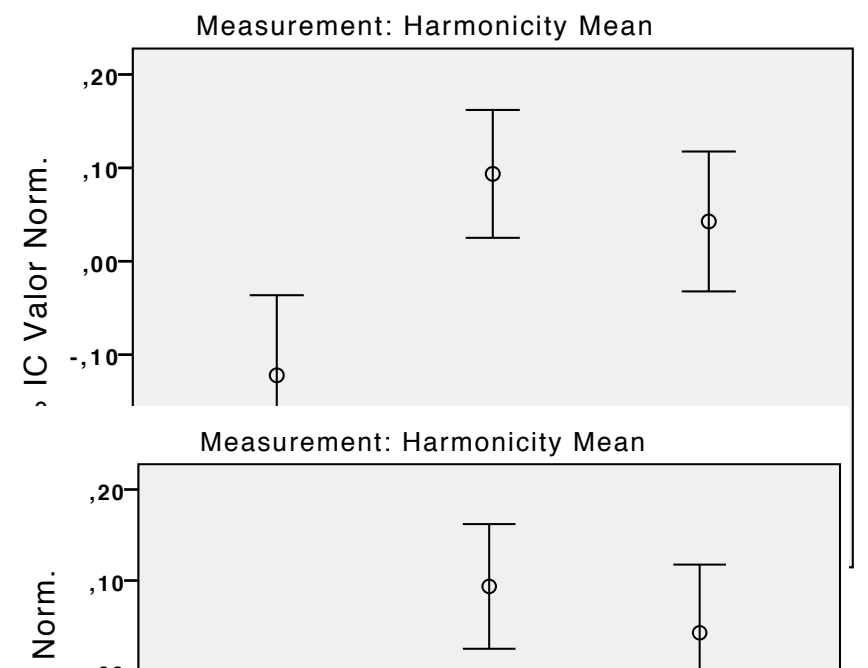

Figura 4.48. Medias con intervalo de confianza de los diferentes estilos de rebajado en el parámetro armonicidad media.

Como se aprecia en la figura 4.49, el rebajado francés es el menos armónico para todos los oboístas (excepto en los oboístas 1, 3, 6 y 7) siendo muy significativo en los oboístas 5 y 8, ambos de la escuela francesa. Para el resto de oboístas, los rebajados no son significativos en la armonicidad obtenida, siendo sólo el rebajado americano superior al resto en el oboísta 11, aunque no pertenece a la escuela americana.

Measurement: Harmonicity Mean

oboista

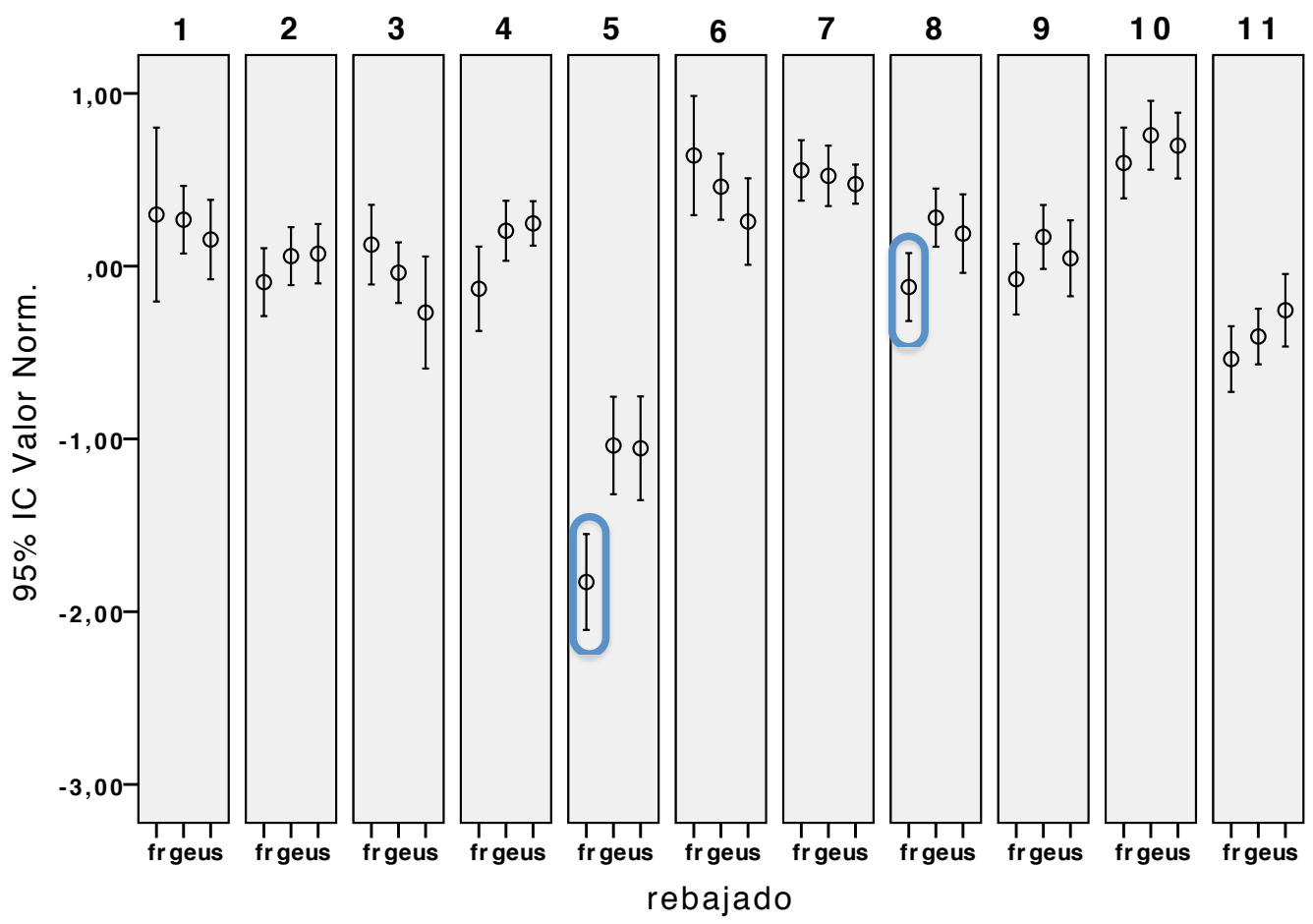

Figura 4.49. Medias con intervalo de confianza de los diferentes estilos de rebajado en función de los oboístas en el parámetro armonicidad media. Se marca con un círculo azul los resultados significativos. 
Se pueden distinguir dos tipos principales de inarmonicidad en los ejercicios que se han grabado: en la figura 4.50 se observa la existencia de un "soplo" además de la señal armónica. En general en la interpretación del oboe se busca un sonido limpio, sin soplo, ya que éste suele ser considerado más bien como un defecto o un mal funcionamiento de la lengüeta. La figura 4.50 muestra claramente que la lengüeta francesa tiene un componente inarmónico en el centro del espectro que es menor en las otras lengüetas.

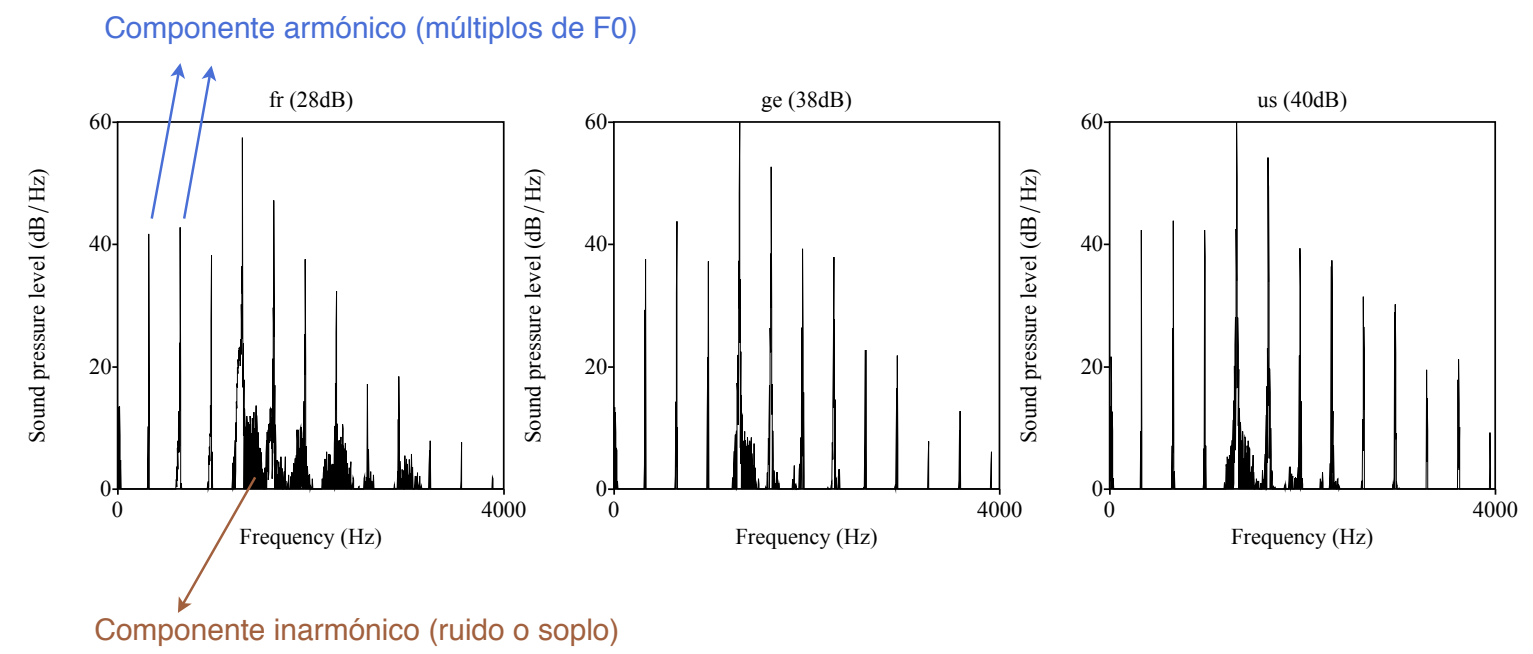

Figura 4.50. Espectro para las lengüetas francesa, alemana y americana con el molde 168 y grosor 57/100 mm (oboísta 5). Se destaca el componente armónico e inarmónico del espectro.

Una segunda fuente de inarmonicidad viene dada cuando aparecen varias frecuencias en competición (figura 4.51), generalmente el componente subarmónico, que son frecuencias que están por debajo de la frecuencia fundamental en un ratio de $1 / x$. La aparición de subarmónicos se debe a una inestabilidad de la lengüeta, producida habitualmente por un tipo de rebajado demasiado flexible que no resiste a la presión necesaria para conseguir la nota. La presencia de dos frecuencias en competición reduce automáticamente la medición de armonicidad. 


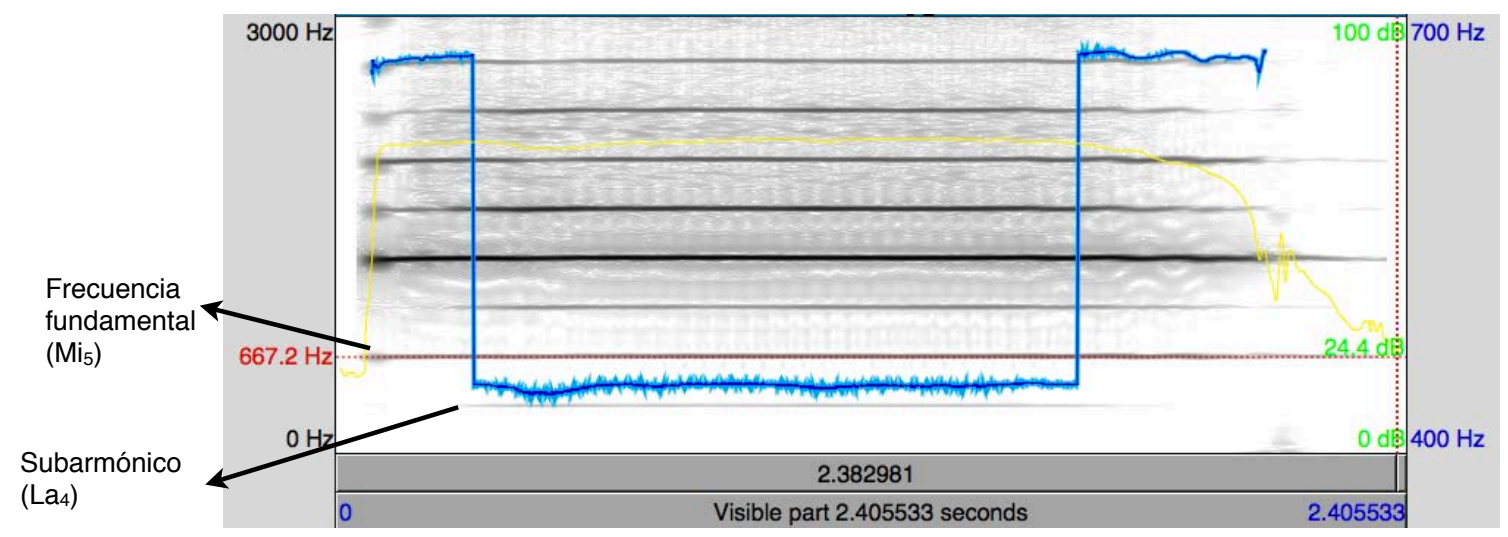

Figura 4.51. Representación en amplitud/tiempo y espectrograma de la lengüeta americana, molde 21 y grosor 59/100 mm en el oboísta 8 en la nota mis del ejercicio arpegio. La línea azul: F0 (en Hz) y la línea amarilla: intensidad (en dB).

Si se analizan los resultados de la armonicidad media dependiendo de las dimensiones físicas de las lengüetas y no sólo del estilo de rebajado, se puede observar en la tabla $4.9 \mathrm{~b}$ que sólo el grosor del lado derecho de la punta de una de las palas junto con el ancho de la pala influyen en la armonicidad media. El $\mathrm{R}^{2}$ corregido obtenido es muy bajo $\left(\mathrm{R}^{2}=, 014\right)$, comparable a la variabilidad explicada por el estilo de rebajado $\left(\eta^{2}=, 021\right.$ cf. tabla A.41).

\begin{tabular}{|c|c|c|c|c|c|c|c|c|c|}
\hline \multicolumn{10}{|c|}{ Resumen del modelo } \\
\hline \multirow[t]{2}{*}{ Modelo } & \multirow[t]{2}{*}{$\mathrm{R}$} & \multirow[t]{2}{*}{$\mathrm{R}^{2}$} & \multirow{2}{*}{$\begin{array}{c}\mathrm{R}^{2} \\
\text { corregida }\end{array}$} & \multirow{2}{*}{$\begin{array}{c}\text { Error típ. de la } \\
\text { estimación }\end{array}$} & \multicolumn{5}{|c|}{ Estadísticos de cambio } \\
\hline & & & & & $\begin{array}{c}\text { Cambio } \\
\text { en } \mathrm{R}^{2}\end{array}$ & $\begin{array}{c}\text { Cambio } \\
\text { en F }\end{array}$ & gl1 & $\mathrm{gl2}$ & $\begin{array}{l}\text { Sig. Cambio } \\
\text { en F }\end{array}$ \\
\hline 2 & 0,122 & 0,015 & 0,014 & 0,99028001 & 0,002 & 4,156 & 1 & 1807 & 0,042 \\
\hline
\end{tabular}

\begin{tabular}{|c|c|c|c|c|c|c|}
\hline \multicolumn{7}{|c|}{ Coeficientes $^{\mathbf{a}, \mathbf{b}}$} \\
\hline \multirow{2}{*}{\multicolumn{2}{|c|}{ Modelo }} & \multicolumn{2}{|c|}{$\begin{array}{l}\text { Coeficientes no } \\
\text { estandarizados }\end{array}$} & \multirow{2}{*}{$\begin{array}{c}\begin{array}{c}\text { Coeficientes } \\
\text { estandarizados }\end{array} \\
\text { Beta }\end{array}$} & \multirow[t]{2}{*}{$\mathrm{t}$} & \multirow[t]{2}{*}{ Sig. } \\
\hline & & $\mathrm{B}$ & Error típ. & & & \\
\hline \multirow[t]{3}{*}{2} & (Constante) & 1,371 & 1,126 & & 1,217 & 0,224 \\
\hline & gr3 dcha & 0,072 & 0,015 & 0,115 & 4,913 & 0,000 \\
\hline & dist7 ancho & $-0,314$ & 0,154 & $-0,048$ & $-2,039$ & 0,042 \\
\hline
\end{tabular}

Tabla 4.9b. Resumen del modelo (arriba) y coeficientes de las variables predictoras de la regresión de la variable dependiente armonicidad media con todas las medidas físicas de las lengüetas. Se muestran los que sí tienen influencia sobre la variable dependiente ( $c f$. leyenda de las variables en la tabla 4.aa y 4.bb) 
4.6.4.6.2.Desviación estándar de la armonicidad

Un ANOVA de varios factores (tabla 4.10) muestra que todos los factores individuales son significativos, siendo el oboísta $\left(\mathrm{F}=18,34, p<, 001, \eta^{2}=, 096\right)$ el que mayor variabilidad explica. Además, existe un efecto cruzado del rebajado*el molde $(\mathrm{F}=9,47, p<$, $001, \eta^{2}=, 022, c f$. A.38 para más detalle).

La figura 4.52 presenta a las lengüetas francesas como las que más desviaciones armónicas producen, es decir, son las más inestables respecto a la armonicidad. Esta desviación es muy significativa respecto a las alemanas y las americanas. Por el contrario, las lengüetas americanas, son las más estables en la armonicidad.

La figura 4.53 confirma que esta inestabilidad en la armonicidad del rebajado francés no se debe a las particularidades de las lengüetas, sino a los diferentes rebajados en su conjunto, si bien, cabe destacar que la lengüeta francesa, molde 21 y grosor $59 \mathrm{~mm}$ destaca particularmente sobre las demás lengüetas francesas, siendo esta lengüeta más estable que el resto de lengüetas francesas.

\begin{tabular}{|l|r|r|r|r|r|r|}
\hline Origen & $\begin{array}{c}\text { Suma de cuadrados } \\
\text { tipo III }\end{array}$ & gl & $\begin{array}{c}\text { Media } \\
\text { cuadrática }\end{array}$ & F & Sig. & $\begin{array}{c}\text { Eta al cuadrado } \\
\text { parcial }\end{array}$ \\
\hline Modelo corregido & 497,963 & 180 & 2,766 & 3,416 & 0,000 & 0,263 \\
\hline Intersección & 0,579 & 1 & 0,579 & 0,715 & 0,398 & 0,000 \\
\hline rebajado & 139,128 & 2 & 69,564 & 85,904 & 0,000 & 0,091 \\
\hline molde & 18,381 & 2 & 9,191 & 11,349 & 0,000 & 0,013 \\
\hline grosor & 6,135 & 1 & 6,135 & 7,576 & 0,006 & 0,004 \\
\hline oboista & 148,542 & 10 & 14,854 & 18,343 & 0,000 & 0,096 \\
\hline rebajado * molde & 30,687 & 4 & 7,672 & 9,474 & 0,000 & 0,022 \\
\hline rebajado * grosor & 5,708 & 2 & 2,854 & 3,525 & 0,030 & 0,004 \\
\hline rebajado * oboista & 20,850 & 20 & 1,042 & 1,287 & 0,176 & 0,015 \\
\hline molde * grosor & 3,369 & 2 & 1,684 & 2,080 & 0,125 & 0,002 \\
\hline molde * oboista & 13,246 & 20 & 0,662 & 0,818 & 0,694 & 0,009 \\
\hline grosor * oboista & 4,131 & 10 & 0,413 & 0,510 & 0,884 & 0,003 \\
\hline
\end{tabular}

Tabla 4.10. Análisis de varianza factorial de la desviación estándar de la armonicidad para los factores rebajado, molde, grosor y oboísta.

Al observar la figura 4.54, se aprecia cómo el rebajado francés es el que mayor desviación armónica provoca, siendo el resultado muy marcado para algunos oboístas, aunque no para otros (oboístas 6, 9, y 10). 


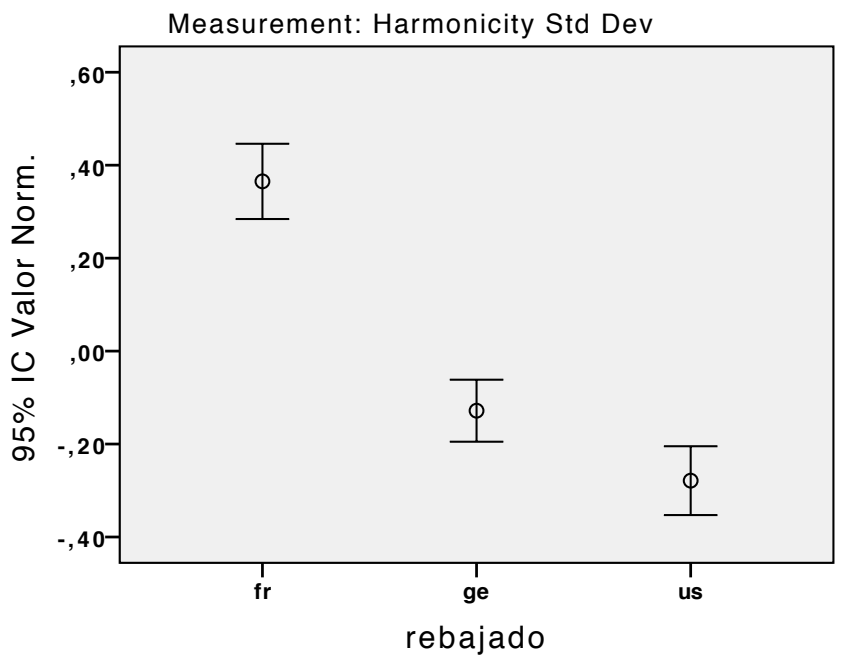

Figura 4.52. Medias con intervalo de confianza de los diferentes estilos de rebajado en el parámetro desviación estándar de la armonicidad.

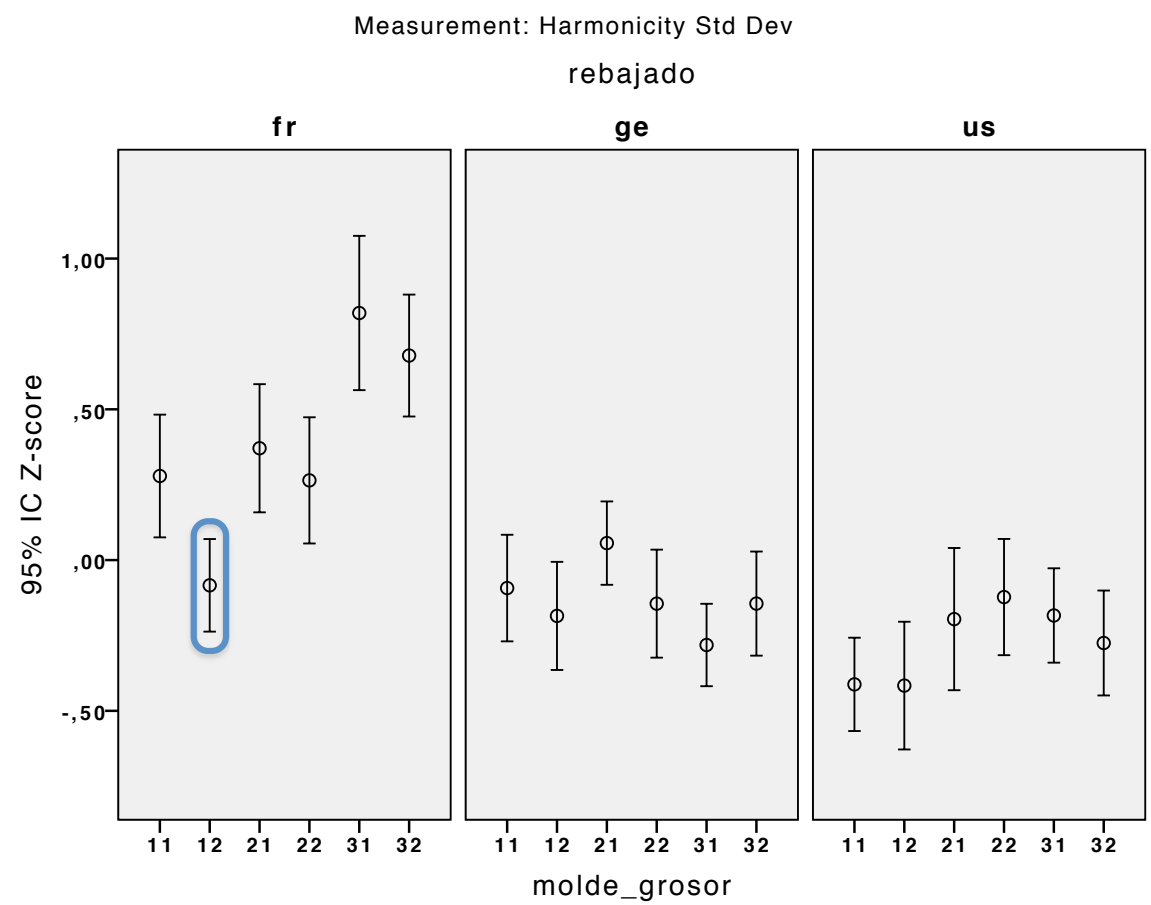

Figura 4.53. Medias con intervalo de confianza comparando todas las lengüetas según el molde, grosor y estilos de rebajado en el parámetro desviación estándar de la armonicidad. El primer número hace referencia al molde $(1=21 ; 2=107 ; 3=168)$ y el segundo número al grosor $(1=57 \mathrm{~mm} ; 2=59 \mathrm{~mm})$. Se marca con un círculo azul los resultados de que son significativos. 


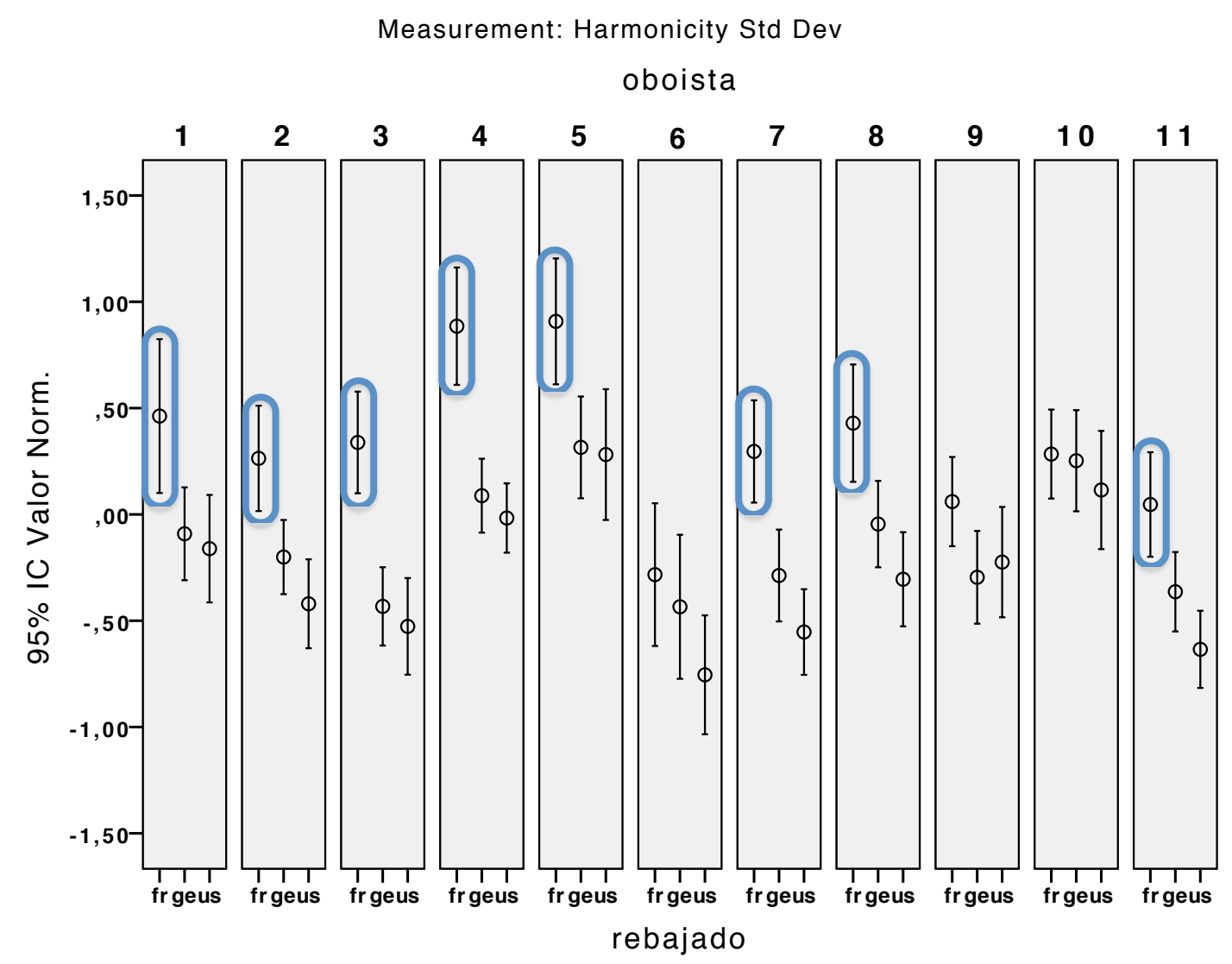

Figura 4.54. Medias con intervalo de confianza de los diferentes estilos de rebajado en función de los oboístas en el parámetro desviación estándar de la armonicidad. Se marca con un círculo azul los resultados significativos.

Si además se analiza el efecto cruzado del rebajado junto al molde, se obtiene un resultado también significativo (tabla 4.10). Al analizar la figura 4.55, se vuelve a ver que el rebajado francés es el más inestable, seguido del alemán y del americano en todos los moldes. Sin embargo, estas diferencias se acentúan en los dos moldes más extremos: el molde 168 es el que más diferencias provoca seguido del molde 107. 


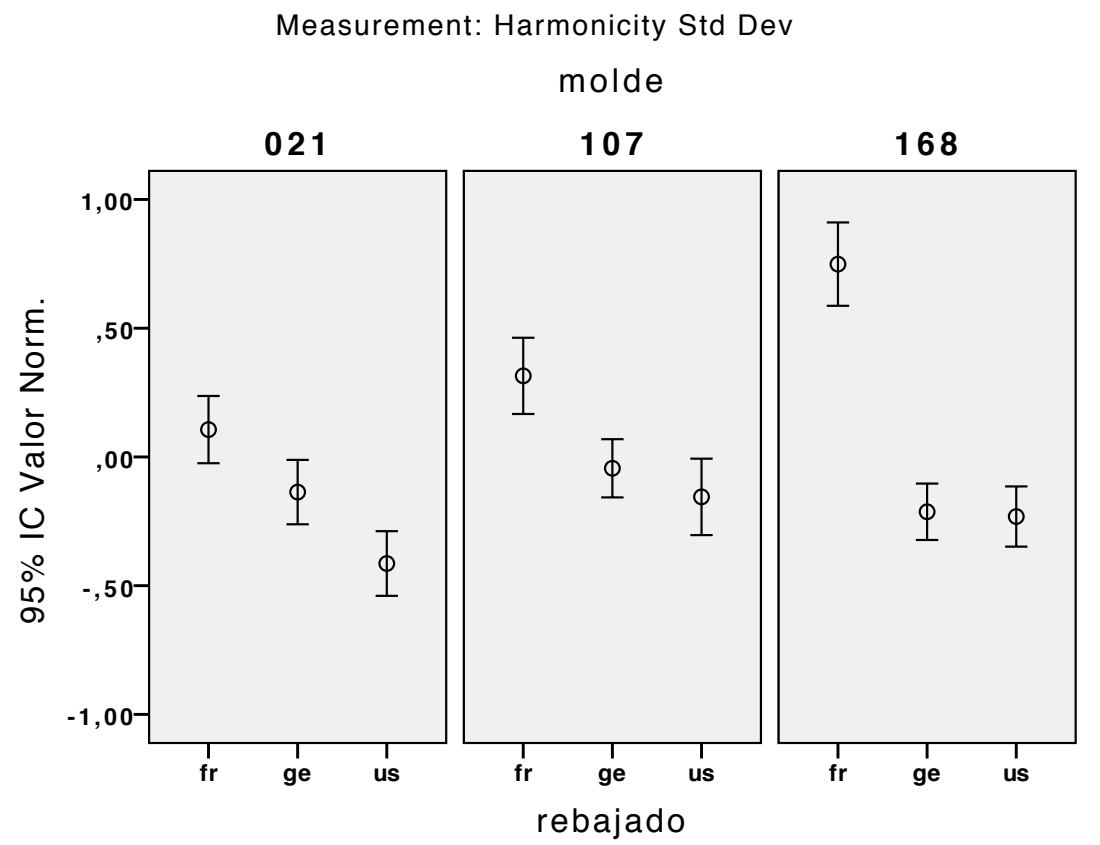

Figura 4.55. Medias con intervalo de confianza de los diferentes estilos de rebajado en función de los moldes en el parámetro desviación estándar de la armonicidad.

\subsubsection{Parámetros relativos al timbre}

4.6.4.7.1.Diferencia de energía de bandas entre las frecuencias por debajo de una $3^{\text {a }}$ mayor.

Un ANOVA de varios factores (tabla 4.11) muestra que el oboísta $(\mathrm{F}=18,87, p<$, $\left.001, \eta^{2}=, 099\right)$ y el rebajado $\left(\mathrm{F}=27,78, p<, 001, \eta^{2}=, 031\right)$ son los factores individuales que tienen una influencia significativa, siendo el oboísta el factor más influyente. Además, existe un efecto cruzado del rebajado*el oboísta $\left(\mathrm{F}=2,63, p<, 001, \eta^{2}=, 030\right)$. Es relevante indicar que ni el grosor ni el molde tienen la menor influencia ( $c f$. A.39 para más detalle).

La medición de diferencias de energía por bandas del espectro puede resumirse en la medición de la energía de la fundamental (F0) respecto a la energía en el resto del espectro. Efectivamente, se han utilizado diferentes bandas espectrales partiendo de la fundamental: un semitono (banda de frecuencia de la fundamental a frecuencia más un semitono), dos semitonos (segunda mayor), 4 semitonos (tercera mayor) y 7 semitonos (quinta justa). Como la energía fuera de los armónicos es prácticamente nula para los sonidos de oboe grabados, la energía se concentra en la fundamental y sus armónicos, con lo que estas mediciones que solo engloban la fundamental dan el mismo resultado. Para tener resultados diferentes, se deberían englobar los sucesivos armónicos, utilizando una 
banda espectral que abarque la fundamental y más de una octava por encima de la fundamental (lo que contendría el primer armónico).

\begin{tabular}{|l|r|r|r|r|r|r|}
\hline Origen & $\begin{array}{c}\text { Suma de } \\
\text { cuadrados tipo III }\end{array}$ & gl & $\begin{array}{c}\text { Media } \\
\text { cuadrática }\end{array}$ & F & Sig. & $\begin{array}{c}\text { Eta al cuadrado } \\
\text { parcial }\end{array}$ \\
\hline Modelo corregido & 450,085 & 180 & 2,500 & 2,985 & 0,000 & 0,238 \\
\hline Intersección & 0,142 & 1 & 0,142 & 0,170 & 0,680 & 0,000 \\
\hline rebajado & 46,551 & 2 & 23,275 & 27,787 & 0,000 & 0,031 \\
\hline molde & 4,796 & 2 & 2,398 & 2,863 & 0,057 & 0,003 \\
\hline grosor & 0,636 & 1 & 0,636 & 0,759 & 0,384 & 0,000 \\
\hline oboista & 158,101 & 10 & 15,810 & 18,874 & 0,000 & 0,099 \\
\hline rebajado * molde & 4,291 & 4 & 1,073 & 1,281 & 0,275 & 0,003 \\
\hline rebajado * grosor & 6,694 & 2 & 3,347 & 3,996 & 0,019 & 0,005 \\
\hline rebajado * oboista & 44,122 & 20 & 2,206 & 2,634 & 0,000 & 0,030 \\
\hline molde * grosor & 11,549 & 2 & 5,774 & 6,894 & 0,001 & 0,008 \\
\hline molde * oboista & 13,927 & 20 & 0,696 & 0,831 & 0,677 & 0,010 \\
\hline grosor * oboista & 8,794 & 10 & 0,879 & 1,050 & 0,399 & 0,006 \\
\hline
\end{tabular}

Tabla 4.11. Análisis de varianza factorial de la diferencia de energía de bandas entre las frecuencias por debajo de una $3^{\text {a }}$ mayor para los factores rebajado, molde, grosor y oboísta.

Se observa en la figura 4.56, que las lengüetas americanas son las que mayor banda de energía obtienen, de forma muy significativa respecto a las alemanas y a las francesas.

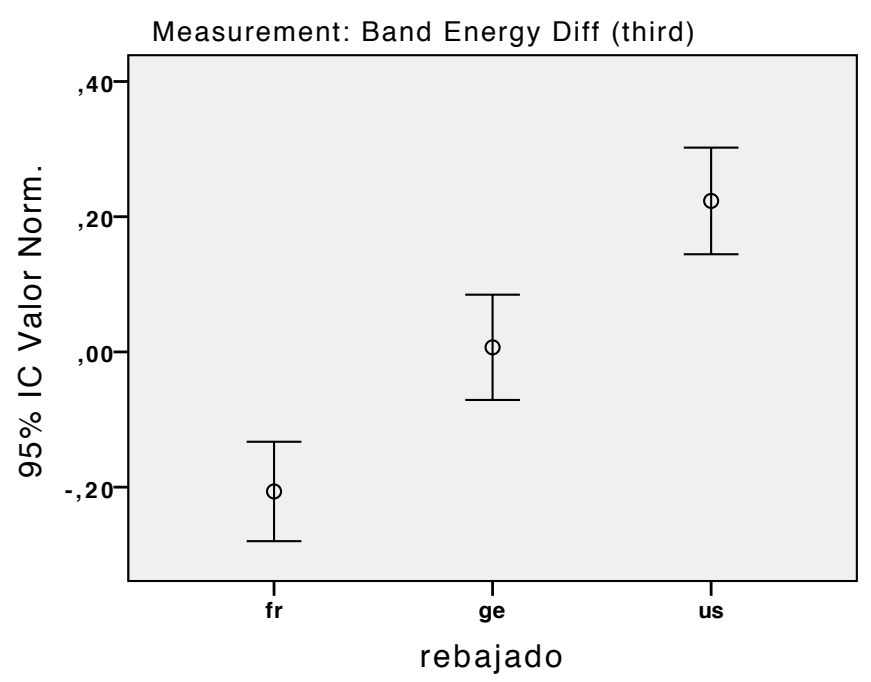

Figura 4.56. Medias con intervalo de confianza de los diferentes estilos de rebajado en el parámetro diferencia de energía de bandas entre las frecuencias por debajo de una $3^{\mathrm{a}}$ mayor.

La figura 4.57 muestra que, excepto para el oboísta 1, para todos los demás oboístas las lengüetas americanas obtienen una mayor riqueza de armónicos en la banda de energía entre la fundamental y su tercera mayor. Esta diferenciación es significativa en algunos oboístas, pero no en todos ellos. 


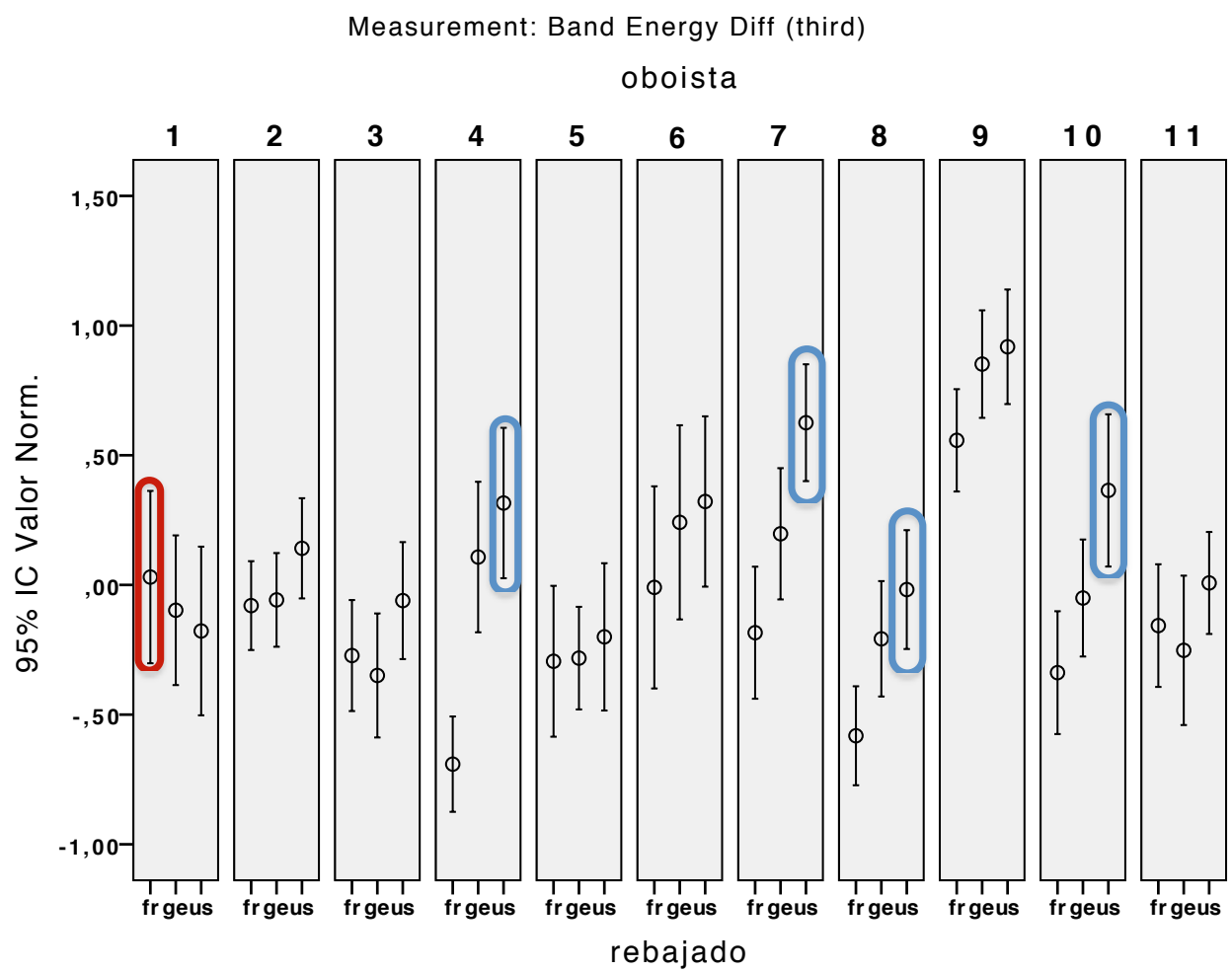

Figura 4.57. Medias con intervalo de confianza de los moldes utilizados en función de los oboístas en el parámetro diferencia de energía de bandas entre las frecuencias por debajo de una $3^{\mathrm{a}}$ mayor. Se marca con un círculo azul los resultados significativos y con un círculo rojo los resultados contrarios a la media.

En la figura 4.58 puede observarse que la diferencia de energía entre la fundamental y el resto del espectro se debe ante todo a la energía presente en la fundamental: la lengüeta francesa tiene muy poca energía, creando un sonido con menos cuerpo que la alemana que presenta mucha energía en la fundamental.
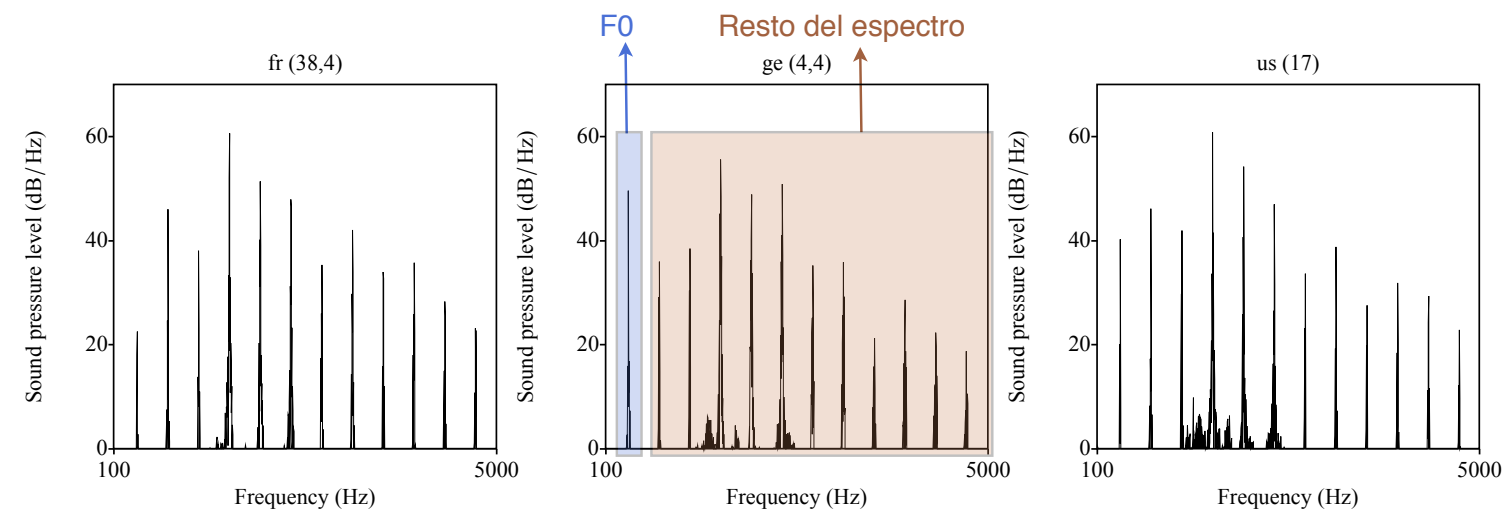

Figura 4.58. Espectro de las lengüetas francesa, alemana y americana para el molde 21, grosor 57 y oboísta 3 , en la nota $\mathrm{Sol}_{4}$ del ejercicio arpegio.

Si se analizan los resultados de la diferencia de energía de bandas ( $3^{\mathrm{a}}$ mayor) dependiendo de las dimensiones físicas de las lengüetas y no sólo del estilo de rebajado, se puede observar en la tabla $4.11 \mathrm{~b}$ que tanto el grosor de la punta como la superficie de rebajado tienen una influencia en esta medición acústica, aunque el $\mathrm{R}^{2}$ corregido obtenido 
es muy bajo $\left(\mathrm{R}^{2}=, 042\right)$, comparable a la variabilidad explicada por el estilo de rebajado $\left(\eta^{2}=, 072 c f\right.$. tabla A.41).

\begin{tabular}{|l|c|c|r|r|r|r|r|r|r|}
\hline \multicolumn{10}{|c|}{ Resumen del modelo } \\
\hline Modelo & $\mathrm{R}$ & $\mathrm{R}^{2}$ & $\mathrm{R}^{2}$ & Error típ. de la & \multicolumn{4}{|c|}{ Estadísticos de cambio } \\
\cline { 6 - 10 } & & & corregida & estimación & $\begin{array}{c}\text { Cambio } \\
\text { en } \mathrm{R}^{2}\end{array}$ & $\begin{array}{c}\text { Cambio } \\
\text { en } \mathrm{F}\end{array}$ & gl1 & $\mathrm{g} 12$ & $\begin{array}{c}\text { Sig. Cambio } \\
\text { en } \mathrm{F}\end{array}$ \\
\hline 2 & 0,207 & 0,043 & 0,042 & 0,97618659 & 0,017 & 31,587 & 1 & 1807 & 0,000 \\
\hline
\end{tabular}

\begin{tabular}{|c|c|c|c|c|c|c|}
\hline \multicolumn{7}{|c|}{ Coeficientes $^{\mathbf{a}, \mathbf{b}}$} \\
\hline \multirow{2}{*}{\multicolumn{2}{|c|}{ Modelo }} & \multicolumn{2}{|c|}{$\begin{array}{l}\text { Coeficientes no } \\
\text { estandarizados }\end{array}$} & \multirow{2}{*}{$\begin{array}{c}\text { Coeficientes } \\
\text { estandarizados }\end{array}$} & \multirow[t]{2}{*}{$\mathrm{t}$} & \multirow[t]{2}{*}{ Sig. } \\
\hline & & $\mathrm{B}$ & Error típ. & & & \\
\hline \multirow[t]{3}{*}{2} & (Constante) & 2,587 & 0,496 & & 5,212 & 0,000 \\
\hline & dg17 asim punta & 0,113 & 0,020 & 0,133 & 5,643 & 0,000 \\
\hline & su24 libre & $-0,015$ & 0,003 & $-0,132$ & $-5,620$ & 0,000 \\
\hline
\end{tabular}

Tabla 4.11b. Resumen del modelo (arriba) y coeficientes de las variables predictoras de la regresión de la variable dependiente diferencia de energía de bandas ( $3^{a}$ mayor) con todas las medidas físicas de las lengüetas. Se muestran los que sí tienen influencia sobre la variable dependiente ( $c f$. leyenda de las variables en la tabla 4.aa y 4.bb).

\subsection{Centro de gravedad del espectro}

Un ANOVA de varios factores (tabla 4.12) muestra que todos los factores individuales son muy significativos $(p<, 001)$, siendo el oboísta $\left(\mathrm{F}=25,66, p<, 001, \eta^{2}=, 130\right)$ el que mayor variabilidad explica. Los efectos cruzados son todos significativos, a excepción del grosor *el oboísta ( $c f$. A.40 para más detalle).

El centro de gravedad espectral mide la distribución de la energía en la parte aguda de las frecuencias del espectro. Un centro de gravedad espectral muy agudo respecto a la fundamental suele indicar un espectro más rico en frecuencias agudas (un sonido más brillante). Al contrario, un centro de gravedad cercano a la fundamental indica la existencia de poca energía en la parte aguda del espectro y, por tanto, que el sonido es más apagado. El caso extremo se encuentra para una señal sinusoidal (una frecuencia pura) donde el centro espectral y la fundamental son el mismo valor. 


\begin{tabular}{|l|r|r|r|r|r|r|}
\hline Origen & $\begin{array}{c}\text { Suma de } \\
\text { cuadrados tipo III }\end{array}$ & gl & $\begin{array}{c}\text { Media } \\
\text { cuadrática }\end{array}$ & F & Sig. & $\begin{array}{c}\text { Eta al cuadrado } \\
\text { parcial }\end{array}$ \\
\hline Modelo corregido & 767,977 & 180 & 4,267 & 6,537 & 0,000 & 0,406 \\
\hline Intersección & 0,087 & 1 & 0,087 & 0,134 & 0,715 & 0,000 \\
\hline rebajado & 127,927 & 2 & 63,964 & 97,996 & 0,000 & 0,102 \\
\hline molde & 108,835 & 2 & 54,417 & 83,370 & 0,000 & 0,088 \\
\hline grosor & 32,741 & 1 & 32,741 & 50,161 & 0,000 & 0,028 \\
\hline oboista & 167,522 & 10 & 16,752 & 25,665 & 0,000 & 0,130 \\
\hline rebajado * molde & 10,766 & 4 & 2,691 & 4,123 & 0,002 & 0,010 \\
\hline rebajado * grosor & 7,939 & 2 & 3,970 & 6,082 & 0,002 & 0,007 \\
\hline rebajado * oboista & 27,998 & 20 & 1,400 & 2,145 & 0,002 & 0,024 \\
\hline molde * grosor & 10,561 & 2 & 5,281 & 8,090 & 0,000 & 0,009 \\
\hline molde * oboista & 23,651 & 20 & 1,183 & 1,812 & 0,015 & 0,021 \\
\hline grosor * oboista & 9,950 & 10 & 0,995 & 1,524 & 0,125 & 0,009 \\
\hline
\end{tabular}

Tabla 4.12. Análisis de varianza factorial del centro de gravedad espectral para los factores rebajado, molde, grosor y oboísta.

En la medición correspondiente al centro de gravedad del espectro, se puede observar en la figura 4.59, que el rebajado francés obtiene un centro espectral más grave que el alemán y el americano. Aunque la figura 4.60 muestra que esta diferencias vienen provocadas más por las particularidades de cada lengüetas que por los estilos de rebajado.

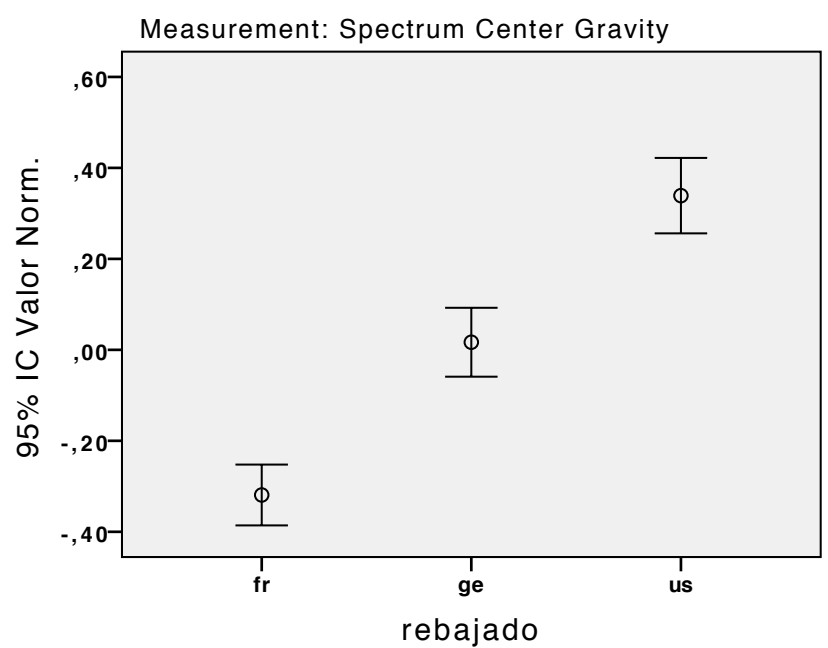

Figura 4.59. Medias con intervalo de confianza de los diferentes estilos de rebajado en el parámetro centro de gravedad del espectro.

La figura 4.61 muestra que el rebajado americano obtiene un centro espectral más agudo, siendo significativo en todos los moldes y todos los grosores respecto al rebajado francés. Respecto al rebajado alemán, es significativo en el molde 107 con todos los grosores, pero sólo con el grosor 59 mm en los moldes 21 y 168, no aportando el grosor 57 $\mathrm{mm}$ diferencias significativas entre ellos. 


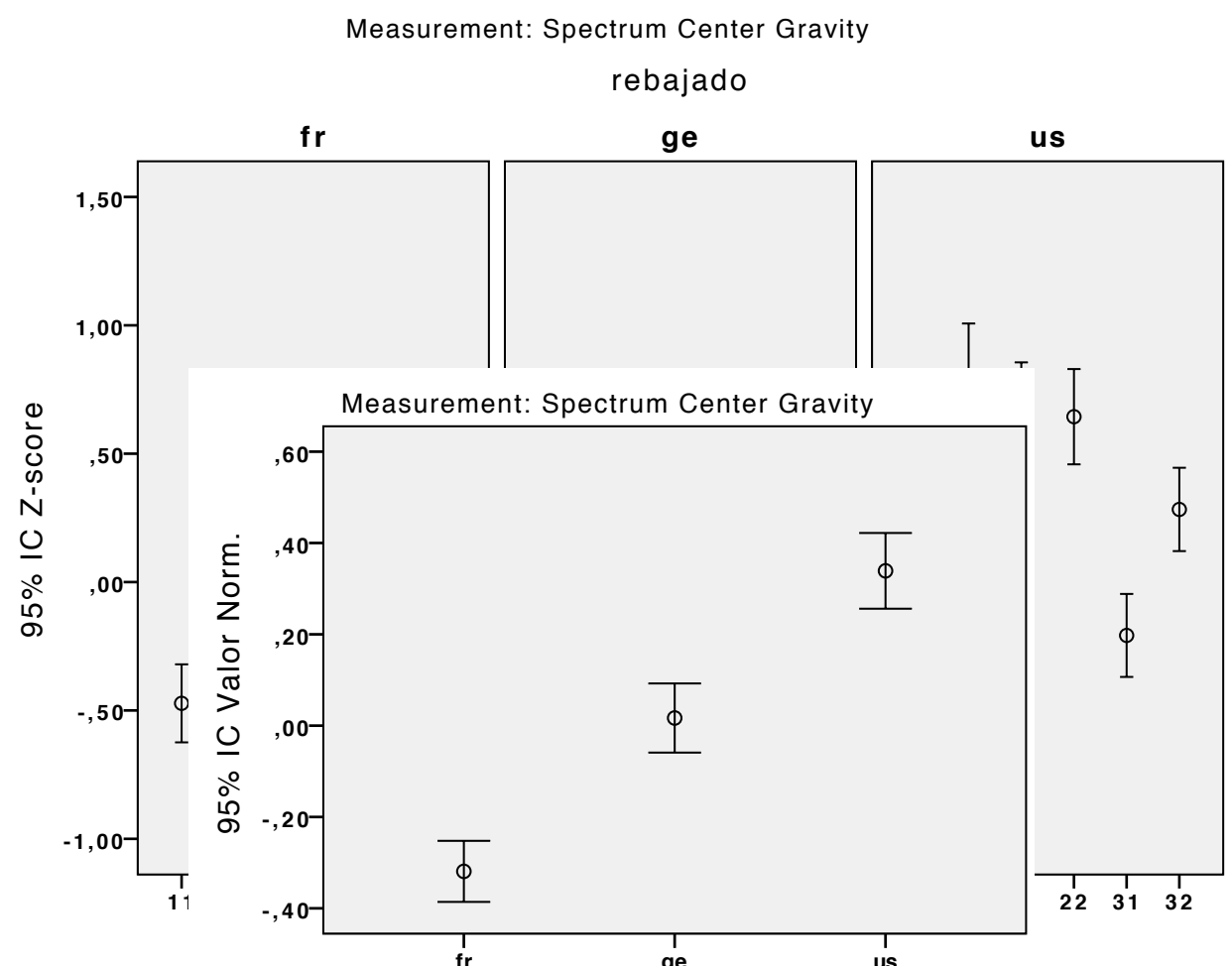

Figura 4.60. Medias con intervalo de confianza comparando todas las lengüetas según el molde, grosor y estilos de rebajado en el parámetro centro de gravedad del espectro. El primer número hace referencia al molde $(1=21 ; 2=107 ; 3=168)$ y el segundo número al grosor $(1=57 \mathrm{~mm} ; 2=59 \mathrm{~mm})$.

Measurement: Spectrum Center Gravity

molde

021

grosor

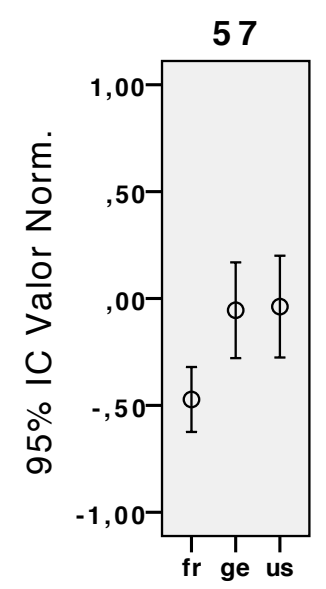

107

grosor

57
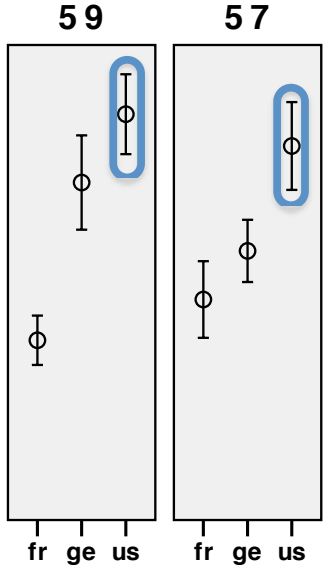

59

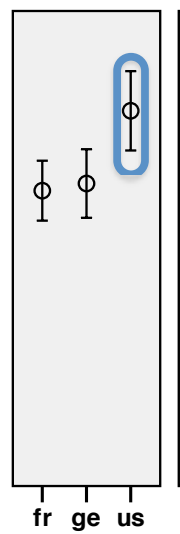

57

59

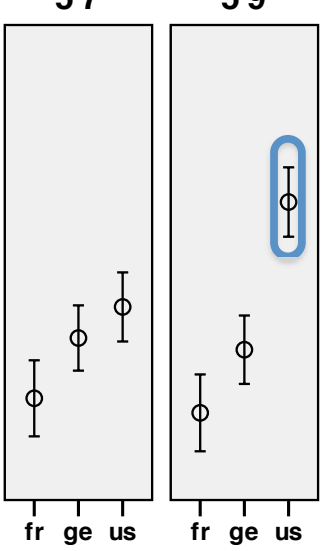

rebajado

Figura 4.61. Medias con intervalo de confianza de los diferentes estilos de rebajado en función de los moldes y del grosor en el parámetro centro de gravedad del espectro. Se marca con un círculo azul los resultados significativos.

La figura 4.62 muestra los espectros para uno de los ejercicios fortissimo y la figura 4.63 para un ejercicio pianissimo: en ambos casos el centro espectral es más grave para la 
lengüeta francesa que pierde armónicos en la parte aguda, y más agudo para la lengüeta americana que tiene mucha más energía en los armónicos por encima de $1600 \mathrm{~Hz}$.

Se observa, igualmente, que en los sonidos fortissimo el centro espectral es más agudo que en los pianissimo, indicando que al tocar más fuerte no solamente se consigue más intensidad, sino que sobre todo se adquieren más armónicos agudos con mayor potencia (cambio tímbrico). Estos cambios también se pueden ver en el apartado dedicado al ejercicio fortissimo ( $c f$. punto 4.6.7).
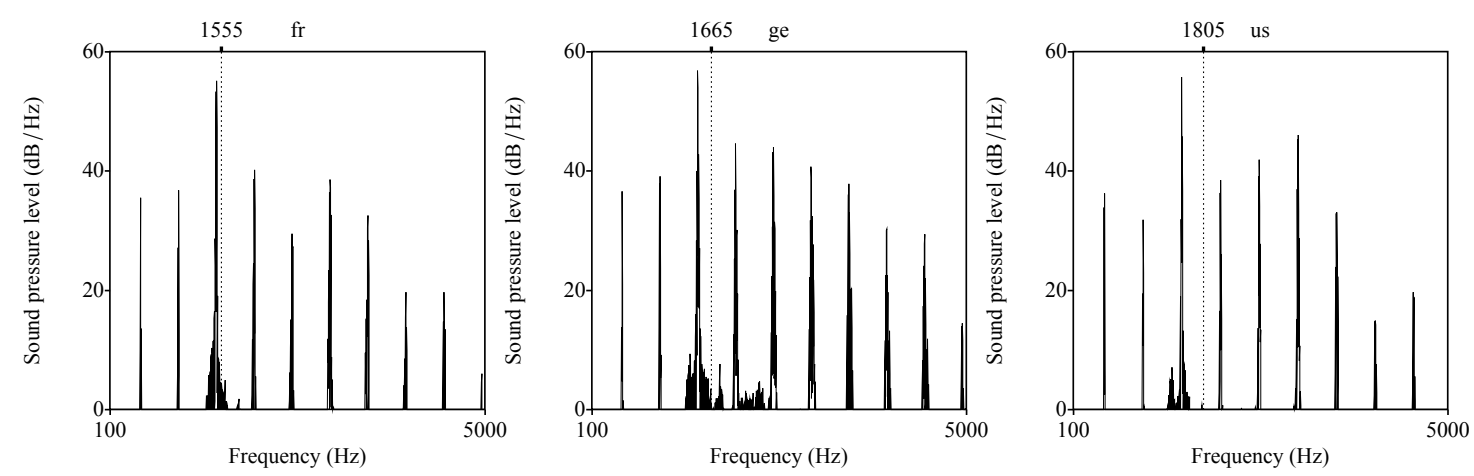

Figura 4.62. Espectro de las lengüetas francesa, alemana y americana para la nota $\mathrm{sol}_{4}$ del ejercicio fortissimo (molde 2,07 grosor $59 \mathrm{~mm}$ y oboísta 8). La línea de puntos indica el centro de gravedad espectral con el valor de la frecuencia correspondiente $(\mathrm{Hz})$.
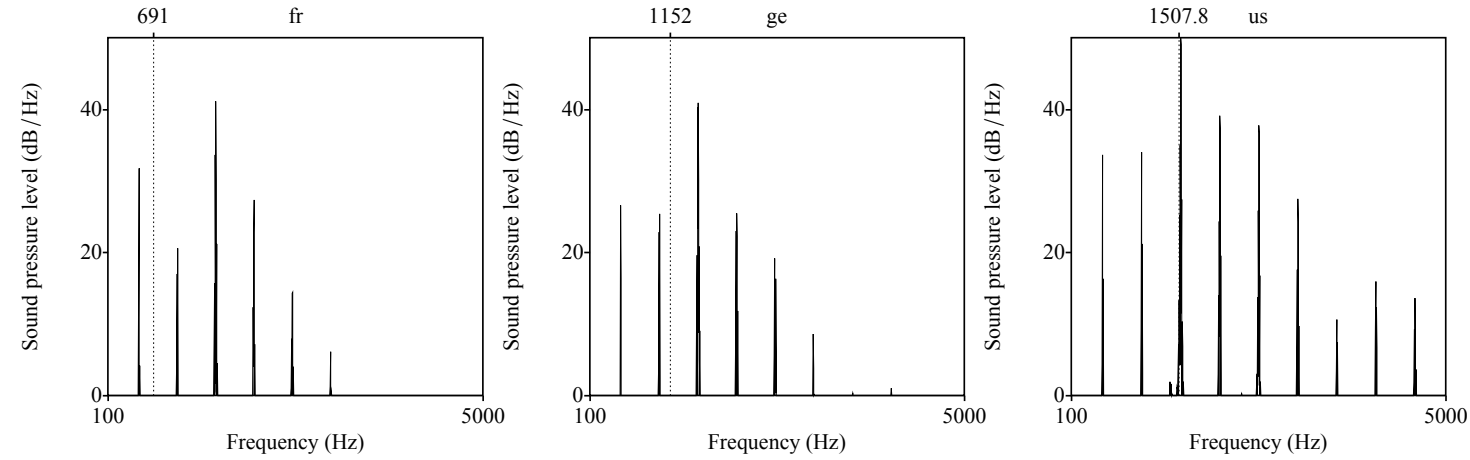

Figura 4.63. Espectro de las lengüetas francesa, alemana y americana para la nota $\mathrm{sol}_{4}$ del ejercicio pianissimo (molde 21, grosor $59 \mathrm{~mm}$ y oboísta 2). La línea de puntos indica el centro de gravedad espectral con el valor de la frecuencia correspondiente $(\mathrm{Hz})$.

Si se analizan los resultados del centro de gravedad del espectro dependiendo de las dimensiones físicas de las lengüetas y no sólo del estilo de rebajado, se puede observar en la tabla $4.12 \mathrm{~b}$ que, al contrario de lo que ocurría con las mediciones de la frecuencia, los grosores individuales de la punta no influyen para en el centro de gravedad del espectro, sino que más bien la diferencia de los grosores en la punta de las palas junto con la superficie total del rebajado y la longitud y ancho de la pala son los parámetros más 
influyentes. El $\mathrm{R}^{2}$ corregido obtenido es muy bajo $\left(\mathrm{R}^{2}=, 199\right)$, comparable a la variabilidad explicada por el estilo de rebajado $\left(\eta^{2}=, 140 \mathrm{cf}\right.$. tabla A.41).

\begin{tabular}{|c|c|c|c|c|c|c|c|c|c|}
\hline \multicolumn{10}{|c|}{ Resumen del modelo } \\
\hline \multirow[t]{2}{*}{ Modelo } & \multirow[t]{2}{*}{$\mathrm{R}$} & \multirow[t]{2}{*}{$\mathrm{R}^{2}$} & \multirow{2}{*}{\begin{tabular}{c|}
$\mathrm{R}^{2}$ \\
corregida
\end{tabular}} & \multirow{2}{*}{$\begin{array}{l}\text { Error típ. de la } \\
\text { estimación }\end{array}$} & \multicolumn{5}{|c|}{ Estadísticos de cambio } \\
\hline & & & & & $\begin{array}{c}\text { Cambio } \\
\text { en } \mathrm{R}^{2}\end{array}$ & $\begin{array}{c}\text { Cambio } \\
\text { en } F\end{array}$ & gl1 & $\mathrm{gl} 2$ & $\begin{array}{l}\text { Sig. Cambio } \\
\text { en F }\end{array}$ \\
\hline 10 & ,449 & 0,20 & 0,199 & 0,89260480 & $-0,001$ & 2,237 & 1 & 1802 & 0,135 \\
\hline
\end{tabular}

\begin{tabular}{|c|c|c|c|c|c|c|}
\hline & & & Coeficientes & & & \\
\hline $\mathrm{Mo}$ & & $\begin{array}{l}\text { Coefici } \\
\text { estanda }\end{array}$ & $\begin{array}{l}\text { tes no } \\
\text { zados }\end{array}$ & $\begin{array}{l}\text { Coeficientes } \\
\text { estandarizados }\end{array}$ & $\mathrm{t}$ & Sig. \\
\hline & & $\mathrm{B}$ & Error típ. & Beta & & \\
\hline 10 & (Constante) & $-145,964$ & 21,992 & & $-6,637$ & 0,000 \\
\hline & su24 libre & $-0,904$ & 0,122 & $-7,898$ & $-7,385$ & 0,000 \\
\hline & dg20 atras cora & 0,025 & 0,006 & 0,090 & 4,038 & 0,000 \\
\hline & dg17 asim punta & 0,112 & 0,020 & 0,131 & 5,655 & 0,000 \\
\hline & dist8 libre & 6,507 & 0,898 & 7,837 & 7,244 & 0,000 \\
\hline & dist7 ancho & 20,394 & 3,000 & 3,091 & 6,799 & 0,000 \\
\hline & rg31 centro lado & $-0,777$ & 0,109 & $-0,279$ & $-7,153$ & 0,000 \\
\hline
\end{tabular}

Tabla 4.12b. Resumen del modelo (arriba) y coeficientes de las variables predictoras de la regresión de la variable dependiente centro de gravedad del espectro con todas las medidas físicas de las lengüetas. Se muestran los que sí tienen influencia sobre la variable dependiente ( $c f$. leyenda de las variables en la tabla 4.aa y 4.bb). 


\subsubsection{Análisis de datos mediante T-test}

En esta parte se realiza una serie de pruebas T pareadas comparando para cada par de lengüetas las mediciones acústicas de un mismo ejercicio de interpretación, así se estudian las características acústicas generales de cada lengüeta en función del rebajado, del molde y del grosor, pudiendo observarse las diferencias existentes entre cada par del factor analizado en cada momento.

\subsubsection{Influencia del grosor}

Si se realiza una prueba T-pareada (paired samples T-test) para examinar si el grosor es significativo o no, se observa en la tabla 4.13, que en el parámetro intensidad el grosor es muy significativo $(p<, 001)$, siendo el grosor $59 / 100 \mathrm{~mm}$ el que proporciona sonidos más pianos. A su vez, el grosor que más desviaciones provoca en la amplitud también es el 59/100 mm obteniendo un valor, como en la intensidad, muy significativo $(p<, 001)$. Tanto la frecuencia media como el centro de gravedad espectral y el number of voiced frames también son muy significativos dependiendo del grosor. En los dos primeros parámetros, el grosor 59/100 mm sobresale del otro grosor utilizado proporcionando mayor estabilidad en la frecuencia y un centro espectral con más riqueza en los componentes armónicos. Sin embargo, el grosor 57/100 $\mathrm{mm}$ proporciona una mayor facilidad a la vibración respecto al grosor 59/100 $\mathrm{mm}$.

Si además se dividen los parámetros que son significativos por ejercicios y se utilizan los valores no normalizados, se pueden observar los resultados obtenidos en la tabla 4.14 para sólo los ejercicios que presentan significatividad. Los ejercicios que no presentan esta significatividad han sido eliminados, para facilitar la lectura de la tabla.

En el parámetro frecuencia media, cabe destacar cómo el grosor 59/100 mm es muy significativo $(p<, 01)$ en las notas do5, $\mathrm{sol}_{4} \mathrm{y}$ en el diminuendo. También destaca el ejercicio pianissimo, que obtiene significatividad en todos los parámetros aparecidos en la tabla, excepto para la desviación estándar de la armonicidad. 


\begin{tabular}{|l|r|r|r|}
\hline \multicolumn{1}{|c|}{ medida } & \multicolumn{1}{c|}{ grosor } & \multicolumn{1}{c|}{ t } & \multicolumn{1}{c|}{ Sig. } \\
\hline Amplitude Std Dev & $57-59$ & $-5,436$ & 0,000 \\
\hline Band Energy Diff (third) & $57-59$ & $-0,953$ & 0,341 \\
\hline F0 Delta (Hz) & $57-59$ & 2,104 & 0,036 \\
\hline F0 Mean (Hz) & $57-59$ & $-7,652$ & 0,000 \\
\hline F0 Std Dev (st) & $57-59$ & 0,390 & 0,697 \\
\hline Harmonicity Mean & $57-59$ & $-0,159$ & 0,874 \\
\hline Harmonicity Std Dev & $57-59$ & 2,888 & 0,004 \\
\hline Intensity (dB) & $57-59$ & $-6,568$ & 0,000 \\
\hline Number Voiced Frames & $57-59$ & 4,727 & 0,000 \\
\hline Spectrum Center Gravity & $57-59$ & $-7,545$ & 0,000 \\
\hline
\end{tabular}

Tabla 4.13. Resumen del análisis de la prueba T, comparando los diferentes grosores en todos los valores acústicos (significatividad bilateral), $c f$. A.42 para más detalle.

Si además se tienen en cuenta los diferentes estilos de rebajado, se observa en la tabla 4.15, que el rebajado alemán es significativo $(p<, 001)$ para todos los parámetros estudiados anteriormente, de forma que existe una relación directa entre el grosor 59/100 $\mathrm{mm}$ del rebajado alemán con todos los parámetros estudiados, excepto en la facilidad de vibración (number voiced frames), en la que es el grosor 57/100 mm el significativo. Lo mismo ocurre con el rebajado francés, que aunque no proporciona la misma significatividad que el alemán, también influye de la misma forma que el anterior, excepto en la frecuencia media, que no consigue significatividad. Además, podemos resaltar que la desviación estándar de la armonicidad es significativa para el rebajado francés y el grosor $57 / 100 \mathrm{~mm}$. 


\begin{tabular}{|c|c|c|c|c|}
\hline medida & ejercicio & grosor & $\mathbf{t}$ & Sig. \\
\hline \multirow[t]{2}{*}{ Amplitude Std Dev } & ADo4 & $57-59$ & $-2,866$ & 0,005 \\
\hline & Pianissimo & $57-59$ & $-2,003$ & 0,048 \\
\hline \multirow[t]{8}{*}{ F0 Mean $(\mathrm{Hz})$} & ADo5 & $57-59$ & $-3,866$ & 0,000 \\
\hline & ADo6 & $57-59$ & $-2,132$ & 0,037 \\
\hline & AMi4 & $57-59$ & $-2,746$ & 0,008 \\
\hline & AMi5 & $57-59$ & $-2,511$ & 0,015 \\
\hline & ASol4 & $57-59$ & $-4,753$ & 0,000 \\
\hline & ASol5 & $57-59$ & $-2,342$ & 0,023 \\
\hline & DIM & $57-59$ & $-3,865$ & $\overline{0,000}$ \\
\hline & Pianissimo & $57-59$ & $-2,335$ & 0,023 \\
\hline \multirow[t]{3}{*}{ Harmonicity Std Dev } & AMi4 & $57-59$ & 2,270 & 0,026 \\
\hline & ASol4 & $57-59$ & 3,268 & $\overline{0,002}$ \\
\hline & DIM & $57-59$ & 2,228 & 0,029 \\
\hline \multirow[t]{5}{*}{ Intensity $(\mathrm{dB})$} & ADo4 & $57-59$ & $-2,841$ & $\overline{0,006}$ \\
\hline & ASol5 & $57-59$ & $-2,404$ & 0,018 \\
\hline & DIM & $57-59$ & $-2,170$ & 0,033 \\
\hline & Fortissimo & $57-59$ & $-2,749$ & 0,007 \\
\hline & Pianissimo & $57-59$ & $-2,922$ & 0,004 \\
\hline \multirow[t]{5}{*}{ Number Voiced Frames } & ADo5 & $57-59$ & 2,417 & $\overline{0,018}$ \\
\hline & AMi4 & $57-59$ & 2,224 & 0,029 \\
\hline & AMi5 & $57-59$ & 2,498 & 0,014 \\
\hline & ASol4 & $57-59$ & 2,616 & $\overline{0,011}$ \\
\hline & Pianissimo & $57-59$ & 2,081 & $\overline{0,040}$ \\
\hline \multirow[t]{9}{*}{ Spectrum Center Gravity } & ADo4 & $57-59$ & $-2,734$ & 0,008 \\
\hline & ADo5 & $57-59$ & $-1,994$ & 0,049 \\
\hline & AMi4 & $57-59$ & $-3,114$ & 0,003 \\
\hline & AMi5 & $57-59$ & $-3,138$ & 0,002 \\
\hline & ASol4 & $57-59$ & $-2,745$ & $\overline{0,007}$ \\
\hline & ASol5 & $57-59$ & $-2,573$ & 0,012 \\
\hline & DIM & $57-59$ & $-2,527$ & 0,013 \\
\hline & Fortissimo & $57-59$ & $-3,021$ & 0,003 \\
\hline & Pianissimo & $57-59$ & $-2,259$ & 0,026 \\
\hline
\end{tabular}

Tabla 4.14. Resumen del análisis de la prueba $\mathrm{T}$, comparando los diferentes grosores en todos los valores acústicos significatives, divididos por ejercicios (significatividad bilateral), $c f$. A.43 para más detalle. 


\begin{tabular}{|c|c|c|c|c|}
\hline medida & rebajado & grosor & $\mathbf{t}$ & Sig. \\
\hline \multirow[t]{3}{*}{ Amplitude Std Dev } & fr & $57-59$ & $-2,638$ & 0,009 \\
\hline & ge & $57-59$ & $-4,183$ & 0,000 \\
\hline & us & $57-59$ & $-2,440$ & 0,015 \\
\hline \multirow[t]{3}{*}{ F0 Mean $(\mathrm{Hz})$} & fr & $57-59$ & $-1,242$ & 0,216 \\
\hline & ge & $57-59$ & $-7,425$ & 0,000 \\
\hline & us & $57-59$ & $-4,797$ & 0,000 \\
\hline \multirow[t]{3}{*}{ Harmonicity Std Dev } & $\mathrm{fr}$ & $57-59$ & 3,513 & 0,001 \\
\hline & ge & $57-59$ & 1,382 & 0,168 \\
\hline & us & $57-59$ & $-0,082$ & 0,935 \\
\hline \multirow[t]{3}{*}{ Intensity $(\mathrm{dB})$} & $\mathrm{fr}$ & $57-59$ & $-4,049$ & 0,000 \\
\hline & ge & $57-59$ & $-5,280$ & 0,000 \\
\hline & us & $57-59$ & $-2,160$ & 0,032 \\
\hline \multirow{3}{*}{ Number Voiced Frames } & fr & $57-59$ & 3,137 & 0,002 \\
\hline & ge & $57-59$ & 4,020 & 0,000 \\
\hline & us & $57-59$ & 1,380 & 0,169 \\
\hline \multirow[t]{3}{*}{ Spectrum Center Gravity } & fr & $57-59$ & $-2,904$ & 0,004 \\
\hline & ge & $57-59$ & $-3,233$ & 0,001 \\
\hline & us & $57-59$ & $-6,864$ & 0,000 \\
\hline
\end{tabular}

Tabla 4.15. Resumen del análisis de la prueba T, comparando los diferentes grosores en todos los valores acústicos significativos, divididos por rebajados (significatividad bilateral), $c f$. A.44 para más detalle.

\subsubsection{Influencia del rebajado}

Al realizar una prueba T-pareada (paired samples T-test) para averiguar si el rebajado influye de forma muy significativa en los parámetros estudiados y qué rebajado es el que más influye, se puede observar en la tabla 4.16 que muchos de los parámetros estudiados son influenciados por el rebajado. A continuación se analizan estos parámetros agrupándolos por categorías.

\begin{tabular}{|l|l|r|r|}
\hline \multicolumn{1}{|c|}{ medida } & \multicolumn{1}{|c|}{ rebajado } & \multicolumn{1}{c|}{ t } & \multicolumn{1}{c|}{ Sig. } \\
\hline \multirow{4}{*}{ Amplitude Std Dev } & fr - ge & $-6,873$ & 0,000 \\
\cline { 2 - 4 } & fr - us & $-6,759$ & 0,000 \\
\cline { 2 - 4 } & ge - us & 0,448 & 0,654 \\
\hline \multirow{2}{*}{ Band Energy Diff (third) } & fr - ge & $-4,729$ & 0,000 \\
\cline { 2 - 4 } & fr - us & $-8,456$ & 0,000 \\
\cline { 2 - 4 } & ge - us & $-4,604$ & 0,000 \\
\hline \multirow{2}{*}{ F0 Delta (Hz) } & fr - ge & 3,905 & 0,000 \\
\cline { 2 - 4 } & fr - us & 3,025 & 0,003 \\
\cline { 2 - 4 } & ge - us & $-0,244$ & 0,807 \\
\hline \multirow{5}{*}{ F0 Mean (Hz) } & fr - ge & $-20,822$ & 0,000 \\
\cline { 2 - 4 } & fr - us & $-48,466$ & 0,000 \\
\cline { 2 - 4 } & ge - us & $-31,348$ & 0,000 \\
\hline F0 Std Dev (st) & fr - ge & 3,582 & 0,000 \\
\cline { 2 - 4 } & fr - us & 1,473 & 0,141 \\
\cline { 2 - 4 } & & &
\end{tabular}




\begin{tabular}{|c|c|c|c|}
\hline medida & rebajado & $\mathbf{t}$ & Sig. \\
\hline & ge - us & $-1,268$ & 0,205 \\
\hline \multirow[t]{3}{*}{ Harmonicity Mean } & fr - ge & $-4,877$ & 0,000 \\
\hline & fr - us & $-3,301$ & 0,001 \\
\hline & ge - us & 1,127 & 0,260 \\
\hline \multirow[t]{3}{*}{ Harmonicity Std Dev } & fr - ge & 8,995 & 0,000 \\
\hline & fr - us & 11,126 & 0,000 \\
\hline & ge - us & 3,259 & 0,001 \\
\hline \multirow[t]{3}{*}{ Intensity $(\mathrm{dB})$} & fr - ge & $-8,099$ & 0,000 \\
\hline & $\mathrm{fr}-\mathrm{us}$ & $-8,685$ & 0,000 \\
\hline & ge - us & $-1,382$ & 0,168 \\
\hline \multirow[t]{3}{*}{ Number Voiced Frames } & fr-ge & 5,194 & 0,000 \\
\hline & $\mathrm{fr}-\mathrm{us}$ & 5,114 & 0,000 \\
\hline & ge - us & 0,796 & 0,426 \\
\hline \multirow[t]{3}{*}{ Spectrum Center Gravity } & fr - ge & $-6,786$ & 0,000 \\
\hline & fr - us & $-13,059$ & 0,000 \\
\hline & ge - us & $-7,436$ & 0,000 \\
\hline
\end{tabular}

Tabla 4.16. Resumen del análisis de la prueba $\mathrm{T}$, comparando los diferentes rebajados en todos los valores acústicos (significatividad bilateral), $c f$. A.45 para más detalle.

\subsection{Parámetros relativos a la afinación}

Los resultados de la tabla 4.16 muestran que el rebajado que mayor rango de frecuencias consigue es el francés respecto al alemán y al americano respectivamente, de forma significativa. Sin embargo, en el parámetro de la frecuencia media, el estilo de rebajado que se adapta es el americano, siendo muy significativo en todos los casos $(p<$, 001) y el que peor frecuencia media consigue es el rebajado francés, siendo también muy significativo respecto al alemán.

Si se analizan los datos por ejercicios, se observa que en el parámetro delta de la frecuencia, el único ejercicio que consigue una significatividad muy alta es la nota mi, con el rebajado francés respecto al americano $(\mathrm{t}=4,7 ; p<, 001)$. Sin embargo, en el parámetro frecuencia media, todos los ejercicios son muy significativos respecto al rebajado americano $(p<, 001)$ excepto en el fortissimo, donde el rebajado alemán no consigue diferenciarse significativamente del francés $(\mathrm{t}=-1,3 ; p=, 171)$. 


\subsection{Parámetros relativos a la estabilidad de la afinación}

Respecto a la desviación estándar, el rebajado alemán es el que mejor mantiene la estabilidad en la afinación, siendo significativo sólo respecto al rebajado francés. El rebajado francés, sin embargo, es el más inestable.

\subsection{Parámetros relativos a la intensidad}

En la intensidad se observa cómo el rebajado francés es el que menor intensidad consigue frente al americano. Sin embargo, el estilo americano es el que más intensidad logra, siendo muy significativo respecto al francés $(\mathrm{t}=-8,7 ; p<, 001)$, pero no frente al alemán; el alemán es significativo frente al francés $(\mathrm{t}=-8,1 ; p<, 001)$.

Si dividimos los parámetros por ejercicios, se advierte que estas diferencias se consiguen en los ejercicios diminuendo, fortissimo y pianissimo, así como en las notas aisladas do 4 , do6 $\mathrm{y} \mathrm{mi}_{4}$.

\subsection{Parámetros relativos a la variabilidad de la intensidad}

Al igual que ocurre con la intensidad, en la desviación estándar de la amplitud, el rebajado francés es el que menor estabilidad proporciona siendo el rebajado alemán el que menor desviación presenta, con significatividad respecto al estilo francés $(\mathrm{t}=-6,9 ; p<, 001)$, pero no al americano.

\subsection{Parámetros relativos a la facilidad de vibración}

Al observar los datos de la cantidad de ciclos con una altura definida ( $N^{o}$ voiced frames) de la tabla 4.16, se ve que las lengüetas con el estilo de rebajado francés tienen una mayor facilidad para la vibración que las alemanas $(\mathrm{t}=5,1 ; p<, 001)$ y las americanas $(\mathrm{t}=5,1$; $p<, 001$ ), siendo las americanas las que peor facilidad de vibración obtienen. Esto se da en todos los ejercicios, siendo significativo en las notas graves como el do4. Sin embargo, en el ejercicio pianissimo, cuando se necesita un rebajado un poco más suave para conseguir el efecto deseado, se observa cómo es el rebajado americano el que consigue de forma muy significativa $(\mathrm{t}=-3,4 ; p=, 001)$ el mejor resultado respecto del rebajado francés.

\subsection{Parámetros relativos a la armonicidad}

La tabla 4.16 muestra que el rebajado francés es el que menor armonicidad consigue y, por consiguiente, el que mayor desviación estándar obtiene; mientras que el 
rebajado alemán es el más armónico, siendo significativo frente al francés ( $\mathrm{t}=-4,9 ; p<, 001)$, pero no al americano.

Si se analizan estas diferencias por ejercicios, se aprecia que es en el pianissimo donde se obtienen mayores diferencias, siendo el rebajado americano el más armónico en este caso, seguido del alemán $(p=, 004)$ y del francés $(p<, 001)$. Del mismo modo, en el ejercicio diminuendo, el rebajado alemán es el más armónico, seguido del americano ( $p=$, 219) y del francés $(p=, 005)$. Sin embargo, cabe destacar la nota aislada do5, que consigue que el rebajado francés sea más armónico que el alemán y el americano, de forma muy significativa en ambos casos $(p<, 001)$. Asimismo, el rebajado americano es el más estable en la armonicidad (el que menor desviación estándar tiene), excepto en las notas aisladas mi 5 y sol5, donde el rebajado americano es más inestable, seguido del francés y del alemán, siendo significativo para la nota $\mathrm{mi}_{5}$ ( $p<, 001$ y $p=, 027$ respectivamente), pero no para el $\operatorname{sol}_{5}(p=, 169$ y $p=, 888$ respectivamente).

\subsection{Parámetros relativos al timbre}

La medición de la energía por bandas de frecuencias fijas crea diferencias muy significativas entre los diferentes estilos de rebajados, siendo el americano muy significativo $(p<, 001)$ en todos los casos.

En la medición correspondiente al centro de gravedad del espectro, se observa que el rebajado americano es que el mayor componente armónico contiene obteniendo un centro de gravedad alto de forma muy significativa $(p<, 001)$ respecto a todos los demás rebajados, siendo el rebajado francés el más pobre en cuanto a componentes armónicos obtenidos.

\subsubsection{Influencia del molde}

Para averiguar la influencia del molde en los parámetros estudiados, se realiza una prueba T-pareada (paired samples T-test) teniendo en cuenta que para los parámetros relativos a la afinación y a la estabilidad de ésta, sólo se comparan los dos moldes más estándares, eliminando, como en los casos anteriores, el molde 168.

La tabla 4.17 muestra que los moldes nos son significativos para los parámetros dependientes de la afinación y su estabilidad. Sin embargo, si se realiza el análisis comparando los datos por ejercicios, se observa que en el parámetro delta de la afinación, 
el molde 107 consigue diferencias significativas respecto al molde 21 en la nota aislada do5 $(\mathrm{t}=-2,5 ; p=, 021)$. En la frecuencia media, destaca el ejercicio fostissimo, donde el molde 107 provoca una diferencia significativa respecto al $21(\mathrm{t}=-3,3 ; p=, 002)$ y en el parámetro que mide la desviación estándar de la frecuencia resalta el ejercicio diminuendo, donde el molde 107 consigue una mayor desviación respecto al 21 de forma significativa $(t=-3,1$; $p=, 003)$.

\begin{tabular}{|l|l|r|r|}
\hline \multicolumn{1}{|c|}{ medida } & molde & \multicolumn{1}{c|}{ t } & \multicolumn{1}{c|}{ Sig. } \\
\hline Amplitude Std Dev & $021-107$ & 5,715 & 0,000 \\
\cline { 2 - 4 } & $021-168$ & 2,773 & 0,006 \\
\cline { 2 - 4 } & $107-168$ & $-2,972$ & 0,003 \\
\hline Band Energy Diff (third) & $021-107$ & 1,256 & 0,210 \\
\cline { 2 - 4 } & $021-168$ & 2,129 & 0,034 \\
\cline { 2 - 4 } & $107-168$ & 1,507 & 0,132 \\
\hline F0 Delta (Hz) & $021-107$ & $-0,583$ & 0,560 \\
\hline F0 Mean (Hz) & $021-107$ & $-1,875$ & 0,061 \\
\hline F0 Std Dev (st) & $021-107$ & $-1,217$ & 0,224 \\
\hline Harmonicity Mean & $021-107$ & $-3,143$ & 0,002 \\
\cline { 2 - 4 } & $021-168$ & 0,572 & 0,568 \\
\cline { 2 - 4 } & $107-168$ & 3,407 & 0,001 \\
\hline Harmonicity Std Dev & $021-107$ & $-3,799$ & 0,000 \\
\cline { 2 - 4 } & $021-168$ & $-4,732$ & 0,000 \\
\cline { 2 - 4 } & $107-168$ & $-0,887$ & 0,375 \\
\hline Intensity (dB) & $021-107$ & 6,156 & 0,000 \\
\cline { 2 - 4 } & $021-168$ & 2,282 & 0,023 \\
\cline { 2 - 4 } & $107-168$ & $-3,847$ & 0,000 \\
\hline Number Voiced Frames & $021-107$ & $-2,746$ & 0,006 \\
\cline { 2 - 4 } & $021-168$ & $-1,463$ & 0,144 \\
\cline { 2 - 4 } & $107-168$ & 1,030 & 0,303 \\
\hline Spectrum Center Gravity & $021-107$ & $-5,171$ & 0,000 \\
\cline { 2 - 4 } & $021-168$ & 7,739 & 0,000 \\
\cline { 2 - 4 } & $107-168$ & 13,798 & 0,000 \\
\hline
\end{tabular}

Tabla 4.17. Resumen del análisis de la prueba $\mathrm{T}$, comparando los diferentes rebajados en todos los valores acústicos (significatividad bilateral), $c f$. A.46 para más detalle.

Respecto al análisis de los datos de la intensidad y su estabilidad (desviación estándar de la amplitud), se aprecia que el molde que mayor intensidad y desviación estándar consigue es el 21 de forma significativa respecto a todos los moldes, seguido del 168 y del 107 respectivamente. Al analizar los datos de la intensidad en referencia a los diferentes ejercicios ejecutados, se destaca sobre todo las diferencias significativas obtenidas en los ejercicios diminuendo y fortissimo. En ambos casos, el molde 21 consigue 
mayor intensidad que el 107 ( $p<, 001$ y $p=, 001$, respectivamente) del mismo modo que lo consigue el 168 respecto al 107 ( $p=, 002$ y $p<, 001$, respectivamente).

En referencia a la facilidad de vibración, sólo el molde 107 obtienen diferencias significativas respecto al molde $21(p=, 006)$, aportando el 107 mayor facilidad a la hora de ejecutar los ejercicios.

Los moldes también influyen de forma significativa en la armonicidad. El molde 107 es el más armónico, seguido del 21 y del 168 siendo significativo en ambos casos ( $p=$, 002 y $p=, 001$ respectivamente). Además, el molde que mayor desviación estándar provoca en la armonicidad es el 168, seguido del $107 \mathrm{y}$ del 21. Si analizamos los datos separándolos por ejercicios, se puede observar que en la nota aislada do5, el molde 21 es el menos armónico respecto al $168(p=, 011)$ y al $107(p=, 005)$; además, en este mismo ejercicio el molde 21 es el que menor desviación estándar provoca respecto al molde 168 $(p<, 001)$. Sin embargo, en la nota aislada sol$_{5}$, cabe destacar que el molde 21 es más armónico que el 168 de forma significativa $(p=, 004)$. Tanto en la nota aislada do 4 como en el ejercicio diminuendo, el molde 21 es el que menor desviación estándar obtiene respecto a los otros dos moldes ( $p<, 001$ y $p=, 001$, respectivamente).

En los parámetros destinados al timbre, sólo se producen diferencias significativas en las diferencias de energía por bandas entre los moldes 21 y $168(p=, 034)$, destacando estas diferencias en la nota aislada do4, donde el molde 21 consigue de forma significativa $(p<, 001)$ una mayor energía que el 168. Se destaca, además, la nota aislada sols, donde esta vez es el molde 107 el que obtiene mayor energía que el 168 de forma significativa ( $p<$, 001). Sin embargo, en el centro de gravedad espectral se obtienen las máximas diferencias respecto a los tres moldes utilizados en la investigación: el molde 107 es el que consigue una mayor cantidad de componentes armónicos frente al 21 y al 168, destacando en los ejercicios do $\operatorname{do}_{5}\left(p<, 024\right.$ y $p<, 001$, respectivamente), $\mathrm{mi}_{4}$ ( $p<, 030$ y $p<, 001$, respectivamente) y diminuendo ( $p<, 017$ y $p<, 001$, respectivamente). 


\subsubsection{Análisis de datos mediante el escalamiento multidimensional}

Mediante el escalamiento multidimensional se intenta visualizar en un gráfico los diferentes datos obtenidos en el análisis acústico. En este caso, el escalamiento multidimensional va a mostrar la similitud existente entre los diferentes estilos de rebajado, los moldes y los grosores de las lengüetas estudiadas.

Al realizar un escalamiento multidimensional (ALSCAL) sobre todas las mediciones acústicas, utilizando un modelo de dos dimensiones, se intenta entender si los diferentes estilos de rebajado, los moldes o los grosores se comportan de forma similar en los ejercicios. La variabilidad explicada por estas dimensiones para todas las mediciones es: $\mathrm{RSQ}=95 \%$.

Las figuras 4.64 y 4.65, muestran la obtención de una asociación clara por estilos de rebajado para la dimensión 1 y la utilización de los diferentes moldes para la dimensión 2.

Estos resultados confirman los datos obtenidos anteriormente mediante los ANOVAS de medidas repetidas y los T-test: las diferentes escuelas de rebajado influyen en las mediciones acústicas estudiadas.

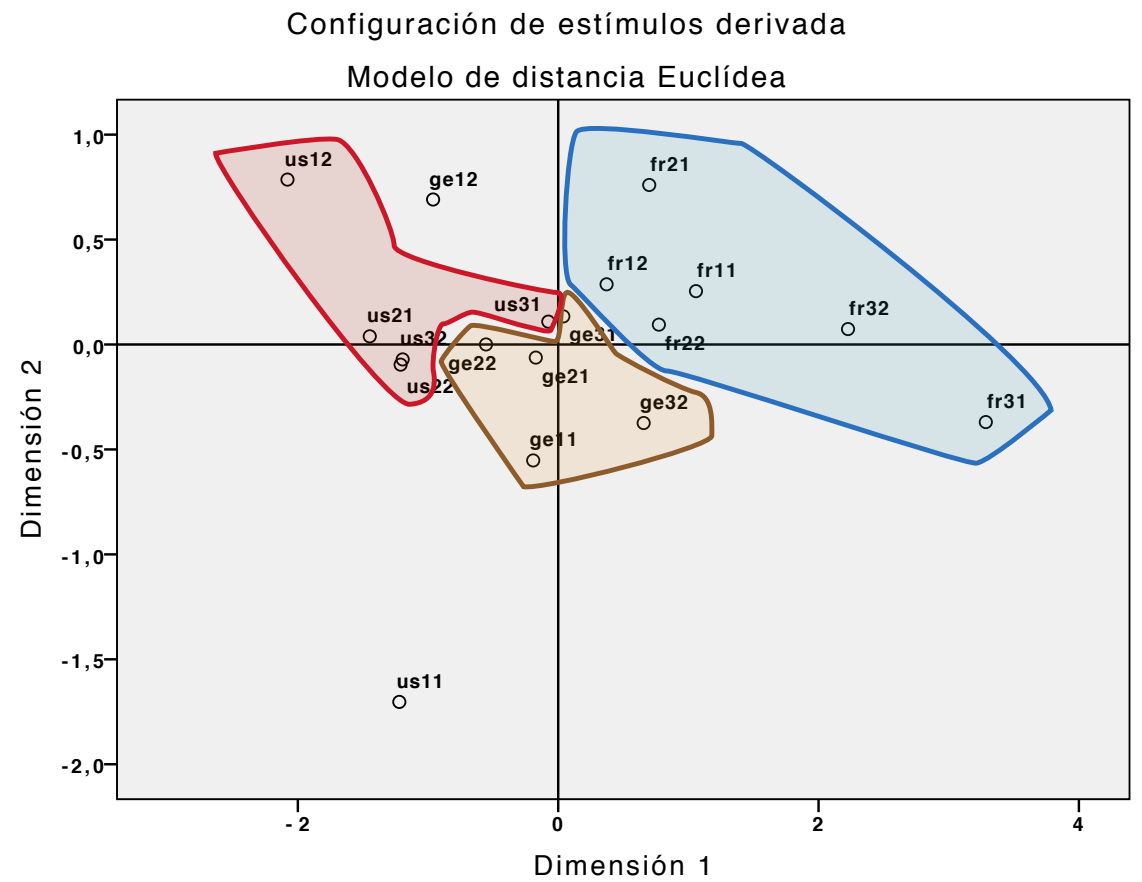

Figura 4.64. Escalamiento multidimensional de todas las mediciones acústicas. Las dos primeras letras codifican el tipo de rebajado, el primer número indica el tipo de molde $(1=21 ; 2=107 ; 3=168)$ y el segundo número el tipo de grosor $(1=57 \mathrm{~mm} ; 2=59 \mathrm{~mm})$. Se marca la dimensión 1 obtenida: estilos de rebajado. 


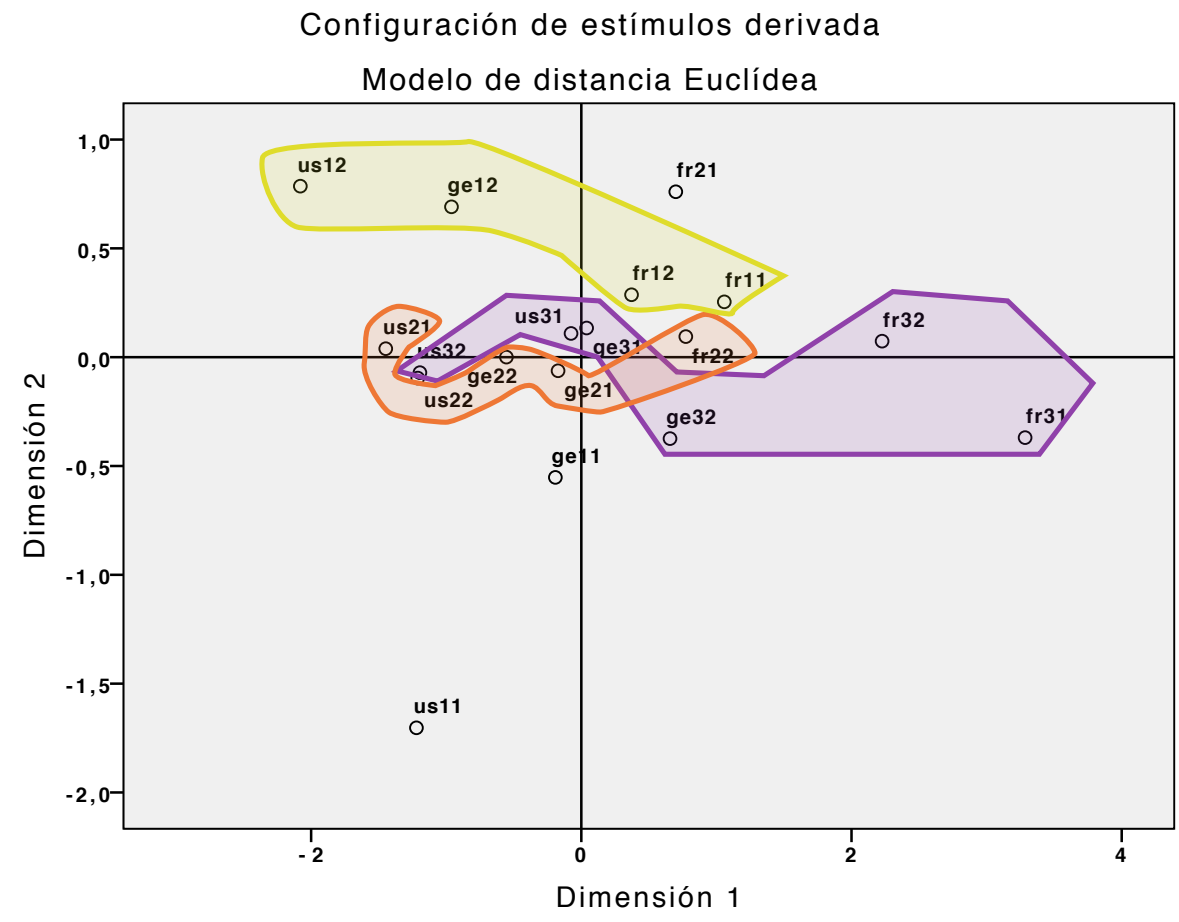

Figura 4.65. Escalamiento multidimensional de todas las mediciones acústicas. Las dos primeras letras codifican el tipo de rebajado, el primer número indica el tipo de molde $(1=21 ; 2=107 ; 3=168)$ y el segundo número el tipo de grosor $(1=57 \mathrm{~mm} ; 2=59 \mathrm{~mm})$. Se marca la dimensión 2 obtenida: moldes.

\subsubsection{Respuestas acústicas en función del ejercicio diminuendo}

Este ejercicio consiste en una nota larga que se ejecuta disminuyendo progresivamente la intensidad sonora. Una buena ejecución implica:

1) un gran ámbito en la intensidad (delta intensidad) pasando del máximo inicial al mínimo final de manera regular, con lo que se crea una nueva medición ad hoc que analiza la diferencia entre intensidad máxima y mínima.

2) una estabilidad en la afinación, ya que se corre el riesgo que con el diminuendo baje la afinación. Para ello se mide la diferencia entre el punto máximo y mínimo de la frecuencia (delta frecuencia) en semitonos.

3) una duración larga de la nota con una altura determinada, antes de que el diminuendo llegue a un soplo, con lo que interesa la medición de la parte con una altura definida (voiced frames).

Un análisis de las otras mediciones acústicas (armonicidad, altura media, intensidad media, centro espectral, bandas de energía, etc.) muestra un comportamiento similar entre 
el ejercicio diminuendo y el comportamiento general de las lengüetas para todos los ejercicios, con lo que se remite al análisis general para esas mediciones.

\subsubsection{Duración de la nota}

Como se ha explicado anteriormente, en el punto 4.6.3.5.1, hay que tener en cuenta que los oboístas no contaban con un metrónomo para verificar la velocidad de la pulsación en la interpretación de los ejercicios, por lo que en esta medición existen longitudes en los diminuendi muy dispares, no siendo un problema de la lengüeta, sino de la realización del ejercicio.

La tabla 4.18 ( $c f$. A.47 para más detalle) muestra que ningún elemento de fabricación de la lengüeta influye en la duración de la nota, con lo que los oboístas parecen compensar las particularidades de la lengüeta al interpretar.

\begin{tabular}{|l|r|r|r|r|r|}
\hline Origen & \multicolumn{1}{|c|}{$\begin{array}{c}\text { Suma de } \\
\text { cuadrados tipo III }\end{array}$} & gl & $\begin{array}{c}\text { Media } \\
\text { cuadrática }\end{array}$ & F & Sig. \\
\hline Modelo corregido & 23,514 & 17 & 1,383 & 1,438 & 0,124 \\
\hline Intersección & 0,005 & 1 & 0,005 & 0,005 & 0,943 \\
\hline rebajado & 4,440 & 2 & 2,220 & 2,308 & 0,103 \\
\hline molde & 2,994 & 2 & 1,497 & 1,556 & 0,214 \\
\hline grosor & 0,745 & 1 & 0,745 & 0,774 & 0,380 \\
\hline rebajado * molde & 2,455 & 4 & 0,614 & 0,638 & 0,636 \\
\hline rebajado * grosor & 0,658 & 2 & 0,329 & 0,342 & 0,711 \\
\hline molde * grosor & 8,113 & 2 & 4,057 & 4,216 & 0,016 \\
\hline
\end{tabular}

Tabla 4.18. Análisis de varianza factorial de la variable Number Voiced Frames para los factores rebajado, molde y grosor (elementos de fabricación de la lengüeta).

\subsubsection{Variación de la afinación}

Un ANOVA de varios factores (tabla 4.19) muestra que el rebajado es el único factor individual que tiene una influencia significativa en la caída de la afinación ( $\mathrm{F}=11,91$, $p<, 001)$, los otros elementos de fabricación de la lengüeta carecen de influencia. Los efectos cruzados no son significativos ( $c f$. A.48 para más detalle). En la figura 4.66 se observa que claramente, el estilo de rebajado francés tiene más ámbito de frecuencia, lo que supone una pérdida de afinación importante, siendo un inconveniente para la interpretación, lo que se verifica a través de una prueba T pareada (tabla 4.20, cf. A.49 para más detalle). 


\begin{tabular}{|l|r|r|r|r|r|}
\hline Origen & \multicolumn{1}{|c|}{$\begin{array}{c}\text { Suma de } \\
\text { cuadrados tipo III }\end{array}$} & \multicolumn{1}{c|}{ gl } & \multicolumn{1}{c|}{$\begin{array}{c}\text { Media } \\
\text { cuadrática }\end{array}$} & \multicolumn{1}{c|}{ F } & \multicolumn{1}{c|}{ Sig. } \\
\hline Modelo corregido & 1,483 & 17 & 0,087 & 2,578 & 0,001 \\
\hline Intersección & 34,593 & 1 & 34,593 & 1022,477 & 0,000 \\
\hline rebajado & 0,806 & 2 & 0,403 & 11,913 & 0,000 \\
\hline molde & 0,135 & 2 & 0,067 & 1,994 & 0,140 \\
\hline grosor & 0,033 & 1 & 0,033 & 0,978 & 0,324 \\
\hline rebajado * molde & 0,332 & 4 & 0,083 & 2,454 & 0,048 \\
\hline rebajado * grosor & 0,098 & 2 & 0,049 & 1,447 & 0,238 \\
\hline molde * grosor & 0,026 & 2 & 0,013 & 0,390 & 0,677 \\
\hline
\end{tabular}

Tabla 4.19. Análisis de varianza factorial de la variable delta de frecuencia (en semitonos) para los factores rebajado, molde y grosor (elementos de fabricación de la lengüeta).

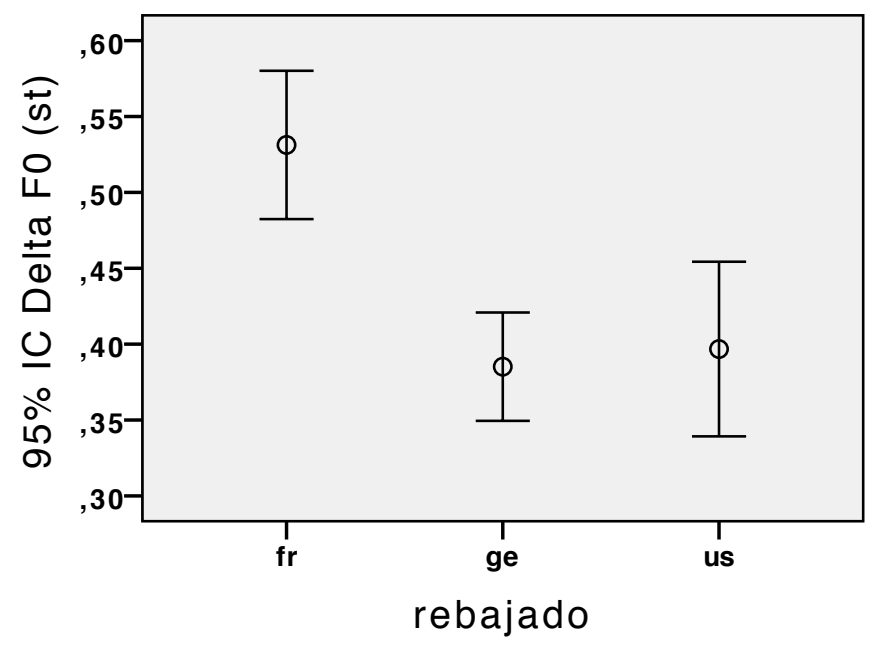

Figura 4.66. Media con intervalo de confianza de la diferencia de afinación (delta de frecuencia), en semitonos, por tipos de rebajado.

\begin{tabular}{|l|r|r|}
\hline \multicolumn{1}{|c|}{ rebajado } & \multicolumn{1}{c|}{ t } & \multicolumn{1}{c|}{ Sig. } \\
\hline fr-ge & 5,679 & 0,000 \\
\hline fr-us & 3,463 & 0,001 \\
\hline ge-us & $-0,522$ & 0,604 \\
\hline
\end{tabular}

Tabla 4.20. Resumen del análisis de la prueba T pareada comparando el delta de frecuencia (en semitonos) para los diferentes estilos de rebajado.

Un ANOVA de varios factores (tabla 4.21, $c f$. A.50 para más detalle) muestra que el rebajado es más influyente que el oboísta, aunque ambos tienen una significatividad importante $(p<, 001)$ y su efecto cruzado es igualmente importante, como se puede apreciar en la figura 4.67: en general, el rebajado francés suele provocar una mayor diferencia de afinación, pero para algunos oboístas el resultado es muy marcado y para otros no es significativo. 


\begin{tabular}{|l|r|r|r|r|r|}
\hline Origen & \multicolumn{1}{|c|}{$\begin{array}{c}\text { Suma de } \\
\text { cuadrados tipo III }\end{array}$} & \multicolumn{1}{c|}{ gl } & $\begin{array}{c}\text { Media } \\
\text { cuadrática }\end{array}$ & \multicolumn{1}{c|}{ F } & \multicolumn{1}{l|}{ Sig. } \\
\hline Modelo corregido & 2,972 & 32 & 0,093 & 3,414 & 0,000 \\
\hline Intersección & 31,181 & 1 & 31,181 & 1146,323 & 0,000 \\
\hline rebajado & 0,665 & 2 & 0,333 & 12,229 & 0,000 \\
\hline oboista & 0,882 & 10 & 0,088 & 3,243 & 0,001 \\
\hline rebajado * oboista & 1,321 & 20 & 0,066 & 2,428 & 0,001 \\
\hline
\end{tabular}

Tabla 4.21. Análisis de varianza factorial de la variable delta de frecuencia (en semitonos) para los factores rebajado y oboísta.

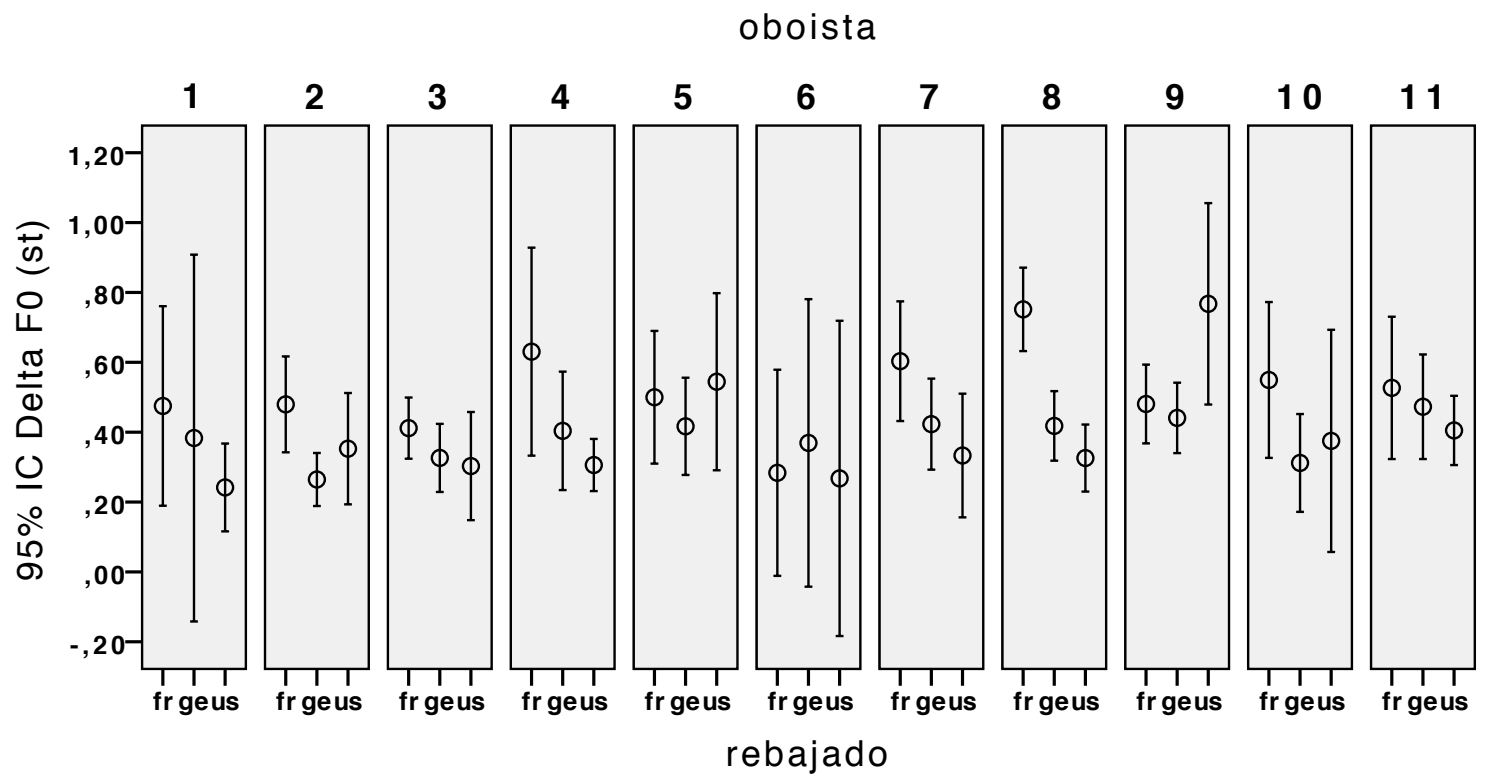

Figura 4.67. Medias con intervalo de confianza de la diferencia de afinación (delta de frecuencia), en semitonos, por estilo de rebajado y oboísta.

\subsubsection{3. Ámbito de intensidad}

Finalmente, se abarca el parámetro acústico que mejor mide el ejercicio diminuendo, es decir, la diferencia de intensidad entre el punto máximo inicial y el punto mínimo final. Un ANOVA de varios factores muestra en la tabla 4.22 ( $c f$. A.51 para más detalle) que ninguno de los parámetros de fabricación de la lengüeta influye significativamente en el delta de intensidad ( $c f$. figura 4.68), lo que se verifica a través de una prueba T pareada (tabla 4.23, cf. A.52 para más detalle). 


\begin{tabular}{|l|r|r|r|r|r|}
\hline Origen & \multicolumn{1}{c|}{$\begin{array}{c}\text { Suma de } \\
\text { cuadrados tipo } \\
\text { III }\end{array}$} & gl & \multicolumn{1}{c|}{$\begin{array}{c}\text { Media } \\
\text { cuadrática }\end{array}$} & Fig. \\
\hline Modelo corregido & 46,374 & 17 & 2,728 & 0,863 & 0,618 \\
\hline Intersección & 146571,209 & 1 & 146571,209 & 46369,252 & 0,000 \\
\hline rebajado & 1,250 & 2 & 0,625 & 0,198 & 0,821 \\
\hline molde & 4,225 & 2 & 2,113 & 0,668 & 0,514 \\
\hline grosor & 0,034 & 1 & 0,034 & 0,011 & 0,918 \\
\hline rebajado * molde & 13,627 & 4 & 3,407 & 1,078 & 0,369 \\
\hline rebajado * grosor & 1,458 & 2 & 0,729 & 0,231 & 0,794 \\
\hline molde * grosor & 8,890 & 2 & 4,445 & 1,406 & 0,248 \\
\hline
\end{tabular}

Tabla 4.22. Análisis de varianza factorial de la variable delta de la intensidad (en dB) para los factores rebajado, molde y grosor (elementos de fabricación de la lengüeta).

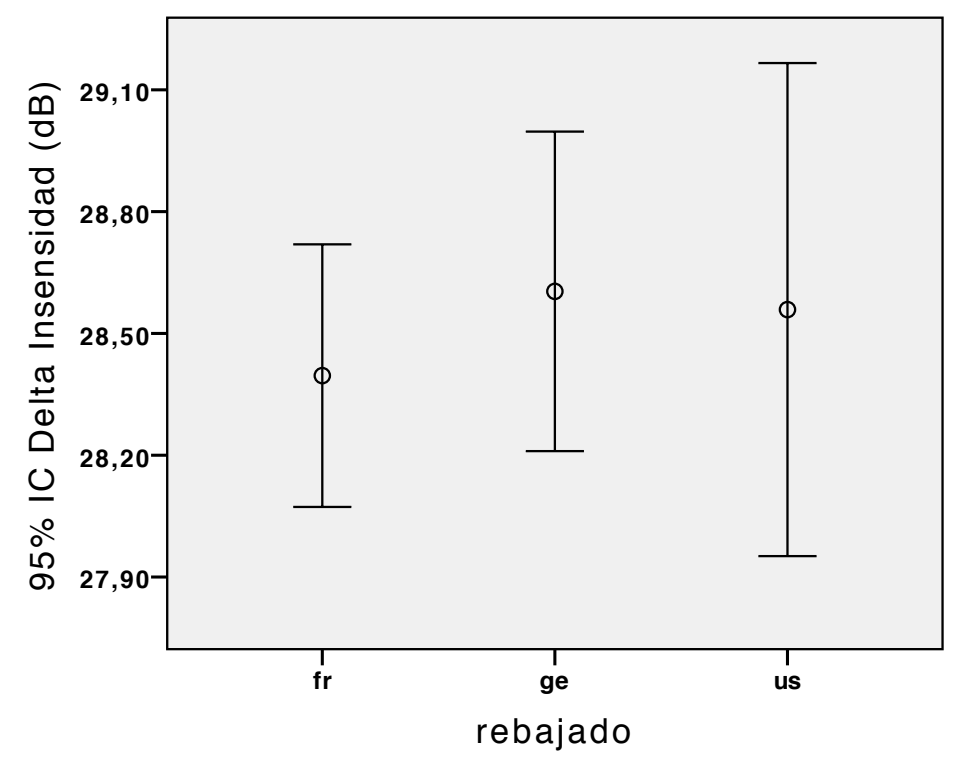

Figura 4.68. Media con intervalo de confianza de la diferencia de intensidad (en dB) por tipos de rebajado.

\begin{tabular}{|l|c|c|}
\hline rebajado & \multicolumn{1}{c|}{ t } & \multicolumn{1}{c|}{ Sig. } \\
\hline fr - ge & $-1,108$ & 0,273 \\
\hline fr - us & $-0,470$ & 0,640 \\
\hline ge - us & 0,126 & 0,900 \\
\hline
\end{tabular}

Tabla 4.23. Resumen del análisis de la prueba T pareada comparando el delta de intensidad (en dB) para los diferentes estilos de rebajado.

Se observa que el oboísta $(\mathrm{F}=3,68, p<, 001)$ sí tiene un influencia en la realización del ejercicio para conseguir un delta de intensidad mayor, y que el estilo de rebajado tiene un efecto cruzado con el oboísta $(\mathrm{F}=2,4, p=, 001)$ como se puede observar en la tabla 4.24 (cf. A.53 para más detalle). La figura 4.69 no muestra una tendencia clara del comportamiento del estilo de rebajado en función del oboísta. 


\begin{tabular}{|l|r|r|r|r|r|}
\hline Origen & \multicolumn{1}{|c|}{$\begin{array}{c}\text { Suma de } \\
\text { cuadrados tipo III }\end{array}$} & \multicolumn{1}{c|}{ gl } & \multicolumn{1}{c|}{$\begin{array}{c}\text { Media } \\
\text { cuadrática }\end{array}$} & \multicolumn{1}{c|}{ F } & \multicolumn{1}{c|}{ Sig. } \\
\hline Modelo corregido & 206,074 & 32 & 6,440 & 2,681 & 0,000 \\
\hline Intersección & 137508,541 & 1 & 137508,541 & 57241,082 & 0,000 \\
\hline rebajado & 0,682 & 2 & 0,341 & 0,142 & 0,868 \\
\hline oboista & 88,499 & 10 & 8,850 & 3,684 & 0,000 \\
\hline rebajado * oboista & 116,144 & 20 & 5,807 & 2,417 & 0,001 \\
\hline
\end{tabular}

Tabla 4.24. Análisis de varianza factorial de la variable delta de la intensidad (en $\mathrm{dB}$ ) para los factores rebajado y oboísta.

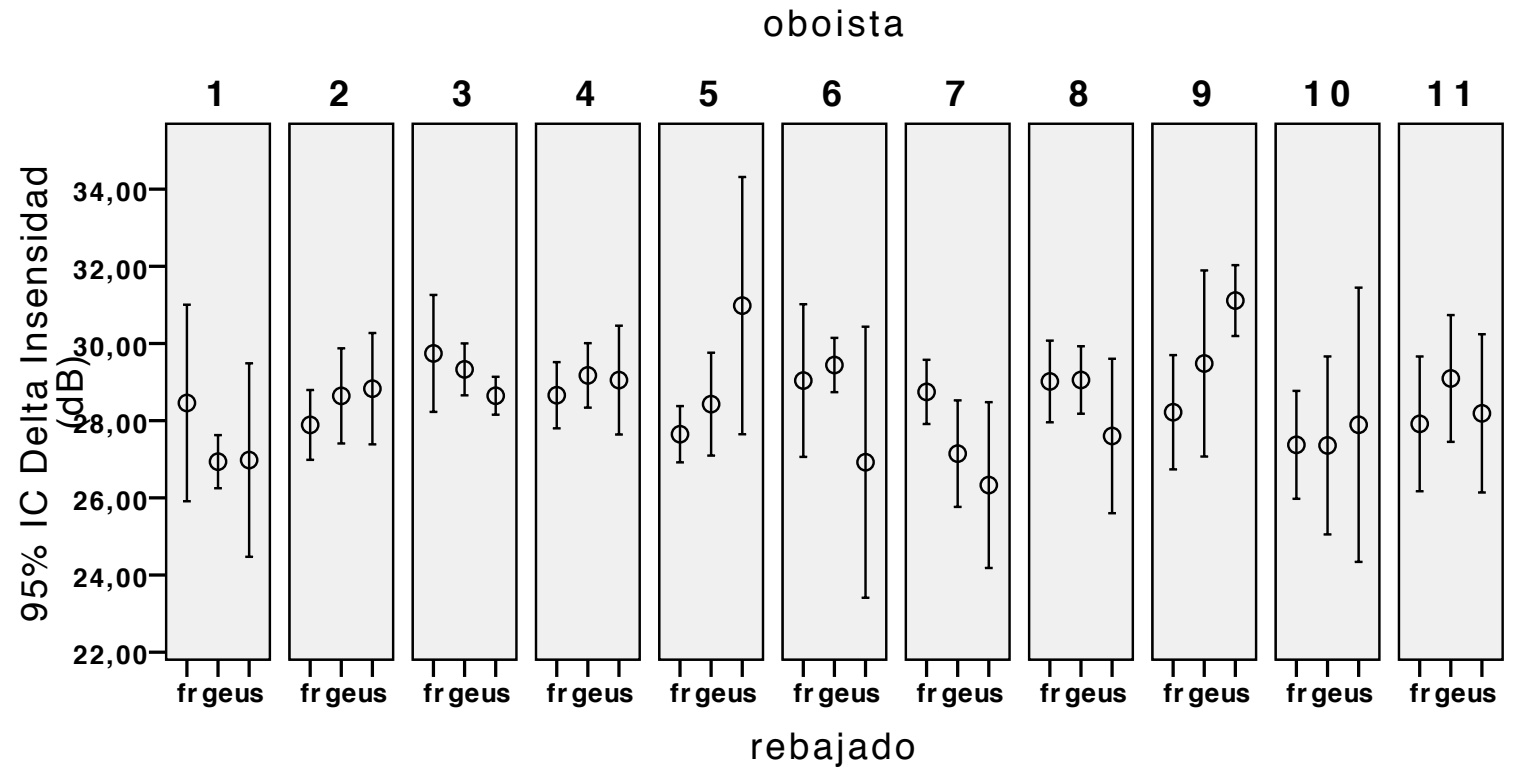

Figura 4.69. Medias con intervalo de confianza de la diferencia de intensidad (en dB) por estilo de rebajado y oboísta.

\subsubsection{Correlación entre ámbito de intensidad y de afinación}

Se debe verificar si existe una correlación (tabla 4.25) entre la amplitud del delta de intensidad conseguido (elemento deseado) y la amplitud del delta de frecuencia (elemento indeseado). Existe una correlación muy significativa $(p=, 001)$ aunque débil $(\mathrm{r}=, 241)$ con lo que se puede estimar que el mayor ámbito de intensidad está asociado a una mayor caída de afinación, aunque no es sistemático. Esto se puede comprobar en la tabla 4.26, donde se ve que para ciertos oboístas no hay ninguna correlación significativa entre delta de intensidad y de afinación (e incluso la correlación es negativa), para otros hay una correlación marcada y significativa. 


\begin{tabular}{|l|l|r|r|}
\hline \multicolumn{3}{|c|}{ Correlaciones } \\
\hline \multirow{3}{*}{ Delta F0 (st) } & & Delta F0 (st) & \multicolumn{1}{c|}{ Delta Insensidad (dB) } \\
\cline { 2 - 5 } & Corr. & & 1 \\
\cline { 2 - 5 } & Sig. & & 0,001 \\
\cline { 2 - 4 } & $\mathrm{N}$ & 181 & 181 \\
\hline
\end{tabular}

Tabla 4.25. Correlación de Pearson y significatividad bilateral entre el delta de intensidad y de afinación.

\begin{tabular}{|c|c|c|c|c|}
\hline \multicolumn{5}{|c|}{ Correlaciones } \\
\hline oboísta & & & Delta F0 (st) & Delta Insensidad (dB) \\
\hline \multirow[t]{2}{*}{1} & \multirow[t]{2}{*}{ Delta F0 (st) } & Corr. & 1 & 0,378 \\
\hline & & Sig. & & 0,316 \\
\hline \multirow[t]{2}{*}{2} & \multirow[t]{2}{*}{ Delta F0 (st) } & Corr. & 1 & $-0,293$ \\
\hline & & Sig. & & 0,238 \\
\hline \multirow[t]{2}{*}{3} & \multirow[t]{2}{*}{ Delta F0 (st) } & Corr. & 1 & $-0,083$ \\
\hline & & Sig. & & 0,744 \\
\hline \multirow[t]{2}{*}{4} & \multirow[t]{2}{*}{ Delta F0 (st) } & Corr. & 1 & 0,117 \\
\hline & & Sig. & & 0,644 \\
\hline \multirow[t]{2}{*}{5} & \multirow[t]{2}{*}{ Delta F0 (st) } & Corr. & 1 & $-0,090$ \\
\hline & & Sig. & & 0,721 \\
\hline \multirow[t]{2}{*}{6} & \multirow[t]{2}{*}{ Delta F0 (st) } & Corr. & 1 & 0,494 \\
\hline & & Sig. & & 0,146 \\
\hline \multirow[t]{2}{*}{7} & \multirow[t]{2}{*}{ Delta F0 (st) } & Corr. & 1 &, $673^{* *}$ \\
\hline & & Sig. & & 0,002 \\
\hline \multirow[t]{2}{*}{8} & \multirow[t]{2}{*}{ Delta F0 (st) } & Corr. & 1 & 0,290 \\
\hline & & Sig. & & 0,243 \\
\hline \multirow[t]{2}{*}{9} & \multirow[t]{2}{*}{ Delta F0 (st) } & Corr. & 1 & ,588* \\
\hline & & Sig. & & 0,010 \\
\hline \multirow[t]{2}{*}{10} & \multirow[t]{2}{*}{ Delta F0 (st) } & Corr. & 1 & 0,363 \\
\hline & & Sig. & & 0,139 \\
\hline \multirow[t]{2}{*}{11} & \multirow[t]{2}{*}{ Delta F0 (st) } & Corr. & 1 & $-0,205$ \\
\hline & & Sig. & & 0,414 \\
\hline \multicolumn{5}{|c|}{ **. La correlación es significativa al nivel 0,01 (bilateral). } \\
\hline \multicolumn{5}{|c|}{ *. La correlación es significante al nivel 0,05 (bilateral). } \\
\hline
\end{tabular}

Tabla 4.26. Correlación de Pearson y significatividad bilateral ( $\mathrm{N}=18$ para todos los casos, excepto para el oboísta $1 \mathrm{~N}=9$ ) entre el delta de intensidad y de afinación para los diferentes oboístas.

Al analizar las lengüetas de todos los oboístas, se observa que la lengüeta con el molde 107 y grosor 57 en el oboísta 8 es la lengüeta donde más diferencias de frecuencia existe entre rebajados. Aunque en la tabla 4.36 se puede ver que la correlación entre el delta de la afinación y el de la intensidad en el oboísta 8 no es significativa, la figura 4.70 muestra gráficamente los efectos de los rebajados: caídas y subidas de afinación y de intensidad como en la alemana, o descensos más progresivos como en la americana. 

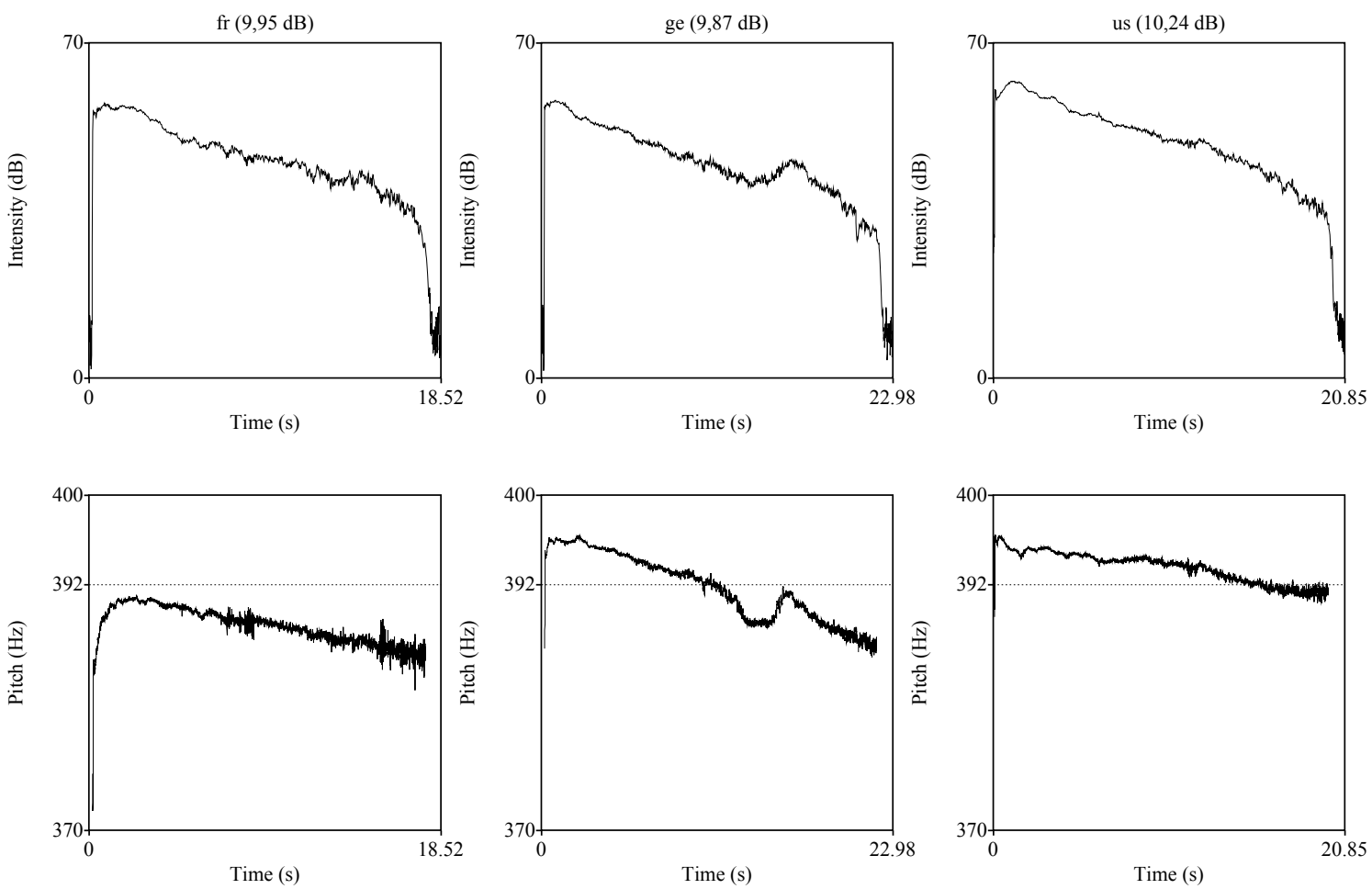

Figura 4.70. Evolución de la intensidad (en dB, arriba) y la frecuencia (en Hz, abajo) de las lengüetas francesa, alemana y americana, molde 107 y grosor 57/100 mm en el oboísta 8 . Se marca la referencia del $\mathrm{Sol}_{4}(392 \mathrm{~Hz})$.

\subsubsection{Respuestas acústicas en función del ejercicio pianissimo}

Este ejercicio se realiza al interpretar la nota si4 con la mínima intensidad sonora posible. Una buena ejecución implica:

1) una intensidad mínima, para averiguar qué lengüeta consigue tocar más piano.

2) una estabilidad en la afinación, ya que en el transcurso del pianissimo es posible una caída de la afinación. Para ello se mide la diferencia entre el punto máximo y mínimo de la frecuencia (delta frecuencia) en $\mathrm{Hz}$.

\subsubsection{Intensidad mínima}

Un ANOVA de varios factores muestra en la tabla 4.27 (cf. A.54 para más detalle), al analizar los diferentes elementos de fabricación de la lengüeta eliminando la posible influencia del oboísta en la intensidad, que el rebajado es el único factor que influye de forma significativa $\left(\mathrm{F}=4,61, p=, 011, \eta^{2}=, 051\right)$. Ninguno de los efectos cruzados es significativo. En la figura 4.71 se observa claramente que el estilo de rebajado francés es el 
que menos intensidad consigue, por lo que es el estilo de rebajado más conveniente para la interpretación, lo que se verifica a través de una prueba T pareada (tabla 4.28, $c f$. A.55 para más detalle).

\begin{tabular}{|l|r|r|r|r|r|r|}
\hline Origen & \multicolumn{1}{c|}{$\begin{array}{c}\text { Suma de } \\
\text { cuadrados tipo } \\
\text { III }\end{array}$} & \multicolumn{1}{|c|}{ gl } & $\begin{array}{c}\text { Media } \\
\text { cuadrática }\end{array}$ & F & Sig. & $\begin{array}{c}\text { Eta al } \\
\text { cuadrado } \\
\text { parcial }\end{array}$ \\
\hline Modelo corregido & 19,109 & 17 & 1,124 & 1,138 & 0,322 & 0,101 \\
\hline Intersección & 0,022 & 1 & 0,022 & 0,022 & 0,882 & 0,000 \\
\hline rebajado & 9,116 & 2 & 4,558 & 4,614 & 0,011 & 0,051 \\
\hline molde & 1,430 & 2 & 0,715 & 0,724 & 0,486 & 0,008 \\
\hline grosor & 2,402 & 1 & 2,402 & 2,432 & 0,121 & 0,014 \\
\hline rebajado * molde & 3,020 & 4 & 0,755 & 0,764 & 0,550 & 0,017 \\
\hline rebajado * grosor & 1,279 & 2 & 0,639 & 0,647 & 0,525 & 0,007 \\
\hline molde * grosor & 0,621 & 2 & 0,310 & 0,314 & 0,731 & 0,004 \\
\hline
\end{tabular}

Tabla 4.27. Análisis de varianza factorial de la intensidad (en dB) para los factores rebajado, molde y grosor (elementos de fabricación de la lengüeta).

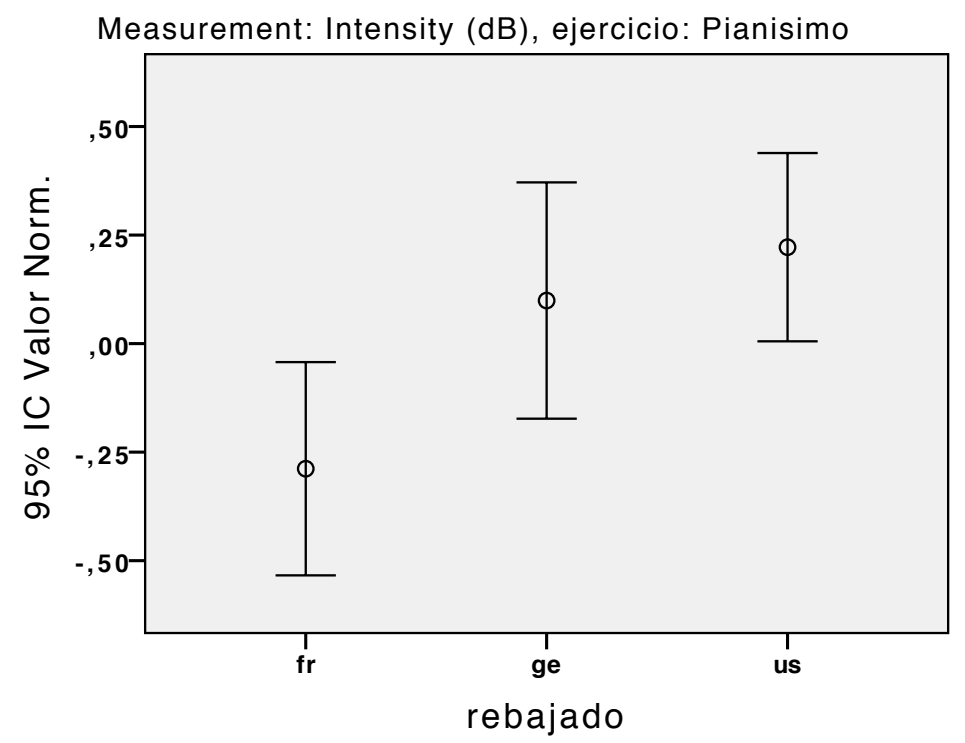

Figura 4.71. Media con intervalo de confianza de la diferencia de intensidad (en dB) por tipos de rebajado.

\begin{tabular}{|c|c|l|c|c|}
\hline medida & ejercicio & \multicolumn{1}{|c|}{ rebajado } & \multicolumn{1}{c|}{ t } & \multicolumn{1}{c|}{ Sig. } \\
\hline Intensity (dB) & Pianissimo & $\mathrm{fr}-\mathrm{ge}$ & $-2,612$ & 0,012 \\
\cline { 3 - 5 } & & $\mathrm{fr}-\mathrm{us}$ & $-4,857$ & 0,000 \\
\cline { 3 - 5 } & & $\mathrm{ge}-\mathrm{us}$ & $-1,408$ & 0,165 \\
\hline
\end{tabular}

Tabla 4.28. Resumen del análisis de la prueba $\mathrm{T}$ pareada comparando la intensidad (en $\mathrm{dB}$ ) para los diferentes estilos de rebajado.

Si se incorpora ahora al análisis el factor oboísta, se observa en la tabla 4.29 (cf. A. 56 para más detalle), que es el factor más influyente $\left(\mathrm{F}=28,85, p<, 001, \eta^{2}=, 648\right)$, aunque tanto el rebajado como el oboísta tienen una significatividad importante $(p<, 001)$. Sin 
embargo, su efecto cruzado no es significativo, como se puede apreciar en la figura 4.72: en general, el rebajado francés consigue producir una menor intensidad, pero para los oboístas el resultado no es significativo.

\begin{tabular}{|l|r|r|r|r|r|r|}
\hline Origen & \multicolumn{1}{|c|}{$\begin{array}{c}\text { Suma de } \\
\text { cuadrados tipo } \\
\text { III }\end{array}$} & \multicolumn{1}{|c|}{ gl } & \multicolumn{1}{c|}{$\begin{array}{c}\text { Media } \\
\text { cuadrática }\end{array}$} & \multicolumn{1}{c|}{ F } & Sig. & \multicolumn{1}{c|}{$\begin{array}{c}\text { Eta al } \\
\text { cuadrado } \\
\text { parcial }\end{array}$} \\
\hline Modelo corregido & 128,614 & 32 & 4,019 & 10,450 & 0,000 & 0,680 \\
\hline Intersección & 2,869 & 1 & 2,869 & 7,460 & 0,007 & 0,045 \\
\hline rebajado & 6,219 & 2 & 3,110 & 8,085 & 0,000 & 0,093 \\
\hline oboista & 110,987 & 10 & 11,099 & 28,856 & 0,000 & 0,648 \\
\hline rebajado * oboista & 6,392 & 20 & 0,320 & 0,831 & 0,673 & 0,096 \\
\hline
\end{tabular}

Tabla 4.29. Análisis de varianza factorial de la intensidad (en dB) para los factores rebajado y oboísta.

Measurement: Intensity (dB), ejercicio: Pianisimo

oboista

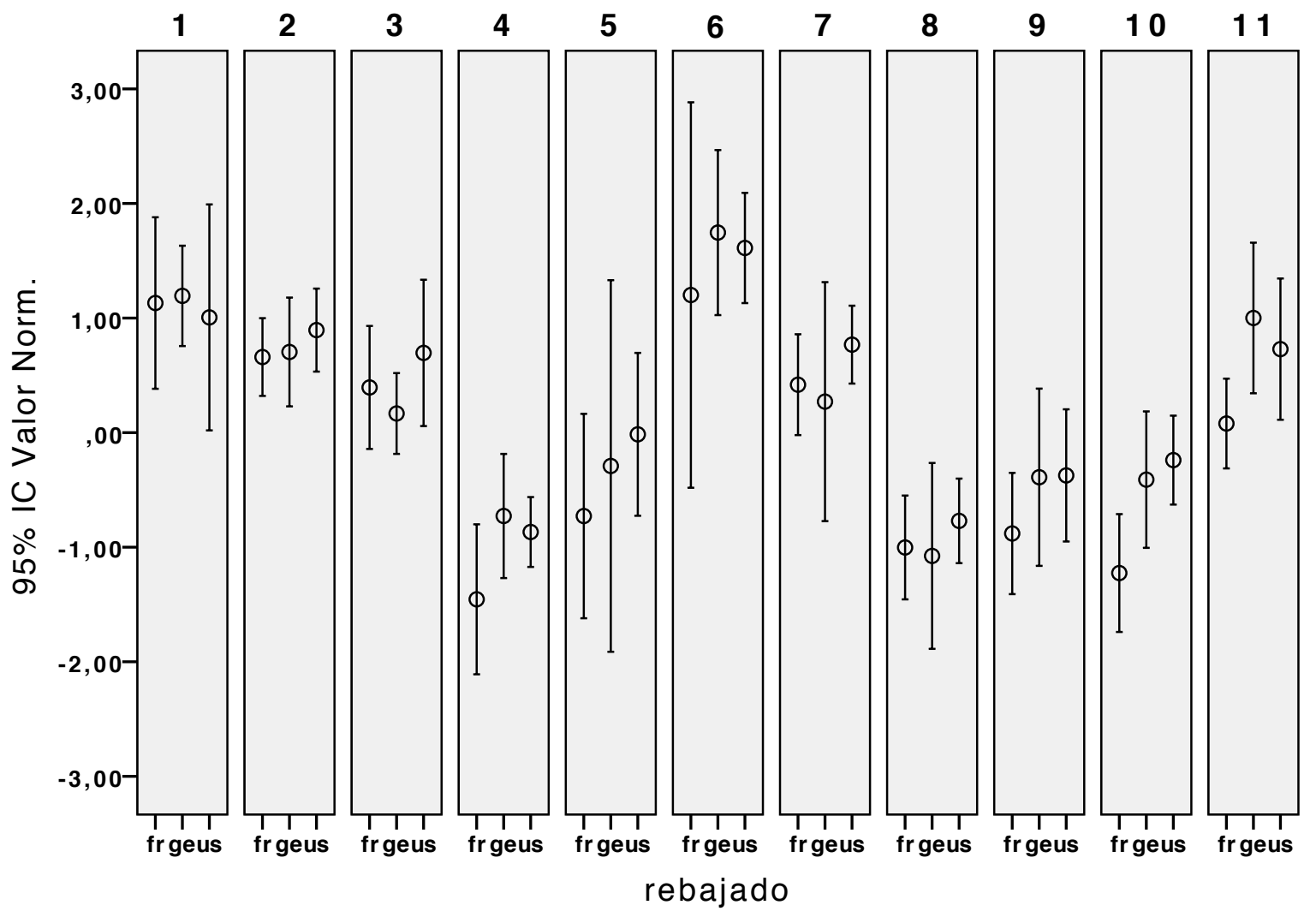

Figura 4.72. Medias con intervalo de confianza de la intensidad (en dB) por estilo de rebajado y oboísta.

\subsubsection{Estabilidad en la afinación}

Un ANOVA de varios factores muestra en la tabla 4.30 ( $c f$. A.57 para más detalle) que el rebajado es el único factor que influye de forma muy significativa $(\mathrm{F}=6,04, p=, 003$, $\left.\eta^{2}=, 095\right)$. Ninguno de los efectos cruzados es significativo. En la figura 4.73 se observa, 
que el estilo de rebajado francés es el que mayor desviación en la afinación consigue, convirtiéndose en el rebajado menos conveniente desde el punto de vista de la interpretación, lo que se verifica a través de una prueba T pareada (tabla 4.31, $c f$. A.58 para más detalle).

\begin{tabular}{|l|r|r|r|r|r|r|}
\hline Origen & $\begin{array}{c}\text { Suma de } \\
\text { cuadrados tipo } \\
\text { III }\end{array}$ & gl & $\begin{array}{c}\text { Media } \\
\text { cuadrática }\end{array}$ & F & Sig. & $\begin{array}{c}\text { Eta al cuadrado } \\
\text { parcial }\end{array}$ \\
\hline Modelo corregido & 20,403 & 11 & 1,855 & 1,892 & 0,047 & 0,153 \\
\hline Intersección & 0,121 & 1 & 0,121 & 0,124 & 0,726 & 0,001 \\
\hline rebajado & 11,844 & 2 & 5,922 & 6,040 & 0,003 & 0,095 \\
\hline molde & 0,406 & 1 & 0,406 & 0,414 & 0,521 & 0,004 \\
\hline grosor & 0,0000892 & 1 & 0,0000892 & 0,000 & 0,992 & 0,000 \\
\hline rebajado * molde & 0,353 & 2 & 0,176 & 0,180 & 0,836 & 0,003 \\
\hline rebajado * grosor & 0,439 & 2 & 0,220 & 0,224 & 0,800 & 0,004 \\
\hline molde * grosor & 3,886 & 1 & 3,886 & 3,964 & 0,049 & 0,033 \\
\hline
\end{tabular}

Tabla 4.30. Análisis de varianza factorial del delta de afinación (en $\mathrm{Hz}$ ) para los factores rebajado, molde y grosor (elementos de fabricación de la lengüeta).

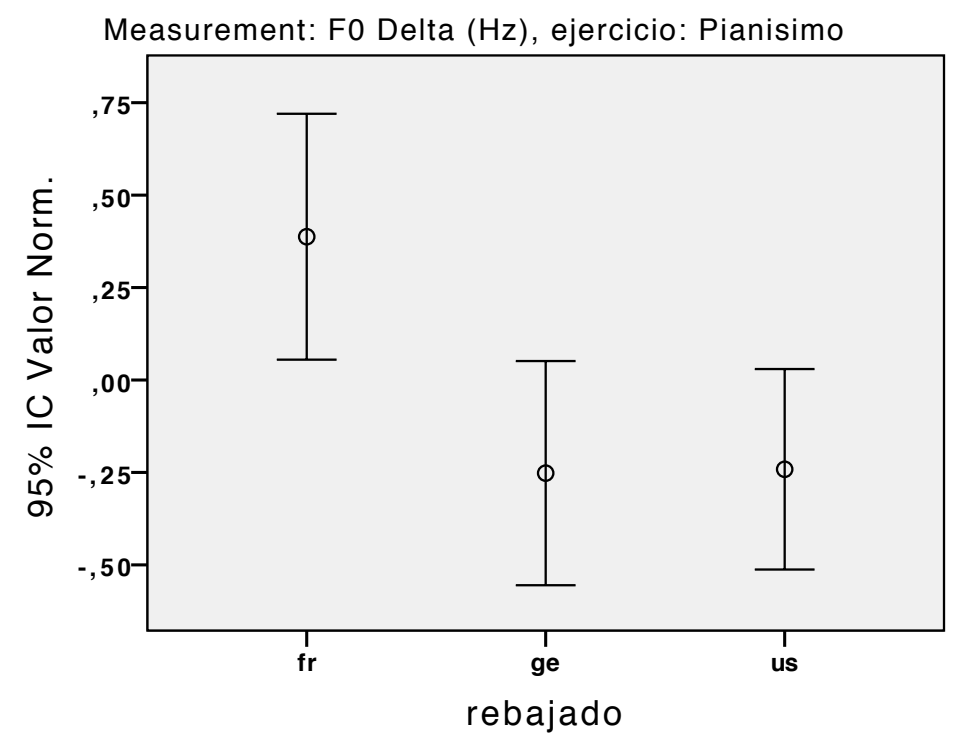

Figura 4.73. Media con intervalo de confianza del delta de afinación (en $\mathrm{Hz}$ ) por tipos de rebajado.

\begin{tabular}{|c|c|l|c|c|}
\hline medida & ejercicio & rebajado & \multicolumn{1}{c|}{ t } & \multicolumn{1}{c|}{ Sig. } \\
\hline F0 Delta (Hz) & Pianissimo & fr - ge & 2,337 & 0,025 \\
\cline { 3 - 5 } & & fr - us & 3,365 & 0,002 \\
\cline { 3 - 5 } & & ge - us & 0,068 & 0,946 \\
\hline
\end{tabular}

Tabla 4.31. Resumen del análisis de la prueba T pareada comparando el delta de afinación (en Hz) para los diferentes estilos de rebajado. 
Si se incorpora al análisis el factor oboísta, se observa en la tabla 4.32 (cf. tabla A. 59 para más detalle), que es el factor más influyente $\left(\mathrm{F}=3,21, p=, 001, \eta^{2}=, 255\right)$, aunque tanto el rebajado como el oboísta tienen una significatividad importante. Sin embargo, su efecto cruzado no es significativo, como se puede apreciar en la figura 4.74: el rebajado francés consigue una mayor inestabilidad en la afinación, pero para los oboístas el resultado no es significativo.

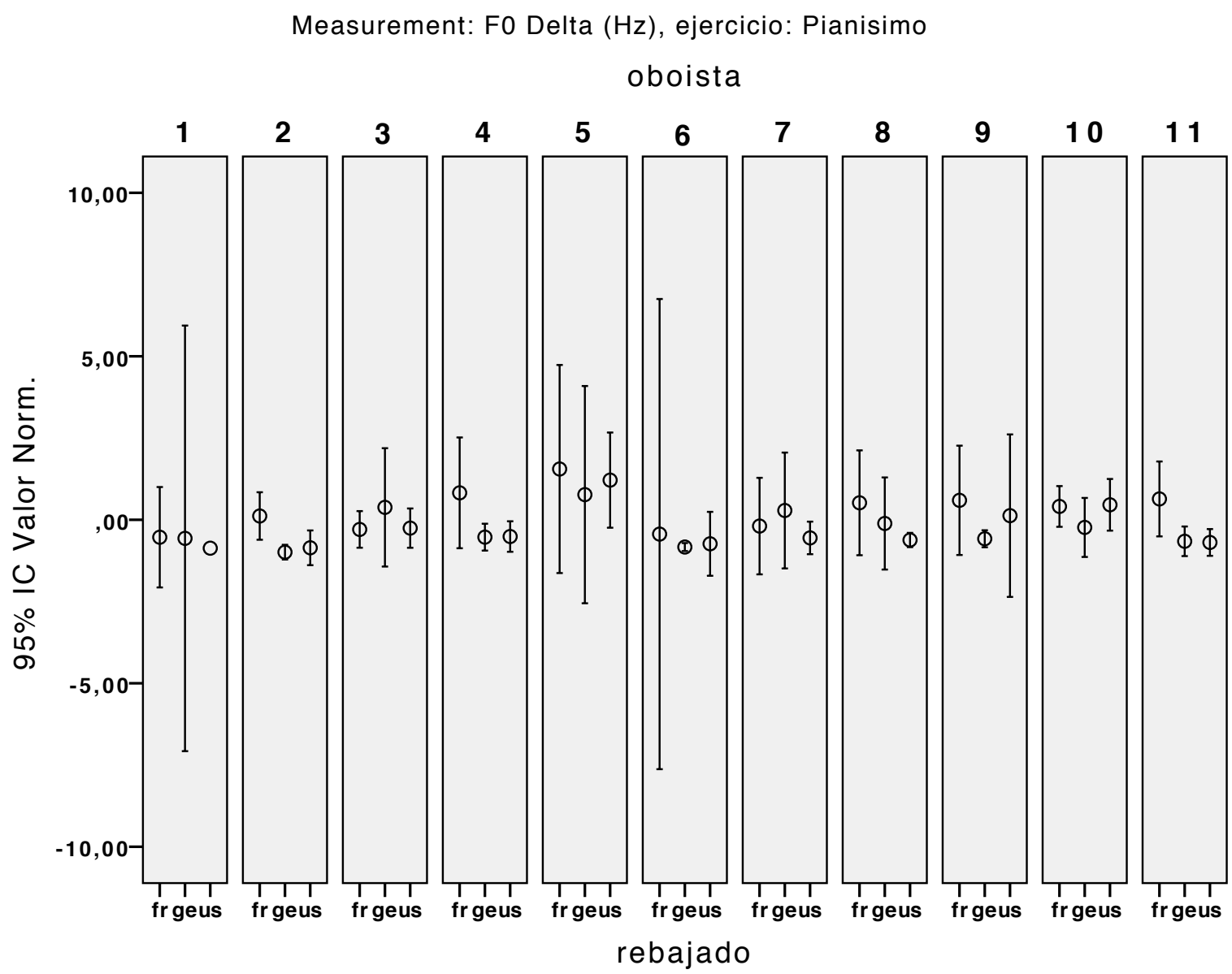

Figura 4.74. Medias con intervalos de confianza del delta de afinación (en Hz) por estilo de rebajado y oboísta.

\begin{tabular}{|l|r|r|r|r|r|r|}
\hline Origen & $\begin{array}{c}\text { Suma de cuadrados } \\
\text { tipo III }\end{array}$ & gl & \multicolumn{1}{c|}{$\begin{array}{c}\text { Media } \\
\text { cuadrática }\end{array}$} & F & Sig. & $\begin{array}{c}\text { Eta al cuadrado } \\
\text { parcial }\end{array}$ \\
\hline Modelo corregido & 52,756 & 32 & 1,649 & 1,928 & 0,008 & 0,396 \\
\hline Intersección & 1,035 & 1 & 1,035 & 1,210 & 0,274 & 0,013 \\
\hline rebajado & 8,769 & 2 & 4,385 & 5,127 & 0,008 & 0,098 \\
\hline oboista & 27,505 & 10 & 2,751 & 3,216 & 0,001 & 0,255 \\
\hline rebajado * oboista & 13,662 & 20 & 0,683 & 0,799 & 0,709 & 0,145 \\
\hline
\end{tabular}

Tabla 4.32. Análisis de varianza factorial del delta de afinación (en Hz) para los factores rebajado y oboísta. 


\subsubsection{Respuestas acústicas en función del ejercicio fortissimo}

Este ejercicio se realiza al interpretar la nota si4 con la máxima intensidad sonora posible. Una buena ejecución implica:

1) una intensidad máxima, para averiguar qué lengüeta consigue tocar más forte.

2) la riqueza en el timbre, es decir, al analizar el centro de gravedad del espectro se puede averiguar qué rebajado contiene un mayor componente armónico.

\subsubsection{Intensidad máxima}

Un ANOVA de varios factores muestra en la tabla 4.33 ( $c f$. A.60 para más detalle) que ninguno de los factores individuales influyen de forma significativa, además sus efectos cruzados no son significativos. En la figura 4.75 se observa claramente que el estilo de rebajado francés es el que menor intensidad consigue, por lo que es el menos conveniente para la interpretación de este ejercicio. El rebajado alemán es el que mayor intensidad consigue, seguido muy de cerca del americano, lo que se verifica a través de una prueba T pareada (tabla 4.34, cf. A.61 para más detalle).

\begin{tabular}{|l|r|r|r|r|r|r|}
\hline Origen & $\begin{array}{c}\text { Suma de cuadrados } \\
\text { tipo III }\end{array}$ & gl & $\begin{array}{c}\text { Media } \\
\text { cuadrática }\end{array}$ & F & Sig. & $\begin{array}{c}\text { Eta al cuadrado } \\
\text { parcial }\end{array}$ \\
\hline Modelo corregido & 12,325 & 17 & 0,725 & 0,706 & 0,794 & 0,065 \\
\hline Intersección & 0,015 & 1 & 0,015 & 0,014 & 0,905 & 0,000 \\
\hline rebajado & 5,383 & 2 & 2,692 & 2,620 & 0,076 & 0,030 \\
\hline molde & 3,041 & 2 & 1,520 & 1,480 & 0,231 & 0,017 \\
\hline grosor & 0,746 & 1 & 0,746 & 0,726 & 0,395 & 0,004 \\
\hline rebajado * molde & 0,357 & 4 & 0,089 & 0,087 & 0,986 & 0,002 \\
\hline rebajado * grosor & 0,757 & 2 & 0,379 & 0,369 & 0,692 & 0,004 \\
\hline molde * grosor & 0,444 & 2 & 0,222 & 0,216 & 0,806 & 0,003 \\
\hline
\end{tabular}

Tabla 4.33. Análisis de varianza factorial de la intensidad (en dB) para los factores rebajado, molde y grosor (elementos de fabricación de la lengüeta). 


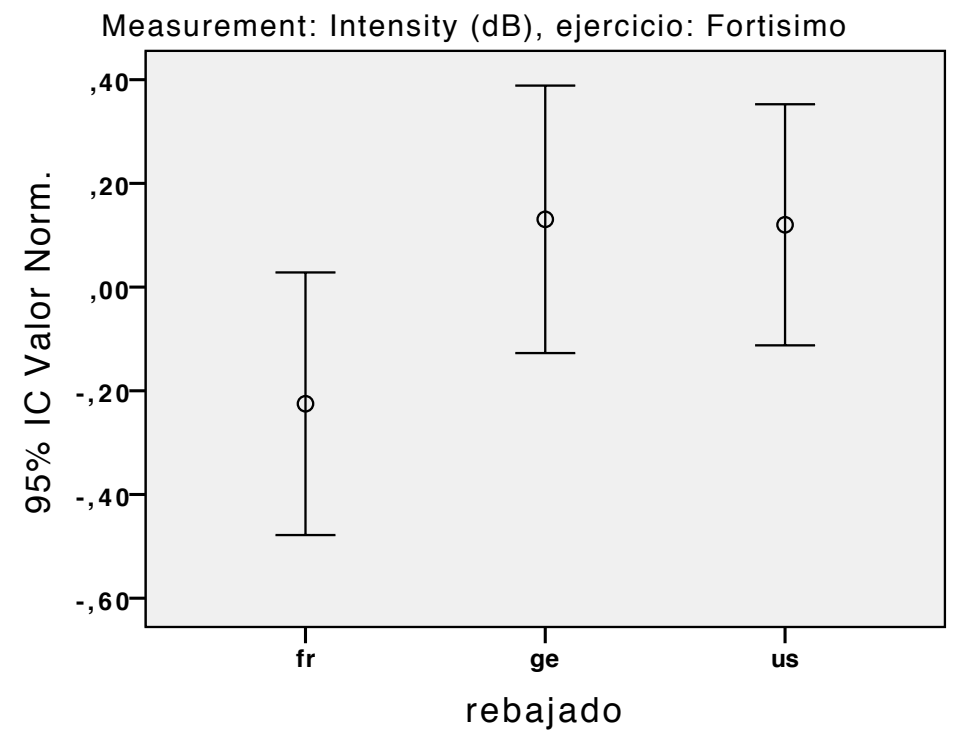

Figura 4.75. Media con intervalo de confianza de la diferencia de intensidad (en dB) por tipos de rebajado.

\begin{tabular}{|c|c|l|r|r|}
\hline medida & ejercicio & \multicolumn{1}{|c|}{ rebajado } & \multicolumn{1}{c|}{ t } & \multicolumn{1}{c|}{ Sig. } \\
\hline Intensity $(\mathrm{dB})$ & \multirow{2}{*}{ Fortissimo } & fr - ge & $-5,472$ & 0,000 \\
\cline { 3 - 5 } & & fr - us & $-4,568$ & 0,000 \\
\cline { 3 - 5 } & & ge - us & 0,046 & 0,964 \\
\hline
\end{tabular}

Tabla 4.34. Resumen del análisis de la prueba T pareada comparando la intensidad (en $\mathrm{dB}$ ) para los diferentes estilos de rebajado.

Al incorporar al análisis el factor oboísta, se observa en la tabla 4.35 (cf. A.62 para más detalle) que es el factor más influyente $\left(\mathrm{F}=109,62, p<, 001, \eta^{2}=, 875\right)$, aunque tanto el rebajado como el oboísta tienen una significatividad importante $(p<, 001)$ su efecto cruzado no es significativo, como se puede apreciar en la figura 4.76: el rebajado francés no consigue producir una intensidad equiparable a la de los otros rebajados (excepto en el oboísta 1), pero para los oboístas el resultado no es significativo.

\begin{tabular}{|l|r|r|r|r|r|r|}
\hline Origen & \multicolumn{1}{|c|}{$\begin{array}{c}\text { Suma de } \\
\text { cuadrados tipo III }\end{array}$} & \multicolumn{1}{c|}{ gl } & $\begin{array}{c}\text { Media } \\
\text { cuadrática }\end{array}$ & \multicolumn{1}{c|}{ F } & Sig. & $\begin{array}{c}\text { Eta al cuadrado } \\
\text { parcial }\end{array}$ \\
\hline Modelo corregido & 166,636 & 32 & 5,207 & 36,557 & 0,000 & 0,882 \\
\hline Intersección & 0,972 & 1 & 0,972 & 6,823 & 0,010 & 0,042 \\
\hline rebajado & 3,344 & 2 & 1,672 & 11,737 & 0,000 & 0,130 \\
\hline oboista & 156,157 & 10 & 15,616 & 109,625 & 0,000 & 0,875 \\
\hline rebajado * oboista & 2,790 & 20 & 0,140 & 0,979 & 0,490 & 0,111 \\
\hline
\end{tabular}

Tabla 4.35. Análisis de varianza factorial de la intensidad (en dB) para los factores rebajado y oboísta. 
Measurement: Intensity $(\mathrm{dB})$, ejercicio: Fortisimo oboista

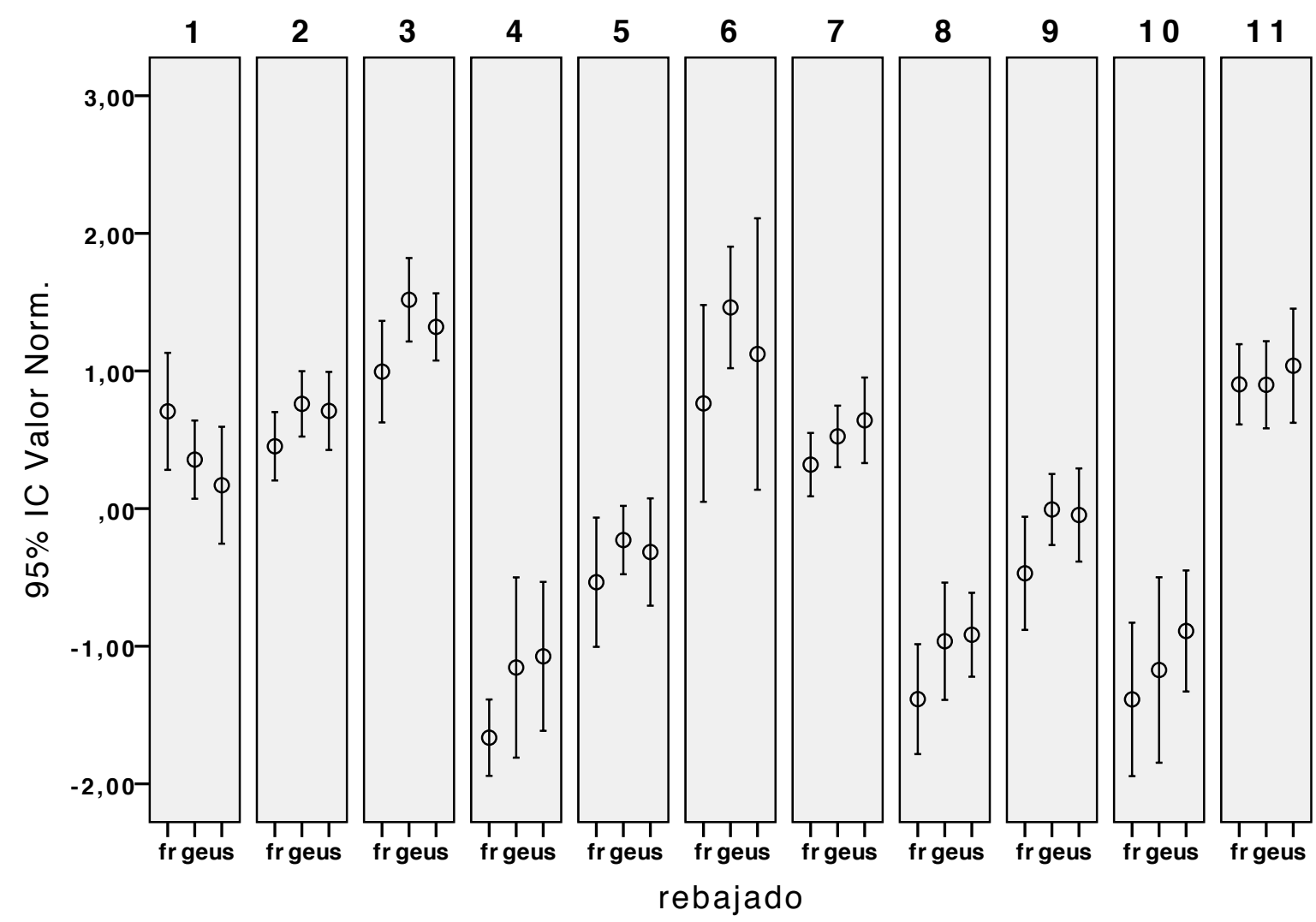

Figura 4.76. Medias con intervalo de confianza de la intensidad por estilo de rebajado y oboísta.

\subsubsection{Riqueza en el timbre}

Un ANOVA de varios factores muestra en la tabla 4.36 ( $c f$. A.63 para más detalle) que todos los elementos de fabricación son significativos. El rebajado es el más significativo $\left(\mathrm{F}=17,73, p<, 001, \eta^{2}=, 171\right)$, seguido del molde $\left(\mathrm{F}=7,98, p<, 001, \eta^{2}=, 085\right)$ y el grosor $\left(\mathrm{F}=5,83, p=, 017, \eta^{2}=, 033\right)$, aunque sus efectos cruzados no son significativos. En la figura 4.77 se observa que el estilo de rebajado americano es el que obtiene un centro de gravedad espectral más agudo, por lo que es el estilo de rebajado con una sonoridad más rica en este ejercicio, lo que se verifica a través de una prueba T pareada (tabla 4.37, $c f$. A. 64 para más detalle). 


\begin{tabular}{|l|r|r|r|r|r|r|}
\hline Origen & $\begin{array}{c}\text { Suma de } \\
\text { cuadrados tipo } \\
\text { III }\end{array}$ & \multicolumn{1}{|c|}{ gl } & \multicolumn{1}{c|}{$\begin{array}{c}\text { Media } \\
\text { cuadrática }\end{array}$} & \multicolumn{1}{c|}{ F } & Sig. & $\begin{array}{c}\text { Eta al cuadrado } \\
\text { parcial }\end{array}$ \\
\hline Modelo corregido & 54,495 & 17 & 3,206 & 4,099 & 0,000 & 0,288 \\
\hline Intersección & 0,110 & 1 & 0,110 & 0,141 & 0,708 & 0,001 \\
\hline rebajado & 27,744 & 2 & 13,872 & 17,739 & 0,000 & 0,171 \\
\hline molde & 12,490 & 2 & 6,245 & 7,986 & 0,000 & 0,085 \\
\hline grosor & 4,563 & 1 & 4,563 & 5,835 & 0,017 & 0,033 \\
\hline rebajado * molde & 5,382 & 4 & 1,345 & 1,721 & 0,148 & 0,038 \\
\hline rebajado * grosor & 2,286 & 2 & 1,143 & 1,462 & 0,235 & 0,017 \\
\hline molde * grosor & 0,742 & 2 & 0,371 & 0,474 & 0,623 & 0,005 \\
\hline
\end{tabular}

Tabla 4.36. Análisis de varianza factorial del centro de gravedad del espectro para los factores rebajado, molde y grosor (elementos de fabricación de la lengüeta).

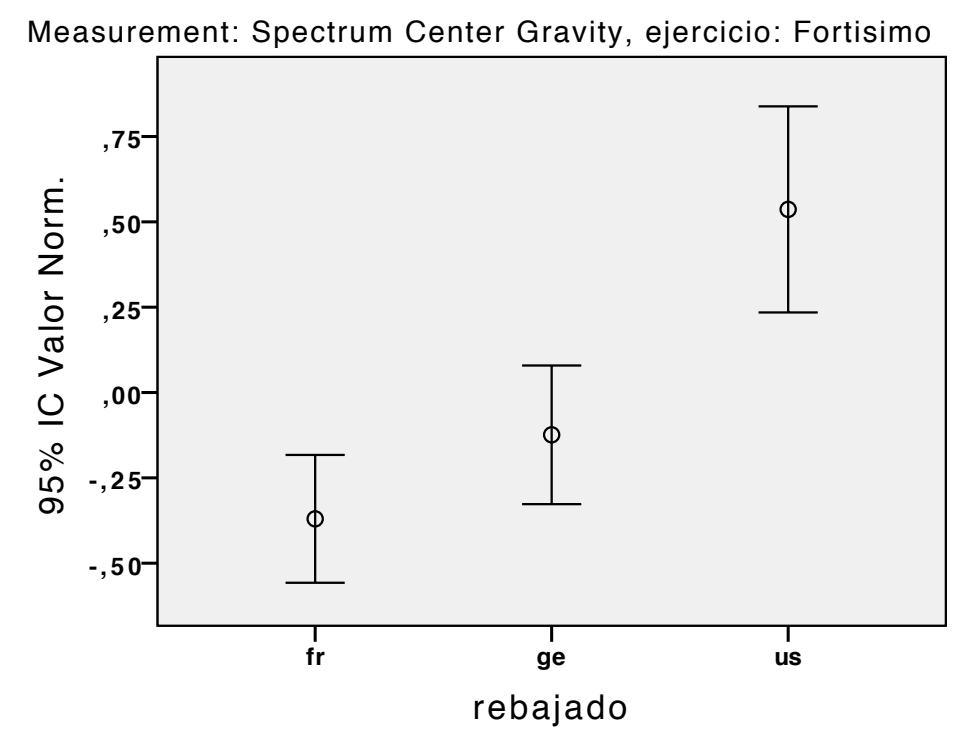

Figura 4.77. Media con intervalo de confianza del centro de gravedad del espectro por tipos de rebajado.

\begin{tabular}{|c|l|l|l|l|}
\hline \multicolumn{1}{|c|}{ medida } & \multicolumn{1}{|c|}{ ejercicio } & \multicolumn{1}{c|}{ rebajado } & \multicolumn{1}{c|}{ t } & \multicolumn{1}{c|}{ Sig. } \\
\hline Spectrum Center Gravity & \multirow{2}{*}{ Fortissimo } & fr - ge & $-1,999$ & 0,051 \\
\cline { 3 - 5 } & & fr - us & $-5,616$ & 0,000 \\
\cline { 3 - 5 } & & ge - us & $-4,662$ & 0,000 \\
\hline
\end{tabular}

Tabla 4.37. Resumen del análisis de la prueba pareada comparando el centro de gravedad del espectro para los diferentes estilos de rebajado.

Si se incorpora al análisis el factor oboísta, se observa en la tabla 4.38 (cf. A.65 para más detalle) que es el factor más influyente $\left(\mathrm{F}=7,03, p<, 001, \eta^{2}=, 310\right)$, aunque tanto el rebajado como el oboísta tienen una significatividad importante $(p<, 001)$ su efecto cruzado no es significativo, como se puede apreciar en la figura 4.78: en general, el rebajado americano consigue un sonido con más riqueza tímbrica, pero para los oboístas el resultado no es significativo. 


\begin{tabular}{|l|r|r|r|r|r|r|}
\hline Origen & \multicolumn{1}{|c|}{$\begin{array}{c}\text { Suma de } \\
\text { cuadrados tipo III }\end{array}$} & gl & $\begin{array}{c}\text { Media } \\
\text { cuadrática }\end{array}$ & \multicolumn{1}{c|}{ F } & Sig. & $\begin{array}{c}\text { Eta al cuadrado } \\
\text { parcial }\end{array}$ \\
\hline Modelo corregido & 88,376 & 32 & 2,762 & 4,309 & 0,000 & 0,468 \\
\hline Intersección & 0,0000107 & 1 & 0,0000107 & 0,000 & 0,997 & 0,000 \\
\hline rebajado & 24,144 & 2 & 12,072 & 18,836 & 0,000 & 0,194 \\
\hline oboista & 45,113 & 10 & 4,511 & 7,039 & 0,000 & 0,310 \\
\hline rebajado * oboista & 15,424 & 20 & 0,771 & 1,203 & 0,258 & 0,133 \\
\hline
\end{tabular}

Tabla 4.38. Análisis de varianza factorial del centro de gravedad del espectro para los factores rebajado y oboísta.

Measurement: Spectrum Center Gravity, ejercicio: Fortisimo

oboista

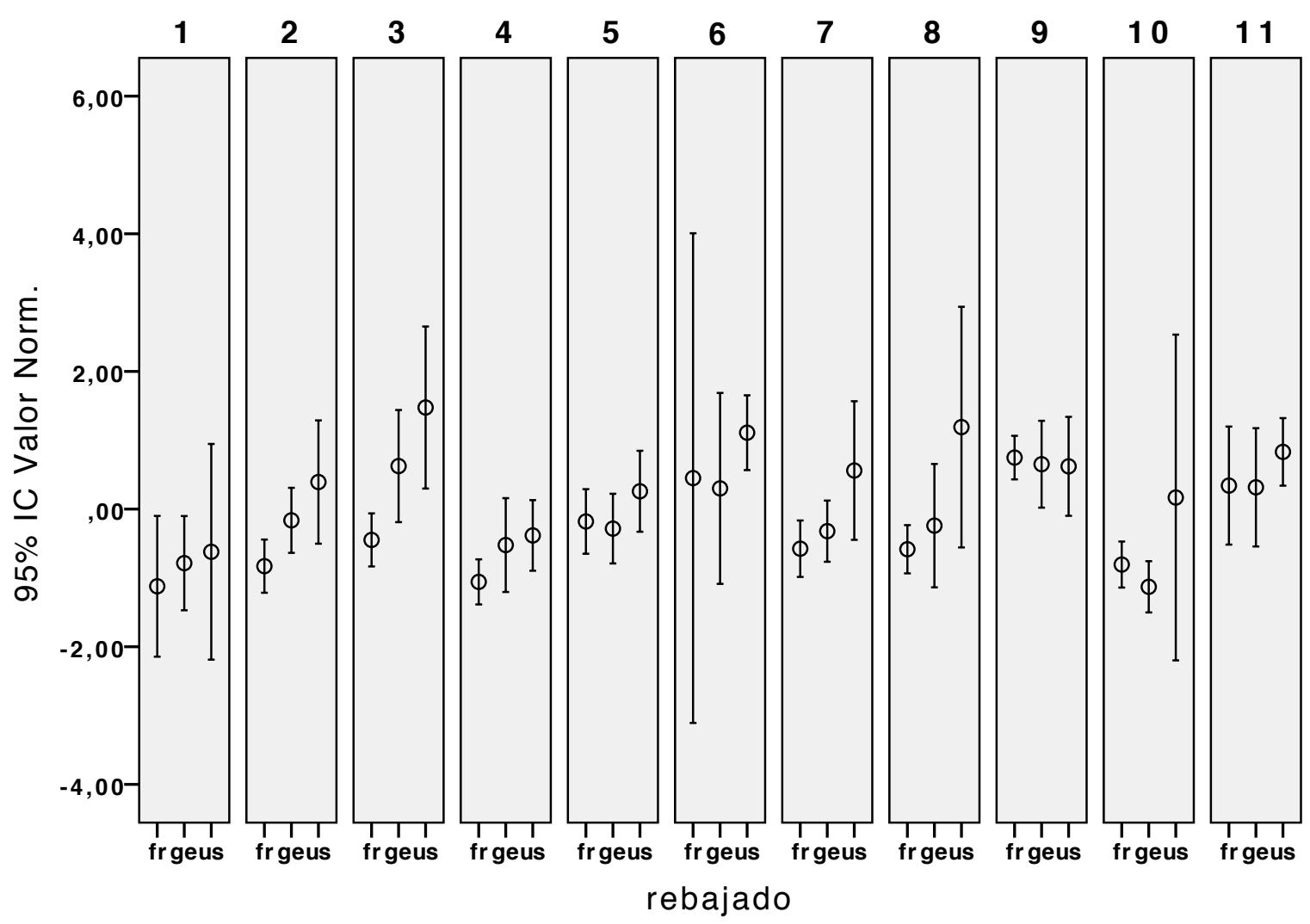

Figura 4.78. Medias con intervalo de confianza del centro de gravedad del espectro por estilo de rebajado y oboísta.

En la figura 4.79 se distingue que el centro de gravedad espectral es claramente más agudo para la lengüeta americana que para el resto, lo que puede apreciarse con más detalle en la figura 4.80 (espectro alisado), en la que se observa que la lengüeta americana tiene mucha más presencia de energía en los armónicos agudos, siendo la parte más grave del espectro casi idéntica en los tres rebajados. Esto provoca a la vez un cambio de intensidad global y un cambio de timbre. 

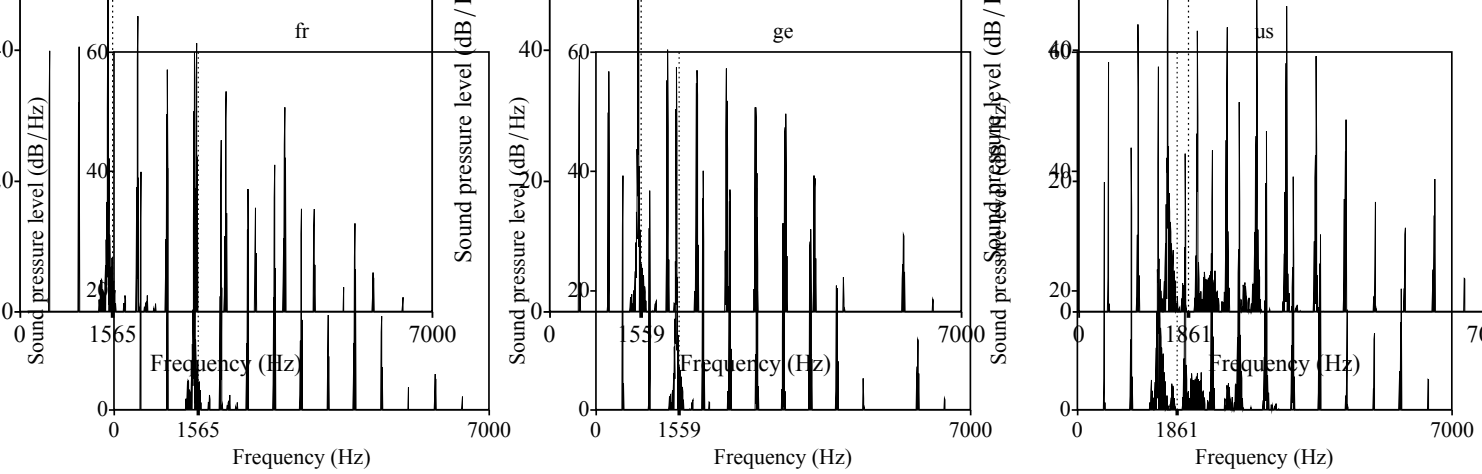

Figura 4.79. Espectros de las lengüetas francesa, alemana y americana para el fortissimo (molde 21 grosor 59 y oboísta 10). La línea de puntos indica la posición del centro de gravedad espectral (valor en Hz).

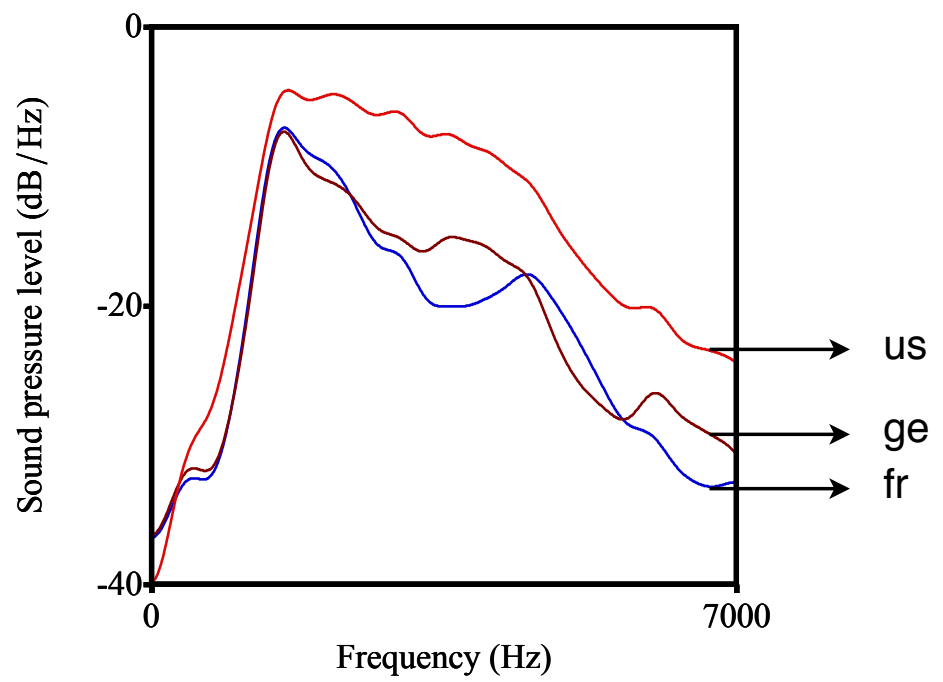

Figura 4.80. Superposición de los espectros alisados (alisado cepstral con ventana de $1000 \mathrm{~Hz}$ ) de las lengüetas francesa (azul), alemana (marrón) y americana (rojo) el fortissimo (molde 21 grosor 59 y oboísta 10).

\subsubsection{Comparación de las lengüetas en el ejercicio fortissimo y pianissimo}

Si se analizan los valores de intensidad de los ejercicios fortissimo y pianissmo de las diferentes lengüetas, se puede observar en la tabla 4.39 que globalmente están los valores correlacionados: si una lengüeta consigue mayor intensidad en el fortissimo, también consigue mayor intensidad en el pianissmo, por lo que no destaca ninguna lengüeta que consiga pianos muy pianos y fortes muy fortes. 


\begin{tabular}{|l|l|r|r|}
\hline \multicolumn{3}{|c|}{ Correlaciones } \\
\hline & \multicolumn{2}{|c|}{ Intensidad $f f(\mathrm{~dB})$} & Intensidad $p p(\mathrm{~dB})$ \\
\hline Intensidad $f f(\mathrm{~dB})$ & Corr. & 1 &, $715^{* *}$ \\
& Sig. & & 0,000 \\
\hline Intensidad $p p(\mathrm{~dB})$ & Corr. &, $715^{* *}$ & 1 \\
& Sig. & 0,000 & \\
\cline { 2 - 4 } & $* *$ La correlación es significativa al nivel 0,01 (bilateral). \\
\hline
\end{tabular}

Tabla 4.39. Correlación de Pearson y significatividad bilateral ( $\mathrm{N}=181$ para todos los casos) entre las intensidades de ejercicio pianissimo y fortissimo.

Un ANOVA de un factor indica que no existen diferencias significativas entre las intensidades conseguidas por las diferentes lengüetas (tabla 4.40 y figura 4.80b). Además, una prueba post hoc de Bonferroni (tabla 4.41) muestra que en las diferencias de intensidades, las lengüetas francesas son las que menor intensidad obtienen siendo, por el contrario, las americanas las que mayor intensidad logran.

\begin{tabular}{|c|c|c|c|c|c|c|}
\hline \multicolumn{7}{|c|}{ ANOVA de un factor } \\
\hline & & $\begin{array}{c}\text { Suma de } \\
\text { cuadrados }\end{array}$ & gl & $\begin{array}{c}\text { Media } \\
\text { cuadrática }\end{array}$ & $\mathbf{F}$ & Sig. \\
\hline \multirow{3}{*}{$\begin{array}{l}\text { Diferencia Intensidad } \\
f f-p p(\mathrm{~dB})\end{array}$} & Inter-grupos & 86,242 & 2 & 43,121 & 1,886 & 0,155 \\
\hline & Intra-grupos & 4069,804 & 178 & 22,864 & & \\
\hline & Total & 4156,047 & 180 & & & \\
\hline \multirow[t]{3}{*}{ Intensidad $f f(\mathrm{~dB})$} & Inter-grupos & 105,263 & 2 & 52,632 & 2,088 & 0,127 \\
\hline & Intra-grupos & 4487,838 & 178 & 25,213 & & \\
\hline & Total & 4593,102 & 180 & & & \\
\hline \multirow[t]{3}{*}{ Intensidad $p p(\mathrm{~dB})$} & Inter-grupos & 350,513 & 2 & 175,257 & 3,824 & 0,024 \\
\hline & Intra-grupos & 8157,825 & 178 & 45,830 & & \\
\hline & Total & 8508,339 & 180 & & & \\
\hline
\end{tabular}

Tabla 4.40. Análisis de varianza de un factor para las diferentes intensidades conseguidas por las lengüetas en los ejercicios pianissimo y fortissimo. 


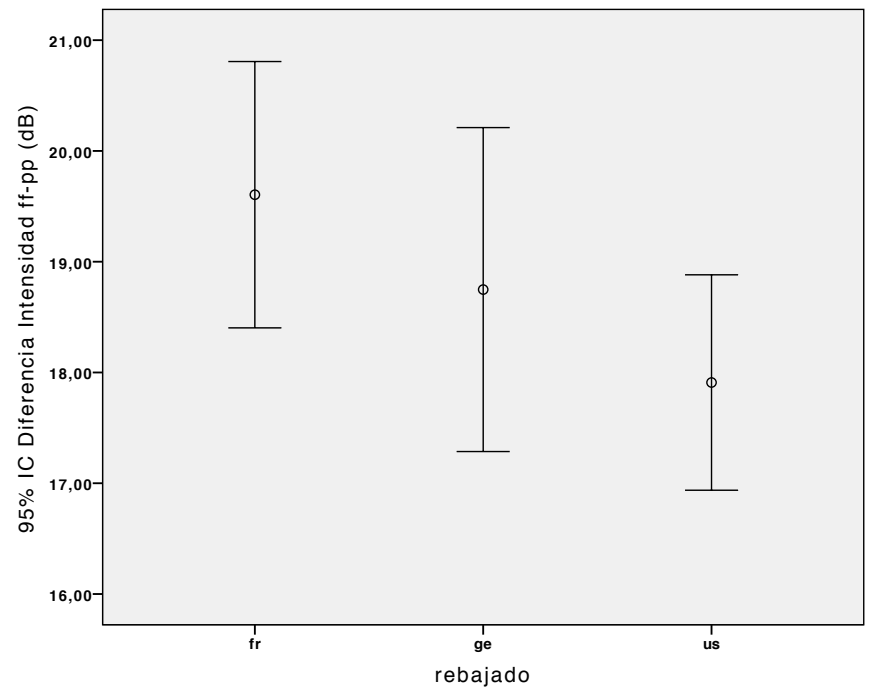

Figura 4.80b. Media con intervalo de confianza de la diferencia de intensidad ff-pp (dB) por tipos de rebajado.

\begin{tabular}{|c|c|c|c|c|c|c|c|}
\hline \multicolumn{8}{|c|}{ Comparaciones múltiples } \\
\hline \multicolumn{8}{|l|}{ Bonferroni } \\
\hline \multirow{2}{*}{$\begin{array}{l}\text { Variable } \\
\text { dependiente }\end{array}$} & \multirow{2}{*}{$\begin{array}{l}\text { (I) } \\
\text { rebajado }\end{array}$} & \multirow{2}{*}{$\begin{array}{l}(\mathrm{J}) \\
\text { rebajado }\end{array}$} & \multirow{2}{*}{$\begin{array}{c}\text { Diferencia } \\
\text { de medias } \\
(\mathrm{I}-\mathrm{J})\end{array}$} & \multirow{2}{*}{$\begin{array}{l}\text { Error } \\
\text { típico }\end{array}$} & \multirow[t]{2}{*}{ Sig. } & \multicolumn{2}{|c|}{ Intervalo de confianza al 95\% } \\
\hline & & & & & & Límite inferior & $\begin{array}{l}\text { Límite } \\
\text { superior }\end{array}$ \\
\hline \multirow{6}{*}{$\begin{array}{l}\text { Diferencia } \\
\text { Intensidad } f f-p p \\
(\mathrm{~dB})\end{array}$} & \multirow[t]{2}{*}{$\mathrm{fr}$} & ge & 0,85635 & 0,86942 & 0,978 & $-1,2449$ & 2,9576 \\
\hline & & us & 1,69548 & 0,87300 & 0,161 & $-0,4144$ & 3,8054 \\
\hline & \multirow[t]{2}{*}{ ge } & fr & $-0,85635$ & 0,86942 & 0,978 & $-2,9576$ & 1,2449 \\
\hline & & us & 0,83913 & 0,86942 & 1,000 & $-1,2621$ & 2,9404 \\
\hline & \multirow[t]{2}{*}{ us } & fr & $-1,69548$ & 0,87300 & 0,161 & $-3,8054$ & 0,4144 \\
\hline & & ge & $-0,83913$ & 0,86942 & 1,000 & $-2,9404$ & 1,2621 \\
\hline \multirow[t]{6}{*}{ Intensidad $f f(\mathrm{~dB})$} & \multirow[t]{2}{*}{$\mathrm{fr}$} & ge & $-1,676$ & 0,913 & 0,204 & $-3,88$ & 0,53 \\
\hline & & us & $-1,557$ & 0,917 & 0,274 & $-3,77$ & 0,66 \\
\hline & \multirow[t]{2}{*}{ ge } & fr & 1,676 & 0,913 & 0,204 & $-0,53$ & 3,88 \\
\hline & & us & 0,119 & 0,913 & 1,000 & $-2,09$ & 2,33 \\
\hline & \multirow[t]{2}{*}{ us } & fr & 1,557 & 0,917 & 0,274 & $-0,66$ & 3,77 \\
\hline & & ge & $-0,119$ & 0,913 & 1,000 & $-2,33$ & 2,09 \\
\hline \multirow[t]{6}{*}{ Intensidad $p p(\mathrm{~dB})$} & \multirow[t]{2}{*}{ fr } & ge & \begin{tabular}{l|}
$-2,532$ \\
\end{tabular} & 1,231 & 0,123 & $-5,51$ & 0,44 \\
\hline & & us & $-3,252^{*}$ & 1,236 & 0,028 & $-6,24$ & $-0,27$ \\
\hline & \multirow[t]{2}{*}{ ge } & fr & 2,532 & 1,231 & 0,123 & $-0,44$ & 5,51 \\
\hline & & us & $-0,721$ & 1,231 & 1,000 & $-3,70$ & 2,25 \\
\hline & \multirow[t]{2}{*}{ us } & fr & $3,252^{*}$ & 1,236 & 0,028 & 0,27 & 6,24 \\
\hline & & ge & 0,721 & 1,231 & 1,000 & $-2,25$ & 3,70 \\
\hline
\end{tabular}

Tabla 4.41. Prueba post hoc de Bonferroni para las diferentes intensidades conseguidas por las lengüetas en los ejercicios pianissimo y fortissimo.

En las figuras 4.81 y 4.82 se puede ver gráficamente los resultados explicados anteriormente: las lengüetas americanas son, en general, las que mayor intensidad consiguen tanto en el fortissimo como en el pianissimo, mientras que las francesas logran menor intensidad en ambos ejercicios. 


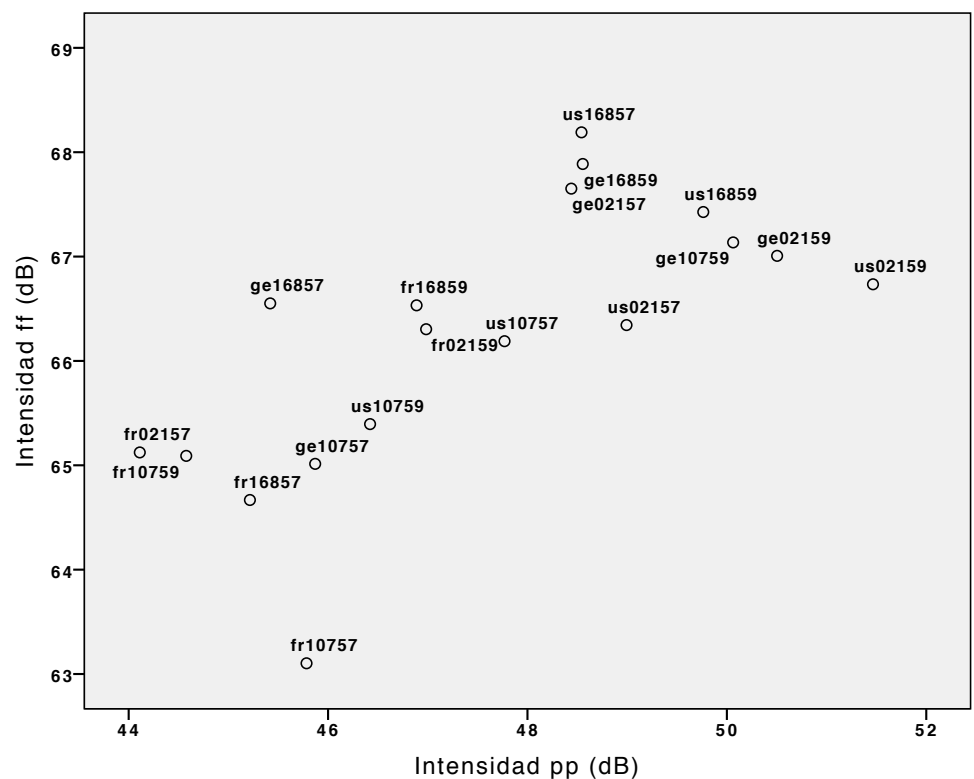

Figura 4.81. Medias de las intensidades (en $\mathrm{dB}$ ) de las lengüetas para los ejercicios pianissimo y fortissimo.

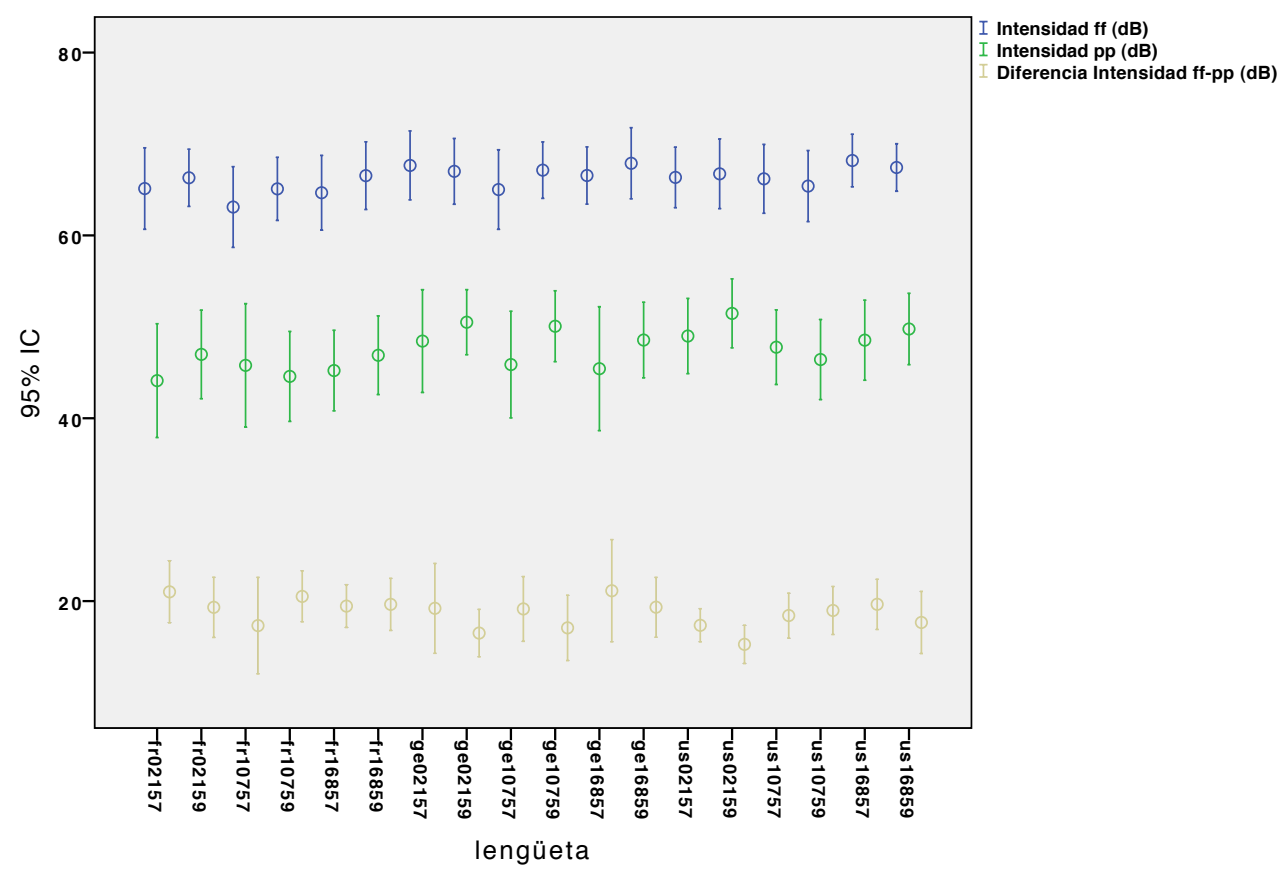

Figura 4.82. Medias de las intensidades (en $\mathrm{dB}$ ) de las lengüetas para los ejercicios pianissimo, fortissimo y la diferencia de intensidades (en $\mathrm{dB}$ ) entre los dos ejercicios para cada una de las lengüetas. 


\subsubsection{Discusión}

Como se ha discutido anteriormente, en el estudio preliminar, existían diferencias entre los estilos de rebajado ligadas a los parámetros del timbre, sin embargo, los demás parámetros acústicos estudiados no desencadenaban ningún patrón ligado al estilo de rebajado, sino que más bien marcaban la existencia de diferencias intrínsecas de las lengüetas entre sí.

En este estudio principal, se han aumentado el número de lengüetas, de factores ligados a la fabricación de las mismas y de intérpretes, para poder analizar más correctamente todos los parámetros acústicos medidos.

Si se analiza los resultados globales de comparación de las lengüetas, se observa que existe una diferencia clara para todos los parámetros acústicos estudiados en función del rebajado. Sin embargo, cabe destacar que el factor que mayor variabilidad explica en todos los parámetros acústicos estudiados (excepto en la frecuencia media) es el oboísta.

El rebajado influye en todos los parámetros ligados a la frecuencia, destacando el rebajado francés por ser el más inestable y el americano el más estable. En los parámetros ligados a la intensidad, el rebajado también influye de forma considerable, siendo el francés el que menos intensidad consigue y el más inestable en la desviación estándar de la amplitud. En los parámetros que estudian la armonicidad y su estabilidad, sobresale el rebajado alemán por ser el más armónico, el americano por ser el más estable y el francés por ser el menos armónico y el más inestable. Por último, en los parámetros ligados al timbre, cabe destacar a las lengüetas americanas como las que obtienen un centro de gravedad más agudo y las francesas con un centro de gravedad más grave, al perder armónicos en la parte aguda del espectro.

Los otros dos factores ligados a la fabricación de las lengüetas introducidos en este estudio son el grosor y el molde. Se percibe al analizar los datos que estos dos factores también influyen en algunos parámetros acústicos, si bien no de forma tan predominante como el rebajado.

El molde influye en todos los parámetros acústicos excepto en la frecuencia y su estabilidad y en la diferencia de energía por bandas. En la intensidad, el molde estándar 21 predomina sobre los otros dos moldes utilizados, consiguiendo una mayor potencia sonora. 
La armonicidad viene influenciada por el molde 107 que es más armónico que el 21 y el 168, siendo este último el que mayor desviación armónica provoca. El molde también influye en los parámetros del timbre, aunque de forma más diversa según los ejercicios interpretados.

El grosor influye en menor modo que el rebajado y el molde, no siendo significativo en las mediciones de la desviación estándar de la frecuencia, de la armonicidad media y de la diferencia de energía por bandas. El grosor 59/100 mm aporta mayor estabilidad en la frecuencia y en la intensidad y obtiene mayor riqueza en el sonido que el grosor $57 / 100 \mathrm{~mm}$.

Cuando se analizan las diferencias de comportamiento de las lengüetas en cada ejercicio, sí existen diferencias por estilo de rebajado. El estilo de rebajado francés parece el menos aconsejable cuando se trata de jugar con los cambios de intensidad del ejercicio diminuendo, ya que los estilos de rebajado no influyen en el ámbito de intensidad conseguido, pero sí en la pérdida de afinación.

En el ejercicio pianissimo se puede pensar que las lengüetas francesas son las idóneas, ya que son las que menos intensidad proporcionan. Sin embargo, existe un problema con este estilo de rebajado: son muy inestables en la afinación. Las alemanas,

por el contrario, aunque no consiguen esa intensidad mínima de las francesas, son más estables en afinación respecto a las francesas y a las americanas, por lo que se convierten en las más idóneas por sus características globales.

En el ejercicio fortissimo las lengüetas americanas son las idóneas ya que, aunque las lengüetas alemanas consiguen mayor intensidad, la diferencia respecto a las americanas no es significativa, por lo que éstas también consiguen una intensidad muy alta y además son las que tienen mayor presencia de energía en los armónicos agudos.

\subsubsection{Conclusiones}

Se puede responder afirmativamente a la cuestión principal de este experimento: el estilo de rebajado sí genera diferencias significativas en las mediciones acústicas. Mientras que en el experimento preliminar estas diferencias se dan en muchos casos por la variabilidad intrínseca de las lengüetas, que superan generalmente las diferencias entre estilos de rebajado, en el experimento principal, todos los estilos de rebajado se realizaron 
a partir de la misma sección de tubo de caña. Además, los estilos de rebajado francés y alemán se realizaron a máquina, es decir, manteniéndose todas sus mediciones constantes hasta la finalización de las lengüetas. Del mismo modo, los otros dos factores introducidos en esta investigación para averiguar si también influían en las mediciones acústicas, el grosor y el molde, también se prepararon con máquinas. Tan solo el estilo de rebajado americano se realizó a mano, por la inexistencia de este tipo de máquinas. Se puede afirmar que las características intrínsecas de cada lengüeta se mantienen constantes en la manera de lo posible, por lo que la influencia del rebajado, del molde o del grosor no está contaminada en el estudio principal.

En el estudio principal, la hipótesis de la influencia del rebajado y del grosor en la frecuencia se verifica, apareciendo las lengüetas francesas como las más inestables en la afinación, debido a sus puntas tan marcadas y finas, que le otorgan una flexibilidad excesiva y por lo tanto una complejidad a la hora de controlar su afinación. Por otra parte, se creía que las lengüetas americanas iban a ser mucho más inestables que las francesas, pero su rebajado también excesivamente fino en la punta se ve contrarrestado en el centro, caracterizándose por tener una gran capa de madera que compensa ese desequilibrio. El grosor también influye en la frecuencia, de forma que las palas más delgadas son más inestables que las gruesas, por lo que las lengüetas fabricadas con el grosor 59/100 mm aportan mayor estabilidad. Sin embargo, al contrario de lo que se pensaba, los moldes 21 y 107 (el molde 168 se descartó para este análisis debido a su incongruencia en las medidas generales), no influyen de forma significativa, seguramente porque las características que ofrecen los dos moldes son más bien parecidas que contradictorias.

La hipótesis de la influencia del rebajado, el grosor y el molde en los aspectos de la intensidad y su desviación también se verifica. Las lengüetas francesas son las que menos intensidad consiguen debido a que su superficie vibratoria es muy delgada, provocando que se saturen más fácilmente y no admitan una mayor cantidad de presión de aire por parte de los oboístas; el mismo proceso ocurre con el grosor: el grosor 57/100 mm es más fino, por lo que admite menos volumen de aire que el 59/100 mm. En esta ocasión destaca el molde 21 sobre los otros tres, al ser el molde con las medidas más estándares proporciona una mejor captación de la potencia sonora que el 107 y que el 168. 
Los parámetros ligados a la armonicidad también cumplen con la hipótesis de la influencia del rebajado en ellos. Como ocurría con la frecuencia y la intensidad, el estilo de rebajado francés es el menos armónico e inestable proporcionado por sus características tan flexibles, frente al rebajado alemán que es el más armónico y el más rígido de todos los rebajados. Aunque en estos parámetros el grosor no influye de forma significativa, sí lo hacen los moldes, destacando el 168 como el que más ruido e inestabilidad provoca, debido a la descompensación en sus medidas físicas.

Por último, la última hipótesis de la influencia del rebajado, el grosor y el molde en el timbre también se verifica, tal y como ocurría en el estudio preliminar. En esta ocasión, no son las lengüetas alemanas las que destacan con mayor componente armónico, sino que son las americanas siendo estas diferencias muy significativas respecto a las alemanas y las francesas respectivamente. Esto se debe a que las lengüetas americanas son más estables, en cuanto a flexibilidad y rigidez, que las francesas y las alemanas. Se encuentran entre la flexibilidad exagerada de las francesas y la rigidez extrema de las alemanas, por lo que aportan un timbre más brillante, con mayor energía en los armónicos agudos que las francesas y las alemanas. Además, el molde y el grosor también influyen de forma significativa en el timbre: mientras que la influencia del molde es un poco más aleatoria y depende de los ejercicios interpretados, el grosor 59/100 mm dota a las lengüetas de más madera y evita así una flexibilidad excesiva, aportando mayor energía en los armónicos.

\subsection{Experimento de evaluación interpretativa (propiocepción del instrumentista)}

\subsubsection{Introducción}

Con la realización de este experimento se analiza si las evaluaciones de la calidad del sonido de las lengüetas son realmente unas evaluaciones puramente auditivas o, si por el contrario, existe una parte importante que se debe a la propiocepción y al control de la lengüeta en el momento de ejecutar los ejercicios por parte de los oboístas. Para ello, se han diseñado dos experimentos: el primero se encarga de recoger las puntuaciones de los oboístas intérpretes el día de la grabación, dependiendo estas puntuaciones de las sensaciones obtenidas en ese momento (evaluación interpretativa); y el segundo, recoge las 
puntuaciones de los propios oboístas intérpretes al escuchar sus grabaciones y las de otros oboístas sin saberlo (evaluación auditiva).

\subsubsection{Hipótesis}

Como se ha explicado en los antecedentes, si la percepción y la propiocepción están íntimamente ligadas al conocimiento musical, es necesario estudiar la vinculación entre estos dos parámetros para poder ver la relación existente entre ellos. Además, si la propiocepción regula el movimiento e interviene en la percepción y en la autoconciencia, gracias a ella se podría explicar la experiencia musical. Con este experimento, se va a estudiar cómo a partir de la experiencia musical, los oboístas son capaces de metaforizar las sensaciones que les provocan las diferentes lengüetas y si estas sensaciones son compartidas por diferentes oboístas. Si tal como explicaba Reed (2007), la conexión entre lo imaginado y lo producido no funciona, los oboístas darán a las lengüetas una mala puntuación, mientras que si por el contrario esta conexión sí se efectúa, las lengüetas serán puntuadas positivamente.

Este experimento trata de recoger la apreciación del oboísta al ejecutar un ejercicio con una lengüeta dada, influyendo tanto la propiocepción muscular como la audición del sonido, así pues, se emite la hipótesis que los oboístas son capaces de puntuar las sensaciones provocadas por las diferentes lengüetas y que además, estas sensaciones son compartidas de forma coherente entre ellos.

\subsubsection{Método}

Diez oboístas participaron en las diferentes sesiones de grabación de los cinco ejercicios seleccionados para este experimento. Todos los oboístas que participaron en la grabación puntuaron en una escala del 1 al 7 cada lengüeta con la que interpretaban, de forma que el oboísta evaluaba la lengüeta al acabar cada ejercicio, dando una puntuación a la facilidad de ejecución y a calidad del ejercicio. Además, se puntuaba la lengüeta de forma global según su timbre, flexibilidad, rigidez, equilibrio y calidad global, también se puntuaba el imaginarse interpretando piezas de diferentes estilos con esa lengüeta dada .

Los parámetros individuales a puntuar eran: facilidad y calidad del arpegio, del legato, del fortissimo y del pianissimo. 
Los parámetros globales a puntuar eran: puntuación global; timbre; flexibilidad y equilibrio.

Los parámetros que puntuaban los diferentes estilos eran: concierto de Vivaldi en do mayor; concierto de Mozart en do mayor; concierto de Strauss y sonata de Dutilleux.

Los datos se recogían en una hoja de cálculo excel por una persona ajena al experimento (figura 4.83), obteniendo 361 puntuaciones por oboísta y un total de 3610 puntuaciones con todos los oboístas. La duración media de la grabación para cada oboísta fue de una hora y media, aproximadamente. Los oboístas no consideraron la tarea de puntuar como una tarea muy difícil.

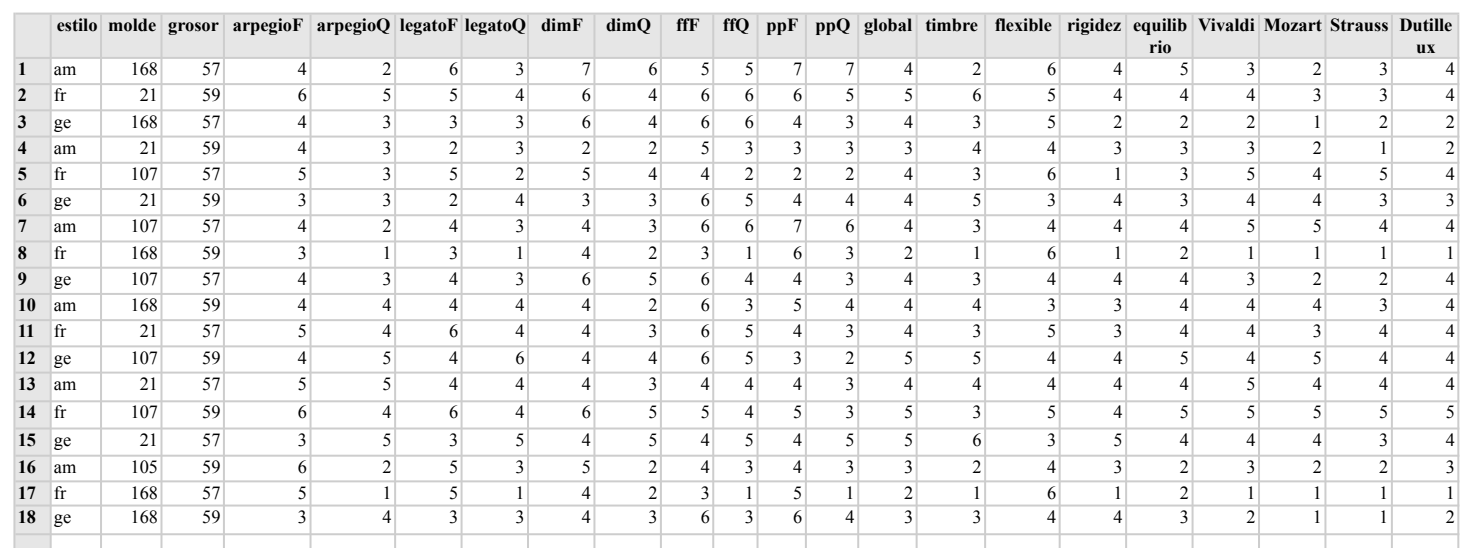

Figura 4.83. Captura de pantalla de la recogida de datos de la puntuación de los oboístas durante la grabación.

\subsubsection{Resultados}

\subsubsection{Concordancia de las respuestas}

En el experimento de evaluación interpretativa, la primera constatación es que los oboístas se ponen globalmente de acuerdo en el comportamiento propioceptivo de las lengüetas. Se aprecia en la tabla 4.42 que los valores del Alfa de Cronbach son más altos para la evaluación global de la facilidad $(\alpha=, 813)$, pero siguen siendo altos para la evaluación global de la calidad de cada ejercicio $(\alpha=, 760)$ y de los parámetros globales de la lengüeta $(\alpha=, 778)$. No es de extrañar que la adecuación a los estilos de cada compositor/ período sea más baja, ya que tiene un componente subjetivo e incluso se puede pensar que un mismo oboísta pueda cambiar de decisión respecto a la adecuación de una lengüeta para interpretar a Vivaldi o a Dutilleux. 
De los parámetros globales ( $c f$. tabla 4.42), el que mayor coincidencia de valoraciones obtiene es la flexibilidad, pero parámetros más sujetos a valoraciones subjetivas como el timbre (que propiamente hablando no es propioceptivo) también consiguen una concordancia de las respuestas. En general, los oboístas se ponen de acuerdo en valorar el comportamiento de una lengüeta: flexibilidad, rigidez y equilibrio (tabla 4.42), con lo que se puede establecer que son parámetros mensurables que significan lo mismo para diferentes oboístas.

Destaca la altísima concordancia en la facilidad para realizar los arpegios y las frases en legato, ambos ejercicios miden el comportamiento global del oboe al pasar por todos los registros. Al contrario, destaca la discrepancia de la realización del fortissimo, y en menor medida del pianissimo ( $c f$. tabla 4.42).

La evaluación de la calidad del ejercicio tiene globalmente menos concordancia que la facilidad, aunque en la ejecución del fortissimo y pianissimo, los oboístas se ponen más de acuerdo en la calidad que en la facilidad, lo que puede ser contra intuitivo.

\begin{tabular}{|c|c|c|c|}
\hline tipo pregunta & Alfa & pregunta & Alfa \\
\hline \multirow{5}{*}{ calidad } & \multirow{5}{*}{,760 } & arpegio &, 771 \\
\hline & & legato & ,759 \\
\hline & & $\operatorname{dim}$ &, 597 \\
\hline & & ff & ,689 \\
\hline & & $\mathrm{pp}$ &, 770 \\
\hline \multirow{5}{*}{ facilidad } & \multirow{5}{*}{813} & arpegio &, 814 \\
\hline & & legato & ,886 \\
\hline & & $\operatorname{dim}$ &, 762 \\
\hline & & $\mathrm{ff}$ & ,479 \\
\hline & & $\mathrm{pp}$ & ,649 \\
\hline \multirow{5}{*}{ globales } & \multirow{5}{*}{,778 } & equilibrio &, 771 \\
\hline & & flexible &, 842 \\
\hline & & rigidez & .762 \\
\hline & & timbre &, 788 \\
\hline & & global &, 712 \\
\hline \multirow{4}{*}{ estilos } & \multirow{4}{*}{,615 } & Dutilleux & ,668 \\
\hline & & Mozart & ,483 \\
\hline & & Strauss & ,591 \\
\hline & & Vivaldi & ,613 \\
\hline
\end{tabular}

Tabla 4.42. Tabla estadísticos de fiabilidad (Alfa de Cronbach) para las diferentes preguntas que respondían los oboístas $(\mathrm{N}=10)$ al ejecutar los ejercicios durante la grabación. 


\subsubsection{Influencia del rebajado}

4.7.4.2.1.Respuestas de todos los oboístas agrupados

Al igual que ocurría con los análisis acústicos, al realizar un primer análisis, se observa que el molde tiene poca influencia en los valores globales y que, además, el molde 168 perturba el comportamiento esperado de las lengüetas en función de su tipo de rebajado (figura 4.84). Como se explicó en el punto 4.6.1, esto se debe a que el molde 168 tiene unas dimensiones fuera de lo común, es un molde demasiado ancho, más habitual para la realización de lengüetas en los oboes barrocos u oboes de amor que en los modernos. Así pues, se comparan los resultados utilizando sólo los moldes habituales 21 y 107.

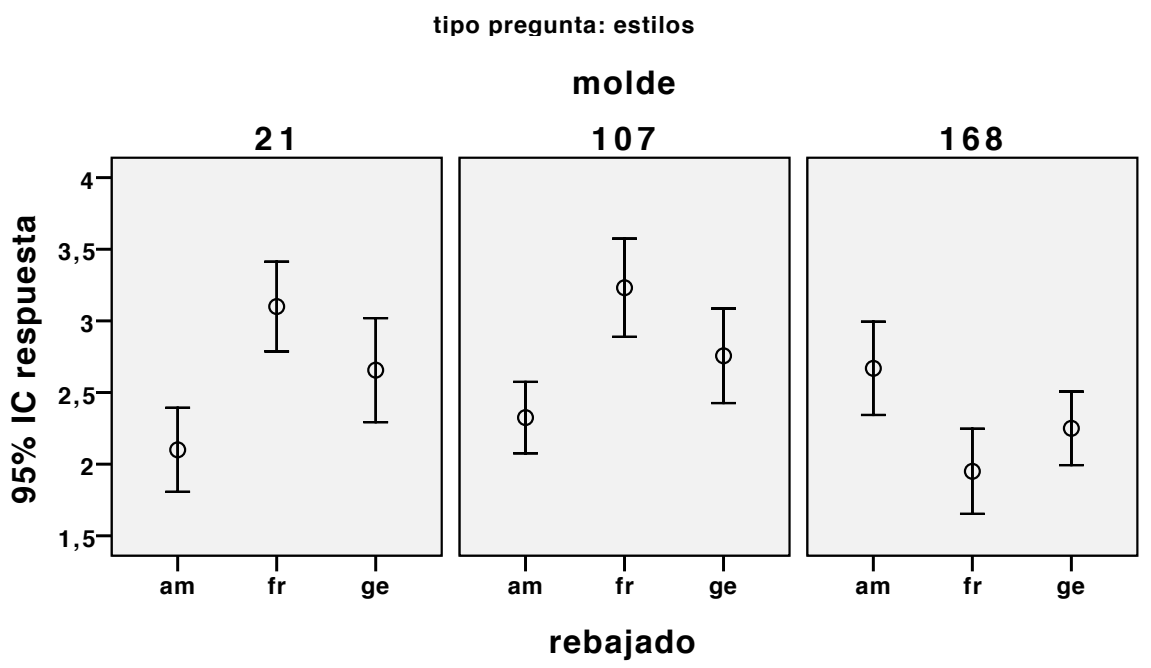

Figura 4.84. Medias de la valoración de las lengüetas para los diferentes estilos en función del tipo de rebajado y tipo de molde.

Se efectúa un ANOVA con medidas repetidas en función del rebajado para las diferentes respuestas de los oboístas. Se debe tener en cuenta que siempre se aplica el resultado de Greenhouse-Geisser y que cuando este resultado no es significativo, pero sí lo es la prueba de Mauchly, se aplica el resultado de la esfericidad asumida (como por ejemplo en la tabla 4.43: pregunta Strauss).

La tabla 4.43 ( $c f$. A.66 para más detalle), muestra que el estilo de rebajado tiene una influencia significativa en casi todas las respuestas. La facilidad del pianissimo y la facilidad del fortissimo son las únicas dos preguntas no significativas. 


\begin{tabular}{|c|c|c|c|c|c|c|c|}
\hline $\begin{array}{l}\text { tipo de } \\
\text { pregunta }\end{array}$ & pregunta & $\begin{array}{c}\text { Suma de cuadrados } \\
\text { tipo III }\end{array}$ & gl & $\begin{array}{c}\text { Media } \\
\text { cuadrática }\end{array}$ & $\mathbf{F}$ & Sig. & $\begin{array}{c}\text { Eta al cuadrado } \\
\text { parcial }\end{array}$ \\
\hline \multirow[t]{5}{*}{ calidad } & arpegio & 21,679 & 1,993 & 10,879 & 5,872 & 0,004 & 0,131 \\
\hline & $\operatorname{dim}$ & 20,429 & 1,765 & 11,573 & 6,995 & 0,003 & 0,152 \\
\hline & $\mathrm{ff}$ & 24,454 & 1,814 & 13,481 & 7,751 & 0,001 & 0,166 \\
\hline & legato & 21,237 & 1,841 & 11,533 & 6,466 & 0,003 & 0,142 \\
\hline & $\mathrm{pp}$ & 12,413 & 1,928 & 6,439 & 3,186 & 0,049 & 0,076 \\
\hline \multirow[t]{5}{*}{ facilidad } & arpegio & 82,279 & 1,930 & 42,637 & 22,147 & 0,000 & 0,362 \\
\hline & $\operatorname{dim}$ & 59,267 & 1,762 & 33,630 & 16,904 & 0,000 & 0,302 \\
\hline & $\mathrm{ff}$ & 5,104 & 1,680 & 3,038 & 1,733 & 0,189 & 0,043 \\
\hline & legato & 120,087 & 1,886 & 63,667 & 45,362 & 0,000 & 0,538 \\
\hline & $\mathrm{pp}$ & 6,467 & 1,584 & 4,082 & 1,173 & $\mathbf{0 , 3 0 7}$ & 0,029 \\
\hline \multirow[t]{4}{*}{ estilos } & Dutilleux & 17,029 & 1,941 & 8,772 & 5,702 & 0,005 & 0,128 \\
\hline & Mozart & 16,800 & 1,836 & 9,149 & 4,549 & 0,016 & 0,104 \\
\hline & Strauss & 13,079 & 2 & 6,540 & 3,268 & 0,043 & 0,077 \\
\hline & Vivaldi & 31,354 & 1,860 & 16,855 & 8,367 & 0,001 & 0,177 \\
\hline \multirow[t]{5}{*}{ globales } & equilibrio & 19,888 & 1,932 & 10,295 & 6,908 & 0,002 & 0,150 \\
\hline & flexible & 95,017 & 1,936 & 49,088 & 32,042 & 0,000 & 0,451 \\
\hline & global & 18,654 & 1,889 & 9,875 & 6,983 & 0,002 & 0,152 \\
\hline & rigidez & 43,879 & 1,956 & 22,437 & 8,638 & 0,000 & 0,181 \\
\hline & timbre & 37,850 & 1,857 & 20,385 & 11,594 & 0,000 & 0,229 \\
\hline
\end{tabular}

Tabla 4.43. Efectos intra-sujetos del ANOVA con medidas repetidas utilizando los datos de GreenhouseGeisser (excepto en Strauss que se utilizan los datos de esfericidad asumida), para las diferentes preguntas que respondían los oboístas en función del rebajado.

Una prueba post hoc de Bonferroni ( $c f$. A.67, para más detalle) muestra que para la valoración de la calidad del sonido, el rebajado americano es el que más diferencias marca respecto al alemán y al francés (figura 4.85) con excepción del pianissimo, que no genera diferencias, y del fortissimo, donde las lengüetas que marcan la diferencia son las alemanas.

Para la pregunta facilidad, los intérpretes también se ponen significativamente de acuerdo en que las lengüetas francesas son las que con más facilidad se realizan los ejercicios (figura 4.86), a excepción del fortissimo y del pianissimo, que no generan diferencias significativas. 


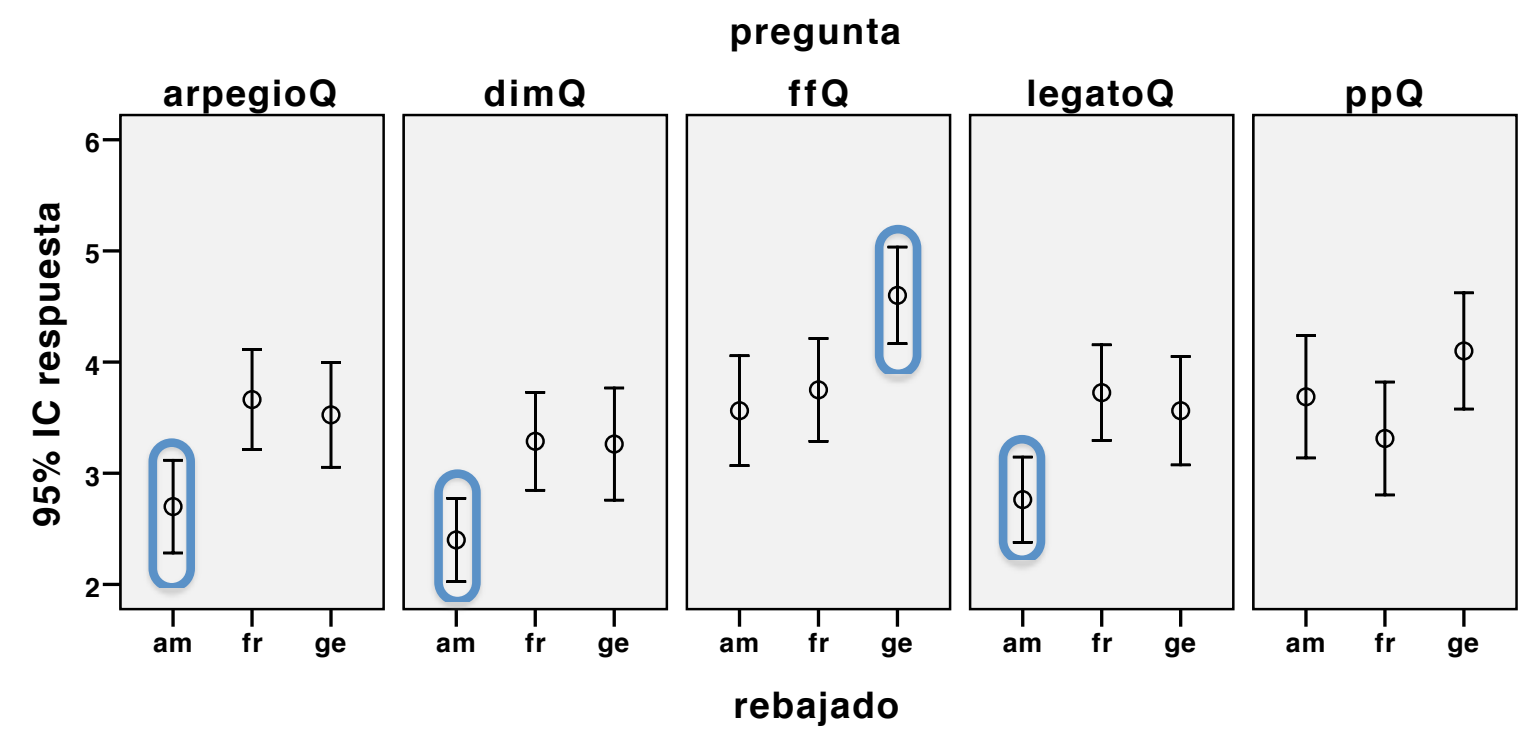

Figura 4.85. Medias de la valoración de las lengüetas para la calidad de los cinco ejercicios en función del tipo de rebajado. Se marca con un círculo azul los valores que se diferencian significativamente en una prueba post hoc de Bonferroni.
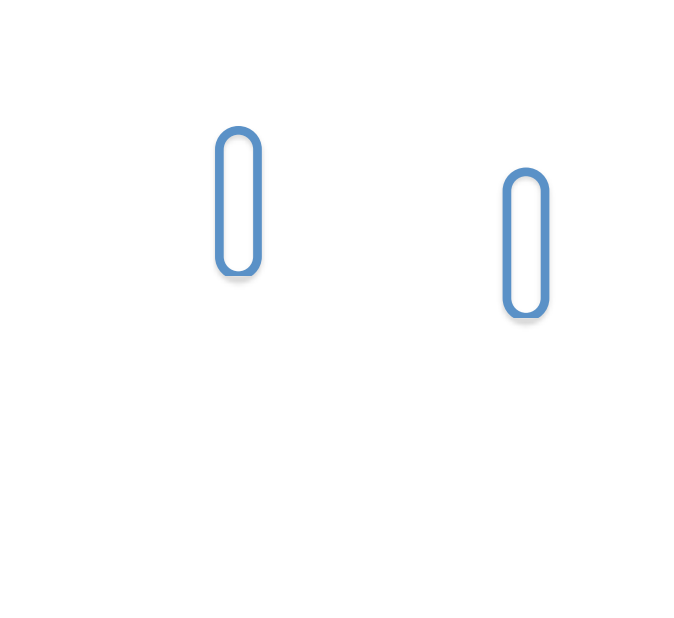

\section{pregunta}
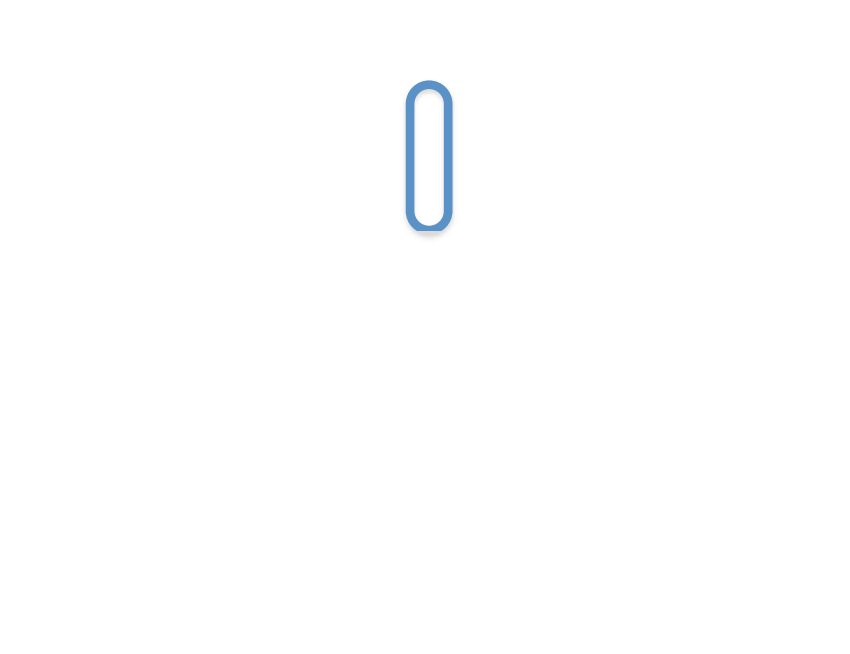

Figura 4.86. Medias de la valoración de las lengüetas para la facilidad de los cinco ejercicios en función del tipo de rebajado. Se marca con un círculo azul los valores que se diferencian significativamente en una prueba post hoc de Bonferroni.

Dentro de las puntuaciones de las lengüetas de forma global, se aprecia en la figura 4.87 que para la pregunta equilibrio las lengüetas menos valoradas son las americanas respecto a las francesas $(p=, 016)$ y a las alemanas $(p=, 001)$. Las lengüetas francesas son significativamente $(p<, 001)$ más flexibles que las lengüetas de las otras dos escuelas. Las lengüetas alemanas son significativamente más rígidas que las francesas $(p<, 001)$, pero no lo son más que las americanas $(p=, 903)$. En cuanto al timbre, las lengüetas peor valoradas son las americanas respecto a las francesas $\mathrm{y}$, de forma muy significativa, respecto a las 
alemanas $(p<, 001)$. De forma global, las lengüetas mejor valoradas son las francesas respecto a las alemanas y a las americanas $(p<, 001)$.

Respecto a la adecuación de la lengüeta para interpretar diferentes estilos musicales, la lengüeta peor valorada es la americana y de forma muy significativa para su utilización en el concierto en do mayor de Vivaldi $(p<, 001)$, en el concierto en do mayor de Mozart ( $p=, 018)$, y en la sonata de Dutilleux $(p=, 017)$, respecto a la francesa.
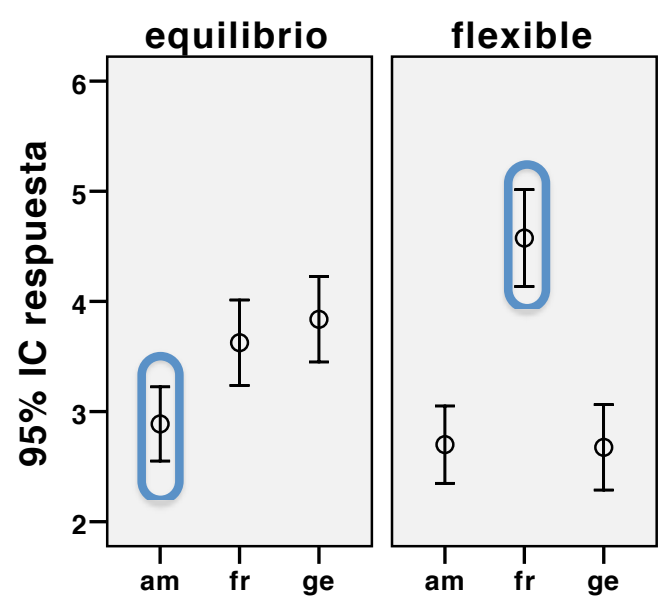

\section{pregunta}
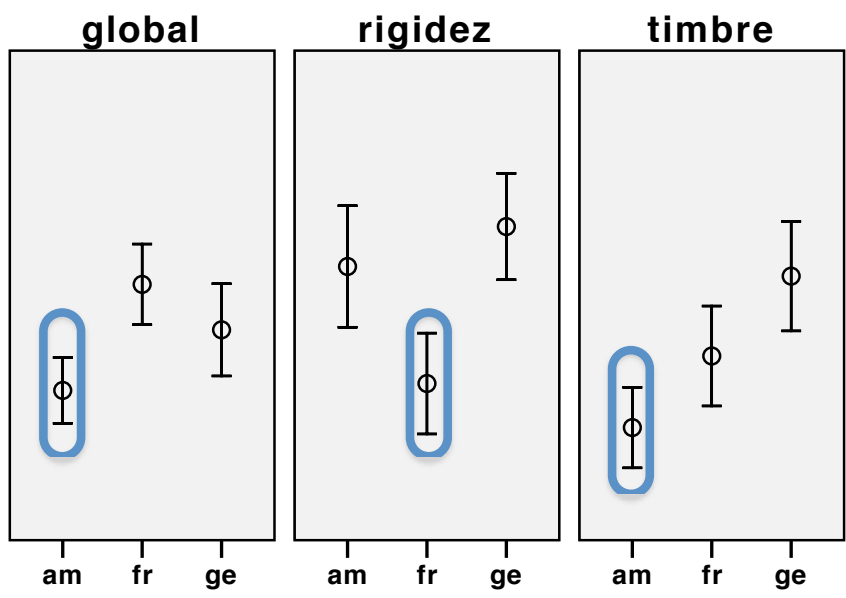

rebajado

Figura 4.87. Media de las respuestas generales de los oboístas en función del rebajado para el equilibrio, flexibilidad, valoración global, rigidez y timbre. Se marca con un círculo azul los valores que se diferencian significativamente en una prueba post hoc de Bonferroni.

Al realizar un escalamiento multidimensional (ALSCAL) sobre todas las respuestas dadas por todos los oboístas, utilizando un modelo de dos dimensiones, se intenta entender si los oboístas utilizan criterios similares en sus puntuaciones. La variabilidad explicada por estas dimensiones para todas las respuestas es: $\mathrm{RSQ}=85 \%$ (respuestas agrupadas), $\mathrm{RSQ}=83 \%$ (respuestas sobre la calidad), $\mathrm{RSQ}=87 \%$ (respuestas sobre la facilidad), $\mathrm{RSQ}=$ $88 \%$ (respuestas sobre la globalidad), $\mathrm{RSQ}=76 \%$ (respuestas sobre los estilos). Las figuras $4.88,4.89,4.90,4.91$ y 4.92 muestran la obtención de una asociación clara por estilos de rebajado para la dimensión 1. 


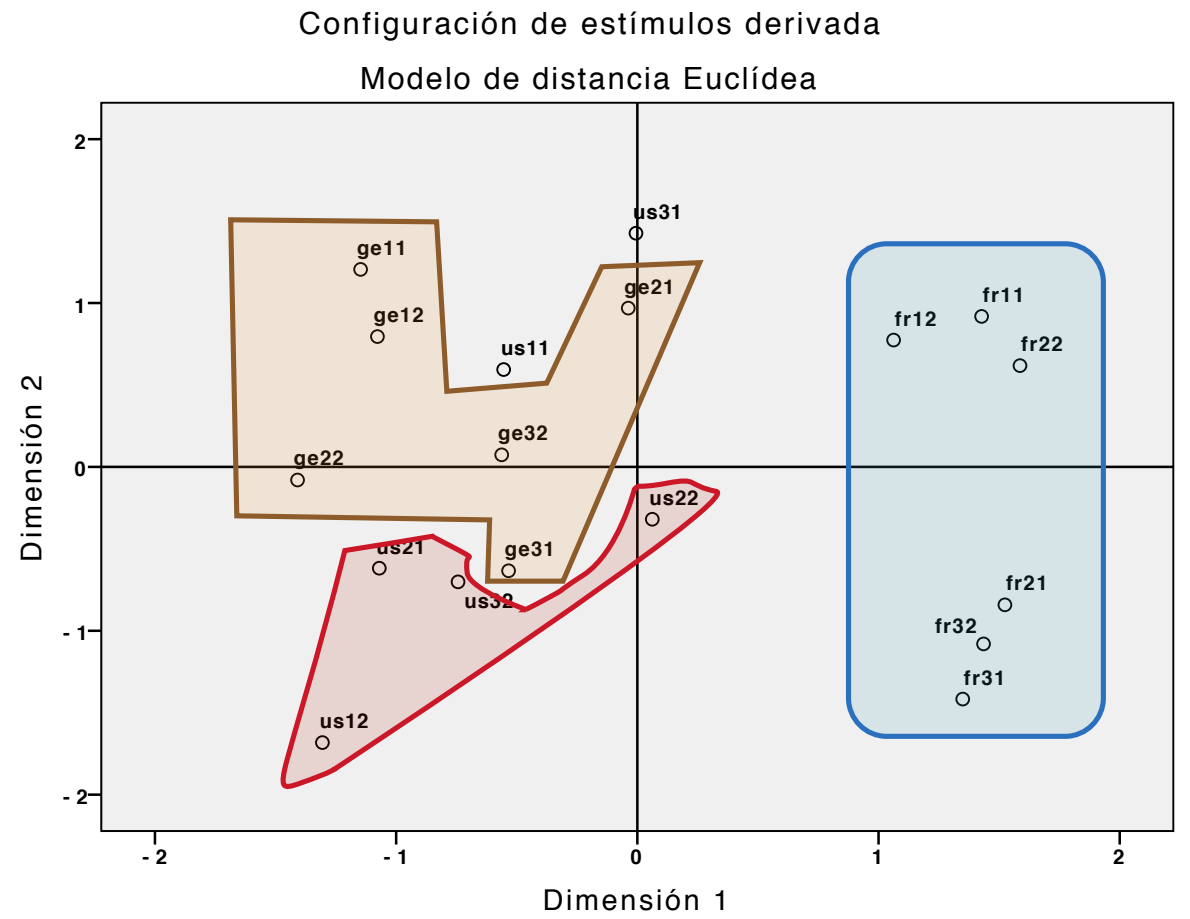

Figura 4.88. Escalamiento multidimensional de todas las respuestas dadas por todos los oboístas. Las dos primeras letras codifican el tipo de rebajado, el primer número indica el tipo de molde $(1=21 ; 2=107 ; 3=168)$ y el segundo número el tipo de grosor $(1=57 \mathrm{~mm} ; 2=59 \mathrm{~mm})$.

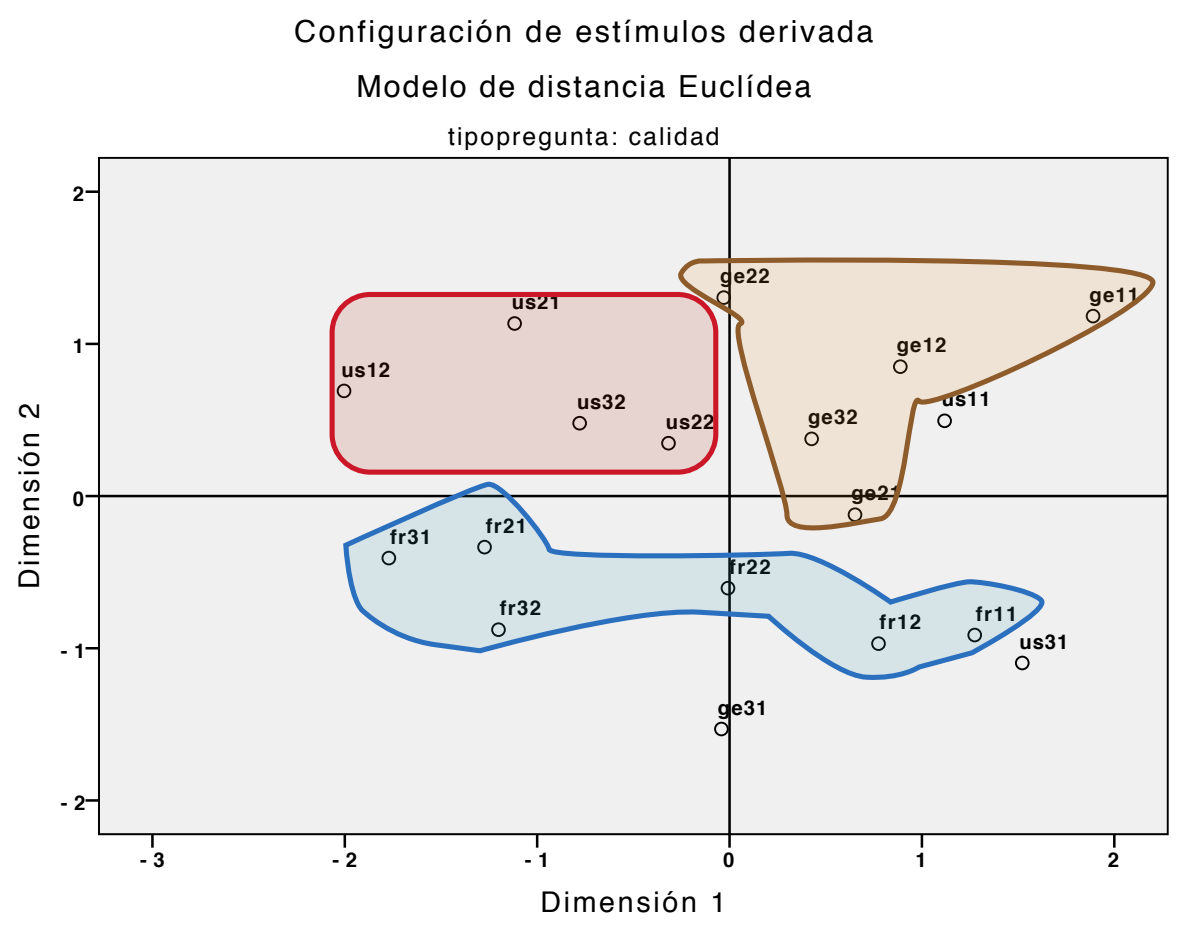

Figura 4.89. Escalamiento multidimensional de las respuestas sobre la calidad dadas por todos los oboístas. Las dos primeras letras codifican el tipo de rebajado, el primer número indica el tipo de molde $(1=21$; $2=107 ; 3=168)$ y el segundo número el tipo de grosor $(1=57 \mathrm{~mm} ; 2=59 \mathrm{~mm})$. 


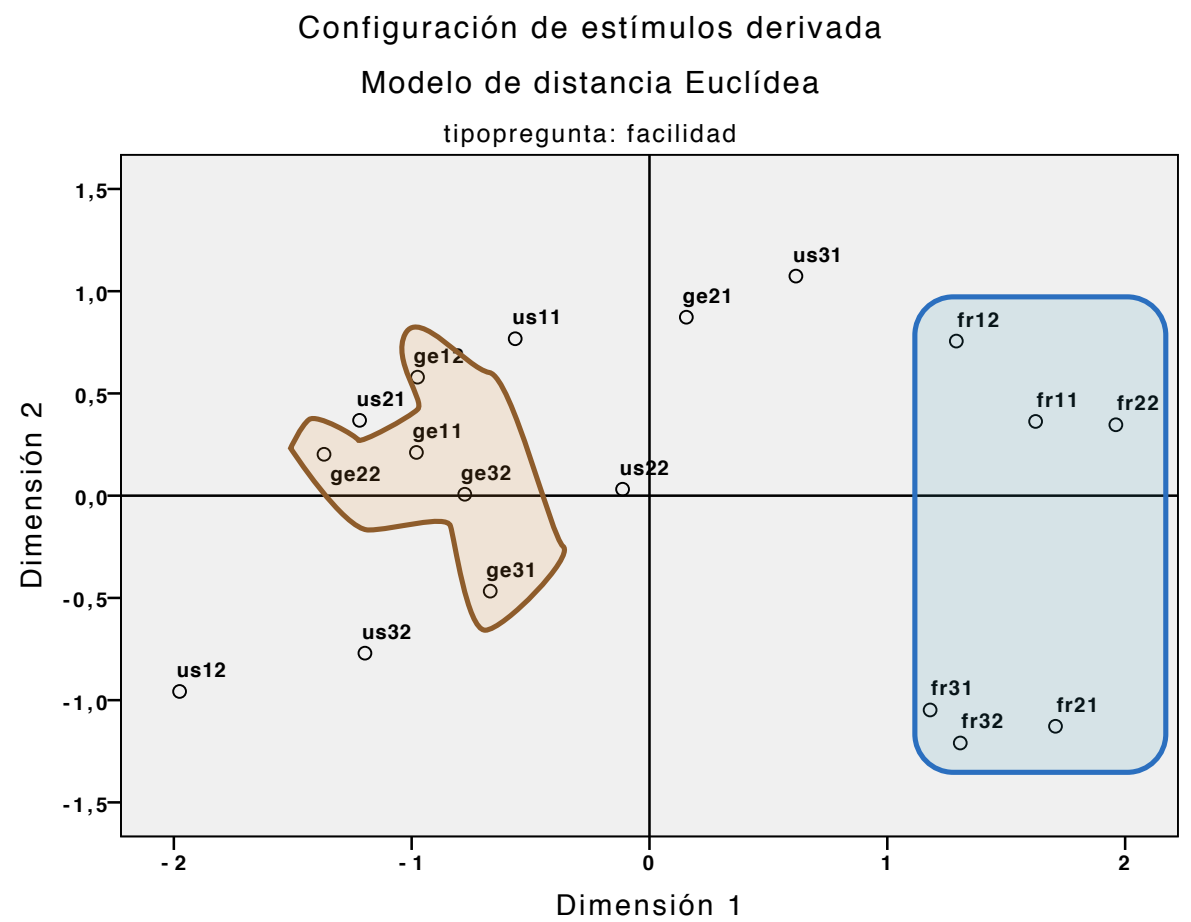

Figura 4.90. Escalamiento multidimensional de las respuestas sobre la facilidad dadas por todos los oboístas.

Las dos primeras letras codifican el tipo de rebajado, el primer número indica el tipo de molde $(1=21$; $2=107 ; 3=168)$ y el segundo número el tipo de grosor $(1=57 \mathrm{~mm} ; 2=59 \mathrm{~mm})$.

\section{Configuración de estímulos derivada}

Modelo de distancia Euclídea

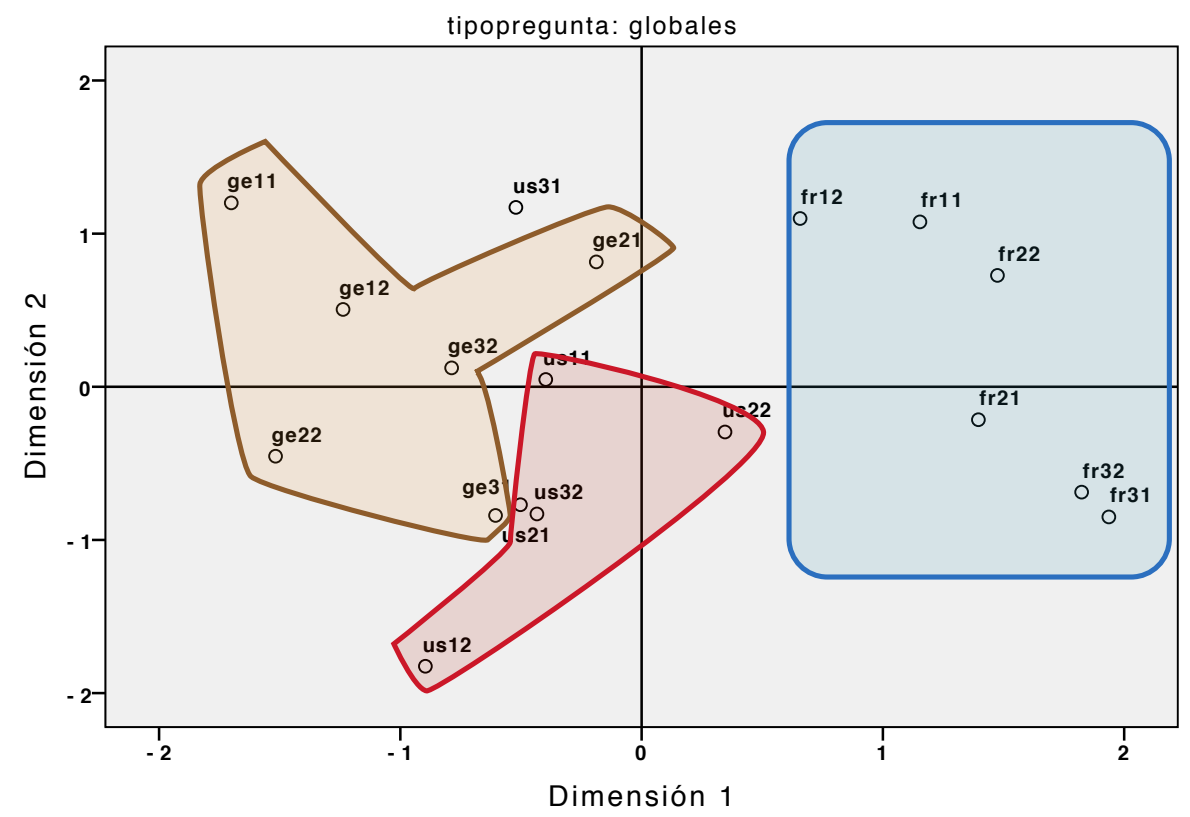

Figura 4.91. Escalamiento multidimensional de las respuestas sobre las puntuaciones globales dadas por todos los oboístas. Las dos primeras letras codifican el tipo de rebajado, el primer número indica el tipo de molde $(1=21 ; 2=107 ; 3=168)$ y el segundo número el tipo de grosor $(1=57 \mathrm{~mm} ; 2=59 \mathrm{~mm})$. 


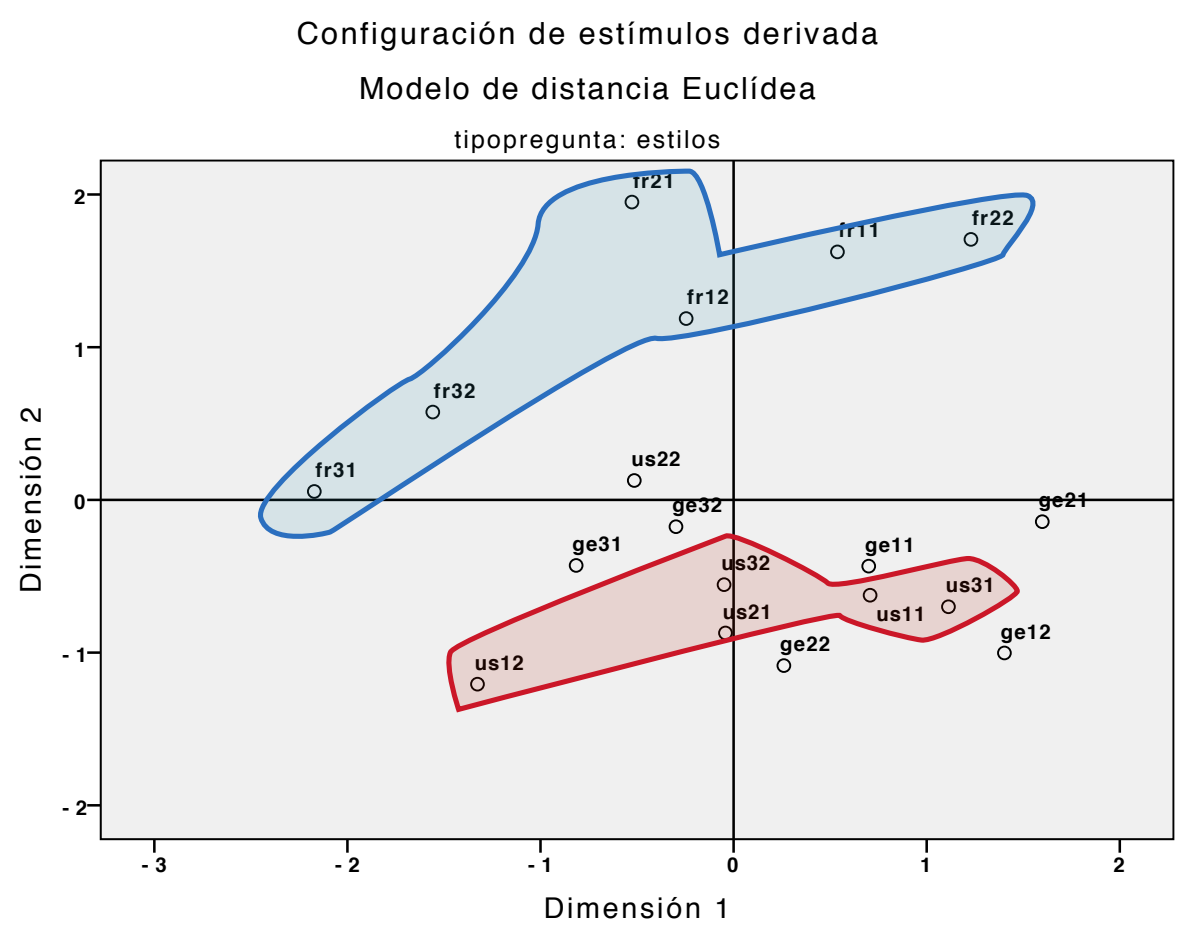

Figura 4.92. Escalamiento multidimensional de las respuestas sobre los estilos dadas por todos los oboístas.

Las dos primeras letras codifican el tipo de rebajado, el primer número indica el tipo de molde $(1=21$; $2=107 ; 3=168)$ y el segundo número el tipo de grosor $(1=57 \mathrm{~mm} ; 2=59 \mathrm{~mm})$.

\subsection{Respuestas separadas por oboístas}

Al realizar un ANOVA con medidas repetidas de las respuestas dadas por los oboístas comparando a todos los oboístas entre sí (cf. A.68 para más detalle), se puede observar que no existe un patrón de respuestas por escuelas de interpretación, sino que más bien cada oboísta contesta lo que quiere. Sin embargo, se destaca a algunos oboístas en ciertas preguntas, por ejemplo, cuando los oboístas responden sobre la calidad de los ejercicios, por norma general para ningún oboísta es significativo el rebajado, sobre todo en el ejercicio arpegio, aunque existen varias excepciones: el oboísta 6 distingue por rebajados en la calidad de los ejercicios legato $\left(\mathrm{F}=10,78, p=, 032, \eta^{2}=, 782\right)$ y diminuendo $\left(\mathrm{F}=16,05, p=, 016, \eta^{2}=, 843\right)$; el oboísta 5 en la calidad del fortissimo $(\mathrm{F}=15,46, p=, 010$, $\left.\eta^{2}=, 838\right)$ y el oboísta 10 en la calidad del pianissimo $\left(\mathrm{F}=14,33, p=, 032, \eta^{2}=, 827\right)$, siendo esta pregunta la única en la que el oboísta 10 distingue entre rebajados.

Las preguntas referentes a la facilidad obtienen mayor diferenciación de rebajados, sobre todo los ejercicios más complejos que analizan casi todo el ámbito del oboe, como son el arpegio y el legato. Sin embargo, en la facilidad del pianissimo sólo distingue por rebajados el oboísta $5\left(\mathrm{~F}=9,2, p=, 049, \eta^{2}=, 754\right)$, mientras que en la facilidad del 
diminuendo son los oboístas $5\left(\mathrm{~F}=18,05, p=, 020, \eta^{2}=, 858\right)$ y $6\left(\mathrm{~F}=11,91, p=, 019, \eta^{2}=, 799\right)$ los que consiguen diferenciar entre rebajados.

En cuanto a las preguntas globales, el oboísta que más distingue en todas las respuestas, a excepción del timbre, es el oboísta 6: distingue por rebajados para el equilibrio $\left(\mathrm{F}=9,6, p=, 039, \eta^{2}=, 762\right)$, flexibilidad $\left(\mathrm{F}=13,72, p=, 016, \eta^{2}=, 821\right)$, globalidad $\left(\mathrm{F}=9,6, p=, 017, \eta^{2}=, 762\right)$ y rigidez $\left(\mathrm{F}=7,18, p=, 047, \eta^{2}=, 705\right)$, siendo el único que distingue los rebajados en la globalidad. El oboísta 4 es el único capaz de distinguir entre rebajado en referencia al timbre $\left(\mathrm{F}=19,45, p=, 004, \eta^{2}=, 866\right)$. Cabe destacar que son los propios oboístas, en general, los que afirman que los diferentes rebajados varían de forma considerable el timbre del oboe, pero cuando son preguntados por ellos al interpretar los diferentes ejercicios, no suelen distinguirlos.

En los estilos de interpretación de las obras, las escuelas de rebajado son diferenciados por los oboístas 4, 5, 6 y 8 de forma alternante (a excepción del oboísta 6 que distingue los rebajados en todos los casos).

También sobresalen los oboístas 9 y 11 que no distinguen en ningún ejercicio por rebajados; mientras que el oboísta 8 sólo distingue en la pregunta de estilos sobre Mozart, al igual que el oboísta 10, que sólo distingue en la calidad del pianissimo. Por el contrario, el oboísta 6 es el que más distingue por rebajados, sobre todo cuando contesta a las preguntas sobre los estilos musicales, ya que es el único al que le afectan de forma significativa en todos los estilos.

Al realizar un escalamiento multidimensional (ALSCAL) sobre los oboístas según las respuestas dadas, utilizando un modelo de dos dimensiones, se intenta entender si los oboístas pertenecientes a diferentes escuelas de interpretación utilizan criterios similares en sus puntuaciones. La variabilidad explicada por estas dimensiones para todas las respuestas es: $\mathrm{RSQ}=86 \%$ (respuestas sobre la calidad), $\mathrm{RSQ}=90 \%$ (respuestas sobre la facilidad), $\mathrm{RSQ}=83 \%$ (respuestas sobre la globalidad), $\mathrm{RSQ}=85 \%$ (respuestas sobre los estilos). Las figuras 4.93, 4.94, 4.95 y 4.96 muestran la obtención de una asociación clara por los instrumentistas de la escuela alemana para la dimensión 1. 


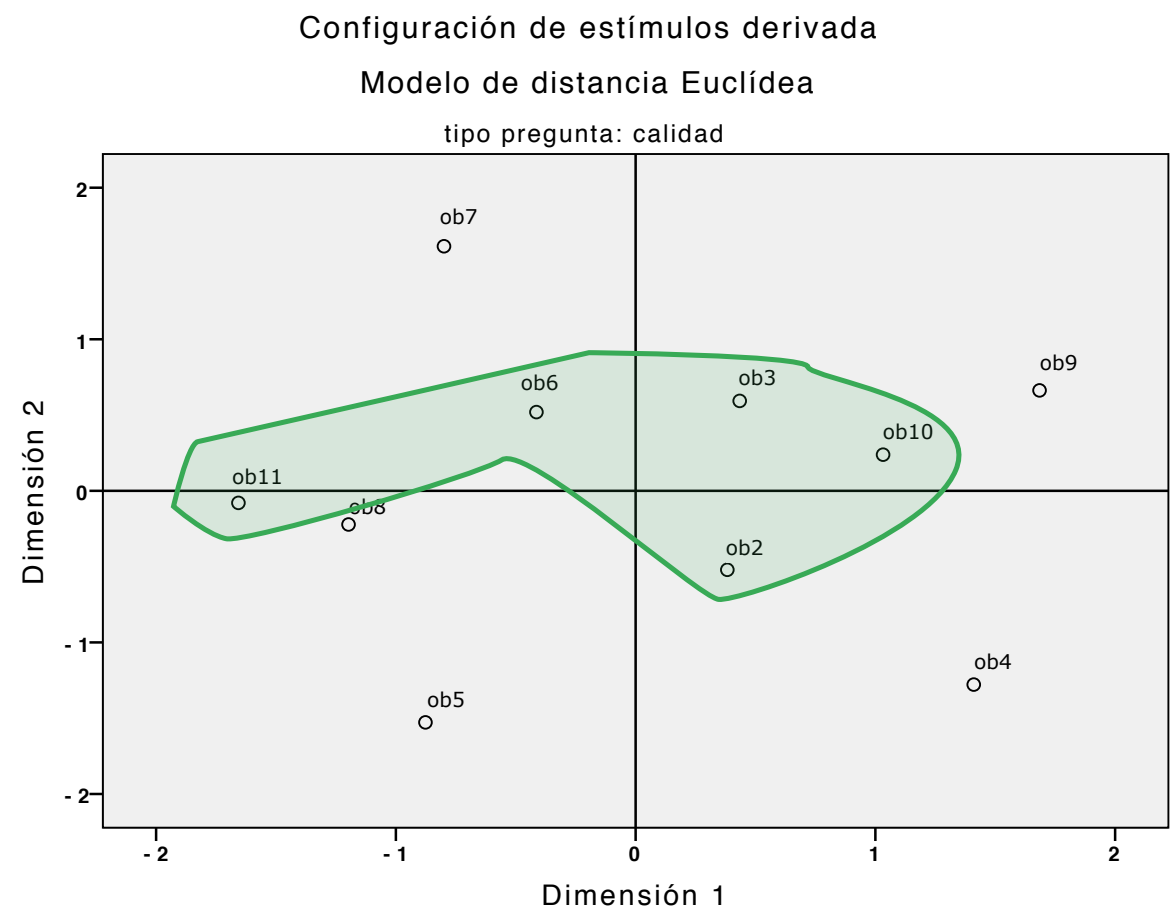

Figura 4.93. Escalamiento multidimensional de los oboístas según sus puntuaciones sobre la calidad. Se marca con color verde a los oboístas de la escuela alemana.

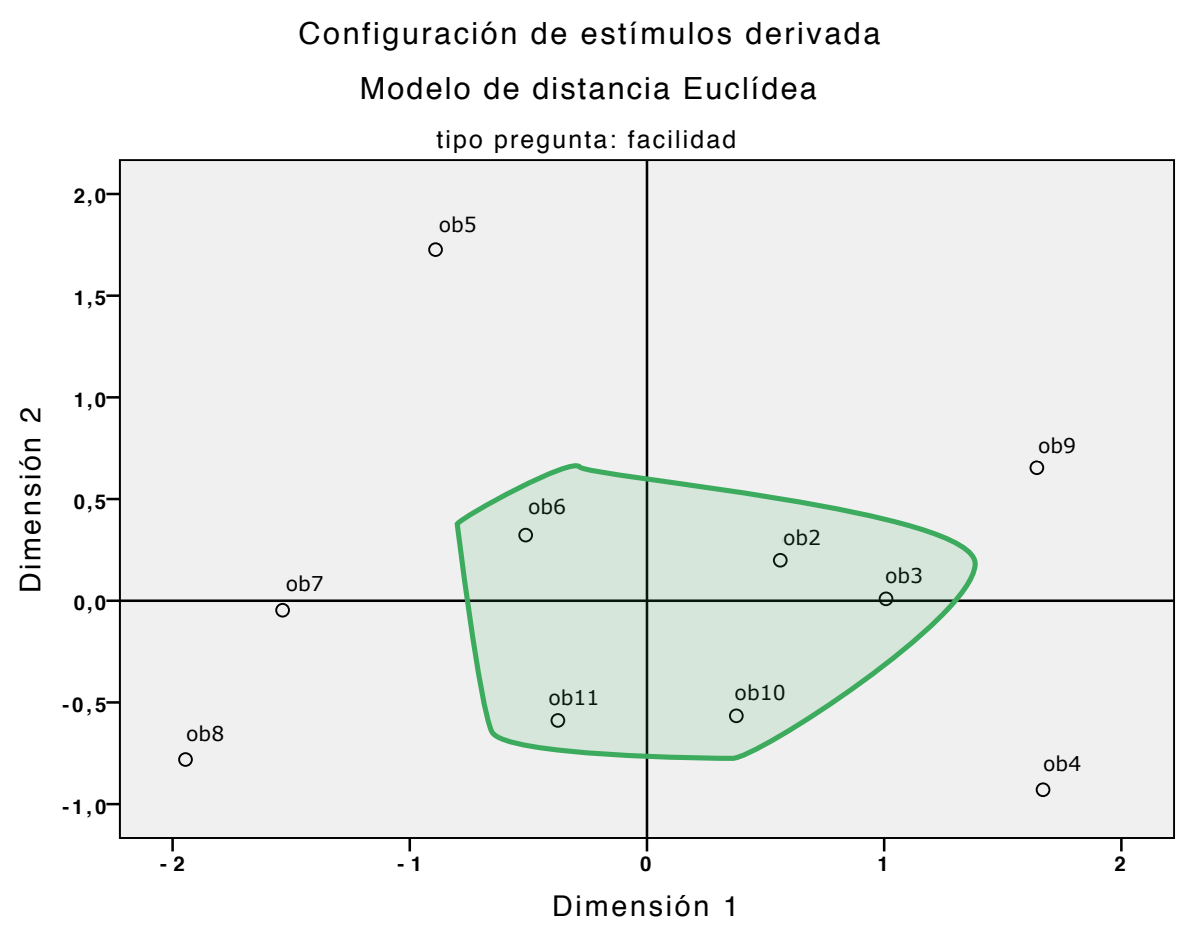

Figura 4.94. Escalamiento multidimensional de los oboístas según sus puntuaciones sobre la facilidad. Se marca con color verde a los oboístas de la escuela alemana. 


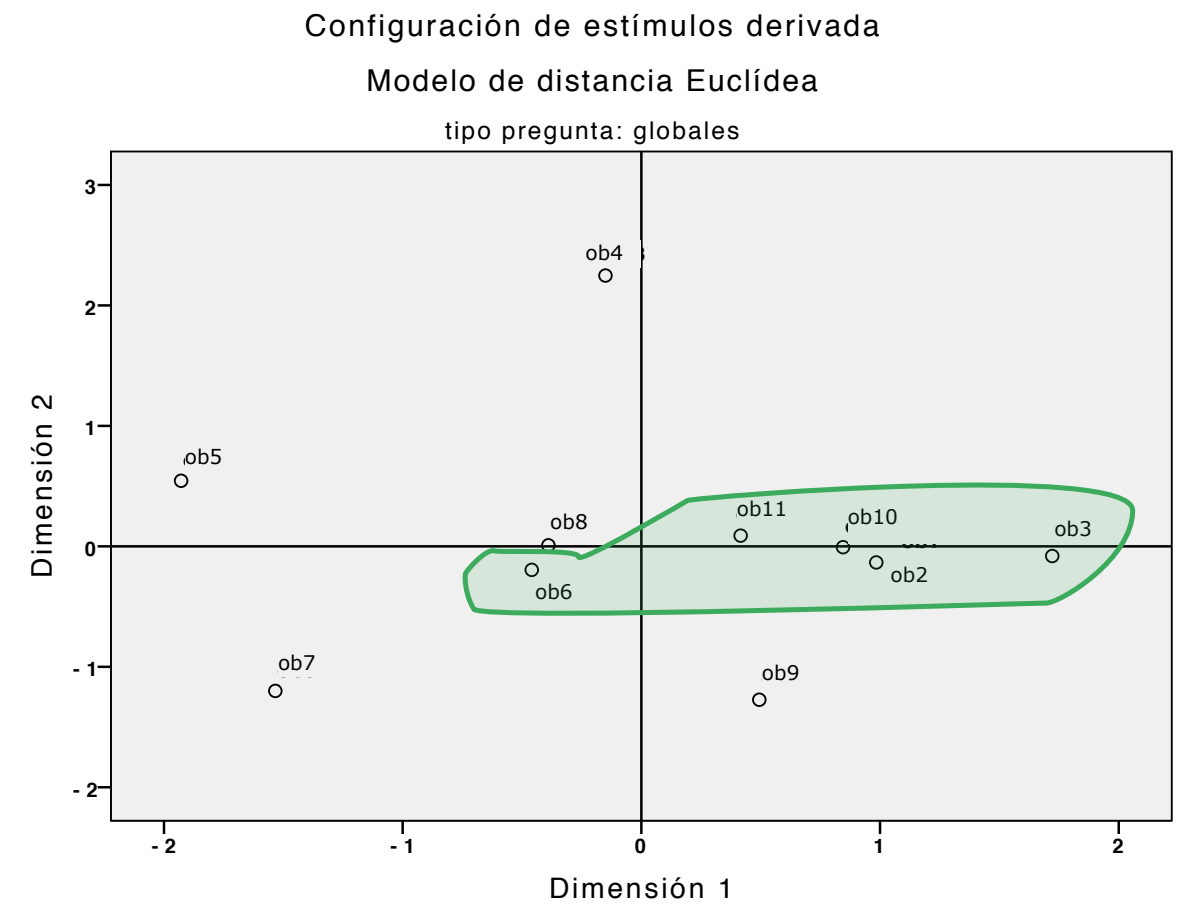

Figura 4.95. Escalamiento multidimensional de los oboístas según sus puntuaciones sobre la globalidad. Se marca con color verde a los oboístas de la escuela alemana.

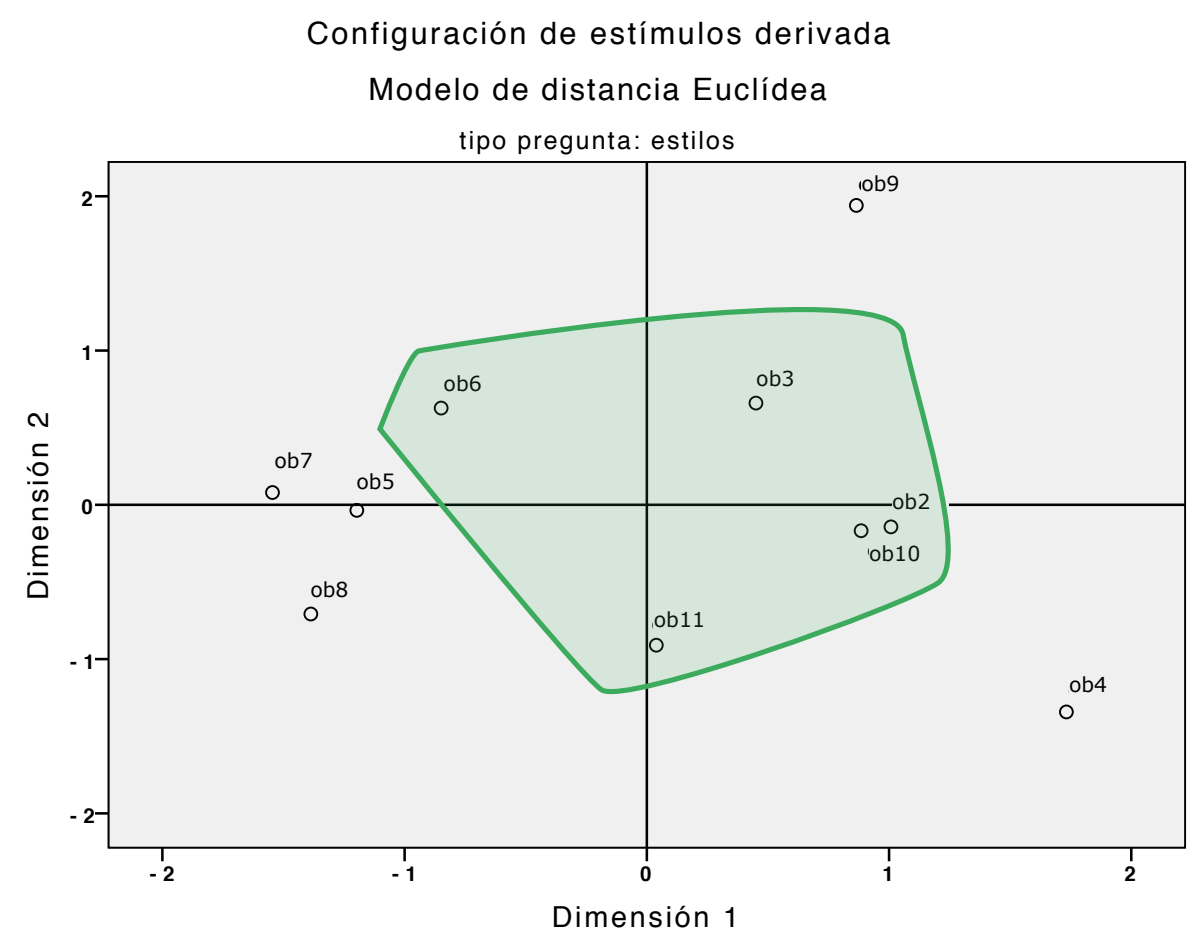

Figura 4.96. Escalamiento multidimensional de los oboístas según sus puntuaciones sobre los estilos. Se marca con color verde a los oboístas de la escuela alemana. 


\subsubsection{Correlaciones}

Si se estudian las respuestas de todos los oboístas en conjunto, se observa en la tabla 4.44, que todas las respuestas sobre la facilidad de interpretación de los ejercicios están relacionadas. Es decir, cuando los oboístas consideran que una lengüeta funciona bien para un ejercicio, funciona bien para todos los demás y al contrario. Esta valoración confirma que no existe una lengüeta buena para el diminuendo y pésima para el legato, por poner un ejemplo. Además, los resultados muestran que la correlación más fuerte existe entre el arpegio y el legato. Si una lengüeta realiza un buen arpegio, el resultado será muy parecido para el legato, aunque oboísticamente son dos ejercicios completamente diferentes: en uno se realizan cortes en la emisión con sus correspondientes ataques y en el otro existe una continuidad de columna de aire, sin interrupción del sonido. Quizás esta correlación tan alta se deba porque los dos ejercicios abarcan casi la totalidad del registro del oboe, es decir, son ejercicios complejos, largos y en todos los registros, mientras que los otros tres ejercicios son más cortos y sólo se interpreta una nota.

\begin{tabular}{|c|c|c|c|c|c|c|}
\hline \multicolumn{7}{|c|}{ Correlaciones } \\
\hline & & arpegioF & $\operatorname{dim} F$ & $\mathrm{ffF}$ & legatoF & $\mathrm{ppF}$ \\
\hline \multirow[t]{2}{*}{ arpegioF } & Corr. & 1 &, $639^{* *}$ &, $402^{* *}$ & $821^{* *}$ &, $397^{* *}$ \\
\hline & Sig. & & 0,000 & 0,000 & 0,000 & 0,000 \\
\hline \multirow[t]{2}{*}{$\operatorname{dimF}$} & Corr. &, $639^{* *}$ & 1 & $290^{* *}$ &, $671^{* *}$ &, $492^{* *}$ \\
\hline & Sig. & 0,000 & & 0,000 & 0,000 & 0,000 \\
\hline \multirow[t]{2}{*}{$\mathrm{ffF}$} & Corr. &, $402^{* *}$ & ,290** & 1 & $279^{* *}$ & ,400** \\
\hline & Sig. & 0,000 & 0,000 & & 0,000 & 0,000 \\
\hline \multirow[t]{2}{*}{ legatoF } & Corr. &, $821^{* *}$ & $671^{* *}$ & $279^{* *}$ & 1 &, $485^{* *}$ \\
\hline & Sig. & 0,000 & 0,000 & 0,000 & & 0,000 \\
\hline
\end{tabular}

Tabla 4.44. Correlación de Pearson y significatividad bilateral ( $\mathrm{N}=180$ en todos los casos) para las preguntas referentes a la facilidad de interpretación de los diferentes ejercicios que respondían los oboístas.

Lo mismo ocurre con la calidad, la tabla 4.45 muestra que todos los valores están correlacionados: cuando a los oboístas una lengüeta les parece de buena calidad para un ejercicio también les parece buena para el resto. Además, la correlación más alta se da también entre el arpegio y el legato, al igual que ocurría con la facilidad.

En relación a las puntuación globales que los oboístas dan a todas las lengüetas, se aprecia que también están correlacionadas con la excepción del equilibrio y la rigidez. Seguramente, la puntuación de la rigidez no llegó a ser entendida por todos los oboístas 
por igual, por lo que algunos puntuaron la flexibilidad con la misma puntuación que la rigidez. Además, se puede ver en la tabla 4.46, que el equilibrio de las lengüetas es el valor más correlacionado con la puntuación global, es decir, los oboístas consideran que el equilibrio es la característica que engloba todas las propiedades de la lengüeta para una valoración global.

\begin{tabular}{|l|l|r|r|r|r|r|}
\hline \multicolumn{7}{|c|}{ Correlaciones } \\
\hline \multirow{2}{*}{ arpegioQ } & & arpegioQ & dimQ & ffQ & legatoQ & \multicolumn{1}{c|}{ ppQ } \\
\hline \multirow{2}{*}{ dimQ } & Corr. & 1 &, $577^{* *}$ &, $507^{* *}$ &, $\mathbf{8 2 4}^{* *}$ &, $481^{* *}$ \\
\cline { 2 - 7 } & Sig. & & 0,000 & 0,000 & 0,000 & 0,000 \\
\hline \multirow{2}{*}{ ffQ } & Corr. &, $577^{* *}$ & 1 &, $526^{* *}$ &, $652^{* *}$ &, $504^{* *}$ \\
\cline { 2 - 7 } & Sig. & 0,000 & & 0,000 & 0,000 & 0,000 \\
\hline \multirow{2}{*}{ legatoQ } & Corr. &, $507^{* *}$ &, $526^{* *}$ & 1 &, $464^{* *}$ &, $578^{* *}$ \\
\cline { 2 - 7 } & Sig. & 0,000 & 0,000 & & 0,000 & 0,000 \\
\cline { 2 - 7 } & Corr. &, $824^{* *}$ &, $652^{* *}$ &, $464^{* *}$ & 1 &, $503^{* *}$ \\
\cline { 2 - 7 } & Sig. & 0,000 & 0,000 & 0,000 & & 0,000 \\
\hline **. La correlación es significativa al nivel 0,01 (bilateral). \\
\hline *. La correlación es significante al nivel 0,05 (bilateral).
\end{tabular}

Tabla 4.45. Correlación de Pearson y significatividad bilateral ( $\mathrm{N}=180$ en todos los casos) para las preguntas referentes a la calidad de interpretación de los diferentes ejercicios que respondían los oboístas.

\begin{tabular}{|c|c|c|c|c|c|c|}
\hline \multicolumn{7}{|c|}{ Correlaciones } \\
\hline & & global & $\begin{array}{c}\text { global: } \\
\text { equilibrio }\end{array}$ & $\begin{array}{c}\text { global: } \\
\text { flexibilidad }\end{array}$ & $\begin{array}{l}\text { global: } \\
\text { rigidez }\end{array}$ & global: timbre \\
\hline \multirow[t]{2}{*}{ global } & Corr. & 1 &, $745^{* *}$ & ,614** &,$- 222^{* *}$ &, $712^{* *}$ \\
\hline & \begin{tabular}{|l} 
Sig. \\
S.
\end{tabular} & & 0,000 & 0,000 & 0,003 & 0,000 \\
\hline \multirow{2}{*}{$\begin{array}{l}\text { global: } \\
\text { equilibrio }\end{array}$} & Corr. &, $745^{* * *}$ & 1 & ,429** & 0,009 &, $671^{* *}$ \\
\hline & Sig. & 0,000 & & 0,000 & 0,902 & 0,000 \\
\hline \multirow{2}{*}{$\begin{array}{l}\text { global: } \\
\text { flexibilidad }\end{array}$} & Corr. & ,614** & ,429** & 1 &,$- 420^{* *}$ & $262^{* *}$ \\
\hline & Sig. & 0,000 & 0,000 & & 0,000 & 0,000 \\
\hline \multirow[t]{2}{*}{ global: rigidez } & Corr. &,$- 222^{* *}$ & 0,009 &,$- 420^{* *}$ & 1 & 0,017 \\
\hline & \begin{tabular}{|l} 
Sig. \\
\end{tabular} & 0,003 & 0,902 & 0,000 & & 0,819 \\
\hline \multicolumn{7}{|c|}{ **. La correlación es significativa al nivel 0,01 (bilateral). } \\
\hline \multicolumn{7}{|c|}{ *. La correlación es significante al nivel 0,05 (bilateral). } \\
\hline
\end{tabular}

Tabla 4.46. Correlación de Pearson y significatividad bilateral ( $\mathrm{N}=180$ en todos los casos) para las preguntas referentes a las características globales de los diferentes ejercicios que respondían los oboístas.

La tabla 4.47 presenta los resultados de las correlaciones de los diferentes estilos puntuados por los oboístas. Cabe destacar que los oboístas en ningún momento interpretaron las obras elegidas como representativas de cada época, sino que sólo imaginaron cómo sería tocar con esa lengüeta una pieza en concreto, por lo que la valoración de estos estilos es muy subjetiva y los resultados deben analizarse con cautela. 
No obstante, se advierte una correlación directa entre todos los estilos elegidos, siendo más marcado el barroco y el clásico.

\begin{tabular}{|l|l|r|r|r|r|}
\hline \multicolumn{7}{|c|}{ Correlaciones } \\
\hline \multirow{2}{*}{ Vivaldi } & & \multicolumn{1}{|c|}{ Vivaldi } & \multicolumn{1}{c|}{ Mozart } & \multicolumn{1}{c|}{ Strauss } & \multicolumn{1}{c|}{ Dutilleux } \\
& Corr. & 1 & $\mathbf{8 5 4}^{* *}$ &, $762^{* *}$ &, $697^{* *}$ \\
\cline { 2 - 6 } & Sig. & & 0,000 & 0,000 & 0,000 \\
\hline \multirow{2}{*}{ Mozart } & Corr. &, $854^{* *}$ & 1 &, $864^{* *}$ &, $763^{* *}$ \\
\cline { 2 - 6 } & Sig. & 0,000 & & 0,000 & 0,000 \\
\hline \multirow{2}{*}{ Strauss } & Corr. &, $762^{* *}$ &, $864^{* *}$ & 1 &, $765^{* *}$ \\
\cline { 2 - 6 } & Sig. & 0,000 & 0,000 & & 0,000 \\
\hline **. La correlación es significativa al nivel 0,01 (bilateral). \\
\hline *. La correlación es significante al nivel 0,05 (bilateral).
\end{tabular}

Tabla 4.47. Correlación de Pearson y significatividad bilateral ( $\mathrm{N}=180$ en todos los casos) para las preguntas referentes a los estilos de los diferentes ejercicios que respondían los oboístas.

Si se efectúa el análisis de las correlaciones globales separando las puntuaciones dadas por los oboístas (tabla 4.48), se observa que las puntuaciones son más dispares para algunos oboístas: la flexibilidad no tiene correlación con el equilibrio ni la globalidad (oboístas 2 y 3) o la rigidez no tiene correlación con el equilibrio (oboístas 3, 5, 6, 7, 9 y 11). De forma generalizada aparecen tres grupos: aquellos que correlacionan más la globalidad con el equilibrio, es decir, una lengüeta equilibrada obtiene mayor puntuación globalmente (oboístas 2, 3, 4, 5 y 10); aquellos que correlacionan la globalidad con el timbre: una lengüeta que suena bien obtiene mayor puntuación global o al contrario (oboístas 6, 7 y 8); y aquellos que correlacionan la globalidad con la flexibilidad: cuanto más flexible es una lengüeta, más puntuación global obtiene o al revés (oboístas 9 y 11). Ninguno de estos grupos estaría relacionado con ninguna escuela de interpretación (alemana o francesa), ya que en ambos grupos hay oboístas pertenecientes a las dos escuelas.

\begin{tabular}{|c|c|c|c|c|c|c|c|}
\hline \multicolumn{8}{|c|}{ Correlaciones } \\
\hline oboísta & & & global & $\begin{array}{c}\text { global: } \\
\text { equilibrio }\end{array}$ & $\begin{array}{c}\text { global: } \\
\text { flexibilidad }\end{array}$ & $\begin{array}{l}\text { global: } \\
\text { rigidez }\end{array}$ & $\begin{array}{l}\text { global: } \\
\text { timbre }\end{array}$ \\
\hline \multirow[t]{7}{*}{ Ob2 } & \multirow[t]{2}{*}{ global } & Corr. & 1 &, $763^{* *}$ & $-0,336$ & ,664** &, $748^{* *}$ \\
\hline & & Sig. & & 0,000 & 0,173 & 0,003 & 0,000 \\
\hline & \multirow[t]{2}{*}{ global: equilibrio } & Corr. &, $763^{* *}$ & 1 & $-0,189$ &, $696^{* *}$ & 0,444 \\
\hline & & Sig. & 0,000 & & 0,452 & 0,001 & 0,065 \\
\hline & \multirow[t]{2}{*}{ global: flexibilidad } & Corr. & $-0,336$ & $-0,189$ & 1 &,$- 650^{* *}$ &,$- 637^{* *}$ \\
\hline & & Sig. & 0,173 & 0,452 & & 0,004 & 0,004 \\
\hline & global: rigidez & Corr. & ,664** & ,696*** &,$- 650^{* *}$ & $\overline{1}$ & ,644** \\
\hline
\end{tabular}




\begin{tabular}{|c|c|c|c|c|c|c|c|}
\hline \multicolumn{8}{|c|}{ Correlaciones } \\
\hline \multirow[t]{2}{*}{ oboísta } & & & global & $\begin{array}{c}\text { global: } \\
\text { equilibrio }\end{array}$ & $\begin{array}{c}\text { global: } \\
\text { flexibilidad }\end{array}$ & $\begin{array}{l}\text { global: } \\
\text { rigidez }\end{array}$ & $\begin{array}{l}\text { global: } \\
\text { timbre }\end{array}$ \\
\hline & & Sig. & 0,003 & 0,001 & 0,004 & & 0,004 \\
\hline \multirow[t]{8}{*}{ Ob3 } & \multirow[t]{2}{*}{ global } & Corr. & 1 &, $841^{* *}$ & 0,370 & 0,061 &, $735^{* *}$ \\
\hline & & Sig. & & 0,000 & 0,130 & 0,809 & 0,001 \\
\hline & \multirow[t]{2}{*}{ global: equilibrio } & Corr. &, $841^{* *}$ & 1 & 0,392 & 0,091 & $851^{* *}$ \\
\hline & & Sig. & 0,000 & & 0,108 & 0,721 & 0,000 \\
\hline & \multirow[t]{2}{*}{ global: flexibilidad } & Corr. & 0,370 & 0,392 & 1 &, $810^{* *}$ & $-0,050$ \\
\hline & & Sig. & 0,130 & 0,108 & & 0,000 & $\overline{0,844}$ \\
\hline & \multirow[t]{2}{*}{ global: rigidez } & Corr. & 0,061 & 0,091 & ,810** & 1 & $-0,243$ \\
\hline & & Sig. & 0,809 & 0,721 & 0,000 & & 0,331 \\
\hline \multirow[t]{8}{*}{$\mathrm{Ob} 4$} & \multirow[t]{2}{*}{ global } & Corr. & 1 & ,931** & $886^{* *}$ &,$- 503^{*}$ & $828^{* *}$ \\
\hline & & Sig. & & 0,000 & 0,000 & 0,033 & 0,000 \\
\hline & \multirow[t]{2}{*}{ global: equilibrio } & Corr. & ,931** & 1 & ,834** &,$- 534^{*}$ & $839^{* *}$ \\
\hline & & Sig. & 0,000 & & 0,000 & 0,022 & 0,000 \\
\hline & \multirow[t]{2}{*}{\begin{tabular}{|l|} 
global: flexibilidad \\
\end{tabular}} & Corr. &, $886^{* *}$ &, $834^{* *}$ & 1 &,$- 640^{* *}$ & ,640** \\
\hline & & Sig. & 0,000 & 0,000 & & 0,004 & 0,004 \\
\hline & \multirow[t]{2}{*}{ global: rigidez } & Corr. &,$- 503^{*}$ &,$- 534^{*}$ &,$- 640^{* *}$ & 1 & $-0,309$ \\
\hline & & Sig. & 0,033 & 0,022 & 0,004 & & 0,211 \\
\hline \multirow[t]{8}{*}{ Ob5 } & \multirow[t]{2}{*}{ global } & Corr. & 1 & ,844** &, $775^{* *}$ &,$- 700^{* *}$ & 0,434 \\
\hline & & Sig. & & 0,000 & 0,000 & 0,001 & 0,072 \\
\hline & \multirow[t]{2}{*}{ global: equilibrio } & Corr. &, $844^{* *}$ & 1 & ,587* & $-0,424$ &, $641^{* *}$ \\
\hline & & Sig. & 0,000 & & 0,010 & 0,079 & 0,004 \\
\hline & \multirow[t]{2}{*}{ global: flexibilidad } & Corr. &, $775^{* *}$ & ,587* & 1 &,$- 883^{* *}$ & $-0,070$ \\
\hline & & Sig. & 0,000 & 0,010 & & 0,000 & 0,783 \\
\hline & \multirow[t]{2}{*}{ global: rigidez } & Corr. &,$- 700^{* *}$ & $-0,424$ &,$- 883^{* *}$ & 1 & 0,024 \\
\hline & & Sig. & 0,001 & 0,079 & 0,000 & & 0,924 \\
\hline \multirow[t]{8}{*}{ Ob6 } & \multirow[t]{2}{*}{ global } & Corr. & 1 &, $778^{* *}$ &, $706^{* *}$ & $-0,345$ & $816^{* *}$ \\
\hline & & Sig. & & 0,000 & 0,001 & 0,161 & 0,000 \\
\hline & \multirow[t]{2}{*}{ global: equilibrio } & Corr. &, $778^{* *}$ & 1 &, $655^{* *}$ & $-0,125$ &, $642^{* *}$ \\
\hline & & Sig. & 0,000 & & 0,003 & 0,621 & 0,004 \\
\hline & \multirow[t]{2}{*}{ global: flexibilidad } & Corr. &, $706^{* *}$ & $655^{* *}$ & 1 &,$- 612^{* *}$ & 0,459 \\
\hline & & Sig. & 0,001 & 0,003 & & 0,007 & 0,056 \\
\hline & \multirow[t]{2}{*}{ global: rigidez } & Corr. & $-0,345$ & $-0,125$ &,$- 612^{* *}$ & 1 & $-0,128$ \\
\hline & & Sig. & 0,161 & 0,621 & 0,007 & & 0,612 \\
\hline \multirow[t]{8}{*}{$\mathrm{Ob} 7$} & \multirow[t]{2}{*}{ global } & Corr. & 1 & ,566* &, $764^{* *}$ &,$- 775^{* *}$ &, $804^{* *}$ \\
\hline & & Sig. & & 0,014 & 0,000 & 0,000 & 0,000 \\
\hline & global: equilibrio & Corr. &, $566^{*}$ & 1 & ,521* & $-0,300$ &, $576^{*}$ \\
\hline & & Sig. & 0,014 & & 0,026 & 0,227 & 0,012 \\
\hline & global: flexibilidad & Corr. &, $764^{* *}$ & ,521* & 1 &,$- 694^{* *}$ &, $723^{* *}$ \\
\hline & & Sig. & 0,000 & 0,026 & & 0,001 & 0,001 \\
\hline & global: rigidez & Corr. &,$- 775^{* *}$ & $-0,300$ &,$- 694^{* *}$ & 1 & $-0,424$ \\
\hline & & Sig. & 0,000 & 0,227 & 0,001 & & 0,080 \\
\hline
\end{tabular}




\begin{tabular}{|c|c|c|c|c|c|c|c|}
\hline \multicolumn{8}{|c|}{ Correlaciones } \\
\hline oboísta & & & global & $\begin{array}{c}\text { global: } \\
\text { equilibrio }\end{array}$ & $\begin{array}{c}\text { global: } \\
\text { flexibilidad }\end{array}$ & $\begin{array}{l}\text { global: } \\
\text { rigidez }\end{array}$ & $\begin{array}{l}\text { global: } \\
\text { timbre }\end{array}$ \\
\hline \multirow[t]{8}{*}{$\mathrm{Ob} 8$} & \multirow[t]{2}{*}{ global } & Corr. & 1 &, $622^{* *}$ & $-0,035$ & 0,378 &, $739^{* *}$ \\
\hline & & Sig. & & 0,006 & 0,889 & 0,122 & 0,000 \\
\hline & \multirow[t]{2}{*}{ global: equilibrio } & Corr. & ,622** & 1 & $-0,412$ &, $708^{* *}$ &, $538^{*}$ \\
\hline & & Sig. & 0,006 & & 0,089 & 0,001 & 0,021 \\
\hline & \multirow[t]{2}{*}{ global: flexibilidad } & Corr. & $-0,035$ & $-0,412$ & 1 &,$- 729^{* *}$ & 0,124 \\
\hline & & Sig. & 0,889 & 0,089 & & 0,001 & 0,624 \\
\hline & \multirow[t]{2}{*}{ global: rigidez } & Corr. & |0,378 & ,708** &,$- 729^{* *}$ & 1 & 0,341 \\
\hline & & Sig. & 0,122 & 0,001 & 0,001 & & 0,165 \\
\hline \multirow[t]{8}{*}{ Ob9 } & \multirow[t]{2}{*}{ global } & Corr. & 1 &, $736^{* *}$ &, $854^{* *}$ & $-0,049$ &, $764^{* *}$ \\
\hline & & Sig. & & 0,001 & 0,000 & 0,847 & 0,000 \\
\hline & \multirow[t]{2}{*}{ global: equilibrio } & Corr. &, $736^{* *}$ & 1 & ,639** & 0,098 &, $736^{* *}$ \\
\hline & & Sig. & 0,001 & & 0,004 & 0,698 & 0,000 \\
\hline & \multirow[t]{2}{*}{ global: flexibilidad } & Corr. &, $854^{* *}$ & ,639** & 1 & $-0,155$ &, $585^{*}$ \\
\hline & & Sig. & 0,000 & 0,004 & & 0,540 & 0,011 \\
\hline & \multirow[t]{2}{*}{ global: rigidez } & Corr. & $-0,049$ & 0,098 & $-0,155$ & 1 & 0,155 \\
\hline & & Sig. & 0,847 & 0,698 & 0,540 & & 0,539 \\
\hline \multirow[t]{8}{*}{ Ob10 } & \multirow[t]{2}{*}{ global } & Corr. & 1 &, $819^{* *}$ & ,486* & 0,456 &, $513^{*}$ \\
\hline & & Sig. & & 0,000 & 0,041 & 0,057 & 0,029 \\
\hline & \multirow[t]{2}{*}{ global: equilibrio } & Corr. &, $819^{* *}$ & 1 & 0,219 & ,534* &, $493^{*}$ \\
\hline & & Sig. & 0,000 & & 0,383 & 0,022 & 0,038 \\
\hline & \multirow[t]{2}{*}{ global: flexibilidad } & Corr. & , 486* & 0,219 & 1 & $-0,277$ & $-0,055$ \\
\hline & & Sig. & 0,041 & 0,383 & & 0,266 & 0,827 \\
\hline & \multirow[t]{2}{*}{ global: rigidez } & Corr. & 0,456 & ,534* & $-0,277$ & 1 &, $534^{*}$ \\
\hline & & Sig. & 0,057 & 0,022 & 0,266 & & 0,022 \\
\hline \multirow[t]{8}{*}{ Ob11 } & \multirow[t]{2}{*}{ global } & Corr. & 1 & ,568* &, $775^{* *}$ & 0,075 & ,706 $6^{* *}$ \\
\hline & & Sig. & & 0,014 & 0,000 & 0,768 & 0,001 \\
\hline & \multirow[t]{2}{*}{ global: equilibrio } & Corr. &, $568^{*}$ & 1 & 0,404 & 0,461 &, $754^{* *}$ \\
\hline & & Sig. & 0,014 & & 0,097 & 0,054 & 0,000 \\
\hline & \multirow[t]{2}{*}{ global: flexibilidad } & Corr. & , $775^{* *}$ & 0,404 & 1 & $-0,307$ &, $504^{*}$ \\
\hline & & Sig. & 0,000 & 0,097 & & 0,215 & 0,033 \\
\hline & \multirow[t]{2}{*}{ global: rigidez } & Corr. & 0,075 & 0,461 & $-0,307$ & 1 & 0,270 \\
\hline & & Sig. & 0,768 & 0,054 & 0,215 & & 0,279 \\
\hline \multicolumn{8}{|c|}{ **. La correlación es significativa al nivel 0,01 (bilateral). } \\
\hline & & ive & bilate & & & & \\
\hline
\end{tabular}

Tabla 4.48. Correlación de Pearson y significatividad bilateral ( $\mathrm{N}=18$ en todos los casos) para las preguntas referentes a las características globales de los diferentes ejercicios que respondían los oboístas separado por cada oboísta. 
Las tablas 4.44 y 4.45 muestran la existencia de una correlación entre el legato y el arpegio, si se dividen las puntuaciones del grupo separadamente por oboístas, se aprecia en la tabla 4.49, que esta correlación se da en casi todos los casos: excepto en el oboísta 10, que es el único que no correlaciona la facilidad del arpegio con la facilidad del legato. El resto de oboístas asocian la puntuación de la facilidad del arpegio junto con la facilidad del legato y la puntuación de la calidad del arpegio junto a la calidad del legato. Como se explicó anteriormente, esto se debe a que, aunque son ejercicios bastante diferentes, son muy parecidos en cuanto a duración del ejercicio, complejidad y registro abarcado del oboe, por lo que provocan en los oboístas más similitudes que, por ejemplo, el ejercicio pianissimo.

\begin{tabular}{|c|c|c|c|c|c|c|}
\hline \multicolumn{7}{|c|}{ Correlaciones } \\
\hline oboísta & & & arpegioF & arpegioQ & legatoF & legatoQ \\
\hline \multirow[t]{6}{*}{ Ob2 } & \multirow[t]{2}{*}{ arpegioF } & Corr. & 1 & 0,101 & ,730** & 0,000 \\
\hline & & Sig. & & 0,690 & 0,001 & 1,000 \\
\hline & \multirow[t]{2}{*}{ arpegioQ } & Corr. & 0,101 & 1 & $-0,019$ & $841^{* *}$ \\
\hline & & Sig. & 0,690 & & 0,939 & 0,000 \\
\hline & \multirow[t]{2}{*}{ legatoF } & Corr. &, $730^{* *}$ & $-0,019$ & 1 & $-0,025$ \\
\hline & & Sig. & 0,001 & 0,939 & & 0,922 \\
\hline \multirow[t]{6}{*}{ Ob3 } & \multirow[t]{2}{*}{ arpegioF } & Corr. & 1 & ,505* & ,839** & 0,437 \\
\hline & & Sig. & & 0,033 & 0,000 & 0,070 \\
\hline & \multirow[t]{2}{*}{ arpegioQ } & Corr. & ,505* & 1 & 0,357 & ,531* \\
\hline & & Sig. & 0,033 & & 0,145 & 0,023 \\
\hline & \multirow[t]{2}{*}{ legatoF } & Corr. & ,839** & 0,357 & 1 & ,670 \\
\hline & & Sig. & 0,000 & 0,145 & & 0,002 \\
\hline \multirow[t]{6}{*}{ Ob4 } & \multirow[t]{2}{*}{ arpegioF } & Corr. & 1 & $821^{* *}$ &, $810^{* *}$ &, $711^{* *}$ \\
\hline & & Sig. & & 0,000 & 0,000 & 0,001 \\
\hline & \multirow[t]{2}{*}{ arpegioQ } & Corr. & $821^{* *}$ & 1 & ,658** &, $751^{* *}$ \\
\hline & & Sig. & 0,000 & & 0,003 & 0,000 \\
\hline & \multirow[t]{2}{*}{ legatoF } & Corr. & $810^{* *}$ & ,658** & 1 & , $779^{* *}$ \\
\hline & & Sig. & 0,000 & 0,003 & & 0,000 \\
\hline \multirow[t]{6}{*}{ Ob5 } & \multirow[t]{2}{*}{ arpegioF } & Corr. & 1 & 0,212 & $807^{* *}$ & 0,143 \\
\hline & & Sig. & & 0,398 & 0,000 & 0,571 \\
\hline & \multirow[t]{2}{*}{ arpegioQ } & Corr. & 0,212 & 1 & $-0,101$ & ,949** \\
\hline & & Sig. & 0,398 & & 0,689 & 0,000 \\
\hline & \multirow[t]{2}{*}{ legatoF } & Corr. & $807^{* *}$ & $-0,101$ & 1 & $-0,086$ \\
\hline & & Sig. & 0,000 & 0,689 & & 0,736 \\
\hline \multirow[t]{3}{*}{ Ob6 } & \multirow[t]{2}{*}{ arpegioF } & Corr. & 1 & 0,432 & $809^{* *}$ & 0,297 \\
\hline & & Sig. & & 0,073 & 0,000 & 0,231 \\
\hline & arpegioQ & Corr. & 0,432 & 1 & 0,425 &, $867^{* *}$ \\
\hline
\end{tabular}




\begin{tabular}{|c|c|c|c|c|c|c|}
\hline \multicolumn{7}{|c|}{ Correlaciones } \\
\hline \multirow[t]{4}{*}{ oboísta } & & & arpegioF & arpegioQ & legatoF & legatoQ \\
\hline & & Sig. & 0,073 & & 0,078 & 0,000 \\
\hline & \multirow[t]{2}{*}{ legatoF } & Corr. & $809^{* *}$ & 0,425 & 1 & 0,442 \\
\hline & & Sig. & 0,000 & 0,078 & & 0,066 \\
\hline \multirow[t]{6}{*}{$\mathrm{Ob} 7$} & \multirow[t]{2}{*}{ arpegioF } & Corr. & 1 &, $867^{* *}$ &, $933^{* *}$ &, $847^{* *}$ \\
\hline & & Sig. & & 0,000 & 0,000 & 0,000 \\
\hline & \multirow[t]{2}{*}{ arpegioQ } & Corr. & $867^{* *}$ & 1 &, $800^{* *}$ & ,933** \\
\hline & & Sig. & 0,000 & & 0,000 & 0,000 \\
\hline & \multirow[t]{2}{*}{ legatoF } & Corr. & ,933** & $800^{* *}$ & 1 & $842^{* *}$ \\
\hline & & Sig. & 0,000 & 0,000 & & 0,000 \\
\hline \multirow[t]{6}{*}{ Ob8 } & \multirow[t]{2}{*}{ arpegioF } & Corr. & 1 & 0,149 &, $786^{* *}$ & $-0,084$ \\
\hline & & Sig. & & 0,554 & 0,000 & 0,741 \\
\hline & \multirow[t]{2}{*}{ arpegioQ } & Corr. & 0,149 & 1 & 0,442 &, $797^{* *}$ \\
\hline & & Sig. & 0,554 & & 0,066 & 0,000 \\
\hline & \multirow[t]{2}{*}{ legatoF } & Corr. &, $786^{* *}$ & 0,442 & 1 & 0,088 \\
\hline & & Sig. & 0,000 & 0,066 & & 0,729 \\
\hline \multirow[t]{6}{*}{ Ob9 } & \multirow[t]{2}{*}{ arpegioF } & Corr. & 1 & ,569* &, $844^{* * *}$ &, $512^{*}$ \\
\hline & & Sig. & & 0,014 & 0,000 & 0,030 \\
\hline & \multirow[t]{2}{*}{ arpegioQ } & Corr. & ,569* & 1 & ,510* & $816^{* *}$ \\
\hline & & Sig. & 0,014 & & 0,031 & 0,000 \\
\hline & \multirow[t]{2}{*}{ legatoF } & Corr. & $844^{* *}$ & ,510* & 1 &, $497^{*}$ \\
\hline & & Sig. & 0,000 & 0,031 & & 0,036 \\
\hline \multirow[t]{6}{*}{ Ob10 } & \multirow[t]{2}{*}{ arpegioF } & Corr. & 1 & $856^{* *}$ & 0,420 & ,620** \\
\hline & & Sig. & & 0,000 & 0,083 & 0,006 \\
\hline & \multirow[t]{2}{*}{ arpegioQ } & Corr. & $856^{* *}$ & 1 & 0,256 & $602^{* *}$ \\
\hline & & Sig. & 0,000 & & 0,304 & 0,008 \\
\hline & \multirow[t]{2}{*}{ legatoF } & Corr. & 0,420 & 0,256 & 1 &, $733^{* *}$ \\
\hline & & Sig. & 0,083 & 0,304 & & 0,001 \\
\hline \multirow[t]{6}{*}{ Ob11 } & \multirow[t]{2}{*}{ arpegioF } & Corr. & 1 & ,698** &, $712^{* *}$ & 0,450 \\
\hline & & Sig. & & 0,001 & 0,001 & 0,061 \\
\hline & \multirow[t]{2}{*}{ arpegioQ } & Corr. & ,698** & 1 &, $710^{* *}$ &, $671^{* *}$ \\
\hline & & Sig. & 0,001 & & 0,001 & 0,002 \\
\hline & \multirow[t]{2}{*}{ legatoF } & Corr. &, $712^{* *}$ &, $710^{* *}$ & 1 & $840^{* *}$ \\
\hline & & Sig. & 0,001 & 0,001 & & 0,000 \\
\hline
\end{tabular}

Tabla 4.49. Correlación de Pearson y significatividad bilateral ( $\mathrm{N}=18$ en todos los casos) para las preguntas referentes a la facilidad y calidad del arpegio y legato de los diferentes ejercicios que respondían los oboístas, separado por cada oboísta. 


\subsubsection{Comparación de la evaluación interpretativa con la acústica}

Después de haber analizado la propiocepción en los oboístas se quiere averiguar si existe algún parámetro acústico que pueda explicar las puntuaciones dadas por los oboístas a las lengüetas utilizadas en la grabación.

Para ello, se realiza una serie de regresiones donde todos los parámetros acústicos se relacionan con las puntuaciones de los ejercicios.

\subsubsection{Resultados}

\subsection{Facilidad del arpegio}

Al analizar todos los parámetros acústicos para ver cuáles pueden estar relacionados con la facilidad del arpegio en la propiocepción, se puede observar en la tabla 4.50 , que sólo la facilidad de vibración (number of voiced frames) tiene una relación directa, aunque con un $\mathrm{R}^{2}$ corregido muy bajo.

Como se ha explicado anteriormente, la medición del number of voiced frames no estuvo controlada en la grabación, así cada oboístas interpretó con una duración estimada los ejercicios, por lo que los resultados deben ser tomados con precaución.

\begin{tabular}{|c|c|c|c|c|c|c|c|c|c|}
\hline \multicolumn{10}{|c|}{ Resumen del modelo } \\
\hline \multirow[t]{2}{*}{ Modelo } & \multirow[t]{2}{*}{$\mathrm{R}$} & \multirow[t]{2}{*}{$\mathrm{R}^{2}$} & \multirow{2}{*}{$\begin{array}{c}\mathrm{R}^{2} \\
\text { corregida }\end{array}$} & \multirow{2}{*}{$\begin{array}{l}\text { Error típ. de } \\
\text { la estimación }\end{array}$} & \multicolumn{5}{|c|}{ Estadísticos de cambio } \\
\hline & & & & & $\begin{array}{c}\text { Cambio en } \\
\mathrm{R}^{2}\end{array}$ & $\begin{array}{c}\text { Cambio } \\
\text { en F }\end{array}$ & gl1 & $\mathrm{g} 12$ & $\begin{array}{c}\text { Sig. Cambio } \\
\text { en F }\end{array}$ \\
\hline 1 & 0,188 & 0,035 & 0,030 & 1,691 & 0,035 & 6,246 & 1 & 170 & 0,013 \\
\hline
\end{tabular}

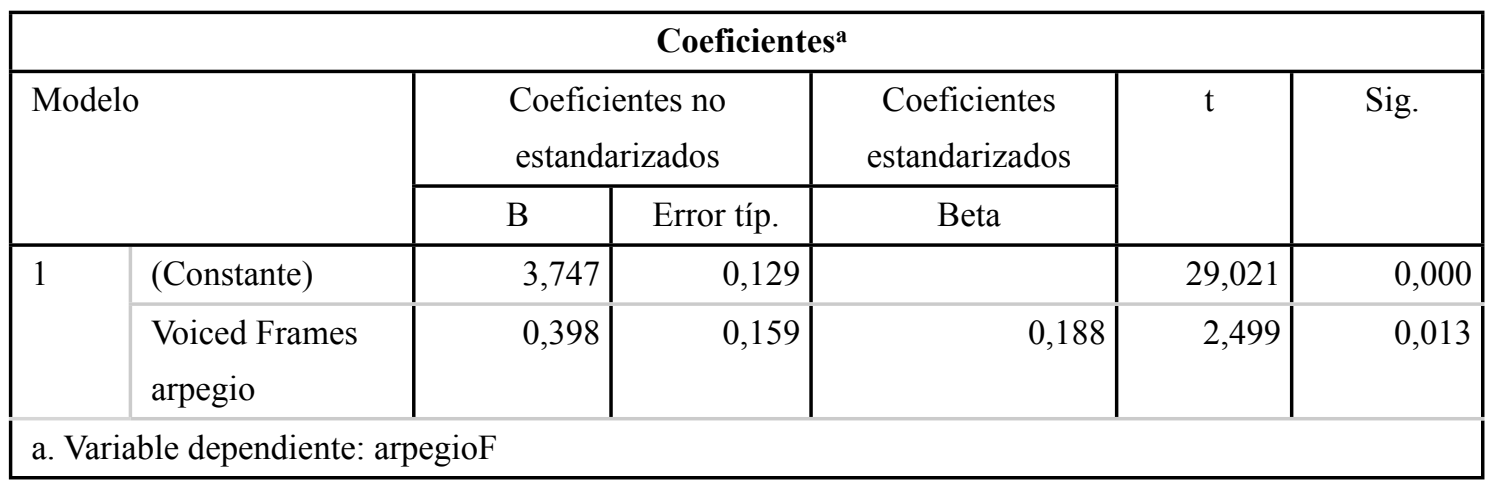

Tabla 4.50. Resumen del modelo (arriba) y coeficientes de las variables predictoras de la regresión de la variable dependiente "facilidad del arpegio" con todos los parámetros acústicos. Se muestran los que sí tienen influencia sobre la variable dependiente. 


\subsection{Calidad del arpegio}

Al analizar todos los parámetros acústicos para ver cuáles pueden estar relacionados con la calidad del arpegio en la propiocepción, se puede observar en la tabla 4.51, que sólo la armonicidad media del arpegio tiene una relación directa, aunque con un $\mathrm{R}^{2}$ corregido muy bajo.

La armonicidad media mide la cantidad de ruido o soplo presente en el sonido, por lo que la explicación de la puntuación de la calidad mediante este parámetro acústico está muy relacionado.

\begin{tabular}{|c|c|c|c|c|c|c|c|c|c|}
\hline \multicolumn{10}{|c|}{ Resumen del modelo } \\
\hline \multirow[t]{2}{*}{ Modelo } & \multirow[t]{2}{*}{$\mathrm{R}$} & \multirow[t]{2}{*}{$\mathrm{R}^{2}$} & \multirow{2}{*}{$\begin{array}{c}\mathrm{R}^{2} \\
\text { corregida }\end{array}$} & \multirow{2}{*}{$\begin{array}{l}\text { Error típ. de } \\
\text { la estimación }\end{array}$} & \multicolumn{5}{|c|}{ Estadísticos de cambio } \\
\hline & & & & & $\begin{array}{c}\text { Cambio en } \\
\mathrm{R}^{2}\end{array}$ & $\begin{array}{c}\text { Cambio } \\
\text { en } \mathrm{F}\end{array}$ & gl1 & $\mathrm{gl} 2$ & $\begin{array}{c}\text { Sig. Cambio } \\
\text { en } \mathrm{F}\end{array}$ \\
\hline 1 & 0,235 & 0,055 & 0,050 & 1,489 & 0,055 & 9,963 & 1 & 170 & 0,002 \\
\hline
\end{tabular}

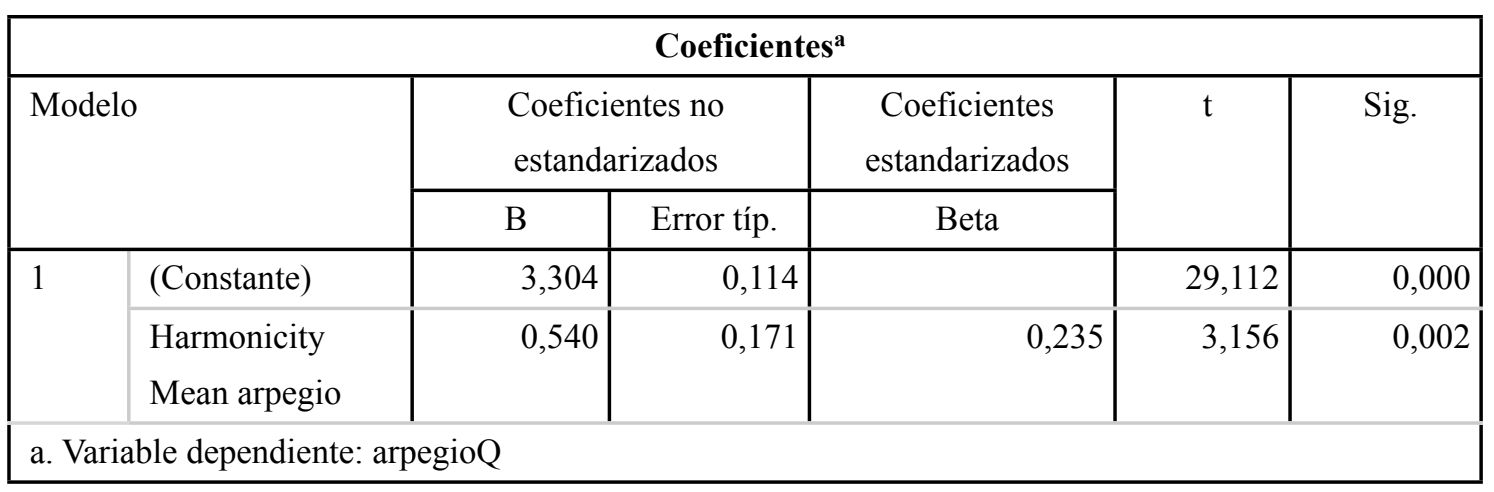

Tabla 4.51. Resumen del modelo (arriba) y coeficientes de las variables predictoras de la regresión de la variable dependiente "calidad del arpegio" con todos los parámetros acústicos. Se muestran los que sí tienen influencia sobre la variable dependiente.

\subsection{Facilidad del legato}

Al analizar todos los parámetros acústicos para ver cuáles pueden estar relacionados con la facilidad del legato en la propiocepción, se puede observar en la tabla 4.52, que la frecuencia media de todos los ejercicios, el number of voiced frames del arpegio y la armonicidad media del arpegio, tienen una relación directa, aunque $\mathrm{R}^{2}$ corregido sigue siendo bajo.

La facilidad del legato viene explicada a través de dos parámetros acústicos relacionados con la ejecución: la frecuencia media y el number of voced frames. Si se considera que la facilidad de un ejercicio está vinculada a la ejecución, estos dos 
parámetros están muy relacionados con las puntuaciones de los oboístas. No obstante, cabe remarca que la medición del number of voiced frames no se controló, como se ha comentado anteriormente. El otro parámetro acústico vinculado tiene que ver más con la calidad de sonido que con la facilidad, además cabe destacar que la armonicidad media que se relaciona no es la del legato, sino la del arpegio. En el análisis de datos del punto 4.7.4.3, se pudo observar cómo la facilidad y la calidad del arpegio y del legato estaban correlacionadas, por lo que no es de extrañar que un mismo parámetro acústico pueda explicar dos ejercicios diferentes.

\begin{tabular}{|c|c|c|c|c|c|c|c|c|c|}
\hline \multicolumn{10}{|c|}{ Resumen del modelo } \\
\hline \multirow[t]{2}{*}{ Modelo } & \multirow[t]{2}{*}{$\mathrm{R}$} & \multirow[t]{2}{*}{$\mathrm{R}^{2}$} & \multirow{2}{*}{$\begin{array}{c}\mathrm{R}^{2} \\
\text { corregida }\end{array}$} & \multirow{2}{*}{$\begin{array}{c}\text { Error típ. de } \\
\text { la estimación }\end{array}$} & \multicolumn{5}{|c|}{ Estadísticos de cambio } \\
\hline & & & & & $\begin{array}{c}\text { Cambio en } \\
\mathrm{R}^{2}\end{array}$ & $\begin{array}{c}\text { Cambio } \\
\text { en F }\end{array}$ & gl1 & $\mathrm{gl} 2$ & $\begin{array}{l}\text { Sig. Cambio } \\
\text { en F }\end{array}$ \\
\hline 3 & 0,411 & 0,169 & 0,154 & 1,520 & 0,019 & 3,937 & 1 & 168 & 0,049 \\
\hline
\end{tabular}

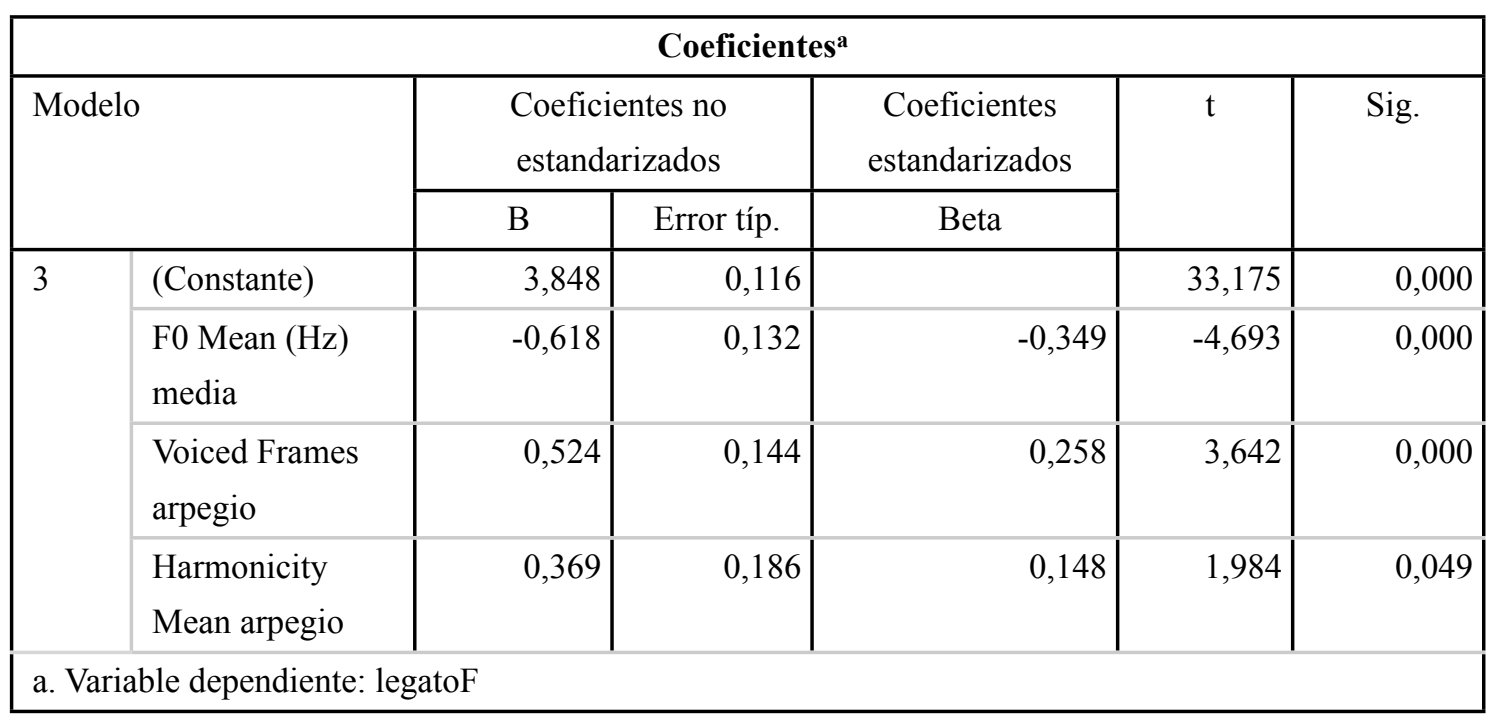

Tabla 4.52. Resumen del modelo (arriba) y coeficientes de las variables predictoras de la regresión de la variable dependiente "facilidad del legato" con todos los parámetros acústicos. Se muestran los que sí tienen influencia sobre la variable dependiente.

\subsection{Calidad del legato}

Al analizar todos los parámetros acústicos para ver cuáles pueden estar relacionados con la calidad del legato en la propiocepción, se puede observar en la tabla 4.53, que sólo la armonicidad media tiene una relación directa, aunque con un $\mathrm{R}^{2}$ corregido muy bajo. 
La calidad del sonido del legato viene explicada por un parámetro acústico relacionado con el sonido, pero del arpegio. Tal y como se acaba de explicar, estos dos ejercicios están fuertemente correlacionados ( $c f$. punto 4.7.4.3).

\begin{tabular}{|c|c|c|c|c|c|c|c|c|c|}
\hline \multicolumn{10}{|c|}{ Resumen del modelo } \\
\hline \multirow[t]{2}{*}{ Modelo } & \multirow[t]{2}{*}{$\mathrm{R}$} & \multirow[t]{2}{*}{$\mathrm{R}^{2}$} & \multirow{2}{*}{$\begin{array}{c}\mathrm{R}^{2} \\
\text { corregida }\end{array}$} & \multirow{2}{*}{$\begin{array}{l}\text { Error típ. de } \\
\text { la estimación }\end{array}$} & \multicolumn{5}{|c|}{ Estadísticos de cambio } \\
\hline & & & & & $\begin{array}{c}\text { Cambio en } \\
\mathrm{R}^{2}\end{array}$ & $\begin{array}{c}\text { Cambio } \\
\text { en } \mathrm{F}\end{array}$ & gl1 & $\mathrm{gl} 2$ & $\begin{array}{c}\text { Sig. Cambio } \\
\text { en F }\end{array}$ \\
\hline 1 & 0,196 & 0,038 & 0,033 & 1,427 & 0,038 & 6,796 & 1 & 170 & 0,010 \\
\hline
\end{tabular}

\begin{tabular}{|c|c|c|c|c|c|c|}
\hline \multicolumn{7}{|c|}{ Coeficientes $^{a}$} \\
\hline \multirow{2}{*}{\multicolumn{2}{|c|}{ Modelo }} & \multicolumn{2}{|c|}{$\begin{array}{l}\text { Coeficientes no } \\
\text { estandarizados }\end{array}$} & \multirow{2}{*}{$\begin{array}{c}\text { Coeficientes } \\
\text { estandarizados }\end{array}$} & \multirow[t]{2}{*}{$\mathrm{t}$} & \multirow[t]{2}{*}{ Sig. } \\
\hline & & $\mathrm{B}$ & Error típ. & & & \\
\hline \multirow[t]{2}{*}{1} & (Constante) & 3,301 & 0,109 & & 30,346 & 0,000 \\
\hline & $\begin{array}{l}\text { Harmonicity } \\
\text { Mean arpegio }\end{array}$ & 0,428 & 0,164 & 0,196 & 2,607 & 0,010 \\
\hline
\end{tabular}

Tabla 4.53. Resumen del modelo (arriba) y coeficientes de las variables predictoras de la regresión de la variable dependiente "calidad del arpegio" con todos los parámetros acústicos. Se muestran los que sí tienen influencia sobre la variable dependiente.

\subsection{Facilidad del diminuendo}

Al analizar todos los parámetros acústicos para ver cuáles pueden estar relacionados con la facilidad del diminuendo en la propiocepción, se puede observar en la tabla 4.54, que la frecuencia mínima, el centro de gravedad espectral y la diferencia de bandas de energía ( $3^{\mathrm{a}}$ mayor) en el diminuendo, tienen una relación directa, aunque con un $\mathrm{R}^{2}$ corregido bajo.

Es interesante destacar cómo la facilidad de este ejercicio está vinculada a dos parámetros acústicos que nada tienen que ver con la ejecución, sino con la calidad del sonido: el centro de gravedad espectral y la diferencia de bandas de energía ( $3^{\mathrm{a}}$ mayor). El parámetro acústico que sí está relacionado con la ejecución mide la frecuencia mínima del ejercicio, sin embargo, no aparece ningún parámetro de ejecución relacionado con la intensidad en un ejercicio donde el delta de la intensidad es muy importante para su realización. 


\begin{tabular}{|c|c|c|c|c|c|c|c|c|c|}
\hline \multicolumn{10}{|c|}{ Resumen del modelo } \\
\hline \multirow[t]{2}{*}{ Modelo } & \multirow[t]{2}{*}{$\mathrm{R}$} & \multirow[t]{2}{*}{$\mathrm{R}^{2}$} & \multirow{2}{*}{$\begin{array}{c}\mathrm{R}^{2} \\
\text { corregida }\end{array}$} & \multirow{2}{*}{$\begin{array}{l}\text { Error típ. de } \\
\text { la estimación }\end{array}$} & \multicolumn{5}{|c|}{ Estadísticos de cambio } \\
\hline & & & & & $\begin{array}{c}\text { Cambio en } \\
\mathrm{R}^{2}\end{array}$ & $\begin{array}{c}\text { Cambio } \\
\text { en F }\end{array}$ & gl1 & $\mathrm{g} 12$ & $\begin{array}{l}\text { Sig. Cambio } \\
\text { en F }\end{array}$ \\
\hline 3 & 0,454 & 0,207 & 0,192 & 1,508 & 0,020 & 4,223 & 1 & 168 & 0,041 \\
\hline
\end{tabular}

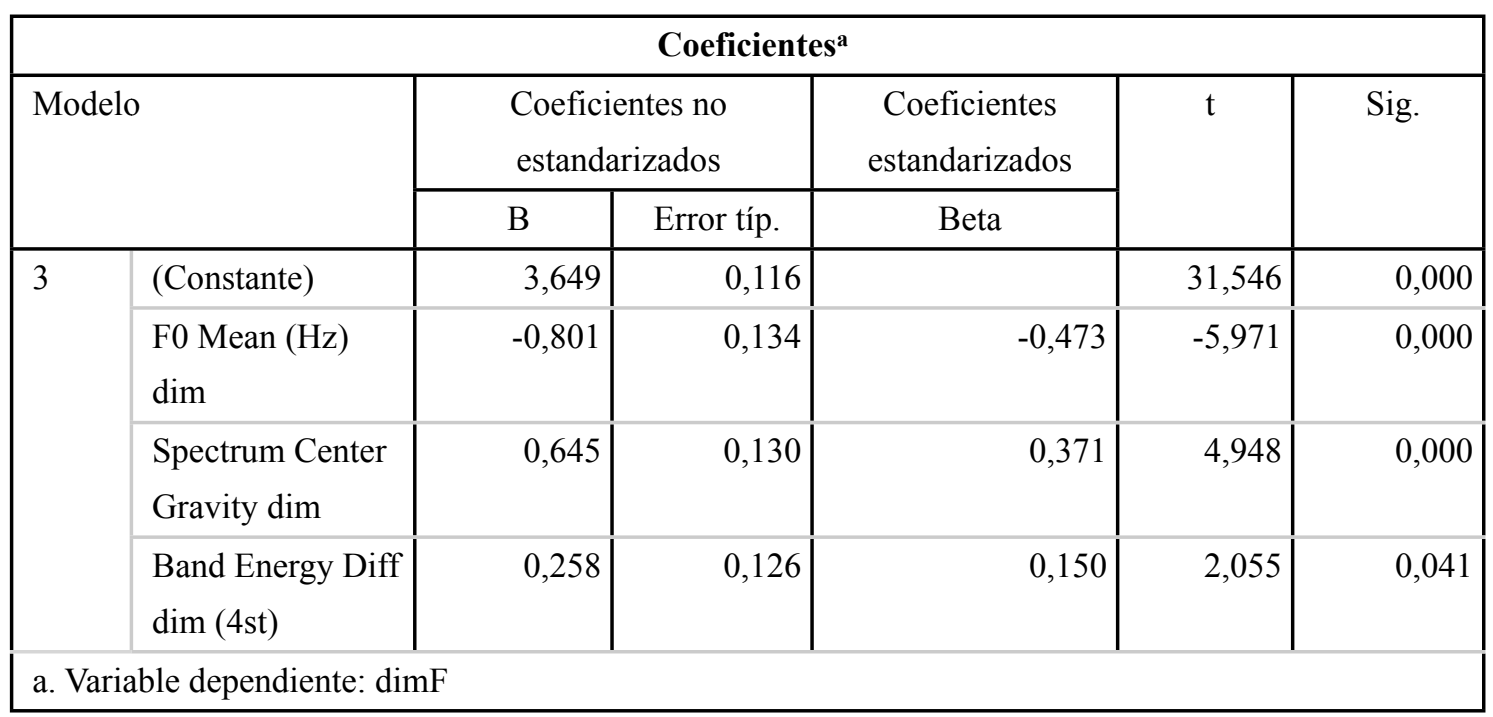

Tabla 4.54. Resumen del modelo (arriba) y coeficientes de las variables predictoras de la regresión de la variable dependiente "facilidad del diminuendo" con todos los parámetros acústicos. Se muestran los que sí tienen influencia sobre la variable dependiente.

\subsection{Calidad del diminuendo}

Al analizar todos los parámetros acústicos para ver cuáles pueden estar relacionados con la calidad del arpegio en la propiocepción, se puede observar en la tabla 4.55, que el centro de gravedad espectral, la frecuencia mínima y la armonicidad media del diminuendo, tienen una relación directa, aunque con un $\mathrm{R}^{2}$ corregido muy bajo.

Cabe remarcar que, al igual que en la calidad del arpegio y del legato, en la calidad del diminuendo también está presente la armonicidad media del diminuendo.

\begin{tabular}{|c|c|c|c|c|c|c|c|c|c|}
\hline \multicolumn{10}{|c|}{ Resumen del modelo } \\
\hline \multirow[t]{2}{*}{ Modelo } & \multirow[t]{2}{*}{$\mathrm{R}$} & \multirow[t]{2}{*}{$\mathrm{R}^{2}$} & \multirow{2}{*}{$\begin{array}{c}\mathrm{R}^{2} \\
\text { corregida }\end{array}$} & \multirow{2}{*}{$\begin{array}{l}\text { Error típ. de } \\
\text { la estimación }\end{array}$} & \multicolumn{5}{|c|}{ Estadísticos de cambio } \\
\hline & & & & & $\begin{array}{c}\text { Cambio en } \\
\mathrm{R}^{2}\end{array}$ & $\begin{array}{c}\text { Cambio } \\
\text { en F }\end{array}$ & gl1 & $\mathrm{g} 12$ & $\begin{array}{c}\text { Sig. Cambio } \\
\text { en } \mathrm{F}\end{array}$ \\
\hline 3 & 0,351 & 0,123 & 0,108 & 1,374 & 0,025 & 4,721 & 1 & 168 & 0,031 \\
\hline
\end{tabular}

\begin{tabular}{|c|c|c|c|c|c|c|}
\hline \multicolumn{7}{|c|}{ Coeficientes $^{\mathrm{a}}$} \\
\hline \multirow{2}{*}{\multicolumn{2}{|c|}{ Modelo }} & \multicolumn{2}{|c|}{$\begin{array}{l}\text { Coeficientes no } \\
\text { estandarizados }\end{array}$} & $\begin{array}{c}\text { Coeficientes } \\
\text { estandarizados }\end{array}$ & \multirow[t]{2}{*}{$\mathrm{t}$} & \multirow[t]{2}{*}{ Sig. } \\
\hline & & B & Error típ. & Beta & & \\
\hline 3 & (Constante) & 2,933 & 0,105 & & 27,887 & 0,000 \\
\hline
\end{tabular}




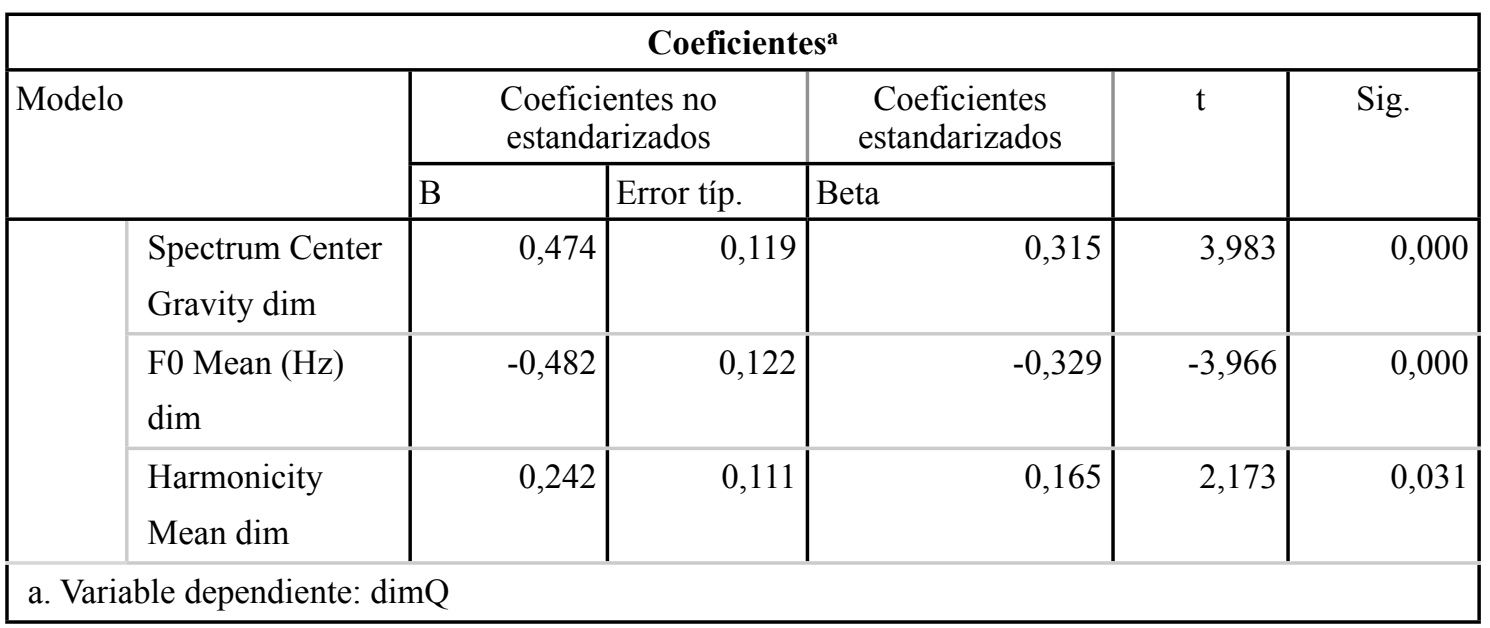

Tabla 4.55. Resumen del modelo (arriba) y coeficientes de las variables predictoras de la regresión de la variable dependiente "calidad del diminuendo" con todos los parámetros acústicos. Se muestran los que sí tienen influencia sobre la variable dependiente.

\subsection{Facilidad del fortissimo}

Al analizar todos los parámetros acústicos para ver cuáles pueden estar relacionados con la facilidad del fortissimo en la propiocepción, se puede observar en la tabla 4.56, que sólo la desviación estándar de la frecuencia (en semitonos) en el fortissimo tiene una relación directa, aunque con un $\mathrm{R}^{2}$ corregido muy bajo.

\begin{tabular}{|c|c|c|c|c|c|c|c|c|c|}
\hline \multicolumn{10}{|c|}{ Resumen del modelo } \\
\hline \multirow[t]{2}{*}{ Modelo } & \multirow[t]{2}{*}{$\mathrm{R}$} & \multirow[t]{2}{*}{$\mathrm{R}^{2}$} & \multirow{2}{*}{$\begin{array}{c}\mathrm{R}^{2} \\
\text { corregida }\end{array}$} & \multirow{2}{*}{$\begin{array}{l}\text { Error típ. de } \\
\text { la estimación }\end{array}$} & \multicolumn{5}{|c|}{ Estadísticos de cambio } \\
\hline & & & & & $\begin{array}{c}\text { Cambio en } \\
\mathrm{R}^{2}\end{array}$ & $\begin{array}{c}\text { Cambio } \\
\text { en } \mathrm{F}\end{array}$ & g11 & $\mathrm{gl} 2$ & $\begin{array}{c}\text { Sig. Cambio } \\
\text { en F }\end{array}$ \\
\hline 1 & 0,170 & 0,029 & 0,023 & 1,387 & 0,029 & 5,043 & 1 & 170 & 0,026 \\
\hline
\end{tabular}

\begin{tabular}{|c|c|c|c|c|c|c|}
\hline \multicolumn{7}{|c|}{ Coeficientes $^{a}$} \\
\hline \multirow{2}{*}{\multicolumn{2}{|c|}{ Modelo }} & \multicolumn{2}{|c|}{$\begin{array}{l}\text { Coeficientes no } \\
\text { estandarizados }\end{array}$} & \multirow{2}{*}{$\begin{array}{c}\text { Coeficientes } \\
\text { estandarizados }\end{array}$} & \multirow[t]{2}{*}{$\mathrm{t}$} & \multirow[t]{2}{*}{ Sig. } \\
\hline & & B & Error típ. & & & \\
\hline \multirow[t]{2}{*}{1} & (Constante) & 4,870 & 0,106 & & 46,028 & 0,000 \\
\hline & F0 Std Dev (st) ff & $-0,234$ & 0,104 & $-0,170$ & $-2,246$ & 0,026 \\
\hline
\end{tabular}

Tabla 4.56. Resumen del modelo (arriba) y coeficientes de las variables predictoras de la regresión de la variable dependiente "facilidad del fortissimo" con todos los parámetros acústicos. Se muestran los que sí tienen influencia sobre la variable dependiente.

\subsection{Calidad del fortissimo}

Al analizar todos los parámetros acústicos para ver cuáles pueden estar relacionados con la calidad del fortissimo en la propiocepción, se puede observar en la 
tabla 4.57, que sólo la frecuencia media (en $\mathrm{Hz}$ ) en el fortissimo tiene una relación directa, aunque con un $\mathrm{R}^{2}$ corregido muy bajo.

En esta ocasión, la calidad del ejercicio viene explicada por un parámetro que nada tiene que ver con la ejecución, además, es el único ejercicio de calidad sonora donde no está presente el parámetro de la armonicidad media. Que la calidad del fortissimo esté relacionada con la frecuencia media demuestra que para los oboístas un fortissimo de calidad depende más de la afinación de la nota con una gran cantidad de aire que un buen sonido.

\begin{tabular}{|c|c|c|c|c|c|c|c|c|c|}
\hline \multicolumn{10}{|c|}{ Resumen del modelo } \\
\hline \multirow[t]{2}{*}{ Modelo } & \multirow[t]{2}{*}{$\mathrm{R}$} & \multirow[t]{2}{*}{$\mathrm{R}^{2}$} & \multirow{2}{*}{$\begin{array}{c}\mathrm{R}^{2} \\
\text { corregida }\end{array}$} & \multirow{2}{*}{$\begin{array}{l}\text { Error típ. de } \\
\text { la estimación }\end{array}$} & \multicolumn{5}{|c|}{ Estadísticos de cambio } \\
\hline & & & & & $\begin{array}{c}\text { Cambio en } \\
\mathrm{R}^{2}\end{array}$ & $\begin{array}{c}\text { Cambio } \\
\text { en F }\end{array}$ & gl1 & g12 & $\begin{array}{c}\text { Sig. Cambio } \\
\text { en F }\end{array}$ \\
\hline 1 & 0,180 & 0,032 & 0,027 & 1,502 & 0,032 & 5,674 & 1 & 170 & 0,018 \\
\hline
\end{tabular}

\begin{tabular}{|c|c|c|c|c|c|c|}
\hline \multicolumn{7}{|c|}{ Coeficientes $^{\mathrm{a}}$} \\
\hline \multirow{2}{*}{\multicolumn{2}{|c|}{ Modelo }} & \multicolumn{2}{|c|}{$\begin{array}{l}\text { Coeficientes no } \\
\text { estandarizados }\end{array}$} & \multirow{2}{*}{$\begin{array}{c}\text { Coeficientes } \\
\text { estandarizados }\end{array}$} & \multirow[t]{2}{*}{$\mathrm{t}$} & \multirow[t]{2}{*}{ Sig. } \\
\hline & & B & Error típ. & & & \\
\hline \multirow[t]{2}{*}{1} & (Constante) & 3,962 & 0,115 & & 34,590 & 0,000 \\
\hline & F0 Mean $(\mathrm{Hz}) \mathrm{ff}$ & $-0,268$ & 0,113 & $-0,180$ & $-2,382$ & 0,018 \\
\hline \multicolumn{7}{|c|}{ a. Variable dependiente: ffQ } \\
\hline
\end{tabular}

Tabla 4.57. Resumen del modelo (arriba) y coeficientes de las variables predictoras de la regresión de la variable dependiente "calidad del fortissimo" con todos los parámetros acústicos. Se muestran los que sí tienen influencia sobre la variable dependiente.

\subsection{Facilidad del pianissimo}

Al analizar todos los parámetros acústicos para ver cuáles pueden estar relacionados con la facilidad del pianissimo en la propiocepción, se puede observar en la tabla 4.58, que tanto el delta de la frecuencia como la desviación estándar de la amplitud en el pianissimo tienen una relación directa, aunque con un $\mathrm{R}^{2}$ corregido muy bajo.

Los dos parámetros acústicos que explican este ejercicio están muy vinculados a la ejecución del mismo, ya que miden tanto la inestabilidad de la afinación como de la intensidad. 


\begin{tabular}{|c|c|c|c|c|c|c|c|c|c|}
\hline \multicolumn{10}{|c|}{ Resumen del modelo } \\
\hline \multirow{2}{*}{ Modelo } & \multirow[t]{2}{*}{$\mathrm{R}$} & \multirow[t]{2}{*}{$\mathrm{R}^{2}$} & \multirow{2}{*}{$\begin{array}{c}\mathrm{R}^{2} \\
\text { corregida }\end{array}$} & \multirow{2}{*}{$\begin{array}{l}\text { Error típ. de } \\
\text { la estimación }\end{array}$} & \multicolumn{5}{|c|}{ Estadísticos de cambio } \\
\hline & & & & & $\begin{array}{c}\text { Cambio en } \\
\mathrm{R}^{2}\end{array}$ & $\begin{array}{c}\text { Cambio } \\
\text { en F }\end{array}$ & gl1 & $\mathrm{gl} 2$ & $\begin{array}{c}\text { Sig. Cambio } \\
\text { en F }\end{array}$ \\
\hline 2 & 0,292 & 0,085 & 0,074 & 1,653 & 0,053 & 9,744 & 1 & 167 & 0,002 \\
\hline
\end{tabular}

\begin{tabular}{|c|c|c|c|c|c|c|}
\hline \multicolumn{7}{|c|}{ Coeficientes $^{\mathrm{a}}$} \\
\hline \multirow{2}{*}{\multicolumn{2}{|c|}{ Modelo }} & \multicolumn{2}{|c|}{$\begin{array}{l}\text { Coeficientes no } \\
\text { estandarizados }\end{array}$} & \multirow{2}{*}{$\begin{array}{c}\text { Coeficientes } \\
\text { estandarizados }\end{array}$} & \multirow[t]{2}{*}{$\mathrm{t}$} & \multirow[t]{2}{*}{ Sig. } \\
\hline & & $\mathrm{B}$ & Error típ. & & & \\
\hline \multirow[t]{3}{*}{2} & (Constante) & 3,891 & 0,127 & & 30,680 & 0,000 \\
\hline & F0 Delta $(\mathrm{Hz}) \mathrm{pp}$ & $-0,356$ & 0,111 & $-0,247$ & $-3,197$ & 0,002 \\
\hline & $\begin{array}{l}\text { Amplitude Std } \\
\text { Dev pp }\end{array}$ & $-0,416$ & 0,133 & $-0,241$ & $-3,122$ & 0,002 \\
\hline \multicolumn{7}{|c|}{ a. Variable dependiente: $\mathrm{ppF}$} \\
\hline
\end{tabular}

Tabla 4.58. Resumen del modelo (arriba) y coeficientes de las variables predictoras de la regresión de la variable dependiente "facilidad del pianissimo" con todos los parámetros acústicos. Se muestran los que sí tienen influencia sobre la variable dependiente.

\subsection{Calidad del pianissimo}

Al analizar todos los parámetros acústicos para ver cuáles pueden estar relacionados con la calidad del pianissimo en la propiocepción, se puede observar en la tabla 4.59, que la desviación estándar de la amplitud, la armonicidad media y el centro de gravedad espectral en el pianissimo tienen una relación directa, aunque con un $\mathrm{R}^{2}$ corregido bajo.

La armonicidad media vuelve aparecer como el parámetro común de la calidad de todos los ejercicios (excepto en el fortissimo), la desviación estándar de la amplitud y el centro de gravedad espectral están muy relacionados con la medición de la calidad del pianissimo, ya que además de medir las posibles oscilaciones del sonido en cuanto a intensidad, se tiene en cuenta la energía del sonido producido. 


\begin{tabular}{|c|c|c|c|c|c|c|c|c|c|}
\hline \multicolumn{10}{|c|}{ Resumen del modelo } \\
\hline \multirow[t]{2}{*}{ Modelo } & \multirow[t]{2}{*}{$\mathrm{R}$} & \multirow[t]{2}{*}{$\mathrm{R}^{2}$} & \multirow{2}{*}{$\begin{array}{c}\mathrm{R}^{2} \\
\text { corregida }\end{array}$} & \multirow{2}{*}{$\begin{array}{l}\text { Error típ. de } \\
\text { la estimación }\end{array}$} & \multicolumn{5}{|c|}{ Estadísticos de cambio } \\
\hline & & & & & $\begin{array}{c}\text { Cambio en } \\
\mathrm{R}^{2}\end{array}$ & $\begin{array}{c}\text { Cambio } \\
\text { en F }\end{array}$ & gl1 & $\mathrm{g} 12$ & $\begin{array}{l}\text { Sig. Cambio } \\
\text { en F }\end{array}$ \\
\hline 3 & 0,353 & 0,124 & 0,109 & 1,542 & 0,021 & 3,983 & 1 & 166 & 0,048 \\
\hline
\end{tabular}

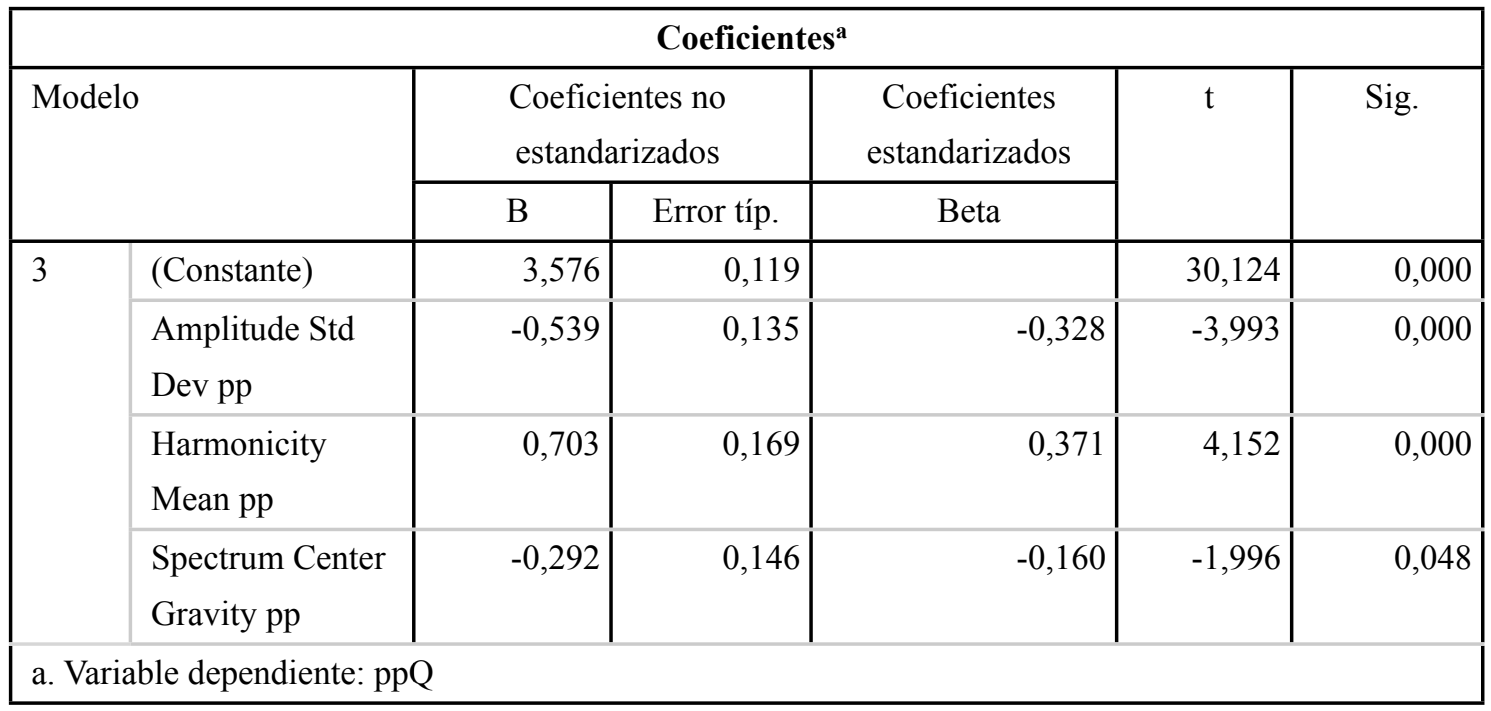

Tabla 4.59. Resumen del modelo (arriba) y coeficientes de las variables predictoras de la regresión de la variable dependiente "calidad del pianissimo" con todos los parámetros acústicos. Se muestran los que sí tienen influencia sobre la variable dependiente.

\subsection{Global}

Al analizar todos los parámetros acústicos para ver cuáles pueden estar relacionados con la puntuación global de las lengüetas en la propiocepción, se puede observar en la tabla 4.60, que la desviación estándar de la frecuencia en el pianissimo, la desviación estándar de la frecuencia en el arpegio, la frecuencia media en el pianissimo, la diferencia de bandas de energía ( $2^{\mathrm{a}}$ mayor) en el pianissimo y la desviación estándar de la amplitud en el pianissimo tienen una relación directa, aunque con un $\mathrm{R}^{2}$ corregido bajo.

Todos estos parámetros acústicos están relacionados con los ejercicios pianissimo y arpegio. Por una parte, la globalidad se relaciona con parámetros ligados a la ejecución, como la desviación estándar de la frecuencia o la frecuencia media, por lo que para los oboístas es muy importante el comportamiento de la lengüeta en la afinación para darle una puntuación global alta o no. Por otra parte, los dos parámetros relacionados con la calidad del sonido están ligados al ejercicio pianissimo y miden tanto las inestabilidades de la intensidad como la cantidad de energía del sonido. 


\begin{tabular}{|c|c|c|c|c|c|c|c|c|c|}
\hline \multicolumn{10}{|c|}{ Resumen del modelo } \\
\hline \multirow[t]{2}{*}{ Modelo } & \multirow[t]{2}{*}{$\mathrm{R}$} & \multirow[t]{2}{*}{$\mathrm{R}^{2}$} & \multirow{2}{*}{$\begin{array}{c}\mathrm{R}^{2} \\
\text { corregida }\end{array}$} & \multirow{2}{*}{$\begin{array}{l}\text { Error típ. de } \\
\text { la estimación }\end{array}$} & \multicolumn{5}{|c|}{ Estadísticos de cambio } \\
\hline & & & & & $\begin{array}{c}\text { Cambio en } \\
\mathrm{R}^{2}\end{array}$ & $\begin{array}{c}\text { Cambio } \\
\text { en F }\end{array}$ & gl1 & $\mathrm{g} 12$ & $\begin{array}{l}\text { Sig. Cambio } \\
\text { en F }\end{array}$ \\
\hline 5 & 0,435 & 0,189 & 0,165 & 1,099 & 0,022 & 4,361 & 1 & 164 & 0,038 \\
\hline
\end{tabular}

\begin{tabular}{|c|c|c|c|c|c|c|}
\hline \multicolumn{7}{|c|}{ Coeficientes $^{\mathrm{a}}$} \\
\hline \multirow{2}{*}{\multicolumn{2}{|c|}{ Modelo }} & \multicolumn{2}{|c|}{$\begin{array}{l}\text { Coeficientes no } \\
\text { estandarizados }\end{array}$} & \multirow{2}{*}{$\begin{array}{c}\text { Coeficientes } \\
\text { estandarizados }\end{array}$} & \multirow[t]{2}{*}{$\mathrm{t}$} & \multirow[t]{2}{*}{ Sig. } \\
\hline & & B & Error típ. & & & \\
\hline \multirow[t]{6}{*}{5} & (Constante) & 2,660 & 0,307 & & 8,666 & 0,000 \\
\hline & $\begin{array}{l}\text { F0 Std Dev (st) } \\
\text { pp }\end{array}$ & $-0,348$ & 0,092 & $-0,284$ & $-3,773$ & 0,000 \\
\hline & $\begin{array}{l}\text { F0 Std Dev (st) } \\
\text { arpegio }\end{array}$ & $-0,680$ & 0,199 & $-0,263$ & $-3,419$ & 0,001 \\
\hline & F0 Mean $(\mathrm{Hz}) \mathrm{pp}$ & $-0,239$ & 0,097 & $-0,199$ & $-2,460$ & 0,015 \\
\hline & $\begin{array}{l}\text { Band Energy Diff } \\
\text { (2st) pp }\end{array}$ & 0,043 & 0,014 & 0,217 & 2,970 & 0,003 \\
\hline & $\begin{array}{l}\text { Amplitude Std } \\
\text { Dev pp }\end{array}$ & $-0,190$ & 0,091 & $-0,157$ & $-2,088$ & 0,038 \\
\hline \multicolumn{7}{|c|}{ a. Variable dependiente: global } \\
\hline
\end{tabular}

Tabla 4.60. Resumen del modelo (arriba) y coeficientes de las variables predictoras de la regresión de la variable dependiente "global" con todos los parámetros acústicos. Se muestran los que sí tienen influencia sobre la variable dependiente.

\subsection{Equilibrio}

Al analizar todos los parámetros acústicos para ver cuáles pueden estar relacionados con la puntuación del equilibrio en la propiocepción, se puede observar en la tabla 4.61, que la desviación estándar de la frecuencia en el pianissimo y en el arpegio, el number of voiced frames en el pianissimo, el delta de la frecuencia en el diminuendo y las diferencias de energía por bandas ( $2^{\mathrm{a}}$ mayor) tienen una relación directa, aunque con un $\mathrm{R}^{2}$ corregido bajo.

Al igual que en la globalidad, el equilibrio también depende de varios parámetros acústicos ligados a la ejecución y a la calidad del sonido, aunque en esta ocasión, la mayoría de los parámetros se relacionan con la ejecución y sobre todo con la frecuencia. Las puntuaciones de los oboístas para que una lengüeta sea equilibrada también depende de la diferencia de energía por bandas, es decir, la relación de la energía de la fundamental frente al resto del espectro. 


\begin{tabular}{|c|c|c|c|c|c|c|c|c|c|}
\hline \multicolumn{10}{|c|}{ Resumen del modelo } \\
\hline \multirow[t]{2}{*}{ Modelo } & \multirow[t]{2}{*}{$\mathrm{R}$} & \multirow[t]{2}{*}{$\mathrm{R}^{2}$} & \multirow{2}{*}{$\begin{array}{c}\mathrm{R}^{2} \\
\text { corregida }\end{array}$} & \multirow{2}{*}{$\begin{array}{l}\text { Error típ. de } \\
\text { la estimación }\end{array}$} & \multicolumn{5}{|c|}{ Estadísticos de cambio } \\
\hline & & & & & $\begin{array}{c}\text { Cambio en } \\
\mathrm{R}^{2}\end{array}$ & $\begin{array}{c}\text { Cambio } \\
\text { en F }\end{array}$ & gl1 & $\mathrm{g} 12$ & $\begin{array}{l}\text { Sig. Cambio } \\
\text { en F }\end{array}$ \\
\hline 6 & 0,427 & 0,182 & 0,163 & 1,165 & $-0,012$ & 2,424 & 1 & 164 & 0,121 \\
\hline
\end{tabular}

\begin{tabular}{|c|c|c|c|c|c|c|}
\hline \multicolumn{7}{|c|}{ Coeficientes $^{\mathbf{a}}$} \\
\hline \multirow{2}{*}{\multicolumn{2}{|c|}{ Modelo }} & \multicolumn{2}{|c|}{$\begin{array}{l}\text { Coeficientes no } \\
\text { estandarizados }\end{array}$} & \multirow{2}{*}{$\begin{array}{l}\text { Coeficientes } \\
\text { estandarizados }\end{array}$} & \multirow[t]{2}{*}{$\mathrm{t}$} & \multirow[t]{2}{*}{ Sig. } \\
\hline & & $\mathrm{B}$ & \multirow{2}{*}{ Error típ. } & & & \\
\hline \multirow[t]{5}{*}{6} & (Constante) & 2,574 & & & 8,167 & 0,000 \\
\hline & $\begin{array}{l}\text { F0 Std Dev (st) } \\
\text { arpegio }\end{array}$ & $-0,573$ & 0,202 & $-0,209$ & $-2,834$ & 0,005 \\
\hline & Voiced Frames pp & 0,256 & 0,092 & 0,199 & 2,796 & 0,006 \\
\hline & $\begin{array}{l}\text { F0 Delta }(\mathrm{Hz}) \\
\operatorname{dim}\end{array}$ & $-0,316$ & 0,113 & $-0,207$ & $-2,794$ & 0,006 \\
\hline & $\begin{array}{l}\text { Band Energy Diff } \\
\text { (2st) pp }\end{array}$ & 0,035 & 0,015 & 0,170 & 2,388 & 0,018 \\
\hline \multicolumn{7}{|c|}{ a. Variable dependiente: global: equiilibrio } \\
\hline
\end{tabular}

Tabla 4.61. Resumen del modelo (arriba) y coeficientes de las variables predictoras de la regresión de la variable dependiente "equilibrio" con todos los parámetros acústicos. Se muestran los que sí tienen influencia sobre la variable dependiente.

\subsection{Flexibilidad}

Al analizar todos los parámetros acústicos para ver cuáles pueden estar relacionados con la puntuación de la flexibilidad en la propiocepción, se puede observar en la tabla 4.62, que la frecuencia media del diminuendo, la intensidad del arpegio, la desviación estándar de la amplitud del arpegio, la desviación estándar de la frecuencia del arpegio y la desviación estándar de la frecuencia en el pianissimo tienen una relación directa, aunque con un $\mathrm{R}^{2}$ corregido bajo.

La flexibilidad de las lengüetas también está relacionada con varias mediciones acústicas de ejecución y calidad del sonido de diversos ejercicios. En primer lugar, una lengüeta flexible está ligada a los parámetros de ejecución que miden la frecuencia del arpegio, pianissimo y diminuendo, es decir, los oboístas consideran que para que una lengüeta sea flexible ha de poder controlarse la afinación en estos tres ejercicios. En segundo lugar, la intensidad y las inestabilidades de la amplitud en el arpegio son las mediciones ligadas a la calidad del sonido de una lengüeta flexible. 


\begin{tabular}{|l|c|c|r|r|r|c|c|c|c|}
\hline \multicolumn{9}{|c|}{ Resumen del modelo } \\
\hline Modelo & $\mathrm{R}$ & $\mathrm{R}^{2}$ & $\begin{array}{c}\mathrm{R}^{2} \\
\text { corregida }\end{array}$ & $\begin{array}{c}\text { Error típ. de } \\
\text { la estimación }\end{array}$ & \multicolumn{5}{|c|}{ Estadísticos de cambio } \\
\cline { 6 - 10 } & & & & & $\begin{array}{c}\text { Cambio en } \\
\mathrm{R}^{2}\end{array}$ & $\begin{array}{c}\text { Cambio } \\
\text { en } \mathrm{F}\end{array}$ & g11 & gl2 & $\begin{array}{c}\text { Sig. Cambio } \\
\text { en F }\end{array}$ \\
\hline 5 & 0,476 & 0,226 & 0,203 & 1,356 & 0,022 & 4,701 & 1 & 164 & 0,032 \\
\hline
\end{tabular}

\begin{tabular}{|c|c|c|c|c|c|c|}
\hline \multicolumn{7}{|c|}{ Coeficientes $^{\mathrm{a}}$} \\
\hline \multirow{2}{*}{\multicolumn{2}{|c|}{ Modelo }} & \multicolumn{2}{|c|}{$\begin{array}{l}\text { Coeficientes no } \\
\text { estandarizados }\end{array}$} & \multirow{2}{*}{$\begin{array}{c}\begin{array}{c}\text { Coeficientes } \\
\text { estandarizados }\end{array} \\
\text { Beta } \\
\end{array}$} & \multirow[t]{2}{*}{$\mathrm{t}$} & \multirow[t]{2}{*}{ Sig. } \\
\hline & & $\mathrm{B}$ & Error típ. & & & \\
\hline \multirow[t]{6}{*}{5} & (Constante) & 3,348 & 0,104 & & 32,117 & 0,000 \\
\hline & $\begin{array}{l}\text { F0 Mean (Hz) } \\
\operatorname{dim}\end{array}$ & $-0,772$ & 0,132 & $-0,504$ & $-5,834$ & 0,000 \\
\hline & $\begin{array}{l}\text { Intensity }(\mathrm{dB}) \\
\text { arpegio }\end{array}$ & 1,355 & 0,363 & 0,835 & 3,730 & 0,000 \\
\hline & $\begin{array}{l}\text { Amplitude Std } \\
\text { Dev arpegio }\end{array}$ & $-1,118$ & 0,360 & $-0,679$ & $-3,105$ & 0,002 \\
\hline & $\begin{array}{l}\text { F0 Std Dev (st) } \\
\text { arpegio }\end{array}$ & $-0,640$ & 0,262 & $-0,196$ & $-2,441$ & 0,016 \\
\hline & $\begin{array}{l}\text { F0 Std Dev (st) } \\
\text { pp }\end{array}$ & $-0,247$ & 0,114 & $-0,159$ & $-2,168$ & 0,032 \\
\hline \multicolumn{7}{|c|}{ a. Variable dependiente: global: flexibilidad } \\
\hline
\end{tabular}

Tabla 4.62. Resumen del modelo (arriba) y coeficientes de las variables predictoras de la regresión de la variable dependiente "flexibilidad" con todos los parámetros acústicos. Se muestran los que sí tienen influencia sobre la variable dependiente.

\subsection{Rigidez}

Al analizar todos los parámetros acústicos para ver cuáles pueden estar relacionados con la rigidez en la propiocepción, se puede observar en la tabla 4.63, que tanto el delta de la intensidad como el delta de la frecuencia en el diminuendo tienen una relación directa, aunque con un $\mathrm{R}^{2}$ corregido muy bajo.

La rigidez está ligada a un parámetro de la ejecución y a otro de calidad del sonido, ambos del ejercicio diminuendo. Es decir, los oboístas analizan la rigidez a partir de la cantidad de intensidad y frecuencia que pueden controlar en el ejercicio diminuendo. 


\begin{tabular}{|c|c|c|c|c|c|c|c|c|c|}
\hline \multicolumn{10}{|c|}{ Resumen del modelo } \\
\hline \multirow[t]{2}{*}{ Modelo } & \multirow[t]{2}{*}{$\mathrm{R}$} & \multirow[t]{2}{*}{$\mathrm{R}^{2}$} & \multirow{2}{*}{$\begin{array}{c}\mathrm{R}^{2} \\
\text { corregida }\end{array}$} & \multirow{2}{*}{$\begin{array}{l}\text { Error típ. de } \\
\text { la estimación }\end{array}$} & \multicolumn{5}{|c|}{ Estadísticos de cambio } \\
\hline & & & & & $\begin{array}{c}\text { Cambio en } \\
\mathrm{R}^{2}\end{array}$ & $\begin{array}{c}\text { Cambio } \\
\text { en F }\end{array}$ & gl1 & $\mathrm{g} 12$ & $\begin{array}{l}\text { Sig. Cambio } \\
\text { en F }\end{array}$ \\
\hline 2 & 0,315 & 0,099 & 0,088 & 1,693 & 0,056 & 10,290 & 1 & 167 & 0,002 \\
\hline
\end{tabular}

\begin{tabular}{|c|c|c|c|c|c|c|}
\hline \multicolumn{7}{|c|}{ Coeficientes $^{a}$} \\
\hline \multirow{2}{*}{\multicolumn{2}{|c|}{ Modelo }} & \multicolumn{2}{|c|}{$\begin{array}{l}\text { Coeficientes no } \\
\text { estandarizados }\end{array}$} & \multirow{2}{*}{$\begin{array}{c}\text { Coeficientes } \\
\text { estandarizados }\end{array}$} & \multirow[t]{2}{*}{$\mathrm{t}$} & \multirow[t]{2}{*}{ Sig. } \\
\hline & & $\mathrm{B}$ & Error típ. & & & \\
\hline \multirow[t]{3}{*}{2} & (Constante) & $-2,467$ & 2,091 & & $-1,180$ & 0,240 \\
\hline & $\begin{array}{l}\text { Delta Intensidad } \\
\text { (dB) dim }\end{array}$ & 0,261 & 0,075 & 0,264 & 3,497 & 0,001 \\
\hline & Delta F0 (st) dim & $-2,152$ & 0,671 & $-0,242$ & $-3,208$ & 0,002 \\
\hline
\end{tabular}

Tabla 4.63. Resumen del modelo (arriba) y coeficientes de las variables predictoras de la regresión de la variable dependiente "rigidez" con todos los parámetros acústicos. Se muestran los que sí tienen influencia sobre la variable dependiente.

\subsection{Timbre}

Al analizar todos los parámetros acústicos para ver cuáles pueden estar relacionados con el timbre en la propiocepción, se puede observar en la tabla 4.64, que la desviación estándar de la frecuencia en el pianissimo, el delta de la frecuencia en el diminuendo, la desviación estándar de la amplitud en el pianissimo y la media de la diferencia de energía por bandas ( $3^{\mathrm{a}}$ mayor) tienen una relación directa, aunque con un $\mathrm{R}^{2}$ corregido bajo.

El timbre está relacionado con la medición de la diferencia de energía por bandas y la desviación estándar de la amplitud, dos parámetros acústicos muy vinculados a la calidad del sonido. Sin embargo, cabe destacar que dos de los parámetros acústicos relacionados también con el timbre están ligados a la ejecución y más concretamente a la estabilidad de la frecuencia. 


\begin{tabular}{|c|c|c|c|c|c|c|c|c|c|}
\hline \multicolumn{10}{|c|}{ Resumen del modelo } \\
\hline \multirow[t]{2}{*}{ Modelo } & \multirow[t]{2}{*}{$\mathrm{R}$} & \multirow[t]{2}{*}{$\mathrm{R}^{2}$} & \multirow{2}{*}{$\begin{array}{c}\mathrm{R}^{2} \\
\text { corregida }\end{array}$} & \multirow{2}{*}{$\begin{array}{l}\text { Error típ. de } \\
\text { la estimación }\end{array}$} & \multicolumn{5}{|c|}{ Estadísticos de cambio } \\
\hline & & & & & $\begin{array}{c}\text { Cambio en } \\
\mathrm{R}^{2}\end{array}$ & $\begin{array}{c}\text { Cambio } \\
\text { en F }\end{array}$ & gl1 & $\mathrm{g} 12$ & $\begin{array}{l}\text { Sig. Cambio } \\
\text { en F }\end{array}$ \\
\hline 4 & 0,369 & 0,136 & 0,115 & 1,433 & 0,023 & 4,451 & 1 & 165 & 0,036 \\
\hline
\end{tabular}

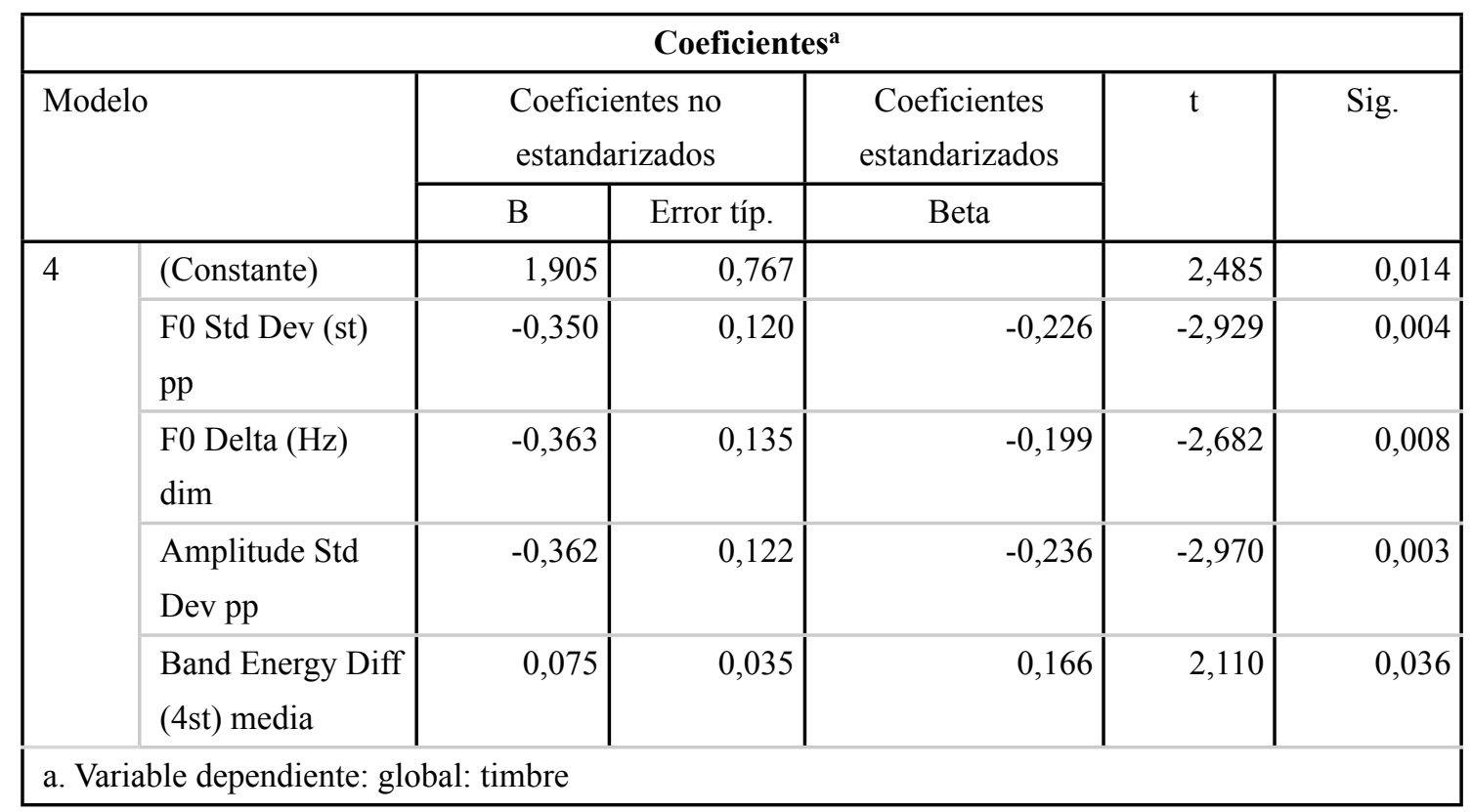

Tabla 4.64. Resumen del modelo (arriba) y coeficientes de las variables predictoras de la regresión de la variable dependiente "timbre" con todos los parámetros acústicos. Se muestran los que sí tienen influencia sobre la variable dependiente.

\subsection{Vivaldi}

Al analizar todos los parámetros acústicos para ver cuáles pueden estar relacionados con la puntuación de los estilos en Vivaldi en la propiocepción, se puede observar en la tabla 4.65, que la desviación estándar de la frecuencia en el arpegio, la frecuencia media en el pianissimo y la diferencia de energía por bandas ( $2^{\mathrm{a}}$ mayor) en el pianissmo tienen una relación directa, aunque con un $\mathrm{R}^{2}$ corregido muy bajo.

Los tres parámetros acústicos que explican la puntuación dada por los oboístas están relacionados tanto con la ejecución, ligados siempre a la frecuencia, como a la calidad del sonido, mediante la diferencia de energía por bandas. Destaca que estas diferencias de bandas de energía estén asociadas al ejercicio pianissimo cuando el concierto de Vivaldi no se caracteriza por ser un concierto con un matiz predominantemente en piano. 


\begin{tabular}{|c|c|c|c|c|c|c|c|c|c|}
\hline \multicolumn{10}{|c|}{ Resumen del modelo } \\
\hline \multirow[t]{2}{*}{ Modelo } & \multirow[t]{2}{*}{$\mathrm{R}$} & \multirow[t]{2}{*}{$\mathrm{R}^{2}$} & \multirow{2}{*}{$\begin{array}{c}\mathrm{R}^{2} \\
\text { corregida }\end{array}$} & \multirow{2}{*}{$\begin{array}{l}\text { Error típ. de } \\
\text { la estimación }\end{array}$} & \multicolumn{5}{|c|}{ Estadísticos de cambio } \\
\hline & & & & & $\begin{array}{c}\text { Cambio en } \\
\mathrm{R}^{2}\end{array}$ & $\begin{array}{c}\text { Cambio } \\
\text { en F }\end{array}$ & gl1 & $\mathrm{g} 12$ & $\begin{array}{l}\text { Sig. Cambio } \\
\text { en F }\end{array}$ \\
\hline 3 & 0,327 & 0,107 & 0,091 & 1,374 & 0,027 & 5,102 & 1 & 166 & 0,025 \\
\hline
\end{tabular}

\begin{tabular}{|c|c|c|c|c|c|c|}
\hline \multicolumn{7}{|c|}{ Coeficientes $^{\mathbf{a}}$} \\
\hline \multirow{2}{*}{\multicolumn{2}{|c|}{ Modelo }} & \multicolumn{2}{|c|}{$\begin{array}{l}\text { Coeficientes no } \\
\text { estandarizados }\end{array}$} & \multirow{2}{*}{$\begin{array}{c}\text { Coeficientes } \\
\text { estandarizados }\end{array}$} & \multirow[t]{2}{*}{$\mathrm{t}$} & \multirow[t]{2}{*}{ Sig. } \\
\hline & & $\mathrm{B}$ & Error típ. & & & \\
\hline \multirow[t]{4}{*}{3} & (Constante) & 2,024 & 0,380 & & 5,329 & 0,000 \\
\hline & $\begin{array}{l}\text { F0 Std Dev (st) } \\
\text { arpegio }\end{array}$ & $-0,911$ & 0,247 & $-0,294$ & $-3,683$ & 0,000 \\
\hline & F0 Mean (Hz) pp & $-0,382$ & 0,118 & $-0,266$ & $-3,245$ & 0,001 \\
\hline & $\begin{array}{l}\text { Band Energy Diff } \\
\text { (2st) pp }\end{array}$ & 0,040 & 0,018 & 0,171 & 2,259 & 0,025 \\
\hline
\end{tabular}

Tabla 4.65. Resumen del modelo (arriba) y coeficientes de las variables predictoras de la regresión de la variable dependiente "Vivaldi" con todos los parámetros acústicos. Se muestran los que sí tienen influencia sobre la variable dependiente.

\subsection{Mozart}

Al analizar todos los parámetros acústicos para ver cuáles pueden estar relacionados con la puntuación de los estilos en Mozart en la propiocepción, se puede observar en la tabla 4.66, que el centro de gravedad del espectro en el diminuendo, la frecuencia media en el pianissimo y la desviación estándar de la frecuencia en el arpegio tienen una relación directa, aunque con un $\mathrm{R}^{2}$ corregido muy bajo.

Al igual que en el concierto de Vivaldi, el concierto de Mozart está relacionado con tres parámetros acústicos tanto de ejecución como de calidad sonora. Los dos parámetros ligados a la ejecución son los mismos que para el concierto de Vivaldi y están vinculados a la frecuencia. La calidad sonora viene representada por el centro de gravedad del ejercicio diminuendo, que está relacionado con que un sonido sea más o menos brillante, dependiendo de la distribución de la energía en la parte aguda de las frecuencias del espectro. 


\begin{tabular}{|l|c|c|r|r|r|c|c|c|c|}
\hline \multicolumn{9}{|c|}{ Resumen del modelo } \\
\hline Modelo & $\mathrm{R}$ & $\mathrm{R}^{2}$ & $\begin{array}{c}\mathrm{R}^{2} \\
\text { corregida }\end{array}$ & $\begin{array}{c}\text { Error típ. de } \\
\text { la estimación }\end{array}$ & \multicolumn{5}{|c|}{ Estadísticos de cambio } \\
\cline { 6 - 10 } & & & & & $\begin{array}{c}\text { Cambio en } \\
\mathrm{R}^{2}\end{array}$ & $\begin{array}{c}\text { Cambio } \\
\text { en } \mathrm{F}\end{array}$ & g11 & gl2 & $\begin{array}{c}\text { Sig. Cambio } \\
\text { en F }\end{array}$ \\
\hline 3 & 0,359 & 0,129 & 0,113 & 1,330 & 0,027 & 5,117 & 1 & 166 & 0,025 \\
\hline
\end{tabular}

\begin{tabular}{|c|c|c|c|c|c|c|}
\hline \multicolumn{7}{|c|}{ Coeficientes $^{\mathrm{a}}$} \\
\hline \multirow{2}{*}{\multicolumn{2}{|c|}{ Modelo }} & \multicolumn{2}{|c|}{$\begin{array}{l}\text { Coeficientes no } \\
\text { estandarizados }\end{array}$} & \multirow{2}{*}{$\begin{array}{c}\begin{array}{c}\text { Coeficientes } \\
\text { estandarizados }\end{array} \\
\text { Beta }\end{array}$} & \multirow[t]{2}{*}{$\mathrm{t}$} & \multirow[t]{2}{*}{ Sig. } \\
\hline & & $\mathrm{B}$ & Error típ. & & & \\
\hline \multirow[t]{4}{*}{3} & (Constante) & 2,412 & 0,102 & & 23,533 & 0,000 \\
\hline & $\begin{array}{l}\text { Spectrum Center } \\
\text { Gravity dim }\end{array}$ & 0,413 & 0,113 & 0,284 & 3,670 & 0,000 \\
\hline & F0 Mean (Hz) pp & $-0,354$ & 0,113 & $-0,252$ & $-3,136$ & 0,002 \\
\hline & $\begin{array}{l}\text { F0 Std Dev (st) } \\
\text { arpegio }\end{array}$ & $-0,551$ & 0,244 & $-0,181$ & $-2,262$ & 0,025 \\
\hline \multicolumn{7}{|c|}{ a. Variable dependiente: Mozart } \\
\hline
\end{tabular}

Tabla 4.66. Resumen del modelo (arriba) y coeficientes de las variables predictoras de la regresión de la variable dependiente "Mozart" con todos los parámetros acústicos. Se muestran los que sí tienen influencia sobre la variable dependiente.

\subsection{Strauss}

Al analizar todos los parámetros acústicos para ver cuáles pueden estar relacionados con la puntuación de los estilos en Strauss en la propiocepción, se puede observar en la tabla 4.67, que el centro de gravedad del espectro en el diminuendo, las diferencias de energía por bandas $\left(3^{\mathrm{a}}\right.$ mayor) en el arpegio, la frecuencia media en el fortissimo y la desviación estándar de la frecuencia en el arpegio tienen una relación directa, aunque con un $\mathrm{R}^{2}$ corregido bajo.

Los cuatro parámetros relacionados con la puntuación del concierto de Strauss están también vinculados a la ejecución y a la calidad sonora. Al igual que en los otros dos conciertos, la ejecución está ligada a parámetros de la frecuencia, destacando la aparición por primera vez de una medición acústica relacionada con el fortissimo. Las mediciones acústicas relacionadas con la calidad sonora son el centro de gravedad del diminuendo y la diferencia de energía por bandas en el arpegio. 


\begin{tabular}{|c|c|c|c|c|c|c|c|c|c|}
\hline \multicolumn{10}{|c|}{ Resumen del modelo } \\
\hline \multirow[t]{2}{*}{ Modelo } & \multirow[t]{2}{*}{$\mathrm{R}$} & \multirow[t]{2}{*}{$\mathrm{R}^{2}$} & \multirow{2}{*}{$\begin{array}{c}\mathrm{R}^{2} \\
\text { corregida }\end{array}$} & \multirow{2}{*}{$\begin{array}{l}\text { Error típ. de } \\
\text { la estimación }\end{array}$} & \multicolumn{5}{|c|}{ Estadísticos de cambio } \\
\hline & & & & & $\begin{array}{c}\text { Cambio en } \\
\mathrm{R}^{2}\end{array}$ & $\begin{array}{c}\text { Cambio } \\
\text { en F }\end{array}$ & gl1 & $\mathrm{g} 12$ & $\begin{array}{c}\text { Sig. Cambio } \\
\text { en F }\end{array}$ \\
\hline 4 & 0,418 & 0,175 & 0,155 & 1,307 & 0,020 & 4,038 & 1 & 165 & 0,046 \\
\hline
\end{tabular}

\begin{tabular}{|c|c|c|c|c|c|c|}
\hline \multicolumn{7}{|c|}{ Coeficientes $^{\mathrm{a}}$} \\
\hline \multicolumn{2}{|c|}{ Modelo } & \multicolumn{2}{|c|}{$\begin{array}{l}\text { Coeficientes no } \\
\text { estandarizados }\end{array}$} & \multirow{2}{*}{$\begin{array}{c}\text { Coeficientes } \\
\text { estandarizados }\end{array}$} & \multirow[t]{2}{*}{$\mathrm{t}$} & \multirow[t]{2}{*}{ Sig. } \\
\hline & & B & Error típ. & & & \\
\hline \multirow[t]{5}{*}{4} & (Constante) & 0,343 & 0,834 & & 0,411 & 0,681 \\
\hline & $\begin{array}{l}\text { Spectrum Center } \\
\text { Gravity dim }\end{array}$ & 0,400 & 0,113 & 0,273 & 3,547 & 0,001 \\
\hline & $\begin{array}{l}\text { Band Energy Diff } \\
\text { (4st) arpegio }\end{array}$ & 0,103 & 0,042 & 0,190 & 2,469 & 0,015 \\
\hline & F0 Mean (Hz) ff & $-0,339$ & 0,109 & $-0,244$ & $-3,109$ & 0,002 \\
\hline & $\begin{array}{l}\text { F0 Std Dev (st) } \\
\text { arpegio }\end{array}$ & $-0,490$ & 0,244 & $-0,160$ & $-2,009$ & 0,046 \\
\hline
\end{tabular}

Tabla 4.67. Resumen del modelo (arriba) y coeficientes de las variables predictoras de la regresión de la variable dependiente "Strauss" con todos los parámetros acústicos. Se muestran los que sí tienen influencia sobre la variable dependiente.

\subsection{Dutilleux}

Al analizar todos los parámetros acústicos para ver cuáles pueden estar relacionados con la puntuación de los estilos en Dutilleux en la propiocepción, se puede observar en la tabla 4.68, que la desviación estándar de la amplitud en el arpegio, la desviación estándar de la frecuencia en el arpegio, la desviación estándar de la frecuencia en el pianissimo, las diferencias de energía por bandas ( $3^{\mathrm{a}}$ mayor) en el arpegio y el number of voiced frames en el arpegio tienen una relación directa, aunque con un $\mathrm{R}^{2}$ corregido bajo.

La sonata de Dutilleux se relaciona con cuatro mediciones acústicas legadas a la ejecución y una a la calidad sonora. Es la primera obra donde además de los parámetros ligados a la frecuencia aparece también la desviación estándar de la amplitud, ligada a la inestabilidad de la intensidad, seguramente relacionados por la gran cantidad de dinámicas que aparecen en la sonata. El parámetro acústico vinculado a la calidad sonora es la diferencia de energías por banda del ejercicio arpegio. 


\begin{tabular}{|c|c|c|c|c|c|c|c|c|c|}
\hline \multicolumn{10}{|c|}{ Resumen del modelo } \\
\hline \multirow[t]{2}{*}{ Modelo } & \multirow[t]{2}{*}{$\mathrm{R}$} & \multirow[t]{2}{*}{$\mathrm{R}^{2}$} & \multirow{2}{*}{$\begin{array}{c}\mathrm{R}^{2} \\
\text { corregida }\end{array}$} & \multirow{2}{*}{$\begin{array}{l}\text { Error típ. de } \\
\text { la estimación }\end{array}$} & \multicolumn{5}{|c|}{ Estadísticos de cambio } \\
\hline & & & & & $\begin{array}{c}\text { Cambio en } \\
\mathrm{R}^{2}\end{array}$ & $\begin{array}{c}\text { Cambio } \\
\text { en F }\end{array}$ & gl1 & $\mathrm{g} 12$ & $\begin{array}{c}\text { Sig. Cambio } \\
\text { en F }\end{array}$ \\
\hline 5 & 0,380 & 0,144 & 0,118 & 1,347 & 0,021 & 3,990 & 1 & 164 & 0,047 \\
\hline
\end{tabular}

\begin{tabular}{|c|c|c|c|c|c|c|}
\hline \multicolumn{7}{|c|}{ Coeficientes $^{\mathrm{a}}$} \\
\hline \multirow{2}{*}{\multicolumn{2}{|c|}{ Modelo }} & \multicolumn{2}{|c|}{$\begin{array}{l}\text { Coeficientes no } \\
\text { estandarizados }\end{array}$} & \multirow{2}{*}{$\begin{array}{c}\text { Coeficientes } \\
\text { estandarizados }\end{array}$} & \multirow[t]{2}{*}{$\mathrm{t}$} & \multirow[t]{2}{*}{ Sig. } \\
\hline & & B & Error típ. & & & \\
\hline \multirow[t]{6}{*}{5} & (Constante) & 0,517 & 0,881 & & 0,587 & 0,558 \\
\hline & $\begin{array}{l}\text { Amplitude Std } \\
\text { Dev arpegio }\end{array}$ & $-0,527$ & 0,126 & $-0,339$ & $-4,168$ & 0,000 \\
\hline & $\begin{array}{l}\text { F0 Std Dev (st) } \\
\text { arpegio }\end{array}$ & $-0,427$ & 0,243 & $-0,138$ & $-1,755$ & 0,081 \\
\hline & $\begin{array}{l}\text { F0 Std Dev (st) } \\
\text { pp }\end{array}$ & $-0,267$ & 0,113 & $-0,183$ & $-2,376$ & 0,019 \\
\hline & $\begin{array}{l}\text { Band Energy Diff } \\
\text { (4st) arpegio }\end{array}$ & 0,098 & 0,044 & 0,177 & 2,210 & 0,029 \\
\hline & $\begin{array}{l}\text { Voiced Frames } \\
\text { arpegio }\end{array}$ & 0,260 & 0,130 & 0,147 & 1,998 & 0,047 \\
\hline
\end{tabular}

Tabla 4.68. Resumen del modelo (arriba) y coeficientes de las variables predictoras de la regresión de la variable dependiente "Dutilleux" con todos los parámetros acústicos. Se muestran los que sí tienen influencia sobre la variable dependiente.

\subsubsection{Discusión}

Al pedir a oboístas que ejecuten ejercicios con diferentes lengüetas y que las evalúen mientras tocan, se obtiene una gran concordancia en las respuestas para la facilidad de ejecución y de la calidad del sonido (en menor medida) de cada ejercicio, así como para la elasticidad, rigidez y calidad general de cada lengüeta. Sobre todo, se encuentra que esta vez existe una clara influencia del estilo de rebajado en la evaluación interpretativa de la lengüeta, que une la propiocepción muscular con la escucha del oboísta. Se debe destacar la gran significatividad de la influencia del rebajado en las respuestas, que suele ser de $p<, 01$, y en algunos casos llega a niveles de significatividad de $p<, 0000005$ (es decir que sobrepasa la precisión del programa SPSS utilizado) para la evaluación de la flexibilidad, la rigidez, la facilidad de ejecución de los arpegios o de los legati (cf. 4.43). Asimismo, los resultados obtenidos en el escalamiento multidimensional sobre las 
respuestas dadas por los oboístas ( $c f$. figuras 4.88, 4.89, 4.90, 4.91 y 4.92) refuerzan los datos obtenidos, ya que se puede vislumbrar el tipo de rebajado como una de las dimensiones obtenidas, además, el rebajado francés, en general, es el que más suele distinguirse en las diferentes dimensiones, siendo el rebajado americano el que menos se agrupa y distribuyéndose sus lengüetas por todo el rango de cada dimensión.

Cuando se analiza a los oboístas por separado, no se obtiene ninguna explicación de los datos según las escuelas de interpretación, ni para las correlaciones ( $c f$. tabla 4.48) ni para las puntuaciones según el estilo de rebajado ( $c f$. tabla A.68). Sin embargo, los resultados del escalamiento multidimensional realizado para los oboístas según sus puntuaciones ( $c f$. figuras 4.93, 4.94, 4.95 y 4.96) muestra la aparición de una dimensión para la escuela de interpretación alemana.

Finalmente, cuando se comparan las mediciones acústicas con las respuestas propioceptivas dadas por los oboístas, cabe destacar que todas las respuestas relacionadas con la calidad sonora de todos los ejercicios (excepto en el fortissimo) están relacionados con la armonicidad media, un parámetro acústico que se encarga de medir la cantidad de ruido existente en el sonido interpretado. Asimismo, cuando los oboístas evalúan las respuestas globales, en todos los casos excepto en la rigidez, estas respuestas vienen relacionadas con parámetros ligados tanto a la ejecución como a la calidad sonora.

\subsubsection{Conclusiones}

Se puede afirmar que el estilo de rebajado tiene una importancia propioceptiva y sensorio-motora muy importante. En primer lugar, los oboístas generan una gran concordancia con sus respuestas, sobre todo a las que hacen referencia a la facilidad y calidad de los ejercicios y a la flexibilidad, rigidez y calidad sonora en general, lo que da a entender que siguen unos patrones para puntuar las diferentes lengüetas. En segundo lugar, además de la concordancia, se observa que en estas mismas valoraciones, influyen considerablemente los diferentes estilos de rebajado. Como se ve en las figuras 4.85, 4.86 y 4.87, todos los ejercicios generan diferencias excepto el pianissimo y el fortissimo, observando que las lengüetas americanas son las menos apreciadas en cuanto a calidad sonora y las francesas son las consideradas más fáciles de interpretar. Si bien es cierto que no se ha utilizado a ningún oboísta de la escuela americana, cabe remarcar que quizás este 
rechazo hacia la sonoridad del estilo de rebajado americano viene dado por la gran diferencia en la forma de rebajar que tiene respecto a los otros dos estilos. Por lo que esto no hace más que corroborar que los estilos de rebajado influyen de forma considerable en la propiocepción.

Se puede concluir que el molde tiene poca influencia en la propiocepción y que aunque el molde 168 genera diferencias, éstas vienen dadas más por su desproporción dentro de las medidas de las lengüetas óptimas para la interpretación del oboe moderno que ningún otro aspecto de propiocepción propiamente dicho.

\subsection{Experimento de evaluación auditiva}

\subsubsection{Introducción}

Este experimento intenta averiguar si las evaluaciones de la calidad de sonido de las lengüetas dadas por los oboístas después de la interpretación de los ejercicios son realmente evaluaciones auditivas. Para ello, se diseña un experimento donde cinco oboístas intérpretes, y un oboísta externo, escuchan sus sonidos y los de otros oboístas, puntuando tanto la calidad sonora como la ejecución del sonido interpretado.

Además, se realiza una diferencia entre evaluación auditiva y autoevaluación auditiva, ya que los oboístas van a evaluar sus propios sonidos (autoevaluación) y los sonidos de un representante de la escuela alemana y de la francesa (evaluación).

\subsubsection{Hipótesis}

Se emite la hipótesis que cuando los oboístas intérpretes evalúan sus propios sonidos a través de un experimento de percepción (evaluación auditiva), no son capaces de puntuar con la misma valoración los ejercicios que ellos mismo han interpretado y los ejercicios escuchados, ya que, a través de la escucha, no consiguen recrear las sensaciones obtenidas en la interpretación.

Asimismo, se emite la hipótesis que los oboístas no van a distinguir por estilos de rebajado ni cuando valoren la ejecución del ejercicio ni cuando valoren la calidad del sonido. 


\subsubsection{Método}

Para esta parte del estudio, se utilizan a cinco oboístas que participaron en la grabación y a otro oboísta externo. La evaluación se realiza auditivamente y se escoge el ejercicio diminuendo por ser una nota aislada que pone a prueba tanto la flexibilidad como la rigidez de la lengüeta.

Los cinco oboístas escucharon el ejercicio diminuendo grabado por ellos mismos, por un oboísta representante de la escuela alemana y por otro de la escuela francesa. Cincuenta y cuatro sonidos fueron evaluados según la calidad de ejecución y la calidad del sonido en una escala del 1 al 7. En este caso, la calidad del sonido no es sinónimo de timbre, en particular porque el sonido y el timbre evolucionan durante un diminuendo. La escucha se realizó con auriculares y con los sonidos intercalados, de forma que los diferentes oboístas no sabían qué sonidos estaban evaluando. El representante de la escuela alemana y el oyente externo evaluaron treinta y seis sonidos: los sonidos representativos de la escuela alemana y los de la francesa. El tiempo de duración del test fue aproximadamente de ocho minutos.

\begin{tabular}{|c|c|c|c|}
\hline Sonido & $\begin{array}{c}\text { Calidad de } \\
\text { ejecución (1-7) }\end{array}$ & $\begin{array}{c}\text { Calidad del sonido } \\
(1-7)\end{array}$ & Comentarios \\
\hline 0 & 1 & 3 & Afinació inestable \\
\hline 0 & 1 & 3 & Afinació inestable \\
\hline 0 & 1 & 2 & $\begin{array}{l}\text { Afinació alta } \\
\text { Afinació inestable }\end{array}$ \\
\hline 0 & 2 & 5 & $\begin{array}{l}\text { Afinació inestable } \\
\text { Bon final }\end{array}$ \\
\hline 0 & 1 & 4 & Afinació inestable \\
\hline
\end{tabular}

Figura 4.97. Captura de pantalla de la herramienta interactiva desarrollada para el test de evaluación auditiva. 


\subsubsection{Resultados}

\subsubsection{Concordancia de las respuestas}

Se observa en la tabla 4.69, que en el experimento de evaluación auditiva, los oboístas evaluadores son bastante coherentes en sus respuestas cuando evalúan si el ejercicio se ha ejecutado bien o mal $(\alpha=803)$, pero en cambio al igual que pasaba en la propiocepción, cuando puntúan la calidad del sonido, la concordancia de las respuestas es menor provocando que el Alfa de Cronbach tenga valores más bajos $(\alpha=, 568)$.

\begin{tabular}{|l|l|l|}
\hline Estímulos & Pregunta & Alfa \\
\hline diminuendo (nota larga) & ejecución &, 803 \\
\cline { 2 - 3 } & calidad sonido &, 568 \\
\hline
\end{tabular}

Tabla 4.69. Tabla resumen con los análisis de fiabilidad del experimento de evaluación auditiva.

\subsubsection{Influencia del rebajado}

Un ANOVA con medidas repetidas muestra en la tabla 4.70 (cf. A.69 y A.70 para más detalle) que los oboístas evaluadores no distinguen por rebajados ni en la ejecución ni en la calidad del sonido. Cabe destacar que la significatividad está en un valor tan alto que demuestra que realmente no hay una influencia del rebajado, aunque se aumente el número de participantes o de muestras.

\begin{tabular}{|c|r|r|r|r|r|r|}
\hline \multicolumn{1}{|c|}{ Origen } & \multicolumn{1}{c|}{$\begin{array}{c}\text { Suma de } \\
\text { cuadrados tipo III }\end{array}$} & gl & $\begin{array}{c}\text { Media } \\
\text { cuadrática }\end{array}$ & F & Sig. & $\begin{array}{c}\text { Eta al cuadrado } \\
\text { parcial }\end{array}$ \\
\hline ejecucion-rebajado & 1,581 & 1,973 & 0,801 & 0,359 & 0,696 & 0,006 \\
\hline calidad sonido-rebajados & 2,075 & 1,824 & 1,138 & 0,601 & 0,535 & 0,010 \\
\hline
\end{tabular}

Tabla 4.70. Efectos intra-sujetos del ANOVA con medidas repetidas utilizando los datos de GreenhouseGeisser para las preguntas que evaluaron todos los oboístas $(\mathrm{N}=6)$ y todos los sonidos del ejercicio diminuendo en función del rebajado de la lengüeta.

Si se realiza un análisis de varianza de las evaluaciones que han hecho los oboístas sobre sus propios ejercicios en función del estilo de rebajado (autoevaluación auditiva) (tabla 4.71, cf. A.71 para más detalle) se observa que algunos evaluadores distinguen entre lengüetas sobre todo evaluando sus propios sonidos (esto puede ser debido a que saben claramente el sonido que querían obtener y lo que ha resultado); por ejemplo, el evaluador 6 distingue de forma muy significativa por rebajado, sobre todo en la ejecución $(p<, 001)$ y el evaluador número 4 también distingue por rebajados en la ejecución, pero no de forma tan significativa $(p=, 038)$. Estos resultados muestran que hay bastante variabilidad entre evaluadores y tan sólo el evaluador 3 y el 6 son capaces de distinguir la calidad del sonido 
por rebajados $(p=, 028$ y $p=, 043$ respectivamente), pero en general no suele haber diferencias significativas.

Se ve pues, que algunos evaluadores son capaces de distinguir entre lengüetas, pero que no parece el criterio fundamental que influencia la ejecución y la calidad del sonido.

\begin{tabular}{|l|l|r|r|}
\hline oboísta & pregunta & \multicolumn{1}{|c|}{ F } & \multicolumn{1}{c|}{ Sig. } \\
\hline \multirow{2}{*}{2} & ejecución &, 577 &, 574 \\
\cline { 2 - 4 } & sonido & 1,792 &, 200 \\
\hline \multirow{2}{*}{3} & ejecución & 1,037 &, 379 \\
\cline { 2 - 4 } & sonido & 4,559 & $\mathbf{0 2 8}$ \\
\hline \multirow{3}{*}{4} & ejecución & 4,079 & $\mathbf{0 3 8}$ \\
\cline { 2 - 4 } & Sonido &, 500 &, 616 \\
\hline \multirow{2}{*}{6} & ejecución & 102,900 & $\mathbf{, 0 0 0}$ \\
\cline { 2 - 4 } & Sonido & 5,073 & $\mathbf{0 4 3}$ \\
\hline \multirow{2}{*}{11} & ejecución & 2,262 &, 139 \\
\cline { 2 - 4 } & sonido & 3,075 &, 076 \\
\hline
\end{tabular}

Tabla 4.71. Resumen del análisis de varianza de un factor, para la autoevaluación auditiva de los oboístas en el ejercicio diminuendo, dividido por oboístas intérpretes y evaluadores en función del rebajado de la lengüeta.

Al ejecutar un análisis de varianza de un factor con todos los oboístas analizando los sonidos representativos de la escuela alemana (oboísta 3) y francesa (oboísta 7), los resultados muestran que tan sólo se distingue la calidad del sonido de los extractos de la escuela alemana ( $p=, 039)$ (tabla $4.72, c f$. A.72 para más detalle).

\begin{tabular}{|l|l|r|r|}
\hline oboísta & \multicolumn{1}{|c|}{ pregunta } & F & \multicolumn{1}{c|}{ Sig. } \\
\hline \multirow{3}{*}{3} & ejecución &, 237 &, 790 \\
\cline { 2 - 4 } & sonido & 3,34 &, $\mathbf{0 3 9}$ \\
\hline 7 & ejecución &, 073 &, 929 \\
\cline { 2 - 4 } & sonido &, 700 &, 499 \\
\hline
\end{tabular}

Tabla 4.72. Resumen del análisis de varianza de un factor para la evaluación auditiva del ejercicio diminuendo realizado por todos los oboístas para los sonidos de la escuela alemana y francesa, en función del rebajado de la lengüeta.

Si, por el contrario, se elimina la autoevaluación del criterio del análisis y se realiza un análisis de varianza de un factor con todos los oboístas que han evaluado al representante de la escuela alemana (oboísta 3) y al de la escuela francesa (oboísta 7), eliminando la evaluación del oboísta 3 (autoevaluación), se aprecia en la tabla 4.73 ( $c f$. A. 73 para más detalle) que no existe ninguna diferencia significativa entre los diferentes rebajados de las lengüetas. 


\begin{tabular}{|l|l|r|r|}
\hline oboísta & \multicolumn{1}{|c|}{ pregunta } & F & \multicolumn{1}{c|}{ Sig. } \\
\hline \multirow{3}{*}{3} & ejecución &, 407 &, 667 \\
\cline { 2 - 4 } & sonido & 2,759 &, 069 \\
\hline 7 & ejecución &, 227 &, 797 \\
\cline { 2 - 4 } & sonido &, 446 &, 641 \\
\hline
\end{tabular}

Tabla 4.73. Resumen del análisis de varianza de un factor para la evaluación auditiva del ejercicio diminuendo realizado por todos los oboístas para los sonidos de la escuela alemana y francesa, en función del rebajado de la lengüeta (excepto el oboísta 3: evitando la autoevaluación).

\subsubsection{Análisis de la evaluación auditiva comparada con el análisis acústico}

En este apartado se comparan todas las respuestas de todos los extractos escuchados y puntuados por los oboístas que realizaron el test de evaluación auditiva, para así investigar si el análisis acústico puede explicar los parámetros perceptivos de "ejecución" y "calidad del sonido". Cabe recordar que en esta ocasión se utilizó a un oboísta externo, que no participó en ningún momento de la grabación (propiocepción).

Para ello, se efectúa una serie de regresiones donde todos los parámetros acústicos se relacionan con algún factor de la ejecución y de la calidad del sonido en la evaluación auditiva.

\subsubsection{Resultados}

\subsection{Ejecución del diminuendo}

Al analizar todos los parámetros acústicos para ver cuáles pueden estar relacionados con la ejecución en la evaluación auditiva, se puede observar en la tabla 4.77, que aparecen seis parámetros relacionados con la evaluación auditiva: la intensidad (en $\mathrm{dB}$ ), la diferencia de energía de bandas ( $5^{\mathrm{a}}$ justa o 7 semitonos) y el delta de la frecuencia (en $\mathrm{Hz}$ ), la frecuencia media (en $\mathrm{Hz}$ ), el centro de gravedad del espectro y la desviación estándar de la amplitud, obteniendo un $\mathrm{R}^{2}$ corregido bajo.

El $\mathrm{R}^{2}$ corregido obtenido en esta ocasión es mayor que en la propiocepción $\left(\mathrm{R}^{2}\right.$ evaluación auditiva=,264; $\mathrm{R}^{2}$ evaluación interpretativa=,192). 


\begin{tabular}{|c|c|c|c|c|c|c|c|c|c|}
\hline \multicolumn{10}{|c|}{ Resumen del modelo } \\
\hline \multirow[t]{2}{*}{ Modelo } & \multirow[t]{2}{*}{$\bar{R}$} & \multirow[t]{2}{*}{$\mathrm{R}^{2}$} & \multirow{2}{*}{$\begin{array}{c}\mathrm{R}^{2} \\
\text { corregid } \\
\mathrm{a}\end{array}$} & \multirow{2}{*}{$\begin{array}{c}\text { Error } \\
\text { típ. de } \\
\text { la } \\
\text { estimaci } \\
\text { ón }\end{array}$} & \multicolumn{5}{|c|}{ Estadísticos de cambio } \\
\hline & & & & & $\begin{array}{c}\text { Cambio en } \\
\mathrm{R}^{2}\end{array}$ & $\begin{array}{c}\text { Cambio } \\
\text { en F }\end{array}$ & gl1 & $\mathrm{gl} 2$ & Sig. Cambio en F \\
\hline 8 & 0,529 & 0,280 & 0,264 & 1,426 & 0,021 & 8,121 & 1 & 273 & 0,005 \\
\hline
\end{tabular}

\begin{tabular}{|c|c|c|c|c|c|c|}
\hline \multicolumn{7}{|c|}{ Coeficientes $^{\mathrm{a}}$} \\
\hline \multirow{2}{*}{\multicolumn{2}{|c|}{ Modelo }} & \multicolumn{2}{|c|}{$\begin{array}{l}\text { Coeficientes no } \\
\text { estandarizados }\end{array}$} & \multirow{2}{*}{$\begin{array}{c}\text { Coeficientes } \\
\text { estandarizados }\end{array}$} & \multirow[t]{2}{*}{$\mathrm{t}$} & \multirow[t]{2}{*}{ Sig. } \\
\hline & & B & Error típ. & & & \\
\hline \multirow[t]{7}{*}{8} & (Constante) & 2,794 & 0,141 & & 19,784 & 0,000 \\
\hline & $\begin{array}{l}\text { Amplitude Std } \\
\text { Dev dim }\end{array}$ & $-1,291$ & 0,453 & $-0,716$ & $-2,850$ & 0,005 \\
\hline & $\begin{array}{l}\text { F0 Mean (Hz) } \\
\text { dim }\end{array}$ & $-0,667$ & 0,126 & $-0,364$ & $-5,289$ & 0,000 \\
\hline & $\begin{array}{l}\text { Delta F0 (Hz) } \\
\text { dim }\end{array}$ & $-0,624$ & 0,148 & $-0,242$ & $-4,226$ & 0,000 \\
\hline & $\begin{array}{l}\text { Band Energy Diff } \\
\text { ( } 7 \mathrm{st}) \operatorname{dim}\end{array}$ & $-0,181$ & 0,105 & $-0,095$ & $-1,717$ & 0,087 \\
\hline & $\begin{array}{l}\text { Intensity (dB) } \\
\text { dim }\end{array}$ & 1,875 & 0,497 & 0,831 & 3,774 & 0,000 \\
\hline & $\begin{array}{l}\text { Spectrum Center } \\
\text { Gravity dim }\end{array}$ & 0,494 & 0,132 & 0,347 & 3,739 & 0,000 \\
\hline
\end{tabular}

Tabla 4.74. Resumen del modelo (arriba) y coeficientes de las variables predictoras de la regresión de la variable dependiente "ejecución en la evaluación auditiva del diminuendo" con todos los parámetros acústicos. Se muestran los que sí tienen influencia sobre la variable dependiente.

\subsection{Calidad sonora del diminuendo}

Cuando se analizan los parámetros acústicos relacionados con la calidad sonora de la evaluación auditiva, se observa en la tabla 4.75 que la intensidad (en dB), la desviación estándar de la amplitud, la frecuencia media (en $\mathrm{Hz}$ ) y el delta de la frecuencia (en $\mathrm{Hz}$ ) son los parámetros más influyentes. Cabe destacar que el delta de la frecuencia (en $\mathrm{Hz}$ ) es un parámetro que poco tiene que ver con la calidad del sonido, sino más bien con la ejecución. El $\mathrm{R}^{2}$ corregido obtenido es más alto que en la propiocepción $\left(\mathrm{R}^{2}\right.$ evaluación auditiva=, 252; $\mathrm{R}^{2}$ evaluación interpretativa=,108). 


\begin{tabular}{|c|c|c|c|c|c|c|c|c|c|}
\hline \multicolumn{10}{|c|}{ Resumen del modelo } \\
\hline \multirow[t]{2}{*}{ Modelo } & \multirow[t]{2}{*}{$\mathrm{R}$} & \multirow[t]{2}{*}{$\mathrm{R}^{2}$} & \multirow{2}{*}{$\begin{array}{c}\mathrm{R}^{2} \\
\text { corregid } \\
\mathrm{a}\end{array}$} & \multirow{2}{*}{\begin{tabular}{c|} 
Error \\
típ. de \\
la \\
estimaci \\
ón \\
\end{tabular}} & \multicolumn{5}{|c|}{ Estadísticos de cambio } \\
\hline & & & & & $\begin{array}{c}\text { Cambio en } \\
\mathrm{R}^{2}\end{array}$ & $\begin{array}{c}\text { Cambio } \\
\text { en } F\end{array}$ & gl1 & $\mathrm{g} 12$ & $\begin{array}{l}\text { Sig. Cambio } \\
\text { en F }\end{array}$ \\
\hline 4 & 0,502 & 0,252 & 0,242 & 1,291 & 0,012 & 4,585 & 1 & 275 & 0,033 \\
\hline
\end{tabular}

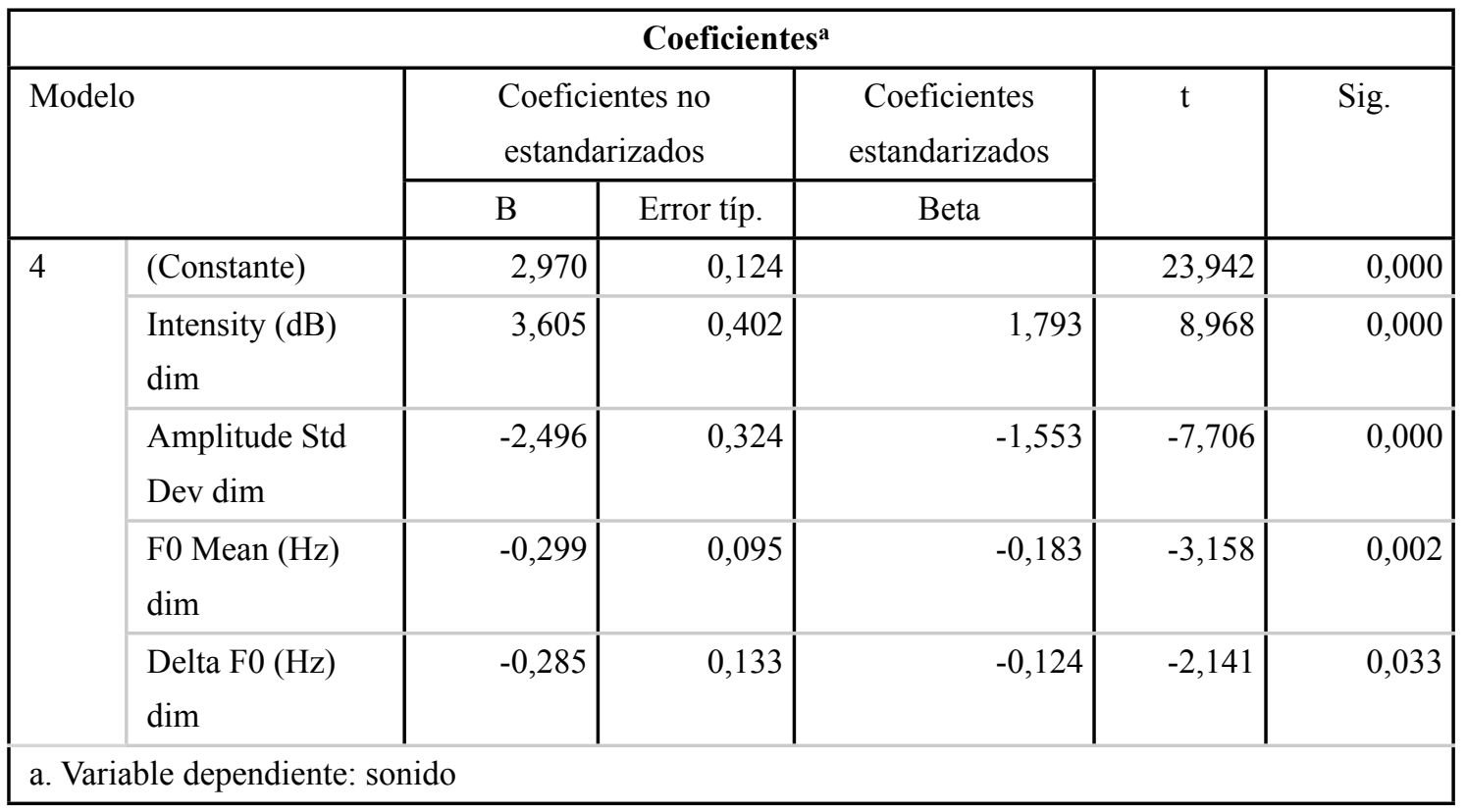

Tabla 4.75. Resumen del modelo (arriba) y coeficientes de las variables predictoras de la regresión de la variable dependiente "calidad del sonido en la evaluación auditiva del diminuendo" con todos los parámetros acústicos. Se muestran los que sí tienen influencia sobre la variable dependiente.

\subsubsection{Discusión}

Después del análisis de los resultados se observa que la evaluación auditiva no genera diferencias por estilos de rebajado, tan solo aparecen diferencias puntuales para algunos oboístas, sobre todo cuando evalúan sus ejercicios interpretados (autoevaluación auditiva, $c f$. tabla 4.71), por lo que se vuelve a corroborar los resultados obtenidos en el experimento preliminar y principal sobre la percepción tímbrica: los diferentes estilos de rebajado no provocan diferencias significativas en la percepción de los oyentes, sean oboístas, músicos no oboístas u oboístas intérpretes.

Por otra parte, es importante remarcar que cuando se comparan las mediciones acústicas con la calidad del sonido en la evaluación auditiva, todos los parámetros acústicos relacionados poco tienen que ver con la calidad del sonido, sino más bien con la ejecución, por lo que todo parece indicar que los oboístas no saben distinguir entre calidad sonora y ejecución interpretativa. 


\subsubsection{Conclusiones}

Se afirma que los diferentes estilos de rebajado no influyen cuando los oboístas escuchan sus propios sonidos o cuando los comparan con los de otro oboísta y aunque hay algún oboísta que puede distinguir entre lengüetas, sobre todo en la ejecución, aparece la paradoja que este mismo oboísta no es capaz de distinguir entre lengüetas cuando interpreta, por lo que seguramente debe entender dos cosas diferentes cuando puntúa la misma acción.

\subsection{Comparación de la evaluación interpretativa y la autoevaluación auditiva}

Después del análisis de las respuestas de los oboístas en el momento de la grabación (evaluación interpretativa) y las respuestas de algunos de estos oboístas cuando escuchaban sus sonidos y los de un representante de la escuela alemana y francesa (autoevaluación auditiva), se analiza si existe alguna relación entre las respuestas dadas por los oboístas en propiocepción y las que daban cuando escuchaban sus propios sonidos.

\subsubsection{Resultados}

\subsubsection{Correlaciones}

Para poder comparar los resultados obtenidos de las respuestas de los oboístas en la autoevaluación auditiva y la evaluación interpretativa, se relacionan la ejecución en la autoevaluación auditiva (a partir de ahora ejecución perceptiva) con la facilidad de la propiocepción y la calidad del sonido en la autoevaluación auditiva (a partir de ahora sonido perceptivo) con la calidad propioceptiva.

En la tabla 4.76 se observan los resultados de los cinco oboístas que han realizado tanto la propiocepción como la autoevaluación auditiva. Así pues, mientras que la ejecución perceptiva está muy correlacionada tanto con el sonido perceptivo como con los dos factores de calidad y ejecución propioceptivos, el sonido perceptivo sólo se correlaciona con la ejecución perceptiva, pero para nada con ninguno de los factores de propiocepción de ejecución y sonido. Y algo parecido ocurre con la propiocepción: la facilidad y la calidad del ejercicio propioceptivo están muy correlacionados con la 
facilidad y calidad propioceptiva respectivamente y con la ejecución perceptiva, pero no lo están para el sonido perceptivo. Esto quiere decir que cuando los oboístas puntúan si un ejercicio está bien o mal ejecutado, tanto perceptiva como propioceptivamente, tienen claro qué es lo que están puntuando; mientras que al ser preguntados por la calidad sonora, en uno u otro caso, no parecen ponerse de acuerdo con ellos mismos, por lo que o no tienen claro qué se les está preguntando en cada momento o no son capaces de establecer un patrón para la evaluación del sonido. Sin embargo, en la tabla 4.77, se pueden comparar estas mismas respuestas separadas por oboístas y, como se aprecia en los resultados, tan sólo el oboísta 3 es capaz de relacionar las dos cualidades sonoras juntas: la calidad del diminuendo y el sonido perceptivo del diminuendo.

Otro dato que sobresale es que no existe tampoco una correlación cuando los oboístas puntúan en la propiocepción el timbre de la lengüeta con la que acaban de interpretar y cuando contestan por la calidad del sonido al autoevaluarse (cf. tabla 4.76). Es decir, los oboístas no relacionan, en este caso, timbre con calidad sonora $(p=, 549)$. Esto puede deberse a que las puntuaciones dadas para el timbre engloban los cinco ejercicios interpretados: arpegio, legato, diminuendo, pianissimo y fotissimo, mientras que la calidad sonora perceptiva es sólo del ejercicio diminuendo.

\begin{tabular}{|c|c|c|c|c|c|c|c|c|c|c|}
\hline \multicolumn{11}{|c|}{ Correlaciones } \\
\hline & & $\begin{array}{l}\text { ejecuci } \\
\text { on perc }\end{array}$ & $\begin{array}{c}\text { sonido } \\
\text { perc }\end{array}$ & $\operatorname{dim} F$ & $\operatorname{dim} Q$ & $\begin{array}{c}\text { global: } \\
\text { equilibr } \\
\text { io }\end{array}$ & \begin{tabular}{|c|} 
global: \\
flexibili \\
dad
\end{tabular} & $\begin{array}{l}\text { global: } \\
\text { rigidez }\end{array}$ & $\begin{array}{l}\text { global: } \\
\text { timbre }\end{array}$ & global \\
\hline \multirow{2}{*}{$\begin{array}{l}\text { ejecucion } \\
\text { perc }\end{array}$} & Corr. & 1 & ,691** &, $349^{* *}$ & ,278* & 0,195 &, $425^{* *}$ &,$- 284^{* *}$ & 0,133 & 0,204 \\
\hline & Sig. & & 0,000 & 0,001 & 0,012 & 0,079 & 0,000 & 0,010 & 0,233 & 0,066 \\
\hline \multirow{2}{*}{$\begin{array}{l}\text { sonido } \\
\text { perc }\end{array}$} & Corr. &, $691^{* * *}$ & 1 & 0,041 & 0,076 & 0,142 &, $219^{*}$ &,$- 250^{*}$ & 0,067 & 0,109 \\
\hline & Sig. & 0,000 & & 0,717 & 0,498 & 0,204 & 0,049 & 0,024 & 0,549 & 0,330 \\
\hline
\end{tabular}

Tabla 4.76. Correlación de Pearson y significatividad bilateral $(\mathrm{N}=82$ para la ejecución perceptiva y el sonido perceptivo y $\mathrm{N}=180$ para el resto los casos) comparando las preguntas de la evaluación externa con las de propiocepción, para el ejercicio diminuendo y sólo para los oboístas que realizan la autoevaluación. 


\begin{tabular}{|c|c|c|c|c|c|c|}
\hline \multicolumn{7}{|c|}{ Correlaciones } \\
\hline oboísta & & & ejecucion perc & sonido perc & $\operatorname{dim} F$ & $\operatorname{dim} Q$ \\
\hline \multirow[t]{6}{*}{ ob. 2} & \multirow{2}{*}{$\begin{array}{l}\text { ejecucion } \\
\text { perc }\end{array}$} & Corr. & 1 & ,592** & ,693** & ,554* \\
\hline & & Sig. & & 0,010 & 0,001 & 0,017 \\
\hline & \multirow[t]{2}{*}{ sonido perc } & Corr. &, $592^{* *}$ & 1 & 0,320 & 0,385 \\
\hline & & Sig. & 0,010 & & 0,195 & 0,114 \\
\hline & \multirow[t]{2}{*}{$\operatorname{dim} F$} & Corr. & ,693** & 0,320 & 1 &, $702^{* *}$ \\
\hline & & Sig. & 0,001 & 0,195 & & 0,001 \\
\hline \multirow[t]{6}{*}{ ob. 3} & \multirow{2}{*}{$\begin{array}{l}\text { ejecucion } \\
\text { perc }\end{array}$} & Corr. & 1 &, $582^{*}$ &, $664^{* *}$ & 0,359 \\
\hline & & Sig. & & 0,011 & 0,003 & 0,143 \\
\hline & \multirow[t]{2}{*}{ sonido perc } & Corr. & ,582* & 1 & 0,458 & ,558* \\
\hline & & Sig. & 0,011 & & 0,056 & 0,016 \\
\hline & \multirow[t]{2}{*}{$\operatorname{dim} F$} & Corr. & ,664** & 0,458 & 1 &, $762^{* *}$ \\
\hline & & Sig. & 0,003 & 0,056 & & 0,000 \\
\hline \multirow[t]{6}{*}{ ob. 4} & \multirow{2}{*}{$\begin{array}{l}\text { ejecucion } \\
\text { perc }\end{array}$} & Corr. & 1 & ,533* & $-0,024$ & 0,078 \\
\hline & & Sig. & & 0,023 & 0,924 & 0,758 \\
\hline & \multirow[t]{2}{*}{ sonido perc } & Corr. & ,533* & 1 & $-0,046$ & $-0,073$ \\
\hline & & Sig. & 0,023 & & 0,858 & 0,772 \\
\hline & \multirow[t]{2}{*}{$\operatorname{dim} F$} & Corr. & $-0,024$ & $-0,046$ & 1 &, $885^{* *}$ \\
\hline & & Sig. & 0,924 & 0,858 & & 0,000 \\
\hline \multirow[t]{6}{*}{ ob. 6} & \multirow{2}{*}{$\begin{array}{l}\text { ejecucion } \\
\text { perc }\end{array}$} & Corr. & 1 & 0,357 & $867^{* *}$ & 0,572 \\
\hline & & Sig. & & 0,311 & 0,001 & 0,084 \\
\hline & \multirow[t]{2}{*}{ sonido perc } & Corr. & 0,357 & 1 & 0,092 & 0,170 \\
\hline & & Sig. & 0,311 & & 0,800 & 0,639 \\
\hline & \multirow[t]{2}{*}{$\operatorname{dim} F$} & Corr. & $867^{* *}$ & 0,092 & 1 &, $653^{* *}$ \\
\hline & & Sig. & 0,001 & 0,800 & & 0,003 \\
\hline \multirow[t]{6}{*}{ ob. 11} & \multirow{2}{*}{$\begin{array}{l}\text { ejecucion } \\
\text { perc }\end{array}$} & Corr. & 1 &, $709^{* *}$ & $-0,172$ & $-0,049$ \\
\hline & & Sig. & & 0,001 & 0,496 & 0,848 \\
\hline & \multirow[t]{2}{*}{ sonido perc } & Corr. &, $709^{* *}$ & 1 & $-0,451$ & $-0,233$ \\
\hline & & Sig. & 0,001 & & 0,060 & 0,352 \\
\hline & \multirow[t]{2}{*}{$\operatorname{dim} F$} & Corr. & $-0,172$ & $-0,451$ & 1 &, $622^{* *}$ \\
\hline & & Sig. & 0,496 & 0,060 & & 0,006 \\
\hline
\end{tabular}

Tabla 4.77. Correlación de Pearson y significatividad bilateral ( $\mathrm{N}=18$ en todos los casos, excepto para el oboísta $6 \mathrm{~N}=10$ ) comparando las preguntas de la evaluación externa con las de propiocepción, para el ejercicio diminuendo y sólo para los oboístas que realizan la autoevaluación de forma individualizada. 


\subsubsection{Análisis de la autoevaluación auditiva comparada con el análisis acústico}

Después de haber analizado la autoevaluación auditiva en los oboístas, se quiere averiguar si existe algún parámetro acústico que pueda explicar tanto la ejecución como la calidad sonora del ejercicio diminuendo.

Para ello, se realiza una serie de regresiones donde todos los parámetros acústicos se relacionan con las puntuaciones de ejecución y calidad del diminuendo que dieron los oboístas al escuchar sus propios sonidos.

Además, se analizan y se comparan con la autoevaluación auditiva, los parámetros acústicos relacionados con la evaluación interpretativa del ejercicio diminuendo, pero en esta ocasión, en vez de utilizar a todos los oboístas como en el punto 4.7.5.1.5 y 4.7.5.1.6, sólo se analizan las respuestas de los cinco oboístas que han realizado tanto la evaluación interpretativa como la autoevaluación auditiva.

\subsubsection{Resultados}

\subsection{Ejecución del diminuendo}

Al analizar todos los parámetros acústicos para ver cuáles pueden estar relacionados con la ejecución en la autoevaluación auditiva, se puede observar en la tabla 4.78, que ésta viene explicada por cuatro parámetros acústicos: la intensidad (en dB), la diferencia de energía de bandas ( $3^{\mathrm{a}}$ mayor), el delta de la frecuencia (en $\mathrm{Hz}$ ) y la desviación estándar de la amplitud media, obteniendo un $\mathrm{R}^{2}$ corregido bajo $\left(\mathrm{R}^{2}=316\right)$.

Cabe destacar que el delta de la frecuencia y la intensidad son dos parámetros acústicos muy ligados a la ejecución del diminuendo y que la diferencia de energía de bandas es una medición basada más en la calidad sonora que en la ejecución.

Si se comparan las regresiones de la evaluación interpretativa (tabla 4.78b) y de la autoevaluación auditiva (tabla 4.78), se observa que mientras la evaluación auditiva está explicada por varios parámetros acústicos, la facilidad del diminuendo en la evaluación interpretativa sólo viene explicada por el delta de la frecuencia, obteniendo un $\mathrm{R}^{2}$ corregido mucho menor que en la autoevaluación auditiva $\left(\mathrm{R}^{2}=, 053\right)$. 


\begin{tabular}{|l|c|r|r|c|}
\hline \multicolumn{5}{|c|}{ Resumen del modelo } \\
\hline Modelo & $\mathrm{R}$ & $\mathrm{R}^{2}$ & $\mathrm{R}^{2}$ corregida & $\begin{array}{c}\text { Error típ. de la } \\
\text { estimación }\end{array}$ \\
\hline 4 & 0,592 & 0,35 & 0,316 & 1,443 \\
\hline
\end{tabular}

\begin{tabular}{|c|c|c|c|c|c|c|}
\hline & & Coeficient & & & & \\
\hline & & Coeficie & ates no & & $\mathrm{t}$ & Sig. \\
\hline & & B & Error típ. & Beta & & \\
\hline 4 & (Constante) & 3,022 & 0,180 & & 16,799 & 0,000 \\
\hline & Intensity $\operatorname{dim}(\mathrm{dB})$ & 1,570 & 0,443 & 0,912 & 3,547 & 0,001 \\
\hline & Band Energy Diff (4st) dim & $-0,600$ & 0,185 & $-0,330$ & $-3,249$ & 0,002 \\
\hline & F0 Delta $(\mathrm{Hz}) \operatorname{dim}$ & $-0,589$ & 0,270 & $-0,211$ & $-2,182$ & 0,032 \\
\hline & Amplitude Std Dev media & $-1,043$ & 0,494 & $-0,548$ & $-2,109$ & 0,038 \\
\hline
\end{tabular}

Tabla 4.78. Resumen del modelo (arriba) y coeficientes de las variables predictoras de la regresión de la variable dependiente "ejecución en la autoevaluación auditiva del diminuendo" con todos los parámetros acústicos. Se muestran los que sí tienen influencia sobre la variable dependiente.

\begin{tabular}{|l|c|r|r|r|}
\hline \multicolumn{5}{|c|}{ Resumen del modelo } \\
\hline Modelo & $\mathrm{R}$ & $\mathrm{R}^{2}$ & $\mathrm{R}^{2}$ corregida & $\begin{array}{c}\text { Error típ. de la } \\
\text { estimación }\end{array}$ \\
\hline 1 & 0,254 & 0,065 & 0,053 & 1,492 \\
\hline
\end{tabular}

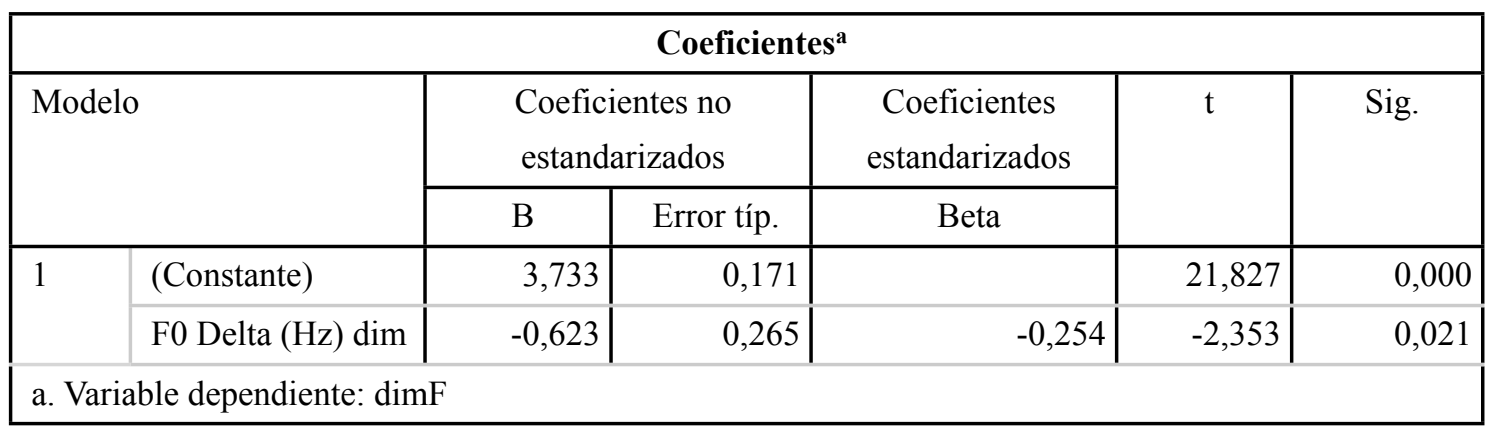

Tabla 4.78b. Resumen del modelo (arriba) y coeficientes de las variables predictoras de la regresión de la variable dependiente "facilidad del diminuendo" con todos los parámetros acústicos para los cinco oboístas que han realizado la autoevaluación auditiva. Se muestran los que sí tienen influencia sobre la variable dependiente.

Si además se realiza una regresión para la ejecución de la autoevaluación auditiva del diminuendo separando los datos por los diferentes oboístas, para así poder determinar qué parámetro acústico influye de manera directa en cada uno para sus respuestas autoevaluadoras, se aprecia en la tabla 4.79, que los únicos oboístas que obtienen alguna explicación acústica son el oboísta 6 y el 11. Mientras que las respuestas del oboísta 6 están directamente relacionadas sólo con el parámetro acústico armonicidad media y obtiene un $\mathrm{R}^{2}$ corregido bastante alto $\left(\mathrm{R}^{2}=, 591\right)$, el oboísta 11 explica sus respuestas 
relacionándolas con la diferencia de frecuencia (en $\mathrm{Hz}$ ) y la armonicidad media, obteniendo un $\mathrm{R}^{2}$ corregido un poco más bajo que el oboísta $6\left(\mathrm{R}^{2}=, 407\right)$. No obstante, cabe destacar que la armonicidad media es un parámetro acústico ligado a la calidad del sonido y no a la ejecución interpretativa.

\begin{tabular}{|c|c|c|c|c|c|c|c|c|c|c|}
\hline \multicolumn{11}{|c|}{ Resumen del modelo } \\
\hline \multirow[t]{2}{*}{ Oboísta } & \multirow{2}{*}{$\begin{array}{l}\text { Model } \\
\text { o }\end{array}$} & \multirow[t]{2}{*}{$\mathrm{R}$} & \multirow[t]{2}{*}{$\mathrm{R}^{2}$} & \multirow{2}{*}{$\begin{array}{c}\mathrm{R}^{2} \\
\text { corregida }\end{array}$} & \multirow{2}{*}{$\begin{array}{c}\text { Error típ. } \\
\text { de la } \\
\text { estimació } \\
n\end{array}$} & \multicolumn{5}{|c|}{ Estadísticos de cambio } \\
\hline & & & & & & $\begin{array}{c}\text { Cambio } \\
\text { en } \mathrm{R}^{2}\end{array}$ & $\begin{array}{c}\text { Cambio } \\
\text { en F }\end{array}$ & g11 & $\mathrm{gl} 2$ & $\begin{array}{c}\text { Sig. } \\
\text { Cambio en } \\
\text { F }\end{array}$ \\
\hline 6 & 1 & 0,798 & 0,637 & 0,591 & 1,175 & 0,637 & 14,028 & 1 & 8 & 0,006 \\
\hline 11 & 2 & 0,691 & 0,477 & 0,407 & 1,691 & 0,210 & 6,021 & 1 & 15 & 0,027 \\
\hline
\end{tabular}

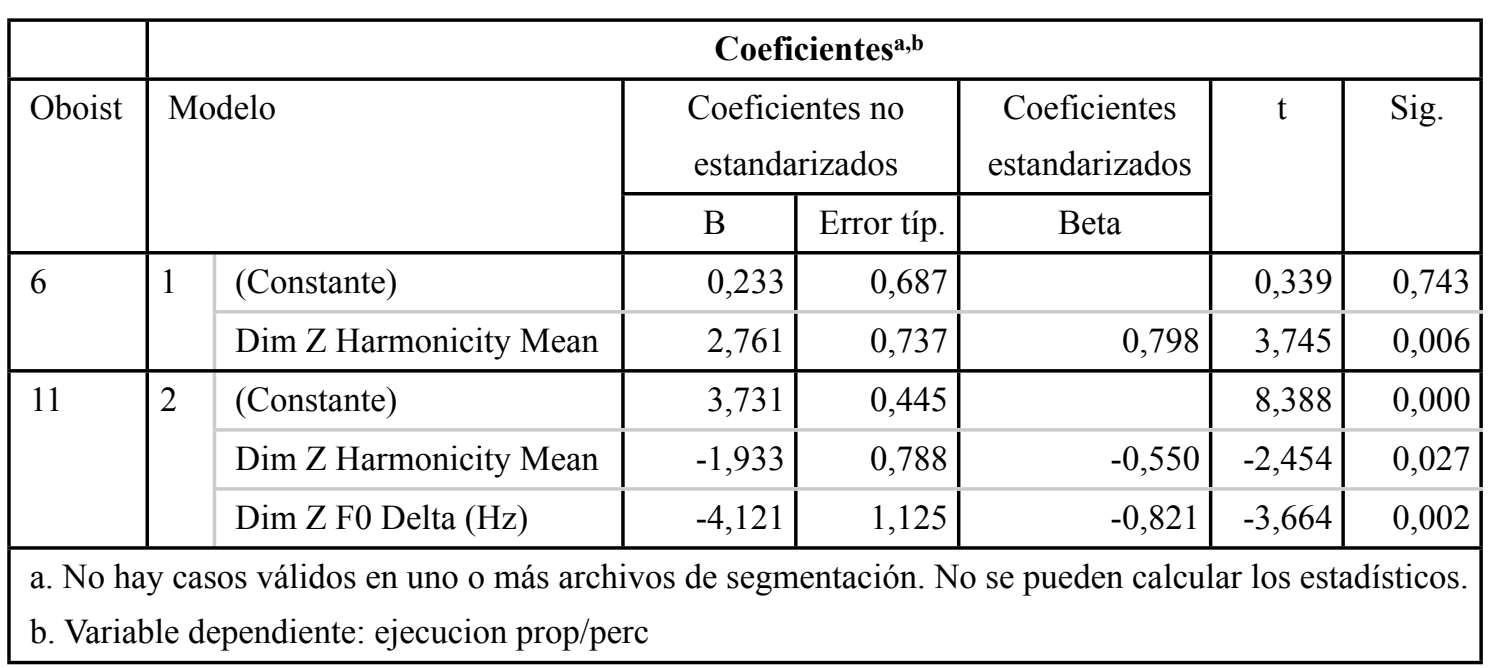

Tabla 4.79. Resumen del modelo (arriba) y coeficientes de las variables predictoras de la regresión de la variable dependiente "ejecución en la autoevaluación auditiva del diminuendo" con todos los parámetros acústicos separados por oboístas. Se muestran los que sí tienen influencia sobre la variable dependiente.

\subsection{Calidad sonora del diminuendo}

La calidad de la autoevaluación auditiva del diminuendo consigue explicarse con tres variables acústicas (tabla 4.80): la intensidad (en dB), la desviación estándar de la amplitud y la diferencia de energía de bandas ( $5^{\mathrm{a}}$ justa o 7 semitonos), obteniendo un $\mathrm{R}^{2}$ corregido alto $\left(\mathrm{R}^{2}=, 587\right)$.

Ninguno de los tres parámetros acústicos relacionados con la calidad sonora en la autoevaluación auditiva coinciden con la calidad del diminuendo en la propiocepción. Es más, sólo uno de los tres parámetros, la diferencia de energía de bandas, está ligado con la calidad sonora, ya que tanto la intensidad como su desviación estándar se relacionan con la ejecución. Asimismo, la calidad del diminuendo en la propiocepción sólo está explicada según el delta de la frecuencia (al igual que la facilidad del diminuendo propioceptivo), un parámetro que está ligado a la ejecución interpretativa y no a la valoración de la calidad 
sonora, obteniendo un $\mathrm{R}^{2}$ corregido mucho más bajo que en la autoevaluación auditiva $\left(\mathrm{R}^{2}=, 095\right)$.

\begin{tabular}{|l|c|r|r|c|}
\hline \multicolumn{5}{|c|}{ Resumen del modelo } \\
\hline Modelo & $\mathrm{R}$ & $\mathrm{R}^{2}$ & $\mathrm{R}^{2}$ corregida & $\begin{array}{c}\text { Error típ. de la } \\
\text { estimación }\end{array}$ \\
\hline 3 & 0,776 & 0,602 & 0,587 & 1,150 \\
\hline
\end{tabular}

\begin{tabular}{|c|c|c|c|c|c|c|}
\hline \multicolumn{7}{|c|}{ Coeficientes $^{\mathrm{a}}$} \\
\hline \multirow{3}{*}{\multicolumn{2}{|c|}{ Modelo }} & \multirow{2}{*}{\multicolumn{2}{|c|}{$\begin{array}{l}\text { Coeficientes no } \\
\text { estandarizados }\end{array}$}} & \multirow{3}{*}{ 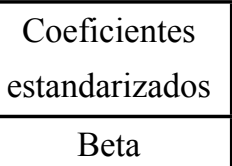 } & \multirow[t]{3}{*}{$\mathrm{t}$} & \multirow[t]{2}{*}{ Sig. } \\
\hline & & & & & & \\
\hline & & B & Error típ. & & & \\
\hline \multirow{4}{*}{3} & (Constante) & 3,195 & 0,140 & & 22,797 & 0,000 \\
\hline & Intensity $(\mathrm{dB}) \operatorname{dim}$ & 2,646 & 0,480 & 1,499 & 5,518 & 0,000 \\
\hline & Amplitude Std Dev dim & $-1,373$ & 0,449 & $-0,835$ & $-3,055$ & 0,003 \\
\hline & Band Energy Diff ( $7 \mathrm{st}$ ) dim & $-0,388$ & 0,140 & $-0,208$ & $-2,775$ & 0,007 \\
\hline \multicolumn{7}{|c|}{ a. Variable dependiente: sonido prop/perc } \\
\hline
\end{tabular}

Tabla 4.80. Resumen del modelo (arriba) y coeficientes de las variables predictoras de la regresión de la variable dependiente "calidad sonora en la autoevaluación auditiva del diminuendo" con todos los parámetros acústicos. Se muestran los que sí tienen influencia sobre la variable dependiente.

\begin{tabular}{|l|c|r|r|c|}
\hline \multicolumn{5}{|c|}{ Resumen del modelo } \\
\hline Modelo & $\mathrm{R}$ & $\mathrm{R}^{2}$ & $\mathrm{R}^{2}$ corregida & $\begin{array}{c}\text { Error típ. de la } \\
\text { estimación }\end{array}$ \\
\hline 1 & 0,326 & 0,106 & 0,095 & 1,389 \\
\hline
\end{tabular}

\begin{tabular}{|c|c|c|c|c|c|c|}
\hline \multicolumn{7}{|c|}{ Coeficientes $^{a}$} \\
\hline \multirow{2}{*}{\multicolumn{2}{|c|}{ Modelo }} & \multicolumn{2}{|c|}{$\begin{array}{l}\text { Coeficientes no } \\
\text { estandarizados }\end{array}$} & \multirow{2}{*}{$\begin{array}{c}\text { Coeficientes } \\
\text { estandarizados }\end{array}$} & \multirow[t]{2}{*}{$\mathrm{t}$} & \multirow[t]{2}{*}{ Sig. } \\
\hline & & B & Error típ. & & & \\
\hline \multirow[t]{2}{*}{1} & (Constante) & 2,771 & 0,159 & & 17,399 & 0,000 \\
\hline & F0 Delta $(\mathrm{Hz}) \operatorname{dim}$ & $-0,760$ & 0,246 & $-0,326$ & $-3,084$ & 0,003 \\
\hline
\end{tabular}

Tabla 4.80b. Resumen del modelo (arriba) y coeficientes de las variables predictoras de la regresión de la variable dependiente "calidad del diminuendo" con todos los parámetros acústicos para los cinco oboístas que han realizado la autoevaluación auditiva. Se muestran los que sí tienen influencia sobre la variable dependiente. 


\subsubsection{Discusión}

Cuando los oboístas puntúan si un ejercicio está bien o mal realizado, tanto interpretativa como auditivamente, las respuestas están correlacionadas, dando a entender que saben exactamente qué están valorando en cada ocasión.

Sin embargo, cuando se analiza la relación entre calidad sonora interpretativa y auditiva e incluso cuando se correlaciona con el timbre (tabla 4.76), se observa que no existe una relación directa entre estos parámetros y que tan sólo un oboísta (tabla 4.77) es capaz de correlacionar el timbre interpretativo con el auditivo, pero no con el timbre en general. Paradójicamente, incluso para la evaluación interpretativa del "timbre", se obtiene una significatividad de $p=, 0001$, por consiguiente, se puede afirmar que lo que el oboísta llama "timbre" mientras está probando una lengüeta no tiene mucho que ver con el timbre definido por la psicoacústica o el timbre de la escucha reducida definida por Schaeffer (1977).

Al realizar la comparación de los parámetros acústicos que explican la evaluación interpretativa y la autoevaluación auditiva, los resultados muestran que, tanto en la ejecución como en la calidad sonora, la autoevaluación auditiva obtiene un $\mathrm{R}^{2}$ corregido mayor que la evaluación interpretativa, dando a entender que cuando a los oboístas se les pide que puntúen en la audición centran su atención en más aspectos auditivos que cuando están sólo interpretando.

Además, al igual que ocurría con la evaluación auditiva, cuando los oboístas puntúan la calidad de sonido en la autoevaluación auditiva, sólo uno de los tres parámetros, la diferencia de energía de bandas, está ligado con la calidad sonora, por lo que todo parece indicar que los oboístas privilegian la ejecución interpretativa, quizás por hábito de profesores o intérpretes, o quizás porque la información sonora no permite realmente distinguir entre calidades de sonido. Se ha demostrado en dos experimentos previos que los oyentes no distinguen auditivamente el timbre de las muestras sonoras de diferentes estilos de rebajado, y puede que tampoco exista una información sonora que permita distinguir la calidad del sonido.

En el "timbre propioceptivo" no se trata solamente de escucha causal (Schaeffer, 1977), es decir, de intentar dilucidar lo que ha causado el sonido, sino de ser la propia 
fuente del sonido. Esto puede explicar que los tratados y manuales de oboe insistan tanto sobre la importancia del rebajado en el "timbre", ya que es algo que los oboístas aprecian al interpretar con diferentes lengüetas, y se puede pensar que en este caso los oboístas se refieren a la capacidad de producir sonidos de calidad homogénea en los diferentes registros y con diferentes intensidades, sin tener irregularidades en la producción sonora.

\subsubsection{Conclusiones}

Se puede afirmar que cuando los oboístas puntúan interpretativamente la calidad sonora y el timbre, están teniendo en cuenta más el comportamiento global de las lengüetas y la conexión de éstas con ellos mismos que la evaluación puramente auditiva de los ejercicios interpretados.

En resumen, se concluye que existe una gran importancia del estilo de rebajado para el intérprete en el momento de ejecutar ejercicios precisos, ya que tiene una influencia marcada en la elasticidad y rigidez de la lengüeta y en su comportamiento global, pero esta importancia no se encuentra en el timbre o en el sonido producido, a pesar de la insistencia que tienen los teóricos e intérpretes del oboe en afirmar que los diferentes estilos de rebajado provocan cambios en el timbre. 
5. Discusión general y conclusiones 


\subsection{Discusión general}

\subsubsection{Percepción tímbrica}

En el experimento preliminar se ha podido ver cómo los diferentes estilos de rebajado no influyen de forma significativa en la percepción de los oyentes. Es más, los resultados obtenidos, sobre todo del escalamiento multidimensional ( $c f$. figura 3.13) muestran que en las frases largas, es decir en los estímulos complejos, los oyentes sí son capaces de asociar los diferentes sonidos, pero no bajo el estilo de rebajado, sino según los diferentes ataques de interpretación y según los diferentes oboístas. Este experimento muestra, además, que los oyentes oboístas no tienen un patrón de escucha diferente a los oyentes no oboístas.

Por otra parte, en el experimento principal, se aumentaron el número de lengüetas (de seis a dieciocho), las variables en la confección de éstas (además del rebajado, el molde y el grosor) y el número de oboístas (de dos a diez), para así poder realizar los experimentos de percepción tímbrica de forma más fina y con un mayor número de muestras. Además, las variables que afectan a la construcción de las lengüetas fueron controladas desde el principio al seleccionar los tubos directamente para la fabricación de las palas, de forma que de estos tubos se obtenían tres palas, una para cada estilo de rebajado.

Así pues, los resultados muestran que en ninguna de las dos tareas realizadas en el experimento principal, los oyentes son capaces de discriminar el timbre de los diferentes estilos de rebajado de las lengüetas, de los moldes o de los grosores utilizados, corroborándose los resultados de Russell (1953) (citado por Fitzgerald, 2003) que consideraba que la combinación del intérprete, del tipo de lengüeta y del instrumento utilizado era lo que hacía diferenciar a los oyentes los timbres en las interpretaciones oboísticas. Es más, mientras que en la primera tarea sólo había un instrumentista, en la segunda se introdujeron hasta cinco oboístas diferentes, siendo este parámetro el único que fueron capaces de discriminar los oyentes, confirmándose los resultados de Snitkin (1975) (citado por Fitzgerald, 2003) que concluyó que las características de calidad de sonido de cada oboísta eran más perceptibles para el oyente que las propiedades de la lengüeta. 


\subsubsection{Estudio acústico}

Los resultados muestran en el experimento preliminar que las diferencias intrínsecas de cada lengüeta predominan en las mediciones acústicas realizadas. Si bien es cierto que en las mediciones del timbre (Kurtosis y Skewness) aparecen diferencias según el estilo de rebajado ( $c f$. punto 3.5.3.8) con una distribución de la energía espectral en la parte grave y media y unos formantes más marcados para las lengüetas alemanas, correspondiéndose a su timbre grave y apagado, como norma general, la lengüeta alemana 2 se diferencia del resto de lengüetas y las lengüetas francesa 2 y americana 2 se parecen más entre sí que entre las lengüetas de su misma escuela.

Al realizar las mediciones acústicas en el experimento principal, los resultados muestran que el estilo de rebajado influye en todos los parámetros acústicos estudiados, aunque el oboísta es el factor que más influye, con excepción de la frecuencia media.

Así pues, en las mediciones acústicas de la afinación y su estabilidad se observa que el rebajado americano es el que mayor frecuencia media obtiene respecto al alemán y al francés ( $c f$. figura 4.19) siendo el rebajado alemán el más estable y el francés el más inestable ( $c f$. figura 4.27). La figura 5.1 resume las mediciones de la frecuencia media y de la desviación estándar obtenidas por todas las lengüetas. En ella se puede observar que las lengüetas francesas con el molde 168 son las que mayor inestabilidad producen en la afinación y, por consiguiente, las que menor frecuencia media obtienen, siendo las alemanas las más estables en afinación y las americanas las que mayor frecuencia media logran, confirmándose así los resultados obtenidos en el análisis de datos. Cabe recordar, que el molde 168 se eliminó de los análisis de la frecuencia y su estabilidad porque provocaba efectos demasiado contrarios a la media por sus características constructivas ( $c f$. punto 4.6.1); en la figura 5.1 puede observarse cómo las dos lengüetas francesas con el molde 168 son las que se desvían considerablemente de la media, tal y como ocurría en las figuras 4.16, 4.17 y 4.18. Al contrario de lo que sucedía en el experimento preliminar, estas diferencias de afinación no se deben a las particularidades de las lengüetas, sino que son los estilos de rebajado los que provocan estas diferencias ( $c f$. figura 4.28). 


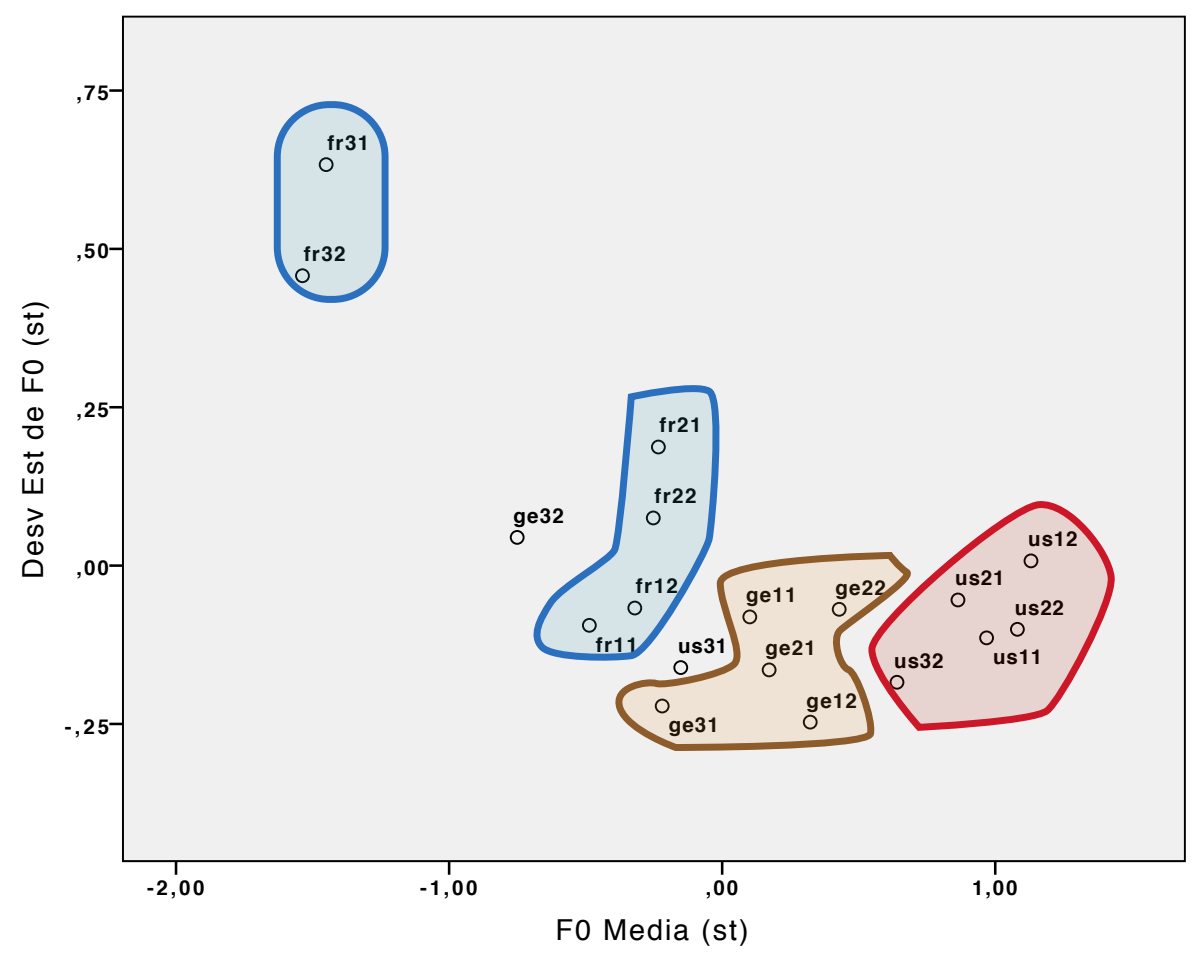

Figura 5.1. Medias de la frecuencia media (en semitonos) y la desviación estándar de la frecuencia (en semitonos) para todas las lengüetas. Las dos primeras letras hacen referencia al rebajado (fr=francés; ge=alemán; us=americano $)$. El primer número hace referencia al molde $(1=21 ; 2=107 ; 3=168)$ y el segundo número al grosor $(1=57 \mathrm{~mm} ; 2=59 \mathrm{~mm})$.

Los resultados de las mediciones acústicas referentes a la intensidad y su estabilidad presentan a las lengüetas francesas como las que menor intensidad obtienen ( $c f$. figura 4.34) y las que mayor estabilidad en la intensidad logran ( $c f$. figura 4.41). La figura 5.2 resume las mediciones de la intensidad y la desviación estándar de la amplitud. Se observa que la lengüeta que mayor intensidad consigue es la americana con molde 21 y grosor $59 \mathrm{~mm}$, siendo una de las más inestables, sólo superada por la alemana con molde 21 y grosor $59 \mathrm{~mm}$. Así pues, como norma general, las francesas suelen ser las que menor intensidad consiguen, pero estas mediciones acústicas sí están influenciadas por las particularidades de las lengüetas, más que por la escuela de rebajado ( $c f$. figura 4.35) 


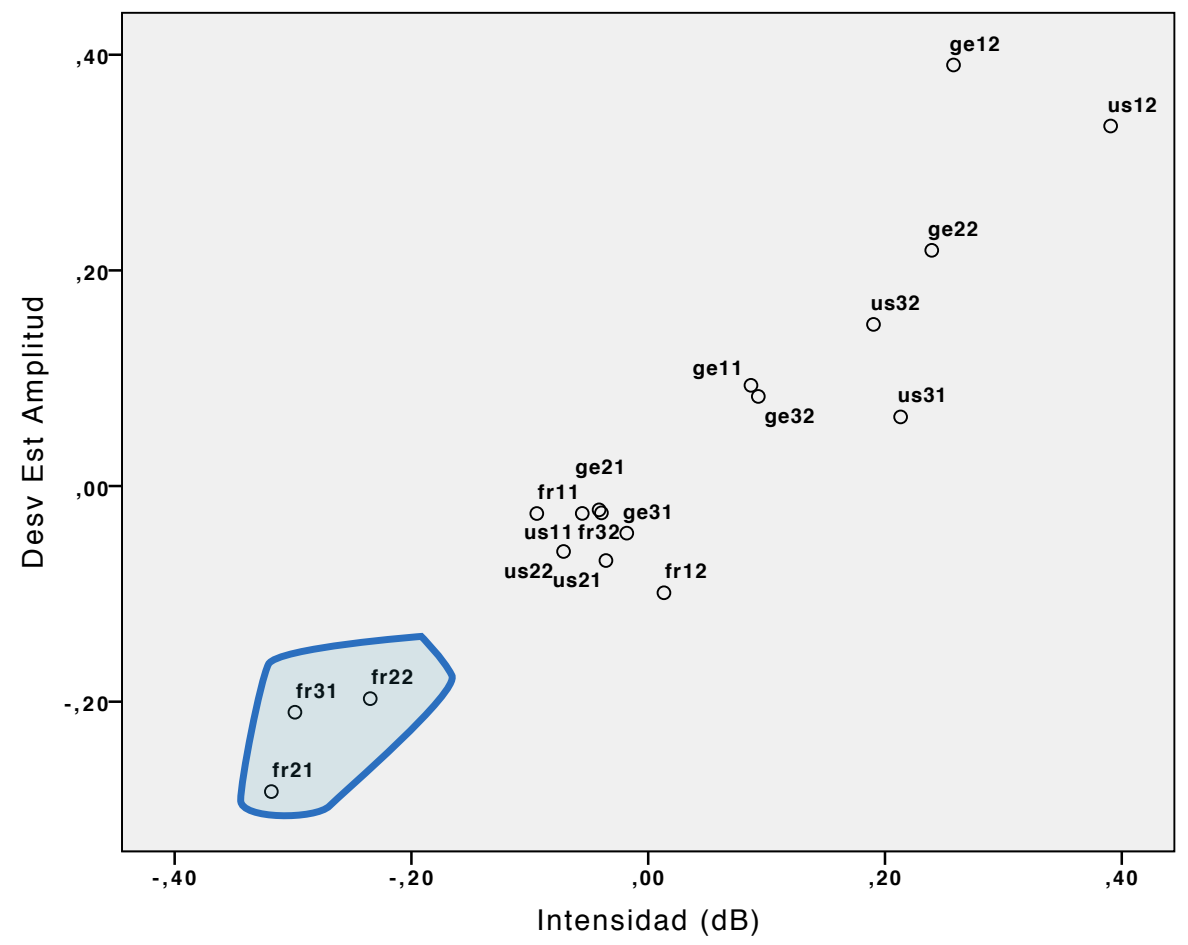

Figura 5.2. Medias de la intensidad (en dB) y la desviación estándar de la amplitud para todas las lengüetas. Las dos primeras letras hacen referencia al rebajado ( $\mathrm{fr}=$ francés; ge=alemán; us=americano). El primer número hace referencia al molde $(1=21 ; 2=107 ; 3=168)$ y el segundo número al grosor $(1=57 \mathrm{~mm} ; 2=59$ $\mathrm{mm})$.

Las mediciones acústicas de la armonicidad y su estabilidad evidencian que las lengüetas alemanas son las más armónicas (cf. figura 4.48) y las francesas las más inestables, ya que son las que mayores desviaciones armónicas producen ( $c f$. figura 4.52). La figura 5.3 resume estas mediciones acústicas y muestra cómo las lengüetas alemanas y americanas son las más armónicas, en especial sobresale la alemana con molde $107 \mathrm{y}$ grosor $57 \mathrm{~mm}$, y las francesas son las que mayor desviación de la armonicicdad obtienen. Cabe destacar que tanto para la armonicicdad como para la desviación estándar de ésta, los resultados no se deben a las particularidades de las lengüetas, sino a las escuelas de rebajado (cf. figura 4.53). 


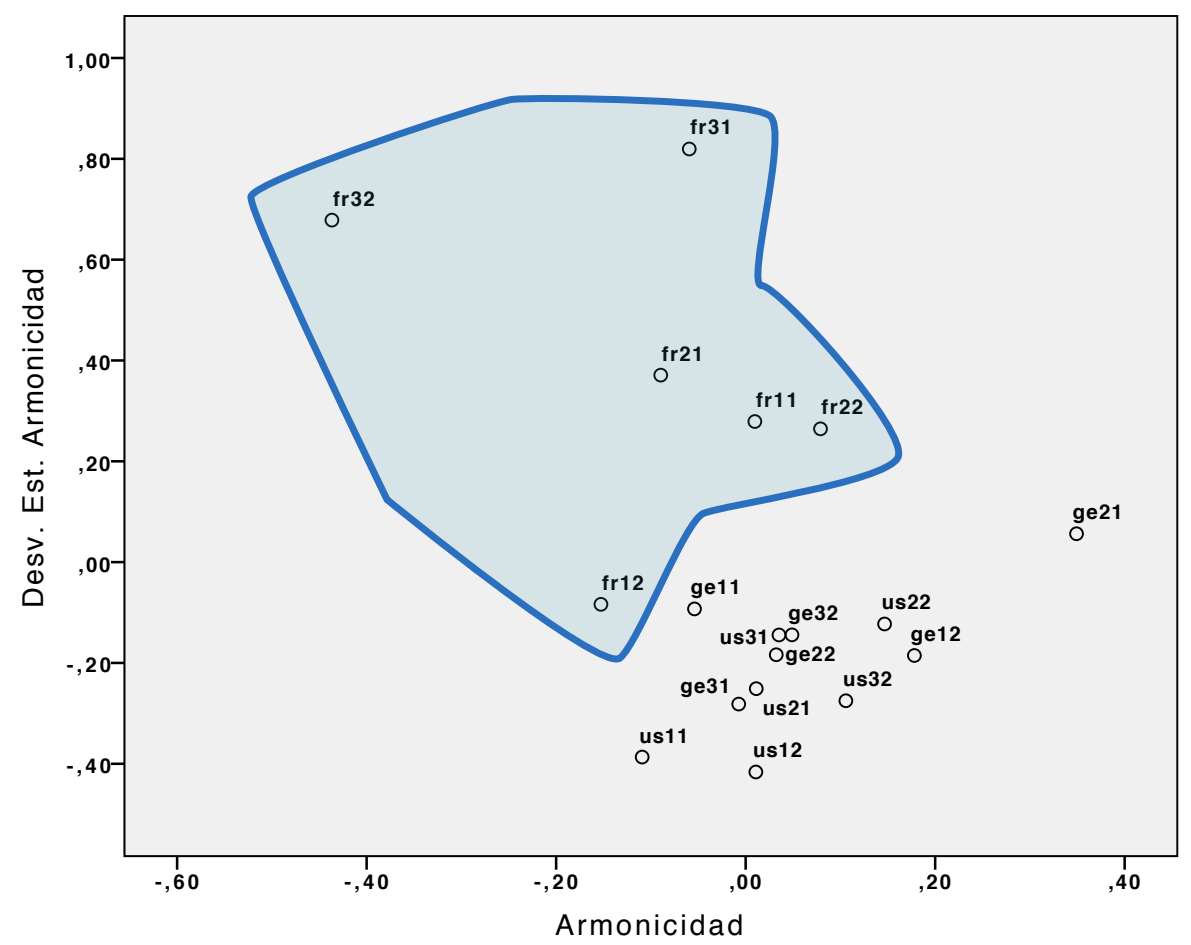

Figura 5.3. Medias de la armonicidad y la desviación estándar de la armonicidad para todas las lengüetas. Las dos primeras letras hacen referencia al rebajado ( $\mathrm{fr}=$ francés; ge=alemán; us=americano). El primer número hace referencia al molde $(1=21 ; 2=107 ; 3=168)$ y el segundo número al grosor $(1=57 \mathrm{~mm} ; 2=59 \mathrm{~mm})$.

Los resultados de los parámetros relativos al timbre revelan que las lengüetas francesas son las que menor diferencia de energía por bandas obtienen creando un sonido con menos cuerpo que las alemanas y las americanas ( $c f$. figura 4.56). Además, las lengüetas americanas consiguen un centro espectral más agudo que indica un espectro más rico en frecuencias agudas o un sonido más brillante, mientras que las francesas obtienen un sonido más apagado, ya que tienen el centro de gravedad con poca energía en la parte aguda del espectro ( $c f$. figura 4.61). La figura 5.4 resume las mediciones de los parámetros relativos al timbre y confirma los resultados obtenidos en los análisis, destacando la lengüeta americana con molde 21 y grosor $59 \mathrm{~mm}$ como la lengüeta con más cuerpo y más rica en frecuencias agudas. 


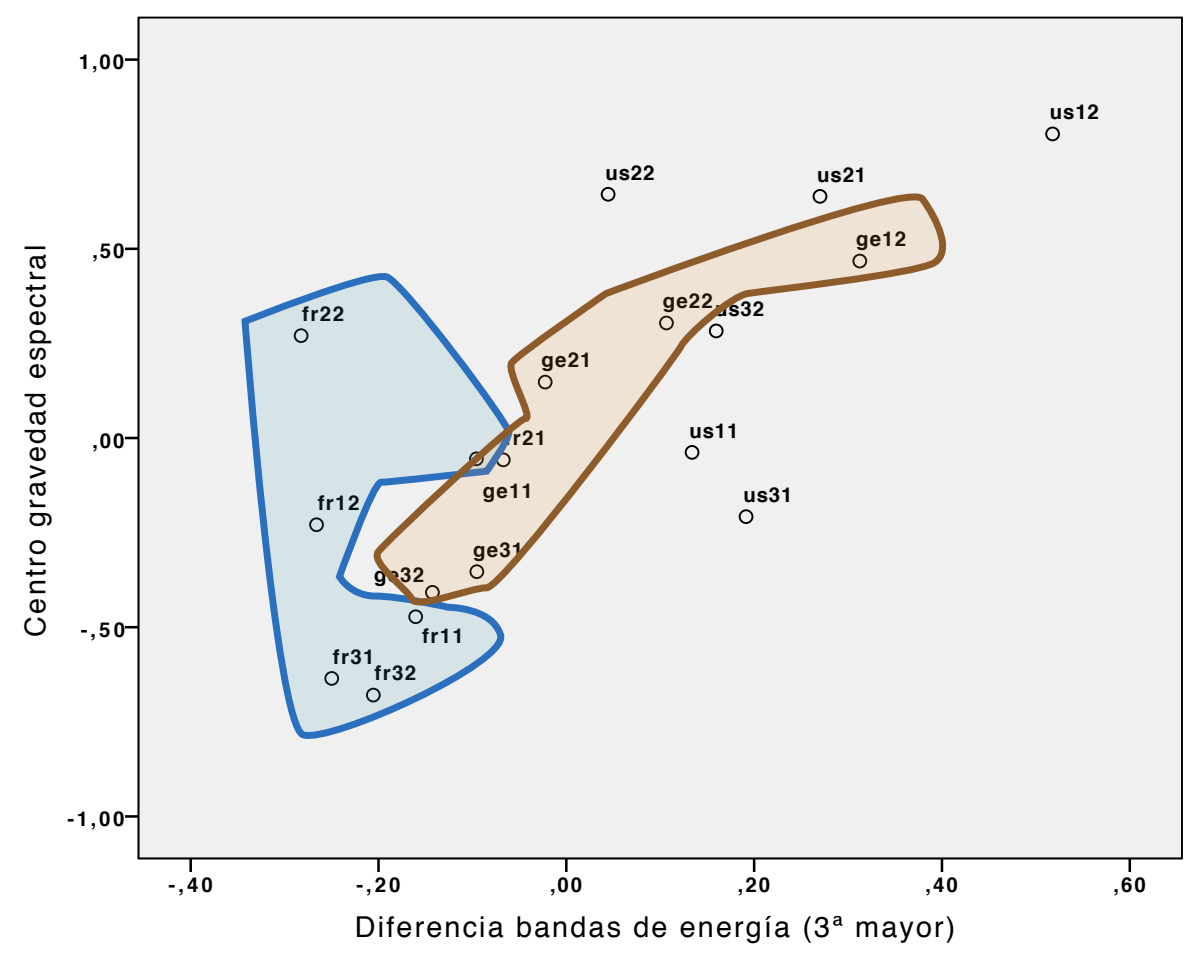

Figura 5.4. Medias de la diferencia de bandas de energía ( $3^{\mathrm{a}}$ mayor) y el centro de gravedad espectral para todas las lengüetas. Las dos primeras letras hacen referencia al rebajado ( $\mathrm{fr}=$ francés; ge=alemán; us $=$ americano $)$. El primer número hace referencia al molde $(1=21 ; 2=107 ; 3=168)$ y el segundo número al grosor $(1=57 \mathrm{~mm} ; 2=59 \mathrm{~mm})$.

Por otra parte, los resultados que analizan las dimensiones físicas de las lengüetas están relacionados con las características atribuidas a los diferentes estilos de rebajado. Así pues, los análisis realizados demuestran que la relación entre el grosor de la punta y la superficie de rebajado tienen una influencia en las mediciones acústicas de la frecuencia y su estabilidad ( $c f$. tabla $4.3 \mathrm{~b}, 4.4 \mathrm{~b}$ y $4.5 \mathrm{~b}$ ). Para las mediciones de la intensidad y su estabilidad son más influyentes los componentes de la parte de atrás de las lengüetas que los grosores individuales de la punta ( $c f$. tabla $4.6 \mathrm{~b}$ y $4.7 \mathrm{~b}$ ). Y en las mediciones del timbre, influye más la superficie del rebajado en general que las medidas individuales tanto de la punta como del corazón o de la parte de atrás ( $c f$. tabla 4.10b y 4.11b).

Finalmente, el molde y el grosor también influyen en las mediciones acústicas realizadas. La superficie de vibración de las lengüetas depende, además de la forma del rebajado, de su contorno externo, contorno que le aporta los diferentes moldes existentes. Así pues, la superficie de vibración es muy importante para la realización de los diferentes ejercicios, por lo que el análisis de datos muestra que el molde influye en todos los parámetros excepto en la frecuencia (al haber eliminado el molde 168 por la gran diferencia que provoca respecto a los otros dos moldes utilizados). Sin embargo, el grosor 
influye en la cantidad de madera restante en las lengüetas después de haber sido rebajadas, por lo que una lengüeta con un grosor de $57 \mathrm{~mm}$ tendrá una superficie de vibración más delgada que otra lengüeta con un grosor de $59 \mathrm{~mm}$. Así pues, el análisis de datos demuestra que el grosor influye en menor medida que el rebajado, los oboístas y el molde, siendo el grosor $59 \mathrm{~mm}$ el más rico en el sonido producido y el que mayor estabilidad ofrece en la afinación y en la intensidad.

\subsubsection{Evaluación interpretativa y auditiva}

El estudio de la evaluación interpretativa y auditiva se propone para el experimento principal a raíz de los resultados obtenidos en el experimento preliminar y principal sobre la percepción tímbrica. Es decir, si los tratados del oboe y los oboístas en general afirman que los diferentes tipos de rebajado influyen en el timbre del oboe ( $c f$. punto 1.1.3) y los resultados perceptivos de esta tesis indican lo contrario, cabe estudiar si lo que los oboístas consideran un cambio de timbre no es sino una sensación propioceptiva de las diferentes lengüetas a la hora de interpretar.

Los resultados muestran que en la evaluación interpretativa los oboístas obtienen una gran concordancia en las respuestas para la facilidad de ejecución, calidad del sonido, flexibilidad, rigidez y calidad general de cada lengüeta. Cabe destacar que en esta ocasión, las diferentes escuelas de rebajado sí influyen de forma significativa en las puntuaciones sobre la flexibilidad, la rigidez, la facilidad de ejecución de los arpegios y de los legati (cf. 4.43) y el escalamiento multidimensional realizado sobre las respuestas dadas por los oboístas ( $c f$. figuras 4.88, 4.89, 4.90, 4.91 y 4.92) corroboran la influencia de las escuelas de rebajado en las puntuaciones, ya que se puede vislumbrar el tipo de rebajado como una de las dimensiones obtenidas. Además, cuando se analizan las respuestas de los oboístas por separado, el escalamiento multidimensional muestra la aparición de una dimensión para la escuela de interpretación alemana ( $c f$. figuras 4.93, 4.94, 4.95 y 4.96), siendo la facilidad de la ejecución el parámetro puntuado donde mejor puede apreciarse esta dimensión $(\mathrm{RSQ}=90 \%)$.

Si se realiza un gráfico donde se unifican y resumen las medias de las respuestas de los oboístas para la facilidad de ejecución y la calidad sonora de todos los ejercicios, se puede observar en la figura 5.5, que se corroboran los resultados de las figuras 4.83 y 4.84 , 
ya que los oboístas consideran las lengüetas francesas como las lengüetas más fáciles y con peor calidad (sobre todo las dos con el molde 168 y la francesa con el molde 107 y grosor $57 \mathrm{~mm}$ ), las alemanas como las de mejor calidad pero más difíciles de interpretar (sobre todo la alemana con molde 21 y grosor $57 \mathrm{~mm}$ ) y las americanas como las de peor calidad y con una facilidad intermedia entre las francesas y las americanas (sobre todo la americana, molde 21 y grosor $59 \mathrm{~mm}$ ).

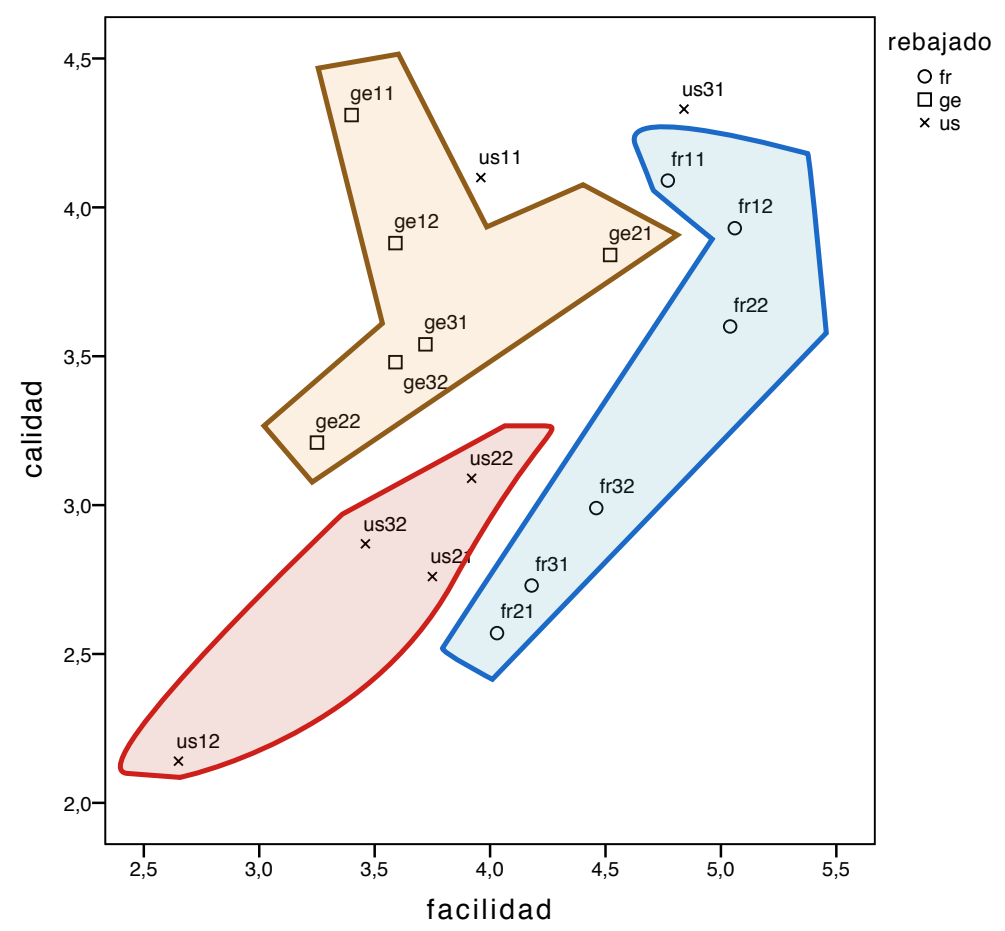

Figura 5.5. Medias de las puntuaciones de los oboístas para la calidad y la facilidad de los cinco ejercicios en función del tipo de rebajado. Se marcan con colores las diferentes escuelas de rebajado. Las dos primeras letras hacen referencia al rebajado ( $\mathrm{fr}=$ francés; ge=alemán; us=americano). El primer número hace referencia al molde $(1=21 ; 2=107 ; 3=168)$ y el segundo número al grosor $(1=57 \mathrm{~mm} ; 2=59 \mathrm{~mm})$.

La figura 5.6 resume y compara las respuestas de los oboístas para la flexibilidad y la rigidez. En ella se ve gráficamente cómo las lengüetas francesas son consideradas las más flexibles y, por consiguiente, las menos rígidas. A su vez, las lengüetas alemanas son las más rígidas, sobre todo respecto a las francesas y las menos flexibles; mientras que las lengüetas americanas obtienen una flexibilidad media y una rigidez alta, pero no tanta como las alemanas. 


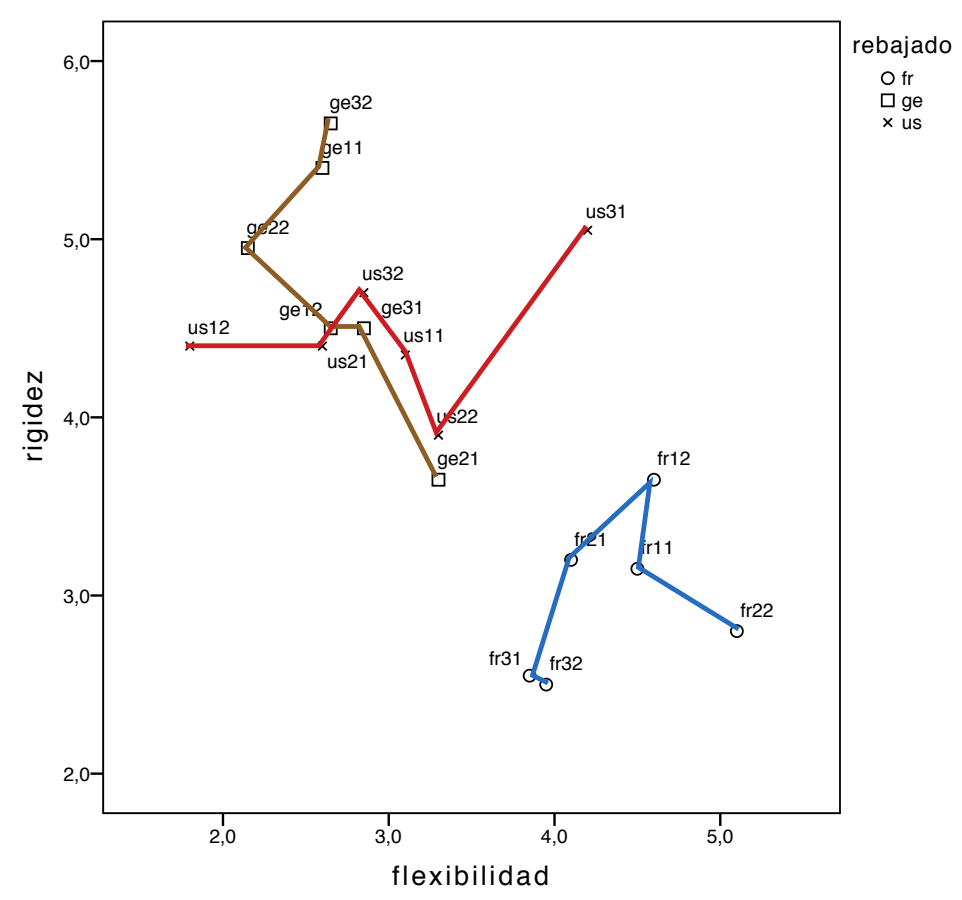

Figura 5.6. Medias de las puntuaciones de los oboístas para la flexibilidad y la rigidez de los cinco ejercicios en función del tipo de rebajado. Se marcan con colores las diferentes escuelas de rebajado. Las dos primeras letras hacen referencia al rebajado (fr=francés; ge=alemán; us=americano). El primer número hace referencia al molde $(1=21 ; 2=107 ; 3=168)$ y el segundo número al grosor $(1=57 \mathrm{~mm} ; 2=59 \mathrm{~mm})$.

En la figura 5.7 se comparan las respuestas dadas para el timbre y la valoración global de las lengüetas. Se puede observar cómo las alemanas son las consideradas con mejor timbre, mientras que las francesas y las americanas están peor valoradas, siendo la lengüeta americana con molde 21 y grosor $59 \mathrm{~mm}$ la peor lengüeta en cuanto a timbre y globalidad general. De forma global, las lengüetas mejor valoradas son las francesas, mientras que las americanas y las alemanas obtienen una puntuación media. 


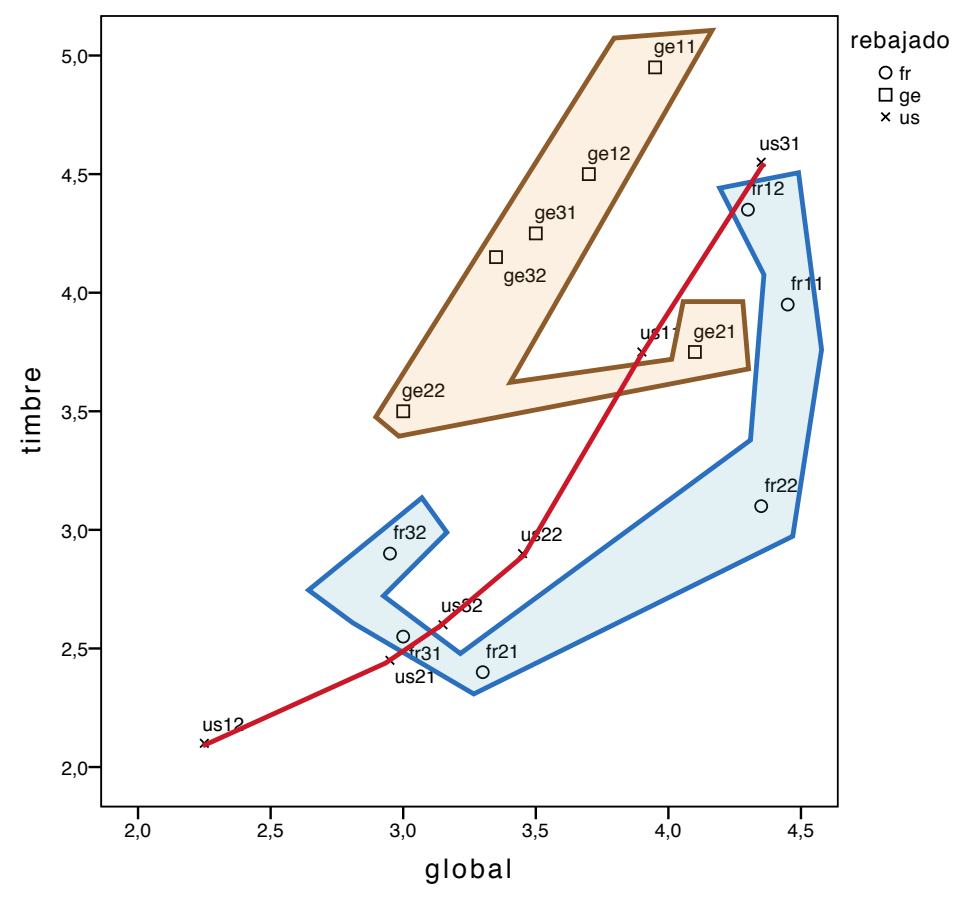

Figura 5.7. Medias de las puntuaciones de los oboístas para la globalidad y el timbre de los cinco ejercicios en función del tipo de rebajado. Se marcan con colores las diferentes escuelas de rebajado. Las dos primeras letras hacen referencia al rebajado ( $\mathrm{fr}=\mathrm{francés;} \mathrm{ge=alemán;} \mathrm{us=americano).} \mathrm{El} \mathrm{primer} \mathrm{número} \mathrm{hace} \mathrm{referencia}$ al molde $(1=21 ; 2=107 ; 3=168)$ y el segundo número al grosor $(1=57 \mathrm{~mm} ; 2=59 \mathrm{~mm})$.

Sin embargo, cuando se analizan los resultados de la evaluación auditiva, se puede observar que el estilo de rebajado no influye en los oboístas intérpretes participantes de este experimento. Se obtiene pues, un contraste muy destacado entre la gran sensibilidad propioceptiva al estilo de rebajado cuando el oboísta usa la lengüeta para producir sonidos, y la ausencia total de percepción del rebajado en la evaluación auditiva del timbre de esos mismos sonidos grabados, aunque sí aparecen diferencias puntuales para algunos oboístas, sobre todo cuando evalúan sus propios ejercicios (tabla 4.71). En una comparación con las teorías de la percepción del habla, existe un enfoque que postula que los oyentes perciben el habla aplicando patrones sobre la señal acústica, y otro enfoque alternativo, la teoría motora de la percepción del habla, que postula que el oyente reconstituye los gestos y las variaciones de posición de los articuladores en el aparato de fonación (Viswanathan et al., 2010). En este caso parece que la valoración de la producción sonora hecha por los oboístas se centra más en la reconstitución del gesto interpretativo, es decir, en la actividad muscular del intérprete, y que dicha actividad es más obvia cuando el oboísta oye lo que él mismo ha producido: en ese caso, la diferenciación del estilo de rebajado de las lengüetas es mayor porque el oboísta-oyente está reviviendo la propiocepción sensorio-motriz del oboísta-ejecutante. 
Por otra parte, cuando se comparan las puntuaciones de la evaluación interpretativa y de la auditiva, los resultados muestran que para la pregunta de facilidad de ejecución, existe una gran correlación entre las dos evaluaciones, mientras que para la pregunta calidad sonora no existe esa correlación entre las dos evaluaciones. Es decir, cuando los oboístas puntúan si un ejercicio está bien o mal interpretado tanto auditivamente como interpretativamente, sí se ponen de acuerdo en sus respuestas y saben qué están contestando; pero cuando puntúan sobre la calidad de un sonido o no tienen claro qué están puntuando o no son capaces de reproducir auditivamente las mismas sensaciones que tuvieron al interpretar, por lo que las respuestas dadas en interpretación no se corresponden a las dadas en audición. Esto confirma el estudio de Geringer y Madsen (1998) que intentaron buscar un patrón de evaluación de los músicos sobre las buenas y las malas interpretaciones, concluyendo que todos los oyentes discriminaban correctamente las buenas y la malas interpretaciones, siendo la afinación el ítem más susceptible en la evaluación, pero no la expresión o la calidad sonora; y la investigación de Wapnick y Ekholm (1997) que concluyeron que los elementos más fiables en la evaluación auditiva de las interpretaciones vocales eran la puntuación global y la precisión de la afinación. Es más, cuando la calidad sonora en la evaluación auditiva se compara también con la puntuación global del timbre de la evaluación interpretativa, tampoco emerge una correlación, es decir, los oboístas no consideran lo mismo el timbre que la calidad sonora.

Finalmente, cabe destacar que cuando se analiza y compara el timbre de la evaluación interpretativa con alguna medición acústica, aparecen dos parámetros acústicos ligados a la ejecución interpretativa (la desviación estándar de la frecuencia y el delta de la frecuencia, $c f$. punto 4.7.5.1.15) y esto es destacable, ya que el timbre es una cualidad del sonido y por lo tanto no debería estar ligada a parámetros de ejecución, por lo que si para los oboístas el timbre sí está ligado a parámetros de ejecución, quizás quiere decir que el timbre propioceptivo es diferente del timbre perceptivo. Por consiguiente, lo que los oboístas consideran timbre del oboe no se trata del timbre definido por la psicoacústica o el timbre de la escucha reducida definida por Schaeffer (1977), sino que más bien cuando describen los cambios de timbre producidos por las lengüetas se están refiriendo a las diferentes sensaciones producidas al interpretar con las distintas lengüetas. 


\subsection{Conclusiones}

Esta tesis aporta un estudio experimental sobre el timbre del oboe y, más concretamente, la influencia de las lengüetas del oboe en el timbre del instrumento. Realizada bajo un enfoque perceptivo, acústico y propioceptivo, esta investigación explica el comportamiento de las lengüetas del oboe dentro de un campo interdisciplinar. La correcta realización de los diferentes tipos de rebajado en las lengüetas del oboe, así como de los experimentos empleados, ha sido uno de los principales objetivos tenidos en cuenta desde el principio. Además, se ha combinando en todo momento un conjunto de diferentes factores a tener en cuenta en la investigación: diversos intérpretes, instrumentos, estilos de rebajado, escuelas de interpretación, grosores y moldes de palas, etc.

Después de la realización de los experimentos de percepción tímbrica se concluye que las diferentes escuelas de rebajado no influyen en la percepción de los oyentes, contradiciéndose estos resultados a los tratados de oboe (Brod, 1830; Rothwell, 1979) que recomiendan uno u otro sonido dependiendo del tipo de rebajado utilizado. Aunque en el experimento preliminar aparecieron ciertas diferencias en el timbre del oboe causadas por los estilos de rebajado, esas diferencias se debieron más a las particularidades de las lengüetas entre sí que a las diferencias otorgadas por los estilos de rebajado, es decir, existían más diferencias entre las dos lengüetas alemanas utilizadas, que entre una lengüeta alemana y otra francesa, por poner un ejemplo. En el experimento principal, se limitaron al máximo esta particularidades de las lengüetas y se corroboraron los resultados obtenidos: los oyentes no fueron capaces de discriminar las diferencias tímbricas atribuidas por los tratados del oboe y los oboístas en general a las escuelas de rebajado.

El estudio acústico realizado sobre todas las lengüetas determina que el estilo de rebajado influye en todas las mediciones acústicas realizadas. Destaca sobre todo en la frecuencia media, siendo el factor más significativo por delante del oboísta, no existiendo en esta ocasión las particularidades intrínsecas de las lengüetas, sino que son los diferentes estilos de rebajado en su conjunto los que proporcionan las diferencias acústicas, siendo las lengüetas americanas las que se caracterizan por tener una afinación más estable y las francesas una afinación más inestable. El molde y el grosor también influyen en el estudio acústico, pero con una significatividad menor que el oboísta y el rebajado. Mientras que el 
molde influye en todos los parámetros excepto en los ligados a la frecuencia y su estabilidad y a la diferencia de energía por bandas, el grosor lo hace en todos los parámetros excepto en la desviación estándar de la frecuencia, en la armonicidad media y en las diferencias de energía por bandas.

El estudio interpretativo se basa en la puntuación de diferentes aspectos ligados a la ejecución y a la calidad sonora de los ejercicios interpretados. Los resultados determinan que el estilo de rebajado influye en estas puntuaciones y que, además, los oboístas de la escuela de interpretación alemana contestan de forma similar a estas respuestas, sobre todo las correspondientes a la facilidad de los ejercicios. En general, los oboístas se ponen de acuerdo en valorar el comportamiento de una lengüeta en cuanto a su flexibilidad, rigidez y equilibrio, con lo que se puede establecer que son parámetros mensurables que significan lo mismo para diferentes oboístas. Para la pregunta equilibrio, timbre y puntuación global, las lengüetas peor valoradas son las americanas, mientras que las lengüetas francesas se caracterizan por ser las más flexibles y las mejor valoradas globalmente y las alemanas por ser las más rígidas y las mejor puntuadas en el timbre. Se obtiene una correlación muy fuerte entre la facilidad del arpegio y la facilidad del legato, así como entre la calidad del arpegio y la calidad del legato, seguramente porque los dos ejercicios son los más largos y los únicos que abarcan todo el registro del oboe.

El estudio auditivo se realiza a partir de las grabaciones realizadas por los oboístas, de forma que algunos oboístas intérpretes puntúan sus propios sonidos (autoevaluación auditiva) y los de los representantes de la escuela de interpretación francesa y alemana (evaluación auditiva) respondiendo a las preguntas de calidad de ejecución y calidad sonora del ejercicio escuchado. Los resultados muestran que los diferentes estilos de rebajado no influyen de forma significativa ni en la evaluación auditiva ni en la autoevaluación auditiva, corroborándose así los resultados obtenidos en los experimentos de percepción tímbrica: los diferentes estilos de rebajado no provocan diferencias significativas en la percepción de los oyentes, sean oboístas, músicos no oboístas u oboístas intérpretes.

El estudio comparativo entre la evaluación interpretativa y la autoevaluación auditiva intenta averiguar si los oboístas intérpretes son capaces de dar la misma puntuación cuando interpretan un ejercicio y cuando lo escuchan, tanto en la ejecución 
como en la calidad sonora. El análisis de los resultados concluye que los oboístas evaluadores se ponen de acuerdo, aunque no completamente, consigo mismos cuando puntúan la ejecución del ejercicio, pero no cuando puntúan la calidad del sonido.

Para averiguar si existe algún parámetro acústico que pueda explicar las puntuaciones obtenidas de los oboístas en la evaluación interpretativa y en la evaluación y autoevaluación auditiva, se realiza una serie de análisis. Los resultados muestran que siempre existe algún parámetro acústico que explique las puntuaciones dadas por los oboístas, tanto interpretativa como auditivamente. Cabe destacar que, mientras en la evaluación interpretativa la calidad sonora parece obtener un patrón de respuesta claro en todos los ejercicios (excepto en el fortissimo) mediante la armonicidad media, en la evaluación y autoevaluación auditiva los parámetros acústicos relacionados, como por ejemplo el delta de la frecuencia, poco tiene que ver con la calidad del sonido, sino más bien con la ejecución interpretativa, por lo que todo parece indicar que los oboístas privilegian la ejecución interpretativa, quizás por hábito de profesores o intérpretes, o quizás porque la información sonora no permite realmente distinguir entre calidades de sonido. Además, al realizar la comparación de los parámetros acústicos que explican la evaluación interpretativa (sólo de los cinco oboístas que han realizado también la autoevaluación auditiva) y la autoevaluación auditiva, los resultados muestran que, tanto en la ejecución como en la calidad sonora, la autoevaluación auditiva obtiene un $\mathrm{R}^{2}$ corregido mayor que la evaluación interpretativa, dando a entender que cuando a los oboístas se les pide que puntúen en la audición centran su atención en más aspectos auditivos que cuando están sólo interpretando.

En conclusión, esta tesis parte de la hipótesis de los tratados del oboe, tanto antiguos como actuales, y la experiencia de los oboístas que afirman que los diferentes estilos de rebajado de las lengüetas influyen en el timbre, siendo capaces los oboístas de percibir estas diferencias tímbricas y, en consecuencia, elegir la lengüeta que más agrada a la hora de interpretar uno u otro repertorio.

Cabe destacar, pues, que ningún tratado ni estudio consultado, realiza una experiencia científica para poder corroborar si, efectivamente, las diferentes escuelas de rebajado poseen características tímbricas capaces de ser percibidas por los oyentes o, si los estilos de rebajado proporcionan diferencias interpretativas capaces de ser medidas por 
parámetros acústicos o, si estas diferencias en los rebajados de las lengüetas proporcionan diferentes sensaciones en los oboístas a la hora de interpretar con cada una de ellas. Es más, Ledet (2008) realizó un estudio pormenorizado de las lengüetas de los principales solistas y profesores internacionales del oboe, agrupándolos por escuelas de interpretación y comparando sus lengüetas, aunque con la única finalidad de ilustrar la gran variedad de lengüetas existentes entre los oboístas.

Los resultados del experimento de percepción tímbrica son completamente contrarios al pensamiento de los oboístas consultados, así pues, si los oboístas creen que son capaces de discriminar las diferencias en los timbres que, según ellos, aportan los estilos de rebajado pero en la experiencia auditiva no pueden discriminar estas diferencias, quizás lo que los oboístas notan son diferencias en la propiocepción a la hora de interpretar con las lengüetas, es decir, diferencias en las sensaciones otorgadas por una $\mathrm{u}$ otra lengüeta.

Además, es necesario remarcar, que en la práctica oboística real, cuando se comparan unas lengüetas se realiza interpretando fragmentos musicales, es decir, sonidos complejos, pero nunca sonidos simples de igual intensidad, duración y altura, por lo que los oboístas cuando creen comparar el timbre de las lengüetas, no están comparando el timbre propiamente dicho, sino que realmente están escuchando y comparando componentes de interpretación.

Por consiguiente, esta investigación llega a la conclusión de que los diferentes estilos de rebajado influyen en las mediciones acústicas y en las evaluaciones interpretativas de los oboístas, pero nunca en las evaluaciones auditivas: ni cuando se trata de distinguir los diferentes timbres ni cuando se evalúa la calidad sonora de los ejercicios. Así pues, el tiempo y esfuerzo dedicado por los oboístas en el perfeccionamiento de los rebajados de las lengüetas está justificado, no por las diferencias tímbricas que ofrecen estos rebajados, sino por las diferencias propioceptivas que son necesarias para la interpretación del oboe, es decir, la relación existente entre el sonido producido y el sonido escuchado por el oboísta.

Esta tesis ha ampliado las investigaciones sobre las lengüetas del oboe en general, demostrando la compleja interacción perceptiva, propioceptiva y acústica del comportamiento de las lengüetas del oboe. 
6. Referencias bibliográficas 


\subsection{Bibliografía}

Acevedo, M. (2003). La percepción sinestésica, vínculos entre lo auditivo y lo visual. Música y educación, 16, 109-121.

Agos-Esparza, A., Elejalde-García, M. J. y Macho-Stadler, E. (2008). Study the mouthpiece of the txistu. J. Acoust. Soc. Am., 23 (5), 3662.

Agulló, J. y Barjau, A. (1990). On the excitation mechanism in reed wind instruments. $J$. Acoust. Soc. Am., 87 (S1), S137.

Aiello, R. y Williamon, A. (2002). Memory. En R. Parncutt y G. E. McPherson (Eds.), The Science and Psychology of Music Performance. Creative Strategies for Teaching and Learning, 167-181. New York: Oxford University Press.

Almeida, A., Vergez, C. y Caussé, R. (2007). Quasistatic nonlinear characteristics of double-reed instruments. J. Acoust. Soc. Am., 121 (1), 536-546.

Allen, D . R., and Strong, W. J. (1985). A model for the synthesis of natural sounding vowels. J . Acoust. Soc. Am., 78, 58-69.

Anderson, T. (1996). Handmaking clarinet reeds: New tools accelerate the process. $J$. Acoust. Soc. Am., 99 (4), 2462-2500.

Andraud, A. (1976). Practical and Progressive Oboe Method, Reedmaking, Melodious and Technical Studies. San Antonio: Southern Music Co.

Artley, J. (1968). How to Make Double Reeds. Old Greenwich: Jack Spratt.

Atig, M., Dalmont, J.-P., y Gilbert, J. (2004). Saturation mechanism in clarinet-like instruments, the effect of the localized non-linear losses. Appl. Acoust. 65, 1133-1154.

Avanzini, F. (2002). Efficiency, accuracy, and stability issues in discrete-time simulations of single reed wind instruments. J. Acoust. Soc. Am., 111 (5), 2293-2301.

Ayers, R.D., y Nordquist, P.R. (2009). Tuning and tone quality of bagpipe drones. $J$. Acoust. Soc. Am., 125 (4), 2652-2652.

Backus, J. (1963). Small-vibration theory of the clarinet. J. Acoust. Soc. Am., 35, 305-313.

Backus, J. (1966). Clarinet-Reed Parameters. J. Acoust. Soc. Am., 39 (6), 1220-1220.

Backus, J. (1974). Input Impedance Curves for Reed Instruments. J. Acoust. Soc. Am., 55 (2), 457.

Backus, J. (1985). The effect of the player's vocal tract on woodwind instrument tone. $J$. Acoust. Soc. Am., 78 (1), 17-20.

Baines, A. (1991). Woodwind Instruments and Their History ( $5^{\mathrm{a}}$ ed.). Mineola: Dover Publications ( $1^{\text {a }}$ ed. 1957). 
Bate, P. (1975). The oboe ( $3^{\mathrm{a}}$ ed.). Londres: Ernest Benn Limited ( $1^{\mathrm{a}}$ ed. 1956).

Baumgart, J., Grothe, T., y Grundmann, R. (2008). Influence of the bocal on the sound of the bassoon. J. Acoust. Soc. Am., 123 (5), 3016.

Beauchamp, J.W. (1999). A comparison of wind instrument time-variant spectra. J. Acoust. Soc. Am., 105 (2), 938-938.

Behrens, S.L., Coyle, W.L., Goodweiler, N.P., y Cottingham, J.P. (2009). Vibrational modes of accordion reeds" J. Acoust. Soc. Am., 126 (4), 2216.

Benade, A. H. y Gaas, D. J. (1968). Sound production in wind instruments. Ann. N.Y. Acad. Sci. 155, 247-263.

Benade A. H. y Gebler, J. M. (1974). Reed Cavity and Neck Proportions in Conical Woodwinds. J. Acoust. Soc. Am., 55 (2), 458.

Benade, A. H. y Hoekje, P. L. (1982). Vocal tract effects in wind instrumeats. J. Acoust. Soc. Am., Suppl. 1 71, S91.

Benade, A. H. (1983). Air column, reed, and player's windway interaction in musical instruments. In VocalFold Physiology, edited by I. R. Titze and R. C. Scherer (The Denver Center for the Performing Arts, Denver, CO), 425-452.

Benade, A. H. y Richards, W. B. (1983). Oboe normal mode adjustment via reed and staple proportioning. J. Acoust. Soc. Am., 73 (5), 1794-1803.

Benade, A. H. y Kouzoupis, S. N. (1985). Spectral envelopes of orchestral instruments. $J$. Acoust. Soc. Am., 78 (S1), S75.

Barret, A. M. R. (1850). A Complete Method for Oboe. Londres: Jullien and Co.

Bartllet, L. W. (1990). Reed Longevity. Double Reed, 13:1.

Bergee, M.J. y McWhirter, J.L. (2005). Selected Influences on Solo and Small-Ensemble Festival Ratings. Replication and Extension. Journal of Research in Music Education, 53 (2), 177-190.

Bergee, M.J. y Westfall C.R. (2005). Stability of a Model Explaining Selected Extramusical Influences on Solo and Small-Ensemble Festival Ratings. Journal of Research in Music Education, 53 (4), 358-374.

Bergee, M.J. (2006). Validation of a Model of Extramusical Influences on Solo and SmallEnsemble Festival Ratings. Journal of Research in Music Education, 56 (3), 244-256.

Bergee, M.J. (2007). Performer, Rater, Occasion, and Sequence as Sources of Variability in Music Performance Assessment. Journal of Research in Music Education, 55 (4), 344-358.

Berman, M. (1988). The Art of Oboe Reed Making. Toronro: Canadian Scholar's Press.

Bigotti, G. (1974). Storia dell'oboe. Padova: G. Zanibon. 
Boersma, P. \& Weenink, D. (consulta 2011). Praat: doing Phonetics by Computer. www.praat.org.

Bonar, N. (1983). Different Kinds of Reeds for Different Kinds of Oboists. Double Reed $6: 3$.

Braasch, J., y Ahrens, C. (1999). On the perception of free reed organ pipes. J. Acoust. Soc. Am., 106 (4), 2287-2288.

Brod, H. (1830). Méthode pour le hautbois (Vol 1 y 2). París: Schonenberger.

Broughton, M. y Stevens, K. (2008). It's not just about sound: investigating marimba performance as and auditory and visual experience. Proceedings of the 8th Australasian Piano Pedagogy Conference. Canberra, ACT.

Burgess, G. y Haynes, B. (2004). The Oboe. New Haven y Londres: Yale University Press.

Cahn, D. (2008). The effects of varying ratios of physical and mental practice, and task difficulty on performance of a tonal pattern. Psychology of Music, 36 (2), 179-191.

Cappelli, G. (1853). Metodo teorico-pratico. Milan: Lucca.

Carterette, E. C. y Kendall, R. A. (1996). Acoustical analyses of natural and emulated orchestral instrument signals. Procedings of the 4th International Conference on Music Perception and Cognition, pp. 97-102.

Caswell, D. (1987). Reed Knives. Double Reed 10:2.

Cerone, P. (1613). El Melopeo y maestro, tratado de música theórica y práctica: en que se pone por extenso, lo que uno para hacerse perfecto músico ha menester saber: y por mayor facilidad, comodidad y claridad del lector, está repartido en XXII libros. Van tan exemplificado y claro, que cualquiera de mediana habilidad con poco trabajo, alcançará aquesta profesión. Nápoles.

Chang, A., O'Sullivan, C. (2008). An Audio-Haptic Aesthetic Framework Influenced by Visual Theory, Haptic Audio Interaction Design, HAID 2008, Jyväskylä: Finland.

Chion, M. (1998). La audiovisión. Introducción a un análisis conjunto de la imagen y el sonido. (2 ed.) Barcelona: Paidós.

Confucio (1982). Los cuatro libros. Rev. Joaquín Pérez Arroyo. Madrid: Alfaguara.

Cottingham, J. (2004). The acoustics of the khaen, bawu, and gourd pipe. J. Acoust. Soc. Am., 116 (4), 2619.

Cottingham, J. y Dieckman, E. (2009). Measured and calculated sounding frequencies of pipes coupled with free reeds. Proceedings of Meetings on Acoustics, Vol. 4.

Cox, E. y Rossing, T. D. (2002). Regimes of oscillation and reed vibrations in lingual organ pipes. J. Acoust. Soc. Am., 111 (5), 2395. 
Cuartero, M. y Payri, B. (2010). Tipos de memoria, aptitudes y estrategias en el proceso de memorización de estudiantes de piano. LEEME, Lista Electrónica Europea de Música en la Educación, 24. En línea: http://musica.rediris.es/leeme/revista/ cuarteropayri10.pdf (Consulta: 09-4-2012).

Dahl, O-H. (2001). Better Oboe Reeds. Copenhague: Mediefabrikkens ApS.

Dalmont, J.P., Ducasse, E., y Ollivier, S. (2002). Saturation mechanism in reed instruments. Proceedings of the Third EEA European Congress on Acoustic, Sevilla, Spain.

Dalmont, J.P., Gilbert, J., y Ollivier, S. (2003). Nonlinear characteristics of single-reed instruments: Quasistatic volume flow and reed opening measurements. J. Acoust. Soc. Am. 114 (4), 2253-2262.

Dalmont, J. P. y Gilbert, J. (2005). An analytical prediction of the oscillation and extinction thresholds of a clarinet. J. Acoust. Soc. Am., 117 (4), 3294-3305.

Dalmont, J.P., Gazengel, B., y Kergomard, J. (2006). Scaling of reed instruments: The case of the saxophone family. J. Acoust. Soc. Am., 119 (5), 3259.

D’Ausilio, A., Bufalari, I. Salmas, P. y Fadiga, L. (2011). The role of the motor system in discriminating normal and degraded speech sounds. Cortex, doi:10.1016/j.cortex. 2011.05.017

Davis, A.P. (1998). Performance Achievement and Analysis of Teaching during Choral Rehearsals. Journal of Research in Music Education, 46 (4), 496-509.

Donnadieu, S., McAdams, S. y Winsberg, S. (1994). Caractérisation du timbre des sons complexes. I. Analyses multidimensionelle. Journal de Physique IV, (Colloque C5, supplément au Journal de Physique III, Volume 4):593-596.

Duke, R.A. y Henninger, J.C. (1998). Effects of Verbal Corrections on Student Attitude and Performance. Journal of Research in Music Education, 46 (4), 482-495.

Duste, E. (1984). The American Style Oboe Reed. Double Reed 7:3.

Edelman, G. (1989). The Remembered Present: A Biological Theory of Consciousness. Basic Books, New York.

Eguilaz, Mª J. (2009). La memoria en la interpretación guitarrística. Una aproximación a su problemática. LEEME, Lista Electrónica Europea de Música en la Educación, 24. En línea: http://musica.rediris.es/leeme/revista/eguilaz09.pdf (Consulta: 09-4-2012).

Facchinetti, M.L., Boutillo, X. y Constantinescu, A. (2003). Numerical and experimental modal analysis of the reed and pipe of a clarinet. J. Acoust. Soc. Am., 113 (5), 2874-2883.

Fahrbach, G. (1843). Novissimo Metodo per Oboe di facile intelligenza e colla vista special che server possa alla istruzione de Principianti senza l'ajuto del maestro. Milan: Ricordi. 
Farner, S.; Vergez, Ch.; Kergomard, J. y Lizée, A. (2005). Contribution to harmonic balance calculations of self-sustained periodic oscillations with focus on single-reed instruments. J. Acoust. Soc. Am. 119 (3), 1794-1804.

Feltz, D.L. y Landers, D.M. (1983). The effects of mental practice on motor skill learning and performance: a meta-analysis. J. Sport Exerc. Psych., 5, 25-57.

Feltz, D. L., Landers, D. M. y Becker, B. J. (1988). A Revised Meta-analysis of the Mental Practice Literature on Motor Skills Learning. En D. Druckman y J. A. Swets (Eds.) Enhancing Human Performance: Issues, Theories, and Techniques (Part III, pp. 1-65). Washington, DC: National Academy Press.

Finney, S.A. \& Palmer, C. (2003). Auditory feedback and memory for music performance: Sound evidence for an encoding effect. Memory \& Cognition, 31, 51-64.

Fitzgerald, R. (2003). Performer-dependent dimensions of timbre: identifying acoustic cues for oboe tone discrimination. Ph. D., Leeds: The University of Leeds School of Music.

Fletcher, N.H. y Rossing, T.D. (1998). The Physics of Musical Instruments. New York: Springer-Verlag.

Fox, R. L. (1987). The BFC Cane Treatment or Prolonging and Enhancing the Playing Qualities of Reeds. Double Reed 10:1.

Fritz, C. y Wolfe, J. (2005). How do clarinet players adjust the resonances of their vocal tracts for different playing effects?. J. Acoust. Soc. Am., 118 (5), 3306-3315.

Galvao, A. y Kemp, A. (1999). Kinaesthesia and Instrumental Music Instruction: Some Implications. Psychology of Music, 27, 128-137.

Galvao, A. (2006). Cognição, emoção e expertise musical. Psic.: Teor. e Pesq., 22 (2), 169-174.

Garnier, J. F. (1800). Méthode raisonnée pour le hautbois, contenant les Principes nécessaires pour bien jouer de cet instrument, la maniere de fare les anches suivis de 55 leçons, six petits Duos, sis Sonates, sis Airs variés et une étude pour les doigts et l'arrangement de la Langue. París: Pleyel.

Geringer, J.M. y Madsen, C.K. (1998). Musicians' Ratings of Good versus Bad Vocal and String Performances. Journal of Research in Music Education, 46 (4), 522-534.

Geringer, J.M. y Johnson, C.M (2007). Effects of Excerpt Duration, Tempo, and Performance Level on Musicians' Ratings of Wind Band Performances. Journal of Research in Music Education, 55 (4), 289-301.

Gibson, J. J. (1979). The Ecological Approach to Visual Perception. Boston, MA: Houghton-Mifflin.

Gieseking, W. y Leimer, K. (1932/1972). Piano technique. New York: Dover. 
Gillmeister, H., and Eimer, M. (2007). Tactile enhancement of auditory detection and perceived loudness. Brain Res, 1160, 58-68.

Girard, A. (1983). Le Roseau Chantant: une Introduction a la confection d'anches de hautbois. Basel: Musik-Akademie du Stadt.

Goad, P. J. \& Keefe, D. H. (1986). Timbre discrimination of musical instruments in a concert hall. The Journal of the Acoustical Society of America, 79:1, S1-S96.

Goossens, L. \& Rothwell, E. (1977). Oboe. New York: Schirmer Books.

Grand, N., Gilbert, J., and Laloé, F. (1997). Oscillation threshold of woodwinds instruments. Acustica 1, 137-151.

Grey, J. M. (1975). An exploration of musical timbre. PhD (Report STAN-M-2), CCRMA, Department of Music, Stanford University, CA.

Grey, J. M. (1977): Multidimensional perceptual scaling of musical timbre, The Journal of the Acoustical Society of America, 61 (5):1270-1277.

Grey, J. M. (1978): Timbre discrimination in musical patterns, The Journal of the Acoustical Society of America, 64 (2):467-472.

Hadden, W.J., y Vas-Dias, H. A. (1974). Redevelopment of an eighteenth-century oboe reed. J. Acoust. Soc. Am., 59 (1), S51.

Hajda, J. M., Kendall, R. A., Carterette, E. C. y Harshberger, M. L. (1997). Methodological Issues in Timbre Research, In Perception and Cognition of Music, pp. 253-306. Psychology Press, Hove, UK.

Harris, C.M., Eisenstadt, M. y Welss, M. (1963). Sounds of the Highland Bagpipe. Acoustical Society of America, 1321-1327.

Hash, P.M. (2012). An Analysis of the Ratings and Interrater Reliability of High School Band Contests. Journal of Research in Music Education, 60 (1), 81-100.

Haynes, B. (2001). The Eloquent Oboe. A History of the Hautboy from 1640 to 1760. Nueva York: Oxford University Press.

Heinrich, J. M. (1991). "Recherches sur les propriétés densitométriques du matériau cane de provence et ses similaires étrangers; relation avec laqualité musicale; étude associée d'une mesure de dureté," Technical report, Ministère de la Culture, Direction de la Musique et de la Danse, Paris, France.

Hedrick, P. (1972). Oboe Reed Making. Oneonta: Swift Dorr.

Hennig, L. (2008). Timbre Perception. The Journal of the Acoustical Society of America, 124:4, 2493.

Heptner, T. (1987). Zur Akustik der Oboe: Theoretische Errterungen und Experimentelle Ergegnisse. Tibia, 12 (1), 325-339. 
Hewitt, S. (1991). Thoughts Engendered by the Arrival of "The Reed Maker's Manual" A Review. Double Reed 14:2.

Hewitt, M.P. y Smith, B.P. (2004). The Influence of Teaching-Career Level and Primary Performance Instrument on the Assessment of Music Performance. Journal of Research in Music Education, 52 (4), 314-327.

Highben, Z. y Palmer, C. (2003). Effects of Auditory and Motor Mental Practice in Memorized Piano Performance. Bulletin of the Council for Research in Music Education. En línea: http://www.mcgill.ca/files/spl/bcrme04.pdf (Consulta: 09-4-2012).

Hirschberg, A., Gilbert, J., Wijnands, A. P. J., y Houtsma, A. J. M. (1991). "Non-linear behaviour of single-reed woodwind musical instruments," Ned. Akoestish Genootshap, $107,31-43$.

Hughes, E. (1915). Musical memory in piano playing and piano study. Musical Quarterly, $1,592-603$.

Idogawa, T., Iwaki, M., Naoi, T., y Shimizu, M. (1988). An experimental study on the reed vibrations of the woodwind instruments. J. Acoust. Soc. Am., 84 (S1), S161.

Johnson, M. (1987). The body in the Mind. Chicago: University of Chicago Press.

Jost, E. (1967). Akustische und Psychometrische Untersuchungen an Klarrinettenklängen. Arno Volk, Cologne, Germany.

Juchniewicz, J. (2008). The influence of physical movement on the perception of musical performance. Psychology of Music, 36 (4), 417-427.

Kendall, R. A. y Carterette, E. C. (1991). Perceptual scaling of simultaneous wind instrument timbres. Music Perception, 8(4):369-404.

Kendall, R. A. y Carterette, E. C. (1993a). Verbal attributes of simultaneous wind instrument timbres: I. von Bismarck's adjectives. Music Perception, 10(4):445-468.

Kendall, R. A. y Carterette, E. C. (1993b). Verbal attributes of simultaneous wind instrument timbres: II. Adjectives induced from Piston's orchestration. Music Perception, 10(4):469-502.

Kendall, R. A., Carterette, E. C. y Hajda, J. M. (1999). Perceptual and acoustical features of natural and synthetic orchestral instrument tones. Music Perception, 16(3):327-364.

Kergomard, J., Ollivier, S., and Gilbert, J. (2000). Calculation of the spectrum of selfsustained oscillators using a variable truncation method. Acust. Acta Acust., 86, 685703.

Kinney, D.W. Internal Consistency of Performance Evaluations as a Function of Music Expertise and Excerpt. Journal of Research in Music Education, 56 (4), 322-337. 
Krimphoff, J., McAdams, S. y Winsberg, S. (1994). Caractérisation du timbre des sons complexes. II. Analyses acoustiques et quantification psychophysique. Journal de Physique IV, Colloque C5, (supplément au Journal de Physique III, Volume 4):625628.

Lacy, E. (1988). An Experiment in Treatment of Arundo Donax. Journal of the International Double Reed Society, 16.

Lakatos, S. (2000). A common perceptual space for harmonic and percussive timbres. Perception and Psychophysics, 62(7):1426-1439.

Lakin, J. (1975). A Treatment Process for Oboe Cane. Journal of the International Double Reed Society, 3.

Larson, G. (1983). Oboe Reed Tecnique. Los Angeles: Baxter-Northrup.

Ledet, D. (2008). Oboe Reed and Styles. Theory and Practice (2 $2^{\mathrm{a}}$ ed.). Bloomington: Indiana University Press ( $1^{\mathrm{a}}$ ed. 1981).

Lehrer, C. (1980). A Report from Academia: Reeds for Solo Recitals. Double Reed 2:4.

Light, J. (1983). The Oboe Reed Book. DesMoines: Drake University.

Lindevald, I. M. y Gower, J. (1997). Vibrational modes of clarinet reeds. J. Acoust. Soc. Am., 102 (5), 3085.

Llimerà, V. (2006). El Método de Oboé de Enrique Marzo y Feo (1870). Tesis doctoral. Universidad de Valencia, Valencia.

Mack, J. (1974). Effective Guidance for the Young Oboist. Journal of the International Double Reed Society, 2.

Madsen, K. (2009). Effect of aural and visual presentation modes on Argentine and US musicians' evaluations of conducting and choral performance. International Journal of Music Education, 27 (1), 48-58.

Marandas, E., Gibiat, V., Besnainou, C., and Grand, N. (1994). "Caractérisation mécanique des anches simples d'instruments à vent," 3ième Congrès Français d'Acoustique, Toulouse, Suppl. J. Phys. III, 4, C5, 633-636.

Marzo, E. (1870). Método de Oboé progresivo y completo con nociones de Corno Inglés. Madrid: Antonio Romero.

Matthay, T. (1913). Musical interpretation: Its laws and principles, and their application in teaching and performing. Boston, MA: Boston Music.

Matthay, T. (1926). On memorizing and playing from memory and on the laws of practice generally. Oxford: Oxford University Press.

Mayer, R \& Rohner, T. (1953). Oboe Reeds - How to Make and Adjust Them. Evanston: The Instrumentalist Co. 
McAdams, S. (1993). Recognition of sound sources and events, In Thinking in Sound: The Cognitive Psychology of Human Audition, 148-198. Oxford: Clarendon Press.

McAdams, S. (1999). Discrimination of musical instrument sounds resynthesized with simplified spectrotemporal parameters. J. Acoust. Soc. Am., 105 (2), 882-897.

McAdams, S., Winsberg, S., Donnadieu, S., De Soete, G. y Krimphoff, J. (1995). Perceptual scaling of synthesized musical timbres:common dimensions, specificities, and latent subject classes. Psychological Research, 58:177-192.

Melka, V. (1994). Methodological approaches to the investigation of musical timbre. Journal de Physique 4, (Colloque C5, supplément au Journal de Physique III):569576.

Melka, A., Štepánek, Z. y Otcenášek, (1996). Czech and German verbal description of violin sound properties: multidimensional analyses of survey data. Acustica, 82:S214.

Michels, U. (1998). Atlas de música, 1. Madrid: Alianza Editorial, S.A.

Miller, T. E. (1999). The construction and operation of the khaen. J. Acoust. Soc. Am., 106 (4), 2301.

Miklós, A.; Angster, J., Pitsch, S. y Rossing, T. D. (2003). Reed vibration in lingual organ pipes without the resonators. J. Acoust. Soc. Am., 113 (2), 1081-1091.

Miklós, A.; Angster, J., Pitsch, S. y Rossing, T. D. (2006). Interaction of reed and resonator by sound generation in a reed organ pipe. J. Acoust. Soc. Am., 119 (5), 3121-3129.

Morrison, S.J., Price, H.E., Geiger, C.G. y Cornacchio, R.A. (2009). The Effect of Conductor Expressivity on Ensemble Performance Evaluation. Journal of Research in Music Education, 57 (1), 37-49.

Napoles, J. (2009). The Effects of Score Use on Musicians' Ratings of Choral Performances. Journal of Research in Music Education, 57 (3), 267-279.

Nief, G., Gautier, F., Dalmont, J.P., y Gilbert, J. (2008). Influence of wall vibrations on the behavior of a simplified wind instrument. J. Acoust. Soc. Am., 124 (2), 1320-1331.

Norris, C.E. y Borst, J.D. (2007). An Examination of the Reliabilities of Two Choral Festival Adjudication Forms. Journal of Research in Music Education, 55 (3), 237-251.

Obataya, E., y Norimoto, M. (1999). “Acoustic properties of a reed (Arundo donax L.) used for the vibrating plate of a clarinet," J. Acoust. Soc. Am., 106, 1106-1110.

Olazábal, T. (1954). Acústica musical y organología. Buenos Aires: Ricordi Americana.

Orcutt, R. H. \& Roscoe, W. A. (1975). Reed Storage - A Simple Solution. Journal of the International Double Reed Society, 3.

O'Sullivan, C., Chang, A. (2006). An Activity Classification for Vibrotactile Phenomena. Haptic Audio Interaction Design, HAID 2006, Lecture Notes in Computer Science 4129, 145-156. Berlin: Springer-Verlag. 
Palmer, C. y Meyer, R. K. (2000). Conceptual and motor learning in music performance. Psychological Science, 11 (1), 63-68.

Pederiva, P. L. M. (2005). O corpo no processo ensino-aprendizagem de instrumentos musicais: percepção de professores. Dissertação de Mestrado apresentada ao Programa de Pós-Graduação Stricto Sensu em Educação da Universidade Católica de Brasília, visando à obtenção do grau de Mestre.

Pedrell, F. (1901). Emporio Científico é Histórico de Organografia musical antigua española. Barcelona.

Peñalba, A. (2005). El cuerpo en la música a través de la teoría de la Metáfora de Johnson: análisis crítico y aplicación a la música. TRANS Revista Transcultural de Música, 009. En línea: http://www.sibetrans.com/trans/a176/el-cuerpo-en-la-musica-a-traves-de-lateoria-de-la-metafora-de-johnson-analisis-critico-y-aplicacion-a-la-musica (Consulta: 10-4-2012)

Peñalba, A. (2008). El cuerpo en la interpretación musical. Un modelo teórico basado en las propiocepciones en la interpretación de instrumentos acústicos, hiperinstrumentos $e$ instrumentos alternativos. Tesis doctoral. Recuperada de: http://uvadoc.uva.es/ handle/10324/55 (Consulta: 10-4-2012)

Peñalba, A. (2011). Towards a theory of proprioception as a bodily basis for consciousness in music. En D. Clarke y E, Clarke (Eds.). Music and consciosness philosophical, psychological, and cultural perspectives (pp. 215-228). Oxford: Oxford University Press.

Pettijohn II, T.F. y Sacco JR, D.F (2009). Tough times, meaningful music, mature performers: popular Billboard songs and performer preferences across social and economic conditions in the USA. Psychology of Music, 37 (2), 155-179.

Pinard, F., Laine, B. y Vach, H. (2003). Musical quality assessment of clarinet reeds using optical holography. J. Acoust. Soc. Am., 113 (3), 1736-1742.

Plitnik, G.R. y Strong, W.J. (1979). Numerical method for calculating input impedances of the oboe. J. Acoust. Soc. Am. 65 (3), 816-825.

Plitnik, G.R. y Lawson, B.A. (1999). An investigation of correlations between geometry, acoustic variables, and psychoacoustic parameters for French horn mouthpieces. $J$. Acoust. Soc. Am. 106 (2), 1111-1125.

Plitnik, G.R. (2000). Vibration characteristics of pipe organ reed tongues and the effect of the shallot, resonator, and reed curvature. J. Acoust. Soc. Am., 107 (6), 3460-3473.

Plomp, R. (1970). Timbre as a Multidimensional Attribute of Complex Tones, In Frequency Analysis and Periodicity Detection in Hearing, pp. 397-414. Leiden: Sijhoff.

Prince, H.E. y Chang, C. (2005). Conductor and Ensemble Performance Expressivity and State Festival Ratings. Journal of Research in Music Education, 53 (1), 66-77. 
Prince, H.E. (2006). Relationships among Conducting Quality, Ensemble Performance Quality, and State Festival Ratings. Journal of Research in Music Education, 54 (3), 203-214.

Prodan, J.C. (1977). The Effect of the Intonation of the Crow of the Reed on the Tone Quality of the Oboe. Journal of the International Double Reed Society, 5.

Reed, D. (2007). Mental representations in clarinet performance: connections between auditory imagery and motor behaviors. Tesis doctoral. The University of North Carolina, Greensboro.

Reid, J. W. (1983). Cane Selectivity from the Field to the Gouger. Journal of the International Double Reed Society, 11 .

Ricardo da Silva, A., Scavone, G.P., Walstijn, M. v. (2007). Numerical simulations of fluidstructure interactions in single-reed mouthpieces. J. Acoust. Soc. Am., 122 (3), 17981809.

Ricot, D. (2005). Aerodynamic excitation and sound production of blown-closed free reeds without acoustic coupling: The example of the accordion reed. J. Acoust. Soc. Am., 117 (4), 2279-2290.

Riemann, B. (1979). Musiklexikon. Maguncia: Atlantis-Schott.

Ro, T., Hsu, J., Yasar, N. E., Elmore, L. C., and Beauchamp, M. S. 2009. Sound enhances touch perception. Exp. Brain Res, 195, 135-143.

Romero, J., Alba, J. \& Ramis, J. (2006). Estudio preliminar del comportamiento de cañas de oboe. Procedente del $37^{a}$ Congreso Nacional de Acústica TecniAcustica. Gandía: Universitat Politècnica de València.

Ross, S. L. (1985). The effectiveness of Mental Practice in improving the performance of College Trombonist. Journal of Research in Music Education, 33, 221-30.

Rothwell, E. (1979). The Oboist Companion. Volumen 3. Reeds $\left(2^{a}\right.$ ed.). Londres: Oxford University Press ( $1^{\text {a }}$ ed. 1977).

Russell, M.E. (1953). The oboe: a comparison study of specifications with musical effectiveness. $\mathrm{PhD}$, University of Michigan.

Russell, M. (1971). Oboe Reed Making and Problems of the Oboe Player. Old Greenwich: Spratt Music Publishers.

Sachs, C. (1947). Historia de los Instrumentos Musicales. Buenos Aires: Centurión.

Salviani, C. (1848). Metodo completo per oboe cotento nozioni preliminari. Milán: Lucca.

Schade, C. C. (2007). Practical Evaluation of Orofacial Myofunctional Exercises: Implications for Wind Instrument Learning. Music Performance Research, 1(1), 47-65.

Schaeffer P. (1977): Traité des objets musicaux, 2nd edn., Paris: Editions du Seuil. 
Schumacher, R. T. (1981). Ab initio calculations of the oscillations of a clarinet. Acustica $48,71-85$.

Schürmann, M., Caetano, G., Jousmaki, V. y Hari, R. (2004). Hands help hearing: facilitatory audiotactile interaction at low sound-intensity levels. Journal of the Acoustical Society of America, 115, 830-832.

Schuster, C., Hilfiker, R., Amft, O., Scheidhauer, A., Andrews, B., Butler, J., Kischka, U. y Ettlin, T. (2011). Best practice for motor imagery: a systematic literature review on motor imagery training elements in five different disciplines. BMC Medicine, 9:75. En línea: http://www.biomedcentral.com/1741-7015/9/75 (Consulta: 09-4-2012).

Sellner, J. (1830). Méthode pour le hautbois. París: Richault.

Shalita, J. (2003). Making Oboe Reeds. A basic guide to reed making. www.makingoboereeds.com

Sherrington, C. S. (1906). The Integrative Action of the Nervous System. New Haven: Yale University Press.

Silva, F.; Kergomard, J. y Vergezc, Ch. (2008). Interaction of reed and acoustic resonator in clarinetlike systems. J. Acoust. Soc. Am. 124 (5), 3284-3295.

Smyth, T., y Abel, J. S. (2010). Estimation of reed flow signal from instrument performance. J. Acoust. Soc. Am., 128 (4), 2344.

Snitkin, H.R. (1975). Effects of reed type and player on the listener's ability to discriminate differences in oboe tone quality. Tesis doctoral. University of Connecticut.

Sommerfeldt, S. D. y Strog, W. J. (1988). Simulation of a player-clarinet system. J. Acoust. Soc. Am., 83 (5), 1908-1918.

Sprenkle, R. y Ledet, D. (1961). The Art of Oboe Playing. Evanston: Summy Birchard.

Steins, K. (1964). Rohrbau Fur Oboen. Berlin: Bote und Bach.

Stetson, K.A. (2011). Vibration modes of clarinet reeds via digital electronic holography. $J$. Acoust. Soc. Am., 129 (4), 2615.

Stewart, S. E. y Strong, W. J. (1980). Functional model of a simplified clarinet. J. Acoust. Soc. Am., 68, 109-120.

The New Grove, Dictionary of Music \& Musicians. (1980). 20 vol. Londres: Stanley Sadie.

Tonon, T. (2009). Accordion reeds, cavity resonance, and pitch bend. J. Acoust. Soc. Am., $126(4), 2217$.

Tranchefort, R. (2002). Tratado de los instrumentos musicales. Madrid: Alianza Música.

Thompson, S.C. (1979). The effect of the reed resonance on woodwind tone production. $J$. Acoust.Soc. Am., 66 (5), 1299-1307. 
Trentacosti, M. (1978). An Early Approach for Detecting a Good or Bad Piece of Cane. Double Reed 1:1.

Vanweelden, K. y McGee, I.R. (2007). The influence of music style and conductor race on perceptions of ensemble and conductor performance. International Journal of Music Education, 25 (1), 7-17.

Vargas, G., López, I. y Shifres, F. (2007). Modalidades en las estrategias de la trascripción melódica. Música y Bienestar Humano. Actas de la VI Reunión de SACCoM, 67-73.

Veny, L. A. (1828). Méthode abrégée pour le hautbois. París: Pleyel et Cie.

Vergez, C., y Caussé, R. Flow regimes at the output of oboe double-reeds," J. Acoust. Soc. Am., 120 (5), 3333.

Viswanathan, N., Magnuson, J. S. y Fowler, C. A. (2010). Compensation for Coarticulation: Disentangling Auditory and Gestural Theories of Perception of Coarticulatory Effects in Speech. Journal of Experimental Psychology. Human Perception \& Performance, 36 (4), 1005-1015.

Vogt, A. (1816-1824). Méthode pour le hautbois du Celèbre Vogt offerte par Mr. Bruyant son Élève à la Bibliothèque du Conservatoire 1872. París: Biblioteca Nacional de Francia, Ms. Ci 50.

Wapnick, J., Darrow, A.A., Kovacs, J. y Dalrymple, L. (1997). Effects of Physical Attractiveness on Evaluation of Vocal Performance. Journal of Research in Music Education, 45 (3), 470-479.

Wapnick, J. y Ekholm, E. (1997). Expert consensus in solo voice performance evaluation. Journal of Voice, 11 (4), 429-436.

Weber, D. \& Capps, F. (1990). The Reed Maker's Manual: Step by Step Instructions for Making Oboe and English Horn Reeds. Phoenix: D. B. Weber and F. B. Capps.

Webster, J. C., Woodhead, M. M. and Carpenter, A. (1970). Perceptual constancy in complex sound identification. British Journal of Psychology, 61:481-489.

Wedin, L. and Goude, G. (1972). Dimension analysis of instrumental timbre. Scandinavian Journal of Psychology, 13:228-240.

Wessel, D. L. (1973). Psychoacoustics and music: A report from Michigan State University. PACE: Bulletin of the Computer Arts Society, pp. 1-2.

Wilson, E. C., Reed, C. M., y Braida, L. D. (2009). Integration of auditory and vibrotactile stimuli: Effects of phase and stimulus-onset asynchrony. Journal of the Acoustical Society of America, 126, 1960-1974.

Worman, W. E. (1971). Self-sustained nonlinear oscillations of medium amplitude in clarinet-like systems. Tesis doctoral. Case Western Reserve University, Cleveland, $\mathrm{OH}$. 
Yarbrough, C., Wapnick, J. y Kelly, R. (1979). Effect of Videotape Feedback Techniques on Performance, Verbalization, and Attitude of Beginning Conductors. Journal of Research in Music Education, 27 (2), 103-112.

Yarbrough, C y Madsen, K. (1998). The Evaluation of Teaching in Choral Rehearsals. Journal of Research in Music Education, 46 (4), 469-481.

Yarrow, K., Haggard, P., y Rothwell, J. C. 2008. Vibrotactile-auditory interactions are postperceptual. Perception, 37, 1114-1130.

Yau, J. M., Olenczak, J. B., Dammann, J. F., y Bensmaia, S. J. 2009. Temporal frequency channels are linked across audition and touch. Curr. Biol., 19, 561-566. 
7. Anexos 


\subsection{ANEXO A. Tablas y figuras complementarias de análisis estadístico}

\subsubsection{Experimento preliminar}

\subsubsection{Percepción tímbrica}

\begin{tabular}{|c|c|c|c|c|}
\hline \multicolumn{5}{|c|}{ Chi-Square Tests } \\
\hline \multicolumn{2}{|l|}{ Rater } & Value & df & Asymp. Sig. (2-sided) \\
\hline \multirow[t]{6}{*}{ other } & Pearson Chi-Square & , 140 & 1 & ,709 \\
\hline & Continuity Correction & 071 & 1 & ,790 \\
\hline & Likelihood Ratio &, 141 & 1 & ,708 \\
\hline & Fisher's Exact Test & & & \\
\hline & Linear-by-Linear Association & ,139 & 1 & ,709 \\
\hline & $\mathrm{N}$ of Valid Cases & 720 & & \\
\hline \multirow[t]{6}{*}{ oboist } & Pearson Chi-Square & 3,916 & 1 & ,048 \\
\hline & Continuity Correction & 3,493 & 1 &, 062 \\
\hline & Likelihood Ratio & 4,127 & 1 & 042 \\
\hline & Fisher's Exact Test & & & \\
\hline & Linear-by-Linear Association & 3,911 & 1 & ,048 \\
\hline & $\mathrm{N}$ of Valid Cases & 720 & & \\
\hline
\end{tabular}

Tabla A. 1. Prueba de $\chi^{2}$ de Pearson comparando las agrupaciones de los dos grupos de oyentes según las diferentes escuelas de rebajado para el diminuendo.

\begin{tabular}{|c|c|c|c|c|}
\hline \multicolumn{5}{|c|}{ Chi-Square Tests } \\
\hline \multicolumn{2}{|l|}{ Rater } & Value & $\mathrm{df}$ & Asymp. Sig. (2-sided) \\
\hline \multirow[t]{6}{*}{ other } & Pearson Chi-Square & ,237 & 1 &, 626 \\
\hline & Continuity Correction & , 187 & 1 & 665 \\
\hline & Likelihood Ratio & 239 & 1 & 625 \\
\hline & Fisher's Exact Test & & & \\
\hline & Linear-by-Linear Association & ,237 & 1 & ,626 \\
\hline & $\mathrm{N}$ of Valid Cases & 3060 & & \\
\hline \multirow[t]{6}{*}{ oboist } & Pearson Chi-Square & ,501 & 1 & 479 \\
\hline & Continuity Correction & ,424 & 1 &, 515 \\
\hline & Likelihood Ratio &, 505 & 1 & ,477 \\
\hline & Fisher's Exact Test & & & \\
\hline & Linear-by-Linear Association &, 501 & 1 & ,479 \\
\hline & $\mathrm{N}$ of Valid Cases & 3060 & & \\
\hline
\end{tabular}

Tabla A. 2. Prueba de $\chi^{2}$ de Pearson comparando las agrupaciones de los dos grupos de oyentes según las diferentes escuelas de rebajado para las notas graves.

\begin{tabular}{|ll|r|r|r|}
\hline \multicolumn{2}{|c|}{ Chi-Square Tests } \\
\hline Rater & & Value & df & \multicolumn{1}{|c|}{ Asymp. Sig. (2-sided) } \\
\hline \multirow{2}{*}{ other } & Pearson Chi-Square & 1,434 & 1 &, 231 \\
& Continuity Correction & 1,311 & 1 &, 252
\end{tabular}




\begin{tabular}{|c|c|c|c|c|}
\hline \multicolumn{5}{|c|}{ Chi-Square Tests } \\
\hline \multicolumn{2}{|l|}{ Rater } & Value & df & Asymp. Sig. (2-sided) \\
\hline & Likelihood Ratio & 1,418 & 1 & 234 \\
\hline & Fisher's Exact Test & & & \\
\hline & Linear-by-Linear Association & 1,433 & 1 & ,231 \\
\hline & $\mathrm{N}$ of Valid Cases & 3060 & & \\
\hline oboist & Pearson Chi-Square & 1,792 & 1 &, 181 \\
\hline & Continuity Correction & 1,640 & 1 & ,200 \\
\hline & Likelihood Ratio & 1,766 & 1 &, 184 \\
\hline & Fisher's Exact Test & & & \\
\hline & Linear-by-Linear Association & 1,792 & 1 &, 181 \\
\hline & $\mathrm{N}$ of Valid Cases & 3060 & & \\
\hline
\end{tabular}

Tabla A. 3. Prueba de $\chi^{2}$ de Pearson comparando las agrupaciones de los dos grupos de oyentes según las diferentes escuelas de rebajado para las notas agudas.

\begin{tabular}{|ll|r|r|r|}
\hline \multicolumn{9}{|c|}{ Chi-Square Tests } \\
\hline Rater & Value & df & \multicolumn{1}{|c|}{ Asymp. Sig. (2-sided) } \\
\hline other & Pearson Chi-Square & 5,446 & 1 &, 020 \\
& Continuity Correction & 5,215 & 1 &, 022 \\
& Nof Valid Cases & 3060 & & \\
& Pearson Chi-Square &, 916 & &, 338 \\
& Continuity Correction &, 817 & 1 &, 366 \\
& Nof Valid Cases & 3060 & & \\
\end{tabular}

Tabla A. 4. Prueba de $\chi^{2}$ de Pearson comparando las agrupaciones de los dos grupos de oyentes según las diferentes escuelas de rebajado para las frases largas.

\begin{tabular}{|c|c|c|c|c|}
\hline \multicolumn{5}{|c|}{ Chi-Square Tests } \\
\hline \multicolumn{2}{|l|}{ Rater } & Value & $\mathrm{df}$ & Asymp. Sig. (2-sided) \\
\hline \multirow[t]{6}{*}{ other } & Pearson Chi-Square & 13,001 & 1 &, 000 \\
\hline & Continuity Correction & 12,343 & 1 & 000 \\
\hline & Likelihood Ratio & 13,128 & 1 & 000 \\
\hline & Fisher's Exact Test & & & \\
\hline & Linear-by-Linear Association & 12,983 & 1 & 000 \\
\hline & $\mathrm{N}$ of Valid Cases & 720 & & \\
\hline \multirow[t]{6}{*}{ oboist } & Pearson Chi-Square & 11,749 & 1 & 001 \\
\hline & Continuity Correction & 11,105 & 1 & 001 \\
\hline & Likelihood Ratio & 11,865 & 1 & 001 \\
\hline & Fisher's Exact Test & & & \\
\hline & Linear-by-Linear Association & 11,732 & 1 & 001 \\
\hline & $\mathrm{N}$ of Valid Cases & 720 & & \\
\hline
\end{tabular}

Tabla A. 5. Prueba de $\chi^{2}$ de Pearson comparando las agrupaciones de los dos grupos de oyentes según los diferentes oboístas para el diminuendo. 
Influencias en la percepción sonora y en la interpretación del rebajado de la lengüeta del oboe

\begin{tabular}{|ll|r|r|r|}
\hline \multicolumn{2}{|c|}{ Chi-Square Tests } \\
\hline Rater & & Value & df & Asymp. Sig. (2-sided) \\
\hline other & Pearson Chi-Square & 2,156 & 1 &, 142 \\
& Continuity Correction & 1,999 & 1 &, 157 \\
& Likelihood Ratio & 2,191 & 1 &, 139 \\
& Fisher's Exact Test & & &, 142 \\
& Linear-by-Linear Association & 2,155 & 1 &, 022 \\
& N of Valid Cases & 3060 & &, 025 \\
& Pearson Chi-Square & 5,275 & 1 &, 020 \\
Continuity Correction & 5,018 & 1 &, 022 \\
Likelihood Ratio & 5,426 & 1 & \\
Fisher's Exact Test & & & \\
Linear-by-Linear Association & 5,273 & 1 & \\
N of Valid Cases & 3060 & & \\
\hline
\end{tabular}

Tabla A. 6. Prueba de $\chi^{2}$ de Pearson comparando las agrupaciones de los dos grupos de oyentes según los diferentes oboístas para las notas graves.

\begin{tabular}{|ll|r|r|r|}
\hline \multicolumn{9}{|c|}{ Chi-Square Tests } \\
\hline Rater & \multicolumn{1}{|c|}{ Value } & \multicolumn{1}{c|}{ df } & \multicolumn{1}{c|}{ Asymp. Sig. (2-sided) } \\
\hline other & Pearson Chi-Square & 7,782 & 1 &, 005 \\
& Continuity Correction & 7,492 & 1 &, 006 \\
& Nof Valid Cases & 3060 & & \\
& Pearson Chi-Square & 403 & 1 &, 525 \\
oboist & Continuity Correction &, 333 & 1 &, 564 \\
& N of Valid Cases & 3060 & & \\
\hline
\end{tabular}

Tabla A. 7. Prueba de $\chi^{2}$ de Pearson comparando las agrupaciones de los dos grupos de oyentes según los diferentes oboístas para las notas agudas.

\begin{tabular}{|c|c|c|c|c|}
\hline \multicolumn{5}{|c|}{ Chi-Square Tests } \\
\hline \multicolumn{2}{|l|}{ Rater } & Value & $\mathrm{df}$ & Asymp. Sig. (2-sided) \\
\hline \multirow[t]{6}{*}{ other } & Pearson Chi-Square & 11,125 & 1 & 001 \\
\hline & Continuity Correction & 10,794 & 1 & 001 \\
\hline & Likelihood Ratio & 11,483 & 1 & 001 \\
\hline & Fisher's Exact Test & & & \\
\hline & Linear-by-Linear Association & 11,122 & 1 & 001 \\
\hline & $\mathrm{N}$ of Valid Cases & 3060 & & \\
\hline \multirow[t]{6}{*}{ oboist } & Pearson Chi-Square & 48,329 & 1 &, 000 \\
\hline & Continuity Correction & 47,588 & 1 & 000 \\
\hline & Likelihood Ratio & 52,970 & 1 &, 000 \\
\hline & Fisher's Exact Test & & & \\
\hline & Linear-by-Linear Association & 48,313 & 1 & 000 \\
\hline & $\mathrm{N}$ of Valid Cases & 3060 & & \\
\hline
\end{tabular}

Tabla A. 8. Prueba de $\chi^{2}$ de Pearson comparando las agrupaciones de los dos grupos de oyentes según los diferentes oboístas para las frases largas. 


\begin{tabular}{|c|c|c|c|c|}
\hline \multicolumn{5}{|c|}{ Chi-Square Tests } \\
\hline \multicolumn{2}{|l|}{ Rater } & Value & $\mathrm{df}$ & Asymp. Sig. (2-sided) \\
\hline \multirow[t]{6}{*}{ other } & Pearson Chi-Square & 26,411 & 1 & ,000 \\
\hline & Continuity Correction & 25,902 & 1 & ,000 \\
\hline & Likelihood Ratio & 26,402 & 1 & ,000 \\
\hline & Fisher's Exact Test & & & \\
\hline & Linear-by-Linear Association & 26,402 & 1 & ,000 \\
\hline & $\mathrm{N}$ of Valid Cases & 3060 & & \\
\hline \multirow[t]{6}{*}{ oboist } & Pearson Chi-Square & 247,465 & 1 & 000 \\
\hline & Continuity Correction & 245,838 & 1 & ,000 \\
\hline & Likelihood Ratio & 261,554 & 1 & ,000 \\
\hline & Fisher's Exact Test & & & \\
\hline & Linear-by-Linear Association & 247,385 & 1 & ,000 \\
\hline & $\mathrm{N}$ of Valid Cases & 3060 & & \\
\hline
\end{tabular}

Tabla A. 9. Prueba de $\chi^{2}$ de Pearson comparando las agrupaciones de los dos grupos de oyentes según los diferentes ataques para las notas graves.

\begin{tabular}{|c|c|c|c|c|}
\hline \multicolumn{5}{|c|}{ Chi-Square Tests } \\
\hline \multicolumn{2}{|l|}{ Rater } & Value & $\mathrm{df}$ & Asymp. Sig. (2-sided) \\
\hline \multirow[t]{6}{*}{ other } & Pearson Chi-Square & 15,465 & 1 &, 000 \\
\hline & Continuity Correction & 15,091 & 1 & ,000 \\
\hline & Likelihood Ratio & 15,442 & 1 &, 000 \\
\hline & Fisher's Exact Test & & & \\
\hline & Linear-by-Linear Association & 15,460 & 1 & ,000 \\
\hline & $\mathrm{N}$ of Valid Cases & 3060 & & \\
\hline \multirow[t]{6}{*}{ oboist } & Pearson Chi-Square & 34,791 & 1 & ,000 \\
\hline & Continuity Correction & 34,169 & 1 & ,000 \\
\hline & Likelihood Ratio & 34,848 & 1 &, 000 \\
\hline & Fisher's Exact Test & & & \\
\hline & Linear-by-Linear Association & 34,780 & 1 &, 000 \\
\hline & $\mathrm{N}$ of Valid Cases & 3060 & & \\
\hline
\end{tabular}

Tabla A. 10. Prueba de $\chi^{2}$ de Pearson comparando las agrupaciones de los dos grupos de oyentes según los diferentes ataques para las notas agudas.

\begin{tabular}{|c|c|c|c|c|}
\hline \multicolumn{5}{|c|}{ Chi-Square Tests } \\
\hline \multicolumn{2}{|l|}{ Rater } & Value & $\mathrm{df}$ & Asymp. Sig. (2-sided) \\
\hline \multirow[t]{5}{*}{ other } & Pearson Chi-Square & 121,503 & 1 & 000 \\
\hline & Continuity Correction & 120,497 & 1 & 000 \\
\hline & Likelihood Ratio & 122,816 & 1 & 000 \\
\hline & Fisher's Exact Test & & & \\
\hline & Linear-by-Linear Association & 121,463 & 1 & ,000 \\
\hline
\end{tabular}


Influencias en la percepción sonora y en la interpretación del rebajado de la lengüeta del oboe

\begin{tabular}{|ll|r|r|r|}
\hline \multicolumn{2}{|c|}{ Chi-Square Tests } \\
\hline Rater & \multicolumn{1}{|c|}{ Value } & df & Asymp. Sig. (2-sided) \\
\hline oboist & Pearson Chi-Square & 3060 & & \\
& Continuity Correction & 317,346 & 1 &, 000 \\
& Likelihood Ratio & 315,608 & 1 &, 000 \\
& Fisher's Exact Test & 337,349 & 1 &, 000 \\
& Linear-by-Linear Association & & &, 000 \\
& N of Valid Cases & 317,243 & & 1 \\
\end{tabular}

Tabla A. 11. Prueba de $\chi^{2}$ de Pearson comparando las agrupaciones de los dos grupos de oyentes según los diferentes ataques para las frases largas.

\begin{tabular}{|ll|r|r|r|}
\hline \multicolumn{2}{|c|}{ Chi-Square Tests } \\
\hline Rater & & Value & df & Asymp. Sig. (2-sided) \\
\hline other & Pearson Chi-Square & 566 & 1 &, 452 \\
& Continuity Correction &, 343 & 1 &, 558 \\
& Likelihood Ratio &, 593 & 1 &, 441 \\
& Fisher's Exact Test & & & \\
& Linear-by-Linear Association &, 566 & 1 &, 452 \\
& N of Valid Cases & 720 & &, 066 \\
& Pearson Chi-Square & 3,376 & 1 &, 096 \\
Continuity Correction & 2,772 & 1 &, 049 \\
Likelihood Ratio & 3,877 & 1 &, 066 \\
Fisher's Exact Test & & & \\
Linear-by-Linear Association & 3,371 & 1 & \\
N of Valid Cases & 720 & & \\
\hline
\end{tabular}

Tabla A. 12. Prueba de $\chi^{2}$ de Pearson comparando las agrupaciones de los dos grupos de oyentes según las diferentes lengüetas para el diminuendo.

\begin{tabular}{|c|c|c|c|c|}
\hline \multicolumn{5}{|c|}{ Chi-Square Tests } \\
\hline \multicolumn{2}{|l|}{ Rater } & Value & df & Asymp. Sig. (2-sided) \\
\hline \multirow[t]{6}{*}{ other } & Pearson Chi-Square & ,745 & 1 & ,388 \\
\hline & Continuity Correction & ,626 & 1 & ,429 \\
\hline & Likelihood Ratio & ,730 & 1 & ,393 \\
\hline & Fisher's Exact Test & & & \\
\hline & Linear-by-Linear Association & ,745 & 1 & ,388 \\
\hline & $\mathrm{N}$ of Valid Cases & 3060 & & \\
\hline \multirow[t]{4}{*}{ oboist } & Pearson Chi-Square & 9,813 & 1 & ,002 \\
\hline & Continuity Correction & 9,348 & 1 &, 002 \\
\hline & Likelihood Ratio & 10,800 & 1 & ,001 \\
\hline & Fisher's Exact Test & & & \\
\hline
\end{tabular}




\begin{tabular}{|l|r|r|r|}
\hline \multicolumn{2}{|c|}{ Chi-Square Tests } \\
\hline Rater & \multicolumn{1}{|c|}{ Value } & df & Asymp. Sig. (2-sided) \\
\hline \multirow{2}{*}{ Linear-by-Linear Association } & 9,809 & &, 002 \\
& & 1 & \\
N of Valid Cases & 3060 & & \\
\hline
\end{tabular}

Tabla A. 13. Prueba de $\chi^{2}$ de Pearson comparando las agrupaciones de los dos grupos de oyentes según las diferentes lengüetas para las notas graves.

\begin{tabular}{|c|c|c|c|c|}
\hline \multicolumn{5}{|c|}{ Chi-Square Tests } \\
\hline \multicolumn{2}{|l|}{ Rater } & Value & $\mathrm{df}$ & Asymp. Sig. (2-sided) \\
\hline \multirow[t]{6}{*}{ other } & Pearson Chi-Square & 3,998 & 1 & ,046 \\
\hline & Continuity Correction & 3,725 & 1 & 054 \\
\hline & Likelihood Ratio & 3,839 & 1 & 050 \\
\hline & Fisher's Exact Test & & & \\
\hline & Linear-by-Linear Association & 3,996 & 1 &, 046 \\
\hline & $\mathrm{N}$ of Valid Cases & 3060 & & \\
\hline \multirow[t]{6}{*}{ oboist } & Pearson Chi-Square & 2,514 & 1 & ,113 \\
\hline & Continuity Correction & 2,277 & 1 & ,131 \\
\hline & Likelihood Ratio & 2,416 & 1 &, 120 \\
\hline & Fisher's Exact Test & & & \\
\hline & Linear-by-Linear Association & 2,514 & 1 & ,113 \\
\hline & $\mathrm{N}$ of Valid Cases & 3060 & & \\
\hline
\end{tabular}

Tabla A. 14. Prueba de $\chi^{2}$ de Pearson comparando las agrupaciones de los dos grupos de oyentes según las diferentes lengüetas para las notas agudas.

\begin{tabular}{|c|c|c|c|c|}
\hline \multicolumn{5}{|c|}{ Chi-Square Tests } \\
\hline \multicolumn{2}{|l|}{ Rater } & Value & $\mathrm{df}$ & Asymp. Sig. (2-sided) \\
\hline \multirow[t]{6}{*}{ other } & Pearson Chi-Square & 6,222 & 1 &, 013 \\
\hline & Continuity Correction & 5,895 & 1 &, 015 \\
\hline & Likelihood Ratio & 6,571 & 1 &, 010 \\
\hline & Fisher's Exact Test & & & \\
\hline & Linear-by-Linear Association & 6,220 & 1 &, 013 \\
\hline & $\mathrm{N}$ of Valid Cases & 3060 & & \\
\hline \multirow[t]{6}{*}{ oboist } & Pearson Chi-Square & 18,130 & 1 & ,000 \\
\hline & Continuity Correction & 17,531 & 1 & ,000 \\
\hline & Likelihood Ratio & 20,476 & 1 &, 000 \\
\hline & Fisher's Exact Test & & & \\
\hline & Linear-by-Linear Association & 18,124 & 1 &, 000 \\
\hline & $\mathrm{N}$ of Valid Cases & 3060 & & \\
\hline
\end{tabular}

Tabla A. 15. Prueba de $\chi^{2}$ de Pearson comparando las agrupaciones de los dos grupos de oyentes según las diferentes lengüetas para las frases largas. 


\subsubsection{Acústica de la lengüeta}

\begin{tabular}{|c|c|c|c|c|c|c|c|c|c|}
\hline \multicolumn{10}{|c|}{ Paired Samples Test $^{\mathrm{a}}$} \\
\hline & & \multicolumn{8}{|c|}{ Paired Differences } \\
\hline & & \multirow[b]{2}{*}{ Mean } & \multirow{2}{*}{$\begin{array}{c}\text { Std, } \\
\text { Deviation }\end{array}$} & \multirow{2}{*}{$\begin{array}{c}\text { Std, } \\
\text { Error } \\
\text { Mean }\end{array}$} & \multicolumn{2}{|c|}{$\begin{array}{c}95 \% \text { Confidence Interval of } \\
\text { the Difference }\end{array}$} & \multirow[b]{2}{*}{$\mathrm{t}$} & \multirow[b]{2}{*}{$\mathrm{df}$} & \multirow{2}{*}{$\begin{array}{l}\text { Sig, }(2- \\
\text { tailed) }\end{array}$} \\
\hline & & & & & Lower & Upper & & & \\
\hline Pair 1 & all - al2 &,- 3154 & 2,4546 & ,5488 & $-1,4642$ & ,8333 &,- 575 & 19 & ,572 \\
\hline Pair 2 & all - am1 & 4838 & 2,7125 & 6222 &,- 8235 & 1,7912 & ,778 & 18 & ,447 \\
\hline Pair 3 & al1 - am2 & 1,4013 & 2,6670 & ,5963 & , 1531 & 2,6495 & 2,350 & 19 & ,030 \\
\hline Pair 4 & all - fr1 & ,7128 & 2,6687 & ,5967 &,- 5361 & 1,9618 & 1,195 & 19 & 247 \\
\hline Pair 5 & all - fr2 & 2,1894 & 2,2428 & ,50152 & 1,1397 & 3,2391 & 4,366 & 19 & ,000 \\
\hline Pair 6 & $\mathrm{a} 2$ - am1 & ,7083 & 2,9005 & ,6654 &,- 6896 & 2,1063 & 1,064 & 18 & ,301 \\
\hline Pair 7 & $\mathrm{al} 2-\mathrm{am} 2$ & 1,7167 & 1,9712 & 4407 & ,7941 & 2,6393 & 3,895 & 19 & , 001 \\
\hline Pair 8 & $\mathrm{a} 2$ - fr1 & 1,0283 & 2,3959 & ,5357 &,- 0930 & 2,1496 & 1,919 & 19 &, 070 \\
\hline Pair 9 & al2 - fr2 & 2,5048 & 2,0398 & ,45613 & 1,5501 & 3,4595 & 5,492 & 19 &, 000 \\
\hline Pair 10 & $\mathrm{am} 1-\mathrm{am} 2$ & 95787 & 2,1760 & 4992 &,- 0909 & 2,0066 & 1,919 & 18 & ,071 \\
\hline Pair 11 & am1 - fr1 & ,1322 & 2,7320 & ,6267 & $-1,18451$ & 1,4491 & ,211 & 18 & ,835 \\
\hline Pair 12 & $\mathrm{am} 1-\mathrm{fr} 2$ & 1,8220 & 2,1830 & ,5008 & ,7698 & 2,8742 & 3,638 & 18 & ,002 \\
\hline Pair 13 & $\mathrm{am} 2-\mathrm{fr} 1$ &,- 6884 & 1,6716 & ,3737 & $-1,4708$ & ,0938 & $-1,842$ & 19 & 081 \\
\hline Pair 14 & $\mathrm{am} 2-\mathrm{fr} 2$ & ,7880 & 1,4898 & ,3331 & ,09083 & 1,4853 & 2,366 & 19 & 029 \\
\hline Pair 15 & $\mathrm{fr} 1-\mathrm{fr} 2$ & 1,4765 & 1,8339 & 4100 & 6182 & 2,334 & 3,601 & 19 & ,002 \\
\hline
\end{tabular}

Tabla A.16. Test T comparando las diferentes lengüetas en los valores de intensidad (en dB).

\begin{tabular}{|c|c|c|c|c|c|c|c|c|c|}
\hline \multicolumn{10}{|c|}{ Paired Samples Test ${ }^{\mathrm{a}}$} \\
\hline & & \multicolumn{8}{|c|}{ Paired Differences } \\
\hline & & \multirow[b]{2}{*}{ Mean } & \multirow{2}{*}{$\begin{array}{c}\text { Std, } \\
\text { Deviation }\end{array}$} & \multirow{2}{*}{$\begin{array}{c}\text { Std, } \\
\text { Error } \\
\text { Mean }\end{array}$} & \multicolumn{2}{|c|}{$\begin{array}{l}95 \% \text { Confidence Interval of } \\
\text { the Difference }\end{array}$} & \multirow[b]{2}{*}{$\mathrm{t}$} & \multirow[b]{2}{*}{$\mathrm{df}$} & \multirow{2}{*}{$\begin{array}{l}\text { Sig, }(2- \\
\text { tailed })\end{array}$} \\
\hline & & & & & Lower & Upper & & & \\
\hline Pair 1 & al1 - al2 &,- 0007 & ,0096 & ,0019 &,- 0047 & ,0032 &,- 385 & 24 & ,703 \\
\hline Pair 2 & al1 - am1 & 0011 & 0123 & ,0025 &,- 0040 & ,0063 & ,449 & 23 & ,657 \\
\hline Pair 3 & al1 - am2 & ,0060 & ,0101 & ,0020 & ,0018 & ,0102 & 2,979 & 24 & ,007 \\
\hline Pair 4 & all - fr1 & ,0027 &, 0101 & ,0020 &,- 0014 & ,0069 & 1,340 & 24 & ,193 \\
\hline Pair 5 & all - fr2 & ,0087 & ,0092 & ,0018 & 0049 & ,0125 & 4,746 & 24 & 000 \\
\hline Pair 6 & $\mathrm{al} 2-\mathrm{am} 1$ & 0015 & ,0152 & 0031 &,- 0049 & 0079 & ,493 & 23 & ,627 \\
\hline Pair 7 & $\mathrm{a} 2-\mathrm{am} 2$ & ,0067 &, 0114 & ,0022 & ,0020 & ,0114 & 2,973 & 24 & 007 \\
\hline Pair 8 & $\mathrm{al} 2$ - fr1 & ,0034 &, 0114 & ,0022 &,- 0012 & ,0082 & 1,510 & 24 & , 144 \\
\hline Pair 9 & $\mathrm{a} 2 \mathrm{-}-\mathrm{fr} 2$ & ,0094 & ,0120 & ,0024 & 0045 & ,0144 & 3,956 & 24 & ,001 \\
\hline Pair 10 & $\mathrm{am} 1$ - am2 & ,0050 & ,0099 & ,0020 & ,0008 & ,0092 & 2,496 & 23 & 020 \\
\hline Pair 11 & $\mathrm{am} 1$ - fr1 & ,0013 & ,0117 & ,0024 &,- 0036 & ,0063 &, 565 & 23 &, 577 \\
\hline Pair 12 & $\mathrm{am} 1$ - fr2 & ,0079 & ,0097 & ,0019 & ,0038 & ,0120 & 4,028 & 23 & 001 \\
\hline Pair 13 & $\mathrm{am} 2-\mathrm{fr} 1$ &,- 0033 & ,0064 & ,0012 &,- 0059 &,- 0006 & $-2,560$ & 24 & ,017 \\
\hline Pair 14 & $\mathrm{am} 2-\mathrm{fr} 2$ & ,0027 & ,0056 & ,0011 & ,0003 & ,0050 & 2,417 & 24 & ,024 \\
\hline Pair 15 & $\mathrm{fr} 1-\mathrm{fr} 2$ & ,0060 & ,00701 & 0014 & 0031 & 0089 & 4,297 & 24 & ,000 \\
\hline
\end{tabular}




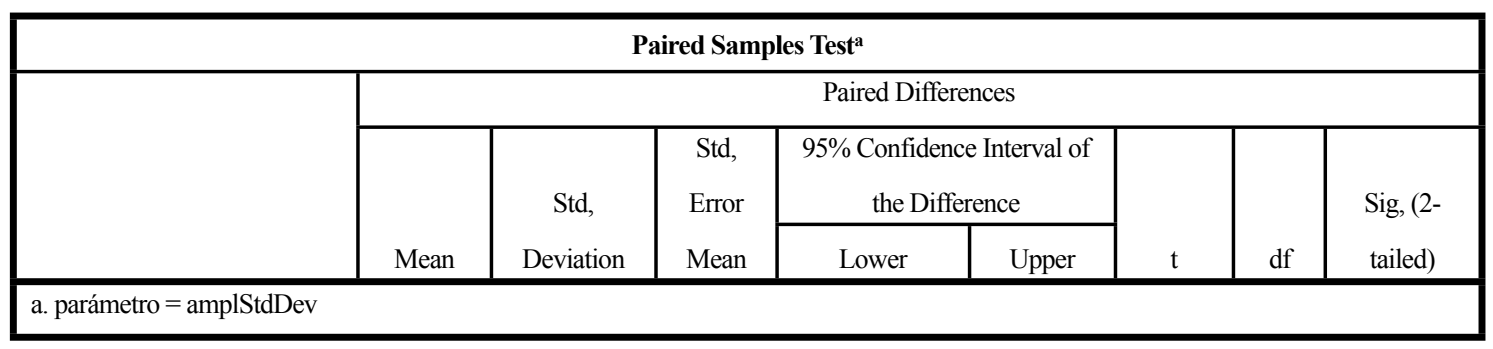

Tabla A.17. Test T comparando las diferentes lengüetas en los valores de desviación estándar de la amplitud.

\begin{tabular}{|c|c|c|c|c|c|c|c|c|c|}
\hline \multicolumn{10}{|c|}{ Paired Samples Test ${ }^{\mathrm{a}}$} \\
\hline & & \multicolumn{8}{|c|}{ Paired Differences } \\
\hline & & \multirow[b]{2}{*}{ Mean } & \multirow{2}{*}{$\begin{array}{c}\text { Std, } \\
\text { Deviation }\end{array}$} & \multirow{2}{*}{$\begin{array}{c}\text { Std, } \\
\text { Error } \\
\text { Mean }\end{array}$} & \multicolumn{2}{|c|}{$\begin{array}{c}95 \% \text { Confidence Interval of } \\
\text { the Difference }\end{array}$} & \multirow[b]{2}{*}{$\mathrm{t}$} & \multirow[b]{2}{*}{$\mathrm{df}$} & \multirow{2}{*}{$\begin{array}{l}\text { Sig, (2- } \\
\text { tailed) }\end{array}$} \\
\hline & & & & & Lower & Upper & & & \\
\hline Pair 1 & $\mathrm{al} 1-\mathrm{al} 2$ &,- 5894 & 1,0545 & ,2419 & $-1,0977$ &,- 0812 & $-2,437$ & 18 &, 025 \\
\hline Pair 2 & all - am1 & 6125 & 1,5432 & ,3637 &,- 1548 & 1,3800 & 1,684 & 17 &, 110 \\
\hline Pair 3 & al1 - am2 & 1949 & ,4729 &, 1084 &,- 0330 & ,4228 & 1,797 & 18 & ,089 \\
\hline Pair 4 & al1 - fr1 & 0014 & 2915 & ,0668 &,- 1391 & , 1419 & 022 & 18 & ,983 \\
\hline Pair 5 & al1 - fr2 &,- 3333 & ,6846 &, 1570 &,- 6633 &,- 0033 & $-2,122$ & 18 & ,048 \\
\hline Pair 6 & $\mathrm{al2}-\mathrm{am} 1$ & 1,2807 & 2,1119 & ,4977 & ,2305 & 2,3310 & 2,573 & 17 & 020 \\
\hline Pair 7 & $\mathrm{a} 2-\mathrm{am} 2$ & ,7844 & 1,4799 & ,3395 & ,07110 & 1,4977 & 2,310 & 18 & ,033 \\
\hline Pair 8 & al2 - fr1 & ,5909 & 1,2267 & ,2814 &,- 0003 & 1,1821 & 2,100 & 18 & ,050 \\
\hline Pair 9 & al2 - fr2 & ,2561 & ,4553 &, 1044 &, 03664 & ,4756 & 2,452 & 18 & ,025 \\
\hline Pair 10 & $\mathrm{am} 1-\mathrm{am} 2$ &,- 4069 & 1,5764 &, 3715 & $-1,1909$ & ,3770 & $-1,095$ & 17 & ,289 \\
\hline Pair 11 & am1 - fr1 &,- 6067 & 1,6335 & ,3850 & $-1,4191$ & ,2055 & $-1,576$ & 17 & ,133 \\
\hline Pair 12 & $\mathrm{am} 1$ - fr2 &,- 9693 & 1,9489 & ,4593 & $-1,9385$ &,- 0001 & $-2,110$ & 17 & ,050 \\
\hline Pair 13 & am2 - fr1 & -1934 & ,3936 & ,0903 &,- 3832 &,- 0037 & $-2,143$ & 18 & ,046 \\
\hline Pair 14 & $\mathrm{am} 2$ - fr2 &,- 5282 & 1,0937 & ,2509 & $-1,0554$ &,- 0011 & $-2,105$ & 18 & ,050 \\
\hline Pair 15 & fr1 - fr2 &,- 3347 & ,8207 & ,1882 &,- 7303 & ,0608 & $-1,778$ & 18 & ,092 \\
\hline
\end{tabular}

Tabla A.18. Test T comparando las diferentes lengüetas en los valores frecuencia media (F0 en semitonos).

\begin{tabular}{|c|c|c|c|c|c|c|c|c|c|}
\hline \multicolumn{10}{|c|}{ Paired Samples Test ${ }^{\mathrm{a}}$} \\
\hline & & \multicolumn{8}{|c|}{ Paired Differences } \\
\hline & & \multirow[b]{2}{*}{ Mean } & \multirow{2}{*}{$\begin{array}{c}\text { Std, } \\
\text { Deviation }\end{array}$} & \multirow{2}{*}{$\begin{array}{c}\text { Std, } \\
\text { Error } \\
\text { Mean }\end{array}$} & \multicolumn{2}{|c|}{$\begin{array}{c}95 \% \text { Confidence Interval of } \\
\text { the Difference }\end{array}$} & \multirow[b]{2}{*}{$\mathrm{t}$} & \multirow[b]{2}{*}{$\mathrm{df}$} & \multirow{2}{*}{$\begin{array}{l}\mathrm{Sig},(2- \\
\text { tailed) }\end{array}$} \\
\hline & & & & & Lower & Upper & & & \\
\hline Pair 1 & all - al2 & 1,2882 & 2,3314 & ,5087 & ,22697 & 2,3495 & 2,532 & 20 & ,020 \\
\hline Pair 2 & al1 - am1 & ,2670 & 1,6320 & ,3561 &,- 4758 & 1,0099 & ,750 & 20 & ,462 \\
\hline Pair 3 & al1 - am2 &,- 3686 & 1,0292 & ,2245 &,- 8371 & ,0998 & $-1,641$ & 20 & ,116 \\
\hline Pair 4 & al1 - fr1 & 0660 & 3474 & 0758 &,- 0921 & ,2242 &, 871 & 20 & ,394 \\
\hline Pair 5 & all - fr2 & 1,1376 & 2,1754 & ,4747 & ,1473 & 2,1278 & 2,396 & 20 & ,026 \\
\hline Pair 6 & $\mathrm{al} 2-\mathrm{am} 1$ & $-1,0211$ & 2,3218 & ,5066 & $-2,0780$ & ,0357 & $-2,015$ & 20 & 057 \\
\hline Pair 7 & $\mathrm{a} 12-\mathrm{am} 2$ & $-1,6569$ & 2,7510 & 6003 & $-2,9091$ &,- 4046 & $-2,760$ & 20 & ,012 \\
\hline Pair 8 & al2 - fr1 & $-1,2222$ & 2,2875 & 4991 & $-2,2634$ &,- 1809 & $-2,448$ & 20 & 024 \\
\hline
\end{tabular}




\begin{tabular}{|c|c|c|c|c|c|c|c|c|c|}
\hline \multicolumn{10}{|c|}{ Paired Samples Test ${ }^{\mathrm{a}}$} \\
\hline & & \multicolumn{8}{|c|}{ Paired Differences } \\
\hline & & \multirow[b]{2}{*}{ Mean } & \multirow{2}{*}{$\begin{array}{c}\text { Std, } \\
\text { Deviation }\end{array}$} & \multirow{2}{*}{$\begin{array}{l}\text { Std, } \\
\text { Error } \\
\text { Mean }\end{array}$} & \multicolumn{2}{|c|}{$\begin{array}{c}95 \% \text { Confidence Interval of } \\
\text { the Difference }\end{array}$} & \multirow[b]{2}{*}{$\mathrm{t}$} & \multirow[b]{2}{*}{$\mathrm{df}$} & \multirow{2}{*}{$\begin{array}{l}\text { Sig, }(2- \\
\text { tailed) }\end{array}$} \\
\hline & & & & & Lower & Upper & & & \\
\hline Pair 9 & al2 - fr2 &,- 1506 & ,6577 & ,1435 &,- 4500 & , 1487 & $-1,049$ & 20 & ,306 \\
\hline Pair 10 & $\mathrm{am} 1-\mathrm{am} 2$ &,- 6357 & 1,7268 & ,3768 & $-1,4217$ &, 1503 & $-1,687$ & 20 & , 107 \\
\hline Pair 11 & $\mathrm{am} 1$ - fr1 &,- 2010 & 1,6926 & ,3693 &,- 9715 & ,5694 &,- 544 & 20 &, 592 \\
\hline Pair 12 & $\mathrm{am} 1$ - fr2 &, 8705 & 2,2279 & ,4861 &,- 14358 & 1,8846 & 1,791 & 20 & 089 \\
\hline Pair 13 & am2 - fr1 & ,4347 & 1,0958 & ,2391 &,- 0641 & ,9335 & 1,818 & 20 & ,084 \\
\hline Pair 14 & am 2 - fr2 & 1,5062 & 2,5624 & ,5591 & ,3398 & 2,6726 & 2,694 & 20 & ,014 \\
\hline Pair 15 & fr1 - fr2 & 1,0715 & 2,0591 & ,4493 & ,1342 & 2,008 & 2,385 & 20 & ,027 \\
\hline
\end{tabular}

Tabla A.19. Test T comparando las diferentes lengüetas en los valores de desviación estándar de la afinación (F0 en semitonos).

\begin{tabular}{|c|c|c|c|c|c|c|c|c|c|}
\hline \multicolumn{10}{|c|}{ Paired Samples Testa } \\
\hline & & \multicolumn{8}{|c|}{ Paired Differences } \\
\hline & & \multirow[b]{2}{*}{ Mean } & \multirow{2}{*}{$\begin{array}{c}\text { Std, } \\
\text { Deviation }\end{array}$} & \multirow{2}{*}{$\begin{array}{c}\text { Std, } \\
\text { Error } \\
\text { Mean }\end{array}$} & \multicolumn{2}{|c|}{$\begin{array}{c}95 \% \text { Confidence Interval of } \\
\text { the Difference }\end{array}$} & \multirow[b]{2}{*}{$\mathrm{t}$} & \multirow[b]{2}{*}{$\mathrm{df}$} & \multirow{2}{*}{$\begin{array}{l}\text { Sig, }(2- \\
\text { tailed })\end{array}$} \\
\hline & & & & & Lower & Upper & & & \\
\hline Pair 1 & al1 - al2 & 0160 & ,0333 & ,0072 & ,0008 & ,0312 & 2,208 & 20 & ,039 \\
\hline Pair 2 & al1 - am1 & 0051 & 0388 & 0084 &,- 0125 & ,0228 & 608 & 20 &, 550 \\
\hline Pair 3 & al1 - am2 &,- 0046 & 0281 & 0061 &,- 0174 & ,0081 &,- 764 & 20 & ,454 \\
\hline Pair 4 & all - fr1 & 0091 & 0326 & 0071 &,- 0057 & 0240 & 1,286 & 20 & ,213 \\
\hline Pair 5 & al1 - fr2 & 0250 & 0356 & 0077 & 0088 & 0412 & 3,228 & 20 & 004 \\
\hline Pair 6 & $\mathrm{a} 2$ - am1 &,- 0109 & 0352 & 0076 &,- 0269 &, 0050 & $-1,423$ & 20 &, 170 \\
\hline Pair 7 & $\mathrm{al} 2-\mathrm{am} 2$ &,- 0207 & 0344 & 0075 &,- 0364 &,- 0050 & $-2,763$ & 20 &, 012 \\
\hline Pair 8 & $\mathrm{a} 2$ - fr1 &,- 0069 & 0437 & 0095 &,- 0268 & ,0130 &,- 724 & 20 & ,477 \\
\hline Pair 9 & $\mathrm{al} 2$ - fr2 & ,0089 & 0333 & ,0072 &,- 0061 & 0241 & 1,237 & 20 & ,230 \\
\hline Pair 10 & $\mathrm{am} 1-\mathrm{am} 2$ &,- 0098 & ,0303 & ,0066 &,- 0236 & ,0039 & $-1,488$ & 20 & ,152 \\
\hline Pair 11 & $\mathrm{am} 1$ - fr1 & 0040 & 0384 & ,0084 &,- 0135 & ,0215 & ,479 & 20 & 637 \\
\hline Pair 12 & $\mathrm{am} 1$ - fr2 & ,0199 & ,0366 & 0079 & ,0032 & ,0366 & 2,493 & 20 & ,022 \\
\hline Pair 13 & $\mathrm{am} 2-\mathrm{fr} 1$ & ,0138 & ,0309 & ,0067 &,- 0002 & 0279 & 2,051 & 20 & 054 \\
\hline Pair 14 & $\mathrm{am} 2-\mathrm{fr} 2$ & 0297 & ,0356 & ,0077 & ,0135 & 0460 & 3,828 & 20 & ,001 \\
\hline Pair 15 & $\mathrm{fr} 1-\mathrm{fr} 2$ & 0159 & ,0377 & ,0082 &,- 0012 & 0331 & 1,930 & 20 & 068 \\
\hline
\end{tabular}

Tabla A.20. Test T comparando las diferentes lengüetas en los valores de jitter.

\begin{tabular}{|c|c|c|c|c|c|c|c|c|}
\hline \multicolumn{9}{|c|}{ Paired Samples Test ${ }^{\mathrm{a}}$} \\
\hline & \multicolumn{8}{|c|}{ Paired Differences } \\
\hline & \multirow[b]{2}{*}{ Mean } & \multirow{2}{*}{$\begin{array}{c}\text { Std, } \\
\text { Deviation }\end{array}$} & \multirow{2}{*}{$\begin{array}{l}\text { Std, Error } \\
\text { Mean }\end{array}$} & \multicolumn{2}{|c|}{$\begin{array}{c}95 \% \text { Confidence Interval } \\
\text { of the Difference }\end{array}$} & \multirow[b]{2}{*}{$\mathrm{t}$} & \multirow[b]{2}{*}{$\mathrm{df}$} & \multirow{2}{*}{$\begin{array}{l}\text { Sig, (2- } \\
\text { tailed) }\end{array}$} \\
\hline & & & & Lower & Upper & & & \\
\hline Pair $1 \quad$ all - al2 & 11,4347 & 42,6516 & 8,8934 & $-7,0091$ & 29,8787 & 1,286 & 22 & 212 \\
\hline
\end{tabular}




\begin{tabular}{|c|c|c|c|c|c|c|c|c|c|}
\hline \multicolumn{10}{|c|}{ Paired Samples Test ${ }^{\mathrm{a}}$} \\
\hline & & \multicolumn{8}{|c|}{ Paired Differences } \\
\hline & & \multirow[b]{2}{*}{ Mean } & \multirow{2}{*}{$\begin{array}{c}\text { Std, } \\
\text { Deviation }\end{array}$} & \multirow{2}{*}{$\begin{array}{l}\text { Std, Error } \\
\text { Mean }\end{array}$} & \multicolumn{2}{|c|}{$\begin{array}{c}95 \% \text { Confidence Interval } \\
\text { of the Difference }\end{array}$} & \multirow[b]{2}{*}{$\mathrm{t}$} & \multirow[b]{2}{*}{$\mathrm{df}$} & \multirow{2}{*}{$\begin{array}{l}\text { Sig, (2- } \\
\text { tailed) }\end{array}$} \\
\hline & & & & & Lower & Upper & & & \\
\hline Pair 2 & all - aml & $-3,4545$ & 25,6324 & 5,4648 & $-14,8193$ & 7,9102 &,- 632 & 21 & ,534 \\
\hline Pair 3 & al1 - am2 &, 1304 & 14,9158 & 3,1101 & $-6,3196$ & 6,5805 & ,042 & 22 & ,967 \\
\hline Pair 4 & al1 - fr1 & 8,9565 & 23,9060 & 4,9847 & $-1,3812$ & 19,2942 & 1,797 & 22 & 086 \\
\hline Pair 5 & al1 - fr2 & $-11,3913$ & 52,4289 & 10,9321 & $-34,0632$ & 11,2806 & $-1,042$ & 22 & ,309 \\
\hline Pair 6 & $\mathrm{al} 2-\mathrm{am} 1$ & $-14,9545$ & 48,6459 & 10,3713 & $-36,5229$ & 6,6138 & $-1,442$ & 21 & ,164 \\
\hline Pair 7 & al2 - am2 & $-11,3043$ & 35,1224 & 7,3235 & $-26,4924$ & 3,8837 & $-1,544$ & 22 & ,137 \\
\hline Pair 8 & al2 - fr1 & $-2,4782$ & 50,7380 & 10,5796 & $-24,4190$ & 19,4625 &,- 234 & 22 &, 817 \\
\hline Pair 9 & $\mathrm{al} 2$ - fr2 & $-22,8260$ & 73,0893 & 15,2401 & $-54,4323$ & 8,7801 & $-1,498$ & 22 & , 148 \\
\hline Pair 10 & $\mathrm{am} 1$ - am2 & 3,36363 & 29,8768 & 6,3697 & $-9,8829$ & 16,6102 &, 528 & 21 & ,603 \\
\hline Pair 11 & $\mathrm{am} 1$ - fr1 & 13,0000 & 40,5509 & 8,6454 & $-4,9792$ & 30,9792 & 1,504 & 21 & , 148 \\
\hline Pair 12 & $\mathrm{am} 1$ - fr2 & $-9,0000$ & 53,9647 & 11,5053 & $-32,9266$ & 14,9266 &,- 782 & 21 & ,443 \\
\hline Pair 13 & $\mathrm{am} 2$ - fr1 & 8,8260 & 21,2081 & 4,4222 &,- 3450 & 17,9971 & 1,996 & 22 & 058 \\
\hline Pair 14 & $\mathrm{am} 2$ - fr2 & $-11,5217$ & 49,4054 & 10,3017 & $-32,8862$ & 9,8427 & $-1,118$ & 22 & ,275 \\
\hline Pair 15 & fr1 - fr2 & $-20,3478$ & 37,6667 & 7,8540 & $-36,6361$ & $-4,0595$ & $-2,591$ & 22 & 017 \\
\hline
\end{tabular}

Tabla A.21. Test T comparando las diferentes lengüetas en los valores de facilidad de vibración (No. Voiced Frames).

\begin{tabular}{|c|c|c|c|c|c|c|c|c|c|}
\hline \multicolumn{10}{|c|}{ Paired Samples Test ${ }^{\mathrm{a}}$} \\
\hline & & \multicolumn{8}{|c|}{ Paired Differences } \\
\hline & & \multirow[b]{2}{*}{ Mean } & \multirow{2}{*}{$\begin{array}{c}\text { Std, } \\
\text { Deviation }\end{array}$} & \multirow{2}{*}{$\begin{array}{c}\text { Std, } \\
\text { Error } \\
\text { Mean }\end{array}$} & \multicolumn{2}{|c|}{$\begin{array}{l}95 \% \text { Confidence Interval of } \\
\text { the Difference }\end{array}$} & \multirow[b]{2}{*}{$\mathrm{t}$} & \multirow[b]{2}{*}{$\mathrm{df}$} & \multirow{2}{*}{$\begin{array}{l}\text { Sig, }(2- \\
\text { tailed) }\end{array}$} \\
\hline & & & & & Lower & Upper & & & \\
\hline Pair 1 & al1 - al2 & $-1,2152$ & 3,4702 & ,6940 & $-2,6477$ & 2171 & $-1,751$ & 24 & ,093 \\
\hline Pair 2 & all - am1 & 2,9870 & 4,6770 & ,9546 & 1,0121 & 4,9619 & 3,129 & 23 & ,005 \\
\hline Pair 3 & all - am2 & ,6379 & 3,7668 &, 7533 &,- 9168 & 2,1928 & 847 & 24 & ,405 \\
\hline Pair 4 & al1 - fr1 &,- 2997 & 3,5430 & ,7086 & $-1,7622$ & 1,1627 &,- 423 & 24 & 676 \\
\hline Pair 5 & al1 - fr2 & ,0898 & 2,6907 &, 5381 & $-1,0207$ & 1,2005 & ,167 & 24 & 869 \\
\hline Pair 6 & $\mathrm{a} 2$ - am1 & 4,1426 & 5,8751 & 1,1992 & 1,6618 & 6,6235 & 3,454 & 23 & ,002 \\
\hline Pair 7 & $\mathrm{a} 2 \mathrm{-am} 2$ & 1,8532 & 4,0304 &, 8060 & , 1895 & 3,5169 & 2,299 & 24 & 031 \\
\hline Pair 8 & al2 - fr1 & ,9155 & 3,6596 &, 7319 &,- 5951 & 2,4261 & 1,251 & 24 & ,223 \\
\hline Pair 9 & al2 - fr2 & 1,3051 & 3,2219 & ,6443 &,- 02481 & 2,6351 & 2,025 & 24 & ,054 \\
\hline Pair 10 & $\mathrm{am} 1-\mathrm{am} 2$ & $-2,2768$ & 2,8709 & ,5860 & $-3,4891$ & $-1,0645$ & $-3,885$ & 23 & ,001 \\
\hline Pair 11 & am1 - fr1 & $-3,3636$ & 3,7939 &, 7744 & $-4,9656$ & $-1,7615$ & $-4,343$ & 23 & ,000 \\
\hline Pair 12 & $\mathrm{am} 1$ - fr2 & $-2,9255$ & 5,2133 & 1,0641 & $-5,1269$ &,- 7241 & $-2,749$ & 23 & 011 \\
\hline Pair 13 & $\mathrm{am} 2$ - fr1 &,- 9377 & 2,8059 & ,5611 & $-2,0959$ & ,2205 & $-1,671$ & 24 & , 108 \\
\hline Pair 14 & $\mathrm{am} 2$ - fr2 &,- 5481 & 4,5886 & ,9177 & $-2,4421$ & 1,3459 &,- 597 & 24 & ,556 \\
\hline Pair 15 & $\mathrm{fr} 1-\mathrm{fr} 2$ &, 3896 & 3,8660 & ,7732 & $-1,2062$ & 1,9854 & ,504 & 24 & ,619 \\
\hline
\end{tabular}

Tabla A22. Test T comparando las diferentes lengüetas en los valores de armonicidad media. 


\begin{tabular}{|c|c|c|c|c|c|c|c|c|c|}
\hline \multicolumn{10}{|c|}{ Paired Samples Test ${ }^{a}$} \\
\hline & & \multicolumn{8}{|c|}{ Paired Differences } \\
\hline & & \multirow[b]{2}{*}{ Mean } & \multirow{2}{*}{$\begin{array}{c}\text { Std, } \\
\text { Deviation }\end{array}$} & \multirow{2}{*}{$\begin{array}{c}\text { Std, Error } \\
\text { Mean }\end{array}$} & \multicolumn{2}{|c|}{$\begin{array}{l}95 \% \text { Confidence Interval } \\
\text { of the Difference }\end{array}$} & \multirow[b]{2}{*}{$\mathrm{t}$} & \multirow[b]{2}{*}{ df } & \multirow{2}{*}{$\begin{array}{l}\text { Sig, }(2- \\
\text { tailed) }\end{array}$} \\
\hline & & & & & Lower & Upper & & & \\
\hline Pair 1 & al1 - al2 & $-23,0693$ & 53,4317 & 10,6863 & $-45,1249$ & $-1,0138$ & $-2,159$ & 24 & ,041 \\
\hline Pair 2 & al1 - am1 & 29,5328 & 53,6025 & 10,9415 & 6,8984 & 52,1671 & 2,699 & 23 & 013 \\
\hline Pair 3 & al1 - am2 & 26,4218 & 50,3021 & 10,0604 & 5,6581 & 47,1855 & 2,626 & 24 & ,015 \\
\hline Pair 4 & al1 - fr1 & 12,0020 & 23,7864 & 4,7572 & 2,1834 & 21,8206 & 2,523 & 24 & ,019 \\
\hline Pair 5 & all - fr2 & 20,8253 & 37,2863 & 7,4572 & 5,4343 & 36,2164 & 2,793 & 24 &, 010 \\
\hline Pair 6 & $\mathrm{al} 2-\mathrm{am} 1$ & 51,5894 & 93,5625 & 19,0983 & 12,0814 & 91,0974 & 2,701 & 23 & ,013 \\
\hline Pair 7 & $\mathrm{al} 2-\mathrm{am} 2$ & 49,4912 & 81,0151 & 16,2030 & 16,0498 & 82,9326 & 3,054 & 24 & ,005 \\
\hline Pair 8 & $\mathrm{al} 2$ - fr1 & 35,0714 & 63,4705 & 12,6941 & 8,8720 & 61,2707 & 2,763 & 24 & ,011 \\
\hline Pair 9 & $\mathrm{a} 2 \mathrm{-fr} 2$ & 43,8947 & 78,7037 & 15,7407 & 11,4074 & 76,3820 & 2,789 & 24 & 010 \\
\hline Pair 10 & $\mathrm{am} 1$ - am2 & $-2,2640$ & 45,0014 & 9,1858 & $-21,2665$ & 16,7384 &,- 246 & 23 & ,808 \\
\hline Pair 11 & $\mathrm{am} 1$ - fr1 & $-16,6979$ & 36,6656 & 7,4843 & $-32,1804$ & $-1,2153$ & $-2,231$ & 23 & ,036 \\
\hline Pair 12 & $\mathrm{am} 1$ - fr2 & $-5,9904$ & 27,9330 & 5,7018 & $-17,7854$ & 5,8046 & $-1,051$ & 23 & ,304 \\
\hline Pair 13 & $\mathrm{am} 2-\mathrm{fr} 1$ & $-14,4197$ & 40,4813 & 8,0962 & $-31,1296$ & 2,2900 & $-1,781$ & 24 & ,088 \\
\hline Pair 14 & $\mathrm{am} 2-\mathrm{fr} 2$ & $-5,5964$ & 35,4341 & 7,0868 & $-20,2229$ & 9,0300 &,- 790 & 24 & ,437 \\
\hline Pair 15 & $\mathrm{fr} 1$ - fr2 & 8,8233 & 23,8933 & 4,7786 & $-1,0393$ & 18,6860 & 1,846 & 24 & ,077 \\
\hline
\end{tabular}

Tabla A.23. Test T comparando las diferentes lengüetas en los valores de Kurtosis.

\begin{tabular}{|c|c|c|c|c|c|c|c|c|c|}
\hline \multicolumn{10}{|c|}{ Paired Samples Test ${ }^{\mathrm{a}}$} \\
\hline & & \multicolumn{8}{|c|}{ Paired Differences } \\
\hline & & \multirow[b]{2}{*}{ Mean } & \multirow{2}{*}{$\begin{array}{c}\text { Std, } \\
\text { Deviation }\end{array}$} & \multirow{2}{*}{$\begin{array}{c}\text { Std, } \\
\text { Error } \\
\text { Mean }\end{array}$} & \multicolumn{2}{|c|}{$\begin{array}{c}95 \% \text { Confidence Interval of } \\
\text { the Difference }\end{array}$} & \multirow[b]{2}{*}{$\mathrm{t}$} & \multirow[b]{2}{*}{$\mathrm{df}$} & \multirow{2}{*}{$\begin{array}{l}\text { Sig, (2- } \\
\text { tailed) }\end{array}$} \\
\hline & & & & & Lower & Upper & & & \\
\hline Pair 1 & al1 - al2 &,- 9983 & 1,9042 & ,3808 & $-1,7844$ &,- 2123 & $-2,621$ & 24 &, 015 \\
\hline Pair 2 & al1 - am1 & 1,6852 & 3,1857 & ,6502 & 3400 & 3,0305 & 2,592 & 23 & ,016 \\
\hline Pair 3 & al1 - am2 & 1,1348 & 2,6186 &, 5237 & 0539 & 2,2158 & 2,167 & 24 &, 040 \\
\hline Pair 4 & all - fr1 & ,8391 & 1,1675 & ,2335 &, 35725 & 1,3211 & 3,594 & 24 & 001 \\
\hline Pair 5 & al1 - fr2 & 1,3783 & 1,9015 & ,3803 & 5934 & 2,1633 & 3,624 & 24 & ,001 \\
\hline Pair 6 & $\mathrm{al} 2$ - am1 & 2,6369 & 4,4543 & ,9092 & ,7560 & 4,5178 & 2,900 & 23 & ,008 \\
\hline Pair 7 & $\mathrm{a} 2-\mathrm{am} 2$ & 2,1332 & 3,4967 & 6993 & 6898 & 3,5766 & 3,050 & 24 & ,006 \\
\hline Pair 8 & al2 - fr1 & 1,8375 & 2,3432 & ,4686 & ,8703 & 2,8048 & 3,921 & 24 & ,001 \\
\hline Pair 9 & $\mathrm{a} 2 \mathrm{2}-\mathrm{fr} 2$ & 2,3767 & 3,3068 & ,6613 & 1,0117 & 3,7417 & 3,594 & 24 & ,001 \\
\hline Pair 10 & $\mathrm{am} 1-\mathrm{am} 2$ &,- 4917 & 2,2383 & ,4568 & $-1,4369$ & ,4534 & $-1,076$ & 23 & ,293 \\
\hline Pair 11 & am1 - fr1 &,- 7985 & 2,4009 & 4900 & $-1,8123$ & ,2152 & $-1,629$ & 23 & ,117 \\
\hline Pair 12 & am1 - fr2 &,- 2169 & 1,8299 & ,3735 &,- 9897 & ,5557 &,- 581 & 23 & ,567 \\
\hline Pair 13 & am 2 - fr1 &,- 2957 & 1,9120 & ,3824 & $-1,0849$ & ,4935 &,- 773 & 24 & ,447 \\
\hline Pair 14 & $\mathrm{am} 2-\mathrm{fr} 2$ & ,2434 & 1,6173 & ,3234 &,- 4241 & 9111 & ,753 & 24 & ,459 \\
\hline Pair 15 & $\mathrm{fr} 1$ - fr2 & ,5391 & 1,3320 & 2664 &,- 01064 & 1,0890 & 2,024 & 24 & ,054 \\
\hline
\end{tabular}

Tabla A.24. Test T comparando las diferentes lengüetas en los valores de Skewness. 


\subsubsection{Experimento principal}

\subsubsection{Percepción tímbrica}

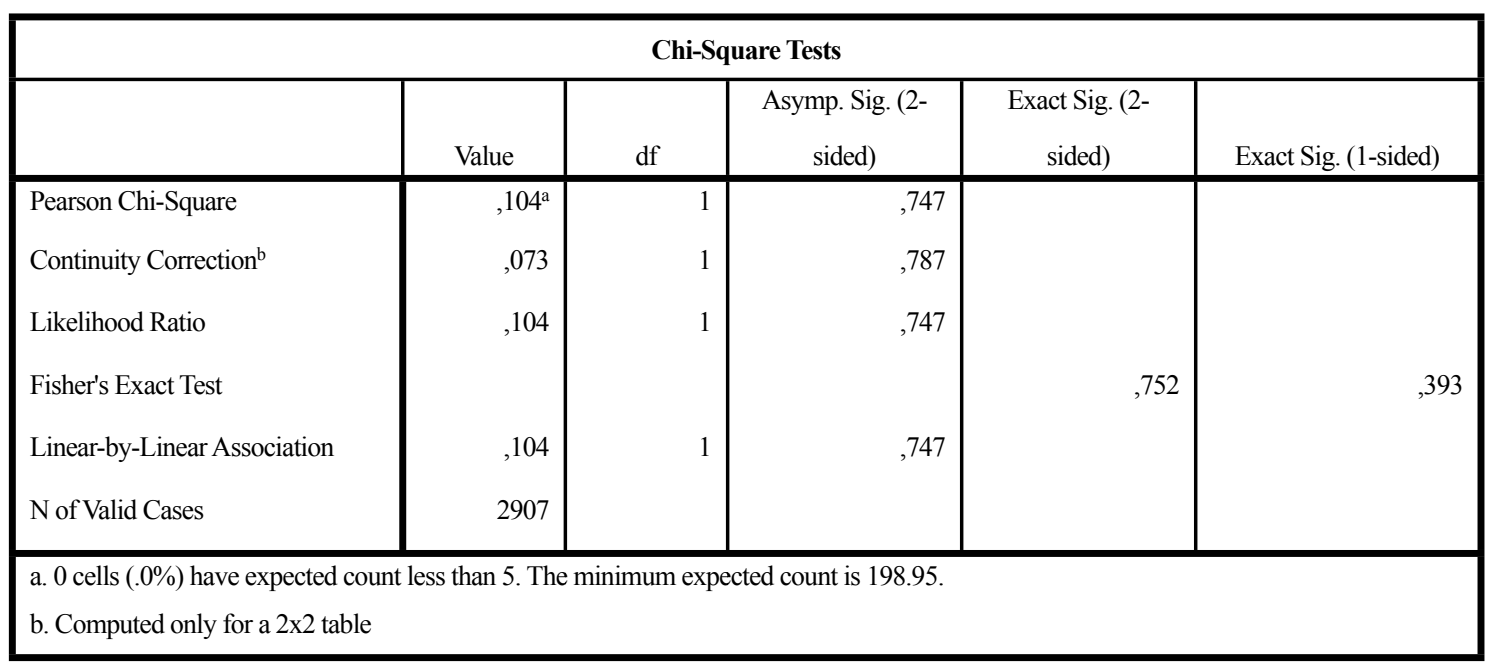

Tabla A.25. Prueba de $\chi^{2}$ de Pearson comparando las agrupaciones de los oyentes según los diferentes grosores en el estímulo 1.

\begin{tabular}{|c|c|c|c|c|c|}
\hline \multicolumn{6}{|c|}{ Chi-Square Tests } \\
\hline & Value & $\mathrm{df}$ & $\begin{array}{l}\text { Asymp. Sig. (2- } \\
\text { sided) }\end{array}$ & $\begin{array}{l}\text { Exact Sig. (2- } \\
\text { sided) }\end{array}$ & Exact Sig. (1-sided) \\
\hline Pearson Chi-Square & $2,899^{\mathrm{a}}$ & 1 & ,089 & \multirow{6}{*}{089} & \multirow{6}{*}{, 050} \\
\hline Continuity Correction ${ }^{\mathrm{b}}$ & 2,721 & 1 & ,099 & & \\
\hline Likelihood Ratio & 2,874 & 1 & ,090 & & \\
\hline Fisher's Exact Test & & \multirow{3}{*}{1} & \multirow{3}{*}{089} & & \\
\hline Linear-by-Linear Association & 2,898 & & & & \\
\hline $\mathrm{N}$ of Valid Cases & 3610 & & & & \\
\hline a. 0 cells $(.0 \%)$ have expected & in $5 . \mathrm{Th}$ & um exp & $\mathrm{d}$ count is 165.00 . & & \\
\hline b. Computed only for a $2 \times 2$ tat & & & & & \\
\hline
\end{tabular}

Tabla A.26. Prueba de $\chi^{2}$ de Pearson comparando las agrupaciones de los oyentes según los diferentes grosores en el estímulo 2.

\begin{tabular}{|c|c|c|c|c|c|}
\hline \multicolumn{6}{|c|}{ Chi-Square Tests } \\
\hline & Value & $\mathrm{df}$ & $\begin{array}{l}\text { Asymp. Sig. (2- } \\
\text { sided) }\end{array}$ & $\begin{array}{l}\text { Exact Sig. (2- } \\
\text { sided) }\end{array}$ & Exact Sig. (1-sided) \\
\hline Pearson Chi-Square &, $796^{\mathrm{a}}$ & 1 & 372 & \multirow{6}{*}{,387 } & \multirow{6}{*}{,202 } \\
\hline Continuity Correction ${ }^{b}$ & 696 & 1 & ,404 & & \\
\hline Likelihood Ratio & ,788 & 1 & ,375 & & \\
\hline Fisher's Exact Test & & & & & \\
\hline Linear-by-Linear Association & ,796 & 1 & .372 & & \\
\hline $\mathrm{N}$ of Valid Cases & 2907 & & & & \\
\hline $\begin{array}{l}\text { a. } 0 \text { cells }(.0 \%) \text { have expected } \\
\text { b. Computed only for a } 2 \times 2 \text { tal }\end{array}$ & & $n$ expe & ount is 125.26 . & & \\
\hline
\end{tabular}


Tabla A.27. Prueba de $\chi^{2}$ de Pearson comparando las agrupaciones de los oyentes según los diferentes moldes en el estímulo 1.

\begin{tabular}{|c|c|c|c|c|c|}
\hline \multicolumn{6}{|c|}{ Chi-Square Tests } \\
\hline & Value & $\mathrm{df}$ & $\begin{array}{l}\text { Asymp. Sig. (2- } \\
\text { sided) }\end{array}$ & $\begin{array}{l}\text { Exact Sig. (2- } \\
\text { sided) }\end{array}$ & Exact Sig. (1-sided) \\
\hline Pearson Chi-Square & $1,015^{\mathrm{a}}$ & 1 &, 314 & \multirow{6}{*}{, 327} & \multirow{6}{*}{, 171} \\
\hline Continuity Correction ${ }^{\mathrm{b}}$ & 902 & 1 &, 342 & & \\
\hline Likelihood Ratio & 1,004 & 1 & ,316 & & \\
\hline Fisher's Exact Test & & & & & \\
\hline Linear-by-Linear Association & 1,015 & 1 &, 314 & & \\
\hline $\mathrm{N}$ of Valid Cases & 2907 & & & & \\
\hline $\begin{array}{l}\text { a. } 0 \text { cells }(.0 \%) \text { have expected } \\
\text { b. Computed only for a } 2 \times 2 \text { tal }\end{array}$ & in 5. The & $\mathrm{um} \exp$ & ted count is 125.26 & & \\
\hline
\end{tabular}

Tabla A.28. Prueba de $\chi^{2}$ de Pearson comparando las agrupaciones de los oyentes según las diferentes escuelas de rebajado en el estímulo 1.

\begin{tabular}{|c|c|c|c|c|c|}
\hline \multicolumn{6}{|c|}{ Chi-Square Tests } \\
\hline & Value & $\mathrm{df}$ & $\begin{array}{c}\text { Asymp. Sig. (2- } \\
\text { sided) }\end{array}$ & $\begin{array}{c}\text { Exact Sig. (2- } \\
\text { sided) }\end{array}$ & Exact Sig. (1-sided) \\
\hline Pearson Chi-Square & $418^{\mathrm{a}}$ & 1 &, 518 & \multirow{6}{*}{, 540} & \multirow{6}{*}{,276 } \\
\hline Continuity Correction ${ }^{\mathrm{b}}$ & ,349 & 1 &, 555 & & \\
\hline Likelihood Ratio & ,415 & 1 &, 520 & & \\
\hline Fisher's Exact Test & & & & & \\
\hline Linear-by-Linear Association & ,417 & 1 &, 518 & & \\
\hline $\mathrm{N}$ of Valid Cases & 3610 & & & & \\
\hline a. 0 cells $(.0 \%)$ have expected & n. The & $\mathrm{mes}$ & count is 134.20 . & & \\
\hline
\end{tabular}

Tabla A.29. Prueba de $\chi^{2}$ de Pearson comparando las agrupaciones de los oyentes según las diferentes escuelas de rebajado en el estímulo 2.

\begin{tabular}{|c|c|c|c|c|c|}
\hline \multicolumn{6}{|c|}{ Chi-Square Tests } \\
\hline & Value & $\mathrm{df}$ & $\begin{array}{c}\text { Asymp. Sig. (2- } \\
\text { sided) }\end{array}$ & $\begin{array}{c}\text { Exact Sig. (2- } \\
\text { sided) }\end{array}$ & Exact Sig. (1-sided) \\
\hline Pearson Chi-Square & $6,907^{\mathrm{a}}$ & 1 & ,009 & \multirow{6}{*}{, 010} & \multirow{6}{*}{006} \\
\hline Continuity Correction ${ }^{\mathrm{b}}$ & 6,562 & 1 & ,010 & & \\
\hline Likelihood Ratio & 6,569 & 1 & 010 & & \\
\hline Fisher's Exact Test & & & & & \\
\hline Linear-by-Linear Association & 6,905 & 1 & ,009 & & \\
\hline $\mathrm{N}$ of Valid Cases & 3610 & & & & \\
\hline a. 0 cells $(.0 \%)$ have expected c & 5. The & $m \exp$ & th is 79.20 . & & \\
\hline
\end{tabular}

Tabla A.30. Prueba de $\chi^{2}$ de Pearson comparando las agrupaciones de los oyentes según los diferentes 
oboístas de rebajado en el estímulo 2.

\subsubsection{Acústica de la lengüeta}

\begin{tabular}{|c|c|c|c|c|c|c|}
\hline \multicolumn{7}{|c|}{ Pruebas de los efectos inter-sujetos ${ }^{\mathrm{a}}$} \\
\hline \multicolumn{7}{|l|}{ Variable dependiente: Valor Norm. } \\
\hline Origen & $\begin{array}{c}\text { Suma de } \\
\text { cuadrados tipo III }\end{array}$ & $\mathrm{gl}$ & $\begin{array}{c}\text { Media } \\
\text { cuadrática }\end{array}$ & $\mathrm{F}$ & Sig. & $\begin{array}{c}\text { Eta al } \\
\text { cuadrado } \\
\text { parcial }\end{array}$ \\
\hline Modelo corregido & $753,012^{b}$ & 119 & 6,328 & 47,140 & 0,000 & 0,829 \\
\hline Intersección & 130,435 & 1 & 130,435 & 971,685 & 0,000 & 0,456 \\
\hline rebajado & 338,465 & 2 & 169,232 & 1260,714 & 0,000 & 0,685 \\
\hline molde & 0,231 & 1 & 0,231 & 1,718 & 0,190 & 0,001 \\
\hline grosor & 10,445 & 1 & 10,445 & 77,811 & 0,000 & 0,063 \\
\hline oboista & 273,124 & 10 & 27,312 & 203,467 & 0,000 & 0,637 \\
\hline rebajado $*$ molde & 1,860 & 2 & 0,930 & 6,929 & 0,001 & 0,012 \\
\hline rebajado * grosor & 2,005 & 2 & 1,003 & 7,469 & 0,001 & 0,013 \\
\hline rebajado * oboista & 10,344 & 19 & 0,544 & 4,056 & 0,000 & 0,062 \\
\hline molde * grosor & 1,004 & 1 & 1,004 & 7,483 & 0,006 & 0,006 \\
\hline molde * oboista & 7,650 & 9 & 0,850 & 6,332 & 0,000 & 0,047 \\
\hline grosor * oboista & 7,698 & 10 & 0,770 & 5,735 & 0,000 & 0,047 \\
\hline rebajado * molde * grosor & 0,977 & 2 & 0,489 & 3,640 & 0,027 & 0,006 \\
\hline rebajado $*$ molde $*$ oboista & 7,620 & 16 & 0,476 & 3,548 & 0,000 & 0,047 \\
\hline rebajado $*$ grosor $*$ oboista & 10,009 & 16 & 0,626 & 4,660 & 0,000 & 0,060 \\
\hline molde * grosor * oboista & 3,105 & 8 & 0,388 & 2,892 & 0,003 & 0,020 \\
\hline rebajado $*$ molde $*$ grosor $*$ oboista & 10,819 & 16 & 0,676 & 5,037 & 0,000 & 0,065 \\
\hline Error & 155,579 & 1159 & 0,134 & & & \\
\hline Total & 1008,390 & 1279 & & & & \\
\hline Total corregida & 908,591 & 1278 & & & & \\
\hline $\begin{array}{l}\text { a. } \text { Measurement }=F 0 \text { Mean (st) } \\
\text { b. } \text { R cuadrado }=, 829 \text { (R cuadrado cor }\end{array}$ & & & & & & \\
\hline
\end{tabular}

Tabla A.31. Análisis de varianza factorial sobre la frecuencia media (en semitonos) para los factores rebajado, molde, grosor y oboísta.

\begin{tabular}{|c|c|c|c|c|c|c|}
\hline \multicolumn{7}{|c|}{ Pruebas de los efectos inter-sujetos $^{\mathrm{a}}$} \\
\hline \multicolumn{7}{|c|}{ Variable dependiente: Valor Norm. } \\
\hline Origen & $\begin{array}{c}\text { Suma de } \\
\text { cuadrados tipo III }\end{array}$ & $\mathrm{gl}$ & $\begin{array}{c}\text { Media } \\
\text { cuadrática }\end{array}$ & $\mathrm{F}$ & Sig. & $\begin{array}{c}\text { Eta al } \\
\text { cuadrado } \\
\text { parcial }\end{array}$ \\
\hline Modelo corregido & $166,794^{b}$ & 119 & 1,402 & 1,670 & 0,000 & 0,146 \\
\hline Intersección & 7,212 & 1 & 7,212 & 8,593 & 0,003 & 0,007 \\
\hline rebajado & 15,714 & 2 & 7,857 & 9,362 & 0,000 & 0,016 \\
\hline
\end{tabular}


Influencias en la percepción sonora y en la interpretación del rebajado de la lengüeta del oboe

\begin{tabular}{|c|c|c|c|c|c|c|}
\hline \multicolumn{7}{|c|}{ Pruebas de los efectos inter-sujetos ${ }^{\mathrm{a}}$} \\
\hline \multicolumn{7}{|l|}{ Variable dependiente: Valor Norm. } \\
\hline Origen & \begin{tabular}{c|} 
Suma de \\
cuadrados tipo III
\end{tabular} & $\overline{\mathrm{gl}}$ & $\begin{array}{c}\text { Media } \\
\text { cuadrática }\end{array}$ & $\mathrm{F}$ & Sig. & $\begin{array}{c}\text { Eta al } \\
\text { cuadrado } \\
\text { parcial }\end{array}$ \\
\hline molde & 0,095 & 1 & 0,095 & 0,113 & 0,737 & 0,000 \\
\hline grosor & 3,497 & 1 & 3,497 & 4,167 & 0,041 & 0,004 \\
\hline oboista & 42,747 & 10 & 4,275 & 5,093 & 0,000 & 0,042 \\
\hline rebajado $*$ molde & 2,958 & 2 & 1,479 & 1,762 & 0,172 & 0,003 \\
\hline rebajado * grosor & 0,175 & 2 & 0,088 & 0,104 & 0,901 & 0,000 \\
\hline rebajado * oboista & 37,238 & 19 & 1,960 & 2,335 & 0,001 & 0,037 \\
\hline molde * grosor & 0,796 & 1 & 0,796 & 0,948 & 0,330 & 0,001 \\
\hline molde * oboista & 4,161 & 9 & 0,462 & 0,551 & 0,838 & 0,004 \\
\hline grosor * oboista & 6,203 & 10 & 0,620 & 0,739 & 0,688 & 0,006 \\
\hline rebajado * molde * grosor & 1,749 & 2 & 0,874 & 1,042 & 0,353 & 0,002 \\
\hline rebajado $*$ molde $*$ oboista & 9,197 & 16 & 0,575 & 0,685 & 0,811 & 0,009 \\
\hline rebajado $*$ grosor $*$ oboista & 13,882 & 16 & 0,868 & 1,034 & 0,417 & 0,014 \\
\hline molde * grosor * oboista & 2,955 & 8 & 0,369 & 0,440 & 0,897 & 0,003 \\
\hline rebajado * molde * grosor * oboista & 12,572 & 16 & 0,786 & 0,936 & 0,527 & 0,013 \\
\hline Error & 972,696 & 1159 & 0,839 & & & \\
\hline Total & 1145,411 & 1279 & & & & \\
\hline Total corregida & 1139,490 & 1278 & & & & \\
\hline \multicolumn{7}{|l|}{ a. Measurement = F0 Delta $(\mathrm{en} \mathrm{Hz})$} \\
\hline
\end{tabular}

Tabla A.32. Análisis de varianza factorial sobre el delta de la frecuencia para los factores rebajado, molde, grosor y oboísta.

\begin{tabular}{|c|c|c|c|c|c|c|}
\hline \multicolumn{7}{|c|}{ Pruebas de los efectos inter-sujetos ${ }^{a}$} \\
\hline \multicolumn{7}{|c|}{ Variable dependiente: Valor Norm. } \\
\hline Origen & $\begin{array}{c}\text { Suma de } \\
\text { cuadrados tipo III }\end{array}$ & $\mathrm{gl}$ & $\begin{array}{c}\text { Media } \\
\text { cuadrática }\end{array}$ & $\mathrm{F}$ & Sig. & $\begin{array}{c}\text { Eta al } \\
\text { cuadrado } \\
\text { parcial }\end{array}$ \\
\hline Modelo corregido & $174,777^{b}$ & 119 & 1,469 & 1,578 & 0,000 & 0,139 \\
\hline Intersección & 3,840 & 1 & 3,840 & 4,125 & 0,042 & 0,004 \\
\hline rebajado & 8,297 & 2 & 4,149 & 4,457 & 0,012 & 0,008 \\
\hline molde & 0,513 & 1 & 0,513 & 0,551 & 0,458 & 0,000 \\
\hline grosor & 0,093 & 1 & 0,093 & 0,100 & 0,752 & 0,000 \\
\hline oboista & 49,824 & 10 & 4,982 & 5,352 & 0,000 & 0,044 \\
\hline rebajado * molde & 1,718 & 2 & 0,859 & 0,923 & 0,398 & 0,002 \\
\hline rebajado * grosor & 0,072 & 2 & 0,036 & 0,039 & 0,962 & 0,000 \\
\hline
\end{tabular}




\begin{tabular}{|c|c|c|c|c|c|c|}
\hline \multicolumn{7}{|c|}{ Pruebas de los efectos inter-sujetos ${ }^{\mathrm{a}}$} \\
\hline \multicolumn{7}{|l|}{ Variable dependiente: Valor Norm. } \\
\hline Origen & \begin{tabular}{c|} 
Suma de \\
cuadrados tipo III
\end{tabular} & $\mathrm{gl}$ & $\begin{array}{c}\text { Media } \\
\text { cuadrática }\end{array}$ & $\mathrm{F}$ & Sig. & $\begin{array}{c}\text { Eta al } \\
\text { cuadrado } \\
\text { parcial }\end{array}$ \\
\hline rebajado * oboista & 29,889 & 19 & 1,573 & 1,690 & 0,032 & 0,027 \\
\hline molde * grosor & 0,101 & 1 & 0,101 & 0,108 & 0,742 & 0,000 \\
\hline molde * oboista & 2,969 & 9 & 0,330 & 0,354 & 0,956 & 0,003 \\
\hline grosor * oboista & 5,257 & 10 & 0,526 & 0,565 & 0,844 & 0,005 \\
\hline rebajado * molde * grosor & 3,938 & 2 & 1,969 & 2,115 & 0,121 & 0,004 \\
\hline rebajado $*$ molde $*$ oboista & 19,299 & 16 & 1,206 & 1,296 & 0,191 & 0,018 \\
\hline rebajado $*$ grosor $*$ oboista & 9,085 & 16 & 0,568 & 0,610 & 0,878 & 0,008 \\
\hline molde * grosor * oboista & 4,140 & 8 & 0,517 & 0,556 & 0,814 & 0,004 \\
\hline rebajado $*$ molde $*$ grosor $*$ oboista & 18,970 & 16 & 1,186 & 1,274 & 0,206 & 0,017 \\
\hline Error & 1078,947 & 1159 & 0,931 & & & \\
\hline Total & 1256,377 & 1279 & & & & \\
\hline Total corregida & 1253,724 & 1278 & & & & \\
\hline $\begin{array}{l}\text { a. Measurement = F0 Std Dev (st) } \\
\text { b. } \text { R cuadrado }=, 139 \text { (R cuadrado cor }\end{array}$ & & & & & & \\
\hline
\end{tabular}

Tabla A.33. Análisis de varianza factorial sobre la desviación estándar de la frecuencia (en semitonos) para los factores rebajado, molde, grosor y oboísta.

\begin{tabular}{|c|c|c|c|c|c|c|}
\hline \multicolumn{7}{|c|}{ Pruebas de los efectos inter-sujetos ${ }^{\mathrm{a}}$} \\
\hline \multicolumn{7}{|c|}{ Variable dependiente: Valor Norm. } \\
\hline Origen & $\begin{array}{c}\text { Suma de } \\
\text { cuadrados tipo III }\end{array}$ & $\mathrm{gl}$ & $\begin{array}{c}\text { Media } \\
\text { cuadrática }\end{array}$ & $\mathrm{F}$ & Sig. & $\begin{array}{c}\text { Eta al } \\
\text { cuadrado } \\
\text { parcial }\end{array}$ \\
\hline Modelo corregido & $1466,818^{b}$ & 180 & 8,149 & 33,102 & 0,000 & 0,776 \\
\hline Intersección & 14,083 & 1 & 14,083 & 57,206 & 0,000 & 0,032 \\
\hline rebajado & 23,116 & 2 & 11,558 & 46,949 & 0,000 & 0,052 \\
\hline molde & 4,581 & 2 & 2,290 & 9,304 & 0,000 & 0,011 \\
\hline grosor & 4,815 & 1 & 4,815 & 19,559 & 0,000 & 0,011 \\
\hline oboista & 1225,114 & 10 & 122,511 & 497,651 & 0,000 & 0,743 \\
\hline rebajado $*$ molde & 3,072 & 4 & 0,768 & 3,120 & 0,014 & 0,007 \\
\hline rebajado * grosor & 1,513 & 2 & 0,756 & 3,073 & 0,047 & 0,004 \\
\hline rebajado * oboista & 30,612 & 20 & 1,531 & 6,217 & 0,000 & 0,067 \\
\hline molde * grosor & 9,903 & 2 & 4,951 & 20,113 & 0,000 & 0,023 \\
\hline molde * oboista & 11,954 & 20 & 0,598 & 2,428 & 0,000 & 0,027 \\
\hline grosor * oboista & 7,780 & 10 & 0,778 & 3,160 & 0,001 & 0,018 \\
\hline rebajado $*$ molde $*$ grosor & 17,223 & 4 & 4,306 & 17,490 & 0,000 & 0,039 \\
\hline
\end{tabular}


Influencias en la percepción sonora y en la interpretación del rebajado de la lengüeta del oboe

\begin{tabular}{|l|r|r|r|r|r|r|}
\hline \multicolumn{7}{|c|}{ Pruebas de los efectos inter-sujetos } \\
\hline Variable dependiente: Valor Norm. & \multicolumn{1}{|c|}{ Suma de } & gl & Media & F & Sig. & $\begin{array}{r}\text { Eta al } \\
\text { cuadrado } \\
\text { cuadrática }\end{array}$ \\
\hline Origen & \multicolumn{3}{|c|}{ parcial } \\
\hline
\end{tabular}

Tabla A.34. Análisis de varianza factorial sobre intensidad (en dB) para los factores rebajado, molde, grosor y oboista.

\begin{tabular}{|c|c|c|c|c|c|c|}
\hline \multicolumn{7}{|c|}{ Pruebas de los efectos inter-sujetos ${ }^{\mathrm{a}}$} \\
\hline \multicolumn{7}{|l|}{ Variable dependiente: Valor Norm. } \\
\hline Origen & $\begin{array}{c}\text { Suma de cuadrados } \\
\text { tipo III }\end{array}$ & gl & $\begin{array}{c}\text { Media } \\
\text { cuadrática }\end{array}$ & $\mathrm{F}$ & Sig. & $\begin{array}{c}\text { Eta al } \\
\text { cuadrado } \\
\text { parcial }\end{array}$ \\
\hline Modelo corregido & $1345,703^{\mathrm{b}}$ & 180 & 7,476 & 23,611 & 0,000 & 0,712 \\
\hline Intersección & 15,216 & 1 & 15,216 & 48,056 & 0,000 & 0,027 \\
\hline rebajado & 14,084 & 2 & 7,042 & 22,240 & 0,000 & 0,025 \\
\hline molde & 5,392 & 2 & 2,696 & 8,515 & 0,000 & 0,010 \\
\hline grosor & 4,104 & 1 & 4,104 & 12,961 & 0,000 & 0,007 \\
\hline oboista & 1074,856 & 10 & 107,486 & 339,461 & 0,000 & 0,664 \\
\hline rebajado $*$ molde & 4,486 & 4 & 1,121 & 3,542 & 0,007 & 0,008 \\
\hline rebajado * grosor & 3,657 & 2 & 1,829 & 5,775 & 0,003 & 0,007 \\
\hline rebajado $*$ oboista & 31,939 & 20 & 1,597 & 5,043 & 0,000 & 0,055 \\
\hline molde * grosor & 10,183 & 2 & 5,092 & 16,081 & 0,000 & 0,018 \\
\hline molde $*$ oboista & 13,777 & 20 & 0,689 & 2,176 & 0,002 & 0,025 \\
\hline grosor * oboista & 13,025 & 10 & 1,302 & 4,114 & 0,000 & 0,023 \\
\hline rebajado $*$ molde $*$ grosor & 12,767 & 4 & 3,192 & 10,080 & 0,000 & 0,023 \\
\hline rebajado $*$ molde $*$ oboista & 27,853 & 33 & 0,844 & 2,666 & 0,000 & 0,049 \\
\hline rebajado * grosor * oboista & 10,168 & 16 & 0,636 & 2,007 & 0,010 & 0,018 \\
\hline molde * grosor $*$ oboista & 16,170 & 16 & 1,011 & 3,192 & 0,000 & 0,029 \\
\hline rebajado * molde * grosor $*$ oboista & 43,140 & 32 & 1,348 & 4,258 & 0,000 & 0,073 \\
\hline Error & 544,297 & 1719 & 0,317 & & & \\
\hline
\end{tabular}




\begin{tabular}{|c|c|c|c|c|c|c|}
\hline \multicolumn{7}{|c|}{ Pruebas de los efectos inter-sujetos $^{\mathrm{a}}$} \\
\hline \multicolumn{7}{|l|}{ Variable dependiente: Valor Norm. } \\
\hline Origen & $\begin{array}{c}\text { Suma de cuadrados } \\
\text { tipo III }\end{array}$ & gl & $\begin{array}{c}\text { Media } \\
\text { cuadrática }\end{array}$ & $\mathrm{F}$ & Sig. & $\begin{array}{c}\text { Eta al } \\
\text { cuadrado } \\
\text { parcial }\end{array}$ \\
\hline Total & 1890,000 & 1900 & & & & \\
\hline Total corregida & 1890,000 & 1899 & & & & \\
\hline \multicolumn{7}{|l|}{ a. Measurement $=$ Amplitude Std Dev } \\
\hline b. $\mathrm{R}$ cuadrado $=, 712(\mathrm{R}$ cuadrado corregida $=, 682)$ & & & & & & \\
\hline
\end{tabular}

Tabla A.35. Análisis de varianza factorial sobre la desviación estándar de la amplitud para los factores rebajado, molde, grosor y oboísta.

\begin{tabular}{|c|c|c|c|c|c|c|}
\hline \multicolumn{7}{|c|}{ Pruebas de los efectos inter-sujetos ${ }^{\mathrm{a}}$} \\
\hline \multicolumn{7}{|l|}{ Variable dependiente: Valor Norm. } \\
\hline Origen & \begin{tabular}{c|} 
Suma de \\
cuadrados tipo III
\end{tabular} & $\mathrm{gl}$ & $\begin{array}{c}\text { Media } \\
\text { cuadrática }\end{array}$ & $\mathrm{F}$ & Sig. & $\begin{array}{c}\text { Eta al } \\
\text { cuadrado } \\
\text { parcial }\end{array}$ \\
\hline Modelo corregido & $610,328^{\mathrm{b}}$ & 180 & 3,391 & 4,555 & 0,000 & 0,323 \\
\hline Intersección & 0,891 & 1 & 0,891 & 1,197 & 0,274 & 0,001 \\
\hline rebajado & 15,090 & 2 & 7,545 & 10,135 & 0,000 & 0,012 \\
\hline molde & 1,700 & 2 & 0,850 & 1,142 & 0,319 & 0,001 \\
\hline grosor & 6,206 & 1 & 6,206 & 8,337 & 0,004 & 0,005 \\
\hline oboista & 239,265 & 10 & 23,927 & 32,141 & 0,000 & 0,158 \\
\hline rebajado $*$ molde & 0,734 & 4 & 0,184 & 0,247 & 0,912 & 0,001 \\
\hline rebajado * grosor & 1,510 & 2 & 0,755 & 1,014 & 0,363 & 0,001 \\
\hline rebajado * oboista & 94,244 & 20 & 4,712 & 6,330 & 0,000 & 0,069 \\
\hline molde * grosor & 9,195 & 2 & 4,597 & 6,176 & 0,002 & 0,007 \\
\hline molde * oboista & 27,998 & 20 & 1,400 & 1,880 & 0,010 & 0,021 \\
\hline grosor * oboista & 13,494 & 10 & 1,349 & 1,813 & 0,054 & 0,010 \\
\hline rebajado $*$ molde $*$ grosor & 6,855 & 4 & 1,714 & 2,302 & 0,057 & 0,005 \\
\hline rebajado $*$ molde $*$ oboista & 33,298 & 33 & 1,009 & 1,355 & 0,086 & 0,025 \\
\hline rebajado * grosor * oboista & 29,357 & 16 & 1,835 & 2,465 & 0,001 & 0,022 \\
\hline molde * grosor * oboista & 16,119 & 16 & 1,007 & 1,353 & 0,156 & 0,012 \\
\hline rebajado $*$ molde $*$ grosor $*$ oboista & 91,104 & 32 & 2,847 & 3,824 & 0,000 & 0,066 \\
\hline Error & 1279,672 & 1719 & 0,744 & & & \\
\hline Total & 1890,000 & 1900 & & & & \\
\hline Total corregida & 1890,000 & 1899 & & & & \\
\hline \multicolumn{7}{|l|}{ a. Measurement $=$ Number Voiced Frames } \\
\hline cuadrado $=, 323(\mathrm{R}$ cuadrado corregida $=$ & & & & & & \\
\hline
\end{tabular}

Tabla A.36. Análisis de varianza factorial el $N^{o}$ Voiced Frames para los factores rebajado, molde, grosor y 
oboísta.

\begin{tabular}{|c|c|c|c|c|c|c|}
\hline \multicolumn{7}{|c|}{ Pruebas de los efectos inter-sujetos ${ }^{a}$} \\
\hline \multicolumn{7}{|l|}{ Variable dependiente: Valor Norm. } \\
\hline Origen & \begin{tabular}{c|} 
Suma de \\
cuadrados tipo III
\end{tabular} & $\mathrm{gl}$ & $\begin{array}{c}\text { Media } \\
\text { cuadrática }\end{array}$ & F & Sig. & $\begin{array}{c}\text { Eta al } \\
\text { cuadrado } \\
\text { parcial }\end{array}$ \\
\hline Modelo corregido & $737,328^{b}$ & 180 & 4,096 & 6,109 & 0,000 & 0,390 \\
\hline Intersección & 2,107 & 1 & 2,107 & 3,142 & 0,076 & 0,002 \\
\hline rebajado & 12,139 & 2 & 6,070 & 9,052 & 0,000 & 0,010 \\
\hline molde & 6,850 & 2 & 3,425 & 5,108 & 0,006 & 0,006 \\
\hline grosor & 0,193 & 1 & 0,193 & 0,288 & 0,592 & 0,000 \\
\hline oboista & 503,746 & 10 & 50,375 & 75,125 & 0,000 & 0,304 \\
\hline rebajado * molde & 3,125 & 4 & 0,781 & 1,165 & 0,324 & 0,003 \\
\hline rebajado * grosor & 3,977 & 2 & 1,988 & 2,965 & 0,052 & 0,003 \\
\hline rebajado * oboista & 34,700 & 20 & 1,735 & 2,587 & 0,000 & 0,029 \\
\hline molde * grosor & 1,727 & 2 & 0,864 & 1,288 & 0,276 & 0,001 \\
\hline molde * oboista & 12,604 & 20 & 0,630 & 0,940 & 0,535 & 0,011 \\
\hline grosor * oboista & 4,577 & 10 & 0,458 & 0,683 & 0,742 & 0,004 \\
\hline rebajado * molde * grosor & 10,872 & 4 & 2,718 & 4,053 & 0,003 & 0,009 \\
\hline rebajado $*$ molde $*$ oboista & 32,722 & 33 & 0,992 & 1,479 & 0,040 & 0,028 \\
\hline rebajado * grosor * oboista & 11,468 & 16 & 0,717 & 1,069 & 0,380 & 0,010 \\
\hline molde * grosor * oboista & 16,964 & 16 & 1,060 & 1,581 & 0,066 & 0,015 \\
\hline rebajado * molde * grosor * oboista & 32,869 & 32 & 1,027 & 1,532 & 0,029 & 0,028 \\
\hline Error & 1152,672 & 1719 & 0,671 & & & \\
\hline Total & 1890,000 & 1900 & & & & \\
\hline Total corregida & 1890,000 & 1899 & & & & \\
\hline \multicolumn{7}{|l|}{ a. Measurement $=$ Harmonicity Mean } \\
\hline b. $\mathrm{R}$ cuadrado $=, 390(\mathrm{R}$ cuadrado corregida $=, 326)$ & & & & & & \\
\hline
\end{tabular}

Tabla A.37. Análisis de varianza factorial de la armonicidad media para los factores rebajado, molde, grosor y oboísta.

\begin{tabular}{|c|c|c|c|c|c|c|}
\hline \multicolumn{7}{|c|}{ Pruebas de los efectos inter-sujetos ${ }^{\mathrm{a}}$} \\
\hline \multicolumn{7}{|c|}{ Variable dependiente: Valor Norm. } \\
\hline Origen & $\begin{array}{c}\text { Suma de } \\
\text { cuadrados } \\
\text { tipo III }\end{array}$ & $\mathrm{gl}$ & $\begin{array}{c}\text { Media } \\
\text { cuadrática }\end{array}$ & $\mathrm{F}$ & Sig. & $\begin{array}{c}\text { Eta al } \\
\text { cuadrado } \\
\text { parcial }\end{array}$ \\
\hline Modelo corregido & $497,963^{b}$ & 180 & 2,766 & 3,416 & 0,000 & 0,263 \\
\hline Intersección & 0,579 & 1 & 0,579 & 0,715 & 0,398 & 0,000 \\
\hline rebajado & 139,128 & 2 & 69,564 & 85,904 & 0,000 & 0,091 \\
\hline molde & 18,381 & 2 & 9,191 & 11,349 & 0,000 & 0,013 \\
\hline
\end{tabular}




\begin{tabular}{|c|c|c|c|c|c|c|}
\hline \multicolumn{7}{|c|}{ Pruebas de los efectos inter-sujetos ${ }^{a}$} \\
\hline \multicolumn{7}{|l|}{ Variable dependiente: Valor Norm. } \\
\hline Origen & $\begin{array}{c}\text { Suma de } \\
\text { cuadrados } \\
\text { tipo III }\end{array}$ & $\mathrm{gl}$ & $\begin{array}{c}\text { Media } \\
\text { cuadrática }\end{array}$ & $\mathrm{F}$ & Sig. & $\begin{array}{c}\text { Eta al } \\
\text { cuadrado } \\
\text { parcial }\end{array}$ \\
\hline grosor & 6,135 & 1 & 6,135 & 7,576 & 0,006 & 0,004 \\
\hline oboista & 148,542 & 10 & 14,854 & 18,343 & 0,000 & 0,096 \\
\hline rebajado $*$ molde & 30,687 & 4 & 7,672 & 9,474 & 0,000 & 0,022 \\
\hline rebajado * grosor & 5,708 & 2 & 2,854 & 3,525 & 0,030 & 0,004 \\
\hline rebajado * oboista & 20,850 & 20 & 1,042 & 1,287 & 0,176 & 0,015 \\
\hline molde * grosor & 3,369 & 2 & 1,684 & 2,080 & 0,125 & 0,002 \\
\hline molde * oboista & 13,246 & 20 & 0,662 & 0,818 & 0,694 & 0,009 \\
\hline grosor * oboista & 4,131 & 10 & 0,413 & 0,510 & 0,884 & 0,003 \\
\hline rebajado $*$ molde $*$ grosor & 3,099 & 4 & 0,775 & 0,957 & 0,430 & 0,002 \\
\hline rebajado $*$ molde $*$ oboista & 31,055 & 33 & 0,941 & 1,162 & 0,243 & 0,022 \\
\hline rebajado $*$ grosor $*$ oboista & 16,086 & 16 & 1,005 & 1,241 & 0,228 & 0,011 \\
\hline molde $*$ grosor $*$ oboista & 10,270 & 16 & 0,642 & 0,793 & 0,695 & 0,007 \\
\hline rebajado * molde * grosor * oboista & 26,070 & 32 & 0,815 & 1,006 & 0,458 & 0,018 \\
\hline Error & 1392,037 & 1719 & 0,810 & & & \\
\hline Total & 1890,000 & 1900 & & & & \\
\hline Total corregida & 1890,000 & 1899 & & & & \\
\hline \multicolumn{7}{|l|}{ a. Measurement $=$ Harmonicity Std Dev } \\
\hline uadrado $=, 263(\mathrm{R}$ cuadrado corregida $=, 186)$ & & & & & & \\
\hline
\end{tabular}

Tabla A.38. Análisis de varianza factorial de la desviación estándar de la armonicidad para los factores rebajado, molde, grosor y oboísta.

\begin{tabular}{|c|c|c|c|c|c|c|}
\hline \multicolumn{7}{|c|}{ Pruebas de los efectos inter-sujetos $^{\mathrm{a}}$} \\
\hline \multicolumn{7}{|c|}{ Variable dependiente: Valor Norm. } \\
\hline Origen & $\begin{array}{c}\text { Suma de } \\
\text { cuadrados tipo } \\
\text { III }\end{array}$ & $\overline{\mathrm{gl}}$ & $\begin{array}{c}\text { Media } \\
\text { cuadrática }\end{array}$ & $\bar{F}$ & Sig. & $\begin{array}{c}\text { Eta al } \\
\text { cuadrado } \\
\text { parcial }\end{array}$ \\
\hline Modelo corregido & $450,085^{b}$ & 180 & 2,500 & 2,985 & 0,000 & 0,238 \\
\hline Intersección & 0,142 & 1 & 0,142 & 0,170 & 0,680 & 0,000 \\
\hline rebajado & 46,551 & 2 & 23,275 & 27,787 & 0,000 & 0,031 \\
\hline molde & 4,796 & 2 & 2,398 & 2,863 & 0,057 & 0,003 \\
\hline grosor & 0,636 & 1 & 0,636 & 0,759 & 0,384 & 0,000 \\
\hline oboista & 158,101 & 10 & 15,810 & 18,874 & 0,000 & 0,099 \\
\hline rebajado $*$ molde & 4,291 & 4 & 1,073 & 1,281 & 0,275 & 0,003 \\
\hline rebajado $*$ grosor & 6,694 & 2 & 3,347 & 3,996 & 0,019 & 0,005 \\
\hline rebajado $*$ oboista & 44,122 & 20 & 2,206 & 2,634 & 0,000 & 0,030 \\
\hline
\end{tabular}




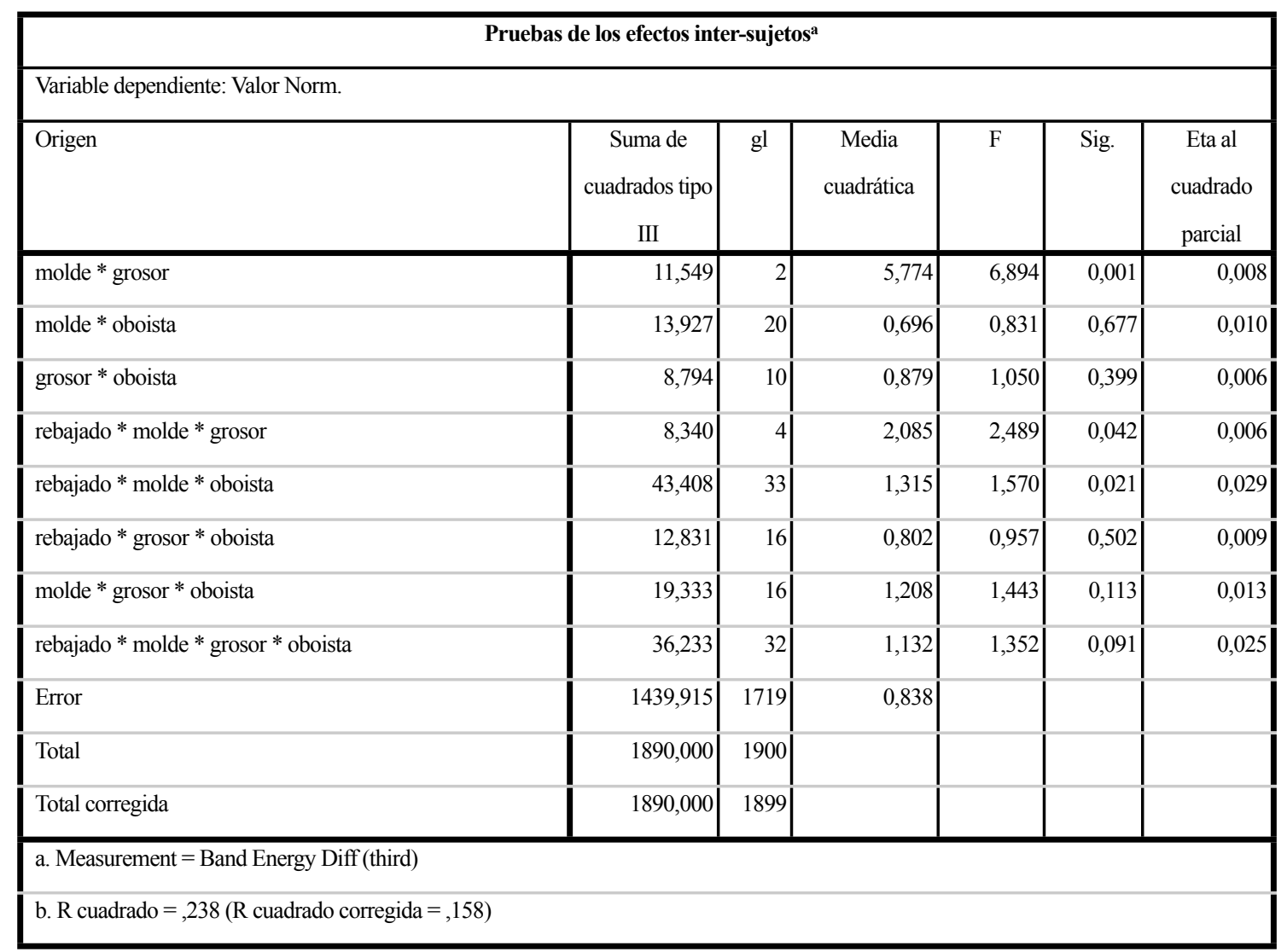

Tabla A.39. Análisis de varianza factorial de la diferencia de energía de bandas entre las frecuencias por debajo de una $3^{\text {a }}$ mayor para los factores rebajado, molde, grosor y oboísta.

\begin{tabular}{|c|c|c|c|c|c|c|}
\hline \multicolumn{7}{|c|}{ Pruebas de los efectos inter-sujetos ${ }^{a}$} \\
\hline \multicolumn{7}{|c|}{ Variable dependiente: Valor Norm. } \\
\hline Origen & $\begin{array}{c}\text { Suma de } \\
\text { cuadrados tipo } \\
\text { III }\end{array}$ & $\mathrm{gl}$ & $\begin{array}{c}\text { Media } \\
\text { cuadrática }\end{array}$ & $\mathrm{F}$ & Sig. & $\begin{array}{c}\text { Eta al } \\
\text { cuadrado } \\
\text { parcial }\end{array}$ \\
\hline Modelo corregido & $767,977^{b}$ & 180 & 4,267 & 6,537 & 0,000 & 0,406 \\
\hline Intersección & 0,087 & 1 & 0,087 & 0,134 & 0,715 & 0,000 \\
\hline rebajado & 127,927 & 2 & 63,964 & 97,996 & 0,000 & 0,102 \\
\hline molde & 108,835 & 2 & 54,417 & 83,370 & 0,000 & 0,088 \\
\hline grosor & 32,741 & 1 & 32,741 & 50,161 & 0,000 & 0,028 \\
\hline oboista & 167,522 & 10 & 16,752 & 25,665 & 0,000 & 0,130 \\
\hline rebajado $*$ molde & 10,766 & 4 & 2,691 & 4,123 & 0,002 & 0,010 \\
\hline rebajado * grosor & 7,939 & 2 & 3,970 & 6,082 & 0,002 & 0,007 \\
\hline rebajado * oboista & 27,998 & 20 & 1,400 & 2,145 & 0,002 & 0,024 \\
\hline molde * grosor & 10,561 & 2 & 5,281 & 8,090 & 0,000 & 0,009 \\
\hline molde * oboista & 23,651 & 20 & 1,183 & 1,812 & 0,015 & 0,021 \\
\hline grosor * oboista & 9,950 & 10 & 0,995 & 1,524 & 0,125 & 0,009 \\
\hline rebajado $*$ molde $*$ grosor & 16,394 & 4 & 4,098 & 6,279 & 0,000 & 0,014 \\
\hline rebajado $*$ molde $*$ oboista & 66,748 & 33 & 2,023 & 3,099 & 0,000 & 0,056 \\
\hline
\end{tabular}




\begin{tabular}{|c|c|c|c|c|c|c|}
\hline \multicolumn{7}{|c|}{ Pruebas de los efectos inter-sujetos ${ }^{\mathrm{a}}$} \\
\hline \multicolumn{7}{|l|}{ Variable dependiente: Valor Norm. } \\
\hline Origen & $\begin{array}{c}\text { Suma de } \\
\text { cuadrados tipo } \\
\text { III }\end{array}$ & $\mathrm{gl}$ & $\begin{array}{c}\text { Media } \\
\text { cuadrática }\end{array}$ & $\mathrm{F}$ & Sig. & $\begin{array}{c}\text { Eta al } \\
\text { cuadrado } \\
\text { parcial }\end{array}$ \\
\hline rebajado $*$ grosor $*$ oboista & 31,289 & 16 & 1,956 & 2,996 & 0,000 & 0,027 \\
\hline molde * grosor * oboista & 28,368 & 16 & 1,773 & 2,716 & 0,000 & 0,025 \\
\hline rebajado $*$ molde * grosor * oboista & 54,420 & 32 & 1,701 & 2,605 & 0,000 & 0,046 \\
\hline Error & 1122,023 & 1719 & 0,653 & & & \\
\hline Total & 1890,000 & 1900 & & & & \\
\hline Total corregida & 1890,000 & 1899 & & & & \\
\hline \multicolumn{7}{|l|}{ a. Measurement $=$ Spectrum Center Gravity } \\
\hline b. $R$ cuadrado $=, 406(R$ cuadrado corregida $=, 344)$ & & & & & & \\
\hline
\end{tabular}

Tabla A.40. Análisis de varianza factorial del centro de gravedad espectral para los factores rebajado, molde, grosor y oboísta.

\begin{tabular}{|c|c|c|c|c|c|c|c|c|}
\hline \multicolumn{9}{|c|}{ Pruebas de efectos intra-sujetos. } \\
\hline Measurement & Origen & & $\begin{array}{c}\text { Suma de } \\
\text { cuadrados } \\
\text { tipo III }\end{array}$ & $\overline{\mathrm{gl}}$ & \begin{tabular}{c|} 
Media \\
cuadrática
\end{tabular} & $\bar{F}$ & Sig. & $\begin{array}{c}\text { Eta al } \\
\text { cuadrado } \\
\text { parcial }\end{array}$ \\
\hline $\begin{array}{l}\text { Amplitude Std } \\
\text { Dev }\end{array}$ & rebajados & $\begin{array}{l}\text { Greenhouse- } \\
\text { Geisser }\end{array}$ & 20,457 & 1,856 & 11,022 & 34,509 & 0,000 & 0,058 \\
\hline $\begin{array}{l}\text { Band Energy } \\
\text { Diff (4st) }\end{array}$ & rebajados & $\begin{array}{l}\text { Greenhouse- } \\
\text { Geisser }\end{array}$ & 59,147 & 1,973 & 29,973 & 43,534 & 0,000 & 0,072 \\
\hline F0 Delta $(\mathrm{Hz})$ & rebajados & $\begin{array}{l}\text { Greenhouse- } \\
\text { Geisser }\end{array}$ & 9,880 & 1,855 & 5,325 & 6,557 & 0,002 & 0,012 \\
\hline F0 Mean $(\mathrm{Hz})$ & rebajados & $\begin{array}{l}\text { Greenhouse- } \\
\text { Geisser }\end{array}$ & 594,265 & 1,977 & 300,619 & 1396,976 & 0,000 & 0,715 \\
\hline F0 Std Dev (st) & rebajados & $\begin{array}{l}\text { Greenhouse- } \\
\text { Geisser }\end{array}$ & 37,201 & 1,866 & 19,934 & 23,293 & 0,000 & 0,040 \\
\hline $\begin{array}{l}\text { Harmonicity } \\
\text { Mean }\end{array}$ & rebajados & $\begin{array}{l}\text { Greenhouse- } \\
\text { Geisser }\end{array}$ & 14,192 & 1,813 & 7,829 & 12,036 & 0,000 & 0,021 \\
\hline Intensity $(\mathrm{dB})$ & rebajados & $\begin{array}{l}\text { Greenhouse- } \\
\text { Geisser }\end{array}$ & 28,135 & 1,938 & 14,515 & 55,866 & 0,000 & 0,091 \\
\hline $\begin{array}{l}\text { Number Voiced } \\
\text { Frames }\end{array}$ & rebajados & $\begin{array}{l}\text { Greenhouse- } \\
\text { Geisser }\end{array}$ & 24,032 & 1,963 & 12,244 & 19,416 & 0,000 & 0,034 \\
\hline $\begin{array}{l}\text { Spectrum } \\
\text { Center Gravity }\end{array}$ & rebajados & $\begin{array}{l}\text { Greenhouse- } \\
\text { Geisser }\end{array}$ & 120,859 & 1,961 & 61,617 & 90,942 & 0,000 & 0,140 \\
\hline
\end{tabular}

Tabla A.41. Efectos intra-sujetos del ANOVA con medidas repetidas para los diferentes parámetros acústicos analizados en función del rebajado. 


\begin{tabular}{|c|c|c|c|c|c|c|c|c|c|}
\hline \multicolumn{10}{|c|}{ Prueba de muestras relacionadas } \\
\hline \multirow[t]{3}{*}{ Measurement } & \multicolumn{6}{|c|}{ Diferencias relacionadas } & \multirow[t]{3}{*}{$\mathrm{t}$} & \multirow[t]{3}{*}{ gl } & \multirow{3}{*}{$\begin{array}{c}\text { Sig. } \\
\text { (bilateral) }\end{array}$} \\
\hline & & Media & $\begin{array}{c}\text { Desviación } \\
\text { típ. }\end{array}$ & $\begin{array}{c}\text { Error típ. de } \\
\text { la media }\end{array}$ & \multicolumn{2}{|c|}{$\begin{array}{c}95 \% \text { Intervalo de } \\
\text { confianza para la } \\
\text { diferencia }\end{array}$} & & & \\
\hline & & & & & Inferior & Superior & & & \\
\hline Amplitude Std Dev & $57-59$ & $-0,1401$ & 0,7518 & 0,0257 & $-0,1908$ & $-0,0895$ & $-5,436$ & 849 & 0,000 \\
\hline Band Energy Diff (third) & $57-59$ & $-0,0368$ & 1,1271 & 0,0386 & $-0,1127$ & 0,0390 & $-0,953$ & 849 & 0,341 \\
\hline F0 Delta (en Hz) & $57-59$ & 0,1072 & 1,2154 & 0,0509 & 0,0071 & 0,2072 & 2,104 & 568 & 0,036 \\
\hline F0 Mean (en Hz) & $57-59$ & $-0,1667$ & 0,5198 & 0,0217 & $-0,2095$ & $-0,1239$ & $-7,652$ & 568 & 0,000 \\
\hline F0 Std Dev (st) & $57-59$ & 0,0201 & 1,2335 & 0,0517 & $-0,0814$ & 0,1217 & 0,390 & 568 & 0,697 \\
\hline Harmonicity Mean & $57-59$ & $-0,0054$ & 1,0090 & 0,0346 & $-0,0734$ & 0,0624 & $-0,159$ & 849 & 0,874 \\
\hline Harmonicity Std Dev & $57-59$ & 0,1091 & 1,1017 & 0,0377 & 0,0349 & 0,1833 & 2,888 & 849 & 0,004 \\
\hline Intensity (en dB) & $57-59$ & $-0,1569$ & 0,6964 & 0,0238 & $-0,2037$ & $-0,1100$ & $-6,568$ & 849 & 0,000 \\
\hline Number Voiced Frames & $57-59$ & 0,1695 & 1,0454 & 0,0358 & 0,0991 & 0,2398 & 4,727 & 849 & 0,000 \\
\hline Spectrum Center Gravity & $57-59$ & $-0,2759$ & 1,0662 & 0,0365 & $-0,3477$ & $-0,2041$ & $-7,545$ & 849 & 0,000 \\
\hline
\end{tabular}

Tabla A.42. Test T comparando los diferentes grosores en todos los valores acústicos.

\begin{tabular}{|c|c|c|c|c|c|c|c|c|c|c|}
\hline \multicolumn{11}{|c|}{ Prueba de muestras relacionadas } \\
\hline \multirow[t]{3}{*}{ Measurement } & \multirow[t]{3}{*}{ ejercicio } & \multicolumn{6}{|c|}{ Diferencias relacionadas } & \multirow[t]{3}{*}{$\mathrm{t}$} & \multirow[t]{3}{*}{$\mathrm{gl}$} & \multirow{3}{*}{$\begin{array}{c}\text { Sig. } \\
\text { (bilater } \\
\text { al) }\end{array}$} \\
\hline & & & \multirow[t]{2}{*}{ Media } & \multirow[t]{2}{*}{$\begin{array}{c}\text { Desviación } \\
\text { típ. }\end{array}$} & \multirow[t]{2}{*}{$\begin{array}{c}\text { Error típ. } \\
\text { de la } \\
\text { media }\end{array}$} & \multicolumn{2}{|c|}{$\begin{array}{c}95 \% \text { Intervalo de } \\
\text { confianza para la } \\
\text { diferencia }\end{array}$} & & & \\
\hline & & & & & & Inferior & Superior & & & \\
\hline \multirow{2}{*}{$\begin{array}{l}\text { Amplitude Std } \\
\text { Dev }\end{array}$} & ADo4 & $57-59$ & $-0,0050$ & 0,0161 & 0,0017 & $-0,0084$ & $-0,0015$ & $-2,866$ & 84 & 0,005 \\
\hline & Pianissimo & $57-59$ & $-0,0007$ & 0,0033 & 0,0003 & $-0,0014$ & 0,0000 & $-2,003$ & 84 & 0,048 \\
\hline \multirow{8}{*}{$\begin{array}{l}\text { F0 Mean (en } \\
\text { Hz) }\end{array}$} & ADo5 & $57-59$ & $-1,6092$ & 3,1426 & 0,4162 & $-2,4431$ & $-0,7754$ & $-3,866$ & 56 & 0,000 \\
\hline & ADo6 & $57-59$ & $-2,7541$ & 9,7538 & 1,2919 & $-5,3421$ & $-0,1660$ & $-2,132$ & 56 & 0,037 \\
\hline & AMi4 & $57-59$ & $-0,5706$ & 1,5692 & 0,2078 & $-0,9870$ & $-0,1543$ & $-2,746$ & 56 & 0,008 \\
\hline & AMi5 & $57-59$ & $-1,3039$ & 3,9212 & 0,5193 & $-2,3443$ & $-0,2634$ & $-2,511$ & 56 & 0,015 \\
\hline & ASol4 & $57-59$ & $-1,1773$ & 1,8702 & 0,2477 & $-1,6736$ & $-0,6811$ & $-4,753$ & 56 & 0,000 \\
\hline & ASol5 & $57-59$ & $-1,5786$ & 5,0886 & 0,6740 & $-2,9288$ & $-0,2284$ & $-2,342$ & 56 & 0,023 \\
\hline & DIM & $57-59$ & $-1,0498$ & 2,0508 & 0,2716 & $-1,5940$ & $-0,5057$ & $-3,865$ & 56 & 0,000 \\
\hline & Pianissimo & $57-59$ & $-0,9323$ & 2,9877 & 0,3992 & $-1,7324$ & $-0,1321$ & $-2,335$ & 55 & 0,023 \\
\hline \multirow{3}{*}{$\begin{array}{l}\text { Harmonicity Std } \\
\text { Dev }\end{array}$} & AMi4 & $57-59$ & 0,2615 & 1,0622 & 0,1152 & 0,0324 & 0,4907 & 2,270 & 84 & 0,026 \\
\hline & ASol4 & $57-59$ & 0,4380 & 1,2361 & 0,1340 & 0,1714 & 0,7047 & 3,268 & 84 & 0,002 \\
\hline & DIM & $57-59$ & 0,3113 & 1,2881 & 0,1397 & 0,0334 & 0,5891 & 2,228 & 84 & 0,029 \\
\hline \multirow[t]{5}{*}{ Intensity (en dB) } & ADo4 & $57-59$ & $-1,0864$ & 3,5263 & 0,3824 & $-1,8471$ & $-0,3258$ & $-2,841$ & 84 & 0,006 \\
\hline & ASol5 & $57-59$ & $-0,9950$ & 3,8161 & 0,4139 & $-1,8182$ & $-0,1719$ & $-2,404$ & 84 & 0,018 \\
\hline & DIM & $57-59$ & $-0,7632$ & 3,2429 & 0,3517 & $-1,4627$ & $-0,0637$ & $-2,170$ & 84 & 0,033 \\
\hline & Fortissimo & $57-59$ & $-0,7905$ & 2,6518 & 0,2876 & $-1,3625$ & $-0,2185$ & $-2,749$ & 84 & 0,007 \\
\hline & Pianissimo & $57-59$ & $-1,9107$ & 6,0282 & 0,6538 & $-3,2109$ & $-0,6104$ & $-2,922$ & 84 & 0,004 \\
\hline \multirow{5}{*}{$\begin{array}{l}\text { Number Voiced } \\
\text { Frames }\end{array}$} & ADo5 & $57-59$ & 8,4588 & 32,2710 & 3,5002 & 1,4981 & 15,4195 & 2,417 & 84 & 0,018 \\
\hline & AMi4 & $57-59$ & 9,0941 & 37,6969 & 4,0888 & 0,9630 & 17,2251 & 2,224 & 84 & 0,029 \\
\hline & AMi5 & $57-59$ & 8,2588 & 30,4772 & 3,3057 & 1,6850 & 14,8326 & 2,498 & 84 & 0,014 \\
\hline & ASol4 & $57-59$ & 9,9882 & 35,2053 & 3,8185 & 2,3946 & 17,5818 & 2,616 & 84 & 0,011 \\
\hline & Pianissimo & $57-59$ & 43,7647 & 193,8605 & 21,0271 & 1,9499 & 85,5794 & 2,081 & 84 & 0,040 \\
\hline Spectrum & ADo4 & $57-59$ & $-31,8714$ & 107,4785 & 11,6576 & $-55,0540$ & $-8,6888$ & $-2,734$ & 84 & 0,008 \\
\hline
\end{tabular}




\begin{tabular}{|c|c|c|c|c|c|c|c|c|c|c|}
\hline \multicolumn{11}{|c|}{ Prueba de muestras relacionadas } \\
\hline \multirow{3}{*}{ Measurement } & \multirow{3}{*}{ ejercicio } & \multicolumn{6}{|c|}{ Diferencias relacionadas } & \multirow[t]{3}{*}{$\mathrm{t}$} & \multirow[t]{3}{*}{$\overline{\mathrm{gl}}$} & \multirow{3}{*}{$\begin{array}{c}\text { Sig. } \\
\text { (bilater } \\
\text { al) }\end{array}$} \\
\hline & & & \multirow[t]{2}{*}{ Media } & \multirow[t]{2}{*}{$\begin{array}{c}\text { Desviación } \\
\text { típ. }\end{array}$} & \multirow[t]{2}{*}{$\begin{array}{c}\text { Error típ. } \\
\text { de la } \\
\text { media }\end{array}$} & \multicolumn{2}{|c|}{$\begin{array}{c}95 \% \text { Intervalo de } \\
\text { confianza para la } \\
\text { diferencia } \\
\end{array}$} & & & \\
\hline & & & & & & Inferior & Superior & & & \\
\hline \multirow{8}{*}{ Center Gravity } & ADo5 & $57-59$ & $-25,1246$ & 116,1456 & 12,5977 & $-50,1766$ & $-0,0725$ & $-1,994$ & 84 & 0,049 \\
\hline & AMi4 & $57-59$ & $-9,9829$ & 29,5584 & 3,2060 & $-16,3585$ & $-3,6073$ & $-3,114$ & 84 & 0,003 \\
\hline & AMi5 & $57-59$ & $-4,3477$ & 12,7724 & 1,3853 & $-7,1026$ & $-1,5927$ & $-3,138$ & 84 & 0,002 \\
\hline & ASol4 & $57-59$ & $-23,9107$ & 80,2978 & 8,7095 & $-41,2305$ & $-6,5908$ & $-2,745$ & 84 & 0,007 \\
\hline & ASol5 & $57-59$ & $-20,9984$ & 75,2308 & 8,1599 & $-37,2253$ & $-4,7714$ & $-2,573$ & 84 & 0,012 \\
\hline & DIM & $57-59$ & $-18,0948$ & 66,0181 & 7,1606 & $-32,3346$ & $-3,8550$ & $-2,527$ & 84 & 0,013 \\
\hline & Fortissimo & $57-59$ & $-17,9477$ & 54,7807 & 5,9418 & $-29,7637$ & $-6,1318$ & $-3,021$ & 84 & 0,003 \\
\hline & Pianissimo & $57-59$ & $-52,6076$ & 214,70911 & 23,2884 & $-98,9193$ & $-6,2959$ & $-2,259$ & 84 & 0,026 \\
\hline
\end{tabular}

Tabla A.43. Test T comparando los diferentes grosores en todos los valores acústicos significativos, dividido por ejercicios.

\begin{tabular}{|c|c|c|c|c|c|c|c|c|c|c|}
\hline \multicolumn{11}{|c|}{ Prueba de muestras relacionadas } \\
\hline \multirow[t]{3}{*}{ Measurement } & \multirow{3}{*}{$\begin{array}{l}\text { rebaja } \\
\text { do }\end{array}$} & \multicolumn{6}{|c|}{ Diferencias relacionadas } & \multirow[t]{3}{*}{$\mathrm{t}$} & \multirow[t]{3}{*}{$\mathrm{gl}$} & \multirow{3}{*}{$\begin{array}{c}\text { Sig. } \\
\text { (bilateral) }\end{array}$} \\
\hline & & & Media & $\begin{array}{c}\text { Desvia } \\
\text { ción } \\
\text { típ. }\end{array}$ & $\begin{array}{c}\text { Error típ. } \\
\text { de la } \\
\text { media }\end{array}$ & $\begin{array}{r}95 \% \text { In } \\
\text { confian } \\
\text { dife }\end{array}$ & $\begin{array}{l}\text { valo de } \\
\text { para la } \\
\text { ncia }\end{array}$ & & & \\
\hline & & & & & & Inferior & Superior & & & \\
\hline \multirow[t]{3}{*}{ Amplitude Std Dev } & fr & $57-59$ & $-0,0769$ & 0,4881 & 0,0291 & $-0,1343$ & $-0,0195$ & $-2,638$ & 279 & 0,009 \\
\hline & ge & $57-59$ & $-0,2357$ & 0,9596 & 0,0563 & $-0,3466$ & $-0,1248$ & $-4,183$ & 289 & 0,000 \\
\hline & us & $57-59$ & $-0,1044$ & 0,7164 & 0,0428 & $-0,1887$ & $-0,0201$ & $-2,440$ & 279 & 0,015 \\
\hline \multirow[t]{3}{*}{ F0 Mean (en Hz) } & fr & $57-59$ & $-0,0469$ & 0,5194 & 0,0377 & $-0,1214$ & 0,0276 & $-1,242$ & 188 & 0,216 \\
\hline & ge & $57-59$ & $-0,2634$ & 0,5017 & 0,0354 & $-0,3333$ & $-0,1934$ & $-7,425$ & 199 & 0,000 \\
\hline & us & $57-59$ & $-0,1851$ & 0,5178 & 0,0385 & $-0,2613$ & $-0,1089$ & $-4,797$ & 179 & 0,000 \\
\hline \multirow[t]{3}{*}{ Harmonicity Std Dev } & fr & $57-59$ & 0,2536 & 1,2081 & 0,0722 & 0,1115 & 0,3957 & 3,513 & 279 & 0,001 \\
\hline & ge & $57-59$ & 0,0800 & 0,9866 & 0,0579 & $-0,0339$ & 0,1941 & 1,382 & 289 & 0,168 \\
\hline & us & $57-59$ & $-0,0053$ & 1,0911 & 0,0652 & $-0,1336$ & 0,1230 & $-0,082$ & 279 & 0,935 \\
\hline \multirow[t]{3}{*}{ Intensity (en dB) } & fr & $57-59$ & $-0,1586$ & 0,6557 & 0,0391 & $-0,2358$ & $-0,0815$ & $-4,049$ & 279 & 0,000 \\
\hline & ge & $57-59$ & $-0,2150$ & 0,6935 & 0,0407 & $-0,2951$ & $-0,1348$ & $-5,280$ & 289 & 0,000 \\
\hline & us & $57-59$ & $-0,0949$ & 0,7351 & 0,0439 & $-0,1814$ & $-0,0084$ & $-2,160$ & 279 & 0,032 \\
\hline \multirow{3}{*}{$\begin{array}{l}\text { Number Voiced } \\
\text { Frames }\end{array}$} & fr & $57-59$ & 0,1908 & 1,0179 & 0,0608 & 0,0711 & 0,3106 & 3,137 & 279 & 0,002 \\
\hline & ge & $57-59$ & 0,2186 & 0,9260 & 0,0543 & 0,1115 & 0,3256 & 4,020 & 289 & 0,000 \\
\hline & us & $57-59$ & 0,0973 & 1,1803 & 0,0705 & $-0,0415$ & 0,2361 & 1,380 & 279 & 0,169 \\
\hline \multirow{3}{*}{$\begin{array}{l}\text { Spectrum Center } \\
\text { Gravity }\end{array}$} & fr & $57-59$ & $-0,1761$ & 1,0148 & 0,0606 & $-0,2955$ & $-0,0567$ & $-2,904$ & 279 & 0,004 \\
\hline & ge & $57-59$ & $-0,2008$ & 1,0580 & 0,0621 & $-0,3231$ & $-0,0785$ & $-3,233$ & 289 & 0,001 \\
\hline & us & $57-59$ & $-0,4535$ & 1,1056 & 0,0660 & $-0,5835$ & $-0,3234$ & $-6,864$ & 279 & 0,000 \\
\hline
\end{tabular}

Tabla A.44. Test T comparando los diferentes grosores en todos los valores acústicos significativos, dividido por rebajados. 


\begin{tabular}{|c|c|c|c|c|c|c|c|c|c|}
\hline \multicolumn{10}{|c|}{ Prueba de muestras relacionadas } \\
\hline \multirow[t]{2}{*}{ Measurement } & \multirow[t]{2}{*}{ rebajado } & \multirow[t]{2}{*}{ Media } & \multirow[t]{2}{*}{$\begin{array}{c}\text { Desviació } \\
\text { n típ. }\end{array}$} & \multirow[t]{2}{*}{$\begin{array}{c}\text { Error típ. de } \\
\text { la media }\end{array}$} & \multicolumn{2}{|c|}{$\begin{array}{c}95 \% \text { Intervalo de } \\
\text { confianza para la } \\
\text { diferencia }\end{array}$} & \multirow[t]{2}{*}{$\mathrm{t}$} & \multirow[t]{2}{*}{$\mathrm{gl}$} & \multirow[t]{2}{*}{$\begin{array}{c}\text { Sig. } \\
\text { (bilateral) }\end{array}$} \\
\hline & & & & & Inferior & Superior & & & \\
\hline \multirow{3}{*}{$\begin{array}{l}\text { Amplitude Std } \\
\text { Dev }\end{array}$} & fr - ge & $-0,2435$ & 0,8384 & 0,0354 & $-0,3131$ & $-0,1739$ & $-6,873$ & 559 & 0,000 \\
\hline & fr - us & $-0,1926$ & 0,6864 & 0,0285 & $-0,2486$ & $-0,1366$ & $-6,759$ & 579 & 0,000 \\
\hline & ge - us & 0,0146 & 0,7866 & 0,0326 & $-0,0495$ & 0,0787 & 0,448 & 579 & 0,654 \\
\hline \multirow{3}{*}{$\begin{array}{l}\text { Band Energy Diff } \\
\text { (third) }\end{array}$} & fr - ge & $-0,2348$ & 1,1752 & 0,0496 & $-0,3323$ & $-0,1372$ & $-4,729$ & 559 & 0,000 \\
\hline & fr - us & $-0,4318$ & 1,2298 & 0,0510 & $-0,5321$ & $-0,3315$ & $-8,456$ & 579 & 0,000 \\
\hline & ge - us & $-0,2124$ & 1,1110 & 0,0461 & $-0,3030$ & $-0,1218$ & $-4,604$ & 579 & 0,000 \\
\hline \multirow[t]{3}{*}{ F0 Delta (en Hz) } & fr - ge & 0,2334 & 1,1638 & 0,0597 & 0,1159 & 0,3510 & 3,905 & 378 & 0,000 \\
\hline & fr - us & 0,2076 & 1,3536 & 0,0686 & 0,0726 & 0,3425 & 3,025 & 388 & 0,003 \\
\hline & ge - us & $-0,0146$ & 1,1700 & 0,0600 & $-0,1326$ & 0,1033 & $-0,244$ & 379 & 0,807 \\
\hline \multirow[t]{3}{*}{ F0 Mean (en Hz) } & fr - ge & $-0,5903$ & 0,5519 & 0,0283 & $-0,6461$ & $-0,5346$ & $-20,822$ & 378 & 0,000 \\
\hline & fr - us & $-1,3667$ & 0,5561 & 0,0281 & $-1,4221$ & $-1,3112$ & $-48,466$ & 388 & 0,000 \\
\hline & ge - us & $-0,7727$ & 0,4805 & 0,0246 & $-0,8212$ & $-0,7243$ & $-31,348$ & 379 & 0,000 \\
\hline \multirow[t]{3}{*}{ F0 Std Dev (st) } & fr - ge & 0,1913 & 1,0399 & 0,0534 & 0,0863 & 0,2963 & 3,582 & 378 & 0,000 \\
\hline & fr - us & 0,1012 & 1,3548 & 0,0686 & $-0,0338$ & 0,2362 & 1,473 & 388 & 0,141 \\
\hline & ge - us & $-0,0854$ & 1,3132 & 0,0673 & $-0,2179$ & 0,0470 & $-1,268$ & 379 & 0,205 \\
\hline \multirow{3}{*}{$\begin{array}{l}\text { Harmonicity } \\
\text { Mean }\end{array}$} & fr - ge & $-0,2218$ & 1,0763 & 0,0454 & $-0,3111$ & $-0,1324$ & $-4,877$ & 559 & 0,000 \\
\hline & $\mathrm{fr}-\mathrm{us}$ & $-0,1763$ & 1,2868 & 0,0534 & $-0,2813$ & $-0,0714$ & $-3,301$ & 579 & 0,001 \\
\hline & ge - us & 0,0447 & 0,9554 & 0,0396 & $-0,0331$ & 0,1226 & 1,127 & 579 & 0,260 \\
\hline \multirow{3}{*}{$\begin{array}{l}\text { Harmonicity Std } \\
\text { Dev }\end{array}$} & fr - ge & 0,5124 & 1,3481 & 0,0569 & 0,4005 & 0,6243 & 8,995 & 559 & 0,000 \\
\hline & $\mathrm{fr}-\mathrm{us}$ & 0,6632 & 1,4357 & 0,0596 & 0,5461 & 0,7803 & 11,126 & 579 & 0,000 \\
\hline & ge - us & 0,1434 & 1,0602 & 0,0440 & 0,0570 & 0,2299 & 3,259 & 579 & 0,001 \\
\hline \multirow[t]{3}{*}{ Intensity (en dB) } & fr - ge & $-0,2565$ & 0,7495 & 0,0316 & $-0,3187$ & $-0,1943$ & $-8,099$ & 559 & 0,000 \\
\hline & fr - us & $-0,2649$ & 0,7345 & 0,0305 & $-0,3248$ & $-0,2049$ & $-8,685$ & 579 & 0,000 \\
\hline & ge - us & $-0,0367$ & 0,6399 & 0,0265 & $-0,0889$ & 0,0154 & $-1,382$ & 579 & 0,168 \\
\hline \multirow{3}{*}{$\begin{array}{l}\text { Number Voiced } \\
\text { Frames }\end{array}$} & fr - ge & 0,2395 & 1,0913 & 0,0461 & 0,1489 & 0,3301 & 5,194 & 559 & 0,000 \\
\hline & $\mathrm{fr}-\mathrm{us}$ & 0,2484 & 1,1699 & 0,0485 & 0,1530 & 0,3438 & 5,114 & 579 & 0,000 \\
\hline & ge - us & 0,0345 & 1,0462 & 0,0434 & $-0,0507$ & 0,1199 & 0,796 & 579 & 0,426 \\
\hline \multirow{3}{*}{$\begin{array}{l}\text { Spectrum Center } \\
\text { Gravity }\end{array}$} & fr - ge & $-0,3165$ & 1,1041 & 0,0466 & $-0,4082$ & $-0,2249$ & $-6,786$ & 559 & 0,000 \\
\hline & fr - us & $-0,6532$ & 1,2047 & 0,0500 & $-0,7515$ & $-0,5550$ & $-13,059$ & 579 & 0,000 \\
\hline & ge - us & $-0,3365$ & 1,0899 & 0,0452 & $-0,4253$ & $-0,2476$ & $-7,436$ & 579 & 0,000 \\
\hline
\end{tabular}

Tabla A.45. Test T comparando los diferentes rebajados en todos los valores acústicos. 


\begin{tabular}{|c|c|c|c|c|c|c|c|c|c|}
\hline \multicolumn{10}{|c|}{ Prueba de muestras relacionadas } \\
\hline \multirow[t]{2}{*}{ Measurement } & \multirow[t]{2}{*}{ molde } & \multirow[t]{2}{*}{ Media } & \multirow[t]{2}{*}{$\begin{array}{l}\text { Desviación } \\
\text { típ. }\end{array}$} & \multirow[t]{2}{*}{$\begin{array}{c}\text { Error típ. de } \\
\text { la media }\end{array}$} & \multicolumn{2}{|c|}{$\begin{array}{c}\text { 95\% Intervalo de } \\
\text { confianza para la } \\
\text { diferencia }\end{array}$} & \multirow[t]{2}{*}{$\mathrm{t}$} & \multirow[t]{2}{*}{$\mathrm{gl}$} & \multirow[t]{2}{*}{$\begin{array}{c}\text { Sig. } \\
\text { (bilateral } \\
\text { ) }\end{array}$} \\
\hline & & & & & Inferior & Superior & & & \\
\hline \multirow{3}{*}{$\begin{array}{l}\text { Amplitude Std } \\
\text { Dev }\end{array}$} & $021-107$ & 0,1905 & 0,7817 & 0,0333 & 0,1250 & 0,2559 & 5,715 & 549 & 0,000 \\
\hline & $021-168$ & 0,1010 & 0,8697 & 0,0364 & 0,0295 & 0,1725 & 2,773 & 569 & 0,006 \\
\hline & $107-168$ & $-0,0753$ & 0,6051 & 0,0253 & $-0,1251$ & $-0,0255$ & $-2,972$ & 569 & 0,003 \\
\hline \multirow{3}{*}{$\begin{array}{l}\text { Band Energy Diff } \\
\text { (third) }\end{array}$} & $021-107$ & 0,0646 & 1,2063 & 0,0514 & $-0,0364$ & 0,1656 & 1,256 & 549 & 0,210 \\
\hline & $021-168$ & 0,1003 & 1,1248 & 0,0471 & 0,0078 & 0,1928 & 2,129 & 569 & 0,034 \\
\hline & $107-168$ & 0,0692 & 1,0965 & 0,0459 & $-0,0210$ & 0,1594 & 1,507 & 569 & 0,132 \\
\hline F0 Delta (en Hz) & $021-107$ & $-0,0285$ & 1,1473 & 0,0490 & $-0,1247$ & 0,0676 & $-0,583$ & 548 & 0,560 \\
\hline F0 Mean (en Hz) & $021-107$ & $-0,0403$ & 0,5038 & 0,0215 & $-0,0825$ & 0,0019 & $-1,875$ & 548 & 0,061 \\
\hline F0 Std Dev (st) & $021-107$ & $-0,0617$ & 1,1886 & 0,0507 & $-0,1614$ & 0,0379 & $-1,217$ & 548 & 0,224 \\
\hline \multirow{3}{*}{$\begin{array}{l}\text { Harmonicity } \\
\text { Mean }\end{array}$} & $021-107$ & $-0,1326$ & 0,9893 & 0,0422 & $-0,2154$ & $-0,0497$ & $-3,143$ & 549 & 0,002 \\
\hline & $021-168$ & 0,0264 & 1,1048 & 0,0463 & $-0,0644$ & 0,1173 & 0,572 & 569 & 0,568 \\
\hline & $107-168$ & 0,1463 & 1,0253 & 0,0429 & 0,0620 & 0,2306 & 3,407 & 569 & 0,001 \\
\hline \multirow{3}{*}{$\begin{array}{l}\text { Harmonicity Std } \\
\text { Dev }\end{array}$} & $021-107$ & $-0,1823$ & 1,1258 & 0,0480 & $-0,2767$ & $-0,0880$ & $-3,799$ & 549 & 0,000 \\
\hline & $021-168$ & $-0,2433$ & 1,2277 & 0,0514 & $-0,3443$ & $-0,1423$ & $-4,732$ & 569 & 0,000 \\
\hline & $107-168$ & $-0,0441$ & 1,1866 & 0,0497 & $-0,1417$ & 0,0535 & $-0,887$ & 569 & 0,375 \\
\hline \multirow[t]{3}{*}{ Intensity (en dB) } & $021-107$ & 0,1869 & 0,7122 & 0,0304 & 0,1273 & 0,2466 & 6,156 & 549 & 0,000 \\
\hline & $021-168$ & 0,0729 & 0,7624 & 0,0319 & 0,0102 & 0,1356 & 2,282 & 569 & 0,023 \\
\hline & $107-168$ & $-0,0991$ & 0,6153 & 0,0258 & $-0,1498$ & $-0,0485$ & $-3,847$ & 569 & 0,000 \\
\hline \multirow{3}{*}{$\begin{array}{l}\text { Number Voiced } \\
\text { Frames }\end{array}$} & $021-107$ & $-0,1162$ & 0,9924 & 0,0423 & $-0,1993$ & $-0,0331$ & $-2,746$ & 549 & 0,006 \\
\hline & $021-168$ & $-0,0663$ & 1,0825 & 0,0453 & $-0,1554$ & 0,0227 & $-1,463$ & 569 & 0,144 \\
\hline & $107-168$ & 0,0432 & 1,0003 & 0,0419 & $-0,0391$ & 0,1255 & 1,030 & 569 & 0,303 \\
\hline \multirow{3}{*}{$\begin{array}{l}\text { Spectrum Center } \\
\text { Gravity }\end{array}$} & $021-107$ & $-0,2477$ & 1,1235 & 0,0479 & $-0,3418$ & $-0,1536$ & $-5,171$ & 549 & 0,000 \\
\hline & $021-168$ & 0,3814 & 1,1765 & 0,0493 & 0,2846 & 0,4782 & 7,739 & 569 & 0,000 \\
\hline & $107-168$ & 0,6064 & 1,0493 & 0,0439 & 0,5201 & 0,6928 & 13,798 & 569 & 0,000 \\
\hline
\end{tabular}

Tabla A.46. Test T comparando los diferentes moldes en todos los valores acústicos.

\begin{tabular}{|c|c|c|c|c|c|}
\hline \multicolumn{6}{|c|}{ Pruebas de los efectos inter-sujetos ${ }^{\mathrm{a}}$} \\
\hline \multicolumn{6}{|c|}{ Variable dependiente: Puntuación Z(Value) } \\
\hline Origen & Suma de cuadrados tipo III & $\mathrm{gl}$ & $\begin{array}{c}\text { Media } \\
\text { cuadrática }\end{array}$ & $\mathrm{F}$ & Sig. \\
\hline Modelo corregido & $23,514^{\mathrm{b}}$ & 17 & 1,383 & 1,438 & 0,124 \\
\hline Intersección & 0,005 & 1 & 0,005 & 0,005 & 0,943 \\
\hline rebajado & 4,440 & 2 & 2,220 & 2,308 & 0,103 \\
\hline molde & 2,994 & 2 & 1,497 & 1,556 & 0,214 \\
\hline grosor & 0,745 & 1 & 0,745 & 0,774 & 0,380 \\
\hline
\end{tabular}


Influencias en la percepción sonora y en la interpretación del rebajado de la lengüeta del oboe

\begin{tabular}{|c|c|c|c|c|c|}
\hline \multicolumn{6}{|c|}{ Pruebas de los efectos inter-sujetos ${ }^{a}$} \\
\hline \multicolumn{6}{|c|}{ Variable dependiente: Puntuación Z(Value) } \\
\hline Origen & Suma de cuadrados tipo III & $\mathrm{gl}$ & $\begin{array}{c}\text { Media } \\
\text { cuadrática }\end{array}$ & $\mathrm{F}$ & Sig. \\
\hline rebajado $*$ molde & 2,455 & 4 & 0,614 & 0,638 & 0,636 \\
\hline rebajado $*$ grosor & 0,658 & 2 & 0,329 & 0,342 & 0,711 \\
\hline molde * grosor & 8,113 & 2 & 4,057 & 4,216 & 0,016 \\
\hline rebajado $*$ molde $*$ grosor & 4,408 & 4 & 1,102 & 1,145 & 0,337 \\
\hline Error & 165,486 & 172 & 0,962 & & \\
\hline Total & 189,000 & 190 & & & \\
\hline Total corregida & 189,000 & 189 & & & \\
\hline \multicolumn{6}{|c|}{ a. Measurement = Number Voiced Frames } \\
\hline b. $\mathrm{R}$ cuadrado $=, 124(\mathrm{R} \mathrm{cu}$ & egida $=, 038)$ & & & & \\
\hline
\end{tabular}

Tabla A.47. Análisis de varianza factorial de la variable Number Voiced Frames para los factores rebajado, molde y grosor (elementos de fabricación de la lengüeta).

\begin{tabular}{|c|c|c|c|c|c|}
\hline \multicolumn{6}{|c|}{ Pruebas de los efectos inter-sujetos } \\
\hline \multicolumn{6}{|c|}{ Variable dependiente: DeltaF0St } \\
\hline Origen & Suma de cuadrados tipo III & $\mathrm{gl}$ & $\begin{array}{c}\text { Media } \\
\text { cuadrática }\end{array}$ & $\mathrm{F}$ & Sig. \\
\hline Modelo corregido & $1,483^{\mathrm{a}}$ & 17 & 0,087 & 2,578 & 0,001 \\
\hline Intersección & 34,593 & 1 & 34,593 & 1022,477 & 0,000 \\
\hline rebajado & 0,806 & 2 & 0,403 & 11,913 & 0,000 \\
\hline molde & 0,135 & 2 & 0,067 & 1,994 & 0,140 \\
\hline grosor & 0,033 & 1 & 0,033 & 0,978 & 0,324 \\
\hline rebajado $*$ molde & 0,332 & 4 & 0,083 & 2,454 & 0,048 \\
\hline rebajado * grosor & 0,098 & 2 & 0,049 & 1,447 & 0,238 \\
\hline molde * grosor & 0,026 & 2 & 0,013 & 0,390 & 0,677 \\
\hline rebajado * molde * grosor & 0,071 & 4 & 0,018 & 0,522 & 0,719 \\
\hline Error & 5,515 & 163 & 0,034 & & \\
\hline Total & 41,633 & 181 & & & \\
\hline Total corregida & 6,998 & 180 & & & \\
\hline
\end{tabular}

Tabla A.48. Análisis de varianza factorial de la variable delta de F0 en semitonos para los factores rebajado, molde y grosor (elementos de fabricación de la lengüeta). 


\begin{tabular}{|c|c|c|c|c|c|c|c|c|c|}
\hline \multicolumn{10}{|c|}{ Prueba de muestras relacionadas } \\
\hline \multirow[t]{2}{*}{ Measurement } & \multirow[t]{2}{*}{ rebajado } & \multirow[t]{2}{*}{ Media } & \multirow[t]{2}{*}{ Desviación típ. } & \multirow[t]{2}{*}{$\begin{array}{c}\text { Error típ. } \\
\text { de la media }\end{array}$} & \multicolumn{2}{|c|}{$\begin{array}{c}95 \% \text { Intervalo de } \\
\text { confianza para la } \\
\text { diferencia }\end{array}$} & \multirow[t]{2}{*}{$\mathrm{t}$} & \multirow[t]{2}{*}{$\mathrm{gl}$} & \multirow[t]{2}{*}{$\begin{array}{c}\text { Sig. } \\
\text { (bilateral) }\end{array}$} \\
\hline & & & & & Inferior & Superior & & & \\
\hline \multirow[t]{3}{*}{ F0 Delta (en st) } & fr-ge & 0,1589 & 0,2094 & 0,0280 & 0,1028 & 0,2150 & 5,679 & 55 & 0,000 \\
\hline & fr-us & 0,1424 & 0,3131 & 0,0411 & 0,0600 & 0,2247 & 3,463 & 57 & 0,001 \\
\hline & ge-us & $-0,0165$ & 0,2408 & 0,0316 & $-0,0798$ & 0,0468 & $-0,522$ & 57 & 0,604 \\
\hline
\end{tabular}

Tabla A.49. Prueba T pareada comparando el delta de F0 (st) para los diferentes estilos de rebajado.

\begin{tabular}{|c|c|c|c|c|c|}
\hline \multicolumn{6}{|c|}{ Pruebas de los efectos inter-sujetos } \\
\hline \multicolumn{6}{|c|}{ Variable dependiente: Delta F0 (st) } \\
\hline Origen & $\begin{array}{c}\text { Suma de cuadrados } \\
\text { tipo III }\end{array}$ & gl & Media cuadrática & $\mathrm{F}$ & Sig. \\
\hline Modelo corregido & $2,972^{\mathrm{a}}$ & 32 & 0,093 & 3,414 & 0,000 \\
\hline Intersección & 31,181 & 1 & 31,181 & 1146,323 & 0,000 \\
\hline rebajado & 0,665 & 2 & 0,333 & 12,229 & 0,000 \\
\hline oboista & 0,882 & 10 & 0,088 & 3,243 & 0,001 \\
\hline rebajado * oboista & 1,321 & 20 & 0,066 & 2,428 & 0,001 \\
\hline Error & 4,026 & 148 & 0,027 & & \\
\hline Total & 41,633 & 181 & & & \\
\hline Total corregida & 6,998 & 180 & & & \\
\hline
\end{tabular}

Tabla A.50. Análisis de varianza factorial de la variable delta de F0 en semitonos para los factores rebajado y oboísta.

\begin{tabular}{|c|c|c|c|c|c|}
\hline \multicolumn{6}{|c|}{ Pruebas de los efectos inter-sujetos } \\
\hline \multicolumn{6}{|c|}{ Variable dependiente: Delta Insensidad (en dB) } \\
\hline Origen & Suma de cuadrados tipo III & $\mathrm{gl}$ & $\begin{array}{c}\text { Media } \\
\text { cuadrática }\end{array}$ & $\mathrm{F}$ & Sig. \\
\hline Modelo corregido & $46,374^{\mathrm{a}}$ & 17 & 2,728 & 0,863 & 0,618 \\
\hline Intersección & 146571,209 & 1 & 146571,209 & 46369,252 & 0,000 \\
\hline rebajado & 1,250 & 2 & 0,625 & 0,198 & 0,821 \\
\hline molde & 4,225 & 2 & 2,113 & 0,668 & 0,514 \\
\hline grosor & 0,034 & 1 & 0,034 & 0,011 & 0,918 \\
\hline rebajado $*$ molde & 13,627 & 4 & 3,407 & 1,078 & 0,369 \\
\hline rebajado * grosor & 1,458 & 2 & 0,729 & 0,231 & 0,794 \\
\hline molde * grosor & 8,890 & 2 & 4,445 & 1,406 & 0,248 \\
\hline rebajado $*$ molde $*$ grosor & 17,429 & 4 & 4,357 & 1,378 & 0,244 \\
\hline Error & 515,236 & 163 & 3,161 & & \\
\hline Total & 147784,383 & 181 & & & \\
\hline
\end{tabular}




\begin{tabular}{|c|c|c|c|c|c|}
\hline \multicolumn{6}{|c|}{ Pruebas de los efectos inter-sujetos } \\
\hline \multicolumn{6}{|c|}{ Variable dependiente: Delta Insensidad (en dB) } \\
\hline Origen & Suma de cuadrados tipo III & $\overline{\mathrm{gl}}$ & $\begin{array}{c}\text { Media } \\
\text { cuadrática }\end{array}$ & $\mathrm{F}$ & Sig. \\
\hline Total corregida & 561,610 & 180 & & & \\
\hline
\end{tabular}

Tabla A.51. Análisis de varianza factorial de la variable delta de la intensidad (en $\mathrm{dB}$ ) para los factores rebajado, molde y grosor (elementos de fabricación de la lengüeta).

\begin{tabular}{|c|c|c|c|c|c|c|c|c|c|}
\hline \multicolumn{10}{|c|}{ Prueba de muestras relacionadas } \\
\hline \multirow[t]{2}{*}{ Measurement } & \multirow[t]{2}{*}{ rebajado } & \multirow[t]{2}{*}{ Media } & \multirow[t]{2}{*}{$\begin{array}{c}\text { Desviación } \\
\text { típ. }\end{array}$} & \multirow{2}{*}{$\begin{array}{c}\text { Error típ. } \\
\text { de la } \\
\text { media }\end{array}$} & \multicolumn{2}{|c|}{$\begin{array}{l}95 \% \text { Intervalo de confianza } \\
\text { para la diferencia }\end{array}$} & \multirow[t]{2}{*}{$\mathrm{t}$} & \multirow[t]{2}{*}{$\mathrm{gl}$} & \multirow[t]{2}{*}{$\begin{array}{c}\text { Sig. } \\
\text { (bilateral) }\end{array}$} \\
\hline & & & & & Inferior & Superior & & & \\
\hline \multirow[t]{3}{*}{ intensidad (en $\mathrm{dB}$ ) } & fr - ge & $-0,2607$ & 1,7604 & 0,2352 & $-0,7321$ & 0,2107 & $-1,108$ & 55 & 0,273 \\
\hline & $\mathrm{fr}-\mathrm{us}$ & $-0,1800$ & 2,9177 & 0,3831 & $-0,9472$ & 0,5872 & $-0,470$ & 57 & 0,640 \\
\hline & ge - us & 0,0438 & 2,6519 & 0,3482 & $-0,6534$ & 0,7411 & 0,126 & 57 & 0,900 \\
\hline
\end{tabular}

Tabla A.52. Prueba T pareada comparando el delta de intensidad (en dB) para los diferentes estilos de rebajado.

\begin{tabular}{|c|c|c|c|c|c|}
\hline \multicolumn{6}{|c|}{ Pruebas de los efectos inter-sujetos } \\
\hline \multicolumn{6}{|c|}{ Variable dependiente: Delta Insensidad (en dB) } \\
\hline Origen & $\begin{array}{c}\text { Suma de cuadrados tipo } \\
\text { III }\end{array}$ & $\mathrm{gl}$ & Media cuadrática & $\mathrm{F}$ & Sig. \\
\hline Modelo corregido & $206,074^{\mathrm{a}}$ & 32 & 6,440 & 2,681 & 0,000 \\
\hline Intersección & 137508,541 & 1 & 137508,541 & 57241,082 & 0,000 \\
\hline rebajado & 0,682 & 2 & 0,341 & 0,142 & 0,868 \\
\hline oboista & 88,499 & 10 & 8,850 & 3,684 & 0,000 \\
\hline rebajado * oboista & 116,144 & 20 & 5,807 & 2,417 & 0,001 \\
\hline Error & 355,536 & 148 & 2,402 & & \\
\hline Total & 147784,383 & 181 & & & \\
\hline Total corregida & 561,610 & 180 & & & \\
\hline
\end{tabular}

Tabla A.53. Análisis de varianza factorial de la variable delta de la intensidad (en dB) para los factores rebajado y oboísta.

\begin{tabular}{|c|c|c|c|c|c|c|}
\hline \multicolumn{7}{|c|}{ Pruebas de los efectos inter-sujetos ${ }^{\mathrm{a}}$} \\
\hline \multicolumn{7}{|c|}{ Variable dependiente: Valor Norm. } \\
\hline Origen & $\begin{array}{c}\text { Suma de cuadrados tipo } \\
\text { III }\end{array}$ & $\mathrm{gl}$ & $\begin{array}{c}\text { Media } \\
\text { cuadrática }\end{array}$ & $\mathrm{F}$ & Sig. & $\begin{array}{c}\text { Eta al cuadrado } \\
\text { parcial }\end{array}$ \\
\hline Modelo corregido & $19,109^{b}$ & 17 & 1,124 & 1,138 & 0,322 & 0,101 \\
\hline Intersección & 0,022 & 1 & 0,022 & 0,022 & 0,882 & 0,000 \\
\hline rebajado & 9,116 & 2 & 4,558 & 4,614 & 0,011 & 0,051 \\
\hline
\end{tabular}




\begin{tabular}{|c|c|c|c|c|c|c|}
\hline \multicolumn{7}{|c|}{ Pruebas de los efectos inter-sujetos ${ }^{\mathrm{a}}$} \\
\hline \multicolumn{7}{|c|}{ Variable dependiente: Valor Norm. } \\
\hline Origen & $\begin{array}{c}\text { Suma de cuadrados tipo } \\
\text { III }\end{array}$ & $\mathrm{gl}$ & $\begin{array}{c}\text { Media } \\
\text { cuadrática }\end{array}$ & $\bar{F}$ & Sig. & $\begin{array}{c}\text { Eta al cuadrado } \\
\text { parcial }\end{array}$ \\
\hline molde & 1,430 & 2 & 0,715 & 0,724 & 0,486 & 0,008 \\
\hline grosor & 2,402 & 1 & 2,402 & 2,432 & 0,121 & 0,014 \\
\hline rebajado $*$ molde & 3,020 & 4 & 0,755 & 0,764 & 0,550 & 0,017 \\
\hline rebajado * grosor & 1,279 & 2 & 0,639 & 0,647 & 0,525 & 0,007 \\
\hline molde * grosor & 0,621 & 2 & 0,310 & 0,314 & 0,731 & 0,004 \\
\hline rebajado $*$ molde $*$ grosor & 1,411 & 4 & 0,353 & 0,357 & 0,839 & 0,008 \\
\hline Error & 169,891 & 172 & 0,988 & & & \\
\hline Total & 189,000 & 190 & & & & \\
\hline Total corregida & 189,000 & 189 & & & & \\
\hline \multicolumn{7}{|c|}{ a. Measurement $=$ Intensity $(\mathrm{en} \mathrm{dB})$, ejercicio $=$ Pianissimo } \\
\hline adrado $=, 101(\mathrm{R}$ & 012) & & & & & \\
\hline
\end{tabular}

Tabla A.54. Análisis de varianza factorial de la intensidad para los factores rebajado, molde y grosor (elementos de fabricación de la lengüeta).

\begin{tabular}{|c|c|c|c|c|c|c|c|c|c|c|}
\hline \multicolumn{11}{|c|}{ Prueba de muestras relacionadas } \\
\hline \multirow[t]{2}{*}{$\begin{array}{l}\text { Measure } \\
\text { ment }\end{array}$} & \multirow[t]{2}{*}{ ejercicio } & \multirow[t]{2}{*}{ rebajado } & \multirow[t]{2}{*}{ Media } & \multirow[t]{2}{*}{$\begin{array}{c}\text { Desviaci } \\
\text { ón típ. }\end{array}$} & \multirow[t]{2}{*}{$\begin{array}{c}\text { Error típ. de } \\
\text { la media }\end{array}$} & \multicolumn{2}{|c|}{$\begin{array}{c}95 \% \text { Intervalo de } \\
\text { confianza para la } \\
\text { diferencia }\end{array}$} & \multirow[t]{2}{*}{$\mathrm{t}$} & \multirow[t]{2}{*}{$\mathrm{gl}$} & \multirow[t]{2}{*}{$\begin{array}{c}\text { Sig. } \\
\text { (bilateral) }\end{array}$} \\
\hline & & & & & & Inferior & Superior & & & \\
\hline \multirow{3}{*}{$\begin{array}{l}\text { Intensity } \\
(\mathrm{en} \mathrm{dB})\end{array}$} & \multirow{3}{*}{$\begin{array}{l}\text { Pianissim } \\
\text { o }\end{array}$} & fr-ge & $-2,4314$ & 6,9672 & 0,9310 & $-4,2972$ & $-0,5656$ & $-2,612$ & 55 & 0,012 \\
\hline & & $\mathrm{fr}-\mathrm{us}$ & $-3,2241$ & 5,0555 & 0,6638 & $-4,5534$ & $-1,8948$ & $-4,857$ & 57 & 0,000 \\
\hline & & ge - us & $-1,0259$ & 5,5510 & 0,7289 & $-2,4855$ & 0,4336 & $-1,408$ & 57 & 0,165 \\
\hline
\end{tabular}

Tabla A.55. Prueba T pareada comparando la intensidad (en dB) para los diferentes estilos de rebajado

\begin{tabular}{|l|r|r|r|r|r|r|}
\hline \multicolumn{7}{|c|}{ Pruebas de los efectos inter-sujetos $^{\mathbf{a}}$} \\
\hline Variable dependiente: Valor Norm. & \multicolumn{1}{|c|}{$\begin{array}{l}\text { Suma de } \\
\text { cuadrados tipo III }\end{array}$} & gl & Media cuadrática & F & Sig. & Eta al cuadrado parcial \\
\hline Origen & $128,614^{b}$ & 32 & 4,019 & 10,450 & 0,000 & 0,680 \\
\hline Modelo corregido & 2,869 & 1 & 2,869 & 7,460 & 0,007 & 0,045 \\
\hline Intersección & 6,219 & 2 & 3,110 & 8,085 & 0,000 & 0,093 \\
\hline rebajado & 110,987 & 10 & 11,099 & 28,856 & 0,000 & 0,648 \\
\hline oboista & 6,392 & 20 & 0,320 & 0,831 & 0,673 & \\
\hline rebajado * oboista & 60,386 & 157 & 0,385 & & & \\
\hline Error & 189,000 & 190 & & & & \\
\hline Total & 189,000 & 189 & & & & \\
\hline Total corregida & & & & & \\
\hline
\end{tabular}




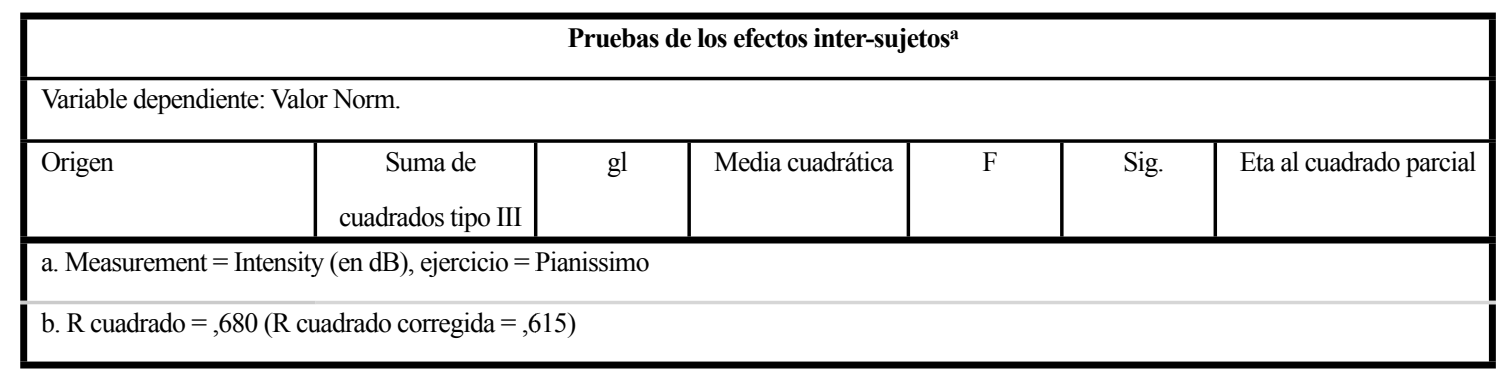

Tabla A.56. Análisis de varianza factorial de la intensidad para los factores rebajado y oboísta.

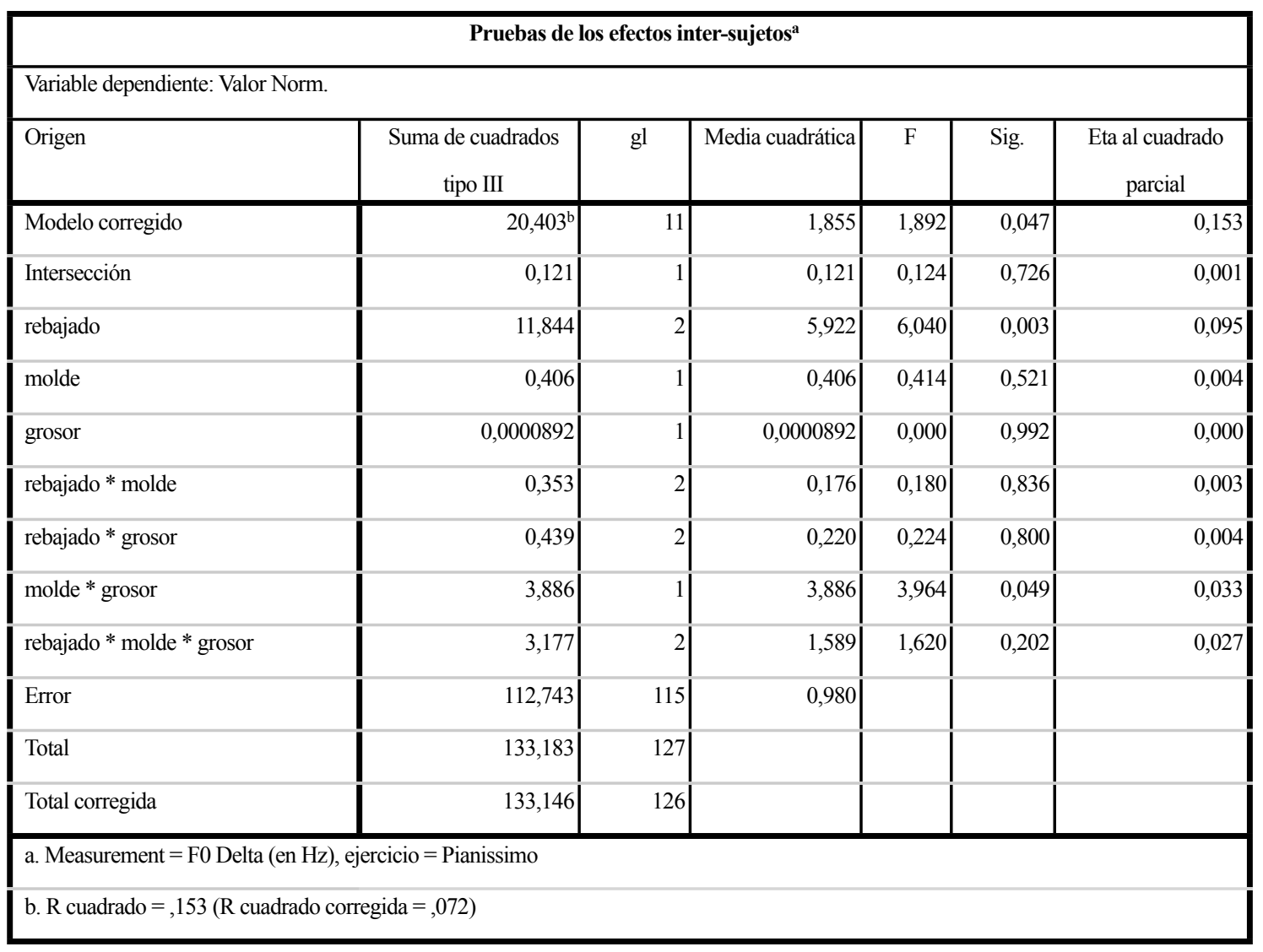

Tabla A.57. Análisis de varianza factorial del delta de afinación (en Hz) para los factores rebajado, molde y grosor (elementos de fabricación de la lengüeta).

\begin{tabular}{|c|c|c|c|c|c|c|c|c|c|c|}
\hline \multicolumn{11}{|c|}{ Prueba de muestras relacionadas } \\
\hline \multirow[t]{2}{*}{$\begin{array}{l}\text { Measure } \\
\text { ment }\end{array}$} & \multirow[t]{2}{*}{ ejercicio } & \multirow[t]{2}{*}{ rebajado } & \multirow[t]{2}{*}{ Media } & \multirow[t]{2}{*}{$\begin{array}{c}\text { Desviación } \\
\text { típ. }\end{array}$} & \multirow[t]{2}{*}{$\begin{array}{c}\text { Error típ. } \\
\text { de la media }\end{array}$} & \multicolumn{2}{|c|}{$\begin{array}{c}95 \% \text { Intervalo de confianza } \\
\text { para la diferencia }\end{array}$} & \multirow[t]{2}{*}{$\mathrm{t}$} & \multirow[t]{2}{*}{$\mathrm{gl}$} & \multirow[t]{2}{*}{ Sig. (bilateral) } \\
\hline & & & & & & Inferior & Superior & & & \\
\hline \multirow{3}{*}{$\begin{array}{l}\text { F0 Delta } \\
\text { (en } \mathrm{Hz})\end{array}$} & \multirow{3}{*}{$\begin{array}{l}\text { Pianissim } \\
\text { o }\end{array}$} & fr-ge & 6,1428 & 15,9872 & 2,6283 & 0,8124 & 11,4732 & 2,337 & 36 & 0,025 \\
\hline & & fr - us & 7,1823 & 13,1576 & 2,1344 & 2,8575 & 11,5071 & 3,365 & 37 & 0,002 \\
\hline & & ge - us & 0,1335 & 12,0788 & 1,9594 & $-3,8367$ & 4,1037 & 0,068 & 37 & 0,946 \\
\hline
\end{tabular}

Tabla A.58. Prueba T pareada comparando el delta de afinación (en Hz) para los diferentes estilos de rebajado. 


\begin{tabular}{|c|c|c|c|c|c|c|}
\hline \multicolumn{7}{|c|}{ Pruebas de los efectos inter-sujetos ${ }^{\mathrm{a}}$} \\
\hline \multicolumn{7}{|c|}{ Variable dependiente: Valor Norm. } \\
\hline Origen & $\begin{array}{c}\text { Suma de cuadrados tipo } \\
\text { III }\end{array}$ & $\mathrm{gl}$ & $\begin{array}{c}\text { Media } \\
\text { cuadrática }\end{array}$ & $\bar{F}$ & Sig. & $\begin{array}{c}\text { Eta al cuadrado } \\
\text { parcial }\end{array}$ \\
\hline Modelo corregido & $52,756^{\mathrm{b}}$ & 32 & 1,649 & 1,928 & 0,008 & 0,396 \\
\hline Intersección & 1,035 & 1 & 1,035 & 1,210 & 0,274 & 0,013 \\
\hline rebajado & 8,769 & 2 & 4,385 & 5,127 & 0,008 & 0,098 \\
\hline oboista & 27,505 & 10 & 2,751 & 3,216 & 0,001 & 0,255 \\
\hline rebajado * oboista & 13,662 & 20 & 0,683 & 0,799 & 0,709 & 0,145 \\
\hline Error & 80,389 & 94 & 0,855 & & & \\
\hline Total & 133,183 & 127 & & & & \\
\hline Total corregida & 133,146 & 126 & & & & \\
\hline \multicolumn{7}{|c|}{ a. Measurement = F0 Delta $(\mathrm{en} \mathrm{Hz})$, ejercicio = Pianissimo } \\
\hline b. $\mathrm{R}$ cuadrado $=, 3 \mathrm{~s}$ & gida $=, 191)$ & & & & & \\
\hline
\end{tabular}

Tabla A.59. Análisis de varianza factorial del delta de afinación (en Hz) para los factores rebajado y oboísta

\begin{tabular}{|c|c|c|c|c|c|c|}
\hline \multicolumn{7}{|c|}{ Pruebas de los efectos inter-sujetos ${ }^{a}$} \\
\hline \multicolumn{7}{|c|}{ Variable dependiente: Valor Norm. } \\
\hline Origen & $\begin{array}{c}\text { Suma de cuadrados } \\
\text { tipo III }\end{array}$ & $\mathrm{gl}$ & $\begin{array}{c}\text { Media } \\
\text { cuadrática }\end{array}$ & $\mathrm{F}$ & Sig. & $\begin{array}{c}\text { Eta al cuadrado } \\
\text { parcial }\end{array}$ \\
\hline Modelo corregido & $12,325^{b}$ & 17 & 0,725 & 0,706 & 0,794 & 0,065 \\
\hline Intersección & 0,015 & 1 & 0,015 & 0,014 & 0,905 & 0,000 \\
\hline rebajado & 5,383 & 2 & 2,692 & 2,620 & 0,076 & 0,030 \\
\hline molde & 3,041 & 2 & 1,520 & 1,480 & 0,231 & 0,017 \\
\hline grosor & 0,746 & 1 & 0,746 & 0,726 & 0,395 & 0,004 \\
\hline rebajado $*$ molde & 0,357 & 4 & 0,089 & 0,087 & 0,986 & 0,002 \\
\hline rebajado * grosor & 0,757 & 2 & 0,379 & 0,369 & 0,692 & 0,004 \\
\hline molde * grosor & 0,444 & 2 & 0,222 & 0,216 & 0,806 & 0,003 \\
\hline rebajado * molde * grosor & 1,522 & 4 & 0,381 & 0,370 & 0,829 & 0,009 \\
\hline Error & 176,675 & 172 & 1,027 & & & \\
\hline Total & 189,000 & 190 & & & & \\
\hline Total corregida & 189,000 & 189 & & & & \\
\hline \multicolumn{7}{|c|}{ a. Measurement $=$ Intensity $(\mathrm{en} \mathrm{dB})$, ejercicio $=$ Fortissimo } \\
\hline $0=, 065(\mathrm{R}$ & $-.027)$ & & & & & \\
\hline
\end{tabular}

Tabla A.60. Análisis de varianza factorial de la intensidad (en $\mathrm{dB}$ ) para los factores rebajado, molde y grosor (elementos de fabricación de la lengüeta). 


\begin{tabular}{|c|c|c|c|c|c|c|c|c|c|c|}
\hline \multicolumn{11}{|c|}{ Prueba de muestras relacionadas } \\
\hline \multirow{3}{*}{$\begin{array}{l}\text { Measure } \\
\text { ment }\end{array}$} & \multirow[t]{3}{*}{ ejercicio } & \multirow[t]{3}{*}{ rebajado } & \multirow[t]{3}{*}{ Media } & \multirow{3}{*}{$\begin{array}{l}\text { Desviación } \\
\text { típ. }\end{array}$} & \multirow{3}{*}{$\begin{array}{c}\text { Error típ. de la } \\
\text { media }\end{array}$} & \multirow{2}{*}{\multicolumn{2}{|c|}{$\begin{array}{c}95 \% \text { Intervalo de } \\
\text { confianza para la } \\
\text { diferencia } \\
\end{array}$}} & \multirow[t]{3}{*}{$\mathrm{t}$} & \multirow[t]{3}{*}{$\mathrm{gl}$} & \multirow{3}{*}{$\begin{array}{c}\text { Sig. } \\
\text { (bilateral) }\end{array}$} \\
\hline & & & & & & & & & & \\
\hline & & & & & & Inferior & Superior & & & \\
\hline \multirow{3}{*}{$\begin{array}{l}\text { Intensity } \\
\text { (en dB) }\end{array}$} & \multirow{3}{*}{$\begin{array}{l}\text { Fortissim } \\
\text { o }\end{array}$} & $\mathrm{fr}$ - ge & $-1,7177$ & 2,3492 & 0,3139 & $-2,3469$ & $-1,0886$ & $-5,472$ & 55 & 0,000 \\
\hline & & $\mathrm{fr}-\mathrm{us}$ & $-1,6364$ & 2,7284 & 0,3583 & $-2,3538$ & $-0,9190$ & $-4,568$ & 57 & 0,000 \\
\hline & & ge - us & 0,0146 & 2,4223 & 0,3181 & $-0,6223$ & 0,6515 & 0,046 & 57 & 0,964 \\
\hline
\end{tabular}

Tabla A.61. Resumen del análisis de la prueba T pareada comparando la intensidad (en dB) para los diferentes estilos de rebajado.

\begin{tabular}{|c|c|c|c|c|c|c|}
\hline \multicolumn{7}{|c|}{ Pruebas de los efectos inter-sujetos ${ }^{a}$} \\
\hline \multicolumn{7}{|c|}{ Variable dependiente: Valor Norm. } \\
\hline Origen & $\begin{array}{c}\text { Suma de } \\
\text { cuadrados tipo III }\end{array}$ & $\overline{\mathrm{gl}}$ & Media cuadrática & $\mathrm{F}$ & Sig. & Eta al cuadrado parcial \\
\hline Modelo corregido & $166,636^{b}$ & 32 & 5,207 & 36,557 & 0,000 & 0,882 \\
\hline Intersección & 0,972 & 1 & 0,972 & 6,823 & 0,010 & 0,042 \\
\hline rebajado & 3,344 & 2 & 1,672 & 11,737 & 0,000 & 0,130 \\
\hline oboista & 156,157 & 10 & 15,616 & 109,625 & 0,000 & 0,875 \\
\hline rebajado * oboista & 2,790 & 20 & 0,140 & 0,979 & 0,490 & 0,111 \\
\hline Error & 22,364 & 157 & 0,142 & & & \\
\hline Total & 189,000 & 190 & & & & \\
\hline Total corregida & 189,000 & 189 & & & & \\
\hline \multicolumn{7}{|c|}{ a. Measurement $=$ Intensity $(\mathrm{en} \mathrm{dB})$, ejercicio $=$ Fortissimo } \\
\hline ado $=$ & do corregida $=$ & & & & & \\
\hline
\end{tabular}

Tabla A.62. Análisis de varianza factorial de la intensidad (en dB) para los factores rebajado y oboísta.

\begin{tabular}{|l|r|r|r|r|r|r|}
\hline \multicolumn{7}{|l|}{ Pruebas de los efectos inter-sujetos } \\
\hline Variable dependiente: Valor Norm. & $\begin{array}{r}\text { Suma de cuadrados } \\
\text { tipo III }\end{array}$ & gl & Media & F & Sig. & $\begin{array}{c}\text { Eta al cuadrado } \\
\text { parcial }\end{array}$ \\
\hline Origen & $54,495^{b}$ & 17 & 3,206 & 4,099 & 0,000 & 0,288 \\
\hline Modelo corregido & 0,110 & 1 & 0,110 & 0,141 & 0,708 & 0,001 \\
\hline Intersección & 27,744 & 2 & 13,872 & 17,739 & 0,000 & 0,171 \\
\hline rebajado & 12,490 & 2 & 6,245 & 7,986 & 0,000 & 0,085 \\
\hline molde & 4,563 & 1 & 4,563 & 5,835 & 0,017 & 0,033 \\
\hline grosor & 5,382 & 4 & 1,345 & 1,721 & 0,148 & 0,038 \\
\hline rebajado * molde & 2,286 & 2 & 1,143 & 1,462 & 0,235 & \\
\hline rebajado * grosor & 0,742 & 2 & 0,371 & 0,474 & 0,623 & 0,017 \\
\hline molde * grosor & 1,994 & 4 & 0,498 & 0,637 & 0,636 & 0,005 \\
\hline rebajado * molde * grosor & 134,505 & 172 & 0,782 & & & 0,015 \\
\hline Error & & & & & \\
\hline
\end{tabular}




\begin{tabular}{|c|c|c|c|c|c|c|}
\hline \multicolumn{7}{|c|}{ Pruebas de los efectos inter-sujetos ${ }^{\mathrm{a}}$} \\
\hline \multicolumn{7}{|c|}{ Variable dependiente: Valor Norm. } \\
\hline Origen & $\begin{array}{c}\text { Suma de cuadrados } \\
\text { tipo III }\end{array}$ & $\mathrm{gl}$ & $\begin{array}{c}\text { Media } \\
\text { cuadrática }\end{array}$ & $\mathrm{F}$ & Sig. & $\begin{array}{c}\text { Eta al cuadrado } \\
\text { parcial }\end{array}$ \\
\hline Total & 189,000 & 190 & & & & \\
\hline Total corregida & 189,000 & 189 & & & & \\
\hline \multicolumn{7}{|c|}{ a. Measurement $=$ Spectrum Center Gravity, ejercicio $=$ Fortissimo } \\
\hline b. $\mathrm{R}$ cuadrado $=$ & $a=, 218)$ & & & & & \\
\hline
\end{tabular}

Tabla A.63. Análisis de varianza factorial del centro de gravedad del espectro para los factores rebajado, molde y grosor (elementos de fabricación de la lengüeta).

\begin{tabular}{|l|l|l|r|r|r|r|r|r|r|}
\hline \multicolumn{2}{|l|}{ Prueba de muestras relacionadas } \\
Measure \\
ment
\end{tabular}

Tabla A.64. Resumen del análisis de la prueba pareada comparando el centro de gravedad del espectro para los diferentes estilos de rebajado.

\begin{tabular}{|c|c|c|c|c|c|c|}
\hline \multicolumn{7}{|c|}{ Pruebas de los efectos inter-sujetos ${ }^{a}$} \\
\hline \multicolumn{7}{|c|}{ Variable dependiente: Valor Norm. } \\
\hline Origen & $\begin{array}{c}\text { Suma de cuadrados tipo } \\
\text { III }\end{array}$ & $\mathrm{gl}$ & Media cuadrática & $\mathrm{F}$ & Sig. & $\begin{array}{c}\text { Eta al cuadrado } \\
\text { parcial }\end{array}$ \\
\hline Modelo corregido & $88,376^{\mathrm{b}}$ & 32 & 2,762 & 4,309 & 0,000 & 0,468 \\
\hline Intersección & 0,0000107 & 1 & 0,0000107 & 0,000 & 0,997 & 0,000 \\
\hline rebajado & 24,144 & 2 & 12,072 & 18,836 & 0,000 & 0,194 \\
\hline oboista & 45,113 & 10 & 4,511 & 7,039 & 0,000 & 0,310 \\
\hline rebajado * oboista & 15,424 & 20 & 0,771 & 1,203 & 0,258 & 0,133 \\
\hline Error & 100,624 & 157 & 0,641 & & & \\
\hline Total & 189,000 & 190 & & & & \\
\hline Total corregida & 189,000 & 189 & & & & \\
\hline \multicolumn{7}{|c|}{ a. Measurement $=$ Spectrum Center Gravity, ejercicio $=$ Fortissimo } \\
\hline b. $\mathrm{R}$ cuadrado $=, 4 \mathrm{C}$ & corregida $=, 359$ ) & & & & & \\
\hline
\end{tabular}

Tabla A.65. Análisis de varianza factorial del centro de gravedad del espectro para los factores rebajado y oboísta. 


\subsubsection{Experimento de evaluación interpretativa (propiocepción del instrumentista)}

\begin{tabular}{|c|c|c|c|c|c|c|c|c|}
\hline \multicolumn{9}{|c|}{ Pruebas de efectos intra-sujetos. } \\
\hline \multicolumn{9}{|c|}{ Medida: MEASURE_1 } \\
\hline pregunta & Origen & & $\begin{array}{c}\text { Suma de } \\
\text { cuadrados } \\
\text { tipo III }\end{array}$ & $\mathrm{gl}$ & $\begin{array}{c}\text { Media } \\
\text { cuadrática }\end{array}$ & F & Sig. & $\begin{array}{c}\text { Eta al cuadrado } \\
\text { parcial }\end{array}$ \\
\hline \multirow[t]{8}{*}{ arpegioF } & \multirow[t]{4}{*}{ rebajados } & $\begin{array}{l}\text { Esfericidad } \\
\text { asumida }\end{array}$ & 82,279 & 2 & 41,140 & 22,147 & 0,000 & 0,362 \\
\hline & & $\begin{array}{l}\text { Greenhouse- } \\
\text { Geisser }\end{array}$ & 82,279 & 1,930 & 42,637 & 22,147 & 0,000 & 0,362 \\
\hline & & Huynh-Feldt & 82,279 & 2,000 & 41,140 & 22,147 & 0,000 & 0,362 \\
\hline & & Límite-inferior & 82,279 & 1,000 & 82,279 & 22,147 & 0,000 & 0,362 \\
\hline & \multirow[t]{4}{*}{ Error(rebajados) } & $\begin{array}{l}\text { Esfericidad } \\
\text { asumida }\end{array}$ & 144,888 & 78 & 1,858 & & & \\
\hline & & $\begin{array}{l}\text { Greenhouse- } \\
\text { Geisser }\end{array}$ & 144,888 & 75,261 & 1,925 & & & \\
\hline & & Huynh-Feldt & 144,888 & 78,000 & 1,858 & & & \\
\hline & & Límite-inferior & 144,888 & 39,000 & 3,715 & & & \\
\hline \multirow[t]{8}{*}{ arpegioQ } & \multirow[t]{4}{*}{ rebajados } & $\begin{array}{l}\text { Esfericidad } \\
\text { asumida }\end{array}$ & 21,679 & 2 & 10,840 & 5,872 & 0,004 & 0,131 \\
\hline & & $\begin{array}{l}\text { Greenhouse- } \\
\text { Geisser }\end{array}$ & 21,679 & 1,993 & 10,879 & 5,872 & 0,004 & 0,131 \\
\hline & & Huynh-Feldt & 21,679 & 2,000 & 10,840 & 5,872 & 0,004 & 0,131 \\
\hline & & Límite-inferior & 21,679 & 1,000 & 21,679 & 5,872 & 0,020 & 0,131 \\
\hline & \multirow[t]{4}{*}{ Error(rebajados) } & $\begin{array}{l}\text { Esfericidad } \\
\text { asumida }\end{array}$ & 143,987 & 78 & 1,846 & & & \\
\hline & & $\begin{array}{l}\text { Greenhouse- } \\
\text { Geisser }\end{array}$ & 143,987 & 77,715 & 1,853 & & & \\
\hline & & Huynh-Feldt & 143,987 & 78,000 & 1,846 & & & \\
\hline & & Límite-inferior & 143,987 & 39,000 & 3,692 & & & \\
\hline \multirow[t]{8}{*}{$\operatorname{dim} F$} & \multirow[t]{4}{*}{ rebajados } & $\begin{array}{l}\text { Esfericidad } \\
\text { asumida }\end{array}$ & 59,267 & 2 & 29,633 & 16,904 & 0,000 & 0,302 \\
\hline & & $\begin{array}{l}\text { Greenhouse- } \\
\text { Geisser }\end{array}$ & 59,267 & 1,762 & 33,630 & 16,904 & 0,000 & 0,302 \\
\hline & & Huynh-Feldt & 59,267 & 1,839 & 32,222 & 16,904 & 0,000 & 0,302 \\
\hline & & Límite-inferior & 59,267 & 1,000 & 59,267 & 16,904 & 0,000 & 0,302 \\
\hline & \multirow[t]{4}{*}{ Error(rebajados) } & $\begin{array}{l}\text { Esfericidad } \\
\text { asumida }\end{array}$ & 136,733 & 78 & 1,753 & & & \\
\hline & & $\begin{array}{l}\text { Greenhouse- } \\
\text { Geisser }\end{array}$ & 136,733 & 68,731 & 1,989 & & & \\
\hline & & Huynh-Feldt & 136,733 & 71,734 & 1,906 & & & \\
\hline & & Límite-inferior & 136,733 & 39,000 & 3,506 & & & \\
\hline
\end{tabular}




\begin{tabular}{|c|c|c|c|c|c|c|c|c|}
\hline \multicolumn{9}{|c|}{ Pruebas de efectos intra-sujetos. } \\
\hline \multicolumn{9}{|c|}{ Medida: MEASURE_1 } \\
\hline pregunta & Origen & & $\begin{array}{c}\text { Suma de } \\
\text { cuadrados } \\
\text { tipo III }\end{array}$ & $\mathrm{gl}$ & $\begin{array}{c}\text { Media } \\
\text { cuadrática }\end{array}$ & $\bar{F}$ & Sig. & $\begin{array}{c}\text { Eta al cuadrado } \\
\text { parcial }\end{array}$ \\
\hline \multirow[t]{8}{*}{$\operatorname{dim} Q$} & \multirow[t]{4}{*}{ rebajados } & $\begin{array}{l}\text { Esfericidad } \\
\text { asumida }\end{array}$ & 20,429 & 2 & 10,215 & 6,995 & 0,002 & 0,152 \\
\hline & & $\begin{array}{l}\text { Greenhouse- } \\
\text { Geisser }\end{array}$ & 20,429 & 1,765 & 11,573 & 6,995 & 0,003 & 0,152 \\
\hline & & Huynh-Feldt & 20,429 & 1,843 & 11,087 & 6,995 & 0,002 & 0,152 \\
\hline & & Límite-inferior & 20,429 & 1,000 & 20,429 & 6,995 & 0,012 & 0,152 \\
\hline & \multirow[t]{4}{*}{ Error(rebajados) } & $\begin{array}{l}\text { Esfericidad } \\
\text { asumida }\end{array}$ & 113,904 & 78 & 1,460 & & & \\
\hline & & $\begin{array}{l}\text { Greenhouse- } \\
\text { Geisser }\end{array}$ & 113,904 & 68,845 & 1,655 & & & \\
\hline & & Huynh-Feldt & 113,904 & 71,863 & 1,585 & & & \\
\hline & & Límite-inferior & 113,904 & 39,000 & 2,921 & & & \\
\hline \multirow[t]{8}{*}{ Dutilleux } & \multirow[t]{4}{*}{ rebajados } & $\begin{array}{l}\text { Esfericidad } \\
\text { asumida }\end{array}$ & 17,029 & 2 & 8,515 & 5,702 & 0,005 & 0,128 \\
\hline & & $\begin{array}{l}\text { Greenhouse- } \\
\text { Geisser }\end{array}$ & 17,029 & 1,941 & 8,772 & 5,702 & 0,005 & 0,128 \\
\hline & & Huynh-Feldt & 17,029 & 2,000 & 8,515 & 5,702 & 0,005 & 0,128 \\
\hline & & Límite-inferior & 17,029 & 1,000 & 17,029 & 5,702 & 0,022 & 0,128 \\
\hline & \multirow[t]{4}{*}{ Error(rebajados) } & $\begin{array}{l}\text { Esfericidad } \\
\text { asumida }\end{array}$ & 116,471 & 78 & 1,493 & & & \\
\hline & & $\begin{array}{l}\text { Greenhouse- } \\
\text { Geisser }\end{array}$ & 116,471 & 75,713 & 1,538 & & & \\
\hline & & Huynh-Feldt & 116,471 & 78,000 & 1,493 & & & \\
\hline & & Límite-inferior & 116,471 & 39,000 & 2,986 & & & \\
\hline \multirow[t]{8}{*}{ equilibrio } & \multirow[t]{4}{*}{ rebajados } & $\begin{array}{l}\text { Esfericidad } \\
\text { asumida }\end{array}$ & 19,888 & 2 & 9,944 & 6,908 & 0,002 & 0,150 \\
\hline & & $\begin{array}{l}\text { Greenhouse- } \\
\text { Geisser }\end{array}$ & 19,888 & 1,932 & 10,295 & 6,908 & 0,002 & 0,150 \\
\hline & & Huynh-Feldt & 19,888 & 2,000 & 9,944 & 6,908 & 0,002 & 0,150 \\
\hline & & Límite-inferior & 19,888 & 1,000 & 19,888 & 6,908 & 0,012 & 0,150 \\
\hline & \multirow[t]{4}{*}{ Error(rebajados) } & $\begin{array}{l}\text { Esfericidad } \\
\text { asumida }\end{array}$ & 112,279 & 78 & 1,439 & & & \\
\hline & & $\begin{array}{l}\text { Greenhouse- } \\
\text { Geisser }\end{array}$ & 112,279 & 75,339 & 1,490 & & & \\
\hline & & Huynh-Feldt & 112,279 & 78,000 & 1,439 & & & \\
\hline & & Límite-inferior & 112,279 & 39,000 & 2,879 & & & \\
\hline \multirow[t]{2}{*}{$\mathrm{ffF}$} & \multirow[t]{2}{*}{ rebajados } & $\begin{array}{l}\text { Esfericidad } \\
\text { asumida }\end{array}$ & 5,104 & 2 & 2,552 & 1,733 & 0,184 & 0,043 \\
\hline & & $\begin{array}{l}\text { Greenhouse- } \\
\text { Geisser }\end{array}$ & 5,104 & 1,680 & 3,038 & 1,733 & 0,189 & 0,043 \\
\hline
\end{tabular}




\begin{tabular}{|c|c|c|c|c|c|c|c|c|}
\hline \multicolumn{9}{|c|}{ Pruebas de efectos intra-sujetos. } \\
\hline \multicolumn{9}{|c|}{ Medida: MEASURE_1 } \\
\hline \multirow[t]{7}{*}{ pregunta } & \multicolumn{2}{|l|}{ Origen } & $\begin{array}{c}\text { Suma de } \\
\text { cuadrados } \\
\text { tipo III }\end{array}$ & $\mathrm{gl}$ & $\begin{array}{c}\text { Media } \\
\text { cuadrática }\end{array}$ & $\mathrm{F}$ & Sig. & $\begin{array}{c}\text { Eta al cuadrado } \\
\text { parcial }\end{array}$ \\
\hline & & Huynh-Feldt & 5,104 & 1,747 & 2,922 & 1,733 & 0,188 & 0,043 \\
\hline & & Límite-inferior & 5,104 & 1,000 & 5,104 & 1,733 & 0,196 & 0,043 \\
\hline & Error(rebajados) & $\begin{array}{l}\text { Esfericidad } \\
\text { asumida }\end{array}$ & 114,896 & 78 & 1,473 & & & \\
\hline & & $\begin{array}{l}\text { Greenhouse- } \\
\text { Geisser }\end{array}$ & 114,896 & 65,522 & 1,754 & & & \\
\hline & & Huynh-Feldt & 114,896 & 68,137 & 1,686 & & & \\
\hline & & Límite-inferior & 114,896 & 39,000 & 2,946 & & & \\
\hline \multirow[t]{8}{*}{ ffQ } & \multirow[t]{4}{*}{ rebajados } & $\begin{array}{l}\text { Esfericidad } \\
\text { asumida }\end{array}$ & 24,454 & 2 & 12,227 & 7,751 & 0,001 & 0,166 \\
\hline & & $\begin{array}{l}\text { Greenhouse- } \\
\text { Geisser }\end{array}$ & 24,454 & 1,814 & 13,481 & 7,751 & 0,001 & 0,166 \\
\hline & & Huynh-Feldt & 24,454 & 1,897 & 12,888 & 7,751 & 0,001 & 0,166 \\
\hline & & Límite-inferior & 24,454 & 1,000 & 24,454 & 7,751 & 0,008 & 0,166 \\
\hline & \multirow[t]{4}{*}{ Error(rebajados) } & $\begin{array}{l}\text { Esfericidad } \\
\text { asumida }\end{array}$ & 123,046 & 78 & 1,578 & & & \\
\hline & & $\begin{array}{l}\text { Greenhouse- } \\
\text { Geisser }\end{array}$ & 123,046 & 70,742 & 1,739 & & & \\
\hline & & Huynh-Feldt & 123,046 & 73,998 & 1,663 & & & \\
\hline & & Límite-inferior & 123,046 & 39,000 & 3,155 & & & \\
\hline \multirow[t]{8}{*}{ flexible } & \multirow[t]{4}{*}{ rebajados } & $\begin{array}{l}\text { Esfericidad } \\
\text { asumida }\end{array}$ & 95,017 & 2 & 47,508 & 32,042 & 0,000 & 0,451 \\
\hline & & $\begin{array}{l}\text { Greenhouse- } \\
\text { Geisser }\end{array}$ & 95,017 & 1,936 & 49,088 & 32,042 & 0,000 & 0,451 \\
\hline & & Huynh-Feldt & 95,017 & 2,000 & 47,508 & 32,042 & 0,000 & 0,451 \\
\hline & & Límite-inferior & 95,017 & 1,000 & 95,017 & 32,042 & 0,000 & 0,451 \\
\hline & \multirow[t]{4}{*}{ Error(rebajados) } & $\begin{array}{l}\text { Esfericidad } \\
\text { asumida }\end{array}$ & 115,650 & 78 & 1,483 & & & \\
\hline & & $\begin{array}{l}\text { Greenhouse- } \\
\text { Geisser }\end{array}$ & 115,650 & 75,491 & 1,532 & & & \\
\hline & & Huynh-Feldt & 115,650 & 78,000 & 1,483 & & & \\
\hline & & Límite-inferior & 115,650 & 39,000 & 2,965 & & & \\
\hline \multirow[t]{5}{*}{ global } & \multirow[t]{4}{*}{ rebajados } & $\begin{array}{l}\text { Esfericidad } \\
\text { asumida }\end{array}$ & 18,654 & 2 & 9,327 & 6,983 & 0,002 & 0,152 \\
\hline & & $\begin{array}{l}\text { Greenhouse- } \\
\text { Geisser }\end{array}$ & 18,654 & 1,889 & 9,875 & 6,983 & 0,002 & 0,152 \\
\hline & & Huynh-Feldt & 18,654 & 1,982 & 9,411 & 6,983 & 0,002 & 0,152 \\
\hline & & Límite-inferior & 18,654 & 1,000 & 18,654 & 6,983 & 0,012 & 0,152 \\
\hline & Error(rebajados) & $\begin{array}{l}\text { Esfericidad } \\
\text { asumida }\end{array}$ & 104,179 & 78 & 1,336 & & & \\
\hline
\end{tabular}




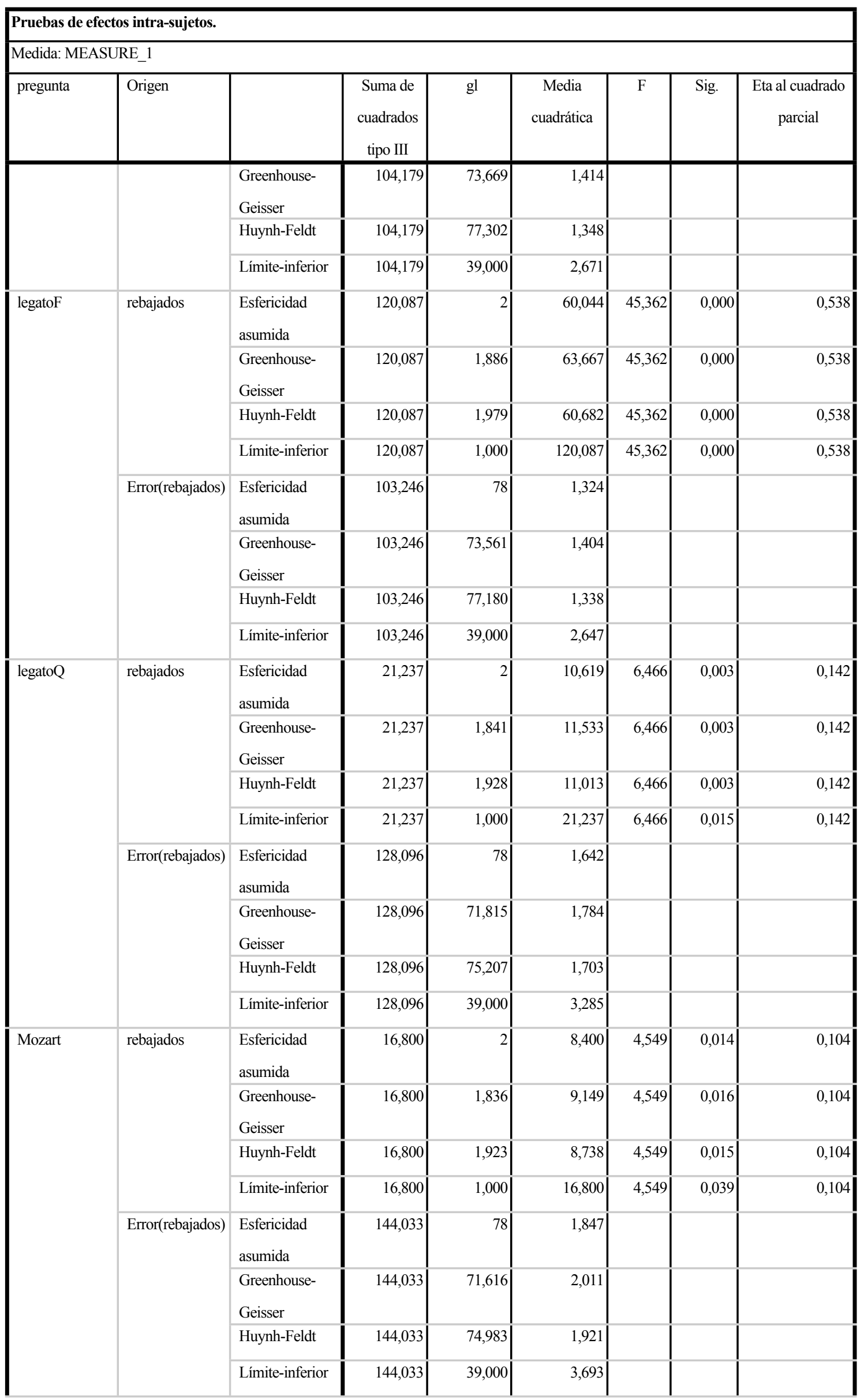




\begin{tabular}{|c|c|c|c|c|c|c|c|c|}
\hline \multicolumn{9}{|c|}{ Pruebas de efectos intra-sujetos. } \\
\hline \multicolumn{9}{|c|}{ Medida: MEASURE_1 } \\
\hline pregunta & Origen & & $\begin{array}{c}\text { Suma de } \\
\text { cuadrados } \\
\text { tipo III }\end{array}$ & $\mathrm{gl}$ & $\begin{array}{c}\text { Media } \\
\text { cuadrática }\end{array}$ & $\mathrm{F}$ & Sig. & $\begin{array}{c}\text { Eta al cuadrado } \\
\text { parcial }\end{array}$ \\
\hline \multirow[t]{8}{*}{$\mathrm{ppF}$} & \multirow[t]{4}{*}{ rebajados } & $\begin{array}{l}\text { Esfericidad } \\
\text { asumida }\end{array}$ & 6,467 & 2 & 3,233 & 1,173 & 0,315 & 0,029 \\
\hline & & $\begin{array}{l}\text { Greenhouse- } \\
\text { Geisser }\end{array}$ & 6,467 & 1,584 & 4,082 & 1,173 & 0,307 & 0,029 \\
\hline & & Huynh-Feldt & 6,467 & 1,640 & 3,943 & 1,173 & 0,308 & 0,029 \\
\hline & & Límite-inferior & 6,467 & 1,000 & 6,467 & 1,173 & 0,285 & 0,029 \\
\hline & \multirow[t]{4}{*}{ Error(rebajados) } & $\begin{array}{l}\text { Esfericidad } \\
\text { asumida }\end{array}$ & 215,033 & 78 & 2,757 & & & \\
\hline & & $\begin{array}{l}\text { Greenhouse- } \\
\text { Geisser }\end{array}$ & 215,033 & 61,780 & 3,481 & & & \\
\hline & & Huynh-Feldt & 215,033 & 63,962 & 3,362 & & & \\
\hline & & Límite-inferior & 215,033 & 39,000 & 5,514 & & & \\
\hline \multirow[t]{8}{*}{ ppQ } & \multirow[t]{4}{*}{ rebajados } & $\begin{array}{l}\text { Esfericidad } \\
\text { asumida }\end{array}$ & 12,413 & 2 & 6,206 & 3,186 & 0,047 & 0,076 \\
\hline & & $\begin{array}{l}\text { Greenhouse- } \\
\text { Geisser }\end{array}$ & 12,413 & 1,928 & 6,439 & 3,186 & 0,049 & 0,076 \\
\hline & & Huynh-Feldt & 12,413 & 2,000 & 6,206 & 3,186 & 0,047 & 0,076 \\
\hline & & Límite-inferior & 12,413 & 1,000 & 12,413 & 3,186 & 0,082 & 0,076 \\
\hline & \multirow[t]{4}{*}{ Error(rebajados) } & $\begin{array}{l}\text { Esfericidad } \\
\text { asumida }\end{array}$ & 151,921 & 78 & 1,948 & & & \\
\hline & & $\begin{array}{l}\text { Greenhouse- } \\
\text { Geisser }\end{array}$ & 151,921 & 75,180 & 2,021 & & & \\
\hline & & Huynh-Feldt & 151,921 & 78,000 & 1,948 & & & \\
\hline & & Límite-inferior & 151,921 & 39,000 & 3,895 & & & \\
\hline \multirow[t]{8}{*}{ rigidez } & \multirow[t]{4}{*}{ rebajados } & $\begin{array}{l}\text { Esfericidad } \\
\text { asumida }\end{array}$ & 43,879 & 2 & 21,940 & 8,638 & 0,000 & 0,181 \\
\hline & & $\begin{array}{l}\text { Greenhouse- } \\
\text { Geisser }\end{array}$ & 43,879 & 1,956 & 22,437 & 8,638 & 0,000 & 0,181 \\
\hline & & Huynh-Feldt & 43,879 & 2,000 & 21,940 & 8,638 & 0,000 & 0,181 \\
\hline & & Límite-inferior & 43,879 & 1,000 & 43,879 & 8,638 & 0,006 & 0,181 \\
\hline & \multirow[t]{4}{*}{ Error(rebajados) } & $\begin{array}{l}\text { Esfericidad } \\
\text { asumida }\end{array}$ & 198,121 & 78 & 2,540 & & & \\
\hline & & $\begin{array}{l}\text { Greenhouse- } \\
\text { Geisser }\end{array}$ & 198,121 & 76,272 & 2,598 & & & \\
\hline & & Huynh-Feldt & 198,121 & 78,000 & 2,540 & & & \\
\hline & & Límite-inferior & 198,121 & 39,000 & 5,080 & & & \\
\hline \multirow[t]{2}{*}{ Strauss } & \multirow[t]{2}{*}{ rebajados } & $\begin{array}{l}\text { Esfericidad } \\
\text { asumida }\end{array}$ & 13,079 & 2 & 6,540 & 3,268 & 0,043 & 0,077 \\
\hline & & $\begin{array}{l}\text { Greenhouse- } \\
\text { Geisser }\end{array}$ & 13,079 & 1,705 & 7,669 & 3,268 & 0,052 & 0,077 \\
\hline
\end{tabular}




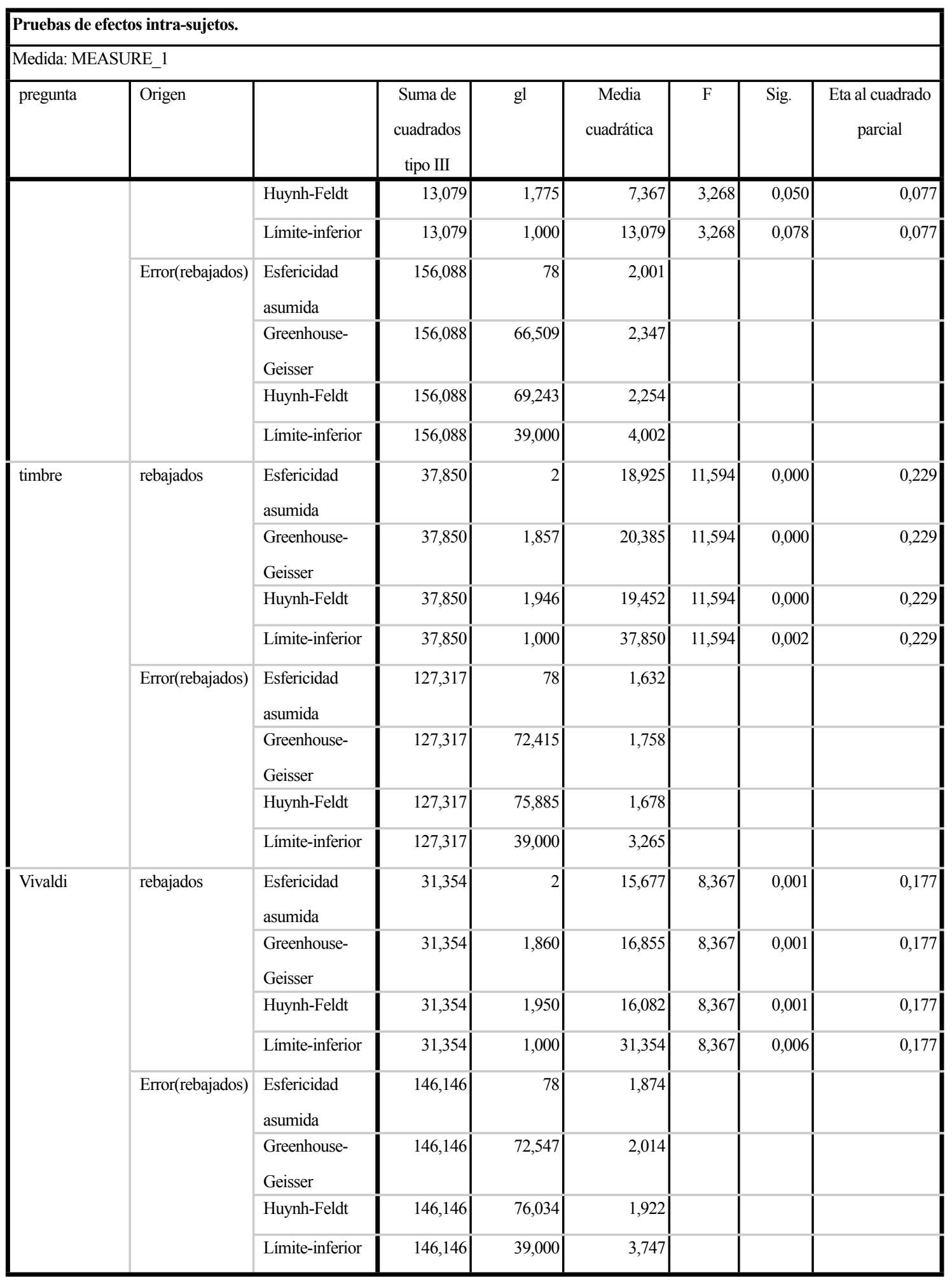

Tabla A.66. Efectos intra-sujetos del ANOVA con medidas repetidas para las diferentes preguntas que respondían los oboístas en función del rebajado. 
Influencias en la percepción sonora y en la interpretación del rebajado de la lengüeta del oboe

\begin{tabular}{|c|c|c|c|c|c|c|c|c|}
\hline \multicolumn{9}{|c|}{ Comparaciones múltiple } \\
\hline \multicolumn{9}{|l|}{ Bonferroni } \\
\hline \multirow[t]{2}{*}{ tipo pregunta } & \multirow[t]{2}{*}{ pregunta } & \multirow[t]{2}{*}{$\begin{array}{l}\text { (I) } \\
\text { rebajado }\end{array}$} & \multirow[t]{2}{*}{$\begin{array}{l}\text { (J) } \\
\text { rebajado }\end{array}$} & \multirow[t]{2}{*}{$\begin{array}{l}\text { Diferencia de } \\
\text { medias (I-J) }\end{array}$} & \multirow[t]{2}{*}{ Error típico } & \multirow[t]{2}{*}{ Sig. } & \multicolumn{2}{|c|}{$\begin{array}{l}\text { Intervalo de confianza al } \\
\qquad 95 \%\end{array}$} \\
\hline & & & & & & & $\begin{array}{l}\text { Límite } \\
\text { inferior }\end{array}$ & $\begin{array}{l}\text { Límite } \\
\text { superior }\end{array}$ \\
\hline \multirow[t]{30}{*}{ calidad } & \multirow[t]{6}{*}{ arpegioQ } & \multirow[t]{2}{*}{1} & 2 & 0,138 & 0,312 & 1,000 & $-0,62$ & 0,90 \\
\hline & & & 3 &, $962^{*}$ & 0,312 & 0,008 & 0,20 & 1,72 \\
\hline & & \multirow[t]{2}{*}{2} & 1 & $-0,138$ & 0,312 & 1,000 & $-0,90$ & 0,62 \\
\hline & & & 3 &, $825^{*}$ & 0,312 & 0,028 & 0,07 & 1,58 \\
\hline & & \multirow[t]{2}{*}{3} & 1 &,$- 962^{*}$ & 0,312 & 0,008 & $-1,72$ & $-0,20$ \\
\hline & & & 2 &,$- 825^{*}$ & 0,312 & 0,028 & $-1,58$ & $-0,07$ \\
\hline & \multirow[t]{6}{*}{$\operatorname{dim} Q$} & \multirow[t]{2}{*}{1} & 2 & 0,025 & 0,310 & 1,000 & $-0,73$ & 0,78 \\
\hline & & & 3 &, $888^{*}$ & 0,310 & 0,015 & 0,14 & 1,64 \\
\hline & & \multirow[t]{2}{*}{2} & 1 & $-0,025$ & 0,310 & 1,000 & $-0,78$ & 0,73 \\
\hline & & & 3 &, $863^{*}$ & 0,310 & 0,019 & 0,11 & 1,61 \\
\hline & & \multirow[t]{2}{*}{3} & 1 &,$- 888^{*}$ & 0,310 & 0,015 & $-1,64$ & $-0,14$ \\
\hline & & & 2 &,$- 863^{*}$ & 0,310 & 0,019 & $-1,61$ & $-0,11$ \\
\hline & \multirow[t]{6}{*}{$\mathrm{ffQ}$} & \multirow[t]{2}{*}{1} & 2 &,$- 850^{*}$ & 0,325 & 0,030 & $-1,64$ & $-0,06$ \\
\hline & & & 3 & 0,188 & 0,325 & 1,000 & $-0,60$ & 0,98 \\
\hline & & \multirow[t]{2}{*}{2} & 1 &, $850^{*}$ & 0,325 & 0,030 & 0,06 & 1,64 \\
\hline & & & 3 & $1,037^{*}$ & 0,325 & 0,005 & 0,25 & 1,83 \\
\hline & & \multirow[t]{2}{*}{3} & 1 & $-0,188$ & 0,325 & 1,000 & $-0,98$ & 0,60 \\
\hline & & & 2 & $-1,037^{*}$ & 0,325 & 0,005 & $-1,83$ & $-0,25$ \\
\hline & \multirow[t]{6}{*}{ legatoQ } & \multirow[t]{2}{*}{1} & 2 & 0,163 & 0,305 & 1,000 & $-0,58$ & 0,90 \\
\hline & & & 3 & ,962* & 0,305 & 0,006 & 0,22 & 1,70 \\
\hline & & \multirow[t]{2}{*}{2} & 1 & $-0,163$ & 0,305 & 1,000 & $-0,90$ & 0,58 \\
\hline & & & 3 & $800^{*}$ & 0,305 & 0,029 & 0,06 & 1,54 \\
\hline & & 3 & 1 &,$- 962^{*}$ & 0,305 & $\overline{0,006}$ & $-1,70$ & $-0,22$ \\
\hline & & & 2 &,$- 800^{*}$ & 0,305 & 0,029 & $-1,54$ & $-0,06$ \\
\hline & ppQ & 1 & 2 & $-0,787$ & 0,369 & 0,104 & $-1,68$ & 0,11 \\
\hline & & & 3 & $-0,375$ & 0,369 & 0,933 & $-1,27$ & 0,52 \\
\hline & & 2 & 1 & 0,787 & 0,369 & 0,104 & $-0,11$ & 1,68 \\
\hline & & & 3 & 0,412 & 0,369 & 0,796 & $-0,48$ & 1,31 \\
\hline & & 3 & 1 & 0,375 & 0,369 & 0,933 & $-0,52$ & 1,27 \\
\hline & & & 2 & $-0,412$ & 0,369 & 0,796 & $-1,31$ & 0,48 \\
\hline estilos & Dutilleux & 1 & 2 & 0,662 & 0,314 & 0,111 & $-0,10$ & 1,43 \\
\hline & & & 3 & $887^{*}$ & 0,314 & 0,017 & 0,12 & 1,65 \\
\hline & & 2 & 1 & $-0,662$ & 0,314 & 0,111 & $-1,43$ & 0,10 \\
\hline
\end{tabular}




\begin{tabular}{|c|c|c|c|c|c|c|c|c|}
\hline \multicolumn{9}{|c|}{ Comparaciones múltiple } \\
\hline \multicolumn{9}{|l|}{ Bonferroni } \\
\hline \multirow[t]{2}{*}{ tipo pregunta } & \multirow[t]{2}{*}{ pregunta } & \multirow[t]{2}{*}{$\begin{array}{l}\text { (I) } \\
\text { rebajado }\end{array}$} & \multirow[t]{2}{*}{$\begin{array}{l}(\mathrm{J}) \\
\text { rebajado }\end{array}$} & \multirow[t]{2}{*}{$\begin{array}{l}\text { Diferencia de } \\
\text { medias (I-J) }\end{array}$} & \multirow[t]{2}{*}{ Error típico } & \multirow[t]{2}{*}{ Sig. } & \multicolumn{2}{|c|}{$\begin{array}{c}\text { Intervalo de confianza al } \\
\qquad 5 \%\end{array}$} \\
\hline & & & & & & & $\begin{array}{l}\text { Límite } \\
\text { inferior }\end{array}$ & $\begin{array}{l}\text { Límite } \\
\text { superior }\end{array}$ \\
\hline & & & 3 & 0,225 & 0,314 & 1,000 & $-0,54$ & 0,99 \\
\hline & & \multirow[t]{2}{*}{3} & 1 &,$- 887^{*}$ & 0,314 & 0,017 & $-1,65$ & $-0,12$ \\
\hline & & & 2 & $-0,225$ & 0,314 & 1,000 & $-0,99$ & 0,54 \\
\hline & \multirow[t]{6}{*}{ Mozart } & \multirow[t]{2}{*}{1} & 2 & 0,300 & 0,321 & 1,000 & $-0,48$ & $\overline{1,08}$ \\
\hline & & & 3 &, $900^{*}$ & 0,321 & 0,018 & 0,12 & 1,68 \\
\hline & & \multirow[t]{2}{*}{2} & 1 & $-0,300$ & 0,321 & 1,000 & $-1,08$ & $\overline{0,48}$ \\
\hline & & & 3 & 0,600 & 0,321 & 0,193 & $-0,18$ & 1,38 \\
\hline & & \multirow[t]{2}{*}{3} & 1 &,$- 900^{*}$ & 0,321 & 0,018 & $-1,68$ & $-0,12$ \\
\hline & & & 2 & $-0,600$ & 0,321 & 0,193 & $-1,38$ & 0,18 \\
\hline & \multirow[t]{6}{*}{ Strauss } & \multirow[t]{2}{*}{1} & 2 & 0,188 & 0,321 & 1,000 & $-0,59$ & 0,97 \\
\hline & & & 3 & 0,775 & 0,321 & 0,052 & $-0,01$ & 1,56 \\
\hline & & \multirow[t]{2}{*}{2} & 1 & $-0,188$ & 0,321 & 1,000 & $-0,97$ & 0,59 \\
\hline & & & 3 & 0,587 & 0,321 & 0,210 & $-0,19$ & 1,37 \\
\hline & & \multirow[t]{2}{*}{3} & 1 & $-0,775$ & 0,321 & 0,052 & $-1,56$ & $\overline{0,01}$ \\
\hline & & & 2 & $-0,587$ & 0,321 & 0,210 & $-1,37$ & 0,19 \\
\hline & \multirow[t]{6}{*}{ Vivaldi } & \multirow[t]{2}{*}{1} & 2 & 0,688 & 0,313 & 0,090 & $-0,07$ & 1,45 \\
\hline & & & 3 & $1,250^{*}$ & 0,313 & 0,000 & 0,49 & 2,01 \\
\hline & & \multirow[t]{2}{*}{2} & 1 & $-0,688$ & 0,313 & \begin{tabular}{l|l|}
0,090 \\
\end{tabular} & $\begin{array}{l}-1,45 \\
\end{array}$ & 0,07 \\
\hline & & & 3 & 0,563 & 0,313 & 0,225 & $-0,20$ & 1,32 \\
\hline & & \multirow[t]{2}{*}{3} & 1 & $-1,250^{*}$ & 0,313 & 0,000 & $-2,01$ & $-0,49$ \\
\hline & & & 2 & $-0,563$ & 0,313 & 0,225 & $-1,32$ & 0,20 \\
\hline \multirow[t]{12}{*}{ facilidad } & \multirow[t]{6}{*}{ arpegioF } & \multirow[t]{2}{*}{1} & 2 & $1,663^{*}$ & 0,342 & 0,000 & 0,83 & 2,49 \\
\hline & & & 3 & $1,838^{*}$ & 0,342 & 0,000 & 1,01 & 2,67 \\
\hline & & 2 & 1 & $-1,663^{*}$ & 0,342 & 0,000 & $-2,49$ & $-0,83$ \\
\hline & & & 3 & 0,175 & 0,342 & 1,000 & $-0,66$ & 1,01 \\
\hline & & 3 & 1 & $-1,838^{*}$ & 0,342 & 0,000 & $-2,67$ & $-1,01$ \\
\hline & & & 2 & $-0,175$ & 0,342 & 1,000 & $-1,01$ & 0,66 \\
\hline & $\operatorname{dim} F$ & 1 & 2 & $1,350^{*}$ & 0,341 & 0,000 & 0,52 & 2,18 \\
\hline & & & 3 & $1,600^{*}$ & 0,341 & 0,000 & 0,77 & 2,43 \\
\hline & & 2 & 1 & $-1,350^{*}$ & 0,341 & 0,000 & $-2,18$ & $-0,52$ \\
\hline & & & 3 & 0,250 & 0,341 & 1,000 & $-0,58$ & 1,08 \\
\hline & & 3 & 1 & $-1,600^{*}$ & 0,341 & 0,000 & $-2,43$ & $-0,77$ \\
\hline & & & 2 & $-0,250$ & 0,341 & 1,000 & $-1,08$ & 0,58 \\
\hline
\end{tabular}


Influencias en la percepción sonora y en la interpretación del rebajado de la lengüeta del oboe

\begin{tabular}{|c|c|c|c|c|c|c|c|c|}
\hline \multicolumn{9}{|c|}{ Comparaciones múltiple } \\
\hline \multirow[t]{2}{*}{ tipo pregunta } & \multirow[t]{2}{*}{ pregunta } & \multirow[t]{2}{*}{$\begin{array}{l}\text { (I) } \\
\text { rebajado }\end{array}$} & \multirow[t]{2}{*}{$\begin{array}{l}(\mathrm{J}) \\
\text { rebajado }\end{array}$} & \multirow[t]{2}{*}{$\begin{array}{l}\text { Diferencia de } \\
\text { medias (I-J) }\end{array}$} & \multirow[t]{2}{*}{ Error típico } & \multirow[t]{2}{*}{ Sig. } & \multicolumn{2}{|c|}{$\begin{array}{c}\text { Intervalo de confianza al } \\
\qquad 95 \%\end{array}$} \\
\hline & & & & & & & $\begin{array}{l}\text { Límite } \\
\text { inferior }\end{array}$ & $\begin{array}{l}\text { Límite } \\
\text { superior }\end{array}$ \\
\hline & \multirow[t]{6}{*}{$\mathrm{ffF}$} & \multirow[t]{2}{*}{1} & 2 & $-0,438$ & 0,315 & 0,504 & $-1,20$ & 0,33 \\
\hline & & & 3 & 0,000 & 0,315 & 1,000 & $-0,77$ & 0,77 \\
\hline & & \multirow[t]{2}{*}{2} & 1 & 0,438 & 0,315 & 0,504 & $-0,33$ & 1,20 \\
\hline & & & 3 & 0,438 & 0,315 & 0,504 & $-0,33$ & 1,20 \\
\hline & & \multirow[t]{2}{*}{3} & 1 & 0,000 & 0,315 & 1,000 & $-0,77$ & 0,77 \\
\hline & & & 2 & $-0,438$ & 0,315 & 0,504 & $-1,20$ & 0,33 \\
\hline & \multirow[t]{6}{*}{ legatoF } & \multirow[t]{2}{*}{1} & 2 & $2,050^{*}$ & 0,300 & 0,000 & 1,32 & 2,78 \\
\hline & & & 3 & $2,188^{*}$ & 0,300 & 0,000 & 1,46 & 2,92 \\
\hline & & \multirow[t]{2}{*}{2} & 1 & $-2,050^{*}$ & 0,300 & 0,000 & $-2,78$ & $-1,32$ \\
\hline & & & 3 & 0,137 & 0,300 & 1,000 & $-0,59$ & 0,87 \\
\hline & & \multirow[t]{2}{*}{3} & 1 & $-2,188^{*}$ & 0,300 & 0,000 & $-2,92$ & $-1,46$ \\
\hline & & & 2 & $-0,137$ & 0,300 & 1,000 & $-0,87$ & 0,59 \\
\hline & \multirow[t]{6}{*}{$\mathrm{ppF}$} & \multirow[t]{2}{*}{1} & 2 & 0,550 & 0,386 & 0,470 & $-0,39$ & 1,49 \\
\hline & & & 3 & 0,150 & 0,386 & 1,000 & $-0,79$ & 1,09 \\
\hline & & \multirow[t]{2}{*}{2} & 1 & $-0,550$ & 0,386 & 0,470 & $-1,49$ & 0,39 \\
\hline & & & 3 & $-0,400$ & 0,386 & 0,906 & $-1,34$ & 0,54 \\
\hline & & \multirow[t]{2}{*}{3} & 1 & $-0,150$ & 0,386 & 1,000 & $-1,09$ & 0,79 \\
\hline & & & 2 & 0,400 & 0,386 & 0,906 & $-0,54$ & 1,34 \\
\hline \multirow[t]{15}{*}{ globales } & \multirow[t]{6}{*}{ equilibrio } & \multirow[t]{2}{*}{1} & 2 & $-0,212$ & 0,260 & 1,000 & $-0,84$ & 0,42 \\
\hline & & & 3 &, $737^{*}$ & 0,260 & 0,016 & 0,11 & 1,37 \\
\hline & & \multirow[t]{2}{*}{2} & 1 & 0,212 & 0,260 & 1,000 & $-0,42$ & 0,84 \\
\hline & & & 3 &, $950^{*}$ & 0,260 & 0,001 & 0,32 & 1,58 \\
\hline & & \multirow[t]{2}{*}{3} & 1 &,$- 737^{*}$ & 0,260 & 0,016 & $-1,37$ & $-0,11$ \\
\hline & & & 2 &,$- 950^{*}$ & 0,260 & 0,001 & $-1,58$ & $-0,32$ \\
\hline & \multirow[t]{6}{*}{ flexible } & 1 & 2 & $1,900^{*}$ & 0,276 & 0,000 & 1,23 & 2,57 \\
\hline & & & 3 & $1,875^{*}$ & 0,276 & 0,000 & 1,21 & 2,54 \\
\hline & & 2 & 1 & $-1,900^{*}$ & 0,276 & 0,000 & $-2,57$ & $-1,23$ \\
\hline & & & 3 & $-0,025$ & 0,276 & 1,000 & $-0,69$ & 0,64 \\
\hline & & 3 & 1 & $-1,875^{*}$ & 0,276 & 0,000 & $-2,54$ & $-1,21$ \\
\hline & & & 2 & 0,025 & 0,276 & 1,000 & $-0,64$ & 0,69 \\
\hline & global & 1 & 2 & 0,412 & 0,255 & 0,325 & $-0,21$ & 1,03 \\
\hline & & & 3 &, $962^{*}$ & 0,255 & 0,001 & 0,34 & 1,58 \\
\hline & & 2 & 1 & $-0,412$ & 0,255 & 0,325 & $-1,03$ & 0,21 \\
\hline
\end{tabular}




\begin{tabular}{|c|c|c|c|c|c|c|c|c|}
\hline \multicolumn{9}{|c|}{ Comparaciones múltiple } \\
\hline \multirow[t]{2}{*}{ tipo pregunta } & \multirow[t]{2}{*}{ pregunta } & \multirow[t]{2}{*}{$\begin{array}{l}\text { (I) } \\
\text { rebajado }\end{array}$} & \multirow[t]{2}{*}{$\begin{array}{l}\text { (J) } \\
\text { rebajado }\end{array}$} & \multirow[t]{2}{*}{$\begin{array}{l}\text { Diferencia de } \\
\text { medias (I-J) }\end{array}$} & \multirow[t]{2}{*}{ Error típico } & \multirow[t]{2}{*}{ Sig. } & \multicolumn{2}{|c|}{$\begin{array}{l}\text { Intervalo de confianza al } \\
\qquad 95 \%\end{array}$} \\
\hline & & & & & & & $\begin{array}{l}\text { Límite } \\
\text { inferior }\end{array}$ & $\begin{array}{l}\text { Límite } \\
\text { superior }\end{array}$ \\
\hline & & & 3 & 0,550 & 0,255 & 0,099 & $-0,07$ & 1,17 \\
\hline & & 3 & 1 &,$- 962^{*}$ & 0,255 & 0,001 & $-1,58$ & $-0,34$ \\
\hline & & & 2 & $-0,550$ & 0,255 & 0,099 & $-1,17$ & 0,07 \\
\hline & rigidez & 1 & 2 & $-1,425^{*}$ & 0,349 & 0,000 & $-2,27$ & $-0,58$ \\
\hline & & & 3 & $-1,063^{*}$ & 0,349 & 0,009 & $-1,91$ & $-0,22$ \\
\hline & & 2 & 1 & $1,425^{*}$ & 0,349 & 0,000 & 0,58 & 2,27 \\
\hline & & & 3 & 0,362 & 0,349 & 0,903 & $-0,48$ & 1,21 \\
\hline & & 3 & 1 & $1,063^{*}$ & 0,349 & 0,009 & 0,22 & 1,91 \\
\hline & & & 2 & $-0,362$ & 0,349 & 0,903 & $-1,21$ & 0,48 \\
\hline & timbre & 1 & 2 & $-0,725$ & 0,309 & 0,062 & $-1,48$ & 0,03 \\
\hline & & & 3 & 0,650 & 0,309 & 0,113 & $-0,10$ & 1,40 \\
\hline & & 2 & 1 & 0,725 & 0,309 & 0,062 & $-0,03$ & 1,48 \\
\hline & & & 3 & $1,375^{*}$ & 0,309 & 0,000 & 0,62 & 2,13 \\
\hline & & 3 & 1 & $-0,650$ & 0,309 & 0,113 & $-1,40$ & 0,10 \\
\hline & & & 2 & $-1,375^{*}$ & 0,309 & 0,000 & $-2,13$ & $-0,62$ \\
\hline
\end{tabular}

Tabla A.67. Prueba post hoc de Bonferroni para las respuestas que contestaban los oboístas en función del estilo de rebajado ( 1 =francés, $2=$ alemán, 3 =americano).

\begin{tabular}{|c|c|c|c|c|c|c|c|c|}
\hline \multicolumn{9}{|c|}{ Pruebas de efectos intra-sujetos. } \\
\hline \multicolumn{9}{|c|}{ Medida: MEASURE_1 } \\
\hline pregunta & oboísta & Origen & $\begin{array}{c}\text { Suma de cuadrados } \\
\text { tipo III }\end{array}$ & $\mathrm{gl}$ & $\begin{array}{c}\text { Media } \\
\text { cuadrática }\end{array}$ & $\mathrm{F}$ & Sig. & $\begin{array}{c}\text { Eta al cuadrado } \\
\text { parcial }\end{array}$ \\
\hline \multirow[t]{10}{*}{ arpegioF } & 2 & rebajados & 8,167 & 1,923 & 4,247 & 9,800 & 0,014 & 0,766 \\
\hline & 3 & rebajados & 18,875 & 1,564 & 12,069 & 6,321 & 0,050 & 0,678 \\
\hline & 4 & rebajados & 35,167 & 1,402 & 25,079 & 9,738 & 0,030 & 0,764 \\
\hline & 5 & rebajados & 33,167 & 1,250 & 26,528 & 5,283 & 0,086 & 0,638 \\
\hline & 6 & rebajados & 15,167 & 1,056 & 14,358 & 6,067 & 0,086 & 0,669 \\
\hline & 7 & rebajados & 25,292 & 1,073 & 23,576 & 13,692 & 0,030 & 0,820 \\
\hline & 8 & rebajados & 1,292 & 1,681 & 0,768 & 1,000 & 0,415 & 0,250 \\
\hline & 9 & rebajados & 7,167 & 1,658 & 4,324 & 3,909 & 0,099 & 0,566 \\
\hline & 10 & rebajados & 0,667 & 1,085 & 0,614 & 0,167 & 0,728 & 0,053 \\
\hline & 11 & rebajados & 0,667 & 1,125 & 0,593 & 0,333 & 0,625 & 0,100 \\
\hline \multirow[t]{2}{*}{ arpegioQ } & 2 & rebajados & 2,667 & 2,000 & 1,333 & 1,333 & 0,332 & 0,308 \\
\hline & 3 & rebajados & 6,125 & 1,317 & 4,650 & 5,727 & 0,073 & 0,656 \\
\hline
\end{tabular}




\begin{tabular}{|c|c|c|c|c|c|c|c|c|}
\hline \multicolumn{9}{|c|}{ Pruebas de efectos intra-sujetos. } \\
\hline pregunta & oboísta & Origen & $\begin{array}{c}\text { Suma de cuadrados } \\
\text { tipo III }\end{array}$ & $\overline{\mathrm{gl}}$ & $\begin{array}{c}\text { Media } \\
\text { cuadrática }\end{array}$ & $\mathrm{F}$ & Sig. & $\begin{array}{c}\text { Eta al cuadrado } \\
\text { parcial }\end{array}$ \\
\hline & 4 & rebajados & 15,500 & 1,051 & 14,742 & 5,936 & 0,088 & 0,664 \\
\hline & 5 & rebajados & 5,167 & 1,751 & 2,951 & 1,431 & 0,313 & 0,323 \\
\hline & 6 & rebajados & 12,167 & 1,933 & 6,295 & 2,772 & 0,143 & 0,480 \\
\hline & 7 & rebajados & 19,542 & 1,171 & 16,695 & 3,326 & 0,153 & 0,526 \\
\hline & 8 & rebajados & 3,375 & 1,242 & 2,716 & 1,110 & 0,377 & 0,270 \\
\hline & 9 & rebajados & 3,167 & 1,443 & 2,194 & 2,280 & 0,207 & 0,432 \\
\hline & 10 & rebajados & 4,667 & 1,021 & 4,570 & 1,235 & 0,348 & 0,292 \\
\hline & 11 & rebajados & 0,667 & 1,525 & 0,437 & 0,214 & 0,760 & 0,067 \\
\hline \multirow[t]{10}{*}{$\operatorname{dimF}$} & 2 & rebajados & 4,667 & 1,745 & 2,674 & 1,750 & 0,259 & 0,368 \\
\hline & 3 & rebajados & 0,292 & 1,185 & 0,246 & 0,063 & 0,853 & 0,021 \\
\hline & 4 & rebajados & 1,167 & 1,242 & 0,939 & 0,216 & 0,717 & 0,067 \\
\hline & 5 & rebajados & 57,167 & 1,075 & 53,155 & 18,053 & 0,020 & 0,858 \\
\hline & 6 & rebajados & 24,500 & 1,480 & 16,554 & 11,919 & 0,019 & 0,799 \\
\hline & 7 & rebajados & 12,167 & 1,306 & 9,319 & 3,982 & 0,117 & 0,570 \\
\hline & 8 & rebajados & 3,792 & 1,239 & 3,059 & 4,200 & 0,114 & 0,583 \\
\hline & 9 & rebajados & 4,167 & 1,830 & 2,276 & 3,261 & 0,118 & 0,521 \\
\hline & 10 & rebajados & 1,500 & 1,346 & 1,114 & 0,380 & 0,631 & 0,112 \\
\hline & 11 & rebajados & 3,500 & 1,424 & 2,459 & 5,727 & 0,066 & 0,656 \\
\hline \multirow[t]{10}{*}{$\operatorname{dim} Q$} & 2 & rebajados & 7,167 & 1,155 & 6,203 & 5,160 & 0,095 & 0,632 \\
\hline & 3 & rebajados & 0,500 & 1,316 & 0,380 & 0,084 & 0,848 & 0,027 \\
\hline & 4 & rebajados & 3,500 & 1,115 & 3,140 & 0,692 & 0,477 & 0,188 \\
\hline & 5 & rebajados & 8,167 & 1,247 & 6,547 & 2,882 & 0,172 & 0,490 \\
\hline & 6 & rebajados & 15,167 & 1,262 & 12,018 & 16,059 & 0,016 & 0,843 \\
\hline & 7 & rebajados & 12,167 & 1,392 & 8,743 & 4,294 & 0,101 & 0,589 \\
\hline & 8 & rebajados & 1,042 & 1,346 & 0,774 & 0,410 & 0,615 & 0,120 \\
\hline & 9 & rebajados & 4,500 & 1,253 & 3,593 & 2,189 & 0,224 & 0,422 \\
\hline & 10 & rebajados & 0,500 & 1,213 & 0,412 & 0,243 & 0,694 & 0,075 \\
\hline & 11 & rebajados & 2,000 & 1,103 & 1,813 & 2,250 & 0,226 & 0,429 \\
\hline \multirow[t]{8}{*}{ Dutilleux } & 2 & rebajados & 2,000 & 1,000 & 2,000 & 3,000 & 0,182 & 0,500 \\
\hline & 3 & rebajados & 0,542 & 1,922 & 0,282 & 0,196 & 0,820 & 0,061 \\
\hline & 4 & rebajados & 16,167 & 1,755 & 9,211 & 3,506 & 0,110 & 0,539 \\
\hline & 5 & rebajados & 13,500 & 1,699 & 7,944 & 9,000 & 0,023 & 0,750 \\
\hline & 6 & rebajados & 15,167 & 1,923 & 7,887 & 54,600 & 0,000 & 0,948 \\
\hline & 7 & rebajados & 3,500 & 1,923 & 1,820 & 4,200 & 0,076 & 0,583 \\
\hline & 8 & rebajados & 0,542 & 1,121 & 0,483 & 1,114 & 0,373 & 0,271 \\
\hline & 9 & rebajados & 8,167 & 1,061 & 7,698 & 2,333 & 0,221 & 0,437 \\
\hline
\end{tabular}




\begin{tabular}{|c|c|c|c|c|c|c|c|c|}
\hline \multicolumn{9}{|c|}{ Pruebas de efectos intra-sujetos. } \\
\hline pregunta & oboísta & Origen & $\begin{array}{c}\text { Suma de cuadrados } \\
\text { tipo III }\end{array}$ & $\overline{\mathrm{gl}}$ & $\begin{array}{c}\text { Media } \\
\text { cuadrática }\end{array}$ & $\mathrm{F}$ & Sig. & $\begin{array}{c}\text { Eta al cuadrado } \\
\text { parcial }\end{array}$ \\
\hline & 11 & rebajados & 4,667 & 1,349 & 3,459 & 1,050 & 0,393 & 0,259 \\
\hline \multirow[t]{10}{*}{ equilibrio } & 2 & rebajados & 1,500 & 1,360 & 1,103 & 0,771 & 0,470 & 0,205 \\
\hline & 3 & rebajados & 0,292 & 1,759 & 0,166 & 0,153 & 0,837 & 0,049 \\
\hline & 4 & rebajados & 19,500 & 1,516 & 12,865 & 15,261 & 0,011 & 0,836 \\
\hline & 5 & rebajados & 4,667 & 1,287 & 3,625 & 1,909 & 0,252 & 0,389 \\
\hline & 6 & rebajados & 10,667 & 1,220 & 8,747 & 9,600 & 0,039 & 0,762 \\
\hline & 7 & rebajados & 7,875 & 1,781 & 4,422 & 1,435 & 0,312 & 0,324 \\
\hline & 8 & rebajados & 4,500 & 1,018 & 4,420 & 1,800 & 0,272 & 0,375 \\
\hline & 9 & rebajados & 8,167 & 1,064 & 7,677 & 2,882 & 0,184 & 0,490 \\
\hline & 10 & rebajados & 6,125 & 1,208 & 5,070 & 2,194 & 0,226 & 0,422 \\
\hline & 11 & rebajados & 0,667 & 1,600 & 0,417 & 1,500 & 0,302 & 0,333 \\
\hline \multirow[t]{10}{*}{$\mathrm{ffF}$} & 2 & rebajados & 1,167 & 1,473 & 0,792 & 0,512 & 0,579 & 0,146 \\
\hline & 3 & rebajados & 7,542 & 1,005 & 7,502 & 5,716 & 0,096 & 0,656 \\
\hline & 4 & rebajados & 8,667 & 1,073 & 8,077 & 1,857 & 0,264 & 0,382 \\
\hline & 5 & rebajados & 10,667 & 1,143 & 9,333 & 4,000 & 0,128 & 0,571 \\
\hline & 6 & rebajados & 2,667 & 1,316 & 2,027 & 1,200 & 0,359 & 0,286 \\
\hline & 7 & rebajados & 3,500 & 1,292 & 2,709 & 1,235 & 0,352 & 0,292 \\
\hline & 8 & rebajados & 0,292 & 1,637 & 0,178 & 0,179 & 0,802 & 0,056 \\
\hline & 9 & rebajados & 3,500 & 1,095 & 3,196 & 1,340 & 0,332 & 0,309 \\
\hline & 10 & rebajados & 10,667 & 1,000 & 10,667 & 4,800 & 0,116 & 0,615 \\
\hline & 11 & rebajados & 0,167 & 1,516 & 0,110 & 0,130 & 0,829 & 0,042 \\
\hline \multirow[t]{10}{*}{ ffQ } & 2 & rebajados & 1,167 & 1,085 & 1,076 & 0,247 & 0,669 & 0,076 \\
\hline & 3 & rebajados & 5,375 & 1,171 & 4,588 & 2,497 & 0,203 & 0,454 \\
\hline & 4 & rebajados & 16,167 & 1,117 & 14,477 & 3,880 & 0,134 & 0,564 \\
\hline & 5 & rebajados & 11,167 & 1,550 & 7,202 & 15,462 & 0,010 & 0,838 \\
\hline & 6 & rebajados & 10,667 & 1,263 & 8,444 & 4,000 & 0,119 & 0,571 \\
\hline & 7 & rebajados & 0,167 & 1,043 & 0,160 & 0,051 & 0,845 & 0,017 \\
\hline & 8 & rebajados & 1,292 & 1,630 & 0,793 & 1,045 & 0,401 & 0,258 \\
\hline & 9 & rebajados & 6,500 & 1,473 & 4,412 & 2,854 & 0,161 & 0,487 \\
\hline & 10 & rebajados & 11,167 & 1,699 & 6,571 & 2,481 & 0,177 & 0,453 \\
\hline & 11 & rebajados & 1,167 & 1,167 & 1,000 & 0,636 & 0,500 & 0,175 \\
\hline
\end{tabular}


Influencias en la percepción sonora y en la interpretación del rebajado de la lengüeta del oboe

\begin{tabular}{|c|c|c|c|c|c|c|c|c|}
\hline \multicolumn{9}{|c|}{ Pruebas de efectos intra-sujetos. } \\
\hline pregunta & oboísta & Origen & $\begin{array}{c}\text { Suma de cuadrados } \\
\text { tipo III }\end{array}$ & $\mathrm{gl}$ & $\begin{array}{c}\text { Media } \\
\text { cuadrática }\end{array}$ & $\bar{F}$ & Sig. & $\begin{array}{c}\text { Eta al cuadrado } \\
\text { parcial }\end{array}$ \\
\hline \multirow[t]{10}{*}{ flexible } & 2 & rebajados & 6,500 & 1,923 & 3,380 & 23,400 & 0,002 & 0,886 \\
\hline & 3 & rebajados & 18,375 & 1,668 & 11,016 & 8,762 & 0,025 & 0,745 \\
\hline & 4 & rebajados & 13,500 & 1,096 & 12,320 & 7,839 & 0,060 & 0,723 \\
\hline & 5 & rebajados & 51,167 & 1,083 & 47,225 & 20,467 & 0,017 & 0,872 \\
\hline & 6 & rebajados & 25,167 & 1,424 & 17,679 & 13,727 & 0,016 & 0,821 \\
\hline & 7 & rebajados & 12,167 & 1,600 & 7,605 & 3,174 & 0,135 & 0,514 \\
\hline & 8 & rebajados & 4,292 & 1,205 & 3,562 & 3,815 & 0,130 & 0,560 \\
\hline & 9 & rebajados & 9,875 & 1,706 & 5,789 & 3,078 & 0,135 & 0,506 \\
\hline & 10 & rebajados & 2,542 & 1,098 & 2,315 & 0,718 & 0,468 & 0,193 \\
\hline & 11 & rebajados & 0,167 & 1,767 & 0,094 & 0,077 & 0,908 & 0,025 \\
\hline \multirow[t]{10}{*}{ global } & 2 & rebajados & 2,667 & 1,600 & 1,667 & 3,000 & 0,145 & 0,500 \\
\hline & 3 & rebajados & 0,542 & 1,337 & 0,405 & 0,379 & 0,630 & 0,112 \\
\hline & 4 & rebajados & 15,167 & 1,445 & 10,493 & 6,067 & 0,060 & 0,669 \\
\hline & 5 & rebajados & 8,167 & 1,067 & 7,657 & 4,742 & 0,112 & 0,612 \\
\hline & 6 & rebajados & 15,875 & 1,844 & 8,611 & 9,605 & 0,017 & 0,762 \\
\hline & 7 & rebajados & 11,625 & 1,107 & 10,497 & 1,755 & 0,275 & 0,369 \\
\hline & 8 & rebajados & 0,125 & 1,446 & 0,086 & 0,273 & 0,708 & 0,083 \\
\hline & 9 & rebajados & 4,875 & 1,746 & 2,792 & 2,208 & 0,201 & 0,424 \\
\hline & 10 & rebajados & 1,167 & 1,043 & 1,118 & 0,467 & 0,550 & 0,135 \\
\hline & 11 & rebajados & 0,167 & 1,056 & 0,158 & 0,200 & 0,696 & 0,062 \\
\hline \multirow[t]{10}{*}{ legatoF } & 2 & rebajados & 11,167 & 1,550 & 7,202 & 15,462 & 0,010 & 0,838 \\
\hline & 3 & rebajados & 24,125 & 1,346 & 17,925 & 42,366 & 0,002 & 0,934 \\
\hline & 4 & rebajados & 20,667 & 1,563 & 13,227 & 18,600 & 0,007 & 0,861 \\
\hline & 5 & rebajados & 45,500 & 1,394 & 32,647 & 17,426 & 0,011 & 0,853 \\
\hline & 6 & rebajados & 29,167 & 1,174 & 24,846 & 58,333 & 0,002 & 0,951 \\
\hline & 7 & rebajados & 33,167 & 1,142 & 29,035 & 35,118 & 0,006 & 0,921 \\
\hline & 8 & rebajados & 2,625 & 1,223 & 2,146 & 1,615 & 0,290 & 0,350 \\
\hline & 9 & rebajados & 8,000 & 1,000 & 8,000 & 6,000 & 0,092 & 0,667 \\
\hline & 10 & rebajados & 7,167 & 1,213 & 5,910 & 3,486 & 0,143 & 0,537 \\
\hline & 11 & rebajados & 1,500 & 1,478 & 1,015 & 0,771 & 0,477 & 0,205 \\
\hline
\end{tabular}




\begin{tabular}{|c|c|c|c|c|c|c|c|c|}
\hline \multicolumn{9}{|c|}{ Pruebas de efectos intra-sujetos. } \\
\hline pregunta & oboísta & Origen & $\begin{array}{c}\text { Suma de cuadrados } \\
\text { tipo III }\end{array}$ & $\mathrm{gl}$ & $\begin{array}{c}\text { Media } \\
\text { cuadrática }\end{array}$ & $\mathrm{F}$ & Sig. & $\begin{array}{c}\text { Eta al cuadrado } \\
\text { parcial }\end{array}$ \\
\hline \multirow[t]{10}{*}{ legatoQ } & 2 & rebajados & 3,500 & 1,576 & 2,220 & 3,316 & 0,129 & 0,525 \\
\hline & 3 & rebajados & 7,542 & 1,816 & 4,154 & 3,251 & 0,119 & 0,520 \\
\hline & 4 & rebajados & 8,667 & 1,350 & 6,420 & 4,333 & 0,103 & 0,591 \\
\hline & 5 & rebajados & 4,167 & 1,755 & 2,374 & 0,904 & 0,446 & 0,231 \\
\hline & 6 & rebajados & 16,167 & 1,246 & 12,973 & 10,778 & 0,032 & 0,782 \\
\hline & 7 & rebajados & 20,792 & 1,480 & 14,044 & 3,276 & 0,136 & 0,522 \\
\hline & 8 & rebajados & 1,125 & 1,188 & 0,947 & 0,388 & 0,606 & 0,114 \\
\hline & 9 & rebajados & 4,542 & 1,343 & 3,382 & 3,442 & 0,137 & 0,534 \\
\hline & 10 & rebajados & 2,167 & 1,699 & 1,275 & 1,444 & 0,311 & 0,325 \\
\hline & 11 & rebajados & 3,500 & 1,324 & 2,644 & 1,615 & 0,288 & 0,350 \\
\hline \multirow[t]{10}{*}{ Mozart } & 2 & rebajados & 0,667 & 1,347 & 0,495 & 0,158 & 0,780 & 0,050 \\
\hline & 3 & rebajados & 0,875 & 1,878 & 0,466 & 0,304 & 0,737 & 0,092 \\
\hline & 4 & rebajados & 38,167 & 1,174 & 32,509 & 11,644 & 0,032 & 0,795 \\
\hline & 5 & rebajados & 12,167 & 1,052 & 11,566 & 8,111 & 0,061 & 0,730 \\
\hline & 6 & rebajados & 20,667 & 1,563 & 13,227 & 18,600 & 0,007 & 0,861 \\
\hline & 7 & rebajados & 4,167 & 1,000 & 4,167 & 6,818 & 0,080 & 0,694 \\
\hline & 8 & rebajados & 1,292 & 1,397 & 0,925 & 7,154 & 0,049 & 0,705 \\
\hline & 9 & rebajados & 7,042 & 1,408 & 5,001 & 1,461 & 0,311 & 0,328 \\
\hline & 10 & rebajados & 2,167 & 1,064 & 2,037 & 0,765 & 0,452 & 0,203 \\
\hline & 11 & rebajados & 2,167 & 1,439 & 1,506 & 0,907 & 0,434 & 0,232 \\
\hline \multirow[t]{10}{*}{$\mathrm{ppF}$} & 2 & rebajados & 1,167 & 1,088 & 1,072 & 0,193 & 0,708 & 0,060 \\
\hline & 3 & rebajados & 0,792 & 1,324 & 0,598 & 0,109 & 0,823 & 0,035 \\
\hline & 4 & rebajados & 18,667 & 1,350 & 13,822 & 2,471 & 0,195 & 0,452 \\
\hline & 5 & rebajados & 30,167 & 1,103 & 27,359 & 9,203 & 0,049 & 0,754 \\
\hline & 6 & rebajados & 10,167 & 1,771 & 5,740 & 2,905 & 0,142 & 0,492 \\
\hline & 7 & rebajados & 8,167 & 1,497 & 5,454 & 1,122 & 0,379 & 0,272 \\
\hline & 8 & rebajados & 0,875 & 1,105 & 0,792 & 0,304 & 0,638 & 0,092 \\
\hline & 9 & rebajados & 2,000 & 1,135 & 1,762 & 0,391 & 0,597 & 0,115 \\
\hline & 10 & rebajados & 4,667 & 1,563 & 2,987 & 4,200 & 0,094 & 0,583 \\
\hline & 11 & rebajados & 3,500 & 1,800 & 1,945 & 1,145 & 0,377 & 0,276 \\
\hline
\end{tabular}


Influencias en la percepción sonora y en la interpretación del rebajado de la lengüeta del oboe

\begin{tabular}{|c|c|c|c|c|c|c|c|c|}
\hline \multicolumn{9}{|c|}{ Pruebas de efectos intra-sujetos. } \\
\hline pregunta & oboísta & Origen & $\begin{array}{c}\text { Suma de cuadrados } \\
\text { tipo III }\end{array}$ & $\mathrm{gl}$ & $\begin{array}{c}\text { Media } \\
\text { cuadrática }\end{array}$ & $\bar{F}$ & Sig. & $\begin{array}{c}\text { Eta al cuadrado } \\
\text { parcial }\end{array}$ \\
\hline \multirow[t]{10}{*}{ ppQ } & 2 & rebajados & 0,500 & 1,559 & 0,321 & 0,111 & 0,853 & 0,036 \\
\hline & 3 & rebajados & 2,792 & 1,509 & 1,850 & 0,440 & 0,618 & 0,128 \\
\hline & 4 & rebajados & 25,167 & 1,482 & 16,982 & 3,512 & 0,125 & 0,539 \\
\hline & 5 & rebajados & 2,167 & 1,228 & 1,765 & 0,448 & 0,582 & 0,130 \\
\hline & 6 & rebajados & 6,000 & 1,770 & 3,390 & 2,700 & 0,156 & 0,474 \\
\hline & 7 & rebajados & 0,167 & 1,725 & 0,097 & 0,028 & 0,959 & 0,009 \\
\hline & 8 & rebajados & 3,167 & 1,770 & 1,789 & 1,781 & 0,253 & 0,373 \\
\hline & 9 & rebajados & 2,667 & 1,391 & 1,917 & 1,500 & 0,305 & 0,333 \\
\hline & 10 & rebajados & 7,167 & 1,000 & 7,167 & 14,333 & 0,032 & 0,827 \\
\hline & 11 & rebajados & 4,167 & 1,817 & 2,294 & 2,419 & 0,178 & 0,446 \\
\hline \multirow[t]{10}{*}{ rigidez } & 2 & rebajados & 3,167 & 1,036 & 3,056 & 1,541 & 0,302 & 0,339 \\
\hline & 3 & rebajados & 21,875 & 1,151 & 19,004 & 6,702 & 0,069 & 0,691 \\
\hline & 4 & rebajados & 19,500 & 1,667 & 11,694 & 3,162 & 0,132 & 0,513 \\
\hline & 5 & rebajados & 37,500 & 1,800 & 20,833 & 10,714 & 0,014 & 0,781 \\
\hline & 6 & rebajados & 13,167 & 1,424 & 9,249 & 7,182 & 0,047 & 0,705 \\
\hline & 7 & rebajados & 23,167 & 1,155 & 20,053 & 16,680 & 0,019 & 0,848 \\
\hline & 8 & rebajados & 7,625 & 1,120 & 6,806 & 1,732 & 0,277 & 0,366 \\
\hline & 9 & rebajados & 2,167 & 1,232 & 1,759 & 0,470 & 0,573 & 0,135 \\
\hline & 10 & rebajados & 11,625 & 1,056 & 11,010 & 4,838 & 0,110 & 0,617 \\
\hline & 11 & rebajados & 6,167 & 1,692 & 3,645 & 2,581 & 0,169 & 0,463 \\
\hline \multirow[t]{10}{*}{ Strauss } & 2 & rebajados & 5,167 & 1,342 & 3,850 & 2,067 & 0,233 & 0,408 \\
\hline & 3 & rebajados & 4,667 & 1,662 & 2,807 & 1,750 & 0,261 & 0,368 \\
\hline & 4 & rebajados & 40,167 & 1,478 & 27,182 & 20,657 & 0,007 & 0,873 \\
\hline & 5 & rebajados & 22,167 & 1,056 & 20,984 & 26,600 & 0,012 & 0,899 \\
\hline & 6 & rebajados & 17,167 & 1,690 & 10,160 & 14,714 & 0,009 & 0,831 \\
\hline & 7 & rebajados & 0,667 & 1,133 & 0,589 & 0,375 & 0,604 & 0,111 \\
\hline & 8 & rebajados & 0,500 & 1,065 & 0,469 & 1,286 & 0,340 & 0,300 \\
\hline & 9 & rebajados & 2,542 & 1,190 & 2,136 & 0,656 & 0,496 & 0,179 \\
\hline & 10 & rebajados & 3,500 & 1,089 & 3,215 & 1,340 & 0,332 & 0,309 \\
\hline & 11 & rebajados & 3,500 & 1,168 & 2,997 & 0,663 & 0,491 & 0,181 \\
\hline
\end{tabular}




\begin{tabular}{|c|c|c|c|c|c|c|c|c|}
\hline \multicolumn{9}{|c|}{ Pruebas de efectos intra-sujetos. } \\
\hline \multicolumn{9}{|c|}{ Medida: MEASURE_1 } \\
\hline pregunta & oboísta & Origen & $\begin{array}{c}\text { Suma de cuadrados } \\
\text { tipo III }\end{array}$ & $\overline{\mathrm{gl}}$ & $\begin{array}{c}\text { Media } \\
\text { cuadrática }\end{array}$ & $\bar{F}$ & Sig. & $\begin{array}{c}\text { Eta al cuadrado } \\
\text { parcial }\end{array}$ \\
\hline \multirow[t]{10}{*}{ timbre } & 2 & rebajados & 4,667 & 1,600 & 2,917 & 2,100 & 0,219 & 0,412 \\
\hline & 3 & rebajados & 3,792 & 1,311 & 2,893 & 1,508 & 0,305 & 0,335 \\
\hline & 4 & rebajados & 33,500 & 1,817 & 18,441 & 19,452 & 0,004 & 0,866 \\
\hline & 5 & rebajados & 9,500 & 1,239 & 7,668 & 2,408 & 0,206 & 0,445 \\
\hline & 6 & rebajados & 12,167 & 1,779 & 6,840 & 3,712 & 0,100 & 0,553 \\
\hline & 7 & rebajados & 4,667 & 1,469 & 3,176 & 1,167 & 0,369 & 0,280 \\
\hline & 8 & rebajados & 2,375 & 1,059 & 2,243 & 1,163 & 0,361 & 0,279 \\
\hline & 9 & rebajados & 6,167 & 1,262 & 4,886 & 2,176 & 0,225 & 0,420 \\
\hline & 10 & rebajados & 10,167 & 1,246 & 8,158 & 6,778 & 0,062 & 0,693 \\
\hline & 11 & rebajados & 0,500 & 1,380 & 0,362 & 0,273 & 0,699 & 0,083 \\
\hline \multirow[t]{10}{*}{ Vivaldi } & 2 & rebajados & 1,167 & 1,627 & 0,717 & 0,724 & 0,503 & 0,194 \\
\hline & 3 & rebajados & 3,042 & 1,778 & 1,711 & 0,753 & 0,500 & 0,201 \\
\hline & 4 & rebajados & 25,167 & 1,018 & 24,719 & 10,067 & 0,049 & 0,770 \\
\hline & 5 & rebajados & 17,167 & 1,595 & 10,763 & 4,478 & 0,084 & 0,599 \\
\hline & 6 & rebajados & 15,167 & 1,627 & 9,324 & 9,414 & 0,023 & 0,758 \\
\hline & 7 & rebajados & 16,792 & 1,993 & 8,425 & 71,118 & 0,000 & 0,960 \\
\hline & 8 & rebajados & 0,000 & 1,000 & 0,000 & 0,000 & 1,000 & 0,000 \\
\hline & 9 & rebajados & 5,375 & 1,609 & 3,340 & 0,729 & 0,500 & 0,195 \\
\hline & 10 & rebajados & 4,500 & 1,043 & 4,313 & 1,800 & 0,271 & 0,375 \\
\hline & 11 & rebajados & 0,167 & 1,397 & 0,119 & 0,036 & 0,921 & 0,012 \\
\hline
\end{tabular}

Tablas A.68. Efectos intra-sujetos del ANOVA con medidas repetidas utilizando los datos de GreenhouseGeisser para las diferentes preguntas que respondían los oboístas, separado por oboístas, en función del rebajado.

\subsubsection{Experimento de evaluación auditiva}

\begin{tabular}{|c|c|c|c|c|c|c|c|}
\hline \multicolumn{8}{|c|}{ Medida: MEASURE_1 } \\
\hline Origen & & $\begin{array}{c}\text { Suma de cuadrados tipo } \\
\text { III }\end{array}$ & $\mathrm{gl}$ & $\begin{array}{c}\text { Media } \\
\text { cuadrática }\end{array}$ & $\mathrm{F}$ & Sig. & $\begin{array}{c}\text { Eta al cuadrado } \\
\text { parcial }\end{array}$ \\
\hline \multirow[t]{4}{*}{$\begin{array}{l}\text { ejecucion } \\
\text { rebajado }\end{array}$} & $\begin{array}{l}\text { Esfericidad } \\
\text { asumida }\end{array}$ & 1,581 & 2 & 0,790 & 0,359 & 0,699 & 0,006 \\
\hline & $\begin{array}{l}\text { Greenhouse- } \\
\text { Geisser }\end{array}$ & 1,581 & 1,973 & 0,801 & 0,359 & 0,696 & 0,006 \\
\hline & Huynh-Feldt & 1,581 & 2,000 & 0,790 & 0,359 & 0,699 & 0,006 \\
\hline & Límite-inferior & 1,581 & 1,000 & 1,581 & 0,359 & 0,551 & 0,006 \\
\hline \multirow[t]{2}{*}{$\begin{array}{l}\text { Error(ejecucionr } \\
\text { ebajado) }\end{array}$} & $\begin{array}{l}\text { Esfericidad } \\
\text { asumida }\end{array}$ & 268,419 & 122 & 2,200 & & & \\
\hline & $\begin{array}{l}\text { Greenhouse- } \\
\text { Geisser }\end{array}$ & 268,419 & 120,371 & 2,230 & & & \\
\hline
\end{tabular}




\begin{tabular}{|c|c|c|c|c|c|c|c|}
\hline \multicolumn{7}{|c|}{ Pruebas de efectos intra-sujetos. } & \\
\hline Origen & & $\begin{array}{c}\text { Suma de cuadrados tipo } \\
\text { III }\end{array}$ & $\overline{\mathrm{gl}}$ & $\begin{array}{c}\text { Media } \\
\text { cuadrática }\end{array}$ & $\mathrm{F}$ & Sig. & $\begin{array}{c}\text { Eta al cuadrado } \\
\text { parcial }\end{array}$ \\
\hline & Huynh-Feldt & 268,419 & 122,000 & 2,200 & & & \\
\hline & Límite-inferior & 268,419 & 61,000 & 4,400 & & & \\
\hline
\end{tabular}

Tabla A.69. Efectos intra-sujetos del ANOVA con medidas repetidas para la pregunta "ejecución" que evaluaron todos los oboístas $(\mathrm{N}=6)$ y todos los sonidos del ejercicio diminuendo en función del rebajado de la lengüeta.

\begin{tabular}{|c|c|c|c|c|c|c|c|}
\hline \multicolumn{8}{|c|}{ Pruebas de efectos intra-sujetos. } \\
\hline Origen & & Suma de cuadrados tipo III & $\overline{\mathrm{gl}}$ & $\begin{array}{c}\text { Media } \\
\text { cuadrática }\end{array}$ & $\mathrm{F}$ & Sig. & $\begin{array}{c}\text { Eta al cuadrado } \\
\text { parcial }\end{array}$ \\
\hline \multirow[t]{4}{*}{ sonido rebajados } & $\begin{array}{l}\text { Esfericidad } \\
\text { asumida }\end{array}$ & 2,075 & 2 & 1,038 & 0,601 & 0,550 & 0,010 \\
\hline & $\begin{array}{l}\text { Greenhouse- } \\
\text { Geisser }\end{array}$ & 2,075 & 1,824 & 1,138 & 0,601 & 0,535 & 0,010 \\
\hline & Huynh-Feldt & 2,075 & 1,877 & 1,105 & 0,601 & 0,540 & 0,010 \\
\hline & Límite-inferior & 2,075 & 1,000 & 2,075 & 0,601 & 0,441 & 0,010 \\
\hline \multirow[t]{4}{*}{$\begin{array}{l}\text { Error(sonido } \\
\text { rebajados) }\end{array}$} & $\begin{array}{l}\text { Esfericidad } \\
\text { asumida }\end{array}$ & 210,591 & 122 & 1,726 & & & \\
\hline & $\begin{array}{l}\text { Greenhouse- } \\
\text { Geisser }\end{array}$ & 210,591 & 111,274 & 1,893 & & & \\
\hline & Huynh-Feldt & 210,591 & 114,523 & 1,839 & & & \\
\hline & Límite-inferior & 210,591 & 61,000 & 3,452 & & & \\
\hline
\end{tabular}

Tabla A.70. Efectos intra-sujetos del ANOVA con medidas repetidas para la pregunta "calidad del sonido" que evaluaron todos los oboístas $(\mathrm{N}=6)$ y todos los sonidos del ejercicio diminuendo en función del rebajado de la lengüeta.

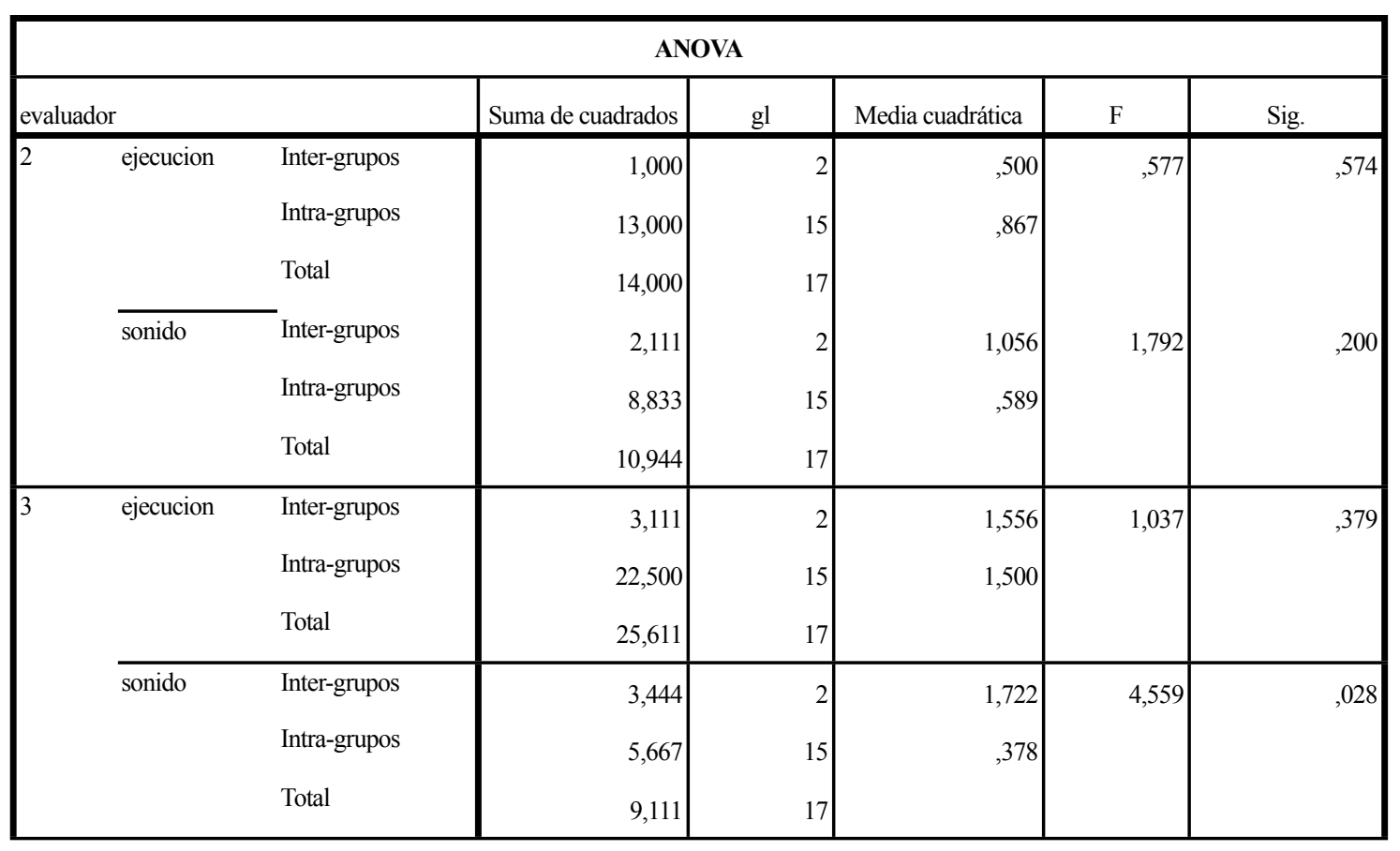




\begin{tabular}{|c|c|c|c|c|c|c|c|}
\hline \multicolumn{8}{|c|}{ ANOVA } \\
\hline \multicolumn{3}{|c|}{ evaluador } & Suma de cuadrados & $\mathrm{gl}$ & Media cuadrática & $\mathrm{F}$ & Sig. \\
\hline 4 & ejecucion & $\begin{array}{l}\text { Inter-grupos } \\
\text { Intra-grupos } \\
\text { Total }\end{array}$ & $\begin{array}{l}3,444 \\
6,333 \\
9,778\end{array}$ & $\begin{array}{r}2 \\
15 \\
17\end{array}$ & $\begin{array}{r}1,722 \\
, 422\end{array}$ & 4,079 & ,038 \\
\hline & sonido & $\begin{array}{l}\text { Inter-grupos } \\
\text { Intra-grupos } \\
\text { Total }\end{array}$ & $\begin{array}{r}, 111 \\
1,667 \\
1,778\end{array}$ & $\begin{array}{r}2 \\
15 \\
17\end{array}$ & $\begin{array}{r}, 056 \\
, 111\end{array}$ &, 500 & ,616 \\
\hline 6 & ejecucion & $\begin{array}{l}\text { Inter-grupos } \\
\text { Intra-grupos } \\
\text { Total }\end{array}$ & $\begin{array}{r}29,400 \\
1,000 \\
30,400\end{array}$ & $\begin{array}{l}2 \\
7 \\
9\end{array}$ & $\begin{array}{r}14,700 \\
, 143\end{array}$ & 102,900 & ,000 \\
\hline & sonido & $\begin{array}{l}\text { Inter-grupos } \\
\text { Intra-grupos } \\
\text { Total }\end{array}$ & $\begin{array}{r}8,817 \\
6,083 \\
14,900\end{array}$ & $\begin{array}{l}2 \\
7 \\
9\end{array}$ & $\begin{array}{r}4,408 \\
, 869\end{array}$ & 5,073 & ,043 \\
\hline 11 & ejecucion & $\begin{array}{l}\text { Inter-grupos } \\
\text { Intra-grupos } \\
\text { Total }\end{array}$ & $\begin{array}{l}19,000 \\
63,000 \\
82,000\end{array}$ & $\begin{array}{r}2 \\
15 \\
17\end{array}$ & $\begin{array}{l}9,500 \\
4,200\end{array}$ & 2,262 & ,139 \\
\hline & sonido & $\begin{array}{l}\text { Inter-grupos } \\
\text { Intra-grupos } \\
\text { Total }\end{array}$ & $\begin{array}{l}18,111 \\
44,167 \\
62,278\end{array}$ & $\begin{array}{r}2 \\
15 \\
17\end{array}$ & $\begin{array}{l}9,056 \\
2,944\end{array}$ & 3,075 & ,076 \\
\hline
\end{tabular}

Tabla A.71. Análisis de varianza de un factor, para la auto-evaluación auditiva de los oboístas en el ejercicio diminuendo, dividido por oboístas intérpretes y evaluadores en función del rebajado de la lengüeta.

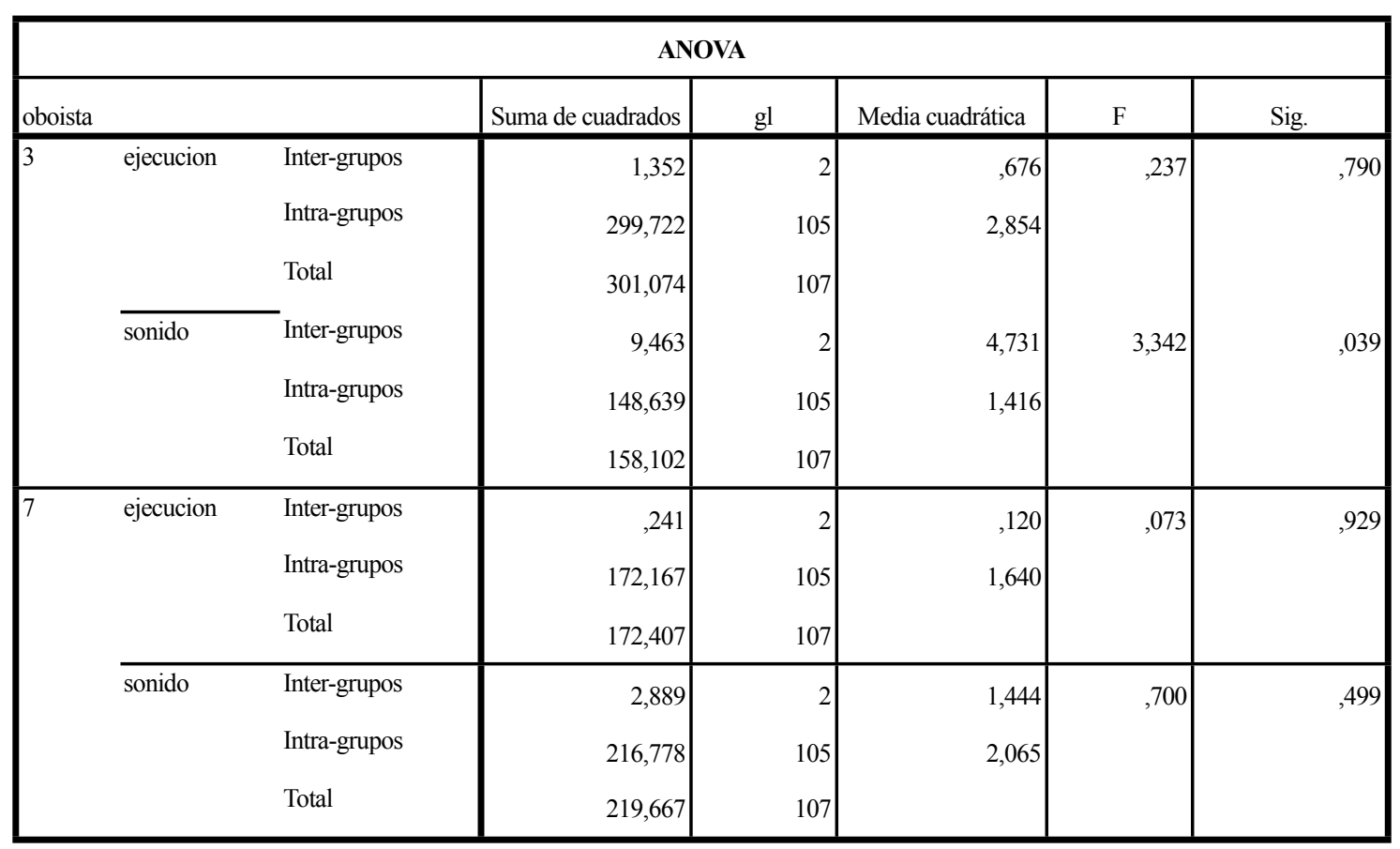

Tabla A.72. Análisis de varianza de un factor para la evaluación auditiva del ejercicio diminuendo realizado por todos los oboístas para los sonidos de la escuela alemana y francesa, en función del rebajado de la lengüeta. 
Influencias en la percepción sonora y en la interpretación del rebajado de la lengüeta del oboe

\begin{tabular}{|c|c|c|c|c|c|c|c|}
\hline \multicolumn{8}{|c|}{ ANOVA } \\
\hline \multicolumn{3}{|c|}{ oboista } & Suma de cuadrados & $\mathrm{gl}$ & Media cuadrática & $\mathrm{F}$ & Sig. \\
\hline \multirow[t]{6}{*}{3} & ejecucion & Inter-grupos & 2,422 & 2 & 1,211 & ,407 & 667 \\
\hline & & Intra-grupos & 258,700 & 87 & 2,974 & & \\
\hline & & Total & 261,122 & 89 & & & \\
\hline & sonido & Inter-grupos & 7,622 & 2 & 3,811 & 2,759 & ,069 \\
\hline & & Intra-grupos & 120,167 & 87 & 1,381 & & \\
\hline & & Total & & 89 & & & \\
\hline \multirow[t]{6}{*}{7} & ejecucion & & ,822 & 2 & ,411 & ,227 & ,797 \\
\hline & & Intra-grupos & 157,633 & 87 & 1,812 & & \\
\hline & & Total & & 89 & & & \\
\hline & sonido & Inter-grupos & 2,022 & 2 & 1,011 & ,446 & 641 \\
\hline & & Intra-grupos & 197,100 & 87 & 2,266 & & \\
\hline & & Total & 199,122 & 89 & & & \\
\hline
\end{tabular}

Tabla A.73. Análisis de varianza de un factor para la evaluación auditiva del ejercicio diminuendo realizado por todos los oboístas para los sonidos de la escuela alemana y francesa, en función del rebajado de la lengüeta (excepto el oboísta 3: evitando la autoevaluación). 